Food and Agriculture Organization 14 of the United Nations

\title{
CLIMATE CHANGE AND FOOD SYSTEMS
}

Global assessments and implications for food security and trade 


\section{CLIMATE CHANGE AND FOOD SYSTEMS}

\section{Global assessments and}

implications for food security and trade

Edited by

Aziz Elbehri

FOOD AND AGRICULTURE ORGANIZATION OF THE UNITED NATIONS ROME, 2015 


\section{Recommended citation:}

FAO 2015. Climate change and food systems: global assessments and implications for food security and trade. Food Agriculture Organization of the United Nations (FAO)

The designations employed and the presentation of material in this information product do not imply the expression of any opinion whatsoever on the part of the Food and Agriculture Organization of the United Nations (FAO) concerning the legal or development status of any country, territory, city or area or of its authorities, or concerning the delimitation of its frontiers or boundaries. The mention of specific companies or products of manufacturers, whether or not these have been patented, does not imply that these have been endorsed or recommended by FAO in preference to others of a similar nature that are not mentioned.

The views expressed in this information product are those of the author(s) and do not necessarily reflect the views or policies of FAO.

ISBN 978-92-5-108699-5

(c) FAO, 2015

FAO encourages the use, reproduction and dissemination of material in this information product. Except where otherwise indicated, material may be copied, downloaded and printed for private study, research and teaching purposes, or for use in non-commercial products or services, provided that appropriate acknowledgement of FAO as the source and copyright holder is given and that FAO's endorsement of users' views, products or services is not implied in any way.

All requests for translation and adaptation rights, and for resale and other commercial use rights should be made via www.fao.org/contact-us/licence-request or addressed to copyright@fao.org.

FAO information products are available on the FAO website (www.fao.org/publications) and can be purchased through publications-sales@fao.org.

\section{(C) Photo credits:}

biodilloversity.wordpress.com

M. Sebastian

Minden Pictures/Colin Monteath

$\mathrm{FAO/Truis} \mathrm{Brekke}$

Safeway-Tuna/1280 


\section{CONTENTS}

Contributing authors

Foreword

\section{CHAPTER 1}

Climate change, food security and trade: An overview of global assessments and policy insights

A1. Robust results from existing climate change impact studies

A2. Current modelling challenges

B1. Climate and nutrition: Improving analysis of climate-nutrition-health links

B2. Climate and water: Growing need for systematic climate-food-water analysis 11

B3. Climate mitigation and food security: Co-benefits versus trade-offs 12

B4. Climate and trade: Understanding the trends and tackling trade-offs 13

B5. Climate and poverty: Mainstreaming adaptation into development

C. PART 3: Policy messages, communication and the need for two-way science-policy dialogue

C1. Matching evidence on climate impacts to the needs of policy-makers

C2. Policy insights on climate change impacts under uncertainty

C3. Harmonizing climate and trade policy

C4. Recommendations for structured science-policy dialogue 


\section{CHAPTER 2}

The Global Gridded Crop Model Intercomparison: Approaches, insights and caveats for modelling climate change impacts on agriculture at the global scale

1. Rationale

2. Biophysical models to assess climate change impacts on agricultural productivity

2.1 Crops and weather

2.2 Model types

3. Challenges for global-scale modelling

3.1 Global consistency vs. data scarcity

4. Recent advances in global-scale crop modelling 34

4.1 Global-scale impacts 34

4.2 Focus regions of climate change impacts 38

4.3 Inter-sectoral interaction 39

5. The Global Gridded Crop Model intercomparison 40

6. Open questions 41

6.1 Model evaluation and validation 42

6.2 Management 42

6.3 Effects of elevated atmospheric carbon dioxide concentrations

6.4 Future challenges: Representative agricultural pathways 44

6.5 Future challenges: Drought and climate extremes 45

6.6 Future challenges: Connecting with field-scale assessments 46

6.7 Future challenges: Informing economic assessment with biophysical climate change impact studies 46

$\begin{array}{ll}\text { 7. Conclusions } & 47\end{array}$

\section{CHAPTER 3}

Economic modelling of climate impacts and adaptation in agriculture: A survey of methods, results and gaps

1. Introduction -62

2. Defining climate adaptation: Analytical perspective 63

3. Global climate models 66

4. Pathway models $\quad 71$

$\begin{array}{lll}4.1 & \text { Crop yield models } & 71\end{array}$

4.2 Water-climate pathway models 76

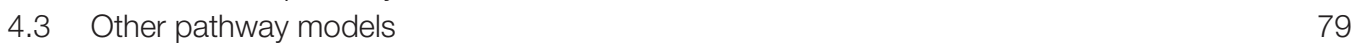

5. Economic models $\quad 80$

5.1 Market- and sector-level models $\quad 80$

5.2 Farm- and household-level models 89

6. Conclusions 


\section{CHAPTER 4}

An overview of climate change impact on crop production and its variability in Europe, related uncertainties and research challenges

1. Introduction

1.1 Background and objectives

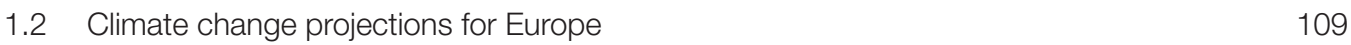

2. Climate change impact assessment methodology for agriculture 113

2.1 Different approaches to assessment 113

2.2 Major shortcomings 116

2.3 Recent progress $\quad 118$

2.4 Current use of crop simulation for assessing effects of climate and adaptation 119

3. Selected impacts for key crops and regions $\quad 121$

$\begin{array}{ll}\text { 3.1 Production trends - past and near future projections } & 121\end{array}$

3.2 Future shifts in production possibilities (suitability) 123

3.3 Projections of relative crop yield change under future climate scenarios $\quad 123$

3.4 Projections of future crop production potential (yields and suitability) 129

3.5 Potential implications for trade and food security 130

4. Discussion of uncertainties 132

5. Recommendations for improving impact assessment 134

\section{CHAPTER 5}

Climate change impact on key crops in Africa: Using crop models and general equilibrium models to bound the predictions

Timothy Thomas and Mark Rosegrant

$\begin{array}{lr}\text { 1. Introduction } & 148\end{array}$

1.1 Population $\quad 150$

$\begin{array}{ll}1.2 \text { Income } & 150\end{array}$

$\begin{array}{llr}1.3 & \text { Agriculture } & 150\end{array}$

2. Climate and climate models $\quad 150$

2.1 Precipitation $\quad 150$

2.2 Temperature 155

3. DSSAT Crop Model Results 156

$\begin{array}{lll}3.1 & \text { Rainfed maize } & 158\end{array}$

3.2 All crops $r 1$

4. Impact model results $\quad 165$

$\begin{array}{llr}4.1 & \text { Maize } & 165\end{array}$

4.2 Sorghum 166

$\begin{array}{lll}4.3 & \text { All crops } & 170\end{array}$

$\begin{array}{lll}4.4 & \text { Malnutrition } & 171\end{array}$ 


\section{CHAPTER 6}

Global climate change, food supply and livestock production systems:

A bioeconomic analysis

Petr Havlík, David Leclère, Hugo Valin, Mario Herrero, Erwin Schmid, Jean-Francois Soussana, Christoph Müller and Michael Obersteiner

1. Introduction $\quad 178$

2. Methodology 179

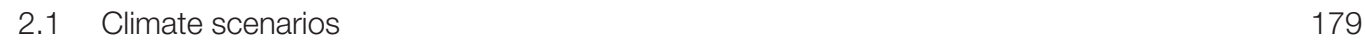

2.2 Biophysical impact modelling 180

2.3 Economic impact modelling 183

3. Results 187

3.1 Livestock sector developments without climate change 187

3.2 Climate change impact on livestock markets 190

3.3 Land management adaptation 193

$\begin{array}{ll}3.4 & \text { Livestock sector adaptation } \\ \end{array}$

4. Conclusions 196

\section{CHAPTER 7}

Grain production trends in the Russian Federation, Ukraine and Kazakhstan in the context of climate change and international trade

Elena Lioubimtseva, Nicolai Dronin and Andrei Kirilenko

1. Introduction

2. Historical trends of grain production and trade 218

2.1 Decline in agriculture in 1991-2001 213

$\begin{array}{ll}2.2 \text { Recovery trends in 2002-2013 } & 215\end{array}$

3. Short-term weather variability and land dynamics 210

4. Impacts of climate change on grain production 222

5. Outlooks for grain production and export 229

6. Conclusions 235

\section{CHAPTER 8}

The potential impact of climate change-induced sea level rise on the global rice market and food security

Ching-Cheng Chang, Huey-Lin Lee and Shih-Hsun Hsu

1. Introduction

2. Model and data

3. Simulation design

4. Simulation results

5. Conclusions 


\section{CHAPTER 9}

An assessment of global banana production and suitability under climate change scenarios

1. Introduction

2. Climatic zones suitable for banana production

3. Climate change impacts through 2070 on areas of climatic zones suitable for banana suitability 268

4. Climate change productions for 24 banana-growing areas in Latin America, Africa and Asia 270

5. Changes in potential productivity for 24 key banana-growing areas in Latin America, Africa and Asia for 2030, 2050 and 2070

5.1 Method to estimate banana GDD and TDU 275

5.2 Method to estimate water deficit in bananas 280

5.3 Results of calculations GDD, TDU and water deficit 280

6. Changes in leaf diseases for six key banana-growing sites in Latin America, Africa and Asia for 2030, 2050, and 2070

7. Changes at the margins - potential areas lost and gained for banana production in 2030, 2050 and 2070

8. Implications of climate change for global banana production

\section{CHAPTER 10}

The role of international trade under a changing climate: Insights from global economic modelling

Helal Ahammad and colleagues

1. Introduction $\quad 294$

2. Modelling international trade 295

2.1 Modelling trade in a general equilibrium framework 295

2.2 Modelling trade in a partial equilibrium framework 297

3. Trade in agricultural commodities: Recent trends 298

4. Description of scenarios 299

5. Implications for trade of the "socio-economic and climatic"scenarios 300

5.1 Agrifood trade in 2050 under scenario S1 301

5.2 Agrifood trade in 2050: A closer look at model agreement 302

5.3 Key drivers of trade: Degree of model agreement 304

5.4 Production-exports nexus: degree of model agreement 308

$\begin{array}{ll}\text { 6. Discussion and conclusions } & 308\end{array}$ 


\section{CHAPTER 11}

Climate change impacts on food systems and implications for climate-compatible food policies

Tim Wheeler

1. Introduction

2. Climate change

3. Climate variability and agriculture

4. Impacts of climate change on food availability

4.1 Global studies of impacts on crop production and yield

4.2 Local, national and regional studies of impacts on crop production and yield

5. Impacts on food access, utilization and stability

6. Mitigation and adaptation in the agricultural sector

7. Understanding and working with uncertainty about climate change impacts on food security

8. Towards climate-compatible food policies

9. Conclusions 


\section{CONTRIBUTING AUTHORS}

Helal AHAmmad

Australian Bureau of Agricultural and Resource

Economics and Sciences

\section{ELodie BLANC}

Massachusetts Institute of Technology

\section{MARY BURFISHER}

United States Naval Academy and

Purdue University

\section{German CALberto}

Bioversity International, Cali, Colombia and CGIAR Research Program on Climate Change, Agriculture and Food Security (CCAFS)

\section{Ching-Cheng CHANG}

Institute of Economics, Academia Sinica,

Taipei, Taiwan

\section{Daniel Mason D'CROZ}

International Food Policy Research Institute

\section{Nicolai DRONIN}

School of Geography, Moscow State University, Russia

\section{AzIz ELBEHRI}

Food and Agriculture Organization of the United Nations (FAO)

\section{JosHUA ELLIOTT}

University of Chicago Computation Institute, USA

\section{SHINICHIRO FUJIMORI}

National Institute for Environmental Studies

\section{Tомоко HASEGAWA}

National Institute for Environmental Studies

\section{Petr HAVLIK}

International Institute for Applied Systems Analysis, Austria

\section{MARIO HERRERO}

Commonwealth Scientific and Industrial Research Organization, Australia

\section{Edwina HEYHOE}

Australian Bureau of Agricultural and Resource Economics and Sciences

\section{JUKKA HÖHN}

Plant Production Research, MTT Agrifood

Research Finland, Finland

\section{SHIH-Hsun HSU}

Department of Agricultural Economics, National Taiwan University, Taipei, Taiwan

\section{AndreI KIRILENKO}

Department of Earth System Science and Policy, University of North Dakota, USA

\section{PAgE KYLE}

Pacific Northwest National Laboratory

\section{DAVID LECLÈRE}

International Institute for Applied Systems Analysis, Austria

\section{Huey-Lin LEE}

Department of Economics, National Chengchi

University, Taipei, Taiwan

\section{ELENA LIOUBIMTSEVA}

Geography and Planning Department, Grand Valley State University, Michigan, USA

\section{Herman LOTZE-CAMPEN}

Potsdam Institute for Climate Impact Research (PIK), Germany

\section{Christoph MÜLLER}

Potsdam Institute for Climate Impact Research (PIK), Germany

\section{Gerald NELSON}

University of Illinois at Urbana-Champaign 
Michael OBERSTEINER

International Institute for Applied Systems Analysis, Austria

\section{MARK ROSEGRANT}

International Food Policy Research Institute (IFPRI)

\section{REIMUnd RÖTTER}

Plant Production Research, MTT Agrifood

Research Finland, Findand

\section{RONALD SANDS}

U.S. Department of Agriculture,

Economic Research Service

\section{ERWIN SCHMID}

University of Natural Resources and Life Sciences,

Vienna, Austria

\section{Christoph SCHMITZ}

Potsdam Institute for Climate Impact Research

(PIK), Germany

\section{Pablo SILES}

CIAT, Nicaragua (previously Bioversity International, Turrialba, Costa Rica)

\section{JEAN-FrancoIs SOUSSANA}

French National Institute for Agricultural Research (INRA), Paris, France

\section{Charles StAVER}

Bioversity International, Montpellier, France and CGIAR Research Program on Climate Change, Agriculture and Food Security (CCAFS)

\section{ANDRZEJ TABEAU}

LEI Part of Wageningen University;

\section{TімотнY THOMAS}

International Food Policy Research Institute (IFPRI)

\section{Hugo VALIN}

International Institute for Applied Systems Analysis, Austria

\section{HANS VAN MEIJL}

LEI Part of Wageningen University;

\section{DomINIQUE VAN DER MENSBRUGGHE}

HE Global Analysis Project, Purdue University;

\section{MARTIN VON LAMPE}

Organization for Economic Co-operation and Development.

\section{TIM WHEELER}

Department of Agriculture, University of Reading, United Kingdom 


\section{FOREWORD}

$T^{T}$ he growing threat of climate change to the global food supply, and the challenges it poses for food security and nutrition, requires urgent concerted policy responses and the deployment of all the scientific knowledge and accumulated evidence at our disposal. It also requires a sharper focus on the important drivers of climate adaptation, including the potential role of trade to mitigate some of the negative impacts of climate change on global food production.

Knowledge of climate change impacts on agriculture has significantly expanded over the past 20 years. Convergent results are showing that climate change will fundamentally alter global food production patterns. Crop productivity impacts are expected to be negative in lowlatitude and tropical regions but somewhat positive in high-latitude regions. Adverse climate impacts on health, including through malnutrition, are gaining increased attention. Higher carbon dioxide concentration $\left[\mathrm{CO}_{2}\right]$ is shown to lower concentrations of zinc, iron and protein and raise starch and sugar content in crop plants that use three-carbon $\left(\mathrm{C}_{3}\right)$ fixation pathway such as wheat, rice and soybeans. These findings exacerbate the malnutrition challenges, including obesity and nutrition deficits in poor communities.

Since water mediates much of the climate change impacts on agriculture, increased water scarcity in many regions of the world presents a major challenge for climate adaptation. Addressing the implications of future water availability for food security is paramount and requires coherent cross-sectoral, national and regional strategies that address water management supply and demand. Marketbased instruments (water pricing, water trading) could enhance efficient water use and improve water demand management. However, strong institutional structures are also required to ensure people's rightful access to this indispensable and geographically bound resource.

Climate change mitigation measures that affect food security involve emission reductions from many sources. Several technologies targeting adaptation can also have mitigation co-benefits. At the same time, many technologies critical for food security present dilemmas and trade-offs in climate mitigation. Current crop-based biofuels contribute to mitigation as a renewable energy, but can exacerbate emissions through indirect land use change (e.g. deforestation). Nitrogen fertilizer a critical input for agricultural productivity - also presents trade-offs between food production and climate mitigation. A win-win solution requires ensuring that fertilizer is accessible to farmers through efficient delivery technologies, but that its use is reduced without negatively affecting yields or exacerbating greenhouse gas emissions.

Climate impact assessments strongly indicate that trade will probably expand from the mid- to high-latitude regions to the low-latitude regions, where production and export potential could be reduced. At the same time, more frequent extreme weather patterns can also adversely impact trade by disrupting transportation, supply chains and logistics. While global markets can play a stabilizing role for prices and supplies, and provide alternative food options for regions negatively impacted by changing conditions, trade alone is not a sufficient adaptation strategy. Trade requires a balance with a domestic adaptation strategy that avoids too much dependence on imports, which may increase a country's risk of and exposure to higher market and price volatility expected under climate change.

Trade policy plays an important role in affecting future trade flow patterns. Progress on climatecompatible trade policies requires ensuring that climate measures do not distort trade and, alternatively, that trade rules do not prevent 
progress on climate change. In the longer term, trade rules should evolve to allow internalization of the cost of carbon to avoid negatively affecting climate change mitigation. Likewise, future climate change mitigation policies should include measures designed to internalize the environmental costs of resources.

Combatting climate change must go hand in hand with alleviating poverty. Adverse effects of climate change are greater among poor people in developing countries who are highly dependent on climate-sensitive natural resources yet have the least adaptive capacity to cope with climate impacts. Consequently, there is increasing support for mainstreaming climate change responses within pro-poor development strategies. Mainstreaming offers the opportunity to implement 'no regrets' actions that can improve resiliency to current and future climate impacts for the most vulnerable groups while avoiding potential trade-offs between adaptation and development strategies.

Although our understanding of climate change impacts on food systems has expanded, more policy-relevant evidence is required. Stronger emphasis needs to be placed on other important drivers like bioenergy, water and trade. Climate impact science also needs to become more systems-based and improve cross-sectoral frameworks to examine a number of critical linkages: climate-food-trade, climate-nutritionhealth, climate-food-water, and climate-foodenergy. Since the effects of food insecurity and environmental impacts are felt locally, more focus should be given to local validation of climate impacts, taking into account spatial variability, possible adaptation responses, local resource availabilities and constraints, and socio-economic determinants. Robust and reliable evidence is critical to the development of policies to address climate change impacts on agriculture, water and trade. This is critical since climate policy must cope with a certain level of unavoidable uncertainty in the evidence base. Consequently, a structured multi-partner dialogue and information exchange between the scientific community and policy makers is necessary to provide evidencebased support to climate-compatible food security policies.

This book examines these issues in detail and is the outcome of an expert consultation organized by FAO in November 2013 which gathered acknowledged experts in climate impact research. The 11 chapters cover the latest scientific and economic evidence on climate impact assessments of crop and livestock systems. The chapters cover methodological overviews of global climate impact assessments (biophysical and economic) of food systems, as well as specific model-based analyses focusing on a particular region (Africa, Europe, Asia, Eastern Europe and Central Asia, South East Asia) and food systems (small grains, rice, livestock, bananas). Each chapter starts with take-home messages for nonspecialist readers.

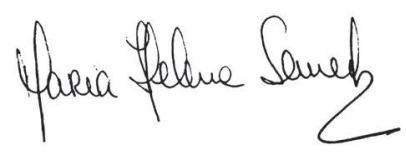

\author{
Maria Helena Semedo \\ Deputy Director-General
}




\section{PREFACE}

his book arose in response to the growing debate about the threat of climate change on the global food supply and the challenges it poses for food security, nutrition, and poverty alleviation. This debate also brought sharper focus on the potential increased role of trade as a driver to mitigate some the negative impacts of climate on global food production.

To assess the best available evidence on the issue and to make it more accessible for policy, the Food and Agriculture Organization of the United Nations (FAO) organized an expert consultation in November 2013 in Rome. During the two day event, a number of acknowledged experts reviewed the current evidence on climate impacts on food systems, examined the research methodologies and gaps, and discussed the policy implications. The consultation also discussed ways to strengthen dialogue between science and policy and to improve information sharing in support of adaptation strategies to cope with climate impacts on global food supply, food security and trade. The present volume is the outcome of this consultation and the contributed papers that followed.

Funding for this work was provided by the Swedish International Development Agency (SIDA) as part of the FAO Multi-Partner Programme Support Mechanism (FMM) (2011-2014).

This book owes its release to many. The first acknowledgement goes to the participants of the expert consultation and the book's contributing authors. David Hallam, Director of the Trade and Markets Division, has actively supported this work and provided the required leadership throughout. Dominique van der Mensbrugghe, then senior economist at FAO, provided valuable expert advice on the consultation program and the active experts in this field. Special thanks are addressed to external peer reviewers of selected book chapters, namely: Joseph Eitzinger, Professor, University of Natural Resources and Applied Life Sciences Austria; Thomas Hertel, Distinguished Professor and Director, the Global Trade Analysis Project, Purdue University; William Liefert, Senior Economist, United States Department of Agriculture, Economic Research Service; and Francesco Tubiello, Senior Officer, Food and Agriculture Organization of the United Nations (FAO).

Special acknowledgement goes to Nadia Laouini who ably managed the administrative support for the November 2013 consultation and for the commissioned papers that followed. Marwan Benali provided valuable technical assistance during and after the consultation. Brett Shapiro carefully copy edited the entire manuscript, while Rita Ashton, Ettore Vecchione and Cinzia Tarisciotti collaborated superbly to format and to create the book art design. 


\section{ACRONYMS}

$\begin{array}{ll}\text { ABM } & \text { Agent-based models } \\ \text { AEM } & \text { agro-ecosystem model } \\ \text { AET } & \text { actual evapotranspiration } \\ \text { AEZ } & \text { Agro-ecological zones } \\ \text { AGGRID } & \text { AgMIP GRIDded crop modelling initiative } \\ \text { AGLW } & \text { Water Resources, Development and Management Service } \\ \text { AGMIP } & \text { Agricultural Model Intercomparison and Improvement Project } \\ \text { AIM } & \text { Asian Pacific Integrated Model } \\ \text { ANZ } & \text { Australia \& New Zealand } \\ \text { AOGCM } & \text { Atmosphere-Ocean General Circulation Models } \\ \text { APEX } & \text { The Agricultural Policy/Environmental eXtender model } \\ \text { APSIM } & \text { Agricultural Production Systems Simulator } \\ \text { AR4 } & \text { 4th Assessment Report of the IPCC } \\ \text { AR5 } & \text { 5th Assessment Report of the IPCC } \\ \text { ASARECA } & \text { Association for Strengthening Agricultural Research in Eastern and } \\ & \text { Central Africa } \\ \text { AVHRR } & \text { Advanced Very High Resolution Radiometer } \\ \text { BEST } & \text { Berkeley Earth Surface Temperature project } \\ \text { BLS } & \text { Basic Linked System } \\ \text { BMZ } & \text { Federal Ministry for Economic Cooperation and Development, Germany } \\ \text { CBA } & \text { Cost benefit analysis } \\ \text { CC } & \text { climate change } \\ \text { CCAFS } & \text { Climate Change, Agriculture and Food Security } \\ \text { CERES } & \text { Clouds and the Earth's Radiant Energy System } \\ \text { CES } & \text { Constant elasticity of substitution } \\ \text { CET } & \text { Constant Elasticity of Transformation } \\ \text { CGCM2 } & \text { Coupled General Circulation Model Phase 2 } \\ \text { CGE } & \text { Computable general equilibrium } \\ \text { CGIAR } & \text { Consultative Group on International Agricultural Research } \\ \text { CIAT } & \text { International Center for Tropical Agriculture } \\ \text { CLUE } & \text { Conversion of Land Use and its Effects } \\ \text { CMIP3 } & \text { Coupled Model Inter-comparison Project Phase 3 } \\ \text { CMIP5 } & \text { Coupled Model Intercomparison Project Phase 5 } \\ \text { CNRM-CM3 } & \text { National Meteorological Research Centre - Climate Model 3 } \\ \text { CO } & \text { carbon dioxide } \\ \text { COMECON } & \text { Council for Mutual Economic Assistance } \\ \text { CORAF } & \text { Conference des Responsables de Recherche Agronomique Africains } \\ \text { CSIRO } & \text { Commonwealth Scientific and Industrial Research Organisation } \\ \text { CSIROMK2 } & \text { Commonwealth Scientific and Industrial Research Organisation Mark 2b } \\ & \end{array}$




\begin{tabular}{|c|c|}
\hline CYF & Climate-yield factors \\
\hline DGVM & Dynamic Global Vegetation Model \\
\hline DIVA & Dynamic Interactive Vulnerability Assessment \\
\hline DRC & Democratic Republic of the Congo \\
\hline DSSAT & Decision Support System for Agrotechnology Transfer \\
\hline EBRD & European Bank for Reconstruction and Development \\
\hline ECHAM4 & Fourth-generation climate model from Max Planck Institute for Meteorology \\
\hline ECHAM5 & Fifth-generation climate model from Max Planck Institute for Meteorology \\
\hline EE4H & leaf four \\
\hline EE5H & leaf five \\
\hline ENVISAGE & Environmental Impact and Sustainability Applied General Equilibrium \\
\hline EPIC & Environmental Policy Integrated Climate \\
\hline EPPA & Predictions and Policy Analysis \\
\hline EPTD & Environment and Production Technology Division \\
\hline ETS & effective temperature sum \\
\hline EU & European Union \\
\hline EV & equivalent variable \\
\hline EVT & evapotranspiration \\
\hline FACCE & Agriculture, Food Security and Climate Change \\
\hline FACE & free air $\mathrm{CO} 2$ enrichment \\
\hline FANRPAN & Food, Agriculture and Natural Resources Policy Analysis Network \\
\hline FAO & Food and Agriculture Organization of the United Nations \\
\hline FAOSTAT & FAO statistics \\
\hline FAPRI-ISU & Food and Agricultural Policy Research Institute - lowa State University \\
\hline FARM & Future Agricultural Resources Model \\
\hline FPU & Food Producing Unit \\
\hline FSM & farming system model \\
\hline GAEZ & Global agro-ecological zones \\
\hline GCAM & Global Change Assessment Model \\
\hline GCM & Global circulation model \\
\hline GDD & Growing degree days \\
\hline GDP & Gross Domestic Product \\
\hline GE & general equilibrium \\
\hline GEF & Global Environmental Facility \\
\hline GGCM & Global Gridded Crop Model \\
\hline GGCMI & Global Gridded Crop Model Intercomparison \\
\hline GHG & Greenhouse gas \\
\hline GHM & Global hydrological modeling \\
\hline GIS & geographical information system \\
\hline GLAM & General Large Area Model \\
\hline GLASS & The Global Assessment of Security model \\
\hline GLC2000 & Global Land Cover 2000 \\
\hline GLOBIOM & Global Biosphere Management Model \\
\hline GNP & gross national product \\
\hline GPS & Global Positioning System \\
\hline
\end{tabular}




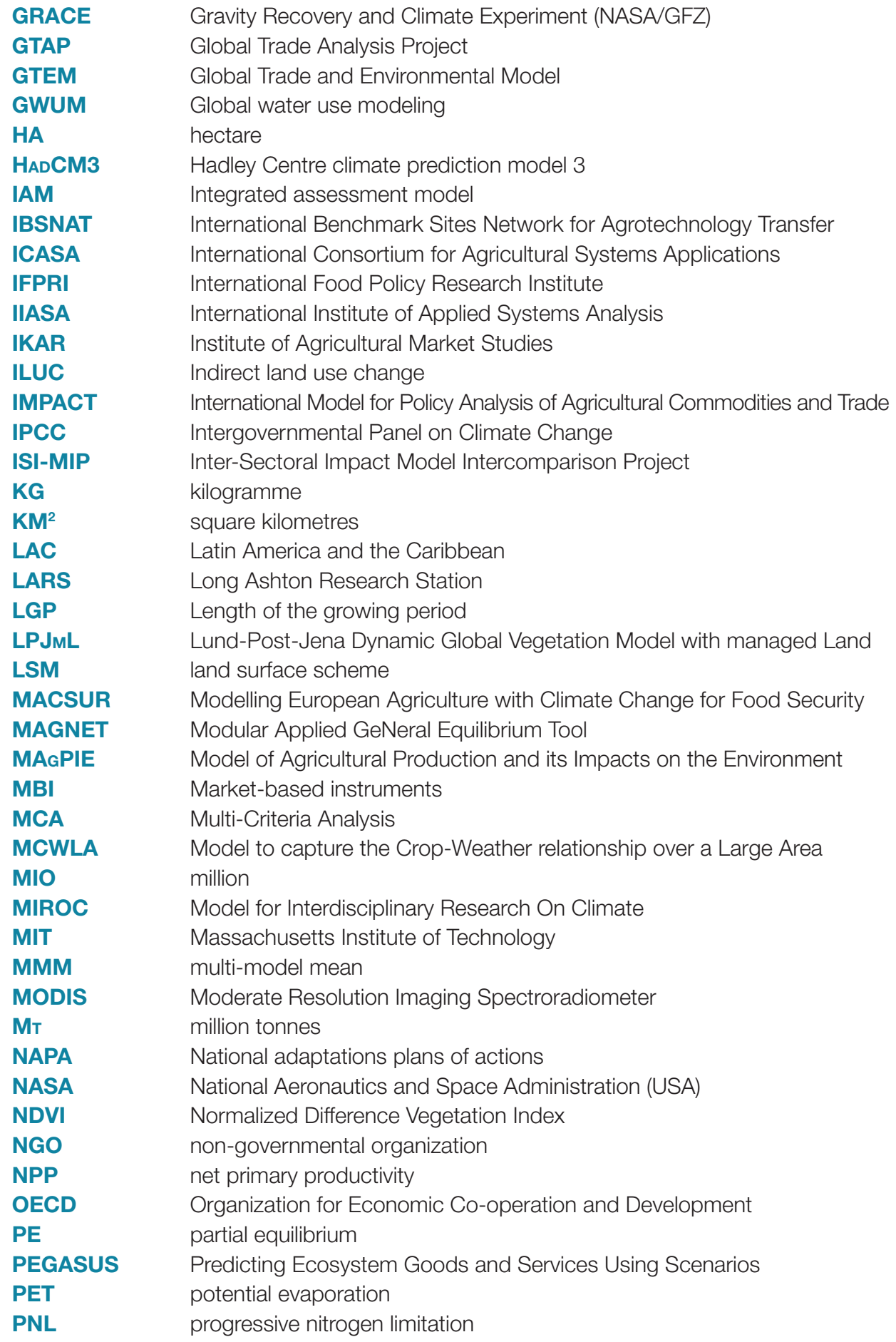




$\begin{array}{ll}\text { PW } & \text { world price } \\ \text { RAIN/PET } & \text { rainfall/potential evaporation } \\ \text { RAP } & \text { Representative Agricultural Pathway } \\ \text { RCM } & \text { Regional Climate Model } \\ \text { RCP } & \text { Representative concentration pathway } \\ \text { SAPWAT } & \text { South African Plant WATer } \\ \text { SLR } & \text { sea-level rise } \\ \text { SPAM } & \text { Spatial Production Allocation Model } \\ \text { SRES } & \text { Special Report on Emissions Scenarios } \\ \text { SREX } & \text { Special Report on Managing the Risks of Extreme Events and Disasters } \\ \text { SSP } & \text { Shared Socio-economic Pathway } \\ \text { SWOPSIM } & \text { Static World Policy Simulation } \\ \text { T/HA } & \text { tonnes/hectare } \\ \text { TDU } & \text { thermal development units } \\ \text { TEM } & \text { Terrestrial Ecosystem Model } \\ \text { TLU } & \text { tropical livestock units } \\ \text { TMAX } & \text { maximum temperature } \\ \text { TMEAN } & \text { mean temperature } \\ \text { TMIN } & \text { minimum temperature } \\ \text { UN } & \text { United Nations } \\ \text { UNFCCC } & \text { United Nations Framework Convention on Climate Change } \\ \text { URB } & \text { urban } \\ \text { USD } & \text { United States dollars } \\ \text { USDA } & \text { United States Department of Agriculture } \\ \text { USSR } & \text { Union of Soviet Socialist Republics } \\ \text { WB } & \text { World Bank } \\ \text { WDI } & \text { World Development Indicators } \\ \text { WMO } & \text { World Meteorological Organization } \\ \text { WOFOST } & \text { World Food Studies } \\ \text { WTMCL } & \text { World Trade Model with Climate-Sensitive Land } \\ \text { WTO } & \text { World Trade Organization } \\ \text { YEXO } & \text { pure climate change impact on crop and grass yields } \\ \text { YILD } & \text { autonomously adapted yields } \\ & \end{array}$




\section{chapter 1}

Page

A. PART 1: CLIMATE CHANGE IMPACT MODELLING CURRENT STATUS AND FUTURE DIRECTION 2

A1. Robust results from existing climate change impact studies

A2. Current modelling challenges $\quad 6$

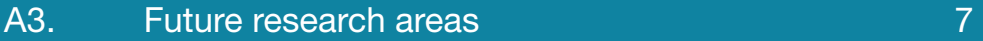

B. PART 2: CRITICAL ISSUES AT THE INTERFACE OF CLIMATE AND FOOD SECURITY

B1. Climate and nutrition:

Improving analysis of climate-nutrition-health links

B2. Climate and water: Growing need for systematic climate-food-water analysis

B3. Climate mitigation and food security:

B4. Climate and trade:

Understanding the trends and tackling trade-offs $\quad 13$

B5. Climate and poverty:

Mainstreaming adaptation into development

C. PART 3: POLICY MESSAGES, COMMUNICATION AND THE NEED FOR TWO-WAY SCIENCE-POLICY DIALOGUE

C1. Matching evidence on climate impacts to the needs of policy-makers

C2. Policy insights on climate change impacts under uncertainty

C3. Harmonizing climate and trade policy

C4. Recommendations for structured science-policy dialogue

References

Citation 


\section{chapter 1}

\section{Climate change, food security and trade: An overview of global assessments and policy insights}

\section{Aziz Elbehri ${ }^{1}$, Joshua Elliott ${ }^{2}$ and Tim Wheeler ${ }^{3}$}

\section{main chapter messages}

- Convergent results are showing that climate change will fundamentally alter global food production patterns, with negative crop productivity impacts likely expected in low latitude and tropical regions but somewhat positive in high latitude regions.

- Water mediates much of climate change impact on agriculture and increased water scarcity in many regions of the world present a major challenge for climate adaptation, food security and nutrition. Tackling the climate-food-watertrade nexus requires deploying coherent crosssectoral, national, and regional strategies.

- Climate impacts on future food supply strongly suggest an enhanced role for trade with expanded flows from the mid-to-high latitude regions to the low latitudes regions, where production and export potential could be reduced. Progress on climate-compatible trade policies requires resolving the trade versus environment trade-offs and ensuring that future trade rules are more aligned with climate objectives.

- Combatting climate change goes hand in hand with alleviating poverty which requires mainstreaming climate responses within propoor development strategies. Mainstreaming should promote 'no regrets' actions that target improved resiliency to current and future climate impacts, especially for the poor and most vulnerable groups.

- Robust and reliable science-based evidence is critical to the development of policies to address climate impacts on food security and trade. A strategic and structured dialogue is required between science and policy and between global and regional impact research with local validation to support policy action.

Food and Agriculture Organization of the United Nations, Italy

University of Chicago Computation Institute, USA

${ }^{3}$ Department of Agriculture, University of Reading, United Kingdom 
PART ONE

\section{Climate change impact modelling - current status and future direction}

F uture land use and food security will be determined largely by the dynamics and interactions of agricultural markets, climatic suitability, adaptive capacity and direct interventions along the supply chain. Perhaps more than any other major economic sector, agriculture is highly dependent on local climatic conditions and is therefore expected to be highly sensitive to changes in climate that are expected in coming decades. This sensitivity is compounded by increasing pressure on the global agricultural system to meet food security objectives and, for some countries, to contribute also to national energy budgets through bioenergy production.

Rapid increases in global demand for agricultural commodities for food, animal feed and fuel are driving dramatic changes in the way we think about crops and land use. Along with recent supply side shocks driven by extreme weather events and other disasters, these conditions have led to increasingly wild swings in agricultural commodity markets that have some stakeholders concerned. In recent years, additional stresses on the land-food system are coming from some of the very mitigation strategies meant to slow climate changes before irreversible impacts occur. Many of the proposed strategies rely heavily on net emissions reductions through terrestrial biosequestration from modified farming practices, reducing application of inorganic fertilizer, avoiding deforestation or increasing afforestation and displacing fossil fuel energy with biomass and biofuel crops.

Conversion of natural lands to crop and/ or livestock production as well as intensifying production on existing agricultural lands will have significant consequences for the environment, such as degradation of soil and water resources, increased greenhouse gas emissions and regional climate effects. Typical farming practices have been shown to reduce soil carbon by as much as 50-66 percent from natural levels [1] and there is little evidence that management practices which could stop or reverse these trends are gaining much traction. It has long been known [2] that direct effects of land-cover change on, for example, surface albedo ${ }^{4}$ and evapotranspiration can be significant drivers of regional patterns of warming and can even have significant implications for changes in global mean variables. These environmental issues pose questions with regard to trade-offs of food and biomass production and increase the threat of environmental limitations on future increases in food production.

\section{A1. Robust results from existing climate change impact studies}

\section{A1.1 Global impacts of climate trends}

Overall expected patterns of climate impacts have been largely stable since the first global scale analyses [3]. Climate impacts in low-latitude regions, given present-day levels of management and technology, are clearly expected to be negative, even at low levels of warming. Impacts in the mid to high latitudes are expected to be more mixed, especially at lower levels of warming. Some high-latitude regions are expected to benefit [4] - sometimes substantially - from warmer temperatures and longer growing seasons; however, other environmental conditions, such as soil quality issues in the far north, will likely constrain expansion.

Recent summary results from the Intergovernmental Panel on Climate Change Fifth Assessment (IPCC AR5) [5] and global model

4 The ratio of reflected radiation from the earth's surface to incident radiation upon it. 
results from the Inter-Sectoral Impacts Model Intercomparison Project (ISI-MIP1) [4, 6, 7] have largely verified these overall patterns and extended them to cover more regions, more crops and higher temperatures. These studies have also added more information regarding the potential for adaptation to ameliorate some portion of likely climate impacts to food production $[5,6]$. Adaptive changes in management - especially planting dates, cultivar choice and sometimes increased irrigation - have been studied to varying extents and are generally estimated to have the potential to increase yields by about $7-15$ percent on average [5], though these results depend strongly on the region and crop being considered and many questions remain. Increasing the concentration of atmospheric carbon dioxide $\left(\mathrm{CO}_{2}\right)$ is widely accepted to have a positive stimulating effect on crop yields under a broad range of other conditions, primarily through increasing the efficiency of photosynthesis, especially in $\mathrm{C}_{3}$ crops (which include wheat, rice and soybeans). The magnitude of this effect, especially in environments with high stress from nutrient, or other, deficiencies, is still a field of active study and debate.

\section{A1.2 Strengths and weaknesses of common model types}

A wide array of models has been applied to the study of climate impacts, at decadal to multidecadal time scales. Models can generally be distinguished as primarily mechanistic or primarily empirical, though most of them fall somewhere between these extremes. Mechanistic models are usually based on field-scale crop models developed over many decades and tend to have the most complex process representations, especially with respect to parameterizing farm management, soil dynamics and genetic properties of different crop cultivars [8-11]. Dynamic global vegetation models have generally evolved from the opposite direction, starting with global-scale land models, often coupled with global earth systems models. Researchers have added crops and related processes to these models using representations of varying complexity, typically with a focus on better representing crucial exchange processes (e.g. carbon, water and energy balance) between land and atmosphere [12-17]. Purely empirical models are used to study global climate impacts, typically at national or continental scales $[18,19]$. These models are useful for capturing in-sample processes and representing hidden variables, but pose challenges for estimation of climate impacts at long time scales, where regimes of atmospheric carbon, technology, management and climate may be fundamentally different from the recent historical past. A newer class of models, called large-area crop models, uses relatively simple representations of key crop processes to produce flexible models that can be statistically calibrated at large scales to capture hidden variables and better reproduce historical trends [20-23].

The scale of application of models and model-based assessments also leads to various trade-offs. Field-scale assessments of climate impacts often benefit from very high quality input and reference data, available at only a handful of experimental sites around the world [e.g. 24]. In addition, the relative simplicity of model execution and data management for these highly localized studies makes it possible to consider many different models and explore detailed subseasonal process differences and uncertainties. Global models require consistent global datasets of climate, soils and management. Many such datasets have been developed for continental or global-scale applications [25-28], but there are often trade-offs in terms of quality and representational complexity in the process of compiling these data.

Bio-economic models of agriculture and food systems (also called agro-economic models) apply results from biophysical model applications within an economic modelling framework (typically a partial or general equilibrium model) [29-35]. These models generally use simple representations of food production and climate impacts combined 
with representations of economies, populations, markets and other demand forces. These models make it possible to parameterize technological change and adaptation in response to prices in a way that is not possible in a purely biophysical assessment.

\section{A1.3 Other drivers of productivity}

For over 30 years it has been generally accepted that trends towards increasing temperatures and changing precipitation patterns in agricultural areas will have major, generally negative, implications for cropland productivity and will increase stress on global food production in the coming decades. In addition to these changes, a number of other related changes in the biosphere could ameliorate or compound these impacts. In fact, it has been suggested that the food security implications of changes in the severity, frequency and extent (both spatially and temporally) of drought events [36] may affect more people in the future than any other climate-related impact [37], though much work is still needed to understand how climate trends will produce precipitation extremes. On the other side of the ledger, increasing concentrations of $\mathrm{CO}_{2}$ in the atmosphere - the very same phenomenon that drives global warming - can have a positive effect on the capacity for photosynthesis and water-use efficiency. These effects vary quite substantially among different crops, especially between those that use $\mathrm{C}_{3}$ and $\mathrm{C}_{4}$ pathways for photosynthesis, and among different regions, depending on the local aridity and the prevalence of other constraining stressors such as nitrogen availability.

For every aspect of future crop production and climate impact, technology and local management practices do and will play a crucial role, and the interactions of environmental, technological and management changes must be better understood and better modelled. Technological change in the agricultural sector proceeded unevenly in the twentieth century (Figure 1) [38]. Maize yields have increased steadily in the United States and China over the last 50 years and show little sign of slowing. Indeed, average yields of maize in the United States surpassed 10.3 tonnes per hectare in 2009, and these increases are expected to continue, at least over the short to medium term [39]. At the same time, average yields in sub-Saharan Africa have been mostly flat, growing

\section{figure 1}

The evolution of average yields for three staple cereal crops in three regions important to global trade and the food, feed and fuel supply [41]. In each plot, the major producer with the highest average per hectare yield is shown (solid blue line), along with the producer for whom yields have grown by the highest fraction in the 50-year period

(dashed yellow line), which is China in all three cases, and an additional region (dotted black line) that, while still important to the global supply, has shown substantially lower average yields and a generally slower pace of increase (and thus presumably has much room to grow given the right conditions)
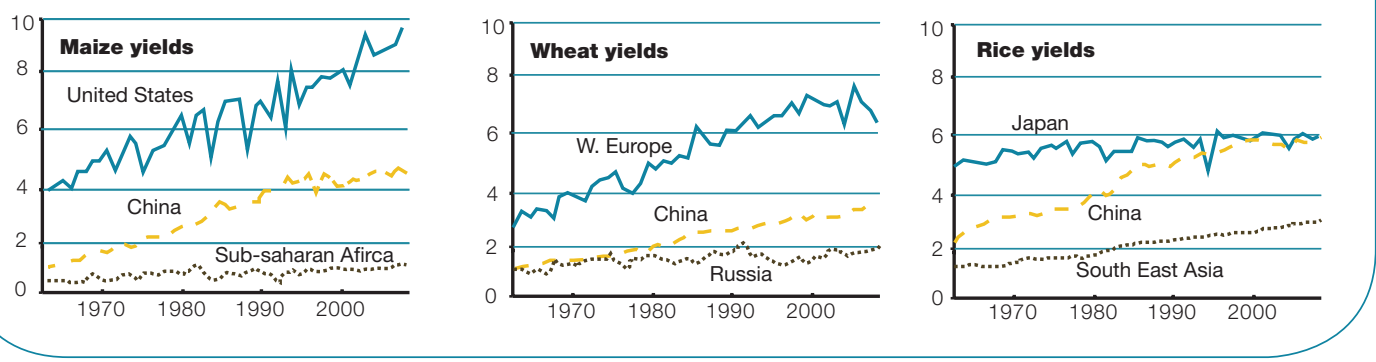
from around 1 tonne per hectare in the 1960s to barely more than 1.5 tonnes per hectare over the last decade. In the case of wheat, average yields in Western Europe have tripled since 1960, but have been largely flat with high volatility since the mid-1990s, potentially indicating a slowing of yield growth [40]. Chinese wheat yields are still significantly lower than those obtained in Western Europe, and are increasing steadily with little sign of slowing. Yields in Russia, meanwhile, have been largely flat for over 30 years but have significant potential for growth.

Rice, the most important staple food crop for a huge portion of the global population, shows a very different profile from the other major cereals. Japan, long the world leader in rice yields, has seen yield growth slow to a crawl over the last 50 years. China, which is both the world's largest producer and largest consumer of rice, saw average yields double from 1960 to 1980 but has struggled to keep up yield growth rates since then and has also seen flat yield trends since the mid1990s. There is still some potential for increased rice yields in South and Southeast Asia, however, with each region accounting for about a quarter of global rice production and averaging 3.5-4 tonnes per hectare in recent years. While in gross terms this is substantially less "slack" than is implied by low yields in maize and wheat crops in large potential bread baskets such as sub-Saharan Africa and Russia, recent trends towards increased rice yields in these areas show that at least here the lower-yielding regions are moving in the right direction.

Substantial yield gaps, defined as the difference between potential and actual yields, caused by imperfect cropland management [42], exist in most parts of the world as a result of market conditions, the availability of resources such as irrigation and fertilizers, and degradation due to poor soil management. The International Food and Policy Research Institute's International Model for Policy Analysis of Agricultural Commodities and Trade (IMPACT) takes the spatial study of climate change impacts beyond analysis of the impacts of climate on key crops at a national level by adding additional analysis that examines global trends and other factors that are changing with the climate, including gross domestic products (GDPs), populations, and agricultural technology development and use (Thomas and Rosegrant, Chapter 5). The model identifies hotspots under climate change where large losses in production are projected to occur, but also areas of climate opportunity, which may have large gains, and/ or areas that were previously unsuitable but can become suitable for crop production at some point. Identification of these climate change hotspots could then provide important information for national policy, as they could be used to aid targeting of resources for adaptation (through policy intervention) or provide incentives, over the longer term, for climate adaptation research - for example, to develop agricultural technologies for the hotspot regions. In extreme cases, hotspots may provide forewarning of areas where agriculture could be untenable in the future, leading to shifts out of agriculture or migration away from the hotspot. Areas identified as climate opportunities, in contrast, could become the focus for inward investment in agriculture and food sectors.

Historically, there have been fewer assessments of climate change impacts on livestock than on the arable sector. Calculation of the uncertainty in livestock projections needs to account for impacts on both feed and fodder, as well as uncertainties in meat and dairy production. For livestock systems based on grazing, Havlik and colleagues (Chapter 6) identified two major sources of uncertainty: which particular crop/ grass growth model was used in the impact assessment; and what assumptions were made about the magnitude of the $\mathrm{CO}_{2}$ fertilization effect on grass growth. They concluded that climate change impacts on grass yields, allowing for these uncertainties, may substantially alter the relative competitiveness of the different systems and hence the overall outcome for the livestock sector in the future. However, projected changes in global milk and meat production by 2050 attributable to direct climate change impacts were comparatively small compared with other influences on demand for 
these products. Global price changes differed by up to 10 percent from the baseline scenario. More substantial differences in uncertainty were found at a regional scale. Climate change effects were most uncertain in the Near East \& North Africa and in sub-Saharan Africa. For example, in the Near East \& North Africa, the change in ruminant meat production due to climate change varied by $+/-20$ percent, depending on the scenario. In sub-Saharan Africa, the effects were the most uncertain, but also potentially the most severe; ruminant production could increase by 20 percent but it could also decrease by 17 percent, with most yield scenarios projecting monogastric meat production to fall by more than 30 percent (Chapter 6).

\section{A2. Current modelling challenges}

\section{A2.1 Mechanisms requiring improved understanding}

Many aspects of modern global agricultural impact models and assessments deserve further study and improvement, especially with regard to the effect of increasing atmospheric $\mathrm{CO}_{2}$ on plant growth, grain formation and crop water use efficiency. Increasing the level of $\mathrm{CO}_{2}$ improves the efficiency of photosynthesis, directly stimulating plant growth. It also reduces sensitivity to drought conditions by improving the efficiency with which crops use the water available in the soil, and can even improve nitrogen use efficiency [43]. These factors can have a compensatory effect on climate impacts, especially in regions where other potential stressors, such as soil quality and availability of key nutrients, are not constraining. These benefits may come with trade-offs in terms of food quality, however. Recent work has found that, in addition to increased caloric productivity, elevated $\mathrm{CO}_{2}$ conditions have substantial negative implications for food nutrition content, with a 40-50 percent increase in $\mathrm{CO}_{2}$ leading to a 5-10 percent reduction in the concentrations of zinc, iron and protein in some crops [44].

Together, these factors will have significant, and potentially transformational, implications for global food and nutrition security and large-scale drought sensitivity. However, global models used to assess climate impacts on crops disagree significantly on the strength of $\mathrm{CO}_{2}$ fertilization effects, with their inclusion doubling or even tripling the range of outcomes within the model ensemble [4]. These differences are closely linked to whether a given model represents the nitrogen cycle and what assumptions are made about fertilizer application rates and nitrogen availability, now and in the future.

\section{A2.2 Data requirements for model improvement}

Perhaps the most important factor limiting the improvement of field-scale crop models is the existence and availability of experimental data, especially for conditions well outside normal experience, such as from large increases in $\mathrm{CO}_{2}$ or extreme temperatures. Availability of data from Free-Air $\mathrm{CO}_{2}$ Enrichment (FACE) experiments $[43,45]$ is beginning to address this issue but many more experiments are needed for many more crops under many different conditions to understand the complex interactions among Carbon, Temperature, Water and Nitrogen (CTWN) [46]. Global-scale impact modelling poses additional challenges. Assessments require high-resolution data on daily weather, soil and environmental conditions, crop-specific cultivation areas, irrigation and fertilizer use and local cropping calendars. High-quality reference data are also necessary to facilitate evaluation of models at the scales of interest. Finally, many applications require long time series of these types of data in order to evaluate distributions, trends and extremes. Recently, significant progress has been made on many of these data requirements, notably including global high-resolution time series reference data from subnational statistics [47] and 
hybrid algorithms combining national statistics and remotely sensed measures of plant growth [48].

\section{A2.3 Accounting for management changes and other human responses}

Technological changes, mainly in the form of new cultivars, field management practices and industrial production techniques for inorganic fertilizers, have led to huge increases in yield in the developed world since the end of World War II. Most assessments of the future socio-economic conditions of the global population assume that crop yields in developed countries will continue to increase linearly or even exponentially, and that crop yields in developing countries will soon begin to accelerate, meeting or even exceeding their pace of growth in the developed world. The recent historical record on growth rates in yield, however, is more mixed (as summarized in Section A1.3, in $[38,40]$ and Figure 1). Yield gaps in the developing world are generally estimated to be 50 percent or more of potential yields [49]. Recent work suggests that average maize yields in sub-Saharan Africa could be doubled by an increase of fertilizer application to about $50 \mathrm{~kg} / \mathrm{ha}$ nitrogen [50]. While modest by global and developed world standards, this level would nevertheless require an increase in fertilizer availability of more than seven times the current level in sub-Saharan Africa and, given present day capacities, this increase is unlikely to be attained in the near future.

Much work is also still needed to identify how the options for agricultural development and adaptation and other likely sociotechnical changes might interact with climate changes in the coming decades. Towards this goal, the Agricultural Model Intercomparison and Improvement Project (AgMIP) has developed protocols [51] for the creation of Representative Agricultural Pathways (RAPs), story lines and scenario information products for the future of agricultural systems that are consistent with the Shared Socio-economic Pathways $[52,53]$ and the Representative Concentration
Pathways $[54,55]$ created for the IPCC AR5 process. RAPs are being developed for many different systems and modelling purposes, at scales ranging from individual farms to national and global food systems.

\section{A3. Future research areas}

\section{A3.1 Multimodel assessment and intermodel comparison: benefits and limitations}

Increasingly, the above considerations have driven interest in scientific assessments of agricultural production, demand, markets and land-use trends. Many collaborative initiatives and institutions around the world have undertaken large-scale projects to address underlying scientific questions about productivity and environmental sustainability, as well as to gather, produce and distribute the technology, data and information products required by stakeholders and policy-makers. To be credible, these assessments must account simultaneously for the socio-economic drivers of demand, the environmental limitations and changes from a warming climate, and the potential and limitations for sociotechnical adaptations to vulnerabilities and impacts. To be maximally useful, they must additionally be able to address the major underlying uncertainties in the system and deliver information products and impact measures across a wide range of spatial and temporal scales.

Examples of ongoing collaborative initiatives include: AgMIP [51]); ISI-MIP [56]; and the Modelling European Agriculture with Climate Change for Food Security project (MACSUR, [57]). AgMIP includes many and various protocoldriven climate scenario simulation exercises for historical model intercomparison and future climate change conditions. It involves ecophysiological and agricultural economics modelling groups, by extending the multimodel applications from global circulation models to ecophysiological and economic trade and impact models [51]. 
ISI-MIP takes a similar protocol-driven approach to AgMIP, expanding the sectoral coverage to include hydrology, biomes and health impacts of climate change. MACSUR is a modelling network focusing on impacts of climate change on European agriculture [57]. MACSUR integrates models covering livestock, crops and economics to describe how climate variability and change will affect regional farming systems and food production in Europe in the short and long terms.

\section{A3.2 Country-scale assessments: data requirements and successful case studies}

Because of the current international nature of agricultural markets and the relevance of global change drivers (climate, population, consumption and regulation), food security and land-use change dynamics must be evaluated at the global scale. The effects of food insecurity and environmental impacts, however, are largely experienced locally and confronted by decision-makers at national or regional scales. For this reason, assessments of impacts and adaptation potential are also needed at national and even sub-national scales. For these assessments to be useful at the level expected by policy-makers and stakeholders at the regional scale, they require higher resolution (in space and time) data with improved representations of local management practices and potential adaptation options (e.g. [58-61] in sub-Saharan Africa, [62, 63] in South America, [64-66] in South Asia and [67] in East Asia).

\section{A3.3 Model projections and uncertainty}

Crop models, especially when run at global scale, are highly complex models that differ widely in terms of process representations, functional implementations, data input choices and basic assumptions. Even with the same version of the same basic underlying model, for example (as in the case of the Economics and Policy Innovations for Climate-Smart Agriculture (EPIC) and Global EPIC (GEPIC) modelling groups from the AgMIP/ ISI-MIP Phase 1 Fast-Track), results often differ substantially [4], due to different assumptions about planting dates and fertilizer application rates, different choices for the functional representation of key processes such as evapotranspiration, and different implementations of the same functional representation (e.g. different choices of parameter values). To begin to understand these differences, the Global Gridded Crop Model Intercomparison (GGCMI), launched by AgMIP in 2013, is carrying out a set of simulation experiments run with harmonized data for a number of the key inputs that drive model differences, including planting dates, growing season length, fertilizer application rates and atmospheric $\mathrm{CO}_{2}$ concentration pathways [68].

\section{A3.4 Incorporating current and future resource constraints}

Concern has been growing recently over constraints to agricultural production and productivity growth caused by the availability of key resources such as land, fresh water and fertilizers. These resource constraints are likely to compound the negative effects of climate change in many regions and hamper efforts at adaptation [6]. Climate change will directly affect the availability of resources such as fresh water for irrigation [69], and sociotechnical changes such as population growth and new energy technologies will directly affect the supply and availability of other key resources, such as land. Evaluation of resource availability and constraints must therefore be done within a broad multisector context that includes assessments by, for example, hydrological models, agro-economic and integrated assessment models, and ecosystem models. ISI-MIP has made some progress in this direction already, including agro-economic, hydrology and biome models in the fast-track phase, and the next round of coordinated assessments should provide greatly 
improved capacity as a result of the addition of new impact sectors such as forestry, biodiversity and energy systems models.

\section{A3.5 Emerging and unknown future technologies}

Technological change is typically incorporated in climate impact assessments through relatively simple parameterizations of productivity growth in agro-economic models, using a method that assumes that the effects of technological and environmental changes on productivity are completely separable [16]. However, the interactions between technology and environment are usually more complex. For example, new tillage practices can reduce the exposure of top soil to the air, reducing evaporation, improving soil moisture characteristics and reducing sensitivity to drought and heat. Breeding can lead to new cultivars that send roots down faster and deeper, increasing access to water in the soil profile, or that are more robust to underwater submergence conditions [70] that could become more common in a future climate. For these reasons, technological change should be included directly in biophysical impacts models and assessments through trends in model parameters and inputs. Getting this right will require renewed engagement between modellers, agronomists, and crop breeders.

\section{A3.6 Improving economic modelling of climate impacts in agriculture}

Improving economic analysis as part of modelling climate impacts in agriculture requires several model improvements. First, it is necessary to improve representation and integration of biophysical processes into economic models. This requires that economists increasingly work with researchers from other disciplines, recognizing that climate change impacts and their analysis pose a multidimensional problem. Also required is the ability to model extreme events and variable climate conditions, as opposed to the usual treatment of gradual climate change, which is much harder to detect but for which most Integrated Assessment Models (IAMs) are designed. Economic models also need to systematically quantify uncertainties related to structure and parameters and to frame economic conclusions in the context of known model limitations. Expressing the model results in probabilistic terms helps decision-makers to understand the risks of under- or overinvesting in adaptation to high- or low-probability climate change outcomes.

\section{A3.7 Economic modelling of climate and trade}

Trade is increasingly a subject of analysis within the economic modelling of climate change. Economic models show that trade can cushion against the large production shocks resulting from climate change and, if unrestricted, trade is expected to increase to compensate for production shortages or shifts in production patterns across regions due to climate [71-77]. However, the empirical evidence is incomplete and fraught with the usual caveats related to uncertainty vis-à-vis future climate outcomes and developments in climate and trade policy. More robust trade analyses in the context of climate change should integrate direct climate impacts on agricultural productivity, demand-side drivers (e.g. consumer diets, labelling, subsidies), resource constraints (such as climate-induced irrigation water shortages), as well as climate policies (e.g. carbon taxes, standards, ecolabelling). Moreover, the two-way linkage between climate and trade is not a settled issue as there remain a number of unanswered questions related to the environmental impact of increased trade (such as indirect land-use change from biofuel trade expansion). 


\section{Critical issues at the interface of climate and food security}

Robust trends on global agricultural productivity are emerging from the growing literature on climate impact assessments, with clear indications of differential responses across regions. While climate change effects on agriculture will be felt everywhere, some regions will be more negatively affected than others, while some regions may benefit from climate warming - up to a point. Convergent results are showing negative effects on food supply in tropical zones but some positive effects in high-latitude regions. Moderate warming may benefit crops in the mid and high latitudes in the short term. However, any warming in seasonally dry and low-latitude regions would decrease yields. Densely populated developing countries in these regions are vulnerable to increased food insecurity [78].

These global trends present the world with multiple global challenges (globalization, sustainability, climate change, increased inequality) locked in increasing interdependence. The first global challenge is how to minimize, if not reverse, the negative impacts of climate on global food supply. Second, climate change is likely to exacerbate the growing inequality as the brunt of the negative climate effects is expected to fall on those countries that are least developed and most vulnerable. For these countries, low levels of economic development, weak institutions, and limited human and financial capital all contribute to limited resilience capacity. The third challenge is how to develop climate-compatible growth strategies that do not conflict with mitigation goals required to minimize further warming. Fourth is how to sustain policy commitments in a world increasingly defined by uncertainty, climate variability and greater policy interdependence.

\section{B1. Climate and nutrition: Improving analysis of climate- nutrition-health links}

Adverse global impacts of climate change on health, including through malnutrition, are gaining increased attention. For example, in Kenya, a positive relationship has been observed between regional trends in climate (rising temperatures and declining rainfall) and childhood stunting since 1975 [80]. Climate-induced health risks develop from a variety of sources, including climate influence on food yields, water supply and quality, and infectious diseases, as well as the adverse health effects of social disruptions, migration and conflicts. In addition to adverse effects on food supply and adequate nutrition, climate change is likely to exacerbate global health concerns such as: increased incidence of new influenza virus strains; decline of available seafood proteins due to ocean warming, acidification and overfishing; and worsening freshwater shortages and resulting displacements and conflicts [80]. Some populations, especially in the least-developed countries, will be more negatively affected than others. Low-income and remotely located populations are more vulnerable to physical hazards, undernutrition, diarrhoea and other infectious diseases. Populations in low-lying islands and coastal areas, like Bangladesh, are also vulnerable to increased storm surges and flooding as the sea levels rise [80].

There is relatively little research on the implications for food quality and possible implications on human nutrition. A recent study reported that $\mathrm{C}_{3}$ grains (e.g. wheat, rice) and legumes have lower concentrations of zinc and iron when grown under field conditions with elevated $\mathrm{CO}_{2}$ levels [44]. $\mathrm{C}_{3}$ crops other than legumes also have lower concentrations of protein. Analysis of food balance sheets from the Food and Agriculture Organization of the United Nations (FAO) found that in 2010 roughly 667 million people were living in countries whose populations received at least 60 percent of their dietary zinc and iron from $\mathrm{C}_{3}$ grains or legumes. Similarly, 1.9 billion people who 
lived in these countries received at least 70 percent of one or both of these nutrients from these crops [44]. In the case of reduced proteins, the health implications from consuming non-leguminous $\mathrm{C}_{3}$ plants are not uniform across regions and depend on local food patterns. In India, where up to a third of the rural population is at risk of not meeting protein requirements, and who depend on $\mathrm{C}_{3}$ plants, decreased protein content due to higher $\mathrm{CO}_{2}$ levels may have serious health consequences [44]. An extensive meta-analysis, covering 7761 observations and 130 species/cultivars, corroborated these findings [81]. This study found that elevated $\mathrm{CO}_{2}$ reduces the overall mineral concentrations (by 8\%) and increases the total non-structural carbohydrates (mainly starch and sugars) in $\mathrm{C}_{3}$ plants. These results offer the first robust documentation of the adverse nutritional impact of climate change, which can exacerbate the prevalence of "hidden hunger" and obesity.

In the economic realm, the IMPACT modelling framework provides projections of climate impacts beyond production changes, all the way to nutrition outcomes. For example, the number and share of children who are malnourished in Africa is projected to be higher with climate change than without climate change, but both the number and share of malnourished children would fall between 2010 and 2050 as incomes rise for other reasons (Chapter 5, Table 13). However, more systematic probing of the nutritional implications of climate impacts on food security is required to generate the evidence required for appropriate policy response.

\section{B2. Climate and water: Growing need for systematic climate-food-water analysis}

Much of the climate change impact on agriculture is mediated through water. In many regions of the world, increased water scarcity under climate change will present a major challenge for climate adaptation. It is of paramount importance to address the implications of future water availability for food security and, by extension, nutrition and health. This requires improved modelling of hydrological processes and climate impacts on water dynamics at appropriate scales. It is also important to address the economics of water use, taking into account the special nature of water as a resource requiring a balanced approach between market instruments and institutional structures.

Hydrological modelling is a growing field of research. Improvements in downscaling techniques are making it possible to reconcile the scale gaps between large-scale climate impacts and local-scale hydrological processes. Interlinked models have also been designed to reconcile the scale difference between the basin-level hydrological models and the more aggregate (or national) level economic models. As water availability has become a global concern in light of climate change, more quantitative global hydrological and economic models are required to help facilitate global policy dialogue on water issues. Recent work has assessed the global impact of diet change on the blue (irrigated) and green (rainfed) water footprints of food consumption [82]. The study showed that when the dietary guidelines are followed, gradually limiting the amount of total protein intake from animal products to 50 percent, 25 percent, 12.5 percent and finally 0 percent reduced water consumption by 6 percent, 11 percent, 15 percent and 21 percent for green water, and by 4 percent, 6 percent, 9 percent and 14 percent for blue water, respectively [82]. These results suggest that reducing animal products in the human diet offers the potential to save water resources, up to the amount currently required to feed 1.8 billion additional people globally.

Economists argue for higher reliance on water markets and water pricing regimes as an effective adaptation tool to help facilitate water use by considering higher-value uses. At the same time, water is not a typical commodity, but a resource whose use is geographically bound, and whose access is determined by rights (not just by market value) and managed through public institutions. 
Water economics present a number of modelling challenges because water is a resource whose use can be optimized in part through market instruments but which requires strong institutional structures to ensure people's rightful and equitable access to water. Modelling economics of water requires improved specification of the level and structure of water prices, the scope of water trading between users and across basins and the costs of water infrastructure investments. A key challenge is the availability of data, which are localized and managed by subnational agencies and lack consistency across regions. More importantly, economic water modelling improvements require including the political economy dimension of water markets (e.g. nonprice water conservation mandates, legal property rights regimes).

\section{B3. Climate mitigation and food security: Co-benefits versus trade-offs}

Climate change mitigation measures that affect food security involve reducing emissions from many sources. Several technologies targeting adaptation can also have mitigation co-benefits. Examples include new varieties with higher yields and enhanced pest and drought resistance, carbon sequestration and ability to survive on marginal lands.

Climate change mitigation and adaptation have revived discussion about the role of agricultural biotechnology and its potential to intensify production of food while reducing pressure on cropland. However, the potential value of biotechnology has been contested, and its dissemination is limited by demands for product labelling and other environmental approvals and controls under the Biosafety Protocol of the United Nations Convention on Biodiversity. Whether biotechnology can find a place among mitigation measures to combat climate change remains an open question.
Biofuel production falls at the interface between renewable energy and climate mitigation. Support to biofuel production in the last two decades, especially in the United States and Western Europe, was prompted in part as a contribution to climate mitigation. However, biofuels have become controversial, especially in relation to indirect landuse change and its association with increased carbon emissions (linked to deforestation). While awaiting economic breakthroughs for secondgeneration biofuels, current biofuel production from crops (rapeseed, maize, canola, sugar cane, soy, palm oil) is expected to continue over the medium term. Given that the net effect on mitigation of current biofuels is still uncertain, many countries have taken a more cautionary approach. Earlier drives for biofuel investments in developing countries have been scaled back due to concerns over food security conflicts. In the area of research, modelling biofuels within integrated assessment models requires more detailed account of land-use change effects. Also required are further advances in analysing climate-energy-food linkages and taking into account policy instruments and technology advances.

Nitrogen fertilizer - a critical input for agricultural productivity for non-legume crops also presents a trade-off in terms of climate mitigation. Reducing emissions related to the production and use of nitrogen fertilizer will increase its cost, reduce its use and hence prevent yield gains required for intensification. There are, in fact, multiple trade-offs. The first is between food production and climate mitigation. Another trade-off is between intensifying agricultural production with the use of fertilizers, which lessens land pressure (hence lowering emissions), or reducing emissions from fertilizer production, resulting in stagnant yields and higher pressure on forests and grasslands. Clearly a balanced approach is required, one that ensures fertilizers remain affordable to farmers but with improvements in use efficiency (through better fertilizer delivery technologies) that would allow for lower fertilizer use without negatively affecting yield. 


\section{B4. Climate and trade: Understanding the trends and tackling trade-offs}

Climate change fundamentally alters global food production patterns and, given the fact that impacts are expected to be worse in low-latitude regions, climate change is likely to exacerbate existing imbalances between the developed and developing world. For crop impacts at least, there is now a coherent pattern of yield changes across the world, with yields expected to increase in some higher latitude regions until about the mid-century before declining, but with almost immediate declines in yields across the tropics [83]. Spatial differences are also observed at regional and subregional scales, particularly where there are substantial differences in elevation. The impacts of climate change (and of climate mitigation policies [84-87]) thus have a major impact on patterns of global trade [88].

It is clear from climate change impact assessments to date that trade will probably expand under climate change. Trade flows would increase from mid to high latitudes towards lowlatitude regions, where production and export potential will be reduced [78]. Climate change is also projected to cause wide variations in the net global food supply as the result of a higher frequency of droughts and extreme weather events [78]. Climate change can transform trade by altering the comparative advantages, while more frequent extreme weather patterns have an adverse impact on trade by disrupting transportation, supply chains and logistics [89].

Trade can also affect climate change. Increased economic activity, including trade, also increases greenhouse gas emissions. In many developing countries that have weak enforcement of environmental protection, growing demand for food crops drives the expansion of production for exports (maize, rice, biofuel feedstocks). In other cases, unregulated exports of forest products can exacerbate deforestation, land degradation and loss of biodiversity.
Global markets can play a stabilizing role for prices and supplies and provide alternative food options for negatively affected regions by changing conditions or by finding regions where food can be produced more efficiently (both in terms of environmental and economic costs). However, trade alone is not a sufficient adaptation strategy, owing to several trade-offs. First, there is serious tension between trade versus the environment. Second, dependence on imports to meet food needs may increase the risk of exposure to higher market and price volatility that is expected under climate change. A recent example can serve as an illustration of future trends. The extreme heat and wildfires in western Russia in the summer of 2010 destroyed one-third of that country's wheat yield, and the subsequent ban on exported grain contributed to a rise in the price of wheat worldwide, exacerbating hunger in Russia and in low-income urban populations in countries such as Pakistan and Egypt [80].

The spatial dimension of climate change impacts will be critical to the development of trade policies. Müller and Elliott (Chapter 2) show how the impacts of climate change on the production of food calories could vary spatially by the end of the century. They attribute uncertainties in these projections to patchy coverage of data for model calibration and testing, lack of knowledge of management practices across the modelling domain and limited physiological understanding of crop response to elevated $\mathrm{CO}_{2}$. They conclude that "consideration of various scenarios on future agricultural management is crucial" to the assessment of future agricultural productivity under climate change.

In addition to the direct impact of climate change on primary production, changing socioeconomics can alter comparative advantages and trade flows, and potentially alter future international competitiveness and agrifood trade patterns (see Ahammad, Chapter 10). Model projections of imports and exports under climate change showed differences across scenarios due to non-climate economic, demographic and technology assumptions. However, Ahammad identified common trends across climate change 
model runs, such as the continued importance of the United States as a net exporter of coarse grains and oilseeds in 2050 and that net trade for the fast-growing developing economies and exports were both projected to decrease by much less than the projected decline in production attributable to climate change. Various projections for trade in China showed contrasting responses on trade, highlighting an important area in which the evidence is uncertain.

\section{B5. Climate and poverty: Mainstreaming adaptation into development}

Combating climate change must go hand in hand with alleviating poverty. Adverse effects of climate are greater among the poor in developing countries, who are highly dependent on climatesensitive natural resources yet have the least adaptive capacity to cope with climate impacts. There is general agreement that development investments in climate change impact are competing with efforts to eradicate poverty over the medium term [91].

Consequently, there is increasing support for mainstreaming climate change responses within human development and poverty alleviation rather than pursuing separate climate and poverty tracks and risking potentially negative outcomes for one or the other of these goals. Such mainstreaming would require policies that can achieve co-benefits for poverty alleviation, climate adaptation and greenhouse gas emission reduction [92, 93, 94]. Mainstreaming involves the integration of information, policies and measures to address climate change in ongoing development planning and decision-making. Mainstreaming should create "no regrets" opportunities for achieving development that are resilient to current and future climate impacts for the most vulnerable groups, and avoid potential trade-offs between adaptation and development strategies, which can result in maladaptation [91].
Given that the task of alleviating poverty is itself formidable, adding climate adaptation and mitigation hugely complicates the process, requiring an innovative framework commensurate with the complexity at hand yet tractable to achieve results. While there is no single methodology to achieve this, some basic concepts exist that can guide mainstreaming adaptation [92]. First among these is the view that climate adaptation is inseparable from the cultural, economic, political, environmental and developmental contexts in which it occurs. Second, responses to climate change often cross spatial and jurisdictional boundaries, requiring coordination to avoid maladaptation. Third, because of positive feedback loops, system trajectories are path-dependent and difficult to change. Fourth, contested rules, values and knowledge cultures determine social decisionmaking processes which respond to change [95]. These basic guidelines clearly suggest a paradigm shift between research, policy and practice [92] so that adaptation pathways must be able to trigger a change along each of three components. Such a shift also means that processes and tools must be developed among all the key stakeholders who can facilitate and manage the contested decisionmaking arena [92].

In practice, how mainstreaming is achieved depends on the adaptation approach taken that is, technology-based (impacts-based) or development-based (vulnerability-based) [91]. Under the former, mainstreaming ensures that projections of climate change impacts are considered in the decision-making about climate investments (known as "climate-proofing"). With the development-based view, adaptation goes beyond "climate-proofing" and recognizes the implication of many actors and the importance of an enabling environment. This approach emphasizes the need to remove existing financial, legal, institutional and knowledge barriers to adaptation, and to strengthen the capacity of people and organizations to adapt. A review by the World Resources Institute of over 100 "adaptation" interventions found that adaptation and development are not totally separable. These 
interventions lie along a continuum, from those that overlap almost completely with development practices that build general resilience to those that are focused more specifically on climate change impacts. [96]

As an illustration of adaptation mainstreaming, a recent study from Bangladesh describes a framework that follows a linear sequence of stages, starting with raising awareness, scientific capacity building, generating evidence and conducting pilot studies to inform and engage the decision-makers in policy planning [91]. Building awareness is a critical first step towards generating enough interest on the part of decision-makers to demand climate vulnerability information. It is necessary to generate evidence that can show how and why climate vulnerability is a problem requiring integration into development decisions. Locally developed information is more likely to be relevant to the decision-making contexts of country decision-makers. Investing in building national capacity is required to generate locally appropriate evidence that is connected to the body of international climate science. For least-developed countries, technology transfer is a critical requisite for successful adaptation strategy and requires creative options to relax the patents and other intellectual property protection constraints to technology transfer from advanced countries to developing countries [97]. The next stage in the framework calls for pilot studies to inform policymakers and to generate incentives to incorporate the lessons learned into policy planning. The final stage involves the full integration of climate change adaptation into policy and planning across different sectors and scales, requiring investment planning that combines "climate proofing" with building resilience among the climate-vulnerable poor. It is at this stage that government stakeholders and decision-makers become fully engaged in adaptation planning.

As our understanding of climate and food security increases, we need to steer it beyond crop yield impacts and expand the debate into new drivers of food productivity (biotechnology, bioenergy and trade). Climate impact on food security should be broadened systematically to include nutrition and health. Of particular relevance is the need to broaden the crop coverage to include crops important for regional (not necessarily global) food security, as well as other land- use enterprises (livestock, agroforestry). Climate impact should also be linked with poverty alleviation and sustainability of resources (water, soils, nitrogen fertilizer). Climate impact science also needs to become more systems-based and multidimensional. For example, addressing the health risks of climate change requires a crosssectional approach because health risks are tied to such sectors as water, agriculture and energy. Improved frameworks are necessary to examine cross-sectoral linkages such as climate-food-trade [79], climate-nutrition-health, climate-food-water and climate-food-energy. In addition, global climate impact analysis should "come down to earth" and be validated at the local level, accounting for spatial variability, possible adaptation responses, local resource availabilities and constraints, and socio-economic determinants.

\section{PART THREE}

\section{Policy messages, communication and the need for two-way science-policy dialogue}

\section{C1. Matching evidence on climate impacts to the needs of policy-makers}

Robust and reliable evidence is critical to the development of policies to address climate impacts on agriculture, food and trade. When used effectively, evidence can be used to guide decisions on policy, highlight options for policy action and also identify areas where insufficient 
evidence currently exists. However, the interaction between those generating evidence (climate science) and the needs of those developing policy is not straightforward. This section considers which factors contribute to an effective science-policy dialogue and highlights examples from this volume of evidence about climate impacts on agriculture, food and trade that are relevant to policy. It concludes with a recommendation for a forum to enable more effective dialogue between science and policy.

There is often a mis-match between the type of evidence produced from the climate impact research community and what is needed for policy development. This can be illustrated with two contrasting examples. The first is that primary evidence, as it is produced, is often too detailed. At the time of publication of the first report of the IPCC in 1990 (with a supplement in 1992) [98], little was known about the impacts of humaninduced climate change on agricultural crops and livestock. The synthesis of climate science knowledge by the IPCC prompted crop scientists to begin investigating the direct effects of warmer temperatures, changed rainfall patterns and elevated concentrations of $\mathrm{CO}_{2}$ on the growth of crops. Over the next two decades many thousands of research papers reported findings on the direct impacts of climate change on all of the world's major food crops in many different countries and regions. This work provided a wealth of detail, but on its own the evidence is not easily interpreted by those looking for high-level conclusions on climate impacts across the sector to guide policy formulation. Instead, it is the syntheses of primary research that more closely meet the policy need for robust and coherent statements of evidence from the underpinning science. Good examples of evidence syntheses include: the "impacts" chapters of the subsequent IPCC reports, most recently in 2014 [99]; a systematic review of crop impacts in Africa and Asia [100]; and a recent meta-analysis of climate change impacts on crops [101]. These syntheses of knowledge provide robust statements of current evidence that can be used with a degree of confidence by those looking for summaries of the state of evidence on climate impacts. A number of such statements regarding climate impacts on food security were recently proposed [83].

The second example of a mis-match between evidence needs for policy and research knowledge is that the evidence is often not specific enough to base policy and operational decisions on it. This may seem to contradict the first point that research evidence is too detailed - but it is a different issue, best illustrated through an example. Knox and colleagues [100] reviewed all studies to date of climate impacts on the major food crops across Africa and South Asia using systematic review criteria as a quality filter. A range of modelling methods, time periods and ensemble sizes (from a single climate model to ensembles of 20 or more climate models) were included. They found that average crop yields were projected to decline across both regions by 8 percent by the 2050s. Across Africa, yields were projected to change by -17 percent (wheat), -5 percent (maize), -15 percent (sorghum) and -10 percent (millet), and across South Asia by -16 percent (maize) and -11 percent (sorghum) under climate change. No mean change in yield was detected for rice. These are all clear and robust statements of impact for crops and regions for which there is good coverage in the evidence base. However, for many crop and country combinations there was not enough evidence to draw any general conclusions; thus, the authors concluded that the evidence was either inconclusive, absent or contradictory for rice, cassava and sugar cane. Those looking for evidence for important African staples such as yam, millet and bananas on which to base climate adaptation policies will find almost nothing on which to base policy advice.

Those that work on the science-policy dialogue are not necessarily drawn from only research institutions or policy organizations. Instead there are a raft of intermediary organizations, such as think tanks, civil society organizations and consultancies, that synthesize, filter, reinterpret and reorganize evidence to aid the uptake of information into policy. For example, the Climate 
Development and Knowledge Network [102] combines research, advisory services and knowledge management in support of locally owned and managed policy processes. Where these organizations also act as portals, they can facilitate sharing of evidence, experiences and lessons from past and current policy initiatives.

A common barrier to the uptake of evidence into policy is that the evidence does not meet, or is not presented in a way that meets, the information needs of those developing policy. Often the research community does not start by defining the information needs of the policy community, but instead works from the evidence in search of applications in policy. Such an approach is often ineffective and will also contributes to a mis-match of information with needs for evidence. The way in which science is communicated for policy development is different from a simple technical summary of the research. For example, the IPCC Summaries for Policy-makers are quite different from the Technical Summaries, even though both are based on the same synthesis of evidence. Effort invested in matching the form of evidence communication to the needs of the intended reader is clearly worthwhile.

Finally, the timing of evidence for policy is absolutely critical. Evidence needs to adjust to policy and political cycles. Many policy-advising intermediary organizations have addressed these communication barriers to provide finer-level and more rapid analyses tailored to specific policy requirements for information and knowledge.

\section{C2. Policy insights on climate change impacts under uncertainty}

Most policies have to cope with levels of uncertainty in the evidence base they use. This is definitely the case for climate adaptation policies, perhaps more so than in other policy areas. Uncertainties for climate policy arise regarding greenhouse gas emission scenarios and from the climate and crop models that are used to form projections of future impacts. Numerical methods can be used to better define the boundaries of uncertainty, by running ensembles of climate models [103] or by systematically varying parameters within climate [104] or crop models [105], but considerable uncertainty in projections will still remain. Rötter and Höhn (Chapter 4, Figure 1) show how uncertainties and errors in climate change impact modelling are propagated along the impact modelling chain.

Policy advice will often define options for action. A robust assessment of the uncertainties in impact projections can contribute to at least a qualitative statement of the risks about individual policy options. Indeed, the absence of any statement of uncertainty implies that each option is equally uncertain. However, it is likely that the precision of these statements will at most be approximate. The calibrated language used by the IPCC to communicate uncertainties in climate science and impacts evidence is a good example [106]. Confidence in IPCC conclusions from the evidence is a product of the degree of expert agreement and the completeness of the evidence base. The likelihood of particular conclusions is defined by a seven point scale - from exceptionally unlikely (0-1\% probability) to virtually certain (99$100 \%$ probability). The guidelines conclude with the recommendation for contributing authors to "communicate uncertainty carefully, using calibrated language for key findings, and provide traceable accounts describing your evaluations of evidence and agreement" [106].

Within the climate impacts research community, formal treatment of uncertainties is often done well, particularly with regard to direct climate impacts on crops or livestock and in cases where these uncertainties are of biophysical origin [107, 108]. However, policies for the agricultural sector or for food trade have to consider a much wider range of uncertainties from political, economic and social sources that are often far harder to foresee and account for than those from biophysical sources. Simulation modelling of possible impact and adaptation pathways can help to at least 
explore uncertainties in these possible "futures". Examples include the Special Report on Emissions Scenarios (SRES) socio-economic pathways developed for the IPCC reports [109], and similar approaches used for the Millennium Ecosystem Assessment [110]. However, simply defining a specific set of possible socio-economic pathways constrains the exploration of uncertainties to those within the boundaries of these projected futures. Lioubimtseva et al. (Chapter 6) conclude that economic and institutional changes in Russia, Ukraine and Kazakhstan have dominated historic changes in grain exports, although there is also an impact of weather variability. The projected effects of climate change by 2020 on grain exports in Russia, Ukraine and Kazakhstan differed in direction - i.e. decreased exports for Ukraine, increased exports for Russia and Kazakhstan and in magnitude, between SRES B2 and A2 socio-economic scenarios (Table 12, Chapter 6).

Climate change as a result of human activities will produce changes in both the mean and variability of climate. Changes in variability add a further dimension to policy development, introducing an element of risk management for adaptation responses and the possibility of threshold events, such as shocks to primary productivity, price or demand for food products [83]. Risk-based approaches to climate adaptation have been developed in response to the challenges of sea-level rise, but climate risks in the agriculture and food sector are inherently more complex.

The concept of resilience came from ecology and describes the ability of an ecological system to recover from a shock, climatic or otherwise. In recent years, those working on adaptation to climate change have applied these concepts to other natural and social systems. The thinking is that better resilience to climate variability and change can be increased through building biological and institutional capacity to respond to shocks, by investing in infrastructure, social protection measures and so on. An appealing aspect of this approach is that it does not matter what the precise degree of projected climate change is, a more resilient society should be better prepared for climate change impacts.

Any effective development intervention to address adaptation should be able to evaluate its outcomes. For adaptation to climate change this is difficult. Waiting until the year 2030, for example, is not a useful strategy. This is a current topic of debate, but a resilience approach seems to address well the problems of making decisions in the face of uncertainty around climate change and its impacts and the challenges of localscale vulnerability. However, to date there are very few examples of evaluation of resilience of communities and societies in practice. Resilience is often evaluated with respect to climate variability in the current climate, but when we expect a change in the mean and variability of climate in the future, how effective can this evaluation be? Risk management options for agriculture under climate change still constitute an important gap in the evidence. Indeed Rötter and Höhn (Chapter 4) conclude that there is a "lack of a comprehensive, well-tested methodology for the assessment of multiple risks to crop production under climate change".

\section{C3. Harmonizing climate with trade policy}

Policy tension between climate mitigation and trade-related economic growth is a necessary outcome that requires careful analysis and appropriate response. While climate science is indisputable, trade policy analysis in the context of climate change is far from conclusive and more analytical work is required to arrive at climatecompatible trade policies. In addition, the role of trade measures in the context of international negotiations on climate change stabilization is unclear. There is no consensus as to whether current World Trade Organization (WTO) trade rules can promote adherence to climate goals or are a threat to mutually agreed climate solutions [78]. Many of the hotly debated issues in the Doha 
Round trade negotiations, including new special safeguard mechanisms, could take on renewed relevance when considering climate change. The proposal to expand the mandate of the Environmental Goods and Services negotiations to include all biofuels is another area of contention, despite its potential to advance more efficient and resource-friendly biofuel production, especially from second generation biofuels. Climate change also underscores the need to help developing countries deal with food and energy price increases, as well as volatile food supplies.

A number of climate change mitigation policies are potentially affected by trade rules [78]. Developed countries that impose national mitigation measures (such as carbon taxes, or cap-and-trade regimes) counter the potential shift of production ("leakage") overseas with unilateral import taxes. Without international agreement on climate policy, such measures would be challenged under WTO rules. Standards and certification systems can be important tools in climate change mitigation and adaptation. However, the use of standards, particularly by governments, may clash with WTO rules. Environmental payments for services, such as payments for forest and soil carbon sequestration, can also address climate change mitigation. However, if granted by governments, these payments could clash with WTO subsidy rules. These cases make clear the need to harmonize rules with climate objectives.

Progress on climate-compatible trade policy requires tackling the considerable apprehension that climate measures can distort trade, and alternatively, that trade rules could stand in the way of greater progress on climate change [90]. In the short term, opportunities for conflict exist as countries pursue unilateral policy choices to stabilize emissions through regulatory regimes, taxation and other instruments. In the longer term, trade rules that do not allow internalization of the cost of carbon would negatively affect climate change mitigation. Tariff structures could be tailored to internalize the cost of carbon and greenhouse gas emissions so that countries can assess higher tariffs on carbon-intensive goods than on goods with lesser carbon footprints [78]. Likewise, future climate change mitigation policies should include measures designed to internalize the environmental costs of resources.

\section{C4. Recommendations for structured science-policy dialogue}

Despite the very real uncertainties in the underlying science, decisions still need to be made by a whole range of decision-makers, from policymakers to practitioners in the agricultural sector (Chapter 10). Decisions can only be made using the best evidence that is available at the time and they cannot wait until "perfect" knowledge is achieved. Wheeler and von Braun [83] provided examples of evidence statements that could be used by those making decisions as policy-makers and practitioners confronted with the prospect of climate change impacts on food security, despite very real uncertainties in current knowledge and future trends. These statements were:

1. Climate change impacts on food security will be worst in countries already suffering high levels of hunger and will worsen over time.

2. The consequences for global undernutrition and malnutrition of doing nothing in response to climate change are potentially large, and will increase over time.

3. Food inequalities will increase, from local to global levels, because the degree of climate change and the extent of its effects on people will differ from one part of the world to another, from one community to the next and between rural and urban areas.

4. People and communities who are vulnerable to the effects of extreme weather now will become more vulnerable in the future and less resilient to climate shocks.

5. There is a commitment to climate change of 20-30 years into the future as a result of past emissions of greenhouse gases that 
necessitates immediate adaptation actions to address global food insecurity over the next two to three decades.

6. Extreme weather events are likely to become more frequent in the future and will increase risks and uncertainties within the global food system.

How can a structured two-way dialogue be achieved between science and policy for production and trade impacts of climate change? One possibility is to set up a structured forum dedicated to providing a portal to climate change impact evidence for agriculture and policy for trade and food security. Such a forum could focus on: the exchange and dissemination of knowledge of latest impact assessment models related to climate-food-trade, climate-food-water, Climate Adaptation and mitigation measures linked to food security, and climate adaptation mainstreaming into development. The forum should provide the scientific links between global and regional climate assessments and facilitate exchange of knowledge between international and regional research centres and between researchers and policy makers. The forum could also operate along specific regional themes focusing on hot spot areas, common regional problems (priority sectors of regional significance; regional water scarcity problems; soil fertility; regional capacity in research $\&$ development). The forum could also facilitate policy feedback back to science to improve data, information and knowledge related to future developments in agriculture in relation to climate change.

The forum should define a number of core principles to guide its ways of working including a firm commitment that evidence generation is demand-led by those in policy; robust and detailed assessments of uncertainties in evidence; and an emphasis on high standards of communication of evidence for policy. The forum should also build on and leverage expertise within existing knowledge networks, international organizations dedicated to climate change food security and specialized in adaptation, mitigation, water, trade and relevant policy analysis. We can be certain that climate change impacts on agricultural production and trade will be substantial, will change over time and will bring challenges to those making policy that have not been encountered to date. These features alone make the establishment of a structured forum dedicated to providing a portal to climate change impact evidence for agriculture and policy for trade and food security an urgent prerogative for policy development.

\section{References}

1. Lal, R. 2004. Soil carbon sequestration impacts on global climate change and food security. Science, 304(5677): 1623-1627.

\section{Henderson-Sellers, A. \& V. Gornitz.} 1984. Possible climatic impacts of land cover transformations, with particular emphasis on tropical deforestation. Climatic Change, 6(3): 231257.

3. Rosenzweig, C. \& M. Parry. 1994. Potential impact of climate change on world food supply. Nature, 367(6459): 133-138.

4. Rosenzweig, C., J. Elliott, D. Deryng, A. Ruane, C. Müller, A. Arneth, K. Boote, C. Folberth, M. Glotteri, N. Khabarov, K. Neumann, F. Piontek, T. Pugh, E. Schmid, E. Stehfest, H. Yang \& J. Jones. 2014. Assessing agricultural risks of climate change in the 21st century in a global gridded crop model intercomparison. Proceedings of the National Academy of Sciences, 111(9): 3268-3273.

5. Challinor, A., J. Watson, D. Lobell, S. Howden, D. Smith \& N. Chhetri. 2014. A metaanalysis of crop yield under climate change and adaptation. Nature Clim. Change, 4(4): 287-291.

6. Elliott, J., D. Deryng, C. Müller, K. Frieler, M. Konzmann, D. Gerten, M. Glotter, M. Flörke, 
Y. Wada, N. Best, S. Eisner, B. Fekete, C. Folberth, I. Foster, S. Gosling, I. Haddeland, N. Khabarov, F. Ludwig, Y. Masaki, S. Olin, C. Rosenzweig, A. Ruane, Y. Satoh, E. Schmid, T. Stacke, Q. Tang \& D. Wisser. 2014. Constraints and potentials of future irrigation water availability on agricultural production under climate change. Proceedings of the National Academy of Sciences, 111(9): 32393244.

7. Pionteka, F., C. Müller, T. Pugh, D. Clark, D. Deryng, J. Elliott, F. González, M. Flörke, C. Folberth, W. Franssen, K. Frieler, A. Friend, S. Gosling, D. Hemming, N. Khabarov, H. Kim, M. Lomas, Y. Masaki, M. Mengel, A. Morse, K. Neumann, K. Nishina, S. Ostberg, R. Pavlick, A. Ruane, J. Schewe, E. Schmid, T. Stacke, Q. Tang, Z. Tessler, A. Tompkins, L. Warszawski, D. Wisser \& H. Schellnhuber. 2014. Multisectoral climate impact hotspots in a warming world. Proceedings of the National Academy of Sciences, 111(9): 3233-3238.

8. Liu, J., J. Williams, A. Zehnder \& H. Yang. 2007. GEPIC - modelling wheat yield and crop water productivity with high resolution on a global scale. Agricultural Systems, 94(2): 478-493.

9. Jones, J., G. Hoogenboom, C. Porter, K. Boote, W. Batchelor, L. Hunt, P. Wilkens, U. Singh, A. Gijsman \& J. Ritchie. 2003. The DSSAT cropping system model. European Journal of Agronomy, 18(3-4): 235-265.

10. Xiong, W., J. Balkovič, M. van der Velde, X. Zhang, R. Izaurral, R. Skalský, E. Lin, N. Mueller \& M. Obersteiner. 2014. A calibration procedure to improve global rice yield simulations with EPIC. Ecological Modelling, 273(0): 128-139.

11. Elliott, J., D. Kelly, J.

Chryssanthacopoulos, M. Glotter, K.

Jhunjhnuwala, N. Best, M. Wilde \& I. Foster. 2014. The parallel system for integrating impact models and sectors. Environmental Modelling \& Software, advance online publication.
12. Gueneau, A., C. Schlosser, K. Strzepek, G. Xiang \& E. Monier. 2012. CLM-AG: An agriculture module for the Community Land Model version 3.5. MIT Joint Program on the Science and Policy of Global Change.

13. Drewniak, B., J. Song, J. Prell, V. Kotamarthi \& R. Jacob. 2013. Modeling agriculture in the Community Land Model. Geosci. Model Dev., 6(2): 495-515.

14. Van den Hoof, C., E. Hanert \& P. Vidale. 2011. Simulating dynamic crop growth with an adapted land surface model - JULES-SUCROS: Model development and validation. Agricultural and Forest Meteorology, 151(2): 137-153.

15. Bondeau, A., P. Smith, S. Zahele, S. Schaphoff, W. Lucht, W. Cramer, D. Gerten, H. Lotze-Campen, C. Müller, M. Reichstein \& B. Smith. 2007. Modelling the role of agriculture for the 20th century global terrestrial carbon balance. Global Change Biology, 13(3): 679-706.

16. Müller, C. \& R. Robertson. 2014. Projecting future crop productivity for global economic modeling. Agricultural Economics, 45(1): 37-50.

17. Waha, K., L. van Bussel, C. Müller \& A. Bondeau. 2012. Climate-driven simulation of global crop sowing dates. Global Ecology and Biogeography, 21(2): 247-259.

18. Lobell, D., W. Schlenker \& J. CostaRoberts. 2011. Climate trends and global crop production since 1980. Science, 333(6042): 616620.

19. Schlenker, W. \& D. Lobell. 2010. Robust negative impacts of climate change on African agriculture. Environmental Research Letters, 5(1): 014010.

20. Challinor, A., T. Wheeler, P. Craufurd, J. Slingo \& D. Grimes. 2004. Design and optimisation of a large-area process-based model for annual 
crops. Agricultural and Forest Meteorology, 124(1-2): 99-120.

21. Tao, F., Z. Zhang, J. Liu \& M. Yokozawa. 2009. Modelling the impacts of weather and climate variability on crop productivity over a large area: A new super-ensemble-based probabilistic projection. Agricultural and Forest Meteorology, 149(8): 1266-1278.

22. Tao, F., M. Yokozawa \& Z. Zhang. 2009. Modelling the impacts of weather and climate variability on crop productivity over a large area: A new process-based model development, optimization, and uncertainties analysis. Agricultural and Forest Meteorology, 149(5): 831-850.

\section{Deryng, D., W, Sacks, C. Barford \&}

N. Ramankutty. 2011. Simulating the effects of climate and agricultural management practices on global crop yield. Global Biogeochem. Cycles, 25(2): GB2006.

\section{Asseng, S., F. Ewert, C. Rosenzweig,} J. Jones, J. Hatfield, A. Ruane, K. Boote, P. Thorburn, R. Rötter, D. Cammarano, N. Brisson, B. Basso, P. Martre, P. Aggarwal, C. Angulo, P. Bertuzzi, C. Biernath, A. Challinor, J. Doltra, S. Gayler, R. Goldberg, R. Grant, L. Heng, J. Hooker, L. Hunt, J. Ingwersen, R. Izaurralde, K. Kersebaum, C. Müller, S. Kumar, C. Nendel, G. O'Leary, J. Olesen, T. Osborne, T. Palosuo, E. Priesack, D. Ripoche, M. Semenov, I. Shcherbak, P. Steduto, C. Stöckle, P. Stratonovitch, T. Streck, I. Supit, F. Tao, M. Travasso, K. Waha, D. Wallach, J. White, J. Williams \& J. Wolf. 2013. Uncertainty in simulating wheat yields under climate change. Nature Climate Change, 3: 827-832.

25. FAO/IIASA/ISRIC/ISSCAS/JRC. 2012. Harmonized world soil database (version 1.2). FAO, Rome, Italy and IIASA, Laxenburg, Austria.

26. Mueller, N., J. Gerber, M. Johnston, D. Ray, N. Ramankutty \& J. Foley. 2012. Closing yield gaps through nutrient and water management. Nature, 490(7419): 254-257.

27. Potter, P., N. Ramankutty, E. Bennett \& S. Donner. 2010. Characterizing the spatial patterns of global fertilizer application and manure production. Earth Interactions, 14(2): 1-22.

28. Sacks, W., D. Deryng, J. Foley \& N. Ramankutty. 2010. Crop planting dates: an analysis of global patterns. Global Ecology and Biogeography, 19(5): 607-620.

29. Popp, A., H. Lotze-Campen \& B. Bodirsky. 2010. Food consumption, diet shifts and associated non- $\mathrm{CO}_{2}$ greenhouse gases from agricultural production. Global Environmental Change-Human and Policy Dimensions, 20(3): 451-462.

30. Nelson, G., H. Valin, R. Sands, P. Havlík, H. Ahammad, D. Deryng, J. Elliott, S. Fujimori, T. Hasegawa, E. Heyhoe, P. Kyle, M. Von Lampe, H. Lotze-Campen, D. d'Croza, H. van Meijl, D. van der Mensbrugghe, C. Müller, A. Popp, R. Robertson, S. Robinson, E. Schmid, C. Schmitz, A. Tabeau \& D. Willenbockel. 2014. Climate change effects on agriculture: Economic responses to biophysical shocks. Proceedings of the National Academy of Sciences, 111(9): 32743279.

31. Nelson, G., D. van der Mensbrugghe, H. Ahammad, E. Blanc, K. Calvin, T. Hasegawa, P. Havlik, E. Heyhoe, P. Kyle, H. Lotze-Campen, M. von Lampe, D. d'Croz, H. van Meijl, C. Müller, J. Reilly, R. Robertson, R. Sands, C. Schmitz, A. Tabeau, K. Takahashi, H. Valin \& D. Willenbockel.2014. Agriculture and climate change in global scenarios: why don't the models agree? Agricultural Economics, 45(1): 85-101.

32. Havlík, P., H. Valin, A. Mosnier, M. Obersteiner, J. Baker, M. Herrero, M. Rufino \& E. Schmid. 2013. Crop productivity and the global livestock sector: Implications for land use change 
and greenhouse gas emissions. American Journal of Agricultural Economics, 95(2): 442-448.

33. Wise, M. \& K. Calvin. 2011. GCAM 3.0 Agriculture and land use: Technical description of modeling approach. Pacific Northwest National Laboratory: Richland, WA, USA.

34. Hertel, T., J. Steinbuks \& U. Baldos. 2013. Competition for land in the global bioeconomy. Agricultural Economics, 44(s1): 129-138.

35. Elliott, E., B. Sharma, N. Best, M. Glotter, J. Dunn, I. Foster, F. Miguez, S. Mueller \& M. Wang. 2014. A spatial modeling framework to evaluate domestic biofuel-induced potential land use changes and emissions. Environmental Science \& Technology, 2014.

36. Sheffield, J. \& E. Wood. 2008. Projected changes in drought occurrence under future global warming from multi-model, multi-scenario, IPCC AR4 simulations. Climate Dynamics, 31(1): 79-105.

37. Romm, J. 2011. Desertification: The next dust bowl. Nature, 478(7370): 450-451.

38. Ray, D., N. Ramankutty, N. Mueller, P. West \& J. Foley. 2012. Recent patterns of crop yield growth and stagnation. Nature Communications, 3: 7.

39. Edgerton, M. 2009. Increasing crop productivity to meet global needs for feed, food, and fuel. Plant Physiology, 149(1): 7-13.

40. Lin, M. \& P. Huybers. 2012. Reckoning wheat yield trends. Environmental Research Letters, 7(2): 024016.

41. FAOSTAT data, http://faostat.fao.org/ 2013.

42. van Ittersum, M., K. Cassman, P. Grassini, J. Wolf, P. Tittonell \& Z. Hochman. 2013. Yield gap analysis with local to global relevance - A review. Field Crops Research, 143(1): 4-17.
43. Leakey, A., E. Ainsworth, C. Bernacchi, A. Rogers, S. Long \& D. Ort. 2009. Elevated $\mathrm{CO}_{2}$ effects on plant carbon, nitrogen, and water relations: six important lessons from FACE. Journal of Experimental Botany, 60(10): 2859-2876.

44. Myers, S., A. Zanobetti, I. Kloog, P. Huybers, A. Leakey, A. Bloom, E. Carlisle, L. Dietterich, G. Fitzgerald, T. Hasegawa, N. Holbrook, R. Nelson, M. Ottman, V. Raboy, H. Sakai, K. Sartor, J. Schwartz, S. Seneweera, M. Tausz \& Y. Usui. 2014. Increasing $\mathrm{CO}_{2}$ threatens human nutrition. Nature, advance online publication.

45. Ainsworth, E.A. \& S.P. Long. 2005. What have we learned from 15 years of free-air $\mathrm{CO}_{2}$ enrichment (FACE)? A meta-analytic review of the responses of photosynthesis, canopy properties and plant production to rising $\mathrm{CO}_{2}$. New Phytologist, 165(2): 351-371.

46. Ruane, A., S. McDermid, C. Rosenzweig, G. Baigorria, J. Jones, C. Romero \& L. Cecil. 2014. Carbon-Temperature-Water change analysis for peanut production under climate change: a prototype for the AgMIP Coordinated Climate-Crop Modeling Project (C3MP). Global Change Biology, 20(2): 394-407.

47. Ray, D., N. Mueller, P. West \& J. Foley. 2013. Yield trends are insufficient to double global crop production by 2050. Plos One, 8(6): 8 .

48. lizumi, T., M. Yokozawa, G. Sakurai, M. Travasso, V. Romanenkov, P. Oettli, T. Newby, Y. Ishigooka \& J. Furuya. 2013. Historical changes in global yields: major cereal and legume crops from 1982 to 2006. Global Ecology and Biogeography, advance online publication.

49. Licker, R., M. Johnston, J. Foley, C. Barford, C. Kucharik, C. Monfreda \& N. Ramankutty. 2010. Mind the gap: how do climate and agricultural management explain the 'yield gap' of croplands around the world? Global Ecology and Biogeography, 19(6): 769-782. 
50. Folberth, C., H. Yang, T. Gaiser, K. Abbaspour \& R. Schulin. 2013. Modeling maize yield responses to improvement in nutrient, water and cultivar inputs in sub-Saharan Africa. Agricultural Systems, 119(0): 22-34.

51. Rosenzweig, C., J. Jones, J. Hatfield, A. Ruane, K. Boote, P. Thorburn, J. Antle, G. Nelson, C. Porter, S. Janssen, S. Asseng, B. Basso, F. Ewert, D. Wallach, G. Baigorria \& J. Winter. 2013. The Agricultural Model Intercomparison and Improvement Project (AgMIP): Protocols and pilot studies. Agricultural and Forest Meteorology, 170: 166-182.

52. Kriegler, E., B. O'Neill, S. Hallegatte, T. Kram, R. Lempert, R. Moss \& T. Willibanks. 2012. The need for and use of socio-economic scenarios for climate change analysis: A new approach based on shared socio-economic pathways. Global Environmental Change, 22(4): 807-822.

53. Moss, R., J. Edmonds, K. Hibbard, M. Manning, S. Rose, D. van Vuuren, T. Carter, S. Emori, M. Kainuma, T. Kram, G. Meehl, J. Mitchell, N. Nakicenovic, K. Riahi, S. Smith, R. Stouffer, A. Thomson, J. Weyant \& T. Wilbanks. 2010. The next generation of scenarios for climate change research and assessment. Nature, 463(7282): 747-756.

54. van Vuuren, D., J. Edmonds, M. Kainuma, K. Riahi, A. Thomson, K. Hibbard, G. Hurtt, T. Kram, V. Krey, J-F. Lamarque, T. Masui, M. Meinshausen, N. Nakicenovic, S. Smith \& S. Rose. 2011. The representative concentration pathways: an overview. Climatic Change, 109(1): 5-31.

55. Taylor, K., R. Stouffer \& G. Meehl. 2012. An overview of CMIP5 and the experiment design. Bulletin of the American Meteorological Society, 93(4): 485-498.

56. Warszawski, L., K. Frieler, V. Huber, F. Piontek, O. Serdeczny \& J. Schewe. 2013.
The Inter-Sectoral Impact Model Intercomparison Project (ISI-MIP): Project framework. Proceedings of the National Academy of Sciences of the United States of America, early view.

57. Trnka, M., R. Rötter, M. Ruiz-Ramos, K-C. Kersebaum, J. Olesen \& M. Semenov. 2014. Adverse weather conditions for wheat production in Europe will become more frequent with climate change. Nature Climate Change, 4 (doi: 10.1038/ nclimate2242).

58. Müller, C., W. Cramer, W. Hare \& H. LotzeCampen. 2011. Climate change risks for African agriculture. Proceedings of the National Academy of Sciences of the United States of America, 108(11): 4313-4315.

59. Crespo, O., S. Hachigonta \& M. Tadross. 2011. Sensitivity of southern African maize yields to the definition of sowing dekad in a changing climate. Climatic Change, 106(2): 267-283.

60. Müller, C., K. Waha, A. Bondeau \& J. Heinke. 2014. Hotspots of climate change impacts in subSaharan Africa and implications for adaptation and development. Global Change Biology.

61. Zinyengere, N., O. Crespo \& S. Hachigonta. 2013. Crop response to climate change in southern Africa: A comprehensive review. Global and Planetary Change, 111(0): 118-126.

62. Marin, F. \& G. Carvalho. 2012. Spatiotemporal variability of sugarcane yield efficiency in the state of São Paulo, Brazil. Pesquisa Agropecuária Brasileira, 47(2): 149-156.

63. Marin, F., J. Jones, A. Singels, F. Royce, E. Assad, G. Pellegrino \& F. Justino. 2013. Climate change impacts on sugarcane attainable yield in southern Brazil. Climatic Change, 117(1-2): 227239.

64. Koehler, A-K., A. Challinor, E. Hawkins \& S. Asseng. 2013. Influences of increasing 
temperature on Indian wheat: quantifying limits to predictability. Environmental Research Letters, 8(3): 034016.

65. Soora, N., P. Aggarwal, R. Saxena, S. Rani, S. Jain \& N. Chauhan. 2013. An assessment of regional vulnerability of rice to climate change in India. Climatic Change, 118(3-4): 683-699.

66. Kumar, S., P. Aggarwal, D. Rani, R. Saxena, N. Chauhan \& S. Jain. 2014. Vulnerability of wheat production to climate change in India. Climate Research 59(3): 173-187.

67. Yang, H. and X. Li. 2000. Cultivated land and food supply in China. Land Use Policy, 17(2): 73-88.

68. Elliott, J., C. Müller, D. Deryng, J. Chryssanthacopoulos, K. Boote, M. Büchner, I. Foster, M. Glotter, J. Heinke, T. lizumi, R. Izaurralde, N. Mueller, D. Ray, C. Rosenzweig, A. Ruane \& J. Sheffield. 2014. The Global Gridded Crop Model Intercomparison (GGCMI): Data and modeling protocol for phase 1 (v1.0). Geoscientific Model Development, in preparation.

69. Schewe, J., J. Heinke, D. Gerten, I. Haddeland, N. Arnell, D. Clark, R. Dankers, S. Eisner, B. Fekete, F. Colón-González, S. Gosling, H. Kim, X. Liu, Y. Masaki, F. Portmannn, Y. Satoh, T. Stacke, Q. Tang, Y. Wada, D. Wisser, T. Albrecht, K. Frieler, F. Piontek, L. Warszawski \& P. Kabatt. 2013. Multimodel assessment of water scarcity under climate change. Proceedings of the National Academy of Sciences, 111(9): 3245-3250.

70. Xu, K., X. Xu, T. Fukao, P. Canlas, R. Maghirang-Rodriguez, S. Heuer, A. Ismail, J. Bailey-Serres, P. Ronald \& D. Mackill. 2006. Sub1A is an ethylene-response-factor-like gene that confers submergence tolerance to rice. Nature, 442(7103): 705-708.

71. Al-Riffai, P., B. Dimaranan \& D. Laborde. 2010. Global trade and environmental impact study of the EU biofuels mandate, Final Report for the Directorate General for Trade of the European Commission, International Food Policy Research Institute.

72. Banse, M., H. vanMeijl, A. Tabeau, G. Woltjer, F. Hellmann \& P. Verburg. 2011. Impact of EU biofuel policies on world agricultural production and land use. Biomass and Bioenergy, 35(6): 2385-2390.

73. Calzadilla A., K. Rehdanz \& R. Tol. 2011. Trade liberalization and climate change: $\mathrm{A}$ computable general equilibrium analysis of the impacts on global agriculture. Water, 3: 526-550. doi:10.3390/w3020526.

74. Keeney, R. \& T. Hertel. 2011. The indirect land use impacts of United States biofuel policies: The importance of acreage, yield, and bilateral trade responses. Amer. J. Agr. Econ., 91(4): 895-909.

75. Liu, J., T. Hertel, F. Taheripour, T. Zhu \& C. Ringler. 2014. International trade buffers the impact of future irrigation shortfalls. Global Environmental Change, 29: 22-31

76. Verma, M., T. Hertel \& N. Diffenbaugh. 2014. Market-oriented ethanol and corn-trade policies can reduce climate-induced US corn price volatility. Environ. Res. Lett., 9: 064028 (10 pp.)

77. Von Lampe, M., D. Willenbockel, H. Ahammad, E. Blanc, Y. Cai, K. Calvin, S. Fujimori, T. Hasegawa, P. Havlik, E. Heyhoe, P. Kyle, H. Lotze-Campen, D. M. d'Croz, G. Nelson, R. Sands, C. Schmitz, A. Tabeau, H. Valin, D. van der Mensbrugghe \& H. van Meijl. 2014. Why do global long-term scenarios for agriculture differ? An overview of the AgMIP Global Economic Model Intercomparison. Agricultural Economics, 45(1): 3-20.

78. Earley, J. 2009. Climate change, agriculture and international trade: Potential conflicts and opportunities. Biores, 3(3). 
79. Pitesky M., A. Gunasekara, C. Cook \& F. Mitloehner. 2014. Adaptation of agricultural and food systems to a changing climate and increasing urbanization. Curr. Sustainable Renewable Energy Rep., 1:43-50

80. McMichael A. 2013. Globalization, climate change, and human health. New Engl. J. Med., 368: 1335-1343.

81. Loladze, I. 2014. Hidden shift of the ionome of plants exposed to elevated $\mathrm{CO}_{2}$ depletes minerals at the base of human nutrition. eLife e:02245. DOI: 107554/Elife.02245

82. Jalava, M., M. Kummu, M. Porkka, S. Siebert \& O. Varis. 2014. Diet change-a solution to reduce water use? Environ. Res. Lett. 9: 074016 (14 pp.)

83. Wheeler, T. \& J. von Braun. 2013. Climate change impacts on global food security. Science, 341(6145): 508-513.

84. Antle, J., S, Capalbo, E. Elliott \& K. Paustian. 2004. Adaptation, spatial heterogeneity, and the vulnerability of agricultural systems to climate change and $\mathrm{CO}_{2}$ fertilization: $\mathrm{An}$ integrated assessment approach. Climatic Change, 64(3): 289-315.

85. Elliott, J., F. Ian, K. Sam \& J. Khun. 2013. Unilateral carbon taxes, border tax adjustments and carbon leakage. Theoretical Inquiries in Law, 14(1): 207-244.

86. Elliott, J., I. Foster, S. Kortum, T. Munson, F. Cervantes \& D. Weisbach. 2010. Trade and carbon taxes. The American Economic Review, p. 465-469.

87. Elliott, J. \& D. Fullerton. 2014. Can a unilateral carbon tax reduce emissions elsewhere? Resource and Energy Economics, 36(1): 6-21.

88. Hertel, T., M. Burke \& D. Lobell. 2010. The poverty implications of climate-induced crop yield changes by 2030. Global Environmental Change, 20(4): 577-585.

89. East African Community. 2013. Climate, food, trade: Where is the policy nexus? Lessons from the East African Community. CUTS International, Geneva.

90. Wu M. \& J. Salzman. 2014. The next generation of trade and environment conflicts: The rise of green industrial policy. Scolarship Law Article, 108( 2). Duke University. (Online: http://scholarship.law.duke.edu/faculty scholarship/3320/).

91. Ayers, J., S. Huq, M. Arif \& S. Hussain. 2014. Mainstreaming climate change adaptation into development: A case study of Bangladesh. WIREs Clim. Change, 5:37-51. doi: 10.1002/ wcc.226

92. Butler J., W. Suadnya, K. Puspadi, Y. Sutaryono, R. Wise, T. Skewes, D. Kirono, E. Bohensky, T. Handayani, P. Habibi, M. Kisman, I. Suharto, Hanartani, S. Supartarningsih, A. Ripaldi, A. Fachry, Y. Yanuartati, G. Abbas, K. Duggan \& A. Ash. 2013. Framing the application of adaptation pathways for rural livelihoods and global change in eastern Indonesian islands. Global Environmental Change, pp:1-15.

93. Perch, L. 2011. Mitigation of What and by What? Adaptation by Whom and for Whom? Dilemmas in delivering for the poor and the vulnerable in international climate policy. Working Paper 79. International Policy Centre for Inclusive Growth, Brasilia, Brazil.

94. Smith, D. \& J. Vivekananda. 2011. Adapting to change: The linked challenges of building resilient communities. Poverty in Focus No. 23. International Policy Centre for Inclusive Growth, Brasilia, Brazil, pp. 17-19.

95. Wise, R., I. Fazey, S. Stafford, S. Park, H. Eakin, A. van Garderen \& B. Campbell. 2013. 
Reconceptualising adaptation to climate change as part of pathways of change and response. Global Environmental Change, pp: 1-15.

96. McGray, H., A. Hammill \& R. Bradley. 2007. Weathering the storm: Options for framing adaptation and development. World Resources Institute: Washington, DC.

97. Dutz, M. \& S. Sharma. 2102. Green growth, technology and innovation policy. Research Working Paper 5932, World Bank, Washington DC.

98. Houghton, J., Callander, B. \& S. Varney. 1992. Climate change 1992: the supplementary report to the IPCC scientific assessment. Cambridge University Press.

99. Porter J. and L. Xie (coordinating lead authors). 2014. Chapter 7: Food Security and Food Production Systems, In IPCC: Climate Change 2014: Impacts, Adaptation, and Vulnerability. Part A: Global and Sectoral Aspects. Contribution of Working Group II to the Fifth Assessment Report of the Intergovernmental Panel on Climate Change [Field, C.B., et al. (eds.)]. Cambridge University Press, Cambridge, United Kingdom and New York, NY, USA

100. Knox, J., T. Hess, A. Daccache \& T. Wheeler. 2012. Climate change impacts on crop productivity in Africa and South Asia. Environmental Research Letters, 7(3): 034032.

101. Challinor, A., J. Watson, D. Lobell, S. Howden, D. Smith \& N. Chhetri. 2014. A metaanalysis of crop yield under climate change and adaptation. Nature Climate Change, 4(4): 287-291.

102. http://cdkn.org/

103. Osborne, T., G. Rose, \& T. Wheeler. 2013. Variation in the global-scale impacts of climate change on crop productivity due to climate model uncertainty and adaptation. Agricultural and Forest Meteorology, 170: 183-194.
104. Murphy, J., D. Sexton, D. Barnett, G. Jones, M. Webb, M. Collins \& D. Stainforth. 2004. Quantification of modelling uncertainties in a large ensemble of climate change simulations. Nature, 430: 768-772.

105. Challinor, A., T. Wheeler, J. Slingo \& J. Hemming. 2005. Quantification of physical and biological uncertainty in the simulation of the yield of a tropical crop using present-day and doubled $\mathrm{CO}_{2}$ climates. Philosophical Transactions of the Royal Society B: Biological Sciences, 360: 2085-2094.

106. Mastrandrea, M., C. Field, T. Stocker, O. Edenhofer, K. Ebi, D. Frame, H. Held,

E. Kriegler, K. Mach, P. Matschoss, G. Plattner, G. Yohe \& F. Zwiers. 2010. Guidance note for lead authors of the IPCC Fifth Assessment Report on consistent treatment of uncertainties. Intergovernmental Panel on Climate Change (IPCC). Available at http://www.ipcc.ch.

107. Challinor, A., F. Ewert, S. Arnold, E. Simelton \& E. Fraser. 2009. Crops and climate change: Progress, trends, and challenges in simulating impacts and informing adaptation. Journal of Experimental Botany, 60(10): 2775-2789.

108. Challinor, A., T. Wheeler, C. Garforth, P. Craufurd \& A. Kassam. 2007. Assessing the vulnerability of food crop systems in Africa to climate change. Climatic Change, 83(3): 381-399.

109. Gaffin, S., C. Rosenzweig, X. Xing \& G. Yetman. 2004. Downscaling and geo-spatial gridding of socio-economic projections from the IPCC Special Report on Emissions Scenarios (SRES). Global Environmental Change, 14(2): 105-123.

110. http://www.millenniumassessment.org/en/ Scenarios.html. 


\section{chapter 2}

Page

1. Rationale 30

2. Biophysical models to assess climate change impacts on agricultural productivity

2.1 Crops and weather

2.2 Model types

3. Challenges for global-scale modelling 33

3.1 Global consistency vs. data scarcity

4. Recent advances in global-scale crop modelling 34

4.1 Global-scale impacts $\quad 34$

4.2 Focus regions of climate change impacts $\quad 38$

4.3 Inter-sectoral interaction $\quad 39$

5. The Global Gridded Crop Model intercomparison 40

6. Open questions 41

6.1 Model evaluation and validation $\quad 42$

6.2 Management 42

6.3 Effects of elevated atmospheric carbon dioxide
concentrations

6.4 Future challenges: Representative agricultural
pathways

6.5 Future challenges: Drought and climate extremes $\quad 45$

6.6 Future challenges: Connecting with field-scale assessments

6.7 Future challenges: Informing economic assessment with biophysical climate change impact studies

$\begin{array}{ll}\text { 7. Conclusions } & 47\end{array}$

$\begin{array}{ll}\text { References } & 48\end{array}$

Citation

Müller, C. and J. Elliott (2015).The Global Gridded Crop Model Intercomparison: Approaches, insights and caveats for modelling climate change impacts on agriculture at the global scale, In: Climate change and food systems: global assessments and implications for food security and trade, Aziz Elbehri (editor). Food Agriculture Organization of the United Nations (FAO), Rome, 2015. 


\section{chapter 2}

The Global Gridded Crop Model

Intercomparison: Approaches, insights

and caveats for modelling climate

change impacts on agriculture at the

global scale

\section{Christoph Müller ${ }^{1}$ and Joshua Elliott ${ }^{2}$}

\section{main chapter messages}

- With international market integration and the global extent of climate change, future agricultural productivity and climate change impacts need to be assessed in consistent frameworks at the global level.

- The diversity of global gridded crop models is brought together in AgMIP and ISI-MIP model intercomparisons to record, evaluate and improve uncertainties and skills in global scale agricultural modeling.

- Central to the challenge are significant uncertainties not only in future climate change projections, but also in current and future management patterns and the effectiveness of carbon dioxide fertilization.
- The agricultural sector is strongly interlinked with other sectors and biophysical cycles (water, carbon). Interactions and co-limitations (e.g. bioenergy, irrigation water) need to be considered explicitly (and carefully).

- The diversity of agricultural practices around the world as well as the high level of management in agricultural systems are a central challenge for modeling efforts but also constitute a strong and varied basis for climate change adaptation measures. 


\section{Rationale}

A griculture is a diverse economic sector that produces food, fibre, material and energy commodities. In most regions, agricultural productivity is directly dependent on weather and climate conditions - more so than any other major economic sector. The agriculture sector also serves a variety of purposes beyond primary production, including nature and resource conservation, recreation, greenhouse gas (GHG) mitigation and various other so-called ecosystem services [Power, 2010]. Agriculture is of central importance to society, and climate change is a major concern for agricultural systems and food security. Due to the rapid expansion of international markets, agriculture has become an increasingly globalized sector over the course of the $20^{\text {th }}$ century. Shocks to production in individual countries resulting from policy or climate change can affect prices across the globe, as demonstrated, for example, during the food price spikes in 2008 and 2010 [Blandford et al., 2010; Piesse and Thirtle, 2009].

Given the importance of the agricultural sector on a global scale, it is crucial to assess impacts of climate change on agricultural productivity with analysis tools that allow sufficient detail to account for interregional differences in climate and management systems, while retaining global coverage to ensure consistency. Biophysical crop models, applied globally, can provide such consistent multi-scale climate change impact assessments. Under the umbrella of the Agricultural Model Intercomparison and Improvement Project (AgMIP) ${ }^{3}$ [Rosenzweig et al., 2014] and as part of the Inter-Sectoral Impact Model Intercomparison Project (ISI-MIP) ${ }^{4}$ [Warszawski et al., 2014], a coordinated climate impact analysis at the global scale was recently conducted using a group of seven Global Gridded Crop Models (GGCMs).

3 See http://www.agmip.org

4 See http://www.isimip.org
Following completion of this fast-track project, designed to provide rapid global analysis for the Fifth Assessment Report of the Intergovernmental Panel on Climate Change (IPCC AR5), the project has expanded rapidly. The resulting Global Gridded Crop Model Intercomparison (GGCMI), which is the flagship project of the new AgMIP GRIDded crop modelling initiative (Ag-GRID, see http://www.agmip.org/ag-grid/), includes more than 20 modelling groups conducting hundreds of coordinated historical and projected future simulations for model intercomparison and improvement and climate impact assessment.

\section{Biophysical models to assess climate change impacts on agricultural productivity}

\subsection{Crops and weather}

Agricultural production is directly dependent on weather conditions, which - together with soil conditions - determine the conditions for plant growth. Weather conditions can be managed to some extent by, for example, using irrigation to compensate for deficient rainfall or timing the cropping season to avoid adverse weather conditions (dry, hot, cold). Greenhouses provide environments in which weather conditions can be managed with precision - including temperature and radiation inputs - but these are only economically feasible at small scales and for high-value crops. Weather extremes that cannot be managed can lead to severe damage, such as from strong winds, hail [e.g. Saa Requejo et al., 2011] or frost events.

All agricultural production, including livestock production, is dependent on suitable weather conditions for plant growth. The central process of plant growth is photosynthesis, in which carbon dioxide $\left(\mathrm{CO}_{2}\right)$ is assimilated with sunlight energy to form primary sugars. These sugars are the 
energy source as well as the building blocks for all biomass generation. About half of the energy stored in the sugars generated by photosynthesis is used to satisfy the plant's own energy demands for the formation of complex molecules, growth and maintenance. Photosynthesis takes place in green leaves and the process is strongly affected by ambient temperature, the availability of $\mathrm{CO}_{2}$ in the air, and availability of sufficient water and nutrient supplies in both soil and plant. Along with a number of micro-nutrients that are necessary in small amounts, nitrogen, phosphorus and potassium (in that order) are the most important plant nutrients and are often applied to fields as artificial fertilizers or manure.

The same pores that plants use to transpire water are also responsible for taking up $\mathrm{CO}_{2}$ for photosynthesis. When these pores close to reduce water transpiration, as happens under dry conditions, the uptake of $\mathrm{CO}_{2}$ is also reduced.

The plants in which photosynthesis is directly stimulated under elevated atmospheric $\mathrm{CO}_{2}$ concentrations are referred to as the $\mathrm{C}_{3}$ plants, because the primary product of their photosynthetic pathway is a sugar with three carbon atoms. Wheat, rice and soybean are the most prominent representatives of this group. Other plants have developed different mechanisms for fixing $\mathrm{CO}_{2}$, in which atmospheric $\mathrm{CO}_{2}$ is intermediately stored in oxaloacetic acid, a four-carbon organic acid. This group of plants is thus referred to as $\mathrm{C}_{4}$ plants. $\mathrm{C}_{4}$ plants are less limited by ambient $\mathrm{CO}_{2}$ concentrations because primary fixation is achieved via a more efficient enzyme and the Rubisco enzyme is isolated from the ambient air. Some important agricultural crops belong to the group of $\mathrm{C}_{4}$ plants, such as maize, sugar cane, millet and sorghum.

Plants with $\mathrm{C}_{4}$ carbon fixation have developed mechanisms to partially decouple the uptake of $\mathrm{CO}_{2}$ from transpiration by concentrating it from the atmosphere and passing this bound $\mathrm{CO}_{2}$ on to where it is needed for photosynthesis. Due to this ability to decouple the $\mathrm{CO}_{2}$ concentration for photosynthesis from ambient atmospheric $\mathrm{CO}_{2}$ concentrations, this group of crops is less sensitive to elevated atmospheric $\mathrm{CO}_{2}$ concentrations.
Many other processes relevant to plant growth and yields are affected by weather conditions: root growth affects access to soil water and nutrients; leaf formation affects a plant's ability to absorb sunlight energy; flowering is threatened by sterility under high temperatures; frost does direct damage to a plant; etc. Indirect effects of weather conditions include the mineralization of organic matter (e.g. humus or applied manure) in soils. Organic matter supplies nutrients to plants and is controlled by soil water content and temperatures. The spread of plant diseases (such as fungi) and insects can also be affected by weather and climate conditions [Gregory et al., 2009] or by elevated atmospheric $\mathrm{CO}_{2}$ concentrations [Dermody et al., 2008; Zavala et al., 2008].

Many of these processes can be accurately modelled as functions of local weather conditions (temperatures, precipitation, incident solar energy, and sometimes wind speeds and humidity), environmental conditions, and management conditions. Crop growth models are constructed to combine such functional representations and are designed with appropriate levels of complexity for various applications at a range of spatial scales.

\subsection{Model types}

Biophysical crop growth models can be categorized into two general types: empirical and process-based models. The distinction is not always completely clear, since most process-based models also include empirical relationships; however, purely empirical models, such as regression models, are quite distinct. The represented processes, data requirements (e.g. number of variables, spatial and temporal resolutions) and model outputs vary greatly among models, depending largely on the research questions and applications that motivated the model's development. At global scale, at least three types of models can be distinguished, each with a broad set of representatives. 
- Gridded versions of site-based process models

These models are based on field-scale models that are applied globally by simply running the model repeatedly for each locale in the (usually gridded) input dataset. These models tend to be the most complex with respect to processes represented in the model, which typically implies high requirements for input data. Field-scale models are often strongly calibrated for the variety and environmental conditions in a single field. This is especially important for central empirical processes, such as radiation use efficiency [Adam et al., 2011]. This calibration is generally not performed in gridded global applications due to a lack of available reference data and the computation required. Instead, cultivar parameters in gridded process models are typically calibrated at a finite set of points, either within the researchers' realm of expertise or more broadly, and then key parameters are extrapolated globally with relatively simple algorithms. For management and soil inputs, models are usually driven with compiled and/or extrapolated observational data [e.g. FAO/IIASA/ISRIC/ISSCAS/JRC, 2012; Mueller et al., 2012; Potter et al., 2010; Sacks et al., 2010]. Examples of this type of model that are participating in the AgGRID GGCMI include: pAPSIM; CropSyst [Confalonieri et al., 2006; Stöckle et al., 2003]; DAYCENT [Stehfest et al., 2007]; pDSSAT [Elliott et al., 2014b; Jones et al., 2003]; and four models based on EPIC [e.g. Liu et al., 2007; Xiong et al., 2014].

\section{- Dynamic global vegetation models}

The second major group consists of GGCMs that have been implemented into existing land surface schemes (LSMs) or dynamic global vegetation models (DGVMs). LSMs are used in climate models to simulate the energy, water, and sometimes carbon and nitrogen exchange between the terrestrial biosphere and the atmosphere. Typically, crops have been introduced into these models to improve the representation of seasonal variations in energy and matter exchanges. DGVMs are developed to study the response of natural ecosystems to climate change and the associated implications for carbon and water cycles. These models have been directly developed for global-scale application and so the exchange mechanisms between vegetation and atmosphere are generally implemented in particular detail (e.g. stomatal conductance and photosynthesis). LSM-type models require weather data at sub-daily resolution (which come from the coupled climate model). However, because their focus has typically been on global applications with relatively low spatial resolutions, these models have few data requirements otherwise. Crop yields are not the primary focus of these models, but have become of increasing interest in the applications of models such as those participating in GGCMI: CLMAg [Gueneau et al., 2012]; CLM-Crop [Drewniak et al., 2013]; ISAM; JULESCrop [Van den Hoof et al., 2011]; LPJmL [Bondeau et al., 2007; Müller and Robertson, 2014; Waha et al., 2012a]; LPJ-GUESS [Lindeskog et al., 2013]; and ORCHIDEE [Berg et al., 2011].

- Large-area crop models or empirical/ process model hybrids

Finally, the third group consists of crop models developed explicitly to simulate agricultural production systems at continental or global scales. These models typically include key process-based representations but eschew some of the complexities of process models (most notably in terms of management and other inputs) in favour of calibrated empirical functions. This provides more flexibility to represent complex systems with hidden variables and provides the kind of computational tractability that is often required in order to do large-scale calibration of historical datasets. Examples of these 
models include CGMS [de Wit and van Diepen, 2008], GLAM [Challinor et al., 2004], MCWLA [Tao et al., 2009a; Tao et al., 2009b], PEGASUS [Deryng et al., 2011] and PRYSBI-2.

\section{Challenges for global- scale modelling}

\subsection{Global consistency vs. data scarcity}

The global scale is especially challenging for agricultural assessment because crop models depend on having good-quality, high-resolution data on weather, soils and farm management that are generally not available in much of the world. This is true for historical and projected future data inputs as well as for reference data against which crop models could be tested and improved. The fundamental processes implemented in crop models have been demonstrated to replicate controlled laboratory or field trials. The hypothesis in global modelling is that these models are valid within the range of parameters necessary for global-scale analyses and future projections.

Reference data are available for individual sites. Some examples include: the results of the free air $\mathrm{CO}_{2}$ enrichment (FACE) experiments on the effects of elevated atmospheric $\mathrm{CO}_{2}$ concentrations [Ainsworth and Long, 2005; Leakey et al., 2009]; the eddy-flux tower measurements on $\mathrm{CO}_{2}$ and water exchange fluxes between the land surface and the atmosphere [Baldocchi et al., 2001]; and a multitude of field trials on management practices or weather modification experiments [Kimball et al., 2012]. Data from these field experiments are not always easily accessible or complete, however, and they certainly do not cover the full range of environmental conditions under which crops are grown globally. Comprehensive global reference data, such as the FAOSTAT archive [FAOSTAT data, 2013], are aggregated in larger spatial units (typically national scale), focus only on productivity (production per area harvested) and have substantial uncertainties with respect to the underlying land-use patterns and the mix of management practices (e.g. share of irrigated production, share of winter varieties, fertilizer use).

Model drivers from projected future scenarios, such as daily weather data from climate model outputs, are subject to large uncertainties, which increase with spatial and temporal resolution [Hawkins and Sutton, 2009; 2011]. As most crop models require bias-corrected weather data at daily resolution, this uncertainty is compounded by the variety of datasets and algorithms used in necessary down-scaling and bias-correction methods [Roudier et al., 2011].

Scenarios for future changes in management practices, including fertilizer application, planting dates, crop mixes, rotation cycles and varieties used must be developed by the crop-modelling community to evaluate potential pathways for adaptation. Scenarios on future socio-economic development, such as the Shared Socioeconomic Pathways (SSPs) [Kriegler et al., 2012], can provide some guidance here, but substantial extensions are required to capture the diversity of agricultural components and, given the important role that agriculture plays for GHG budgets, reference must be made to assumptions on emissions in the Representative Concentration Pathways (RCPs) as well [Rosenzweig et al., 2013].

Despite the substantial uncertainty in reference data and regarding future drivers, global-scale analyses are necessary and inevitable for the assessment of global change and climate change impacts. To be useful in economic models or assessments, for example, these analyses require crop model results that are driven with globally consistent assumptions, modelling details and input datasets. Given the international nature of agricultural markets, the effects of climate change on agricultural production and food security cannot be assessed for individual regions but require globally consistent analyses, in which regional and national analyses can be embedded. A consistent global biophysical perspective is thus essential to enable understanding of how markets will respond 
to altered productivity and patterns of productivity [Nelson et al., 2014a; Nelson et al., 2014b].

\section{Recent advances in global- scale crop modelling}

\subsection{Global-scale impacts}

The extent of future climate change itself is highly uncertain, due in large part to the inherent difficulty in predicting future energy consumption or climate policies. In the latest IPCC report, the upper end of projections for global mean temperature change is $4.1+/-0.5^{\circ} \mathrm{C}$ by 2100 [IPCC, in press]. The increase in global mean temperature, however, does not translate directly to temperature change in agricultural areas. Temperatures are generally expected to increase more rapidly over land, for example, since ocean temperatures - and thus air temperatures above oceans - rise more slowly. There is also the so-called "polar amplification" phenomenon, in which warming proceeds more rapidly at higher latitudes. Finally, mean annual changes may be distributed asymmetrically across seasons (summer vs. winter, spring vs. summer, etc.) and relatively small seasonal shifts may include significant increases in extreme weather events that may last only a few days but are often extremely costly.

Current agricultural areas are likely to be subjected to significant temperature increases, even if effective climate policies are enforced in the near future. Precipitation patterns, incident solar energy (affected by changes in cloudiness), and the prevalence and intensity of extreme events (e.g. heat waves, floods, droughts), are expected to be strongly affected by climate change, as well. These changes are much more difficult to project reliably than are changes in temperatures, and uncertainty is thus considerably higher [Hawkins and Sutton, 2009; 2011]. This is especially true at temporal and spatial resolutions relevant to agriculture [Hawkins and Sutton, 2009; 2011]. Finally, there are additional biophysical uncertainties (such as the effectiveness of carbon dioxide "fertilization"5 under various real-world conditions), socioeconomic unknowns (such as the distribution of management and expected future changes over the coming decades) and uncertain resource constraints (such as the availability of freshwater for irrigation). Forecasts of agricultural productivity, whether under a changed climate or not, should therefore not be expected to have any reliability beyond seasonal lead times. Even so, these assessments are a necessary and invaluable tool for understanding the risks and opportunities and for identifying suitable and sustainable adaptation measures.

Despite the uncertainties, our current understanding allows for some robust conclusions that also facilitate policy-making and planning. Broadly speaking, no large-scale impact study has excluded the possibility that the overall effect of climate change and $\mathrm{CO}_{2}$ on agricultural productivity may be negative. Climate change is clearly a risk for agricultural production and it has the potential to pose a sizeable risk that would affect production patterns, the extents of cultivated areas, and food security and prices [Nelson et al., 2014b]. The recent consolidated study on the impact of global climate change on agriculture, conducted in the framework of the AgMIP and ISI-MIP projects, finds that by 2100 the impact of climate change on crop yields for high-emission climate scenarios ranges between -20 and -45 percent for maize, between -5 and -50 percent for wheat, between -20 and -30 percent for rice, and between -30 and -60 percent for soybean [Rosenzweig et al., 2013a]. These impacts are likely to be at least partially offset by the beneficial effects of $\mathrm{CO}_{2}$ fertilization, especially since carbon fertilization effects are most pronounced in highemission scenarios. Assuming full effectiveness in large-scale production, climate change impacts would then range between -10 and -35 percent for maize, between +5 and -15 percent for wheat, between -5 and -20 percent for rice, and between

5 The term 'carbon dioxide fertilization' is defined as the enhancement of the growth of plants as a result of increased atmospheric $\mathrm{CO}_{2}$ concentration. 


\section{figure 1}

Spatial patterns of food supply impacts. Average annual change in caloric production of maize, soy, wheat and rice by end-of-century for RCP 8.5. Median of six global crop models, driven by outputs of five global climate models from CMIP5. Results are averaged to 309 Food Producing Units (FPUs), assuming no change in farm management and including the effects on crops of increased atmospheric $\mathrm{CO}_{2}$

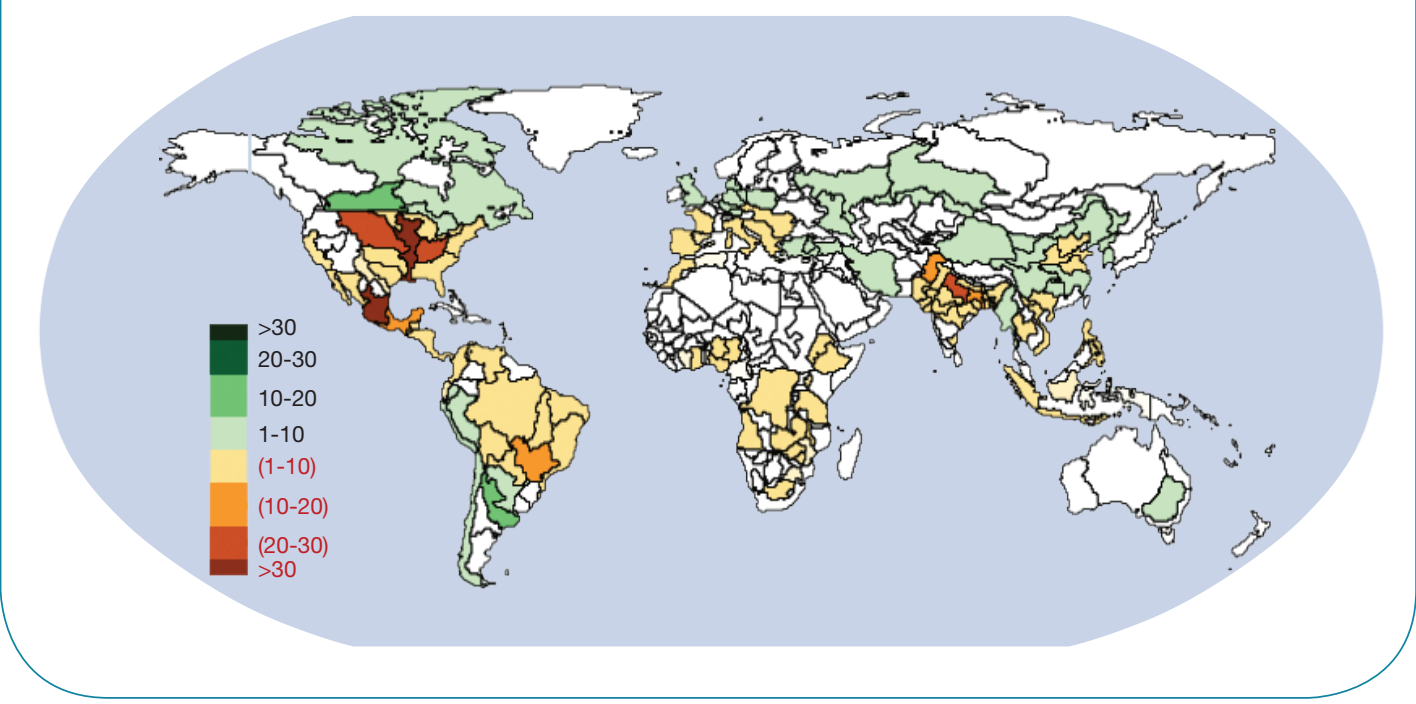

0 and -30 percent for soybean. When viewed in terms of absolute changes in the expected annual caloric production of existing agricultural areas that are attributable to climate (Figure 1), implications for trade patterns become especially clear. Major current global breadbaskets (e.g. in North America and South Asia) are expected to see significant reductions in agricultural production that will reduce their export shares and may require increased imports, as in South Asia, for example.

In models that assume nitrogen is not a limiting factor, climate change impacts are generally somewhat less severe and $\mathrm{CO}_{2}$ fertilization effects are generally more positive, meaning that yields in many areas are projected to increase [Rosenzweig et al., 2013a]. This is especially true in semi-arid regions [Deryng et al., in prep.].

The wealth of global, regional, and site-based studies provides a basis for conclusions that are robust across a broad selection of climate scenarios, management assumptions, locations and scales. Broadly speaking, climate change impacts on agriculture become worse with increasing temperatures. Associated changes in precipitation can cause considerable variation as well, but do not challenge the general relationship.

There are important differences between tropical and temperate/boreal regions that will affect the global patterns of agricultural production and thus affect trade. Tropical regions, including many developing countries, have climates that are already at the upper end of optimal temperature ranges for many agricultural plants and are projected to experience decreasing agricultural productivity even with small increases in temperature. In higher latitudes or at higher altitudes, agricultural production is often constrained by cold temperatures and therefore small increases in temperature of 1 to $2^{\circ} \mathrm{C}$ are projected to be beneficial to agricultural productivity. At higher temperature increases, climate change impacts in these regions are projected to become negative as well, although at a slower pace. Agricultural management is a crucial determinant in any projection of future agricultural productivity. Management systems 
do not only affect the actual strength of climate change impacts on agricultural productivity, their level of flexibility also allows for broad adaptation measures to changing environmental conditions. These measures include some that can be easily implemented at farm level, e.g. adjustments in planting dates [Liu et al., 2013; Waha et al., 2012a], while others may require targeted research (e.g. breeding new varieties) or intensive economic investment (e.g. large-scale expansion of irrigation infrastructure). Tropical regions, which include many developing countries, are assumed to have considerable development potential to increase agricultural productivity through improved management and technology [Deryng et al., 2011; Licker et al., 2010; Neumann et al., 2010; van Ittersum et al., 2013].

Many key aspects of the impact of climate change on agricultural production will require additional research, including the ability of plants to acquire nutrients under different conditions, such as greatly elevated atmospheric $\mathrm{CO}_{2}$ concentrations [Boote et al., 2013; Taub et al., 2008], which is especially important for issues of food quality and nutrition security. The prevalence and propagation of pests and diseases are also likely to change in a warmer climate [Bebber et al., 2013], posing another major management and adaptation challenge for future agricultural production.

Broadly speaking, global-scale climate change impact assessments have not evolved significantly since the first global climate change impact assessment in 1994 [Rosenzweig and Parry, 1994]. Climate change has the potential to damage productivity across all agricultural areas. Tropical areas are likely to experience detrimental impacts even at low levels of global warming and potentially catastrophic impacts at higher levels, while high-latitude and high-altitude areas could profit from small or medium increases in temperatures. There are large uncertainties with respect to the beneficial effects of $\mathrm{CO}_{2}$ fertilization (increased photosynthetic action and reduced water requirements for plant growth under elevated atmospheric $\mathrm{CO}_{2}$ concentrations). The first study of agricultural impacts was conducted by extrapolating just over 100 field-scale assessments [Rosenzweig and Parry, 1994], while models today cover the entirety of current global cropland area and even potentially cropped areas.

Until recently, global-scale climate impact assessments have been relatively scarce and have analysed only a single or small number of assessment models, climate forcings or climate scenarios [e.g. Fischer et al., 2005; Liu et al., 2007; Müller et al., 2009; Nelson et al., 2009; Nelson et al., 2010; Parry et al., 2004; Stehfes et al., 2007]. However, the selection of climate scenarios, even for the same GHG emission scenario, can greatly affect the assessment of climate change impacts [Osborne et al., 2013]. Depending on projected patterns of climate change, which can vary strongly between implementations of $\mathrm{GHG}$ emission scenarios in different climate models, projected impacts on agricultural productivity can be very different [Müller and Robertson, 2014; Osborne et al., 2013].

A recently conducted first-of-its-kind intercomparison of GGCMs within AgMIP [Rosenzweig et al., 2014] and for the agricultural sector in ISI-MIP [Warszawski et al., 2014] allowed for a globally consistent analysis across seven different GGCMs. The project included projections for 20 different climate scenarios (four RCPs [Moss et al., 2010; van Vuuren et al., 2011] implemented by five different climate models as part of the Coupled Model Intercomparison Project CMIP5 [Taylor et al., 2012]: HadGEM2-ES [Jones et al., 2011]; IPSLCM5A-LR [Dufresne et al., 2013]; MIROC-ESMCHEM [Watanabe et al., 2011]; GFDL-ESM2M [Dunne et al., 2013a; Dunne et al., 2013b]; and NorESM1-M [Bentsen et al., 2013; Iversen et al., 2013]) and were bias-corrected against historical weather data [Hempel et al., 2013]). Model groups considered fully irrigated and rain-fed systems [Rosenzweig et al., 2014], using two assumptions on the effectiveness of $\mathrm{CO}_{2}$ fertilization (i.e. none and full). 


\section{table 1}

Global Gridded Crop Models and references for the AgMIP-led ISI-MIP fast-track simulation exercise

\begin{tabular}{|c|c|c|c|}
\hline Model & Version & $\begin{array}{c}\text { References for model } \\
\text { description and } \\
\text { applications }\end{array}$ & Institution \\
\hline EPIC & EPIC0810 & $\begin{array}{l}\text { [lzaurralde et al., 2006; } \\
\text { Williams and Singh, 1995] }\end{array}$ & $\begin{array}{l}\text { BOKU, University of Natural } \\
\text { Resources and Life Sciences, } \\
\text { Vienna }\end{array}$ \\
\hline GEPIC & EAWAG & $\begin{array}{l}\text { [Liu et al., 2007; } \\
\text { Williams et al., 1990] }\end{array}$ & $\begin{array}{l}\text { EAWAG } \\
\text { (Swiss Federal Institute } \\
\text { of Aquatic Science and } \\
\text { Technology) }\end{array}$ \\
\hline GAEZ in IMAGE & 2.4 & $\begin{array}{l}\text { [Bouwman et al., 2006; } \\
\text { Leemans and Solomon, 1993] }\end{array}$ & $\begin{array}{l}\text { Netherland Environmental } \\
\text { Assessment Agency (PBL) }\end{array}$ \\
\hline LPJmL & - & $\begin{array}{l}\text { [Bondeau et al., 2007; } \\
\text { Fader et al., 2010; } \\
\text { Schaphoff et al., 2013; } \\
\text { Waha et al., 2012] }\end{array}$ & $\begin{array}{l}\text { Potsdam Institute for Climate } \\
\text { Impact Research }\end{array}$ \\
\hline LPJ-GUESS & 2.1 with crop module & $\begin{array}{l}\text { [Bondeau et al., 2007; } \\
\text { Lindeskog et al., 2013; } \\
\text { Smith et al., 2001] }\end{array}$ & $\begin{array}{l}\text { Lund University, Department } \\
\text { for Physical Geography and } \\
\text { Ecosystem Science, } \\
\text { IMK-IFU, Karlsruhe Institute } \\
\text { of Technology, Garmisch- } \\
\text { Partenkirchen, Germany }\end{array}$ \\
\hline pDSSAT & $\begin{array}{l}\text { pDSSAT v0.5 (DSSAT } \\
4.0 \text { and } 4.5)\end{array}$ & $\begin{array}{l}\text { [Elliott et al., 2013b; } \\
\text { Jones et al., 2003] }\end{array}$ & $\begin{array}{l}\text { University of Chicago and } \\
\text { Argonne National Laboratory } \\
\text { Computation Institute }\end{array}$ \\
\hline PEGASUS & V. 1.1 & [Deryng et al., 2011] & $\begin{array}{l}\text { Tyndall Centre } \\
\text { University of East Anglia, UK/ } \\
\text { McGill University, Canada }\end{array}$ \\
\hline
\end{tabular}

Results from the participating models (Table 1) are directly comparable with respect to climate and $\mathrm{CO}_{2}$ forcings ${ }^{6}$, but their assumptions and input data on management differed in some important ways. Many of these differences are fundamental to the ways that different groups have chosen to represent management decisions such

6 The term $\mathrm{CO}_{2}$ forcing is short hand expression that links increased $\mathrm{CO}_{2}$ concentration with a given rise of average temperature. The so-called "radiative forcing" is linked to $\mathrm{CO}_{2}$ concentration and the extent of its deviation from an initial state (typically chosen as the pre-industrial $\mathrm{CO}_{2}$ concentration level of 280 part per million value or ppmv). The higher the $\mathrm{CO}_{2}$ concentration, the higher the radiative forcing which in turn raises the radiative energy reaching the earth's surface and cause the average earth temperature to increase. as planting, irrigation and fertilizer application. These differences in assumptions and input data contribute substantial uncertainty in addition to that caused by differences in underlying functional representations of key processes and other model implementation choices. The joint uncertainties of management assumptions and model implementations are often larger than the uncertainty represented by the five climate models selected here, although this depends on the region and scale of analysis.

A compilation of site-based climate change impact studies for the $4^{\text {th }}$ Assessment Report of the IPCC showed that crop yields decline with increasing local temperature changes and associated atmospheric $\mathrm{CO}_{2}$ concentrations and 
precipitation changes [Easterling et al., 2007]. In temperate regions, crops can profit from low to medium increases in local temperatures - e.g. if cold temperature limitations are alleviated or if the associated changes in precipitation and $\mathrm{CO}_{2}$ fertilization lead to higher productivity. In the tropical regions, however, yields typically decline even with small increases in local temperatures.

With the GCCMI, these impact patterns were confirmed for a more comprehensive coverage of regions and climate scenarios, and a response to local temperature rise was documented for soybean, which had not been covered by Easterling et al. [2007]. This modelling exercise could also demonstrate the importance of nitrogen limitation in the assessment of climate change impacts, which indicates the general importance of management constraints for the assessment of climate change impacts on agriculture. If nitrogen limitations are explicitly considered, crops show less profit from $\mathrm{CO}_{2}$ fertilization [Leakey et al., 2009] and amplified negative climate impacts.

Accounting for nitrogen dynamics reduces the inter-model uncertainty associated with the effectiveness of $\mathrm{CO}_{2}$ fertilization on agricultural yields, yet this factor still remains one of the largest single sources of uncertainty. While it is clear that elevated $\mathrm{CO}_{2}$ concentrations stimulate increased photosynthesis in $\mathrm{C}_{3}$ plants, significant questions remain as to how this translates into increases in harvested biomass (e.g. grain mass) [Leakey et al., 2009], especially in real-world field conditions, and to what extent this can lead to unwanted side effects such as declining protein content and quality [Erbs et al., 2010] or higher susceptibility to insect damage [Zavala et al., 2008].

\subsection{Focus regions of climate change impacts}

There are two key types of focus regions for climate change impact assessments: those that are subject to large relative changes in agricultural productivity under climate change; and those that are currently major producers and run some risk of being negatively affected by climate change. Both types have implications for trade patterns but they may require very different assessment and response strategies.

The most substantial relative changes in crop productivity are expected in the low latitudes, across all major crops. Since agriculture is a relatively high share of national gross domestic product (GDP) in many tropical regions, these impacts combine with increasingly globalized agricultural markets to jeopardize food security in a dual way: farmers face decreasing local productivity and income, while food availability is increasingly determined by market access and global food prices. On the other hand, these countries often have average crop productivity that is considerably lower than what environmental conditions should allow (this is the so-called yield gap) [Licker et al., 2010; Neumann et al., 2010]. Better market access, infrastructure, fertilizers, pesticides, machinery and alternative crop varieties may be able to contribute substantially to closing these gaps [Markelova et al., 2009], with implications for development, food security, poverty, climate impacts and potential climate adaptations. A notable exception to this expectation is Egypt, where the yield gap is small [Neumann et al., 2010], irrigation is used extensively, and water resources are strongly limiting. Here, a shift from staple to high-value crops, which would require improved market structures, could increase farm incomes.

India is a key region for study for many reasons. It is likely to experience strong relative impacts of climate change and it is a top global producer of many crops [FAOSTAT data, 2013]. Changes in agricultural productivity in this region are thus extremely critical for both local and global food security. India's comprehensive infrastructure for irrigation [Döll and Siebert, 2000] may render adaptation to more erratic rainfall under climate change relatively easy, yet the overexploitation of groundwater reservoirs [Rodell et al., 2009] and the dependence of surface water reservoirs on monsoon rainfall [Maity and Kumar, 2009] may lead to decreasing freshwater availability for agriculture 
under climate change and could further reduce productivity [Elliott et al., 2014a].

Current yield trends in India are mixed, and largely stagnating for wheat [Ray et al., 2012]. New management practices may help to improve yields [Stoop et al., 2002] and have even led to a recent world record harvest [Kassam and Brammer, 2013]; however, the feasibility and applicability of these techniques at larger scales have been contested [Sumberg et al., 2013]. The preponderance of sequential cropping systems i.e. producing crops in several seasons of the year - in India will complicate simple adaptations, such as changes in planting dates or selection of fast- or slow-maturing varieties, because the implications for adjacent growing periods must be taken into account as well.

Major agricultural producers in temperate zones, such as the European Union for wheat or the United States of America for maize, can also be subject to strong negative impacts under climate change. These include: reduced water availability during the growing season; more frequent and intense heat events, which are most damaging during flowering [Asseng et al., 2011; Edreira et al., 2011; Hawkins et al., 2013a; Teixeira et al., 2013]; and accelerated phenology, which can lead to reduced biomass production [Liu et al., 2013]. However, these regions also tend to have more flexibility for adaptation. Cropping periods tend to become longer in warmer climates as cold temperature limitations in spring and autumn are alleviated. Further, given the dominance of single cropping systems in these regions (i.e. only one cropping cycle per year) farmers have significant flexibility to adjust varieties (e.g. spring vs. winter varieties) or planting dates, to respond to changing conditions [Liu et al., 2013]. Adjustments in planting dates can help to avoid periods with high temperature stress, exploit longer growing periods with varieties that mature more slowly and so have more time for biomass accumulation and grain filling, and target periods with improved water availability. In some temperate regions, multiple cropping systems could even become feasible in future climates, which could strongly increase agricultural productivity per area and year [Zhang et al., 2013].

\subsection{Inter-sectoral interaction}

Agricultural production is highly integrated with other sectors and biogeochemical cycles. The most obvious of these factors are the availability of freshwater and of fertile land, which constitute direct constraints to agricultural production. Irrigation agriculture directly competes with other consumers of freshwater, such as households, industry and energy production. Along with impacts from climate change, socio-economic and environmental factors can thus have a major effect on agricultural productivity and on the potential for climate adaptation through irrigation [Elliott et al., 2014a]. Indirect impacts of global climate change on agricultural productivity, such as those caused by changes in the availability of freshwater for irrigation, tend to follow similar patterns as direct impacts. As a result of climate change, freshwater availability increases in regions in the temperate zones but decreases in regions in the low latitudes, including prominent agricultural and heavily irrigated areas in India, China and Egypt. Increased availability in regions that already have ample freshwater supplies is likely to have only minimal potential to increase production, since small increases in average yield and decreased interannual variability are unlikely to justify large expenditures on irrigation infrastructure [Elliott et al., 2014a]. Constraints on freshwater availability in heavily irrigated areas, however, may lead to large reductions in the irrigated share of overall agricultural production, amplifying direct climate change impacts and increasing weatherinduced variability in these regions.

Freshwater rationing in the form of deficit irrigation has the potential to increase system-level water-use efficiency (i.e. agricultural production per unit of water) by applying sufficient irrigation amounts to reduce, but not eliminate, water stress. This approach of focusing on water productivity rather than land productivity (i.e. 
agricultural production per unit of land) [Fereres and Soriano, 2007] is especially important in dry areas, where availability of water is usually more limiting to agricultural production than land [Geerts and Raes, 2009]. To date, there has been little research conducted on deficit irrigation at the global scale. A recent paper by Liu et al. (2014) tackled this issue using a global general model and may have opened the door for more research on the topic.

Availability of freshwater is also affected by increased competition from socio-economic development [Alcamo et al., 2007]. Economic growth may increase withdrawal of water for industry, even if accompanied by increases in water-use efficiency. Increased energy production, whether from fossil fuels or lowcarbon alternatives, generally requires substantial additional water withdrawal for cooling or cleaning.

Many assessments of likely future climate mitigation pathways project strong increases in biofuel production, which will compete directly for land and water resources with food, feed and fibre producers. Biofuels are a renewable energy source generated from re-growing plant biomass or from other biological sources (e.g. manure). Biofuels are often classified into two categories: first-generation biofuels made from sugar, starch and vegetable oils, which are typically derived from products suitable for human consumption and thus compete directly with food production; and secondgeneration biofuels made from cellulosic material unfit for human consumption. The conversion of cellulose into an energy source compatible with current technologies, especially in the transport sector, is still a major challenge, but its use is increasing as a feedstock for heat and electricity generation. Cellulose-based biofuels, however, compete with food production for resources, most importantly fertile land and water, as well as with many other ecosystem services. While proponents of second-generation biofuels point to the potential for using marginal lands for the production of biomass, the idea of existing "unused land" has been challenged [Searchinger et al., 2008; Elbehri, Segerstedt, and Liu, 2013].
The competition for land and water leads to deforestation of primary and secondary forests, producing direct and indirect land-use change [Melillo et al., 2009], which typically diminishes natural resources and ecosystem services [Metzger et al., 2006] and increases emissions of GHGs [Popp et al., 2010]. Under liberalized global trade regimes, increased demand for agricultural food, feed, fuel and fibre crops can thus lead to significant land-use change, with severe environmental consequences that are often difficult to account for and thus to regulate [Schmitz et al., 2012; Schmitz et al., 2013].

The interaction of agricultural production with other sectors and biogeochemical cycles can also diminish the ability of societies to cope with climate change, by compounding the pressures. Besides reduced response options and secondary impacts, as with the example of the reduced availability of freshwater constraining irrigation [Elliott et al. 2014a], multiple stressors can also reduce the adaptive capacity of societies [Quinn et al. 2011]. As a consequence, agricultural regions that are simultaneously subjected to detrimental impacts in other sectors may experience amplified biophysical impacts, socio-economic consequences, and/or a reduced capacity to respond to change. These "hotspots" should be focal regions for adaptation research [Piontek et al. 2014].

\section{The Global Gridded Crop Model intercomparison}

There are a variety of future climate scenarios: combinations of potential emissions pathways [e.g. Moss et al., 2010; Nakicenovic and Swart, 2000]; their implementation in a general circulation or earth system model; and statistical processing for bias correction [e.g. Hempel et al., 2013; Piani et al., 2010] or downscaling [e.g. Pierce et al., 2009] . However, despite this diversity of scenarios, it is clear that climate change poses a significant threat to agricultural production throughout the cultivated areas of the world. Even so, some regions and crops are confronted by challenges 
both more immediate and more severe than others. There is strong agreement among GGCM simulations that tropical regions will experience substantial negative impacts on agricultural productivity from climate change, given current management practices. While small increases in global mean temperature may be beneficial in cooler regions, climate change impacts are likely to be negative at moderate or high levels of global warming. These findings are largely in agreement with previous site-scale assessments, as summarized by the IPCC's Fourth Assessment Report [Easterling et al., 2007] and earlier globalscale assessments [Rosenzweig and Parry, 1994].

Beyond broad-scale patterns the picture is more opaque, as was recently demonstrated by the first intercomparison of GGCMs within the ISI-MIP and AgMIP frameworks. This is best highlighted by the range of possible assessment outcomes based on the impact model chosen. Indeed, in the ISI-MIP and AgMIP assessments, the differences among impact models were found to dominate the ensemble spread for most measures.

In order to begin to resolve these issues, $\mathrm{Ag}$ GRID has recently undertaken the GGCMI project. This project consists of a set of highly structured, protocol-based global simulation experiments designed by climate and agro-environmental scientists from around the world. The project will proceed in three overlapping phases, each building on the inputs, outputs, and lessons of the ones preceding it. In Phase 1, models will be driven by harmonized management inputs and nine historical climate-forcing datasets (spanning 1948-2012), focusing on model comparison, validation, and historical extremes. In Phase 2, historical data products will be varied to generate a structured input ensemble designed to evaluate model sensitivity and develop highresolution multi-dimensional response surfaces for the space of possible future values of carbon, temperature, water and nitrogen. In Phase 3, a new comprehensive multi-model climate impact assessment will be conducted within the AgMIP and ISI-MIP frameworks, with climate drivers from CMIP5 and CORDEX as well as detailed adaptation scenarios and a focus on the effects of increased frequency and severity of extreme weather events.

Harmonization of assumed growing periods and nitrogen fertilization is a key feature of the GGCMI Phase I protocols, and greatly improves comparability of results between models.

New metrics for model performance are being developed in concordance with metrics developed for general circulation models [Gleckler et al., 2008]. Due to the huge differences in the types and purposes of GGCMs, robust model evaluation will require much more than just the reproduction of yields. Interannual variability, the effects of historic extreme weather events on food production, and crop and region-specific analyses will also be of special interest.

\section{Open questions}

The uncertainty inherent in modelling global-scale climate change impacts on agriculture has several underlying reasons that carry implications for future research. Most important among these is the lack of suitable reference data for model testing, calibration and improvement - an aspect of the modelling challenge that is not likely to see great improvement in the near future. The vulnerability of a particular farm or region to climate change or to climate extremes depends strongly on the dominant management systems employed. In recent decades, much progress has been made in identifying dominant cover classes and some measures of irrigation infrastructure distribution, using remote sensing. However, little information is available regarding management practices (e.g. fertilizer application rates, planting densities, sowing dates) at the high spatial and temporal resolutions and global extent required to enable accurate representations of current management systems in GGCM simulations.

Uncertainty regarding the effectiveness of $\mathrm{CO}_{2}$ fertilization effects, the combination of stimulated photosynthesis in $\mathrm{C}_{3}$ plants and reduced water consumption in all plants under 
elevated atmospheric $\mathrm{CO}_{2}$ concentrations, is especially large in global-scale simulations. These studies include the full range of uncertainties in field-scale modelling, and involve combinations of environmental conditions (e.g. extremely dry, low fertilizer inputs) that are not sufficiently evaluated in laboratory, open-top chamber, or FACE experiments [Ainsworth and Long, 2005; Leakey et al., 2009]. Finally, national and even sub-national yield statistics are often too aggregated to provide a good evaluation of model performance or determination of the responsible underlying mechanisms, due to the large amount of spatial variability in environmental, climate and management conditions. These points are discussed in more detail in the following section.

\subsection{Model evaluation and validation}

For a comprehensive evaluation of GGCMs, long-time series of high-quality global data are required for many crops. National and even subnational statistics are often at too low a resolution to capture the relevant weather-induced variability of crop productivity, which instead is smoothed out by spatial aggregation over larger regions. Changes in production area and management practices are also typically not well documented in these statistics. The only reference yield data available for comparison with sufficient spatial and temporal coverage are national yield statistics, and the absence of high-quality management data is thus a strong constraint on model evaluation. Climate change impacts also differ significantly between irrigated and rain-fed systems, yet their contribution to overall production and average yields in a given region is often unclear, especially with respect to interannual variation, because installed irrigation capacity is not always used to the same extent.

The resolution of national statistics can be improved by assimilating sub-national statistics from a variety of sources [lizumi et al., 2014; Ray et al., 2012], or by incorporating satellitebased observations of productivity [lizumi et al.,
2014; Ray et al., 2012]. These products should greatly improve the scope of possible model evaluations, but care must be taken as these are not direct observations, but combinations of census data, remote sensing and modelling rules. Site-based reference data from FACE experiments [Ainsworth and Long, 2005; Leakey et al., 2009] and eddy-flux measurements [Baldocchi et al., 2001] can also provide valuable insights, but are limited with respect to coverage of agroclimatic regions, management systems and crops.

Phase I of the Ag-GRID GGCMI will use these and other reference datasets to evaluate models over more than six decades.

\subsection{Management}

The only datasets available for crop-specific irrigation shares are based on "installed irrigation equipment" in about the year 2000 but contain no information on the temporal variations or actual irrigation water amounts applied [Portmann et al., 2010] anything on actually irrigated areas [You et al., 2010] or these data are not crop-specific [Thenkabail et al., 2009]. Similarly, there is large uncertainty with respect to growing seasons. Again, national census data may not reflect the sub-national variability or diversity of systems. The data compilations for global-scale applications [Monfreda et al., 2008; Portmann et al., 2010] fail to distinguish between spring and winter varieties or between major differences in management (e.g. rain-fed vs. irrigated systems).

Nitrogen is the most important plant nutrient, which is applied to fields in the form of organic (manure) and inorganic (artificially synthesized ammonium) compounds as well as by atmospheric deposition. Input levels vary greatly across space and time but also across crops and management systems. Observational data are generally available only for artificial fertilizer consumption at national level, with little information about its use for specific regions, crops or cropping systems. Stimulated plant growth, whether due to warmer temperatures in high latitude locations or to elevated $\mathrm{CO}_{2}$ levels, can be inhibited by a deficit 
in nutrient supply, following Liebig's minimum law? . Nutrient deficits can also mask negative climate change impacts by reducing plants' susceptibility to changes in climate. National fertilizer data have been downscaled and assigned to specific crops [Mueller et al., 2012] and will be used in combination with estimates of national manure availability [Potter et al., 2010] for harmonized management data inputs in Ag-GRID's GGCMI model evaluation.

\subsection{Effects of elevated atmospheric carbon dioxide concentrations}

Besides global warming, increased atmospheric $\mathrm{CO}_{2}$ concentrations also stimulate photosynthesis in C3 plants and reduce water requirements for all plants. Plant photosynthesis is constrained by available energy (sunlight being intercepted by leaves), the plant's capacity for photosynthesis (mainly determined by the abundance of the Rubisco enzyme) and the availability of $\mathrm{CO}_{2}$ as a primary input to photosynthesis. In agricultural systems, where nutrient availability and thus nitrogen limitation of Rubisco activity can be managed to some extent, atmospheric $\mathrm{CO}_{2}$ concentrations often limit photosynthetic rates for the majority of plant species. Under such conditions, rising $\mathrm{CO}_{2}$ concentrations in the atmosphere due to anthropogenic emissions can stimulate photosynthesis. This effect is robust and confirmed by long-term field trials, such as the FACE experiments. Elevated atmospheric $\mathrm{CO}_{2}$ concentrations can lead to down-regulation of Rubisco activity in the long run; however, this does not challenge the overall stimulating effect of elevated atmospheric $\mathrm{CO}_{2}$ concentrations on photosynthesis [Leakey et al., 2009].

All plants, independent of their photosynthetic pathways $\left(\mathrm{C}_{3}\right.$ or $\left.\mathrm{C}_{4}\right)$, profit from elevated

This law, popularized by Justus von Liebig, states that states that growth is controlled not by the total amount of resources available, but by the scarcest resource (limiting factor). atmospheric $\mathrm{CO}_{2}$ concentrations in semi-arid and arid environments because of the direct coupling of the carbon and water fluxes between plants and the atmosphere. The pores through which $\mathrm{CO}_{2}$ enters the plant - the stomata - are also the pores through which water vapor leaves the plant during plant transpiration. The opening of the stomata is controlled by the plant's cell pressure, which decreases when the plant dries. As a consequence, plants close their stomata under dry conditions to avoid wilting and this reduces their ability to take up $\mathrm{CO}_{2}$. Under elevated atmospheric $\mathrm{CO}_{2}$ concentrations, stomata can be closed more often to save water without reducing the influx of carbon for photosynthesis, leading to higher crop-water productivity (unit of output per unit of water) [Manzoni et al., 2011; Polley, 2002]. A large body of research, including laboratory work, open-chamber field trials and FACE experiments, has documented the beneficial effects of elevated atmospheric $\mathrm{CO}_{2}$ concentrations on photosynthesis and plant growth [Ainsworth and Long, 2005; Leakey et al., 2009; Polley, 2002].

However, there is still large degree of uncertainty regarding the general effects of elevated atmospheric $\mathrm{CO}_{2}$ concentrations at larger scales and for longer time horizons. To harness increased plant growth under elevated atmospheric $\mathrm{CO}_{2}$ concentrations, farmers will have to adjust fertilization and possibly other management practices, such as the selection of cultivars [Ribeiro et al., 2012]. There are some indications that gains in photosynthesis and total biomass may not lead to proportional gains in yields (e.g. for grains) [Leakey et al., 2009]. Increases in biomass and yield may also lead to decreases in protein concentration and thus in nutrient quality and economic profitability [Pleijel and Uddling, 2012; Taub et al., 2008]. Elevated atmospheric $\mathrm{CO}_{2}$ concentrations have the potential not only to reduce protein concentrations but also to generally alter the chemical composition of plant tissues. These changes have also been shown to change the plants' susceptibility to insect damage 
[Dermody et al., 2008] and may require intensified crop management to avoid losses [Zavala et al., 2008].

\subsection{Future challenges: Representative agricultural pathways}

Agricultural production is strongly dependent on weather conditions and thus susceptible to climate change impacts. However, management is also a central aspect in agricultural production, and mismanagement can lead to substantial reductions in production. The effects of mismanagement on agricultural production are often described using the concept of "yield gap analysis", which describes the difference between yields actually achieved and potential yields - i.e. yields theoretically achievable under given environmental conditions, where no nutrient and water limitations constrain plant growth [van Ittersum and Cassman, 2013; van Ittersum et al., 2013]. Global analyses have shown that there are substantial yield gaps, i.e. management-driven reductions in agricultural productivity, especially in many developing countries [Licker et al., 2010; Neumann et al., 2010], and limited market access was identified as one of the major reasons for this phenomenon [Neumann et al., 2010]. Besides identifying managerial deficits that can lower agricultural productivity, agricultural research can greatly improve agricultural productivity, e.g. by developing novel crop varieties that are more productive or less susceptible to drought phases, heat, insect damage or pests, or new soil and water management techniques. Such targeted agricultural research has led to substantial improvements in agricultural productivity in the past, as, for example, during the so-called "green revolution" [Evenson and Gollin, 2003; Pingali, 2012]. Agricultural research is effective over longer time periods, as research and development typically have multi-annual cycles, and their effects are typically not captured by yield gap analyses because they do not necessarily affect the difference between actual and potential yields, but can move the potential yield level upwards [Dietrich et al., 2012].

Historically, yield increases have resulted from a combination of closing the yield gap and shifting potential yield levels upwards and, in the past, these yield increases have sustained the increases in global population. Recently, yield increases have stalled for many important crops and countries [Lin and Huybers, 2012; Ray et al., 2012] and yield improvements at historic rates have been found to be insufficient to sustain projected future demand for agricultural products [Ray et al., 2013].

Current research on climate change impacts often assumes static management systems [Rosenzweig et al., 2014] or addresses simple on-farm adaptation measures such as soil and water management or the adaptation of sowing dates [Folberth et al., 2012; Laux et al., 2010; Liu et al., 2013; Waha et al., 2012a], which can be assumed to be determined mostly by climatic and weather conditions [Waha et al., 2012b]. Adaptation to climate change can be complex and involve targeted research [Challinor et al., 2009; Challinor et al., 2007; Reidsma et al., 2009; Smith and Olesen 2010] but often can be achieved via simple and inexpensive technologies [Ebi et al., 2011]. The assumption of static management systems in climate change impact assessments is thus not designed to provide assessments of future agricultural productivity but to explore the isolated effect of climate change only. This helps to reduce inconsistencies between biophysical models and economic models that take biophysical climate change impact projections as an input to their economic response [Müller and Robertson, 2014; Nelson et al., 2014a; Nelson et al., 2014b]. However, assumptions regarding management systems can also greatly affect the projected strength of climate change impacts on agricultural productivity [Rosenzweig et al., 2014].

In light of its significance for the assessment of future agricultural productivity and for the assessment of future climate change impacts on agricultural productivity, consideration of various scenarios on future agricultural management is crucial. Such scenarios need to reflect plausible 
possible future circumstances for all socioeconomic and biophysical dimensions that are important for agricultural production. At the global scale these comprise assumptions on future trade patterns, affecting global production patterns, market access for selling agricultural products and buying inputs (fertilizers, pest control, machinery, seeds) and price levels that will determine the profitability of different management options. National and economic unions (e.g. the European Union) may enforce agricultural policies or environmental regulations - including the mitigation of GHG emissions - that affect agricultural management and labour markets. Population growth [Lutz and Samir, 2010], migration [Aaheim et al., 2012; Kniveton et al., 2012; McLeman and Smit, 2006] and urbanization, as well as future educational systems, may affect labour availability for agricultural production as well as production costs [e.g. Martin and Calvin, 2010]. Finally, one central input for agricultural production, namely phosphorus, is in short supply globally and in the hands of very few actors; even though stocks may not be depleted this century [Van Vuuren et al., 2010], this has the potential to affect productivity levels, production costs and production patterns globally [Bouwman et al., 2009; Carpenter and Bennett, 2011;

MacDonald et al., 2011].

In global scale assessments, agricultural systems are not represented in much detail so far, but typically involve assumptions on sowing dates, varieties grown and fertilizer inputs [Rosenzweig et al., 2014]. Future scenarios regarding agricultural system change thus only need to address these dimensions if models do not take up the challenge to better integrate different management systems [e.g. Del Grosso et al., 2009]. This challenge can be more complex for assessments at regional scale [Antle et al., under review].

The most promising approach for developing scenarios of future agricultural production systems, often referred to as Representative Agricultural Pathways (RAPs), is to expand existing (or currently under development) socio-economic scenarios, such as the so-called SSPs [Kriegler et al., 2012]. These typically address some of the relevant dimensions for agricultural productions (e.g. trade liberalization scenarios) but need to be filled out with more explicit assumptions on others (e.g. fertilizer rates, speed of dissemination of betteradapted crop varieties) that just need to be consistent with the general storylines of the SSPS and the more explicit assumptions therein.

\subsection{Future challenges: Drought and climate extremes}

Agricultural production is directly dependent on weather conditions, especially in non-irrigated production systems. The effects of weather variability produce variations in national yield statistics; in many cases, changes in yield variability can be attributed to weather variability [Osborne and Wheeler, 2013]. As variability changes under global warming, this will affect agricultural production [Hawkins et al., 2013b], especially during heat-sensitive phases [e.g. Asseng et al., 2011; Edreira et al., 2011; Teixeira et al., 2013].

Drought affects millions of people globally each year, and warming temperatures and shifting precipitation patterns are likely to exacerbate the problem, increasing both the frequency and severity of large-scale droughts in globally important and agriculturally sensitive regions [Sheffield and Wood, 2008; Solomon et al., 2007; Wehner et al., 2011]. Recent work suggests that extended drought will harm more people in the future than any other climate-related impact, specifically in the area of food security [Romm, 2011]. Therefore, the extent to which climate impact models can reproduce the effects of large-scale drought and heat events is likely to be one of the most important measures of model effectiveness, for determining whether these models are able to represent future impacts successfully. Dozens of specific large-scale extreme hydrological drought and heat events from the historical record (1948-present) have been catalogued by Sheffield and Wood [2011]. 
Many of these events had major agricultural, food security and economic implications, and these can be evaluated using GGCMs in order to test these models under such extreme conditions. This will also result in a standardized, comprehensive multimodel analysis of agricultural drought over the last 6+ decades, comparable among regions and decades, that will improve both the understanding of drought and its effects on crops and food production and the ability of models to represent the consequences of increased drought and heat in the future.

\subsection{Future challenges: Connecting with field-scale assessments}

Crop growth models have been applied to multiple purposes for several decades. Given that models applied to climate change impact assessment do not always employ the most upto-date formulations, Rötter et al. [2011] called for a general re-assessment of model effectiveness, as a first step towards improving model formulations. This effort has been undertaken by AgMIP [Rosenzweig et al., 2013], focusing first on the major cereal crops - wheat [Asseng et al., 2013], maize [Bassu et al., 2014] and rice - while building communities and establishing research teams for other crops, pastures and livestock (see http://www.agmip.org). The projects focus initially on reproducing observations across different environmental gradients and management systems, followed by exploration of model sensitivities to changes in temperature, precipitation and atmospheric $\mathrm{CO}_{2}$ concentrations.

As GGCMs are often based on field-scale models to varying degrees, field-scale model improvements can provide the basis for globalscale improvements. Processes that have been identified as important for future crop productivity, such as temperature extremes [Asseng et al., 2011], tropospheric ozone concentrations [Bender and Weigel, 2011; Leisner and Ainsworth, 2012; Pleijel and Uddling, 2012] and pests and diseases [Bebber et al., 2013; Mediene et al., 2011], will have to be implemented and tested in fieldscale models, before they can be implemented in global-scale assessments. The high quality of data available at some individual field sites greatly facilitates the development and evaluation of process formulations in crop models. Global-scale models can inform field-scale model development as well - for example, by characterizing expected ranges of growing conditions across large areas, as well as their implications for agricultural productivity and modelled sensitivities.

\subsection{Future challenges: Informing economic assessment with biophysical climate change impact studies}

Biophysical climate change impact assessments are a central precondition for understanding climate change impacts on future trade patterns in agricultural markets. There are a number of challenges to making these assessments useful to current agricultural economic assessments. The uncertainty with respect to climate change patterns [Christensen et al., 2007] and impact models [Rosenzweig et al., 2014] needs to be accounted for. A broad variety of issues exist in modelling consistency between economic and biophysical models. One important aspect is the difference between market commodities such as sugar, assumed to be homogeneous by economic models, which can be supplied by very different biophysical crops (here: sugar cane and sugar beet) that differ in their photosynthetic pathways ( $\mathrm{C}_{4}$ for sugar cane, $\mathrm{C}_{3}$ for sugar beet), phenology, and plant organs of interest (stalks or beets). The ability to model these different crop types or assumptions about their mixture in the supply of the commodity sugar can greatly affect the assessment of climate change impacts on the commodity's market shares and production [Müller and Robertson, 2014; Nelson et al., 2014a; Nelson et al., 2014b]. 


\section{Conclusions}

Assessments of climate change impacts on globalscale agricultural productivity have been conducted for the last several decades [Rosenzweig and Parry, 1994]. However, quantification of the uncertainties related to different climate scenarios, impact model implementations, assumptions on management systems and $\mathrm{CO}_{2}$ fertilization has been supplied only recently. The general global pattern of more negative impacts being experienced in the tropical regions than in the higher latitudes has been shown to be reliable across the significant uncertainty embedded in different climate scenarios and impact models used [Rosenzweig et al., 2014]. Available computational power to conduct global-scale climate change impact assessments on agricultural productivity has increased since the study of Rosenzweig and Parry [1994], and models have been adjusted for gridded global simulations [e.g. Elliott et al., 2014b; Liu et al., 2007] and extended to cover agricultural vegetation [e.g. Berg et al., 2011; Bondeau et al., 2007; Deryng et al., 2011; Lindeskog et al., 2013] or developed explicitly for large-scale applications [e.g. Challinor et al., 2004]. Input data on management aspects beyond national fertilizer rates [Liu et al., 2010; Mueller et al., 2012] and some estimates of growing seasons [Portmann et al., 2010; Sacks et al., 2010], as well as good reference data, are scarce, and products have only recently been available [lizumi, et al., 2014; Ray, et al., 2012]. Therefore, evaluation of the performance of GGCMs has been very limited, mainly demonstrating that measurements of specific sites [e.g. Bondeau et al., 2007] or national yield statistics [e.g. Liu et al., 2007] can be reproduced.

The first GGCMI conducted within AgMIP [Rosenzweig et al., 2013], as the agricultural biophysical sector assessment in the ISI-MIP, has shed some initial light on uncertainties across different GGCMs, management assumptions, climate scenarios and assumptions about the effectiveness of $\mathrm{CO}_{2}$ fertilization [Rosenzweig et al., 2014]. This study confirms general patterns of climate change impact found in previous global-scale assessments [e.g. Müller et al., 2009; Rosenzweig and Parry, 1994] and site-specific studies [e.g. as compiled in Easterling et al., 2007].

Future activities to improve our understanding of possible future climate change impacts on biophysical agricultural productivity will be further coordinated by Ag-GRID and its GGCMI and will cover better model evaluation and understanding of key uncertainties (management, $\mathrm{CO}_{2}$ fertilization, temperature extremes) and model improvements (e.g. nutrient dynamics, management options). The project will foster interaction with the crop-specific activities as well as with the Global Economic group in AgMIP to address these challenges.

The role of adaptation to climate change and the biophysical options to increase productivity, especially in regions with strong managerial deficiencies, have not yet been fully explored and will require improved representation of management options in GGCMs. Current analyses of climate change impacts on agricultural productivity are thus not complete projections of future productivity but of the isolated effect of climate change only. Changes in management have the potential to mediate climate change impacts as well as to improve agricultural productivity beyond simply compensating for negative climate change impacts.

Despite considerable uncertainties in terms of climate drivers and biophysical responses of agricultural systems, it is clear that climate change will have significant impacts on agricultural trade. Given the robust pattern of less severe, or even positive, impacts in temperate zones compared to tropical regions, economic measures and trade policies will have to be developed to ensure sufficient income in developing regions to allow them to participate in trade even under declining agricultural yields. 


\section{References}

Aaheim, A., H. Amundsen, T. Dokken \& T. Wei. 2012. Impacts and adaptation to climate change in European economies. Global Environmental Change-Human and Policy Dimensions, 22, 959968, doi: 10.1016/j.gloenvcha.2012.06.005.

Adam, M., L. Van Bussel, P. Leffelaar, H. Van Keulen \& F. Ewert. 2011. Effects of modelling detail on simulated potential crop yields under a wide range of climatic conditions. Ecological Modelling, 222, 131-143, doi: 10.1016/j.ecolmodel.2010.09.001.

Ainsworth, E., \& S. Long. 2005. What have we learned from 15 years of free-air $\mathrm{CO}_{2}$ enrichment (FACE)? A meta-analytic review of the responses of photosynthesis, canopy properties and plant production to rising $\mathrm{CO}_{2}$. New Phytologist, 165, 351-371, doi: 10.1111/j.1469-8137.2004.01224.x.

Alcamo, J., M. Flörke \& M. Märker. 2007. Future long-term changes in global water resources driven by socio-economic and climatic changes. Hydrological Sciences Journal, 52, 247-275.

Antle, J., R. Valdivia, L. Claessens, G. Nelson, C. Rosenzweig, A. Ruane \& J. Vervoort. (under review) Representative Agricultural Pathways and Scenarios: A Trans-Disciplinary Approach to Agricultural Model Inter-comparison, Improvement and Climate Impact Assessment. Global Environmental Change.

Asseng, S., F. Ewert, C. Rosenzweig, J. Jones, J. Hatfield, A. Ruane, K. Boote, P. Thorburn, R. Rotter, D. Cammarano, N. Brisson, B. Basso, P. Martre, P. Aggarwal, C. Angulo, P. Bertuzzi, C. Biernath, A. Challinor, J. Doltra, S. Gayler, R. Goldberg, R. Grant, L. Heng, J. Hooker, L. Hunt, J. Ingwersen, R.C. Izaurralde, K.C. Kersebaum, C. Müller, S. Naresh Kumar, C. Nendel, G. O'Leary, J. Olesen, T. Osborne, T. Palosuo, E. Priesack, D. Ripoche, M. Semenov, I. Shcherbak, P. Steduto, C. Stockle, P. Stratonovitch, T. Streck, I. Supit,
F. Tao, M. Travasso, K. Waha, D. Wallach, J. White, J. Williams \& J. Wolf. 2013. Uncertainty in simulating wheat yields under climate change. Nature Climate Change, 3, 827-832, doi: 10.1038/ NCLIMATE1916.

Asseng, S., I. Foster \& N. Turner. 2011. The impact of temperature variability on wheat yields. Global Change Biology, 17, 997-1012, doi: 10.1111/j.1365-2486.2010.02262.x.

Baldocchi, D., E. Falge, L. Gu, R. Olson, D. Hollinger, S. Running, P. Anthoni, C. Bernhofer, K. Davis, R. Evans, J. Fuentes, A. Goldstein, G. Katul, B. Law, X. Lee, Y. Malhi, T. Meyers, W. Munger, W. Oechel, K. Paw, K. Pilegaard, H. Schmid, R. Valentini, S. Verma, T. Vesala, K. Wilson \& S. Wofsy. 2001. FLUXNET: A New Tool to Study the Temporal and Spatial Variability of Ecosystem-Scale Carbon Dioxide, Water Vapor, and Energy Flux Densities. Bulletin of the American Meteorological Society, 82, 2415-2434.

Bassu, S., N. Brisson, J. Durand, K. Boote, J. Lizaso, J. Jones, C. Rosenzweig, A. Ruane, M. Adam, C. Baron, B. Basso, C. Biernath, H. Boogaard, S. Conijn, M. Corbeels, D. Deryng, G. De Sanctis, S. Gayler, P. Grassini, J. Hatfield, S. Hoek, C. Izaurralde, R. Jongschaap, A. Kemanian, K. Kersebaum, N. Kumar, D. Makowski, C. Müller, C. Nendel, E. Priesack, M. Pravia, H. Soo, F. Sau, I. Shcherbak, F. Tao, E. Teixeira, D. Timlin \& K. Waha 2014. Do various maize crop models give the same responses to climate change factors? Global Change Biology, 20, 7, 2301-2320, doi: 10.1111/gcb.12520.

Bebber, D., M. Ramotowski \& S. Gurr. 2013. Crop pests and pathogens move polewards in a warming world. Nature Clim. Change, 3, 985-988, doi: 10.1038/nclimate1990.

Bender, J. \& H. Weigel. 2011. Changes in atmospheric chemistry and crop health: A review. Agronomy for Sustainable Development, 31, 81 89, doi: 10.1051/agro/2010013. 
Bentsen, M., I. Bethke, J. Debernard, T. Iversen, A. Kirkevag, Ã. Seland, H. Drange, C. Roelandt, I. Seierstad, C. Hoose \& J. Kristjájnsson. 2013. The Norwegian Earth System Model, NorESM1-M - Part 1: Description and basic evaluation of the physical climate. Geosci. Model Dev., 6, 687-720, doi: 10.5194/gmd-6-687-2013.

Berg, A., B. Sultan \& N. de Noblet-Ducoudre. 2011. Including tropical croplands in a terrestrial biosphere model: application to West Africa. Climatic Change, 104, 755-782, doi: 10.1007/ s10584-010-9874-X.

Blandford, D., I. Gaasland, R. Garcia \& E. Vardal. 2010. How Effective are WTO Disciplines on Domestic Support and Market Access for Agriculture? World Econ., 33, 1470-1485, doi: 10.1111/j.1467-9701.2010.01298.x.

Bondeau, A., P. Smith, S. Zaehle, S. Schaphoff, W. Lucht, W. Cramer, D. Gerten, H. Lotze-Campen, C. Müller, M. Reichstein \& B. Smith. 2007. Modelling the role of agriculture for the 20th century global terrestrial carbon balance. Global Change Biology, 13, 679-706, doi: 10.1111/j.13652486.2006.01305.x.

Boote, K., J. Jones, J. White, S. Asseng \& J. Lizaso. 2013. Putting mechanisms into crop production models. Plant Cell Environ, 36, 16581672, doi: 10.1111/pce.12119.

Bouwman, A., T. Kram \& K. Klein Goldewijk. (Eds.) 2006. Integrated modelling of global environmental change. An overview of IMAGE 2.4, 228 pp., Netherlands Environmental Assessment Agency, Bilthoven, The Netherlands.

Bouwman, A., A. Beusen \& G. Billen. 2009. Human alteration of the global nitrogen and phosphorus soil balances for the period 19702050. Global Biogeochemical Cycles, 23, Gb0a04, doi: 10.1029/2009gb003576.
Carpenter, S., \& E. Bennett. 2011. Reconsideration of the planetary boundary for phosphorus.

Environmental Research Letters, 6, 12, doi: 10.1088/1748-9326/6/1/014009.

Challinor, A., F. Ewert, S. Arnold, E. Simelton \& E. Fraser. 2009. Crops and climate change: progress, trends, and challenges in simulating impacts and informing adaptation. Journal of Experimental Botany, 60, 2775-2789, doi: 10.1093/jxb/erp062.

Challinor, A., T. Wheeler, P. Craufurd, C. Ferro \& D. Stephenson. 2007. Adaptation of crops to climate change through genotypic responses to mean and extreme temperatures. Agric Ecosyst Environ, 119, 190-204.

Challinor, A., T. Wheeler, P. Craufurd, J. Slingo \& D. Grimes. 2004. Design and optimisation of a large-area process-based model for annual crops. Agricultural and Forest Meteorology, 124, 99-120.

Christensen, J., B. Hewitson, A. Busuioc, A. Chen, X. Gao, I. Held, R. Jones, R.K. Kolli, W. T. Kwon, R. Laprise, V.M. Rueda, L. Mearns, C.G. Menéndez, J. Räisänen, A. Rinke, A. Sarr \& P. Whetton. 2007. Regional Climate Projections. in Climate Change 2007: The Physical Science Basis. Contribution of Working Group I to the Fourth Assessment Report of the Intergovernmental Panel on Climate Change, edited by S. Solomon, D. Qin, M. Manning, Z. Chen, M. Marquis, K.B. Averyt, M. Tignor \& H.L. Miller, Cambridge University Press, Cambridge, United Kingdom and New York, NY, USA.

Confalonieri, R., D. Gusberti, S. Bocchi \& M. Acutis. 2006. The CropSyst model to simulate the $\mathrm{N}$ balance of rice for alternative management. Agronomy for Sustainable Development, 26, 241 249, doi: 10.1051/agro:2006022.

de Wit, A. \& C. van Diepen. 2008. Crop growth modelling and crop yield forecasting using satellitederived meteorological inputs. International Journal 
of Applied Earth Observation and Geoinformation 10, 414-425, doi: 10.1016/j.jag.2007.10.004.

Del Grosso, S., D. Ojima, W. Parton, E. Stehfest, M. Heistemann, B. DeAngelo \& S. Rose. 2009. Global scale DAYCENT model analysis of greenhouse gas emissions and mitigation strategies for cropped soils. Global and Planetary Change, 67, 44-50, doi: 10.1016/j. gloplacha.2008.12.006.

Dermody, O., B. O'Neill, A. Zangerl, M. Berenbaum \& E. DeLucia. 2008. Effects of elevated $\mathrm{CO}_{2}$ and O-3 on leaf damage and insect abundance in a soybean agroecosystem. Arthropod-Plant Interact., 2, 125-135, doi: 10.1007/s11829-008-9045-4.

Deryng, D., J. Elliott, A. Ruane, C. Folberth, C. Müller, T. Pugh, E. Schmid, K. Boote, D. Conway, D. Gerten, J. Jones, N. Khabarov, S. Olin, S. Schaphoff, H. Yang \& C. Rosenzweig. in prep. Rising $\mathrm{CO}_{2}$ emissions benefit global crop water productivity.

Deryng, D., W. Sacks, C. Barford \& N. Ramankutty. 2011. Simulating the effects of climate and agricultural management practices on global crop yield. Global Biogeochem. Cycles, 25, GB2006, doi: 10.1029/2009GB003765.

Dietrich, J., C. Schmitz, C. Müller, M. Fader, H. Lotze-Campen \& A. Popp. 2012. Measuring agricultural land-use intensity - A global analysis using a model-assisted approach. Ecological Modelling, 232, 109-118, doi: 10.1016/j. ecolmodel.2012.03.002.

Döll, P. \& S. Siebert. 2000. A digital global map of irrigated areas. ICID Journal, 49, 55-66.

Drewniak, B., J. Song, J. Prell, V. Kotamarthi \& R. Jacob. 2013. Modeling agriculture in the Community Land Model. Geosci. Model Dev., 6, 495-515, doi: 10.5194/gmd-6-495-2013.

Dufresne, J., M. Foujols, S. Denvil, A. Caubel, O. Marti, O. Aumont, Y. Balkanski, S. Bekki,
H. Bellenger, R. Benshila, S. Bony, L. Bopp,

P. Braconnot, P. Brockmann, P. Cadule, F. Cheruy,

F. Codron, A. Cozic, D. Cugnet, N. Noblet,

J. Duvel, C. Ethé, L. Fairhead, T. Fichefet,

S. Flavoni, P. Friedlingstein, J. Grandpeix,

L. Guez, E. Guilyardi, D. Hauglustaine, F. Hourdin,

A. Idelkadi, J. Ghattas, S. Joussaume, M. Kageyama, G. Krinner, S. Labetoulle, A. Lahellec, M. Lefebvre, F. Lefevre, C. Levy, Z. Li, J. Lloyd, F. Lott, G. Madec, M. Mancip, M. Marchand, S. Masson, Y. Meurdesoif, J. Mignot, I. Musat, S. Parouty, J. Polcher, C. Rio, M. Schulz, D. Swingedouw, S. Szopa, C. Talandier, P. Terray, N. Viovy \& N. Vuichard. 2013. Climate change projections using the IPSL-CM5 Earth System Model: from CMIP3 to CMIP5. Climate Dynamics, 40, 2123-2165, doi: 10.1007/s00382012-1636-1

Dunne, J., J. John, A. Adcroft, S. Griffies, R. Hallberg, E. Shevliakova, R. Stouffer, W. Cooke, K. Dunne, M. Harrison, J. Krasting, S. Malyshev, P. Milly, P. Phillipps, L. Sentman, B. Samuels, M. Spelman, M. Winton, A. Wittenberg \& N. Zadeh. 2013a. GFDL's ESM2 Global Coupled Climate-Carbon Earth System Models. Part I: Physical Formulation and Baseline Simulation Characteristics. Journal of Climate, 25, 6646-6665, doi: 10.1175/JCLI-D-11-00560.1.

Dunne, J., J. John, E. Shevliakova, R. Stouffer, J. Krasting, S. Malyshev, P. Milly, L. Sentman, A. Adcroft, W. Cooke, K. Dunne, S. Griffies, R. Hallberg, M. Harrison, H. Levy, A. Wittenberg, P. Phillips \& N. Zadeh. 2013b. GFDL's ESM2 Global Coupled Climate-Carbon Earth System Models. Part II: Carbon System Formulation and Baseline Simulation Characteristics*. Journal of Climate, 26, 2247-2267, doi: 10.1175/JCLI-D-12-00150.1.

Easterling, W., P. Aggarwal, P. Batima, K. Brander, L. Erda, S. Howden, A. Kirilenko, J. Morton, J. Soussana, J. Schmidhuber \& F. Tubiello. 2007. Food, fibre and forest products. Climate Change 2007: Impacts, Adaptation and Vulnerability Contribution of Working Group II to the Fourth 
Assessment Report of the Intergovernmental Panel on Climate Change, edited by M.L. Parry, O.F. Canziani, J.P. Palutikof, P.J. Linden \& C.E. Hanson, pp. 273-313, Cambridge University Press, Cambridge, UK.

Ebi, K., J. Padgham, M. Doumbia, A. Kergna, J. Smith, T. Butt \& B. McCarl. 2011. Smallholders adaptation to climate change in Mali. Climatic Change, 108, 423-436.

Edreira, J., E. Carpici, D. Sammarro \& M. Otegui. 2011. Heat stress effects around flowering on kernel set of temperate and tropical maize hybrids. Field Crops Research, 123, 62-73, doi: 10.1016/j. fcr.2011.04.015.

Elbehri, A., A. Segerstedt, \& P. Liu. 2013. Biofuels and the sustainability challenge: a global assessment of sustainability issues, trends and policies for biofuels and related feedstocks, United Nations Food and Agriculture Organization (FAO), Rome, Italy 2013, 174 pp.

Elliott, J., D. Deryng, C. Müller, K. Frieler, M. Konzmann, D. Gerten, M. Glotter, M. Flörke, Y. Wada, N. Best, S. Eisner, B. Fekete, C. Folberth, I. Foster, S. Gosling, I. Haddeland, N. Khabarov, F. Ludwig, Y. Masaki, S. Olin, C. Rosenzweig, A. Ruane, Y. Satoh, E. Schmid, T. Stacke, Q. Tang \& D. Wisser. 2014a. Constraints and potentials of future irrigation water availability on agricultural production under climate change. Proceedings of the National Academy of Sciences of the United States of America.

Elliott, J., D. Kelly, J. Chryssanthacopoulos, M. Glotter, K. Jhunjhnuwala, N. Best, M. Wilde, I. Foster. 2014b. The parallel system for integrating impact models and sectors. Environmental Modelling \& Software, 2014. Published online ahead of print.

Erbs, M., R. Manderscheid, G. Jansen, S. Seddig, A. Pacholski \& H. J. Weigel. 2010, Effects of freeair $\mathrm{CO}_{2}$ enrichment and nitrogen supply on grain quality parameters and elemental composition of wheat and barley grown in a crop rotation. Agric Ecosyst Environ, 136, 59-68.

Evenson, R., \& D. Gollin. 2003. Assessing the impact of the Green Revolution, 1960 to 2000. Science, 300, 758-762, doi: 10.1126/ science.1078710.

Fader, M., S. Rost, C. Müller, A. Bondeau \& D. Gerten. 2010. Virtual water content of temperate cereals and maize: Present and potential future patterns. Journal of Hydrology, 384, 218-231, doi: 10.1016/j.jhydrol.2009.12.011.

FAO/IIASA/ISRIC/ISSCAS/JRC. 2012. Harmonized World Soil Database (version 1.2), edited, FAO, Rome, Italy and IIASA, Laxenburg, Austria.

\section{FAOSTAT data. 2013. http://faostat.fao.org/}

Fereres, E. \& M. Soriano. 2007. Deficit irrigation for reducing agricultural water use. Journal of Experimental Botany, 58, 147-159, doi: 10.1093/ jxb/erl165.

Fischer, G., M. Shah, F. Tubiello \& H. van Velhuizen. 2005. Socio-economic and climate change impacts on agriculture: an integrated assessment, 1990-2080. Philosophical Transactions of the Royal Society B-Biological Sciences, 360, 20672083.

Folberth, C., T. Gaiser, K. Abbaspour, R. Schulin \& H. Yang. 2012. Regionalization of a large-scale crop growth model for sub-Saharan Africa: Model setup, evaluation, and estimation of maize yields. Agric Ecosyst Environ, 151, 21-33, doi: 10.1016/j. agee.2012.01.026.

Geerts, S. \& D. Raes. 2009. Deficit irrigation as an on-farm strategy to maximize crop water productivity in dry areas. Agricultural Water Management, 96, 1275-1284, doi: 10.1016/j. agwat.2009.04.009. 
Gleckler, P., K. Taylor \& C. Doutriaux. 2008. Performance metrics for climate models. Journal of Geophysical Research-Atmospheres, 113, D06104, doi: 10.1029/2007jd008972.

Gregory, P., S. Johnson, A. Newton \& J. Ingram. 2009. Integrating pests and pathogens into the climate change/food security debate. Journal of Experimental Botany, 60, 2827-2838, doi: 10.1093/jxb/erp080.

Gueneau, A., C. Schlosser, K. Strzepek, X. Gao \& E. Monier. 2012. CLM-AG: An Agriculture Module for the Community Land Model version 3.5, MIT Joint Program on the Science and Policy of Global Change.

Hawkins, E., T. Fricker, A. Challinor, C. Ferro, C. Ho \& T. Osborne. 2013a. Increasing influence of heat stress on French maize yields from the 1960s to the 2030s. Global Change Biology, 19, 937-947, doi: $10.1111 / \mathrm{gcb} .12069$.

Hawkins, E., T. Osborne, C. Ho \& A. Challinor. 2013b. Calibration and bias correction of climate projections for crop modelling: An idealised case study over Europe. Agricultural and Forest Meteorology, 170, 19-31, doi: 10.1016/j. agrformet.2012.04.007.

Hawkins, E. \& R. Sutton. 2009. The potential to narrow uncertainty in regional climate predictions. Bulletin of the American Meteorological Society, 90, 1095-1107, doi: 10.1175/2009BAMS2607.1.

Hawkins, E. \& R. Sutton. 2011. The potential to narrow uncertainty in projections of regional precipitation change. Climate Dynamics, 37, 407418, doi: 10.1007/s00382-010-0810-6.

Hempel, S., K. Frieler, L. Warszawski, J. Schewe \& F. Piontek. 2013. A trend-preserving bias correction - the ISI-MIP approach. Earth Syst. Dynam., 4, 219-236, doi: 10.5194/esd-4-2192013. lizumi, T., M. Yokozawa, G. Sakurai, M. Travasso, V. Romanernkov, P. Oettli, T. Newby, Y. Ishigooka \& J. Furuya. 2014. Historical changes in global yields: major cereal and legume crops from 1982 to 2006. Global Ecology and Biogeography, 23, 3, 346-357, doi: 10.1111/geb.12120.

IPCC. in press. Summary for Policymakers, in Climate Change 2013: The Physical Science Basis. Contribution of Working Group I to the Fifth Assessment Report of the Intergovernmental Panel on Climate Change, edited by T.F. Stocker, D. Qin, G.-K. Plattner, M. Tignor, S.K. Allen, J. Boschung, A. Nauels, Y. Xia, \& P.M. Midgley, Cambridge University Press, Cambridge, United Kingdom and New York, NY, USA.

Iversen, T., M. Bentsen, I. Bethke, J. Debernard, A. Kirkevag, Ã. Seland, H. Drange, J. Kristjansson, I. Medhaug, M. Sand \& I. Seierstad. 2013. The Norwegian Earth System Model, NorESM1-M Part 2: Climate response and scenario projections. Geosci. Model Dev., 6, 389-415, doi: 10.5194/ gmd-6-389-2013.

Izaurralde, R., J. Williams, W. McGill, N. Rosenberg \& M. Jakas. 2006. Simulating soil $C$ dynamics with EPIC: Model description and testing against longterm data. Ecological Modelling, 192, 362-384.

Jones, C., J. Hughes, N. Bellouin, S. Hardiman, G. Jones, J. Knight, S. Liddicoat, F. O'Connor, R. Andres, C. Bell, K. Boo, A. Bozzo, N. Butchart, P. Cadule, K. Corbin, M. DoutriauxBoucher, P. Friedlingstein, J. Gornall, L. Gray, P. Halloran, G. Hurtt, W. Ingram, J. Lamarque, R. Law, M. Meinshausen, S. Osprey, E. Palin, L. Parsons Chini, T. Raddatz, M. Sanderson, A. Sellar, A. Schurer, P. Valdes, N. Wood, S. Woodward, M. Yoshioka \& M. Zerroukat. 2011. The HadGEM2-ES implementation of CMIP5 centennial simulations. Geosci. Model Dev., 4, 543-570.

Jones, J., G. Hoogenboom, C. Porter, K. Boote, W. Batchelor, L. Hunt, P. Wilkens, U. Singh, A. Gijsman 
\& J. Ritchie. 2003. The DSSAT cropping system model. European Journal of Agronomy, 18, 235-265.

Kassam, A. \& H. Brammer. 2013. Combining sustainable agricultural production with economic and environmental benefits: A Reply. Geogr. J., 179, 186-187, doi: 10.1111/geoj.12010.

Kimball, B., J. White, G. Wall \& M. Ottman. 2012. Infrared-Warmed and Unwarmed Wheat Vegetation Indices Coalesce Using Canopy-TemperatureBased Growing Degree Days. Agronomy Journal, 104, 114-118, doi: 10.2134/agronj2011.0144.

Kniveton, D., C. Smith \& R. Black. 2012. Emerging migration flows in a changing climate in dryland Africa. Nature Climate Change, 2, 444-447, doi: 10.1038/nclimate1447.

Kriegler, E., B. O'Neill, S. Hallegatte, T. Kram, R. Lempert, R. Moss \& T. Wilbanks. 2012. The need for and use of socio-economic scenarios for climate change analysis: A new approach based on shared socio-economic pathways. Global Environmental Change, 22, 807-822, doi: 10.1016/j.gloenvcha.2012.05.005.

Laux, P., G. Jacket, R. Tingem \& H. Kunstmann. 2010. Impact of climate change on agricultural productivity under rainfed conditions in Cameroon-A method to improve attainable crop yields by planting date adaptations. Agricultural and Forest Meteorology, 150, 1258-1271, doi: 10.1016/j.agrformet.2010.05.008.

Leakey, A., E. Ainsworth, C. Bernacchi, A. Rogers, S. Long \& D. Ort. 2009. Elevated $\mathrm{CO}_{2}$ effects on plant carbon, nitrogen, and water relations: six important lessons from FACE. Journal of Experimental Botany, 60, 2859-2876, doi: 10.1093/jxb/erp096.

Leemans, R. \& A. Solomon. 1993. Modeling the potential change in yield and distribution of the earth's crops under a warmed climate. Climate Research, 3, 79-96.
Leisner, C., \& E. Ainsworth. 2012. Quantifying the effects of ozone on plant reproductive growth and development. Global Change Biology, 18, 606616, doi: 10.1111/j.1365-2486.2011.02535.x.

Licker, R., M. Johnston, J. Foley, C. Barford, C. Kucharik, C. Monfreda \& N. Ramankutty. 2010. Mind the gap: how do climate and agricultural management explain the 'yield gap' of croplands around the world? Global Ecology and Biogeography, 19, 769-782, doi: 10.1111/j.14668238.2010.00563.x.

Lin, M. \& P. Huybers. 2012. Reckoning wheat yield trends. Environmental Research Letters, 7 , 024016, doi: 10.1088/1748-9326/7/2/024016.

Lindeskog, M., A. Arneth, A. Bondeau, K. Waha, J. Seaquist, S. Olin \& B. Smith. 2013. Implications of accounting for land use in simulations of ecosystem carbon cycling in Africa. Earth Syst. Dynam., 4, 385-407, doi: 10.5194/esd-4-3852013.

Liu, J., J. Williams, A. Zehnder \& H. Yang. 2007. GEPIC - modelling wheat yield and crop water productivity with high resolution on a global scale. Agricultural Systems, 94, 478-493, doi: 10.1016/j. agsy.2006.11.019.

Liu, J., L. You, M. Amini, M. Obersteiner, M. Herrero, A. Zehnder \& H. Yang. 2010 A highresolution assessment on global nitrogen flows in cropland. Proceedings of the National Academy of Sciences of the United States of America, 107, 8035-8040, doi: 10.1073/pnas.0913658107.

Liu, Z., K. Hubbard, X. Lin \& X. Yang. 2013. Negative effects of climate warming on maize yield are reversed by the changing of sowing date and cultivar selection in Northeast China. Global Change Biology, 19, 3481-3492, doi: 10.1111/ gcb.12324.

Liu, J., T. Hertel, F. Taheripour, T. Zhu, C. Ringler (2014). International trade buffers the impact of 
future irrigation shortfalls, Global Environmental Change 29 (2014) 22-31

Lutz, W. \& K. Samir. 2010. Dimensions of global population projections: what do we know about future population trends and structures? Philosophical Transactions of the Royal Society B-Biological Sciences, 365, 2779-2791, doi: 10.1098/rstb.2010.0133.

MacDonald, G., E. Bennett, P. Potter \& N. Ramankutty. 2011. Agronomic phosphorus imbalances across the world's croplands. Proceedings of the National Academy of Sciences of the United States of America, 108, 3086-3091, doi: 10.1073/pnas.1010808108.

Maity, R. \& D. Kumar. 2009. Hydroclimatic influence of large-scale circulation on the variability of reservoir inflow. Hydrological Processes, 23, 934-942, doi: 10.1002/hyp.7227.

Manzoni, S., G. Vico, G. Katul, P. Fay, W. Polley, S. Palmroth \& A. Porporato. 2011. Optimizing stomatal conductance for maximum carbon gain under water stress: a meta-analysis across plant functional types and climates. Functional Ecology, 25, 456-467, doi: 10.1111/j.13652435.2010.01822.x

Markelova, H., R. Meinzen-Dick, J. Hellin \& S. Dohrn. 2009. Collective action for smallholder market access. Food Policy, 34, 1-7, doi: 10.1016/j.foodpol.2008.10.001.

Martin, P. \& L. Calvin. 2010. Immigration Reform: What Does It Mean for Agriculture and Rural America? Applied Economic Perspectives and Policy, 32, 232-253, doi: 10.1093/aepp/ppq006.

McLeman, R. \& B. Smit. 2006. Migration as an adaptation to climate change. Climatic Change, 76, 31-53, doi: 10.1007/00584-005-900.

Mediene, S., M. Valantin-Morison, J. Sarthou, S. de Tourdonnet, M. Gosme, M. Bertrand,
J. Roger-Estrade, J. Aubertot, A. Rusch, N. Motisi, C. Pelosi \& T. Dore. 2011. Agroecosystem management and biotic interactions: a review. Agronomy for Sustainable Development, 31, 491514, doi: 10.1007/s13593-011-0009-1.

Melillo, J., J. Reilly, D. Kicklighter, A. Gurgel, T. Cronin, S. Paltsev, B. Felzer, X. Wang, A. Sokolov \& C. Schlosser. 2009. Indirect Emissions from Biofuels: How Important? Science, 326, 1397-1399, doi: 10.1126/science.1180251.

Metzger, M., M. Rounsevell, L. Acosta-Michlik, R. Leemans \& D. Schrotere. 2006. The vulnerability of ecosystem services to land use change. Agric Ecosyst Environ., 114, 69-85.

Monfreda, C., N. Ramankutty \& J. Foley. 2008. Farming the planet: 2. Geographic distribution of crop areas, yields, physiological types, and net primary production in the year 2000. Global Biogeochemical Cycles, 22, doi: Gb102210.1029/2007gb002947.

Moss, R., J. Edmonds, K. Hibbard, M. Manning, S. Rose, D. van Vuuren, T. Carter, S. Emori, M. Kainuma, T. Kram, G. Meehl, J. Mitchell, N. Nakicenovic, K. Riahi, S. Smith, R. Stouffer, A. Thomson, J. Weyant \& T. Wilbanks. 2010. The next generation of scenarios for climate change research and assessment. Nature, 463, 747-756, doi: 10.1038/nature08823

Mueller, N., J. Gerber, M. Johnston, D. Ray, N. Ramankutty \& J. Foley. 2012. Closing yield gaps through nutrient and water management. Nature, 490, 254-257, doi: 10.1038/nature11420.

Müller, C., A. Bondeau, A. Popp, K. Waha \& M. Fader. 2009. Climate change impacts on agricultural yields, The World Bank, Washington, DC.

Müller, C. \& R. Robertson. 2014. Projecting future crop productivity for global economic modeling. Agric. Econ., 45, 1, 37-50. 
Nakicenovic, N. \& R. Swart. (Eds.) 2000.

Special Report on Emission Scenarios, 599 pp., Cambridge University Press, Cambrige, UK.

Nelson, G., D. Mensbrugghe, E. Blanc, K. Calvin, T. Hasegawa, P. Havlík, P. Kyle, H. Lotze-Campen, M. Lampe, D. d'Croz, H. van Meijl, C. Müller, J. Reilly, R. Robertson, R. Sands, C. Schmitz, A. Tabeau, K. Takahashi \& H. Valin. 2014a. Agriculture and Climate Change in Global Scenarios: Why Don't the Models Agree? Agric. Econ., 45, 1, 85101.

Nelson, G., M. Rosegrant, J. Koo, R. Robertson, T. Sulser, T. Zhu, C. Ringler, S. Msangi, A. Palazzo, M. Batka, M. Magalhaes, R. Valmonte-Santos, M. Ewing \& D. Lee. 2009. Climate Change Impact on Agriculture and Costs of Adaptation, 30 pp, International Food Policy Research Institute, Washington D.C.

Nelson, G. , M. Rosegrant, A. Palazzo, I. Gray, C. Ingersoll, R. Robertson, S. Tokgoz, T. Zhu, T. Sulser, C. Ringler, S. Msangi \& L. You. 2010. Food Security, Farming, and Climate Change to 2050, 155 pp., International Food Policy Research Institute, Washington, D.C., USA.

Nelson, G., H. Valin, R. Sands, P. Havlík, H. Ahammad, D. Deryng, J. Elliott, S. Fujimori, E. Heyhoe, P. Kyle, M. Von Lampe, H. LotzeCampen, D. Mason d'Croz, H. van Meijl, D. van der Mensbrugghe, C. Müller, A. Popp,

R. Robertson, S. Robinson, E. Schmid, C. Schmitz, A. Tabeau \& D. Willenbockel. 2014b. Climate change effects on agriculture: Economic responses to biophysical shocks. Proceedings of the National Academy of Sciences of the United States of America, 111, 9, 3274-3279, doi: 10.1073/pnas.1222465110.

Neumann, K., P. Verburg, E. Stehfest \& C. Müller. 2010. A global analysis of the intensification potential for grain production. Agricultural Systems, 103, 316-326, doi: 10.1016/j.agsy.2010.02.004.
Osborne, T., G. Rose \& T. Wheeler. 2013.

Variation in the global-scale impacts of climate change on crop productivity due to climate model uncertainty and adaptation. Agricultural and Forest Meteorology, 170, 183-194.

Osborne, T., \& T. Wheeler. 2013. Evidence for a climate signal in trends of global crop yield variability over the past 50 years. Environmental Research Letters, 8, 024001, doi: 10.1088/17489326/8/2/024001.

Parry, M., C. Rosenzweig, A. Iglesias, M. Livermore \& G. Fischer. 2004. Effects of climate change on global food production under SRES emissions and socioeconomic scenarios. Global Environmental Change - Human and Policy Dimensions, 14, 53-67.

Piani, C., J. Haerter \& E. Coppola. 2010. Statistical bias correction for daily precipitation in regional climate models over Europe. Theoretical and Applied Climatology, 99, 187-192, doi: 10.1007/ s00704-009-0134-9.

Pierce, D., T. Barnett, B. Santer \& P. Gleckler. 2009. Selecting global climate models for regional climate change studies. Proceedings of the National Academy of Sciences of the United States of America, 106, 8441-8446, doi: 10.1073/ pnas.0900094106.

Piesse, J. \& C. Thirtle. 2009. Three bubbles and a panic: An explanatory review of recent food commodity price events. Food Policy, 34, 119-129.

Pingali, P. 2012. Green Revolution: Impacts, limits, and the path ahead. Proceedings of the National Academy of Sciences, 109, 12302-12308, doi: 10.1073/pnas.0912953109.

Piontek, F., C. Müller, T. Pugh, D. Clark, D. Deryng, J. Elliott, F. Colón-González, M. Flörke, C. Folberth, W. Fransseni, K. Frieler, A. Friend, S. Gosling, D. Hemming, N. Khabarov, H. Kim, M. Lomas, Y. Masaki, M. Mengel, A. Morse, K. Neumann, 
K. Nishina, S. Ostberg, R. Pavlick, A. Ruane, J. Schewe, E. Schmid, T. Stacke, Q. Tang, Z. Tessler, A. Tompkins, L. Warszawski, D. Wisser \& H. Schellnhuber. 2014. Multisectoral climate impact hotspots in a warming world. Proceedings of the National Academy of Sciences of the United States of America, 111, 9, 3233-3238, doi: 10.1073/pnas.1222471110.

Pleijel, H. \& J. Uddling. 2012. Yield vs. Quality trade-offs for wheat in response to carbon dioxide and ozone. Global Change Biology, 18, 596-605, doi: 10.1111/j.1365-2486.2011.2489.x.

Polley, H. 2002. Implications of atmospheric and climatic change for crop yield and water use efficiency. Crop Science, 42, 131-140.

Popp, A., H. Lotze-Campen \& B. Bodirsky. 2010. Food consumption, diet shifts and associated non- $\mathrm{CO}_{2}$ greenhouse gases from agricultural production. Global Environmental ChangeHuman and Policy Dimensions, 20, 451-462, doi: 10.1016/j.gloenvcha.2010.02.001.

Portmann, F., S. Siebert \& P. Döll. 2010. MIRCA2000-Global monthly irrigated and rainfed crop areas around the year 2000: A new highresolution data set for agricultural and hydrological modeling. Global Biogeochemical Cycles, 24, Gb1011, doi: 10.1029/2008gb003435.

Potter, P., N. Ramankutty, E. Bennett \& S. Donner. 2010. Characterizing the Spatial Patterns of Global Fertilizer Application and Manure Production. Earth Interactions, 14, 1-22, doi: 10.1175/2009EI288.1.

Power, A. 2010. Ecosystem services and agriculture: tradeoffs and synergies. Philosophical Transactions of the Royal Society B-Biological Sciences, 365, 29592971, doi: 10.1098/rstb.2010.0143.

Quinn, C., G. Ziervogel, A. Taylor, T. Takama \& F. Thomalla. 2011. Coping with Multiple Stresses in Rural South Africa. Ecology and Society, 16, 20, doi: 10.5751/es-04216-160302.
Ray, D., N. Mueller, P. West \& J. Foley. 2013. Yield Trends Are Insufficient to Double Global Crop Production by 2050. Plos One, 8, 8, doi: 10.1371/ journal.pone.0066428.

Ray, D., N. Ramankutty, N. Mueller, P. West \& J. Foley. 2012. Recent patterns of crop yield growth and stagnation. Nat. Commun., 3, 7, doi: 10.1038/ncomms2296.

Reidsma, P., F. Ewert, A. Lansink \& R. Leemans. 2009. Vulnerability and adaptation of European farmers: a multi-level analysis of yield and income responses to climate variability. Reg. Envir. Chang., 9, 25-40, doi: 10.1007/s10113-008-0059-3.

Ribeiro, D., W. Araújo, A. Fernie, J. Schippers \& B. Mueller-Roeber. 2012. Action of Gibberellins on Growth and Metabolism of Arabidopsis Plants Associated with High Concentration of Carbon Dioxide. Plant Physiol., 160, 1781-1794, doi: 10.1104/pp.112.204842.

Rodell, M., I. Velicogna \& J. Famiglietti. 2009. Satellite-based estimates of groundwater depletion in India. Nature, 460, 999-1002, doi: 10.1038/ nature08238.

Romm, J. 2011. Desertification: The next dust bowl. Nature, 478, 450-451, doi: 10.1038/478450a.

Rosenzweig, C., J. Elliott, D. Deryng, A. Ruane, C. Müller, A. Arneth, K. Boote, C. Folberth, M. Glotter, N. Khabarov, K. Neumann, F. Piontek, T. Pugh, E. Schmid, E. Stehfest, H. Yang \& J. Jones. 2014. Assessing agricultural risks of climate change in the 21st century in a global gridded crop model intercomparison. Proceedings of the National Academy of Sciences of the United States of America, 111, 9, 3268-3273, doi: 10.1073/ pnas.1222463110.

Rosenzweig, C., J. Jones, J. Hatfield, A. Ruane, K. Boote, P. Thorburne, J. Antle, G. Nelson, C. Porter, S. Janssen, S. Asseng, B. Basso, 
F. Ewert, D. Wallach, G. Baigorria \& J. Winter. 2013b. The Agricultural Model Intercomparison and Improvement Project (AgMIP): Protocols and pilot studies. Agricultural and Forest Meteorology, 170, 166-182, doi: 10.1016/j. agrformet.2012.09.011.

Rosenzweig, C. \& M. Parry. 1994. Potential impact of climate change on world food supply. Nature, 367, 133-138, doi: 10.1038/367133a0.

Rötter, R., T. Carter, J. Olesen \& J. Porter. 2011. Crop-climate models need an overhaul. Nature Clim. Change, 1, 175-177, doi: 10.1038/ nclimate1152.

Roudier, P., B. Sultan, P. Quirion \& A. Berg. 2011. The impact of future climate change on West African crop yields: What does the recent literature say? Global Environmental Change, 21, 10731083.

Saa Requejo, A., R. García Moreno, M. Díaz Alvarez, F. Burgaz \& M. Tarquis. 2011. Analysis of hail damages and temperature series for peninsular Spain. Nat. Hazards Earth Syst. Sci., 11, 3415-3422, doi: 10.5194/ nhess-11-3415-2011.

Sacks, W., D. Deryng, J. Foley \& N. Ramankutty. 2010. Crop planting dates: an analysis of global patterns. Global Ecology and Biogeography, 19, 607-620, doi: 10.1111/j.1466-8238.2010.00551.x.

Schaphoff, S., U. Heyder, S. Ostberg, D. Gerten, J. Heinke \& W. Lucht. 2013. Contribution of permafrost soils to the global carbon budget. Environmental Research Letters, 8, 014026, doi: 10.1088/1748-9326/8/1/014026.

Schmitz, C., A. Biewald, H. Lotze-Campen, A. Popp, J. Dietrich, B. Bodirsky, M. Krause \& I. Weindl. 2012. Trading more food: Implications for land use, greenhouse gas emissions, and the food system. Global Environmental Change, 22, 189209, doi: 10.1016/j.gloenvcha.2011.09.013.
Schmitz, C., H. Lotze-Campen, A. Popp, M. Krause, J. Dietrich \& C. Müller. 2013. Agricultural trade and tropical deforestation Interactions and related policy options. Reg. Envir. Chang., under review.

Searchinger, T., R. Heimlich, R. Houghton, F. Dong, A. Elobeid, J. Fabiosa, S. Tokgoz, D. Hayes \& T. Yu. 2008. Use of US croplands for biofuels increases greenhouse gases through emissions from land-use change. Science, 319, 1238-1240.

Sheffield, J. \& E. Wood. 2008. Projected changes in drought occurrence under future global warming from multi-model, multi-scenario, IPCC AR4 simulations. Climate Dynamics, 31, 79-105, doi: 10.1007/s00382-007-0340-z.

Sheffield, J. \& E. Wood. 2011. Drought: Past Problems and Future Scenarios, 210 pp., Earthscan, London, UK and Washington DC, USA.

Smith, B., I. Prentice \& M. Sykes. 2001.

Representation of vegetation dynamics in the modelling of terrestrial ecosystems: comparing two contrasting approaches within European climate space. Global Ecology and Biogeography, 10, 621 637.

Smith, P. \& J. Olesen. 2010. Synergies between the mitigation of, and adaptation to, climate change in agriculture. Journal of Agricultural Science, 148, 543-552, doi: 10.1017/s0021859610000341.

Solomon, S., D. Qin, M. Manning, Z. Chen, M. Marquis, K. Averyt, M.Tignor \& H. Miller. 2007. Climate Change 2007: The Physical Science Basis. Contribution of Working Group I to the Fourth Assessment Report of the Intergovernmental Panel on Climate Change, Cambridge University Press, Cambridge, United Kingdom and New York, NY, USA.

Stehfest, E., M. Heistermann, J. Priess, D. Ojima \& J. Alcamo. 2007. Simulation of global crop production with the ecosystem model DayCent. 
Ecological Modelling, 209, 203-219, doi: 10.1016/j.ecolmodel.2007.06.028.

Stöckle, C., M. Donatelli \& R. Nelson. 2003. CropSyst, a cropping systems simulation model. European Journal of Agronomy, 18, 289-307, doi: 10.1016/S1161-0301(02)00109-0.

Stoop, W., N. Uphoff \& A. Kassam. 2002. A review of agricultural research issues raised by the system of rice intensification (SRI) from Madagascar: opportunities for improving farming systems for resource-poor farmers. Agricultural Systems, 71, 249-274.

Sumberg, J., J. Andersson, K. Giller \& J. Thompson. 2013. Response to 'Combining sustainable agricultural production with economic and environmental benefits'. The Geographical Journal, 179, 183-185.

Tao, F., M. Yokozawa \& Z. Zhang. 2009a. Modelling the impacts of weather and climate variability on crop productivity over a large area: A new process-based model development, optimization, and uncertainties analysis. Agricultural and Forest Meteorology, 149, 831 850, doi: 10.1016/j.agrformet.2008.11.004.

Tao, F., Z. Zhang, J. Liu \& M. Yokozawa. 2009b. Modelling the impacts of weather and climate variability on crop productivity over a large area: A new super-ensemble-based probabilistic projection. Agricultural and Forest Meteorology, 149, 1266-1278, doi: 10.1016/j. agrformet.2009.02.015.

Taub, D., B. Miller \& H. Allen. 2008. Effects of elevated $\mathrm{CO}_{2}$ on the protein concentration of food crops: a meta-analysis. Global Change Biology, 14, 565-575, doi: 10.1111/j.1365-2486.2007.01511.x.

Taylor, K., R. Stouffer \& G. Meehl. 2012. An Overview of CMIP5 and the Experiment Design.
Bulletin of the American Meteorological Society, 93, 485-498.

Teixeira, E., G. Fischer, H. van Velthuizen, C. Walter \& F. Ewert. 2013. Global hot-spots of heat stress on agricultural crops due to climate change. Agricultural and Forest Meteorology, 170, 206215, doi: 10.1016/j.agrformet.2011.09.002.

Thenkabail, P., C. Biradar, P. Noojipady,

V. Dheeravath, Y. Li, M. Velpuri, M. Gumma, O. Gangalakunta, H. Turral, X. Cai, J. Vithanage, M. Schull \& R. Dutta. 2009. Global irrigated area map (GIAM), derived from remote sensing, for the end of the last millennium. International Journal of Remote Sensing, 30, 3679-3733, doi: 10.1080/01431160802698919.

Van den Hoof, C., E. Hanert \& P. Vidale. 2011. Simulating dynamic crop growth with an adapted land surface model - JULES-SUCROS: Model development and validation. Agricultural and Forest Meteorology, 151, 137-153, doi: 10.1016/j. agrformet.2010.09.011.

van Ittersum, M. \& K. Cassman. 2013. Yield gap analysis - Rationale, methods and applications Introduction to the Special Issue. Field Crops Research, 143, 1-3.

van Ittersum, M., K. Cassman, P. Grassini, J. Wolf, P. Tittonell \& Z. Hochman. 2013. Yield gap analysis with local to global relevance - A review. Field Crops Research, 143, 4-17, doi: 10.1016/j. fcr.2012.09.009.

van Vuuren, D., J. Edmonds, M. Kainuma, K. Riahi, A. Thomson, K. Hibbard, G. Hurtt, T. Kram, V. Krey, J. Lamarque, T. Masui, M. Meinshausen, N. Nakicenovic, S. Smith \& S. Rose. 2011. The representative concentration pathways: an overview. Climatic Change, 109, 5-31, doi: 10.1007/s10584-011-0148-z. 
van Vuuren, D., A. Bouwman \& A. Beusen. 2010. Phosphorus demand for the 1970-2100 period: A scenario analysis of resource depletion. Global Environmental Change, 20, 428-439, doi: 10.1016/j.gloenvcha.2010.04.004.

Waha, K., C. Müller, A. Bondeau, J. Dietrich, P. Kurukulasuriya, J. Heinke \& H. Lotze-Campen. 2012a. Adaptation to climate change through the choice of cropping system and sowing date in subSaharan Africa. Global Environmental Change, 23, 130-143, doi: 10.1016/j.gloenvcha.2012.11.001.

Waha, K., L. van Bussel, C. Müller \& A. Bondeau. 2012b. Climate-driven simulation of global crop sowing dates. Global Ecology and Biogeography, 21, 247-259, doi: 10.1111/j.14668238.2011.00678.x

Warszawski, L., K. Frieler, V. Huber, F. Piontek, O. Serdeczny \& J. Schewe. 2014. The Inter-Sectoral Impact Model Intercomparison Project (ISI-MIP): Project framework. Proceedings of the National Academy of Sciences of the United States of America, 111, 9, 3228-3232, doi: 10.1073/ pnas.1312330110.

Watanabe, S., T. Hajima, K. Sudo, T. Nagashima, T. Takemura, H. Okajima, T. Nozawa, H. Kawase, M. Abe, T. Yokohata, T. Ise, H. Sato, E. Kato, K. Takata, S. Emori \& M. Kawamiya. 2011. MIROC-ESM 2010: model description and basic results of CMIP5-20c3m experiments. Geosci. Model Dev., 4, 845-872.

Wehner, M., D. Easterling, J. Lawrimore, R. Heim, R. Vose \& B. Santer. 2011. Projections of Future Drought in the Continental United States and Mexico. Journal of Hydrometeorology, 12, 13591377, doi: 10.1175/2011JHM1351.1.

Williams, J., P. Dyke, W. Fuchs, V. Benson, O. Rice \& E. Taylor. 1990. EPIC-Erosion/Productivity Impact Calculator, US Department of Agriculture
Williams, J. \& V. Singh. 1995. The EPIC. Computer Models of Watershed Hydrology, in Water Resources Publications, edited by V.P. Singh, pp. 909-1000, Littleton, USA.

Xiong, W., J. Balkovič, M. van der Velde, X. Zhang, R. Izaurralde, R. Skalský, E. Lin, N. Mueller \& M. Obersteiner. 2014. A calibration procedure to improve global rice yield simulations with EPIC. Ecological Modelling, 273, 128-139, doi: 10.1016/j.ecolmodel.2013.10.026.

You, L., S. Crespo, Z. Guo, J. Koo, W. Ojo, K. Sebastian, M.T. Tenorio, S. Wood \& U. WoodSichra. 2010. Spatial Producition Allocation Model (SPAM) 2000 Version 3 Release 2.

Zavala, J., C. Casteel, E. DeLucia \& M. Berenbaum. 2008. Anthropogenic increase in carbon dioxide compromises plant defense against invasive insects. Proceedings of the National Academy of Sciences of the United States of America, 105, 5129-5133, doi: 10.1073/ pnas.0800568105.

Zhang, G., J. Dong, C. Zhou, X. Xu, M. Wang, H. Ouyang \& X. Xiao. 2013. Increasing cropping intensity in response to climate warming in TibetanPlateau, China. Field Crops Research, 142, 36-46. 
chapter 3

Page

$\begin{array}{ll}\text { 1. Introduction } & 62\end{array}$

2. Defining climate adaptation: Analytical perspective 63

3. Global climate models 66

4. Pathway models $\quad 71$

4.1 Crop yield models $\quad 71$

4.2 Water-climate pathway models $\quad 76$

$\begin{array}{ll}4.3 \text { Other pathway models } & 79\end{array}$

5. Economic models $\quad 80$

5.1 Market- and sector-level models $\quad 80$

$\begin{array}{ll}5.2 \text { Farm- and household-level models } & 89\end{array}$

$\begin{array}{ll}\text { 6. Conclusions } & 94\end{array}$

$\begin{array}{ll}\text { References } & 95\end{array}$

\section{Citation}

Elbehri, A. and M. Burfisher. 2015. Economic modelling of climate impacts and adaptation in agriculture: A survey of methods, results and gaps, In: Climate change and food systems: global assessments and implications for food security and trade, Aziz Elbehri (editor). Food Agriculture Organization of the United Nations (FAO), Rome, 2015. 


\section{chapter 3}

\section{Economic modelling of climate impacts and adaptation in agriculture: A survey of methods, results and gaps}

\section{Aziz Elbehri ${ }^{1}$ and Mary Burfisher ${ }^{2}$}

\section{main chapter messages}

- Integrated assessment models (IAMs) of climate impact report mostly negative and some positive outcomes of climate change on agriculture; but suggest substantial capacity to offset negative climate change through adaptive supply-and-demand responses, productivity-enhancing investments and trade.

- Uncertainty about future climate outcomes requires an integrated modelling framework that combines a variety of biophysical processes with economic scenarios using a range of models structures and socioeconomic pathways closely coordinated through research networks.

- Improving policy-relevant economic analysis of climate impacts and adaptation requires better integration of biophysical processes with socio-economic analyses and stronger use of inter-disciplinary approaches.

- Economic models need to improve the ability to analyse extreme events and to systematically quantify uncertainties and frame economic conclusions in the context of known model limitations.

- As adaptation decisions are inherently local, economic models at the farm/household level require better integration with biophysical and spatial techniques, improve accounting of climate risk and expand food security analysis beyond availability and include access and stability.

\footnotetext{
${ }^{1}$ Food and Agriculture Organization of the United Nations

2 United States Naval Academy and the Global Trade Aalysis Project (GTAP), Purdue University
} 


\section{Introduction}

T

he literature on climate impacts and adaptation in agriculture is growing exponentially. At the same time the need for action on adaptation is urgently felt at local, national and global levels. Climate adaptation planning and interventions at all levels need to be based on the best available evidence to date despite gaps in current knowledge and the persistent uncertainty about the specific climate outcomes and their likelihoods. It is thus imperative to assemble, evaluate and make accessible the scientific and socio-economic advances in our understanding of climate impacts on agriculture and food security.

Climate change and its complex manifestations have brought together different knowledge disciplines from climate science, biophysical processes and socio-economic drivers all the way to issues of geography and sociology. Each of these disciplines contributes to our understanding of climate change effects; but only when fully integrated do we form a more complete assessment that can translate into policy action. While climate science and related biophysical processes have received much attention and effort, the economics of climate adaptation remain understated. Yet the economic analysis of adaptation is an essential step toward forming informed policy action. This paper attempts to fill this gap by providing a broad and informative review of the economic modelling of climate impacts, demonstrating the importance of economics of adaptation within the broad climate impact analysis, and highlighting the strengths, weaknesses and gaps in current economic literature. This paper focuses on agriculture and several important drivers: food security, water and trade.

The chapter has three objectives: (i) to review and synthesize recent findings linking climate impacts to agriculture; (ii) to evaluate the economic literature contributions to evaluating adaptation options and decisions by relevant actors; and (iii) to identify gaps and formulate suggestions for further research. We aim to offer both an informative and critical contribution to the relevant economic literature and in so doing attempt to reach beyond the circle of specialist economists. The models and analytical methods reviewed are examined through their strengths, weaknesses and their relevancy in providing policy-relevant insights.

We place particular emphasis on analyses focusing on climate impacts and highlight the ways in which economic analyses describe climate change adaptations. Special attention is given to the economic models that are part of integrated assessments models which also link with global climate models and impact (or pathway) models. The latter generate biophysical and physical impacts, such as changes in crop yields or crop land inundation. For many economists, the climate and pathway models that provide the foundations of integrated economic climate assessments present new territory, and this introductory overview may be informative. We also review household-level models since much adaptation decision-making takes place at the local or farm level. Throughout the review we look at how the economic models handle climate-related uncertainty.

Our criteria for selecting the analyses included in this survey follow from our objectives. They emphasize timeliness, methodological interest, and applied policy relevance. We selected studies in which all or most of these criteria were met:

(i) Analyses are based on standard global climate modelling projections from no earlier than the $4^{\text {th }}$ Intergovernmental Panel on Climate Change (IPCC) assessment.

(ii) Analyses inform adaptation decision-making processes and are policy relevant.

(iii) Analyses are illustrative and exemplary of current methodologies that analyse climate change impacts and adaptation related to agriculture and food security.

(iv) Analyses offer representative geographic diversity in their application, with emphasis on developing countries. 
These criteria mean that many important contributions to an understanding of the effects of climate change on agriculture and food security have been omitted. Chief among them are studies that focus primarily on climate change mitigation. Mitigating actions taken at the local, national or global level that reduce emissions of greenhouse gases (GHG) could reduce the negative impacts of climate change on agriculture. Mitigation efforts could also directly affect agricultural production by constraining farm production activities that emit relatively high levels of GHG. Model-based adaptation studies that fall strictly outside agriculture and water resources have also been omitted. Theoretical papers have been excluded, since this review focuses on methodologies that offer empirically based policy insights.

\section{Defining climate adaptation: Analytical perspective}

The Intergovernmental Panel on Climate Change (IPCC, 2014) defines adaptation as "the adjustment in natural or human systems in response to actual or expected climatic stimuli or their effects, which moderates harm or exploits beneficial opportunities." This definition points to two aspects: "moderating harm" and "exploiting beneficial opportunities". Climate adaptation may thus be interpreted either broadly encompassing all possible opportunities to mitigate risk/ benefit from climatic changes, or more narrowly focusing on specific activities which avert the highest level or most probable risks (Margulis et al., 2008). This raises the problem of "scope" for delineating what counts as adaptation. One approach is to view adaptation as a set of discrete choices and decisions to resolve well defined problems, a view favoured by economists and climate impact modellers because it facilitates quantification and modelling (Antle and Capalbo, 2010). This approach also tends to favour a narrower definition of adaptation limited to mean simply an activity that is "impact-reducing" in the sense that it reduces negative (or enhances positive) impacts of climate change (Lobell, 2014). An alternative view considers adaptation as a continuous, flexible process, based on learning and adjustments (IPCC, 2014). Under this view, local or farm-level type adaptation must be considered within the broader social context in which farmers make decisions and take actions (Feola et al., 2014).

It has become familiar in the literature to classify adaptation either as planned (through policies, public investments and institutional reforms) or autonomous (taken independently by individual farmers, households and economic agents in response to market forces). Publicsupported planned adaptation covers a wide range of possible actions, including the provision of public investments, taxes and subsidies, and norms and standards. These actions can also facilitate autonomous adaptation. Not surprisingly, economists recommend that such efforts be enacted in a cost-effective manner, preferably through market-based instruments (MBI) such as insurance markets, water markets and various payments for environmental services (IPCC, 2014). Economists also recommend that government-led adaptation interventions should avoid unintentional maladaptation, which can arise when there a disconnect between planned activities and local actions. A typical example comes from the water market. Pfeiffer and Lin (2010) found that subsidizing irrigation water conservation can lead farmers to increase total water use through acreage expansion under irrigation. This example illustrates "the rebound effect" (Roy, 2000) whereby increases in efficiency of resource use result in more being demanded.

Designing appropriate adaptation policies requires a careful analysis of three aspects closely associated with adaptation: vulnerability, adaptive capacity and uncertainty. Vulnerability was initially promoted by IPCC to guide policy (IPCC, 2001) and is characterized in terms of: (i) "exposure" of a region or sector to climate change; (ii) "impact", i.e. how much damage will be caused by climate change in a specific region; and (iii) autonomous adaptation, i.e. what actions can take 


\section{box 1}

Costing adaptation

- stimating the cost of adaptation remains a methodological challenge. While the need for such -estimates the local and global levels is clear, there is little consensus on the size and scope of such estimates due to definitional and measurement difficulties (IPCC, 2014). The few existing global estimates of adaptation cost suffer from a general lack of empirical grounding at the local scale, creating inconsistent adaptation estimates across scales (Agrawala and Fankhauser, 2008). Likewise, local or "project"-level adaptation costing is also rare and fraught with measurement difficulties. The traditional approach of cost benefit analysis (CBA) applied to "adaptation projects" raises several conceptual issues which limit its applicability for evaluating adaptation (Handmer et al., 2012). The main difficulty is data availability and its quality. Costs and benefits are location-specific, and calculating localized impacts requires detailed geographical knowledge of climate change impacts that are either unavailable or are subject to uncertainty (Refsgaard et al., 2013). Many actions have an influence on the impact of climate change without being adaptation projects per se (e.g. enhanced building norms). Also many "adaptation projects" have consequences beyond a reduction in climate change impacts. Valuation and decision-making cannot be separated from the institutional and social contexts (e.g. what is considered as a right), and CBA must also take into account non-market costs and benefits (Hallegatte et al., 2012). More broadly, CBA rarely takes into account resource depletion, environmental change and distributional issues.

Some argue for a shift in economic thinking related to planning climate-compatible adaptation policy away from a single-discipline focus on CBA and toward an inter-disciplinary multidimensional risk analysis (Barker, 2008). Under such an approach, the criteria of robustness, resilience and flexibility are important considerations in evaluating the merits of alternative adaptation options. One approach that has been used in many national adaptation plans of action (NAPA) is Multi-Criteria Analysis (MCA) - a method that recognizes the need to balance among multiple, potentially competing objectives (Keeney and Raiffa, 1993; Martinez-Alier et al., 1998). Using multiple criteria, decision-makers can include a range of social, environmental, technical and economic factors - mainly by quantifying and displaying trade-offs. The MCA is also favoured over CBA when there is lack of financial and economic data to quantify benefits and costs of adaptation. A number of tools based on the MCA framework have been produced. As an illustration, Miller and Belton (2013) report on the United Nations Environment Programme's MCA4climate (UNEP, 2011), used to help formulate adaptation water policy for Yemen. The authors find a high degree of interdependence of the adaptation options available to policy makers. Also, the effectiveness of many behavioral responses to policy change hinge on the presence or absence of governance reforms.

place outside any government planning. The net impact of climate change will determine whether additional measures by planned adaptation are needed (Konrad and Thumy, 2014). Adaptive capacity is defined as the ability of a system to adjust to climate change (including climate variability and extremes), moderate potential damages, or take advantage of opportunities, or cope with the consequences. Agricultural adaptive capacity varies greatly by location, resource endowments, and institutional context of the farmer. Uncertainty is a salient aspect of climate change, has an important influence on the type of adaptation actions and investment decisions to be made, and requires risk management strategies (preventive and risk pooling and diversification 
options such as insurance markets) (Konrad and Thumy).

An effective adaptation strategy is defined not only by what types of interventions to enact but what type of governance to consider. Effective adaptation governance can be guided by the subsidiarity concept which stipulates that decisions about economic activity should be taken by the decision unit at the lowest level of aggregation at which these decisions do not generate major externalities for other decision units (Konrad and Thumy). A related economic concept is the "correspondence principle" introduced by Oates (1972), which applies to how economic decision rights, the payment burden, and the cost or return of economic activities should be assigned. Applied to adaptation, the correspondence principle suggests that the set of economic players who bear the cost of some adaptation measure, those who earn the economic benefits of this measure, and those who decide on this measure should coincide (Konrad and Thumy). The need for such governance arrangements is aptly shown in the case of water resource management, where multiple-decision makers are required, including individual farmers, water users' associations, local and regional authorities up to national governments. Appropriate governance arrangements in this case would determine lines of authority, rights and responsibilities, and the extent of coordination across these different levels of decision making (Ostrom, 2007; Meinzen-Dick, 2007).

The above definitional considerations on climate adaptation set the stage for the review of economic models presented in this paper. We begin with the climate models, followed by the impact models, before we embark on the economic modelling analysis. We follow the integrated assessment framework schematically presented in Figure 1.

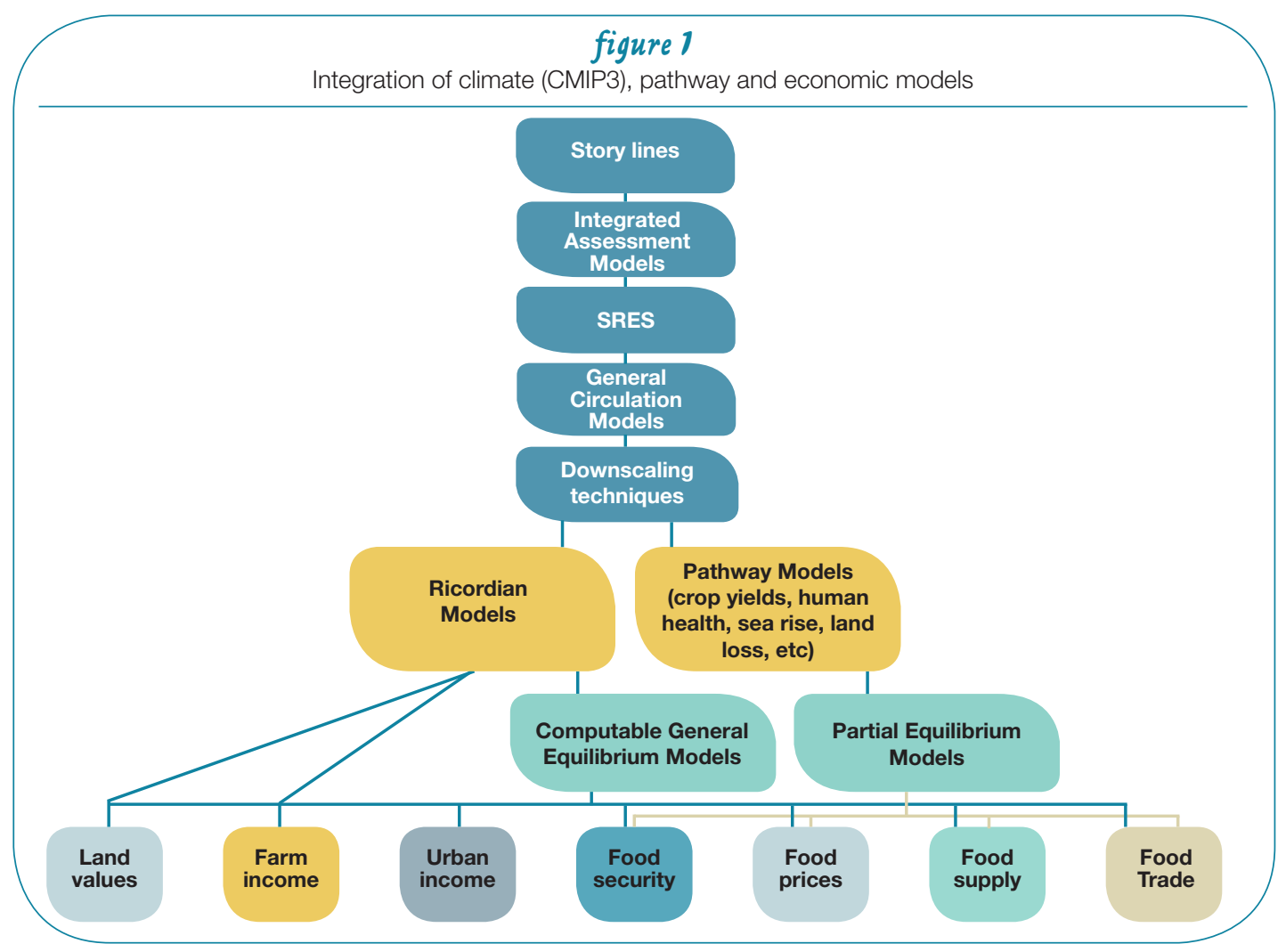




\section{Global climate models}

Almost all of the economic assessments covered in this chapter at the sector level draw on the climate projections prepared for the Fourth Assessment Report of the Intergovernmental Panel on Climate Change (IPCC, 2007), the most recent available at the time of this study. The Fourth Assessment synthesizes climate projections from 24 global climate models that participated in the World Climate Research Project's third Coupled Model Inter-comparison Project (CMIP3).

Global climate models, or general circulation models (GCMs), are numerical models that apply known physical, chemical and biological principles to simulate the interaction of the atmosphere, oceans, land surface, snow, ice and permafrost in determining the earth's climate. ${ }^{3} \mathrm{GCM}$ s have been applied to project the responses of the climate variables (changes in temperature, precipitation, etc.) to increased GHG emissions in the atmosphere. Advances in scientific knowledge, data and computational capacity have led to substantial refinements of GCMs since their initial development in the 1960s, when atmospheric models described influences on climate in terms of the interrelationships between the atmosphere and a motionless ocean slab. The models that participated in CMIP3 included coupled atmospheric-ocean GCMs that described complex, three-dimensional atmospheric and ocean interactions. The CMIP3 also included earth system models, which describe the carbon cycle feedback, whereby changes in temperature due to carbon dioxide $\left(\mathrm{CO}_{2}\right)$ emission lead to changes in land use and vegetative cover, leading to feedback effects on $\mathrm{CO}_{2}$ emissions.

The GCM models use parameters to represent sub-processes that occur at smaller spatial and

3 Useful references on GCMs are Bader (2008), McClusky and Qadummi (2011) and Edwards (2011). LeTruet et al., 2007, describe the development of GCM capabilities from the beginning of the IPCC process through the CMIP3 used in the Fourth Assessment. Flato (2011) and Easterbrook (2011) discuss modelling advances that will be incorporated into the CMIP5 and IPCC's Fifth Assessment. temporal scales. GCMs are tested on their ability to explain climate over a historical training period. The fitted relationships are then used to simulate the effects of alternative climate-forcing scenarios (representative concentration pathways or RCPs) ${ }^{4}$ that describe various levels of human-induced GHG emissions. Their results describe projected changes in climate over the $21^{\text {st }}$ century or more, including changes in temperature, rainfall and atmospheric pressure.

GCMs describe climate changes over relatively large spatial and temporal scales. The GCMs participating in CMIP3 describe the earth's surface in horizontal grids of about 100 to $600 \mathrm{~km}$ width, and up to 30 vertical layers in both the atmosphere and ocean. Their predictions are strongest for temperature, a variable that is relatively consistent over these large spatial scales, while projections for precipitation, a variable influenced by smallerscale, topographical features and cloud formations, are less reliable (McClusky and Qaddami, 2011). Results at these coarse scales are too large relative to the input requirements of most pathway and economic models. GCM outputs therefore are usually downscaled using regional climate models, statistical techniques or spatial estimations. ${ }^{5}$

GCMs contributing to the third and fourth IPCC assessments simulated a common set of greenhouse emission scenarios that depict four broad story lines of alternative, stylized future paths and the interrelationships among five drivers of $\mathrm{GHG}$ emissions: population, economic and social development, energy technology, land use, and government policies (IPCC, 2000) (Table 1). The four story lines, with three subsets

4 For its Fifth Assessment Report, the IPCC adopted four RCPs (RCP2.6, RCP4.5, RCP6 and RCP8.5), each of which designates a given GHG concentration (not emission) trajectory (Moss et al., 2010). Each RCP represents a possible a possible range of radiative forcing values (increased radiative energy) in 2100 relative to pre-industrial values $(+2.6,+4.5$, +6.0 , and +8.5 Watts $/ \mathrm{m} 2$, respectively) (Weyant et al. 2009).

5 Useful references on downscaling are Wilby and Wrigley, (1997), Leung et al., (2003), Strzepak and McClusky (2010), van Vuuren, et al., 2010 and McCloskey and Qaddumi (2011). 


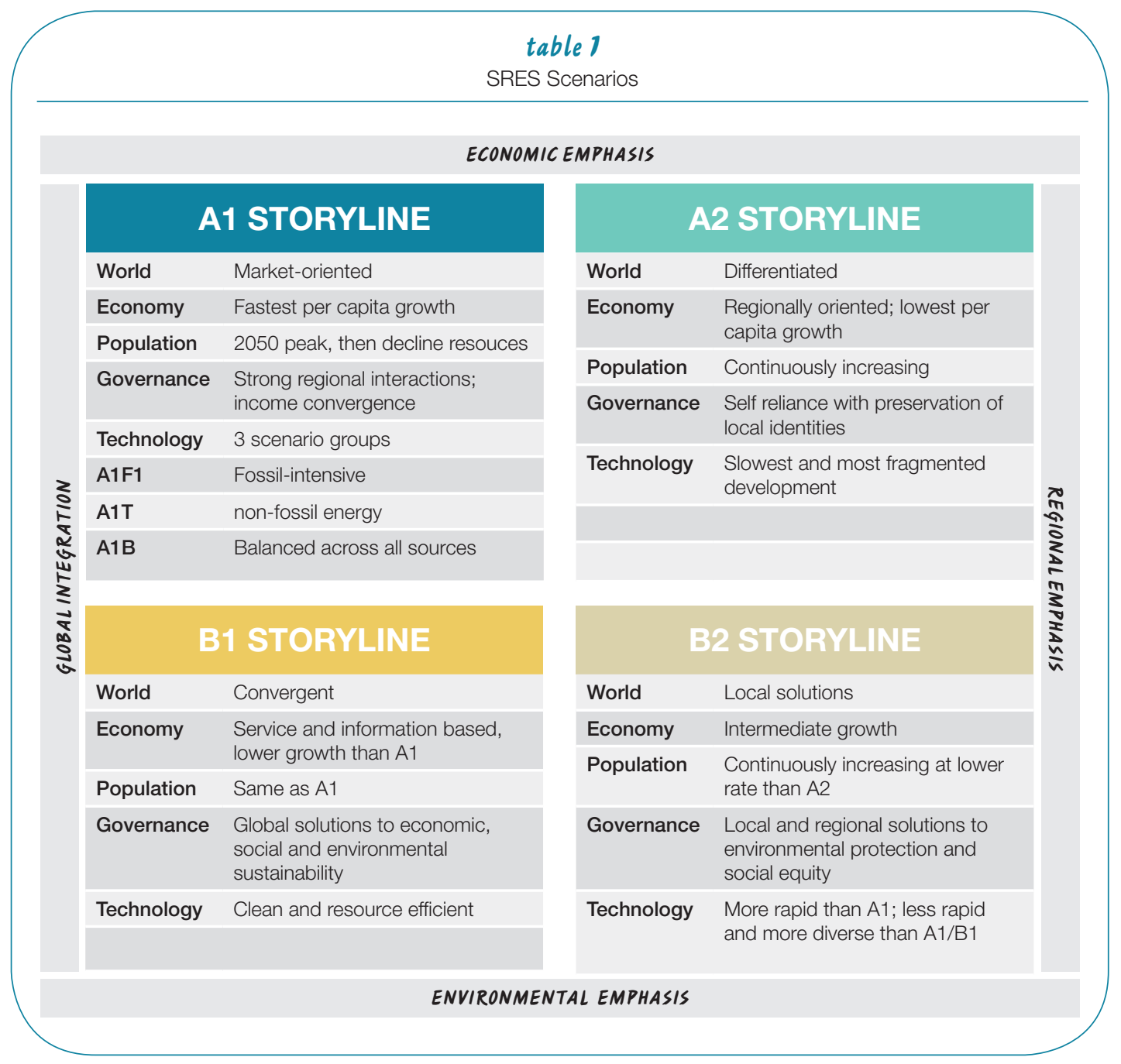

of the A1 story line, were used as inputs into six independent integrated assessment models (IAMs), which quantified their projected effects on GHG emissions, yielding a total of 40 emission scenarios (Figure 2). The use of a range of emission scenarios as inputs into the GCMs addresses the uncertainties about future emission levels due to gaps in current scientific knowledge and to the unpredictability of future human behaviour. There is no probability assigned to the likelihood of any of their occurrences, nor any judgment made about their relative desireability. There is some overlap in the emission levels across the Special Report on
Emissions Scenarios (SRES) due to commonalities in their underlying story lines, but they increasingly diverge over time. Therefore, the longer the time horizon of an economic assessment, the more sensitive are its results to the selection of an SRES.

Climate projections from the same emission scenario can differ across GCMs because of differences in the models' structures and parameter values. The IPCC reports both the mean and the range of the climate projections for each SRES from all participating CMIP3 GCM models, with all models' results given equal weight. The range of model results is useful for illustrating the 
degree of model consensus on particular variables, as well as for defining possible extreme outcomes. For a number of reasons, however, the range in climate projections for each SRES does not represent a probability distribution of outcomes (Knutti, 2010); Masson and Knutti, 2011). The small number of participating GCM models are not independent as they all contain similar laws of nature, they calibrate to and describe the same climate, and they may make the same simplifications in using parameters to represent certain natural processes. Many models, too, are variants of the same genealogical family.

Because of the differences in climate change results across SRESs and GCMs, the selection of both scenario and climate models is a key decision that to a large extent predetermines results of economic assessments. A number of considerations point to the advantages of using climate outputs from more than one SRES and more than one GCM. The IPCC (2000) recommends that two or more individual scenarios (that is, without combining or splicing them) be drawn from more than one SRES family because of the uncertainties associated with the likelihood of any scenario. Many of the economic assessments surveyed here analyse SRES A1B, which is a midto upper-range emission scenario that describes "business as usual," with no mitigation, and SRES $\mathrm{A} 2$ and $\mathrm{A} 1 \mathrm{~F}$ to describe increasingly pessimistic future emission levels. SRES B1 describes an optimistic scenario with emission stabilization.

The selection of GCMs is constrained by whether they report the required climate variables at the spatial and temporal resolutions needed by the impact study. Within the subset of suitable GCMs, it is efficient to choose the model and SRES combinations that represent the widest range in output values for the variables of interest. However, these ranges typically vary across regions and by variable. For example, the same GCM/SRES combination may provide the most extreme outcomes for temperatures in humid tropical zones, but provide little range in precipitation variables compared to other GCM/ SRES combinations. Model performance, in terms of GCM's ability to simulate present-day climate, seems a reasonable selection criterion, but one that can be difficult to actually apply. Models' comparative performances vary across different climate variables and, ultimately, it cannot be known which models predict the future best

\section{figure 2}

Range of carbon dioxide emissions from SRES scenarios

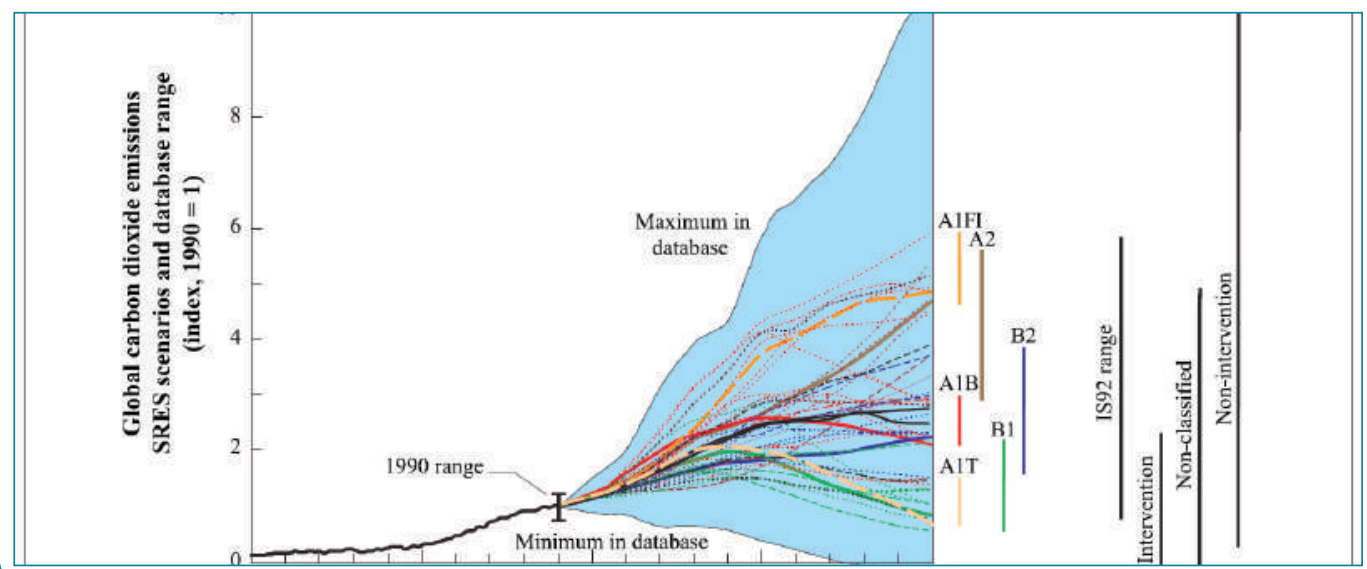

Source: IPCC (2000) 
(Collins, 2007; Gleckler, et al., 2008). Recent model simulations are likely to be more reliable than earlier vintages due to continued modelling improvements.

There are two key sources of uncertainty in GCM climate projections. The first stems from the practice of "parameterizing" sub-processes in GCM models. ${ }^{6}$ Parameters are used to describe the average or expected effects of subprocesses on the larger climate processes that can be modelled explicitly. They can number in the hundreds in some models. Different models incorporate different processes and parameters, and any or all of the models may not capture all of the known and unknown influences that determine the future climate (IPCC, 2007). To address uncertainty about the values assigned to parameters, they have typically been formulated as the mean effect of alternative parameter values, averaged across many model runs, and assuming the same final equilibrium state for the

6 Sub processes include: radiation, water vapor, aerosols, clouds, precipitation, temperature, oceans, soil moisture, biological processes, permafrost, miscellaneous (IPCC, 2014). larger process. To better describe uncertainty about parameter values, GCMs have begun to incorporate stochastic parameter values that are sampled from a known probability of their occurrence for a given final state, and model results are then expressed in terms of probabilities of outcomes across a range of parameter values (McFarlane, 2011; Flato, 2011).

A second source of uncertainty is due to natural variability. Because the temporal scale of GCMs is so long-term, even small differences in a model's initial climate conditions can lead to large differences in results for specific future dates, such as 2050 or 2100 . To address this uncertainty, climate modellers have begun to develop ensembles in which the same simulation is run in a single model across a range of initial conditions that are randomly sampled from observations of the atmosphere. This practice reduces potential model error associated with natural variability due to the effects of short-term weather event phenomena, such as El Nino. Results thus describe probabilistic outcomes with respect to initial conditions in a chaotic weather system (Clark et al., 2010; McFarlane, 2011).

\section{figure 3}

Projected emissions in the representative concentration pathways (RCPs) and extended concentration pathways
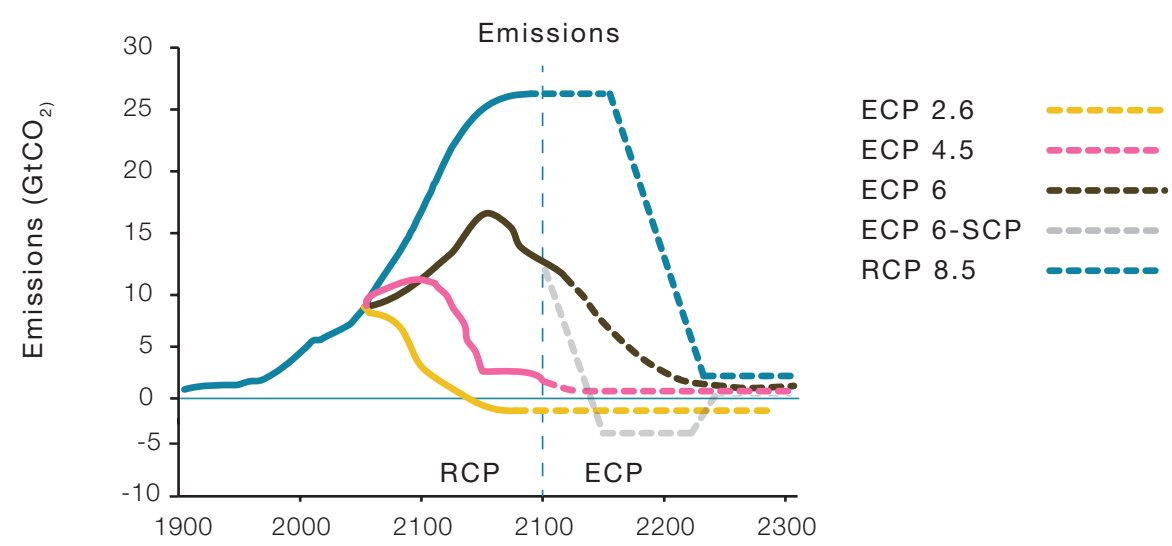
Since 2012/13, new climate change predictions have become available from the climate models and contributed to the IPCC's Fifth Assessment, published in 2014. GCMs participating in the CMIP5 have progressed in a number of ways since the CMIP3 that supported the Fourth Assessment. ${ }^{7}$ Their use of stochastic initial conditions and parameters will result in more outputs being expressed in terms of probabilities that quantify model uncertainties (McFarlane). CMIP5 models also are refining both their spatial and temporal scales to report climate changes in daily increments at grids as small as $50 \mathrm{~km}$ (Easterbrook). Finer resolutions reduce the potential for errors associated with downscaling techniques. Researchers are trying to improve the capacity of models to develop projections for near-term (over the next three decades) and intermediate decadal time periods. This is challenging because in the nearer term, chaotic weather events and anomalies such as El Nino become more important in determining climate conditions. Earth system models that describe the carbon feedback cycle will have a greater role than previously (Flato). Perhaps the most important change under the CMIP5 is the redefinition of the emission scenarios. Instead of the approach taken in the SRES process, which describes the effects of different combinations of human activity on projected emissions, the new set of scenarios specify low, medium and high RCPs of GHG concentration levels that have been described in the open literature (Moss, et al. 2010; van Vuuren et al. 2011, Easterbrook) (Figure 3). These emission levels may result from many kinds and combinations of human activities, including effective mitigation.

The latest generation of GCMs, with improved capabilities in modelling SRESs, suggest that climate change may be experienced sooner and the effects may be more extreme than predicted by the CMIP3. Findings from the Massachussets Institute of Technology's JPM model, published

7 See the CMIP-5 website at http://cmip-pcmdi.Inl. gov/cmip5/ in 2009, describe a mean surface warming in 2091-2100 of 4.1C to $5.1 \mathrm{C}$ relative to 1990 , compared to $2.4 \mathrm{C}$ in their previous 2003 study, and a 90 percent probability of surface warming of between 3.5 to 7.4 degrees (Sokolov, 2009). Their more recent projection builds on modelling improvements and takes into account additional influences on the environment, including the cooling provided by 20th-century volcanoes. Using a high-resolution, century-scale model of the United States, Diffenbaugh et al. (2011) project that 21st-century summer warming will permanently emerge prior to 2020 over most areas of the continental United States. Diffenbaugh and Scherer (2011) use observational data and the CMIP3 generation of SRES A1B output to analyse how soon the world will experience the onset of permanently higher temperatures. They project that many tropical regions in Africa, Asia and South America will experience unprecedented summer heat by 2040 . The most immediate increase will occur in the tropics, with up to 70 percent of seasons in 2010-2039 exceeding late 20thcentury maximums. Onset will be slower in areas of the United States, Europe and China.

Betts et al. (2011) use a GCM to simulate SRES A1F1, the highest emission scenario, which was not examined by the GCMs used in the Fourth Assessment. They project a global warming of $4 \mathrm{C}$ relative to pre-industrial temperatures as soon as the early 2060s. Sanderson et al. (2011) explore the impacts of future emission levels that are about double those projected in SRES A1F1, but which are consistent with the highest levels now appearing in the published literature. They project a mean global warming of over $5 \mathrm{C}$ relative to 1990 , a complete loss of arctic summer sea-ice by 2070 and an additional 43 percent sea level rise due to thermal expansion above A1FI levels by 2100. In counterpoint, Shindell, et al. (2012), using a GCM model developed to more fully account for the countervailing effects of a number of climate change forcings, ${ }^{8}$ identify 14 simple and affordable measures

8 The term climate change "forcing" (often used interchangeably with radiative forcing or $\mathrm{CO}_{2}$ forcing) refers to the effect of increased $\mathrm{CO}_{2}$ concentration 
targeting methane and black carbon reduction that could, in combination, reduce projected mean global warming by about $0.5 \mathrm{C}$ by 2050 .

\section{Pathway models}

Climate change operates indirectly, through multiple pathways, to affect economic activity and human well-being. These pathways include the biophysical effects of changes in temperature, precipitation and $\mathrm{CO}_{2}$ on crop yields, human health, and plant pests and diseases. Sea level rise reduces the land available for cultivation and other economic activities. Storms and flooding can destroy infrastructure, raising the costs of transportation and communication in all sectors of an economy. Climate change also affects hydrological processes and alters surface and groundwater dynamics, with significant impacts on agriculture and non-agriculture water supply. Pathway models quantify such impacts of climate change and generate data used as inputs (or shocks) into economic models. The economic impact assessment models surveyed here focus largely on the economic effects of crop yield shocks, as well as the effects of water supply and demand dynamics. Only briefly do we touch on other pathways, such as rising sea levels, that have direct implications for agriculture. Most include only crop yield shocks, but an increasing number of economic models now account for multiple pathways.

\subsection{Crop yield models}

\section{Dynamic crop growth simulation models}

Crop yield models describe the effects of changes in temperature, precipitation and, in some cases, $\mathrm{CO}_{2}$ on crop yields. There are two different types of crop yield models: dynamic crop growth simulation models and statistical yield models.

(and the extent of its deviation from an initial state, typically chosen as the pre-industrial $\mathrm{CO}_{2}$ concentration level of 280 part per million value or ppmv) and the corresponding increase in radiative energy on the earth surface (measured in watts/ $\mathrm{m} 2$ ). Increased radiative energy in turn translates into higher average temperature (IPCC, 2007).
Dynamic crop growth simulation models simulate plant growth processes and yields. They are called "process" models because they explicitly describe the effects of location-specific environmental conditions (such as temperature and precipitation), plant genetics and farm management practices (such as fertilizer use or planting times) on the biological plant growth process. The models are dynamic in the sense that they simulate incremental, usually daily, changes in plant growth in response to changes in environmental conditions and management practices over the duration of the growing season. The models exclude the role of labour and most exclude plant pests and disease, albeit a new generation of models used for the IPPC Fifth Assessment does attempt to include some of these additional effects.

A crop growth simulation model is calibrated to local growing conditions, often at the field level, using site data on weather for the duration of the growing season, site soils and farm management practices. Selected model parameters are then adjusted, or calibrated, until the crop model can replicate the historic, daily plant growth process over the growing season. To simulate climate change impacts, projected changes in temperatures and rainfall replace the historic observations, and plant growth responses are observed. A growing number of models also simulate the effects of higher atmospheric concentrations of $\mathrm{CO}_{2}$. While higher $\mathrm{CO}_{2}$ levels can stimulate plant vegetative growth, the magnitude of this effect is highly debated (Ainsworth et al., 2008; Tubiello et al., 2007).

A large number of crop growth simulation models have been used to support the analysis of climate change, agriculture and food security. A meta-analysis by Rivington and Koo (2010) finds that the most widely used is the Decision Support System for Agrotechnology (DSSAT) (Jones, et al. 2003). DSSAT contains sub-process models, or modules, for land, management practices, soil and weather, and provides 17 crop models, including the CERES, CROPGRO, InfoCrop and Simulate Underground Bulking STorage Organs (SUBSTOR) 
crop simulation models. Each crop model includes generic parameters that are based on field experience and which describe the growth process of common genetic varieties of cereals, legumes and grasses. Recent applications of the DSSAT model to project the yield effects of alternative SRES scenarios in developing countries include Lal (2011), Thornton, et al., (2011) and Felkner et al. (2009).

Other crop growth models that have been applied in the study of climate change impacts on developing countries include WOFOST (WOrld FOod STudies, documented in Ittersum, et al., 2003; Boorgaard et al., 2011), AquaCrop, developed by FAO (Steduto et al., 2008) and the Agricultural Production Systems Simulator (APSIM), a wiki-modelling framework. ${ }^{9}$

A key contribution of crop growth simulation models in research on climate change adaptation is their ability to simulate the effects of changes in farm management on biophysical plant growth. Analysts can exogenously change planting and harvesting dates, fertilizer use, irrigation, or choice of crops or crop varieties and evaluate the effectiveness of these adaptations in offsetting any negative effects of climate change on crop yields. The idea that farmers do not automatically adapt to changing climate is a common, but outdated, criticism of these models. Many crop simulation models now incorporate automatic adjustments by farmers in planting dates, choice of cultivar and use of irrigation and fertilizer.

Two frequent criticisms of crop simulation models are that their data requirements are intensive and that they are applicable only at small spatial scales that are not readily usable in economic analyses, which are mostly conducted at the regional, national and global scales. The development of large area crop models, including a new feature of DSSAT and recently including PEGASUS 1.0 (Predicting Ecosystem Goods and Services Using Scenarios) (Deryng, 2009; Deryng et al., 2011), and the Model to capture

9 APSIM is documented on its wiki website at: http://www.apsim.info/Wiki/APSIM-and-the-APSIMInitiative.ashx the Crop-Weather relationship over a Large Area (MCWLA) (Tao et al., 2009a), address both critiques by using parsimonious representations of crop growth processes. This has both considerably reduced their data requirements and improved the models' applicability at larger scales.

For example, PEGASUS 1.0 is a global crop model designed to overcome the multiple problems of intensive data requirements, the small scale that typifies many crop yield simulation analyses, and the absence of an automatic farmer response to climate changes. The PEGASUS model, developed so far for soybean, maize and spring wheat, describes daily biophysical plant growth processes in response to climate and to the farm management practices of irrigation, planting and harvesting dates, and fertilizer use. Planting and harvesting dates and choice of cultivars can be fixed or allowed to adjust automatically to changing climate conditions.

Data requirements for PEGASUS are relatively small and they are drawn from newly available global data bases on climate, soils, yields, harvested areas, cropping calendars and irrigation and fertilizer use. These data inputs are aggregated to match the 10' longitude and 10' latitude scales of the climate data. By aggregating model results, PEGASUS can describe the effects of climate variables on yields, planting dates and cultivar choice at the regional and global levels. Planting dates simulated by Derying et al. (2011) matched 74 percent of the observed planting dates in the global cropping area of maize, 91 percent for soybeans and 75 percent for spring wheat. Correlations between simulated and actual yields are also strong. Running two climate change scenarios, SRES A1B and B1, with and without adaptive behavior, Deryng et al. project significant declines in global crop yields in 2050 relative to 2000 , but find that $60-78$ percent of the losses could be averted through adaptation of planting dates and cultivar choices.

A criticism of crop simulation models that is made less frequently, but which is key for economic analysis, relates to uncertainties in the 
climate change projections received from climate inputs and in the crop models themselves. Like GCM models, crop models reduce complexity by simplifying some aspects of the plant growth process at lower levels of the plant growth hierarchy. Parameter values that describe subprocesses may not correctly represent these biophysical processes (Sinclair and Seligman, 2000). While they can be validated with historical crop yield data, climate change inputs may push crop models beyond the ranges of their applicability.

Tao et al. (2008) addresses uncertainty with respect to climate shock inputs derived from GCMs. In a study of future rice yields at six stations in China, they apply Monte Carlo techniques to 20 climate scenarios to develop probabilities for climate change impacts. These results are used as inputs into calibrated DSSAT/CERES crop models, with automatic changes in irrigation and fertilizer applications, to generate probabilistic outcomes for rice yields with respect to uncertainties in future climate projections. For instance, including $\mathrm{CO}_{2}$ fertilization effects, they find that the length of the rice growing season will be reduced with 100 percent probability for increases in mean global warming of 1, 2, and 3C above 1961-1990 levels. Mean yields across stations change by -10.3 percent, -16.3 percent and -19.2 percent, respectively for temperature increases of 1,2 , and $3 \mathrm{C}$.

Tao et al. (2009b) explore uncertainty in both climate model inputs and in the MCWLA crop model's parameters in a study of maize production in two agricultural provinces in China. The crop model assumes endogenous adaptive responses by the farmer, with planting delayed until planting conditions are met, or until the planting window closes. They address climate uncertainty by using ten climate scenarios from five GCMS under SRESs A1F and B1, and 60 sets of crop model parameters, yielding 18,000 simulation yield results. Their probability distribution of results for the Henan province describe mean yield impacts of -10 percent, -16 percent and -24 percent during the 2020s, 2050s, and 2080s, respectively, as a percent of 1961-1990 yields, with 95 percent probability intervals for each period of $(-29,+16)$,
$(-46,+24),(-93,+20)$. Their most important finding is that climate change scenarios contribute more to uncertainty in projected yield impacts than their crop model parameters.

Advances in achieving representative, largearea crop models and in quantifying the uncertainty related to climate change projections and to crop simulation model parameters strengthens the foundations that these models can provide for economic analyses. Yet a number of areas remain to be developed in future crop yield simulation modelling. In Rivington and Koo's (2010) survey, crop simulation modellers identified the most important of these to be a reduction of parameter uncertainty, by improving our understanding of the effects of extreme heat and intra-seasonal climate variability on plant growth processes and yields, and the identifying threshold levels that lead to crop failure. Only half of the models represented in their survey accounted for the fertilization effects of elevated $\mathrm{CO}_{2}$, and the question of how large its yield benefits might be is still open. Applications of crop models to more crops that have a large role in diet in developing countries is also needed, in addition to the current focus on cereals, maize and rice.

Hertel and Lobell (2014) point out that the majority of crop models used in IAMs miss out on several climate-linked processes such as $\mathrm{CO}_{2}$ fertilization, effects of heat stress on grain set and leaf senescence, and pest and disease pressures (Howden, et al., 2007; Rosenzweig et al., 2000) and generally suffer from the lack of development and testing in extreme climate conditions (White et al., 2005, 2011).

\section{Statistical crop yield models}

Statistical yield models are the second, and more common, type of model used to provide crop yield shocks in economic impact analyses, in large part because of their compatibility in spatial scale. Time series or cross-section estimations, or the two combined, describe empirical relationships between observed crop output or yield and projected changes in temperature, rainfall and other climate variables, usually on a monthly or 
annual basis. To analyse climate-change effects on output or yields, projected changes in temperature and rainfall from GCMs replace the historic climate data and new output or yields are calculated.

The key advantage of statistical crop models is that adaptive farmer behaviour is implicitly described in the observed climate-yield relationship, for given land values. This advantage is tempered, however, in that time-series models describe adaptive management changes over the entire period of analysis, without identifying specific adaptive strategies or responses to shortterm climate extremes. Other advantages are that statistical models can be estimated at local, regional and even global levels, and at annual and intra-annual scales. Compared to small-area crop simulation models, their larger scale and temporal dimensions are more compatible with the scale of inputs from climate models, which can eliminate the need for downscaling. Their robustness also can be evaluated based on statistical measures, and their data input requirements are considerably less than those of small-area crop simulation models.

Similar to crop simulation models, recent innovations in statistical crop modelling have focused on quantifying uncertainty. Tebaldi and Lobell (2008) were among the first to analyse uncertainty in both climate change projections and the climate/yield relationships in their crop models. Using three relatively strong global crop models of barley, maize and wheat, with respective R2s of $0.65,0.47$ and 0.41 , the authors first develop probabilistic projections of combinations of temperature and precipitation changes based on SRE A1B from 20 GCMs. A sample of 1000 pairs of temperature/productivity changes are used as predictors in the crop yield models to generate 1000 results. They then carry out a bootstrap analysis of the yield results to describe uncertainty in the estimated model relationships between climate and crop variations. They find mean changes in global yields (without adaptation) between 2030 and 19801999 of +1.6 percent (wheat), -14.1 percent (maize) and -1.8 percent (barley) and report their 95 percent probability intervals.
Lobell et al. (2008) build on these techniques in an analysis of climate-induced yield changes in food-insecure regions, in which they estimate statistical crop yield models to identify priority areas for adaptation investments. Using data on historical crop harvests, monthly temperature and precipitation, and maps of crop locations, Lobell et al. estimated 94 statistical crop models of grains, oilseeds, pulses, sugar and cassava crops in 12 food-insecure regions. To project yields under future climate conditions, the authors utilize outputs for SRESs A1B, A2 and B1from 20 GCMs that participated in the CMIP3. To address the uncertainty in both climate projections and the crop models, Lobell et al. use a Monte Carlo procedure to estimate a probability distribution of production changes in 2030. Based on their analysis, they identify hot spots for region and crop combinations where climate change is likely to have negative impacts, along with corresponding uncertainties about their projection, which vary widely by crop. Their analysis describes South Asia and Southern Africa as two regions that are likely to face the most severe outcomes for some of their crops.

Schlenker and Lobell (2010) carry out a similar analysis of climate change and crop production that addresses potential model errors in both inputs from GCMs and in the crop models. They apply a panel data analysis to $\mathrm{FAO}$ crop yield data to estimate country-level statistical crop yield models for five crops in Sub Saharan Africa, based on temperature and precipitation data from 16 GCMS under the A1B scenario for 2046-2065. They carry out 1000 bootstrap runs for each of the 16 GCMs models, reporting yield results in terms of the distributions of 16,000 impacts. The mean impacts on production describe substantial potential yield losses by the middle of the century of between - 1 and -22 percent, relative to 1961-2000.

A second frontier in statistical crop modeling is their strengthened capability to capture shortterm, intra-seasonal variability, which is found to be important in explaining seasonal yields. Rowhani et al. (2011) compare the effects of intraseasonal, monthly variability with inter-seasonal climate variability on rice, sorghum and maize 
yields in Tanzania, finding that intra-seasonal variability has the dominant impact. To project future climate, Rowhani et al. apply projected temperature and rainfall outputs for SRES A1B from 22 GCMs for 2050. Controlling for intraannual climate variability, Rowhani et al. show that climatic impacts by 2050 on crop yields in Tanzania are underestimated by 4 percent, 9 percent, and 29 percent for maize, sorghum and rice, respectively, when only inter-annual variability is accounted for.

Lobell et al. (2012) also address intra-seasonal variability in their estimation of a statistical yield model of wheat production in India that describes the effects of extreme heat at the grain-filling stage, just prior to maturity. They compute that high heat truncates this process and lowers yields, with stronger effects as temperatures rise above 34C. Their finding is consistent with that of Schlenker and Roberts (2009), who carried out both crosssection (which assumes farmer adaptation) and time series (assumes no adaptation) studies of daily weather and yields in selected areas of the United States. Results of both approaches describe asymmetric, non-linear effects of higher temperatures on corn, soybeans and cotton. Yields increase gradually until optimum temperatures are reached, but temperatures above that level result in very steep yield declines. Schlenker and Roberts project that US area-weighted average yields will decline by 30-46 percent by the end of the century, compared to 1950-2005, under the slowest (B1) warming scenario and decrease by 63-82 percent under the most rapid warming scenario $(\mathrm{A} 1 \mathrm{FI})$, based on the Hadley III GCM model.

\section{Ricardian models}

Ricardian, also called hedonic, models are cross-section estimations of the effects of climate, soils, geography, prices and farmer characteristics on land values or current net returns (Mendelsohn et al., 1994; Mendelsohn, 2009). The models are based on the Ricardian view that land values reflect land productivity. The driving assumption of the model is that farmers seek to maximize their land value and to do so, will make adaptations, such as changes in crop choices, to maximize land productivity as environmental conditions change. Output of the models describe the marginal change in land rents or land values with respect to marginal changes in temperature and precipitation. These relationships can then be combined with climate change projections to provide estimates of climate-change damages expressed in terms of changes in land values or net returns (Schlenker et al., 2006).

The key advantage of the Ricardian model's cross-section approach is that its measure of climate-induced damage takes into account farmers' observed, whole-farm adaptations. At the same time, however, the model always represent equilibrium situations and are not well-suited to describe adaptive transitions over time. Perhaps the model's most important limitation is that prices are implicitly assumed to be constant. If agricultural prices rise as predicted in recent climate literature (e.g., Nelson et al., 2010), then land values also will rise (or not fall as much), so the Ricardian model may overestimate damages (Seo, et al. 2009).

Ricardian models also have been criticized because they do not describe the types and costs of adaptations that have taken place. However, advances in Ricardian analysis have led to important insights on adaptation. The recent body of Ricardian analyses have largely stemmed from two major research programs supported by the Global Environment Facility (GEF) and the World Bank. These generated a series of Ricardian analyses of crop and livestock production in 11 African countries and 7 countries in South America. Under these projects, surveys designed specifically to describe climate change were conducted of over 10,000 farms in Africa and almost 3000 farms in South America that represent a wide range of climates and farming systems.

In summarizing the African case studies, Dinar, et al. (2008) describe their methodological advances using the term "structural Ricardian" analysis. In this approach, farmer optimization is described as a simultaneous, multi-stage procedure. A household model describes the farmer's adaptive choices, such as crop 
switching, then the Ricardian analysis is carried out to assess the net revenue impacts of that adaptive choice. Climate impact damage assessments are calculated by applying the estimated land-value relationships to countrylevel changes in climate derived from outputs of GCM scenarios that vary among the studies. Synthesizing the findings of the African project, Dinar et al. (2008) observe that farmers' perception of a changing climate is already high, and that there are many country-specific differences in the ways that they adapt. General recommendations are the promotion of irrigation and mixed-crop/livestock operations, increased farmer education, and investments in extension and transportation infrastructure.

Building on the full set of South American surveys, Seo and Mendelsohn (2008a) carry out a cross-country analysis that examines how South American farmers adapt to climate by changing crops. They find substantial adaptive activity, with farmers choosing to grow fruits and vegetables in warmer locations; wheat and potatoes in cooler locations; rice, fruits, potatoes, and squash in wetter locations; and maize and wheat and in dryer locations. They project the effects of climate change on crop choice by applying output from the SRES A1 scenario of three GCMS to their estimated parameters, finding that the scenario that projects a relatively dry and hot future will lead farmers to grow more squash, fruits and vegetables and less maize, potatoes, soybeans and wheat in 2020 , with little effect on rice. The scenario that predicts a milder and wetter future will lead farmers to grow more potatoes, fruit and vegetables. These crop choices become magnified over time.

Building on this study, Seo and Mendelsohn (2008b) develop a continental-scale analysis of the impacts of climate change on South American farmers, taking into account both the yield effects of climate change and adaptive crop-switching. Explanatory variables include seasonal and country fixed effects, soil types and electricity use. Equations are estimated for small and large farms, irrigated and nonirrigated farms, and all farms. For all farms, they estimate elasticities of farm value of -1.55 with respect to a $1 \mathrm{C}$ increase in temperature and -1.60 with respect to a $1 \mathrm{~mm} / \mathrm{month}$ increase in precipitation. Climate sensitivities are significantly higher for commercial farms with respect to rainfall $(-3.31)$ and irrigated farms with respect to temperature (-2.36). To project climate change, the elasticities are applied to climate change scenarios from three GCMs, chosen because they provide the broadest range of climate outcomes for the South American countries in the study. Across the entire sample, they find that South American farmers will lose on average 14 percent of their land value by the year 2020, 20 percent by 2060 and 53 percent by 2100 . Losses to small farms will be slightly less than losses to large farms and irrigated farms.

In a summary of the findings from the African and South American analyses, Mendelsohn (2009) drew these general conclusions: Farmers in tropical and subtropical regions are found to suffer damage from even marginal changes in climate, and these damages are greater than those experienced by famers in temperate climates. Rainfall will benefit farmers in semi-arid places, but increased rainfall in very wet places can be harmful. Farmers using irrigation are less vulnerable than are dryland farmers, although this relationship could change in the future if fresh water supplies diminish. Perhaps the most important finding is that small farmers may be less vulnerable to the effects of climate change than are large and specialized commercial farmers because they are able to exercise considerable flexibility in adapting their crop and livestock production as climate conditions change.

\subsection{Water-climate pathway models}

The IPCC and Stern Review conclude that the impacts of climate change on humanity will be felt 'mainly through water', via shifts in rainfall and extreme events (droughts, flooding), and their effects on hydrological systems (Bates et al., 2008; Stern, 2006). Consequently, the vast majority of 
adaptation interventions will involve water resource management.

Bates et al.(2008) summarizes the interactions of climate change with water. Observed warming over recent decades has been linked to changes in the large-scale hydrological cycle, including increasing atmospheric water vapor content; changing precipitation patterns, intensity and extremes; reduced snow cover and widespread melting of ice; and changes in soil moisture and runoff. Over the 20th century, precipitation has mostly increased over land in high northern latitudes, while decreases have dominated from $10^{\circ} \mathrm{S}$ to $30^{\circ} \mathrm{N}$ since the $1970 \mathrm{~s}$. Globally, dry land has doubled since the 1970s and water storage in mountain glaciers significantly contracted. Climate model simulations for the 21 st century consistently show precipitation annual average river runoff and water availability increases in high latitudes and parts of the tropics, and decreases in some subtropical and lower mid-latitude regions. Outside these areas, there remains substantial uncertainty in precipitation projections.

Increased precipitation intensity and variability are projected to increase the risks of flooding and drought, while water supplies stored in glaciers and snow cover are projected to decline, thus reducing water availability during warm and dry periods in regions supplied by melt water from major mountain ranges. Higher water temperatures and changes in extremes, including floods and droughts, are projected to affect water quality and exacerbate water pollution. In addition, sea-level rise is projected to extend areas of salinization of groundwater and estuaries, resulting in a decrease in available freshwater for humans and ecosystems in coastal areas. By the 2050s, the area of land subject to increasing water stress due to climate change is projected to be more than double that with decreasing water stress. While quantitative projections of changes in precipitation, river flows and water levels at the river-basin scale are uncertain, it is very likely that hydrological characteristics will change in the future.

There is well-established literature describing the hydrological processes and their links to climate change. Watershed and macro-scale hydrological models describe the effects of projected changes in precipitation, temperatures and evapotranspiration on water runoff and stream flow, taking into account the moisture-holding capacity of soils. Some IAMs are beginning to incorporate water into their analyses. Since water management is fairly localized, it raises important issues of scale in relation to global hydrological cycles and a major challenge in linking climatic to hydrologic processes shaping water resources (Bell et al., 2014). The gap between GCMs and the needs of hydrological models can be filled through downscaling (Benestad, 2010). Still the challenge of data remains, as the information required to develop water management data inputs to IAMs typically lies with local water management institutions, posing challenges for thorough and consistent data collection (Olmstead, 2013).

Hydrology model results are used in economic assessments of climate change to describe the effects of water stress on crop yields, the effects of floods on road infrastructure, changes in irrigated crop area, and changes in the stream flow used for hydropower and irrigated water supply. McCluskey and Qaddumi (2011), and Strzepak and McClusky (2010) provide useful overviews of three types of hydrological models used to produce these results for economic analyses. Firstly, there are the distributed and gridded models, which describe water run-off at small spatial scales, and can take into account variations among spatial grids in soil qualities and topography. Second are the watershed or water basin models that describe water runoff that occurs over the entire basin area, without describing any interior spatial variations. Third, macro-scale hydrological models simulate runoff and stream flow at very large scales of continents or large river basins. Projected hydrological impacts are derived by using the models to simulate the results from GCMs for future changes in temperature and precipitation.

Still, hydrologic modelling is not a necessary starting point for any model to study climatewater interactions, as relevant climate and water processes can be represented by bounding 
conditions or forcing functions (such as via shifts in yield-response functions) (Bell et al., 2014). For example Hurd et al., (2004) applies the Watershed Allocation and Impact Model (Water-AIM), a partial equilibrium model, which links the investment decisions of water resource planning authorities, the water allocation decisions of water managers, and the water consumption decisions of water users together in a spatially and temporally differentiated framework that is consistent with the geophysical features of individual basins. The model produces basin level "lower bound" estimates of the potential economic impacts of climate change on water resources.

The Water-AIM model structure depicts key physical characteristics of the natural and man-made water supply system, including tributaries, inflows and return flows, diversion points, reservoirs, and basin imports and exports. Seasonal runoff into each basin is based on historical records, and the models solve simultaneously for water allocations and implicit water prices for both consumptive and non-consumptive uses, reservoir storage and releases, and in stream flows over a planning period spanning a number of years and seasons. The model objective function is the expected net economic returns of water users (sum of consumer and producer surplus) as a function of both consumptive and non-consumptive uses of water over time and space subject to a system of constraints (seasonal runoff; surface water diversions; inter-temporal balances in reservoirs between runoff into the reservoir; water storage; water losses; and storage releases).

The scenarios were used to determine runoff under climate change and to condition irrigation demands. To convert the climate scenarios into hydrologic impacts (runoff), runoff projections were obtained through a module which translates changes in monthly average precipitation and temperature into changes in monthly runoff and aggregated at the seasonal level and reported so as to coincide with the inflow points for each of the basin models (Hurd et al., 2004). Water-AIM was then used to estimate the implicit price or marginal value of water for every time period and location.

Water resources at the river basin level can be incorporated into an economic model in one of two ways: through "reservoir" storage (tanks) or through explicit routing of flows along watercourses within a basin. The former is applied in the IMPACT-WATER model (Rosegrant et al., 2008) - an optimisation model that minimizes water shortages within the river basin. The model calculates net irrigation water demand, taking into account crop evapotranspiration, effective rainfall and basin efficiency. Effective rainfall for crop growth can be increased through rainfall harvesting technology. The basin efficiency measures the ratio of beneficial water depletion (crop evapotranspiration and salt leaching) to the total irrigation water depletion at the river basin scale. Future years' basin efficiency is assumed to increase at a prescribed rate in a basin, depending on water infrastructure investment and water management improvement in the basin. The model also determines off-stream water supply for household consumption and for industry, livestock and irrigation sectors. To determine the total amount of water available for various off-stream uses in a basin, hydrologic processes, such as precipitation, evapotranspiration, and runoff are taken into account to assess total renewable water. Once the model solves for total water that could be depleted in each month for various off-stream uses, the model determines the water supply available for different sectors. Assuming domestic water demand is satisfied first, priority is then given to industrial and livestock water demand, whereas irrigation water supply is the residual claimant and is allocated based on profitability of the crop, sensitivity to water stress, and irrigation water demand (total demand minus effective rainfall) of the crop. Using effective irrigation water supply in each basin by crop and by period over a 30-year time horizon, the results are then incorporated in simulating food production, demand and trade.

The second approach to integrating water resources is used by the Water - Global Assessment and Prognosis (WaterGAP) model 
(Alcamo et al., 2003). WaterGAP integrate Global Water Use and Global Hydrology models and covers three water use sectors - households, industry and irrigation - using $0.5^{\circ}$ grid cell resolution and allows for analysis in all large drainage basins worldwide covering 150 countries. The hydrological model calculates the daily water balance of each grid cell, taking into account physiographic characteristics of drainage basins (e.g. soil, vegetation, slope and aquifer type), the inflow from upstream, the extent and hydrological influence of lakes, reservoirs and wetlands, as well as the reduction of river discharge by human water consumption. The effect of changing climate on runoff is taken into account via the impacts of temperature and precipitation. WaterGAP uses a flow-routing scheme whereby the total runoff produced within each cell and the volume of water coming from the cell upstream is transported through a series of linear and nonlinear retention storages representing the groundwater, lakes, reservoirs, wetlands and the river itself. The flow routing covers all 67,000 grid cells representing the total land surface of the Earth and is based on various continental drainage and elevation maps. The cells are connected to each other by their respective drainage direction and are thus organized into drainage basins. WaterGAP computes net and gross irrigation requirements. Net irrigation is the part that is evapotranspired by the plants, while gross irrigation reflects the amount withdrawn from the source.

The Water Use model takes into account basic socio-economic factors that lead to domestic, industrial and agricultural water use, while the Hydrology model incorporates physical and climate factors that lead to runoff and groundwater recharge. Water use modelling allows for changes in water intensity based on structural and technological change. "Structural change", which can lead to increase or decrease in water use intensity, arises from the combination of water-using activities and consumer habits as well as from the change in the mix of waterusing power plants and manufacturers within a particular country. By contrast, "technological change" almost always leads to improvements in the efficiency of water use and a decrease in water intensity.

\subsection{Other pathway models}

The body of research on other climate change pathways is less cohesive than crop yield research, and in some cases less readily translated into economic model shocks. Sea level rise and its effects on land area is a pathway whose research base is relatively well developed. Some recent economic analyses have utilized results from the Dynamic Interactive Vulnerability Assessment (DIVA) interactive modeling tool, which uses a global-scale data system to project coastal impacts, vulnerability and adaptation to sea level rise, and estimates of adaptation costs in coastal areas (Hinkel, 2005, Hinkel and Klein, 2009). Projected coast land loss due to submersion or flooding is derived from simulating SRESs in DIVA.

More economic analyses are incorporating the labour productivity effects of climate change. A recent study by Kjellstrom, et al. (2009) quantifies the effects of climate change on labour productivity in 21 world regions. Hotter workplace temperatures lead workers to reduce work intensity or take more short breaks. Their study applies a physiological model that describes changes in the number of work days due to changes in temperature and humidity, also taking into account projected changes in types of employment as incomes grow in the future. Future changes in labour productivity are analysed under SRESs A2 and B2, with projected increases in global mean temperatures in 2080 of $3.4 \mathrm{C}$ and $2.4 \mathrm{C}$, respectively, using the HadCM3 GCM. Projected changes in labour productivity by 2080 , relative to a baseline climate from 1961-1990, are projected with this approach to be significant, ranging from a loss as high as 25 percent in Central America to a 3 percent increase in productivity in tropical Latin America. 


\section{Economic models}

Economic models build on the results of climate and pathway models to describe the economic impacts of climate change. Different modelling types are applied depending on the research question, the scale (farm, sector, national or global) and the actors targeted (farmers, resource managers, firms, consumers, governments). For expositional purposes, we separate the economic models between sectoral and household (or farm) types. We focus on agriculture and derive the implications for food security, trade and other important drivers.

\subsection{Market- and sector-level models}

\section{Partial equilibrium models}

Partial equilibrium models describe one or more sectors of an economy in detail, while holding price and quantities in the rest of the economy constant. Their main advantage in climate change analysis is that they typically include a finely disaggregated set of agricultural sectors, which facilitates their integration with detailed crop yield models. The chief limitation of partial equilibrium models is that they do not account for linkages between agriculture and the rest of an economy and so they miss potentially important economy-wide impacts of climate change that may originate from agriculture or feedback to agriculture.

\section{- Crops}

Multi-market models are a type of partial equilibrium model that focuses on a subset of interdependent markets in an economy; for example, crop and livestock markets that are linked through acreage allocations and feed demand.

Two examples illustrate the type of analysis with this model category. We start with a widely cited multi-market model used to assess climate change impacts on agriculture and food security the International Model for Policy Analysis of Agricultural Commodities and Trade (IMPACT), developed at the International Food Policy
Research Institute (IFPRI), (Rosegrant, et al.2002; Nelson, et al. 2010). The model describes 32 crop and livestock commodities in 281 food-producing units (FPUs) over a 40-year projection horizon. The FPUs are major river basin areas that are disaggregated from the 115 countries/regions of the model, based on climate and hydrological variations. Crop production is aggregated up from FPU to national and regional levels at which demand and trade are modeled.

Crop production in the IMPACT model is the product of yield times area. Changes in yields over time are a function of exogenous yield growth rates, which vary by crop and location, water availability for irrigated crops, and prices. Area is a function of exogenous area growth rates, water availability for irrigated crops and prices. Domestic demand for food, feed, biofuels and other uses is a function of prices, per capita income and population. Countries and regions are linked through trade as the model iteratively solves for each annual set of equilibrating world prices that achieves zero net global trade; these prices are then transmitted back to producers and consumers.

To develop global projections of climate change impacts on agricultural supply, Nelson et al. (2010) link the IMPACT model with DSSAT crop models calibrated to site-specific locations. To address uncertainty on the supply side, they simulate crop growth based on four climate scenarios that describe 2000 and 2050 climates using the SRES A1B and B1 outputs of the Model for Interdisciplinary Research on Climate (MIROC) and Commonwealth Scientific and Industrial Research Organisation (CSIRO) GCMs, plus a fifth scenario in which historical climate continues ("perfect mitigation"). They also run 30 iterations of DSSAT models for each location, based on stochastically generated daily weather data for 2000 and 2050 climates. The mean yield outcomes are then converted to smooth, linear growth rates that are used to adjust the productivity growth coefficient in the yield equations over the 2010-2050 period. DSSAT crop simulation models are carried out for five crops (rice, wheat, maize, soybeans and groundnuts), and yield results are mapped to other 
crops in the IMPACT model based on similarities in their photosynthetic metabolic pathways. Crop area also adjusts in response to climate change, due to changes in water availability for irrigated area and changes in the suitability of cropping areas.

To quantify uncertainty on the demand side, Nelson et al. (2010) develop three projections of optimistic, pessimistic, and middle-of-theroad (baseline) scenarios for future income and population growth. With five climate scenarios and three demand scenarios, they thus carry out 15 simulations, reporting both mean and standard deviations for key results.

Nelson et al. (2010) find that climate change will slightly reduce average annual yield growth over 2010-2050 from rates that are projected to be otherwise positive for all countries/commodities. Global food prices are expected to rise in the future as demand, driven by population growth and rising incomes, increases relative to supply; climate change will add to those upward price pressures. By 2050, mean projected price increases are 87 percent for maize, 31 percent for rice, and 44 percent for wheat in the most optimistic scenario, compared to 2010. The mean price increases in 2050 with climate change, relative to the 2050 price with perfect mitigation, are 33 percent , 18 percent and 23 percent for maize, rice and wheat. These results are driven by climate change-induced yield reductions countered by yield-boosting technology change, and demandraising population and gross domestic product (GDP) growth.

In the IMPACT model, food security is proxied by two measures: average daily per capita calorie availability and the number of malnourished children under 5. Without climate change, productivity gains and income growth will reduce the number of malnourished children by up to 46 percent in 2050 relative to 2010 in the most optimistic scenario. Some of this achievement will be lost due to climate change.

Using this model, the authors run a scenario of protracted drought in South Asia and assume that adaptation takes place and translates into higher agricultural productivity growth rates (between 2 to 2.5 percent annually for many crops) and improved irrigation efficiency. Under this scenario, the number of malnourished children declines and world agricultural price increases are substantially lowered, in some cases more than offsetting the price increases caused by climate change. These results are driven more by assumed higher productivity rates than by increased irrigation water efficiency since most crop production in Asia is currently rainfed. The authors also conclude that global trade plays a dampening effect, absorbing some of the impacts of climate shocks to individua regions.

Felkner et al.'s (2009) partial equilibrium analysis of rice production in Thailand is of substantial interest because it describes the importance of economic adaptations in reducing the negative yield effects of climate change described in crop yield simulation models. Their study integrates GCM and DSSAT crop simulation models with an estimated three-stage production function to describe rice yield and output in a northeastern province of Thailand. Crop simulation models, calibrated to household rice plots, describe the effects of changes in climate and the use of intermediate inputs, such as seeds and fertilizers, on output at the end of stages one and two of the growing season. The economic model describes farmers' input demand in response to realized output at intermediate stages in the growth process, their adaptive expectations about rainfall, and the prices of inputs and outputs.

Projected climate change is described by ensemble mean monthly projections from multiple climate models processed by a weather simulator to generate 100 realizations each of future climate in 2040-2069 relative to 1960-90. They choose output for the highest (A1F) and lowest (B1) emission scenarios from GCMs used in the Third Assessment.

At the plot level, the predictions of the DSSAT models and the economic models are starkly different. DSSAT models, which assume no adaptive changes in inputs, predict severe declines in yields for about one third of the plots, 
ranging from 30- 40 percent under the low- and high-emission scenarios. The economic model predicts yield declines for more than twice that number of plots in the high-emission scenario, but with an average yield decline of only 13 percent because farmers are allowed to respond to severe climate change with adjustments that prevent large crop failures. Under the low-emission scenario, yields actually increase slightly for most plots. These differences illustrate the importance of a "responsive farmer" assumption in climate change analysis and the potential ability of farmers to adjust to climate change.

One of the criticisms of these types of models is the often simplistic way they approach adaptation in their models. The above IMPACT model treats adaptation indirectly simply by exogenously raising the rate of agricultural productivity and water use efficiency. Because most adaptation occurs in response to extreme events, as opposed to gradual climate change, which is much harder to detect, most IAM type models (which are better suited for gradual climate change and less so for abrupt extreme events) tend to understate the impacts of climate change and overstate producers' adaptation response (Patt et al., 2010).

\section{- Water}

As agriculture is the largest water user, modelling agricultural water use and crop water demand are critical to climate impact analysis. Climate is expected to increase irrigation requirements globally, particularly in semi-arid and arid areas where precipitation is also expected to decline, such as North Africa (IPCC, 2008). Döll (2002) computed irrigation water requirements under climate conditions for the 2020s and the 2070s, and concluded that global irrigation requirements will rise by $3-5$ percent in the 2020 s and by 5-8 percent in the 2070s, and that the increase will affect two-thirds of the global area equipped for irrigation.

According to Döll et al. (2012), ground water accounts globally for 36 percent of domestic water uses, 42 percent of agricultural water uses, and 27 percent of industrial water uses. ${ }^{10}$ Groundwater levels of many aquifers around the world have shown a decreasing trend over the last few decades due to pumping that surpass the groundwater recharge rates, and not to a climate-related decrease in groundwater recharge (Bates et al., 2008). Where the depth of the water table increases and groundwater recharge declines, wetlands dependent on aquifers are jeopardized and the base flow runoff in rivers during dry seasons is reduced.

Climate change affects groundwater recharge rates and depths of groundwater tables (Bates et al., 2008). As many ground waters both change into and are recharged from surface water, impacts of surface water flow regimes are expected to affect groundwater. Increased precipitation variability may decrease groundwater recharge in humid areas because more frequent heavy precipitation events may result in the infiltration capacity of the soil being exceeded more often. In semi-arid and arid areas, however, increased precipitation variability may increase groundwater recharge, due to higher rate infiltration from high-intensity rainfalls than evaporation. As a result of climate change, in many aquifers of the world the spring recharge shifts towards winter and summer recharge declines. Climate-related changes in groundwater recharges have not been observed. This is partly due to lack of data and the slow reaction of groundwater systems to changing recharge conditions.

Economists argue that water markets and water pricing regimes can be effective adaptation tools and can help facilitate water transfer from lower to higher-valued uses (Saliba and

10 Satellite remote sensing is deployed increasingly to estimate groundwater quantities at the global level. Since 2002, the NASA/GFZ Gravity Recovery and Climate Experiment (GRACE) has been providing means to investigate groundwater storage changes through high-precision satellite gravimetry (Ramillien et al., 2008). The GRACE data have been applied to investigate regional groundwater situations, in many regions including California (Famiglietti et al., 2011), the Central United States (Strassberg et al., 2009), and India (Rodell et al., 2009). 
Bush, 1987; Vaux and Howitt, 1984; MedellinAzuara et al., 2008; Olmstead, 2010a). Still, modelling water markets is not easy, as water is not a typical commodity but a resource whose use is geographically bound and whose management is intertwined with strong institutional arrangements. As a result, water prices are generally imperfect signals of resource scarcity and rarely equate marginal water values across users (Olmstead, 2010b). Water prices are typically administratively determined, are unevenly applied, are often based on annual rather than usage based fees, and rarely take full economic value into account (Saleth et al., 2012). ${ }^{11}$

A number of institutional factors affect the development of water markets, including property right arrangements (often tied to historical and current entitlements), and legal and physical limits on water transferability (Saleth et al., 2012). Externalities can also be an obstacle to water pricing such as the problem of "return flows" where irrigation water not lost to evapotranspiration either recharges groundwater aquifers or augments surface water flows within a basin, posing difficulties for pricing water usage (Libecap, 2011). Transaction costs (physical infrastructure, search, legal) are other important barriers to trade in water markets (Olmstead, 2013).

A big challenge in modelling water under climate change is the lack of water price datasets with sufficient geographic scope and which hinder good estimates of the price elasticity of water demand (Olmstead, 2013). Thus, much of the economics literature on water demand has focused on the econometric estimation of demand parameters, including price elasticity. ${ }^{12}$ Estimating

11 Even in the US studies show that aridity and marginal price levels are negatively correlated (Olmstead, 2013).

12 A meta-analysis of 24 US agricultural water demand studies performed between 1963 and 2004 suggests a mean price elasticity of -0.48 (Scheierling et al., 2006) with high variability in reported values.

A review of studies conducted in developing countries suggests that residential price elasticity is in the range of -0.3 to -0.6 , similar to the range estimated for industrialized countries (Nauges and Whittington, 2010). water demand curve remains difficult owing to water-pricing practices. Farmers who withdraw water directly from surface sources usually incur an energy cost to convey water for irrigation, but do not typically pay a volumetric charge for the water itself. Many agricultural water demand curves are estimated for groundwater, using energy costs for pumping to construct a water price variable. While the economics literature contains many estimates of agricultural water demand elasticity, the available data are rarely of sufficient quality to estimate demand functions (Olmstead, 2013).

Water modelling at the river basin level can employ either optimization or simulation type models. Optimization models are used more often because they require less data than simulation models and can avoid the challenges of enumerating individual sets of feasible, optional rules. Moreover, optimization models can automatically implement autonomous adaptation to external shocks (Bell et al., 2014). On the other hand, simulation models may evaluate specific adaptations (such as reservoir schedules, infrastructure improvements or policy choices) across different scenarios or even as discrete choices within the simulation.

The few available estimates of the economic impacts of the water resource effects of climate change make one of two assumptions about adaptation: no adaptation will take place; or water markets will respond in a dynamically efficient manner, maximizing the net benefits of water resources over time (Olmstead, 2013). Both sets of assumptions are problematic since water is rarely managed purely through markets. Examples of models that incorporate water include the IMPACTWater (Rosegrant et al., 2002), which is used to assess adaptation options such as increased water storage and improvement in water use efficiency at the basin and global levels (Nelson et al., 2010; Zhu and Ringler, 2012). The second is WaterGAP (Alcamo et al., 2003) which explicitly models water allowing for multiple water sources, sectoral demands, water infrastructure capacity and water policies.

Global water use modelling (GWUM) is fairly new and is much less advanced than global 
hydrological modelling (GHM). The latter models are rooted in the well-established science of watershed hydrology, whose basic principles are virtually applicable anywhere. In contrast, GWUM has to consider various water use sectors under drastically contrasting socioeconomic and political contexts. In terms of data, GHM can make use of global land cover, soil, topology and long-term climate data available at fine spatial scales, while GWUM lacks consistent global water use data with adequate sub-national disaggregation, and data coverage remains poor even for OECD countries. Thus, few groups quantitatively model global water use (Hoff et al., 2010; Elliott et al., 2013). However, their use can be helpful for global policy dialogue on water issues.

While the literature on climate and hydrological impacts is growing, relatively little work has been done to quantify the global food supply implications. Kummu et al. (2014) apply an LPJJmL vegetation and hydrology model and a historical climate-forcing dataset over the period 1977-2007 to quantify the effects of hydroclimatic variability on global "green" and "blue" water availability and demand in global agriculture, food deficit and trade. The authors calculate the spatial variation in food production, green-blue water availability and the water requirements to produce a reference diet (3000 kilocalories per capita per day, with 80 percent vegetal food and 20 percent animal products) for each FPU. An FPU was considered water-scarce if its water availability was not sufficient to produce the diet (i.e. assuming food self-sufficiency to estimate dependency on trade from elsewhere). The authors isolate the effect of interannual hydroclimatic variability from other factors that drive food production and find that 24 percent of the world's population lives in chronically water-scarce FPUs (i.e. water is scarce every year), while an additional 19 percent live under occasional water scarcity (water is scarce in some years). Among these 2.6 billion people altogether, 55 percent would have to rely on international trade to reach the reference diet, while for
24 percent domestic trade would be enough. For the remaining 21 percent of population exposed to some degree of water scarcity, local food storage and/or intermittent trade would be enough to secure the reference diet over the occasional dry years.

In a recent review of water and climate change, Olmstead (2013) concluded that the current literature offers little guidance on the extent to which the prospect of climate change will alter: (a) the level and structure of water prices; (b) reliance on non-price water conservation mandates, incentives and other policies; (c) legal property rights regimes for water; (d) the allowable extent of and constraints on transferring and leasing water among users, within and across basins; and (e) investment in water supply infrastructure. The author also concludes that a key for future progress in water climate modelling requires better representation of political economic institutional features into the market-driven economic models.

\section{Computable general equilibrium models ${ }^{13}$} Computable general equilibrium (CGE) models are economy-wide models and encompass the economic interactions of a country's producers, consumers, investors, government and trade partners. CGE models describe an initial equilibrium state in which, at the initial set of prices and quantities, all agents are satisfied and there is no momentum for change in supply or demand. Climate shocks lead to endogenous economic responses as price changes signal producers to readjust their production toward products whose relative prices are rising and to adjust their demands for intermediate and factor inputs accordingly. Price and income changes

13 CGE-based analyses falling outside of agriculture or focusing exclusively on climate mitigation are not covered in this review. A good example of such analysis is given by van der Mensbrugghe and Rosen (2010), who used the ENVironmental Impact and Sustainability Applied General Equilibrium (ENVISAGE) model to develop a comprehensive CGE-based assessment for climate mitigation impacts. 
lead consumers to reallocate their demand for commodities. The model solves for a new set of equilibrium prices and quantities, and reports results for macro variables including welfare, GDP, trade balances and exchange rates; and microeconomic variables including industry output, employment and trade.

CGE models can be either single-country, providing detailed accounts of several economic sectors, or multi-country models, where countries (or economic units) are interlinked through international trade and investments. The number of sectors can vary from as little as two (i.e. agriculture and non-agriculture) to a high number of sectors (industries or activities). CGE models can also be static (describe only the change from the initial equilibrium to the post-shock equilibrium, without describing the adjustment path) or recursive dynamic, which can solve sequentially for yearto-year equilibria over a time path, incorporating exogenous, projected changes in population, labour force and productivity. An advantage of recursive dynamic models in climate change analysis is their ability to describe and differentiate the effects of long-run trends in population and productivity growth from climate change shocks on the supply and prices of food in the future.

\section{- Climate and agriculture}

One of the earliest CGE models to analyse climate change impact is the Future Agricultural Resources Model (FARM) developed by the Economic Research Service at the United States Department of Agriculture (USDA) (Darwin and Kennedy, 2000; Darwin, 2004). FARM was based on a geographic information system and divided land endowments into six land classes, characterized by soil temperature and length of growing season. Under this model, climate change induces a redistribution of land across the different land classes, and the model captures the climate effects on crop yields, on pasture and forest productivity. FARM was later linked with the World Trade Model with Climate-Sensitive Land (WTMCL) (Juliá and Duchin, 2007), which accounted for changes in runoff and the resulting changes in water supply for irrigation. However, FARM was highly aggregated, representing the world in eight regional aggregates, while agriculture included only two sectors: crops and livestock.

Since then, there have been many advances in CGE modelling of climate change and adaptation, and many CGE models (both single- and multicountry) have been integrated into IAMs and have incorporated multiple pathways through which climate change affects an economy. Arndt et al. (2010) reported a single-country, integrated CGE framework to study the effects of climate change in Mozambique through four pathways: agricultural crop productivity, irrigation water supply, infrastructure, and loss of land due to sea level rise. In a set of six linked models, the authors analyse four climate scenarios from CMIP3 projections. They address uncertainty about future climate by selecting the highest and lowest projected precipitation effects in 2050 for the globe and for Mozambique.

GCM outputs for precipitation are used as inputs into a river basin model to determine stream flows. These results are used as inputs into water resource models, which estimate water availability inputs to a hydropower model that determines hydroelectric power generation and the supply of water for irrigation. Flood data from the river basin model also inform an infrastructure model, estimated for each of three sub-regions in Mozambique. The infrastructure model provides estimated damage and maintenance costs resulting from the floods, which are determinants of transport productivity and costs. GCM projections for temperature and rainfall also are used in generic crop simulation models that describe the productivity and irrigation requirements for 14 major crops in each of the three sub-national regions of Mozambique. Finally, output from the DIVA model is used to estimate crop land loss due to inundation resulting from sea level rise. All of these data on crop yields, supply of irrigation water, transport costs and loss of land are then passed to a recursive dynamic, single-country CGE model, which is used to estimate the economywide impacts of climate change. 
Using this complex modeling approach, and within the large uncertainties linked to this exercise, Arndt et al. find that climate change will reduce Mozambique's welfare by up to US $\$ 7.4$ billion over the period 2002-2050. They decompose the effects of each of the four pathways, finding that although agriculture is adversely affected by climate change, the dominating effect will be the impact of flooding on transport infrastructure. While losses in agriculture, a key sector, directly affect Mozambique's economic growth, transport-system disruptions have widespread, indirect effects throughout the economy.

Since CGE models can describe household employment and income, they can be used to analyse the poverty and distributional effects of climate change. Ahmed et al. (2011a) analyse the effects of climate change on income distribution due to the change in inter-annual climate volatility between the late $20^{\text {th }}$ and early $21^{\text {st }}$ century. Their analysis is based on a sequence of models in which outputs from GCMs for SRES A2 are used as inputs into statistical crop yield models estimated for three crops in each of 17 regions of Tanzania. The estimated yield impacts are introduced as shocks into a static, single-country CGE model, which is linked to a household micro-simulation model that stratifies Tanzanian households into seven groups based on their sources of income.

To address climate model uncertainty, the authors implement four future climate scenarios into the crop models: the mean climate projections of all 22 GCMs, and projections from three GCMs that describe the greatest volatility in temperature and precipitation combined, and in temperature and precipitation separately. Climate change volatility is measured as a change in the standard deviation of monthly average temperature and precipitation over the January-June growing season for grains between 1971-2001 and 20012031.

Combining national or global CGE models with detailed spatial models has grown in the context of climate analysis and policy, including in agriculture and land use. Rutten et al. (2014) applies a dual modelling approach combining a global macroeconomic CGE model (Modular Applied GeNeral Equilibrium Tool, MAGNET) with a spatial land use model (Conversion of Land Use and its Effects, CLUE) to analyse future land use patterns in Vietnam under various scenarios for the period 2007-2030. The global CGE makes it possible to account for trade linkages important for an export-oriented Vietnam. The analysis examines how the structural change toward manufacturing and services, and urbanization influenced the loss of natural forests in Vietnam landscape, biodiversity and GHG emissions. Moreover, the loss of large paddy rice and other agricultural lands (through sea level rise) in the Red River delta and the Mekong River delta have significant impacts on food security. Combined with a macro-economic model, the analysis identifies inherent trade-offs in policy objectives (growth and urbanization versus GHG emissions and loss of forest land).

Some CGE models analyse the economics of food security in terms of poverty, which is a net result of changes in incomes and changes in the prices of food and other goods in the consumer basket. An increase in poverty goes hand in hand with increased food insecurity due to a decline in the affordability of food. Based on their modelling approach, Ahmed et al. project that, depending on the future weather, poverty in Tanzania could decrease in 2031 relative to 2001 . However, in the most unfavourable climate scenarios, poverty could increase by as much as 2 percent, or approximately 650,000 people.

Tubiello and Fischer (2007) carried out an analysis of the effects of climate change on food that offers a contrasting treatment of food security. They use IIASA's Basic Linked System (BLS) model of the world food system, which comprises a set of 34 agriculture-focused, national and regional CGE models that are linked through financial flows and trade in ten commodities, of which nine are agricultural. The BLS model's calculation of food insecurity is based on the correlation between shares of undernourished in the population and the available national food supply, including domestic production and net imports. The authors first 
process the outputs of two GCM models from the fourth IPCC assessment into the IIASA-FAO AEZ crop simulation models, which simulate impacts on land resource use and potential yields. These outputs are then used as inputs into the BLS model. Three scenarios are explored: a baseline reference point with no climate change; SRES A2, which describes unmitigated climate change; and SRES B1, which is a proxy for mitigated climate change. The recursive dynamic BLS CGE model is then solved in annual steps for 1990-2080. In the baseline, the number of people at risk of hunger is projected to decrease globally to 555 million people. Using these modelling tools, the authors conclude that climate change will reduce but not eliminate that progress.

One challenge for CGE models relates to intra-seasonal climate variability. Because CGE models use annual time steps, they typically lack the ability to account for intra-seasonal variability and short-term climate extremes, such as heat spells, which crop yield models have shown to be key determinants of seasonal yields. Block et al. (2006) demonstrate the importance of brief weather extremes in a CGE-based analysis of climate change impacts on Ethiopia that contrasts outcomes with and without accounting for the incidence of flooding. To describe threshold effects in precipitation, the authors develop annual climate-yield factors (CYF) by crop and agricultural zone within Ethiopia, based on crop sensitivity to water shortages at four stages of growth, choosing the most water-sensitive stage to calculate the CYF. Just as water shortages can reduce yields, so can floods. A flood factor is therefore added to the CYF, decreasing the CYF if the year is significantly wet during the flowering or harvesting stages. The flood factor is also applied to nonagricultural sectors, to represent higher costs of transportation and other damage due to flooding. Their recursive dynamic, single-country CGE model describes the impacts during 2003-2015 of an ensemble of weather experienced during nine historical 12-year time periods. Both drought and flooding reduce productivity and GDP and increase poverty. These effects are more negative when flooding is accounted for. Without the flood factor, the mean increase in poverty rises from 42 percent to 43 percent between 2003 and 2015; with it, the mean projected increase in poverty reaches 54.7 percent.

Another criticism of CGE models is their tendency to generate relatively smaller changes in price effects and welfare even under large crop yield effects of climate change. This is because of the structural nature of the models and their neoclassical perfect market integration assumption in which inputs (capital and labour) are fully utilized and mobile across sectors and activities. Such an assumption lacks realism in light of market rigidities so characteristic of most economies, especially in developing countries. In addition, the functional forms used to describe factor demand and trade also tend to diminish quantity responses to price changes. To address these limitations, and given much of the uncertainty around climate impact analysis, CGS models can make more use of a well-developed tradition of sensitivity analysis and the use of the probability distributions of outcomes in climate change impact studies. This also underscores the importance of efforts to account more comprehensively for the multiple pathways through which climate change may affect an economy's productivity or factor supplies.

\section{- Climate and trade}

One of the advantages of CGE modelling is its contribution to trade and trade policy, and several CGE analyses on climate impact also reported on the implications of trade as a potential adaptation mechanism. Ahmed et al. (2011b) use a static, single-country CGE model of Tanzania to analyse alternative trade regimes in the presence of climate change, finding that open trade policies help to negate the poverty impacts associated with climate shocks. Valenzuela and Anderson (2011) also address the adaptive role of trade in a study that finds that climate change will cause a substantial 12 percent decline in the food selfsufficiency ratio of developing countries by 2050. They use a static, global GGE model to analyse the world economy in 2050 under two scenarios: 
climate change versus no climate change. Both scenarios assume exogenous rates of labour, capital and productivity growth to describe 2050. The climate change shock also imposes yield impacts and labour productivity shocks, some derived from studies that predate CMIP3. They find that developing countries' food self-sufficiency ratio declines from 100 percent to 88 percent, while that of high-income countries rises from 96 percent to 129 percent between 2004 and 2050.

CGE models can also be applied to examine whether trade can moderate the expected rise in production and price volatility under climate change. Verma, Hertel and Diffenbaugh (2014) examine the US ethanol sector under moderate US corn price volatility projected to occur in response to near-term global warming. The authors conclude that if ethanol biofuels are mandate-driven, price volatility will be exacerbated. However, if marketdriven, then the emergence of the corn ethanol sector will both magnify corn price volatility (inherited via more integrated energy markets through crude oil price fluctuations) and moderate the climate-driven supply volatility. The latter dominate with a net impact showing price volatility reduced by 27 percent. In contrast, mandates on ethanol production increase future price volatility by 54 percent under future climate after 2020 . Liberalized international corn trade serves to reduce the impact of near-term climate change on US corn price volatility by 8 percent.

One of the important recent developments in global agriculture has been the growth of policy-supported biofuels, especially in the US and the EU. Although the biofuel policy support was justified in part as a contribution to lower GHG emissions, the role of biofuels has become contentious owing to the concern about the negative environmental impact from indirect land use change (ILUC) and its association with more carbon emissions (linked to deforestation). Several CGE-based analyses have examined the issue of biofuel mandates on global food production, prices and trade (Keeney and Hertel, 2011; AlRiffai, Dimaranan and Laborde, 2010; Banse et al., 2011). The Keeney and Hertel analysis concludes with a cautionary note on the implications of supply shocks for US coarse grains on global markets. The Al-Riffai et al. analysis show that the EU biofuel mandate has a net positive environmental impact from trade despite a slight increase in indirect land use change (mostly from sugar ethanol expansion in exporter Brazil) and that direct emissions are lower due to the shift to more emission-efficient ethanol (sugarcane ethanol from Brazil). While these analyses do help in evaluating policy tradeoffs, one should not draw broader inferences from them owing to the specificity of the policy instruments analysed. For example, while biofuel production shift into Brazil sugar ethanol may be relatively emission-efficient (compared to rapeseed biofuel), this cannot be generalized, as sugar ethanol production in other countries would require irrigation - a resource expected to become more scarce under climate change.

More recently, attention has turned to the climate-water linkages and the mediating role of trade. Calzadilla et al. (2011) also analyse the adaptive role of trade in a study of global trade reform and climate change using Global Trade Analysis Project (GTAP)-W (Berrittella et al., 2007), a 16-region, static CGE model that also includes water as an input into crop production. However, given that production is treated at the national as opposed to river basin level, the inclusion of irrigation water as input into production was deemed unsatisfactory. Liu et al. (2014) expanded this work by developing an improved model version GTAP-BIO-W, which restricts water supply and demand within a specific river basin. The model was linked with the IMPACT-WATER model, using the latter to generate estimates on the irrigation stress at the river basin level due to climate change. These estimates are applied as inputs into the GTAP-BIO-W to model how climate-induced future irrigation shortage will affect crop production, food prices and the resultant effects on bilateral trade patterns. The authors conclude that global irrigation shortfalls do not always translate into less total regional crop output, as the outcome depends on price effects and regional supply response. Second, regional irrigation shortfalls tend to boost 
international agricultural trade as well as alter its geography. Although the overall increase in world food exports is only modest, some types of interregional food trade are strengthened, with North America and Europe shown to export more to Asia.

Recently, as part of the Agricultural Model Intercomparison and Improvement Project (AgMIP), an ensemble of ten global economic models (six general equilibrium models and four partial equilibrium models of the agriculture sector) ran coordinated scenarios to estimate the likely impacts of climate change and socioeconomic drivers on international trade in agrifood commodities (Nelson et al., 2014; von Lompe et al., 2014). The model results (reported by Ahammad et al., in chapter 10 in this volume) show a general agreement on an increasing role for trade under climate change, but the extent of the changes in trade varies substantially between models.

To sum up the above review on climate and trade, it is our view that work in this area is only at the beginning. Although a number of models have reported the positive role trade could play as an adaptation mechanism, many important environmental issues related to trade and climate remain unanswered. ${ }^{14}$ Among the critical climatetrade issues that require further investigation:

(i) More robust evidence of the implications of climate impacts on future food supply in light of projected resource shortages, reduced yields and other climate-induced resource base changes (e.g. sea level rise, loss of crop land, irrigation shortage).

(ii) Better evidence integrating demand-side food drivers (food waste, diets, eco-labelling) and climate-induced supply changes (reduced

14 Kanemoto et al., 2014 show that while developed countries have been able to report decreasing $\mathrm{CO}_{2}$ emissions under the Kyoto protocol, they have done so largely by displacing emission-intensive production offshore. Using a new highly detailed account of emissions embodied in international trade, the authors find that when trade is accounted for, the authors showed that the $\mathrm{CO}_{2}$ emissions by Kyoto signatory countries have actually gone up. yields, irrigation water shortages, cropland and quality loss, including from sea level rise) and their implications for trade.

(iii) Evidence on policy-induced growth of "gray" (or dirty) trade versus "green" (emission-saving) trade and the indirect effect of carbon/energy taxes on agricultural and food trade.

(iv) Integrated energy-food systems, including biofuels, and the implications of climate change on food supply and variability, price volatility, land use change and trade patterns.

(v) Better integrated water-food-climate systems and quantified impacts of water scarcity on food supply, prices and trade patterns.

\subsection{Farm- and household-level models}

Given that much of adaptation in agriculture is local and can be carried out autonomously by individual farmers and household agents, understanding adaptation decision-making at the farm level is an important requirement for adaptation policy. Household models of farmer decision making on adaptation can apply either econometric or simulation techniques. Econometric studies use observed cross-sectional, time series, or panel data to examine the nature of observed adaptations or estimate climate change effects to which farmers have adapted. Advantages of an econometric approach include reliance on real-world data, and an ability to reflect the joint costs and benefits of multiple adaptation strategies to the extent that they are employed together (IPCC, 2014). Nhemachena et al. (2014), use a multivariate probit model to simultaneously examine the determinants of adaptation at the farm level in a three-country study from southern Africa. Seven dependent variables (different varieties, planting different crops, crop diversification, and different planting dates, diversifying from farming to non-farming activities, increased use of irrigation, and increased use of water oil conservation techniques) were regressed against 17 independent (explanatory) variables. 
Results show that household socio-economic characteristics like farming experience, access to free extension services, credit, mixed crop and livestock cropping systems, private property and perception of climate change are expected to have a significant positive impact on use of adaptation measures at the farm level.

Asfaw et al. (2014) use a multivariate probit model at household level data to examine maize farmers' adaptation strategies and crop productivity under climate variability in Malawi. The authors distinguish between exposure, sensitivity and adaptive capacity vis-a-vis climate disruptions and find that exposure to delayed onset of rainfall and to greater climate variability (measured through the coefficient of variation of rainfall and temperature) is positively associated with the choice of risk-reducing agricultural practices such as tree planting, legume intercropping, and soil and water conservation. However, the application of inorganic fertilizer in maize plots (already high due to government subsidies) is reduced due to uncertain risk reduction benefits. Farm wealth and more secure land tenure are positively associated with higher adaptive capacity. The use of both modern and sustainable land management practices is positively correlated with higher maize yields. An important insight from the study is that community (system-level) adaptive capacity is also important and highlights the key role of rural institutions, social capital and supply-side constraints in governing selection decisions for all farm practices examined.

Among the disadvantages of the econometric approach is the inability to trace transmission mechanisms of specific adaptation measures or to isolate the marginal effect of these strategies or measures. Moreover, the findings are not easily transferable to other contexts (e.g. an African study does not apply elsewhere), and the statistical results can be difficult to interpret under multiple possible outcomes (Schlenker et al., 2005).

The simulation approach, by contrast, traces costs and benefits of adaptation strategies through particular mechanisms of interest, typically through climate-biophysical-economic linkages. The economic component of the simulation analysis take one of two pathways:

(i) decision makers are rational actors who consider the benefits and cost consequences of their choices and pursue economically efficient adaptation outcomes (optimization models); or

(ii) application of a decision-rule characterization of the response of actors to climate stressors (scenario-based models) (Dinar and Mendelsohn, 2011; Schlenker et al., 2006). Van Wijk et al. (2014) reviewed a large number of simulation models that apply rule-based management implemented either through rules or through model parameter settings and found that for these scenario ("what if") type models, adaptation can mean very different things depending on the goals, scale and scope of the model (Bell et al., 2014). In the case of optimization models, adaptations (as well as extreme events) may be modelled implicitly (as production responses to shifts in input costs and/or output prices) or explicitly (as choice variables with empirically derived cost functions), but without treatment of adaptations as discrete responses to discrete events or perceptions (De Bruin et al., 2009; Patt et al., 2010).

A major disadvantage of simulation modelling is the high demand for data inputs and calibration. Where data and models are available, farm-level simulation models work well and can perform a wealth of simulation options, such as estimating the incremental change in crop output and water supply in response to changes in climatic conditions and agricultural and water resource management techniques. Another advantage is the opportunity for stakeholder involvement at several stages of the analytic process: designing scope, adjusting parameters, selecting inputs, calibrating results and incorporating adaptation measures of specific local interest (Dinar and Mendelsohn, 2011). 
Combining different analytical tools can also improve the robustness of the ability to predict farmer adaptation responses under climate change. Seo (2014) combines the Agro-ecological zones (AEZ)/Length of the growing period (LGP) methodology developed by FAO and IIASA (FAO/ IIASA 2005, 2012) with the GEF/World Bank data set for African countries to test the model's predictive power vis-à-vis farmers' adaptation responses due to climate change. Seo classifies the farms in three categories - specialized crop farm, mixed farm, specialized livestock farm - and examines whether a farmer is more likely to choose a crop system when the LGP is deemed more suitable for crop production according to the AEZ methodology. The author also looks at whether the net revenue from crop production is higher when the AEZ is deemed more suitable for crops. Seo finds that the AEZ/LGP classification used alone, while well suited to predict crop patterns, is not a good predictor of non-cropping choices, such as such as diversifying portfolios to cope with varying climate factors, and is not a useful indicator of the major grains in the humid zones. Grain yields are found to be much lower in the humid zones then would be predicted by the AEZ method relying solely on LGP.

By examining the socio-economic data from the farm surveys, Seo finds that economic factors play an important role in explaining farmers' decisions. Factors like travel hours to a port or a city, extension services, ownership of property, and the number of household members were all important in explaining economic activities in Africa. For example, export possibilities (proximity to a port) tended to favour crop-only farms, but farms farther away from a nearest city favoured a cropslivestock farm (to take advantage of marketing opportunities in nearby urban centres). Also, a larger farm is more likely to be a livestock-only or a crops-livestock than a crops-only (possibly from labour availability). Overall, the study revealed the type of incorrect inferences when relying solely on biophysical tools such as AEZ/LGP without taking into account the socio-economic determinants. Seo concludes with a strong recommendation for a judicious integration of biophysical tools with economic analysis if we are to arrive at robust predictions of farm adaptation responses under climate change.

\section{- Food security}

Most farm-level models do not yet perform integral analyses of climate change effects on food security (Van Wijk et al., 2014). Aside from food availability (which is readily modelled through changes in production), food access and stability aspects are generally missing from household models. For example, household models typically lack proper accounting of food storage from one season to another season, as these are difficult to incorporate into a model (Van Wijk et al.). Farm household models rarely combine production with nutrition or other socio-economic determinants. Also, most models tend to focus on a few important crops (e.g. maize, millet, sorghum, rice, many legumes) but neglect a host of other minor crops. The latter, however, can play an important role in the diet and cash provision of smallholders but are much more difficult to simulate with the existing models (Rodriguez et al., 2011). Most household models also give limited attention to the importance of non-agricultural activities (whether off-farm employment or 'on-farm non-agricultural activities'), yet these can form important strategies of adaptation to climate change and are essential for improving access to food by poor rural households.

\section{- Risk analysis}

To date, few household models have treated climate-related risk explicitly (Van Wijk et al.). A relevant question for adaptation is how climate (rainfall, temperature) variability affects crop management techniques and net farm returns. Traoré et al. (2014) examine the case of cotton, maize and small grains (millet, sorghum) in the Soudano-Sahel and find that a simple adaptation decision should give priority to planting cotton early; maize and sorghum can be delayed by up to a month without strong yield penalties; and millet should be planted last. Akponipké et al. (2010) 
combine field trials with the APSIM model to investigates optimum nitrogen applications in millet production in the Sahel and conclude that moderate nitrogen application (15 kilograms of nitrogen/hectare) improves both the long-term average and the minimum yearly guaranteed yield without increasing inter-annual variability compared to no N input. Although average yields are lower than with higher nitrogen rates, moderate rates are more appropriate for smallholder, subsistence farmers, as they guarantee higher minimum yields in worst years, thereby reducing their vulnerability. Rurinda et al. (2014) also examine maize and small grains in Southern Africa and conclude that given the superior maize yields over small grains (finger millet, sorghum), substituting maize with small grains is not a robust option for adaptation to increased temperatures and more frequent droughts likely to be experienced in Zimbabwe.

The issue of irrigation management under climate risk is also receiving closer scrutiny. Grove and Oosthuizen (2010) develop an expected utility optimization model to economically evaluate deficit irrigation within a multi-crop setting while taking into account the increasing production risk of deficit irrigation in South Africa. To account for future water supply limitations and the resulting crop yield variability, the authors include multiple irrigation schedules into the South African Plant WATer (SAPWAT) optimization model. They use stochastic budgeting procedures to generate gross margins necessary to incorporate risk into the water use optimization model. The authors apply the model to study the impact of increasing levels of risk aversion on the profitability of deficit irrigation under limited water supply conditions. The authors conclude that although deficit irrigation was stochastically more efficient than full irrigation under limited water supply conditions, irrigation farmers would not willingly choose to conserve water through deficit irrigation and would be expected to be compensated to do so. Deficit irrigation would not save water if the water that was saved through deficit irrigation were used to plant larger areas to increase the overall profitability of the strategy.

Risk management and the role of climatebased risk insurance is an established research area and is receiving renewed interest in light of climate change. Hansen et al. (2009) apply the APSIM model (Helms et al., 1990) to provide detailed climatic risk analyses at household level and to study the effectiveness of crop insurance. ${ }^{15}$ Hansen et al. examined the potential use and value of seasonal forecasts downscaled from a GCM and the risk implications of smallholder farmers in Kenya responding to forecasts. The authors estimate the potential value of GCM-based seasonal precipitation forecasts for maize planting and fertilizer management decisions under profit maximization assumptions in Kenya. The authors reported the first quantitative test of the hypothesis that profit-maximizing use of seasonal forecasts can increase the exposure of smallholder farmers to risk. Under the study simplifying assumptions, the authors find that the risk from ignoring forecasts is greater than the risk associated with responding to forecasts, and the concern that the risk of a "wrong forecast" is a disincentive to risk-averse farmers is not supported. The authors conclude that under more realistic assumptions, appropriate use of seasonal climate forecasts would not increase farmers' risk exposure, although communication failures that distort information about forecast uncertainty could. However, given the limited representativeness of the sites analysed and the simplified assumptions, the authors recommend further validation of the research.

15 While insurance can be used to mitigate against risk and climate uncertainty, due to moral hazard, purchasing insurance may also reduce adaptation or increase maladaptation (Kunreuther and Roth, 1998; Rao and Hess (2009). This can happen when insurance is not fully risk adjusted, as is the case when local or state regulations do not allow insurance rates to be risk-adjusted (Collier et al., 2009). Underinsurance can also arise when agents expect that the public sector will provide disaster assistance (the so-called Samaritan's dilemma) (Gibson et al., 2005; Raschky et al., 2013). 


\section{- Spatial analysis (agent-based models)}

Agent-based models (ABMs) refer to a modelling approach that builds on the tradition of Recursive Farm Programming Models, but simulate all individual farms, their spatial interactions and the natural environment (Berger et al., 2006). It has been argued that ABMs can be very useful for adaptation analysis and for policy guidance. According to Wreford et al. (2010), evaluating climate change impact on agriculture requires examining scenarios at a more localized levels to develop estimates for local area adjustment costs, for cost-benefit analysis for adaptation plans, and for building robust climate resilience policies. The proponents of ABMs argue that climate change is expected to have location-specific impacts, but most models are too aggregated to provide guidance for more targeted policy interventions. Statistical models or Ricardian type models are only useful in capturing humanenvironment interaction at "coarse resolution" and may not have the necessary detail to allow for a more refined assessment of climate change in agriculture. ABMs have been suggested as complementary tools for assessing farmer responses to climate change in agriculture and how these are affected by policies (Moss et al., 2001; Patt and Siebenhuner, 2005; Troost and Berger, 2014).

ABMs can address spatial heterogeneity and effects in a system of distributed, but interdependent and hierarchical, decision-making. While ABMs are not predictive, they are well suited to counter-factual experiments, "what-if"type analyses and policy discussion. According to Berger and Troost (2014), the ABM has the capacity to meet a number of critical requirements for analysing farm-level adaptation options due to climate change. Among these requirements are:

(i) Incorporating fine technical and financial detail at the farm level.

(ii) Facilitating policy analysis based on modelling farmers' decisions, including expectations, learning and risk behaviour. (iii) Accounting for the role of farmers' cumulative experience, capacity to learn from neighbours and exchange of information.

(iv) Allowing for spatial interactions in decision, including issues of local land competition among alternative uses.

(v) Accounting for environmental interactions and feedback and ability to account for events like the occurrence of flooding events or invasion of new pests and diseases.

(vi) Performing sensitivity tests using Monte-Carlo or other methods.

Malanson et al. (2014) examine the effects of extended climatic variability on agricultural land use using an Agent-based model applied to villages in the Nang Rong district of northeastern Thailand. The land use decisions are made by each household in a village for which socio-economic data was collected through intensive surveys from 41 villages in 1984,1994 and 2000 across Nang Rong District. The land use change decision in the ABM has five alternatives: jasmine rice, heavy rice, cassava, sugar cane and unused-by-village. The primary basis for change in a given year is the expected income from the given crops, given their yields and prices, but constrained by labour, assets and a threshold of willingness to change. Climate change is modelled through nine weather scenarios based on timing and amount ([early, normal, late] and [low, normal, high]) of monsoon precipitation. These scenarios are based on data on actual monthly rainfall in Nang Rong from 1900 to 2008.

The household-level land decision-making is presented at the village level to allow for broader inference. Modelled (virtual) villages change their agricultural effort in many different ways. While most "virtual" villages reduce the amount of land under cultivation, primarily with reduction in jasmine rice, others do not. The analysis revealed insights into the role of landscape and society in land use in scenarios of climate change, but the statistical relations are weak, which limits inference. The authors conclude that while ABMs are able in theory to incorporate the variations to which complex systems are sensitive, they require precision in the 
specification of the characteristics of individuals. Imprecision in initial specifications can limit the range of outcomes and create path dependence.

Despite its advantages, the ABM model exhibits two weaknesses that require further attention. The first is the difficulty to extrapolate aggregate regional results from detailed individual farm cases. The second relates to the considerable model uncertainty. Van Wijk et al. (2014) reviewed 14 ABMs and found them to differ widely in their description of component processes and the detail with which climate is taken into account. Also, as most ABMs work on a yearly time-step, this can allow only for tactical and strategic decisions to be modelled, while detailed climate risk analyses in which drought periods and delays in the onset of the rainy seasons occur cannot be easily captured unless transfer functions or adapted crop production values are used that can incorporate these climate effects.

\section{Conclusions}

Since the Stern review was published in 2006 as the first economic assessment of climate change impact, a growing economic literature on climate impact and adaptation has developed. The dominant strand of this literature was centered around IAMS to address a variety of biophysical processes translated into economic shocks. The IAMs were initially applied to climate mitigation problems and climate policy; and later applied to adaptation - an issue that has become of increasing global concern with the realization that climate change is already happening from past emissions and is unaffected by future emission levels. Parallel to IAMs, and given the local nature of adaptation, a growing number of household- or farm-level models are being applied to analyse local climate impacts and evaluate farmer adaptation decision processes. This paper surveys both strands of the literature focusing on agriculture. The survey is presented as a critical yet informative review that describes the results, strengths, weaknesses and gaps.
Results of the IAMs surveyed here report mostly negative and some positive outcomes of climate change on agriculture. These models also suggest, within the limitations and uncertainties of these modelling frameworks, substantial capacity to offset negative climate change through adaptive supply-and-demand responses, productivity-enhancing investments and trade. A number of characteristics are shared by the studies described here. First, they rest on carefully constructed foundations that are as much as possible transparent, timely and consistent in their integration with physical and biophysical models. Most of the assessments are based on climate change projections drawn from the 2007 IPCC Fourth Assessment. Several of the more recent models (that contributed to the Fifth Assessment) are also included and are shown to account for multiple pathways through which climate change affects economies.

\section{- Methodology issues}

Nevertheless, the application of IAMs to adaptation presented a number of challenges. A starting difficulty is the modeller's treatment of adaptation, which varies widely, ranging from implicit or indirect (through assumptions of higher agricultural productivity rate or water-efficiency rate) to a simple specification of a few discrete crop management responses. A second difficulty relates to the issue of uncertainty about future climate outcomes. In IAMs uncertainty has been dealt with by combining several GCM outcomes and a range of socio-economic pathways agreed to under the IPCC framework. More recently, climate modellers have formed research networks to coordinate model scenarios and minimize model-based uncertainty (e.g. AgMip, MACSUR).

Improving economic analysis of adaptation require several model improvements. First, there is the need to improve better representation and integration of biophysical processes into economic models. This require economists to increasingly work with researchers from other disciplines, recognizing that climate change impacts and their analysis is a multi-dimensional problem. Also 
required is the ability to model extreme events and variable climate conditions, as opposed to the usual treatment of gradual climate change, which is much harder to detect but for which most IAMs are designed. Economic models also need to systematically quantify uncertainties related to the economic models' structure and parameters and framing economic conclusions in the context of known model limitations. Expressing the mode results in probabilistic terms will help decisionmakers to understand the risks of under- or overinvesting in adaptation to high- or low-probability climate change outcomes.

Increasingly trade is a subject of analysis within the economic modelling of climate change. However, the empirical evidence is incomplete and fraught with the usual caveats related to uncertainty vis-à-vis future climate outcomes and developments in climate and trade policy. More robust trade analyses in the context of climate change should integrate, climate direct impacts on agricultural productivity, demand-side drivers (consumer diets, labelling, subsidies), resource constraints (such as climate-induced irrigation water shortages), as well as climate policies (carbon-taxes, standards, eco-labelling).

As adaptation decisions are inherently local, many economic models at the farm/household level have tackled climate variability. However, better integrated frameworks are required, especially those that integrate biophysical and spatial techniques (GIS, AEZ-based) with socioinstitutional analyses (multi-criteria analysis, ABMs) to better appraise vulnerability, adaptive capacity and adaptation required (autonomous and planned). Better data collection for CBA is needed, including improvements in accounting for resource depletion, environmental change as well as distributional issues. Moreover, household models need to do better job incorporating climate risk and intra-seasonal climate variability, and develop the capacity to estimate adaptation options outside the current farmers' choice, set in line with the size of the climate shocks and increased variability expected under climate change in order to develop better estimates for local adjustment costs and develop robust climate policies.

\section{References}

Agrawala, S. \& S. Fankhauser (eds.). 2008. Economic aspects of adaptation to climate change. Costs, Benefits and Policy Instruments, Paris, OECD9264046038/978-9264046030.

Ahmed, A., N. Diffenbaugh, T. Hertel \& W. Martin. 2011b. "Agriculture and trade opportunities for Tanzania: Past volatility and future climate change." Working Paper No. 2011/91. United Nations University World Institute for Development Economics Research. Helsinki, Finland.

Ahmed, A., N. Diffenbaugh, T. Hertel, D. Lobell, N. Ramankutty, A. Rios \& P. Rowhani. 2011 a. "Climate volatility and poverty vulnerability in Tanzania," Global Environmental Change 21: 46-55.

Ainsworth, E., A., Andrew, B. Leakey, D. Ort, \& S. Ling. 2008. "FACE-ing the facts: inconsistencies and interdependence among field, chamber and modeling studies of elevated CO2 impacts on crop yield and food supply," New Phytologist 179: 5-9.

Akponikpè, P., G. Michels \& K. Bielders. 2010. Use of the APSIM model in long term simulation to support decision making. Eur. J. Agron. 32,144154.

Alcamo, J., P. Döll, T. Henrichs, F. Kaspar, T. Rösch \& S. Siebert. 2003. Development and testing of the WaterGAP 2 global model of water use and availability. Hydrol. Sci. J.48 (3), 317-337.

Al-Riffai, P., B. Dimaranan \& D. Laborde. 2010. Global Trade and Environmental Impact Study of the EU Biofuels Mandate, Final Report for the Directorate General for Trade of the European Commission, International Food Policy Research Institute. 
Antle, J. \& S. Capalbo. 2010. Adaptation of agricultural and food systems to climate change: an economic and policy perspective. Appl. Econ. Perspect. Policy 32 (3), 386-416 (doi:http://aepp. oxfordjournals.org).

Arndt, C., K. Strzepek, F. Tarp, J. Thurlow, C. Fant \& L. Wright. 2010. "Adapting to climate change: an integrated biophysical and economic assessment for Mozambique." Working Paper No. 2010/101. UN World Institute for Development Economics Research, Helsinki, Finland.

Asfaw, S., N. McCarthy, L. Lipper, A. Arslan, A. Cattaneo \& M. Kachulu. 2014. Climate variability, adaptation strategiesand food security in Malawi. ESA Working Paper No. 14-08. Rome, FAO.

Bader, D., C. Covey, W. Gutowski, I. Held, K. Kunkel, R. Miller, R. Tokmakian \& M. Zhang. 2008. Climate Models - An Assessment of Strengths and Limitations. A Report by the U.S. Climate Change Science Program and the Subcommittee on Global Change Research. Office of Biological and Environmental Research, U.S. Department of Energy, Washington, D.C.

Banse, M., H. vanMeijl, A. Tabeau, G. Woltjer, F. Hellmann \& P. Verburg. 2011. Impact of EU biofuel policies on world agricultural production and land use. Biomass and Bioenergy, 35(6), 2385-2390.

Barker, T. 2008. The economics of avoiding dangerous climate change. An editorial essay on The Stern Review Climatic Change (2008) 89:173-194

Bates, B., K. Zbigniew, S. Wu, \& J. Palutikof. 2008. Climate change and water. IPCC Technical Paper VI, IPCC/WMO/UNEP. June 2008.

Bell, A., T. Zhu, H. Xie \& C Ringler. 2014. Climate-water interactions-Challenges for improved representation in integrated assessment models, Energy Economics xxx(2014):xxx-xxx. (available on line: http://dx.doi.org/10.1016/j. eneco.2013.12.016
Benestad, R. 2010. Downscaling precipitation extremes Correction of analog models through PDF predictions. Theor App/ Climatol (2010) 100:1-21

Berger, T. \& C. Troost. 2014. Agent-based modelling of climate adaptation and mitigation options in agriculture. Journal of Agricultural Economics, Vol. 65, No. 2, 2014, 323-348.

Berger, T., P. Schreinemachers \& J. Woelcke. 2006. "Multi-agent simulation for development of less-favored areas", Agricultural Systems, Vol. 88, pp. 28-43.

Berrittella, M., K. Rehdanz, R. Tol \& J. Zhang. 2007. The Impact of Trade Liberalisation on Water Use: A Computable General Equilibrium Analysis. Hamburg, Germany.

Betts, R., M. Collins, D. Hemming, C. Jones, J. Lowe \& M. Sanderson. 2011. "When could global warming reach $4^{\circ} \mathrm{C}$ ?" Philosophical Transactions of the Royal Society A 369: 67-84. doi: 10.1098/ rsta.2010.0292.

Block, P., K. Strzepek, M. Rosegrant \& D. Xinshen. 2006. "Impacts of considering climate variability on investment decisions in Ethiopia," EPT Discussion Paper 150. International Food Policy Research Institute, Washington, DC.

Boogaard, H. A. De Wit, J. Roller \& C. Van Diepen. 2011. WOFOST CONTROL CENTRE 1.8; User's guide for the WOFOST CONTROL CENTRE 1.8 and the crop growth simulation model WOFOST

7.1.3. Wageningen University and Research Centre, Wageningen, Netherlands.

Calzadilla A., K. Rehdanz \& R. Tol. 2011. "Trade liberalization and climate change: a computable general equilibrium analysis of the impacts on global agriculture," Water 3, 526-550. doi:10.3390/ w3020526. 
Clark, J., R. Weldon, C. Adams \& F. Wirth. 2010. Risk assessment of a shrimp Aquaculture investment in Florida. Aquacult. Econ. Manage. 14, 332-357.

Collier, B., J. Skees \& B. Barnett. 2009.

Weather Index Insurance and Climate Change: Opportunities and Challenges in Lower Income Countries. The Geneva Papers on Risk and Insurance Issues and Practice, 34(3), 401-424. doi:10.1057/gpp.2009.11

Collins, M. 2007. "Ensembles and probabilities: a new era in the prediction of climate change," Philosophical Transactions of the Royal Sociey 365: 1957-1970. doi: 10.1098/rsta.2007.2068.

Darwin, R. 2004. Effects of Greenhouse Gas Emissions on World Agriculture, Food Consumption, and Economic Welfare. Climatic Change 66, 191-238.

Darwin, R. \& D. Kennedy. 2000. Economic effects of $\mathrm{CO} 2$ fertilization of crops: transforming changes in yield into changes in supply. Environmental Modeling \& Assessment 5, 157-168.

De Bruin, K., R. Dellink, A. Ruijs, L. Bolwidt, A. Van Buuren, J. Graveland, R. De Groot, P. Kuikman, S. Reinhard, R. Roetter, V. Tassone, A. Verhagen \& E. van lerland. 2009. Adapting to climate change in The Netherlands: an inventory of climate adaptation options and ranking of alternatives. Climatic change, 95 (1): 23-45.

Deryng, D., W. Sacks, C. Barford \& N. Ramankutty. 2011. "Simulating the effects of climate and agricultural management practices on global crop yield," Global Biogeochemical Cycles 25: 18 pages. doi: 1029/2009BG003765.

Deryng, D. 2009. Simulating the Effects of Climate and Land Management Practices on Global Crop Yield. M.Sc. Thesis, McGill University, Montreal, Quebec, Canada.
Diffenbaugh, N. \& M. Scherer. 2011.

"Observational and model evidence of global emergence of permanent, unprecedented heat in the 20th and 21st centuries: a letter," Climate Change 107: 615-624.

Diffenbaugh, N., M. Ashfaq \& M. Scherer. 2011. "Transient regional climate change: analysis of the summer climate response in a high-resolution, century-scale ensemble experiment over the continental United States," Journal of Geophysical Research 116, D24111. doi:10.1029/2011JD016458.

Dinar, A. \& R. Mendelsohn (eds.). 2011. Handbook on climate change and agriculture. Edward Elgar Publishing Limited, UK.

Dinar, A., R. Hassan, R. Mendelsohn \& J. Benhin. 2008. Climate Change and Agriculture in Africa: Impact Assessment and Adaptation Strategies. EarthScan, London.

Döll P. \& S. Siebert. 2002. Global modeling of irrigation water requirements. Water Resources Research, Volume 38, Issue 4, pages 8-1-8-10.

Döll, P., H. Hoffmann-Dobreva, F. Portmanna, S. Siebertb, A. Eickerc, M. Rodelld, G. Strassberge \& B. Scanlone. 2012. Impact of water withdrawals from groundwater and surface water on continental water storage variations. Journal of Geodynamics, Volumes 59-60, September 2012, pages 143156.

Easterbrook, S. 2011. Serendipity Blog. Downloaded on December 12, 1011 from http://www.easterbrook.ca/steve/?p=2618.

Edwards, P. 2011. "History of climate modeling," WIREs Climate Change 2: 128-139. doi: 10.1002/ wcc.95.

Elliott, J., D. Deryng, C. Muller, K. Frieler, M. Konzmann, D. Gerten, M. Glotter, M. Florke, Y. Wada, N. Best, S. Eisner, C. Folberth, B. Fekete, 
I. Foster, S. Gosling, I. Haddeland, N. Khabarov, F. Ludwig, Y. Masaki, S. Olin, C. Rosenzweig, A. Ruane, Y. Satoh, E. Schmid, T. Stacke, Q. Tang \& D. Wisser. 2014. Constraints and potentials of future irrigation water availability on global agricultural production under climate change. Proceedings of the National Academy of Sciences, 111 (9): 3239-3244. doi:10.1073/ pnas.1222474110.

Famiglietti, J., M. Lo, S. Ho, J. Bethune, K. Anderson, T. Syed \& M. Rodell. 2011. Satellites measure recent rates of groundwater depletion in California's Central Valley. Geophys. Res. Lett. 38 (3), GL046442.

Food and Agriculture Organization. 1998. Crop Evapotranspiration: Guidelines for Computing Crop Requirements.

/International Institute of Applied Systems Analysis (IIASA). 2005. Global Agro-ecological Assessment for Agriculture in the Twenty-first Century. CD-ROM. FAO Land and Water Digital Media Series. FAO, Rome.

\section{/_ 2012. Global Agro-ecological}

Zones (GAEZ v3.0) Model Documentation. FAO, Rome.

Felkner, J., K. Tazhibayeva \& R. Townsend. 2009. "Impact of climate change on rice production in Thailand," American Economic Review 99: 205210. doi:10.1257/aer.99.2.205.

Feola, G., A. Lerner, M. Jain, M. Montefrio \& K. Nicholas. 2014. Farmer responses to multiple stresses in the face of global change: Assessing five case studies to enhance adaptation, (retrieved from: http://ifsa.boku.ac.at/cms/fileadmin/ Proceeding2014/WS 33 Feola.pdf)

Flato, G. 2011. "Earth systems models: an overview," WIREs Climate Change 2: 783-800.
Gibson, C., K. Andersson, E. Ostrom \& S. Shivakumar. 2005. The Samaritan's Dilemma: The Political Economy of Development Aid. Oxford University Press.

Gleckler, P., K. Taylor \& C. Doutriaux. 2008. "Performance metrics for climate models," Journal of Geophysical Research 113, D06104. doi:10.1029/2007JD008972.

Grove, B. \& L. Oosthuizen. 2010. Stochastic efficiency analysis of deficit irrigation with standard risk aversion. Agricult. Water Manage. 97,792-800.

Hallegatte, S., A. Shah, C. Brown, R. Lempert \& S. Gill. 2012. Investment decision making under deep uncertainty--application to climate change. World Bank Policy Research Working Paper, 6193, The World Bank.

Handmer, J., Y. Honda, Z. Kundzewicz, N. Arnell, G. Benito, J. Hatfield, I. Mohamed, P. Peduzzi, S. Wu, B. Sherstyukov, K. Takahashi \& Z. Yan. 2012. Changes in impacts of climate extremes: Human systems and ecosystems. In: Managing the Risks of Extreme Events and Disasters to Advance Climate Change Adaptation: IPCC Special Report [Christopher B. Field, Vicente Barros, Thomas F. Stocker, Qin Dahe, et al. (ed.)]. Cambridge University Press, New York, USA, pp. 231-290.

Hansen, J., A. Mishra, K. Rao, M. Indeje \& R. Ngugi. 2009. Potential value of GCM-based seasonal rainfall forecasts for maize management in semi-arid Kenya. Agric. Syst. 101, 80-90.

Helms, G., J. Richardson, M. Cochran \& M. Rister. 1990. A farm level expert simulation system to aid farmers in selecting among crop insurance strategies. Comput. Electron. Agricult. 4, 169-190.

Hertel, T. \& D. Lobell. 2014. Agricultural adaptation to climate change in rich and poor countries: Current modeling practice and potential for 
empirical contributions, Energy Economics 2014 (available on line: http://dx.doi.org/10.1016/j. eneco.2014.04.014)

Hinkel J., \& R. Klein. 2009. "The DINAS-COAST Project: developing a tool for the dynamic and interactive assessment of coastal vulnerability," Global Environmental Change 19:384-395.

Hinkel, J. 2005. "DIVA: an iterative method for building modular integrated models," Advances in Geosciences 4: 45-50.

Hoff, H., M. Falkenmark, D. Gerten, L. Gordon, L. Karlberg \& J. Rockström. 2010. Greening the Global Water System, Journal of Hydrology, 384, 177-186

Howden, S., J. Soussana, F. Tubiello, N. Chhetri, M. Dunlop \& H. Meinke. 2007. "Adapting agriculture to climate change." Proc. Natl. Acad. Sci., 104: 19691-19696.

Hurd, B., M. Callaway, J. Smith, \& P. Kirshen. 2004. Climatic change and U.S. water resources: from modeled watershed impacts to national estimates. J. Am. Water Res. Assoc. 40 (1), 129-148.

IPCC. 2000 - Nakicenovic, N. \& R. Swart (eds.). Summary for Policymakers: Emissions Scenarios. A Special Report of IPCC Working Group III.

2001. "Climate Change 2001: Impacts, Adaptation \& Vulnerability. Contribution of Working Group II to the Third Assessment Report of the Intergovernmental Panel on Climate Change (IPCC)," Cambridge University Press, Cambridge.

2007. In: Solomon, S., D. Qin, M. Manning, Z. Chen, M. Marquis, K. Avery, M> Tignor \& H. Miller (eds.). The Physical Basis. Contribution of Working Group I to the Fourth Assessment Report of the IPCC, Climate Change. Cambridge: Cambridge University Press; Cambridge, UK.
2008. Climate Change and Water: Technical Paper VI. In: Bates, B., Z. Kundzewicz, S. Wu \& J. Palutikof (eds.). Intergovernmental Panel on Climate Change, Geneva, Switzerland, p. 214. 2014. Economics of Adaptation, Chapter 17 of the Workging Group II, AR5. 2014

Van Ittersum, M., P. Leffelaar, H. van Keulen, M. Kropff, L. Bastiaans \& J. Goudriaan. 2003. "On approaches and applications of the Wageningen crop models," European Journal of Agronomy 18: 201-234.

Jones, J., G. Hoogenboom, C. Porter, K. Boote, W. Batchelor, L. Hunt, P. Wilkens, U. Singh, A. Gijsman \& J. Ritchie. 2003. "The DSSAT cropping system model," European Journal of Agronomy 18: 235-265.

Juliá, R. \& F. Duchin. 2007. World trade as the adjustment mechanism of agriculture to climate change. Climatic Change 82, 393-409.

Kanemoto, K., D. Moran, M. Lenzen \& A. Geschke. 2014. International trade undermines national emission reduction targets: New evidence from air pollution. Global Environmental Change, 24:57-59.

Keeney, R., \& H. Raiffa. 1993. Decisions with multiple objectives: Preferences and value tradeoffs. Cambridge University Press.

Keeney, R. \& T. Hertel. 2011. The Indirect Land Use Impacts Impacts of United States Biofuel Policies: The Importance of Acreage, Yield, and Bilateral Trade Responses. Amer. J. Agr. Econ. 91(4) (November 2009): 895-909.

Kjellstron, T., S. Kovats, S. Lloyd, T. Holt \& R. Tol. 2009. "The direct impact of climate change on regional productivity," Archives of Environmental and Occupational Health 64: 217-227.

Knutti, R. 2010. "The end of model democracy?" Climatic Change 102:395-404. doi 10.1007/ s10584-010-9800-2. 
Konrad, K. \& M. Thumy. 2014. The Role of Economic Policy in Climate Change Adaptation, Economic Studies, Vol. 60 (1): 32-61

Kummu, M., D. Gerten, J. Heinke, J. Konzmann \& O. Varis. 2014. Global analysis of climatedriven interannual variability of food production and related water scarcity. Geophysical Research Abstracts, Vol. 16.

Kunreuther, H. \& R. Roth. 1998. Paying the Price: The Status and Role of Insurance Against Natural Disasters in the United States. Joseph Henry Press.

Lal, M. 2011. "Implications of climate change in sustained agricultural productivity in South Asia," Regional Environmental Change 11 (Suppl 1) S:79-S94.

Le Treut, H., S. Somerville, U. Cubasch, Y. Ding, C. Mauritzen, A. Mokssit, T. Peterson. 2007. "Historical overview of climate change science," in S. Solomon, et al., (eds.). Climate Change 2007: The Physical Science Basis Contribution of Working Group I to the Fourth Assessment Report of the Intergovernmental Panel on Climate Change. Cambridge University Press, Cambridge, United Kingdom and New York.

Leung, L., L. Mearns, F. Giorgi \& R. Wilby. 2003. "Regional climate research," Bulletin of the American Meteorological Society 84: 89-95.

Libecap, G. 2011. Institutional path dependence in climate adaptation: Coman's "Some unsettled problems of irrigation." Am. Econ. Rev. 101 (1), 64-80.

Liu, J., T. Hertel, F. Taheripour, T. Zhu \& C. Ringler. 2014. International trade buffers the impact of future irrigation shortfalls, Global Environmental Change 29 (2014) 22-31.

Lobell, D. 2014. Climate change adaptation in crop production: Beware of illusions, Global Food Security 3 (2014): 72-76.
Lobell, D., A. Sibley \& J. Ortiz-Monasterio. 2012. "Extreme heat effects on wheat senescence in India," Nature Climate Change, January 29. doi: 0.1038/NCLIMATE1356.

Lobell, D., M. Burke, C. Tebaldi, M. Mastrandrea, W. Falcon \& R. Naylor. 2008. "Prioritizing climate change adaptation needs for food security in 2030," Science 319: 607-610.

Malanson, G., A. Verdery, S. Walsh, Y. Sawangdee, B. Heumann, P. McDaniel, B. Frizzelle, N. Williams, X. Yao, B. Entwisle \& R. Rindfuss. 2014. "Changing crops in response to climate: Virtual Nang Rong, Thailand in an agent based simulation" Applied Geography 53 (2014), 202-212.

Margulis, S., A. Bucher. 2008. Economics of adaptation to climate change, Methodology Report, World Bank, December.

Martinez-Alier, J., G. Munda \& J. O’Neill. 1998. Weak comparability of values as a foundation for ecological economics. Ecological Economics, 26, 277-286.

Masson, D. \& R. Knutti. 2011. "Climate model genealogy," Geophysical Research Letters 38: L08703.

McCluskey, A. \& H. Qaddumi. 2011. "Water and climate change: A synthesis of the science." Working Paper. United Nations University - World Institute for Development Economic Research, Helsinki, Finland.

McFarlane, N. 2011. Parameterizations: representing key processes in climate models without resolving them. Wiley Interdisciplinary Reviews: Climate Change. Volume 2, Issue 4, 482-497, July/August 2011. Article first published online: 16 MAY 2011 DOI: 10.1002/wcc.122

Medellın-Azuara, J., J. Harou, M. Olivares, K. Madani, K. Lund, R. Howitt, S. Tanaka, S. Jenkins \& T. Zhu (2008). Adaptability and adaptations of 
California's water supply system to dry climate warming. Climatic Change, 87 (Suppl 1):S75-S90.

Meinzen-Dick, R. 2007. Beyond panaceas in water institutions. Proc Natl Acad Sci USA 104:1520015205.

Mendelsohn, R., W. Nordhaus \& D. Shaw. 1994. The impact of global warming on agriculture: $A$ ricardian analysis. The American Economic Review, 84 (4), 753-771.

Mendelsohn, R. 2009. "The impact of climate change on agriculture in developing countries," Journal of Natural Resources Policy Research 1: 5-19. doi:10.1080/19390450802495882.

Miller, K. \& V. Belton. 2013. Water resource management and climate change adaptation: a holistic and multiple criteria perspective, Mitig Adapt Strateg Glob Change (2014) 19:289-308 (available on line: DOI 10.1007/s11027-013-9537-0).

Moss, R., J. Edmonds, K. Hibbard, M. Manning, S. Rose, D. van Vuuren, T. Carter, S. Emori, M. Kainuma, T. Kram, G. Meehl, J. Mitchell, N. Nakicenovic, K. Riahi, S. Smith, R. Stouffer, A. Thomson, J. Weyant \& T. Wilbanks. 2010. "Perspectives: the next generation of scenarios for climate change research and assessment," Nature 463, 747-756.

Moss, S., C. Pahl-Wostl \& T. Downing. 2001. Agent-based integrated assessment modeling: the example of climate change. Integrated Assessment, 217-30.

Nauges, C. \& D. Whittington. 2010. Estimation of water demand in developing countries: an overview. World Bank Res. Obs. 25, 263-294.

Nelson, G., M. Rosegrant, A. Palazzo, I. Gray, C. Ingersoll, R. Robertson, R. Tokgoz,T. Zhu, T. Sulser, R. Ringler, S. Msangi \& L. You 2010. Food Security, Farming, and Climate Change to 2050: Scenarios, Results, Policy Options. International
Food Policy Research Institute, Washington, D.C. doi: 10.2499/9780896291867.

Nelson, G., D. van der Mensbrugghe, H. Ahammad, E. Blanc, K. Calvin, T. Hasegawa, P. Havlik, E. Heyhoe, P. Kyle, H. Lotze-Campen, M. von Lampe, D. Mason d'Croz, H. van Meijl, C. Müller, J. Reilly, R. Robertson, R. Sands, C. Schmitz, A. Tabeau, K. Takahashi, H. Valin and D. Willenbockel. 2014. Agriculture and climate change in global scenarios: why don't the models agree? Agricultural Economics. Volume 45, Issue 1, 85-101.

Nhemachena, C., R. Hassan \& J. Chakwizira. 2014. An analysis of determinants of farmlevel adaptation measures to climate change in Southern Africa. Journal of Agricultural and Development Economics. Vol 6(5): 231-241. May.

Oates, W. 1972. Fiscal Federalism, Harcourt Brace Jovanovich, New York.

Olmstead, S. 2013. Climate change adaptation and water resource management: A review of the literature, Energy Economics 35 (2013): 1-10

2010a. The economics of water quality. Rev. Environ. Econ. Policy 4 (1), 44-62 (Winter).

2010b. The economics of managing scarce water resources. Rev. Environ. Econ. Policy 4 (2), 179-198 (Summer).

Ostrom, E. 2007. A diagnostic approach for going beyond panaceas. Proc Natl Acad Sci USA 104:15181-15187.

Patt, A., \& B. Siebenhuner. 2005. Agent-based modelling and adaptation to climate change. In C. Kemfert and B. Praetorius (eds.), Die okonomoschen Kosten des Klimwandels und der Klimpolitik (pp. 310-320). Berlin: Deutsches Institute fur Wirtschaftsforschumg. 
Patt, A., D. van Vuuren, F. Berkhout, A. Aaheim, A. Hof, M. Isaac \& R. Mechler. 2010. Adaptation in integrated assessment modeling: where do we stand? Clim. Change. 99 (3-4), 383-402. http://dx.doi.org/10.1007/s10584-009-9687-y.

Pfeiffer, L. \& C. Lin. 2010. The effect of irrigation technology on groundwater use. Choices 3rd Quarter, 25(3).

Ramillien, G., J. Famiglietti \& J. Wahr. 2008. Detection of continental hydrology and glaciology signals from GRACE: a review. Surv. Geophys. 29 (4-5), 361-374.

Rao, K. \& U. Hess. 2009. Scaling up with India: The public sector. In: Index insurance and climate risk: Prospects for development and disaster management. [Hellmuth, M., D. Osgood, U. Hess, A. Moorhead \& H. Bhojwani (eds.)]. International Research Institute for Climate and Society (IRI), New York, USA.

Raschky, P., R. Schwarze, M. Schwindt \& F. Zahn. 2013. Uncertainty of Governmental Relief and the Crowding out of Flood Insurance, Environ Resource Econ 54:179-200(doi10.1007/s10640012-9586-y).

Refsgaard, J., K. Arnbjerg-Nielsen, M. Drews, K. Halsnæs, E. Jeppesen, H. Madsen, A. Markandya, J. Olesen, J. Porter \& J. Christensen. 2013. The role of uncertainty in climate change adaptation strategies-A Danish water management example Mitig. Adapt. Strateg. Glob Change, 18(3), 337359.

Rivington, M. \& J. Koo. 2010. Report on the metaanalysis of crop modelling for climate change and food security survey. Climate Change, Agriculture and Food Security (CCAFS). Copenhagen, Denmark.

Rodell, M., I. Velicogna, \& J. Famiglietti. 2009. Satellite-based estimates of groundwater depletion in India. Nature 460 (7258), 999-1002. http://dx.doi.org/10.1038/ nature08238.
Rodriguez, D., P. deVoil, B. Power, H. Cox, S. Crimp \& H. Meinke. 2011. The intrinsic plasticity off arm businesses and their resilience to change. An Australian example. Field Crops Res.

Rosegrant, M., X. Cai \& S. Cline. 2002. World Water and Food for 2025: Dealing with Scarcity. IFPRI, Washington, D.C., p. 338.

Rosegrant, M., C. Ringler, S. Msangi, T. Sulser, T. Zhu \& S. Cline. 2008. International Model for Policy Analysis of Agricultural Commodities and Trade (IMPACT): Model Description. International Food Policy Research Institute, Washington, D.C.

van der Mensbrugghe, D. \& R. Rosen. 2010. 'Climate, Trade and Development', Paper presented at the 13th Global Economic Analysis Conference, Penang, 9-11 June.

Rosenzweig, C., A. Iglesias, X. Yang, P. Epstein \& E. Chivian. 2000. Climate Change and U.S. Agriculture: The Impacts of Warming and Extreme Weather Events on Productivity, Plant Diseases, and Pests. Center for Health and Global Environment, Harvard Medical School, Boston, MA.

Rowhani, P., D. Lobell, M. Linderman \&

N. Ramankutty. 2011. "Climate variability and crop production in Tanzania," Agricultural and Forest Meteorology 151: 449-460.

Roy, J. 2000. The rebound effect: Some empirical evidence from India. Energy Policy, 28(6-7), 433-438.

Rutten, M., M. Van Dijk, W. Van Rooij \& H. Hilderink. 2014. Land Use Dynamics, Climate Change, and Food Security in Vietnam: A Globalto-local Modeling Approach. World Development Vol. 42, 29-46.

Rurinda, J., P. Mapfumo, M. van Wijk, F. Mtambanengwe, M. Rufino, R. Chikowo, \& K. Giller. 2014. Comparative assessment of 
productivity of maize, finger millet and sorghum for household food security in the face of increasing climatic risk. Eur. J. Agron. 55,29-41.

Saleth, R., A. Dinar \& J. Frisbie. 2012. Climate change, drought, and agriculture: the role of effective institutions and infrastructure. In: Handbook on Climate Change and Agriculture [Dinar, A. and R. Mendelsohn (eds.)]. Edward Elgar: Cheltenham, UK.

Saliba, B. \& D. Bush. 1987. Water Markets in Theory and Practice. Westview Press, Boulder, CO.

Sanderson, B., B. O’Neill, J. Kiehl, G.Meehl, R. Knutti \& W. Washington. 2011. "The response of the climate system to very high greenhouse gas emission scenarios," Environmental Research Letters 6: 034005 (11 pp). doi:10.1088/17489326/6/3/034005.

Scheierling, S., J. Loomis \& R. Young. 2006. Irrigation water demand: a meta-analysis of price elasticities. Water Resour. Res. http://dx.doi.org/ 10.1029/2005WR004009.

Schlenker, W., M. Hanemann \& A. Fisher. 2005. Will US agriculture really benefit from global warming? Accounting for irrigation in the hedonic approach. American Economic Review, 95(1), 395-406.

Schlenker, W., W. Hanemann \& A. Fisher. 2006. The impact of global warming on U.S. agriculture: An econometric analysis of optimal growing conditions, Review of Economics and Statistics, 88 (1), 113-125.

Schlenker, W. \& D. Lobell. 2010. "Robust negative impacts of climate change on African agriculture," Environmental Research Letters 5, 014010. doi:10.1088/1748-9326/5/1/014010.

Schlenker, W. \& M. Roberts. 2009. "Nonlinear temperature effects indicate severe damages to U.S. crop yields under climate change,"
Proceedings of the National Academy of Sciences USA 106: 15,594-15,598.

Seo, S. 2014. Evaluation of the Agro-Ecological Zone methods for the study of climate change with micro farming decisions in sub-Saharan Africa. European Journal of Agronomy 52, 157-165

Seo, S. \& R. Mendehlsohn. 2008b. "A Ricardian analysis of the impact of climate change on South American farms," Chilean Journal of Agricultural Research 68: 69-79.

2008a. "An analysis of crop choice: adapting to climate change in Latin American farms," Ecological Economics, 67: 109-116.

Seo, S., R. Mendelsohn, A. Dinar, R. Hassan \& P. Kurukulasuriya. 2009. A Ricardian analysis of the distribution of climate change impacts on agriculture across Agro-Ecological Zones in Africa. Environmental and Resource Economics 43(3), 313-332.

Shindell, D., J. Kuylenstierna, E. Vignati, R. van Dingenen, M. Amann, Z. Klimont, S. Anenberg, N. Muller, G. Janssens-Maenhout, F. Raes, J. Schwartz, G. Faluvegi, L. Pozzoli, K. Kupiainen, L. Höglund-Isaksson, L. Emberson, D. Streets, V. Ramanathan, K. Hicks, N. Oanh, G. Milly, M. Williams, V. Demkine, D. Fowler. 2012. Simultaneously mitigating near-term climate change and improving human health and food security. Science, 335, 183-189, doi:10.1126/ science.1210026.

Sinclair, T. \& N. Seligman. 2000. "Criteria for publishing papers on crop modeling," Field Crops Research 68:165-172.

Sokolov, A., P. Stone, C. Forest, R. Prinn, M. Sarofim, M. Webster, S. Paltsev, C. Schlosser, D. Kicklighter, S. Dutkiewicz, J. Reilly, C. Wang, B. Felzer, J. Melillo \& H. Jacoby. 2009. Probabilistic Forecast for Twenty-First-Century Climate Based 
on Uncertainties in Emissions (Without Policy) and Climate Parameters. J. Climate, 22, 5175-5204. doi: http://dx.doi.org/10.1175/2009JCLI2863.1

Steduto, P., D. Raes, T. Hsiao, E. Fereres, L. Heng, G. Izzi \& J. Hoogeveen. 2008. "AquaCrop: a new model for crop prediction under water deficit conditions," Options Méditerranéennes, Series A, 8:285-292.

Stern, N. 2006. Stern review: the economics of climate change. London, UK: HM Treasury.

Strassberg, G., B. Scanlon \& D. Chambers. 2009. Evaluation of groundwater storage monitoring with the GRACE satellite: case study of the High Plains aquifer, central United States. Water Resour. Res. http://dx.doi.org/10.1029/2008WR006892.

Strzepek, K. \& A. McClusky. 2010. "Modeling the impact of climate change on global hydrology and water availability." Economics of Adaptation to Climate Change, Discussion Paper No. 8. World Bank, Washington, D.C.

Tao, F., Y. Hayashi, Z. Zhang, T. Sakamoto \& M. Yokozawa. 2008. "Global warming, rice production, and water use in China: developing a probabilistic assessment," Agricultural and Forest Meteorology 148: 94-110.

Tao, F., Z. Zhang, J. Liu \& M. Yokozawa. 2009b. "Modeling the impacts of weather and climate variability on crop productivity over a large area: a new super-ensemble based probability projection," Agricultural and Forest Meteorology 149:1266-1278.

Tao, F., M. Yokozawa \& Z. Zhang. 2009a. "Modeling the impacts of weather and climate variability on crop productivity over a large area: a new process based model development, optimization, and uncertainties analysis," Agricultural and Forest Meteorology 149: 831-850.

Tebaldi, C. \& D. Lobell. 2008. "Towards probabilistic projections of climate change impacts on global crop yields," Geophysical Research

Letters 35: L08705. doi:10.1029/2008GL033423.

Thornton, P., P. Hones, P. Ericksen \& A. Challinor. 2011. "Agriculture and food systems in SubSaharan Africa in a 4C+ world," Philosophical Transactions of the Royal Society, 369: 117-136.

Traore, B, M. van Wijk, K. Descheemaeker, M. Corbeels, M. Rufino \& K. Giller. 2014. Climate adaptation options for Sudano-Sahelian cropping systems. Field Crops Res. 156, 63-75.

Troost, C. \& T. Berger. 2014. Dealing with uncertainty in agent-based simulation: Farmlevel modeling of adaptation to climate change in Southern Germany. American Journal of Agricultural Economics. Advanced public access published August 2014: Downloaded from http:// ajae.oxfordjournals.org/ by guest on September 27, 2014.

Tubiello, F. \& G. Fischer. 2007. "Reducing climate change impacts on agriculture: global and regional effects of mitigation, 2000-2080," Technological Forecasting \& Social Change 74:1030-1056.

Tubiello, F., J. Amthor, K. Boote, M. Donatelli, W. Easterling, G. Fischer, R. Gifford, M. Howden, J. Reilly \& C. Rosenzweig. 2007. "Crop response to elevated CO2 and world food supply A comment on "Food for Thought. . ." by Long et al.," Science 312:1918-1921.

UNEP. 2011. A practical framework for planning pro-development climate policy. UNEP report, Scrieciu S, Bristow S, Puig D (lead authors), United Nations Environment Programme, online at http://www.mca4climate.info.

Valenzuela, E. \& K. Anderson. 2011. "Climate Change \& Food Security to 2050: A Global Economy-wide Perspective," contributed paper for the 55th Annual Conference of the Australian Agricultural and Resource Economics Society. 
Van Vuuren, E., M. Kainuma, K. Riahi, A. Thomson, K. Hibbard, G. Hurtt, T. Kram, V. Krey, J. Lamarque, T. Masui, M. Meinshausen, N. Nakicenovic, S. Smith \& S. Rose. 2011. "The representative concentration pathways: an overview," Climatic Change 109:5-31. doi 10.1007/s10584-011-0148-z.

Van Wijk, M., M. Rufino, D. Enahoro, D. Parsons, S. Silvestri, R. Valdivia \& M. Herrero. 2014. Farm household models to analyse food security in a changing climate: A review, Global Food Security 3: $77-84$.

Vaux, H. \& R. Howitt. 1984. Managing water scarcity: an evaluation of interregional transfers. Water Resour. Res. 20, 785-792.

Verma, M., T., Hertel \& N. Diffenbaugh. 2014. Market-oriented ethanol and corn-trade policies can reduce climate-induced US corn price volatility. Environ. Res. Lett. 9 (2014) 064028 (10pp)

Von Lampe, M., D. Willenbockel, H. Ahammad, E. Blanc, Y. Cai, K. Calvin, S. Fujimori, T. Hasegawa, P. Havlik, E. Heyhoe, P. Kyle, H. Lotze-Campen, D. d'Croz, G. Nelson, R. Sands, C. Schmitz, A. Tabeau, H. Valin, D. van der Mensbrugghe \& H. van Meijl. 2014. Why do global long-term scenarios for agriculture differ? An overview of the AgMIP Global Economic Model Intercomparison. Agricultural Economics Volume 45, Issue 1, 3-20.

White, J., G. Hoogenboom, \& L. Hunt. 2005. A structured procedure for assessing how crop models respond to temperature. Agron. J. 97 (2), 426-439.

Wilby, R. \& T. Wigley. 1997. "Downscaling general circulation model output: a review of methods and limitations," Progress in Physical Geography 21, 530-548.

Wreford, A., D. Moran \& N. Adger. 2010. Climate change and agriculture: Impacts, adaptation, and Mitigtion. (Paris, OECD, 2010).
Zhu, T. \& C. Ringler. 2012. Climate change impacts on water availability and use in the Limpopo River Basin. Water 4 (1), 63-84. http://dx.doi.org/10.3390/w4010063. 


\section{chapter 4}

\section{Page}

1. Introduction 108

1.1 Background and objectives $\quad 108$

1.2 Climate change projections for Europe 109

2. Climate change impact assessment methodology for agriculture

2.1 Different approaches to assessment $\quad 113$

2.2 Major shortcomings $\quad 116$

$\begin{array}{lll}2.3 \text { Recent progress } & 118\end{array}$

2.4 Current use of crop simulation for assessing effects of climate and adaptation $\quad 119$

3. Selected impacts for key crops and regions $\quad 121$

3.1 Production trends - past and near future projections 121

3.2 Future shifts in production possibilities (suitability) 123

3.3 Projections of relative crop yield change under future climate scenarios

3.4 Projections of future crop production potential (yields and suitability) 129

3.5 Potential implications for trade and food security 130

4. Discussion of uncertainties 132

5. Recommendations for improving impact assessment 134

$\begin{array}{ll}\text { References } & 135\end{array}$

Citation

Rötter, R. and J. Höhn. 2015. An overview of climate change impact on crop production and its variability in Europe, related uncertainties and research challenges, In: Climate change and food systems: global assessments and implications for food security and trade, Aziz Elbehri (editor). Food Agriculture Organization of the United Nations (FAO), Rome, 2015. 


\section{chapter 4}

\section{An overview of climate change impact on crop production and its variability in Europe, related uncertainties and research challenges}

\section{Reimund Rötter and Jukka Höhn¹}

\section{main chapter messages}

- Biophysical impacts of climate change (CC) on agricultural potential and yields have been assessed by different approaches, each with its limitations, but rarely used in combination.

- Considerable data constraints prevent rapid progress regarding model improvement.

- According to prevailing CC projections, the direction of most projected impacts on crop production potential and yields indicate gains especially for northern Europe, and little change for southern Europe; while many impact projections agree on this, differences in to the magnitude of change are huge.

- For Europe as a whole, crop production potential is expected to increase under CC, when assuming unchanged climatic variability.
- Uncertainties regarding socio-economic and CC scenarios are considerable - and in conjunction with imperfect impact models, this eventually results in a huge uncertainty range for CC impact projections.

1- Risk to global food production is highest when adverse weather conditions occur simultaneously in several important agricultural regions.

- CC impact assessment methodologies need to focus on adaptation; further improvements of integrated approaches are required to better capture the impacts of climate variability and various extremes events.

- Most importantly, methodologies need to become truly integrated (IAM), multi-scale and transdisciplinary to address $\mathrm{CC}$ adaptation and mitigation adequately. 


\section{Introduction}

\subsection{Background and objectives}

his paper deals primarily with the biophysical assessment of climate change (CC) impacts on agricultural potential and crop yields. Bio-economic impact assessment approaches for agriculture (e.g. Nelson et al., 2009; 2014) are dealt with in detail elsewhere (see other chapters in this volume).

This paper focuses on recent assessments of major European food crops and commodities. Most of the studies examined are based on climate projections generated by global and regional climate models which have been downscaled and fed into process-based crop simulation models (e.g. Supit et al., 2012; Angulo et al., 2013; Asseng et al., 2013; Rosenzweig et al., 2013). We also include results from other biophysical impact assessment studies using methods such as statistical crop yield models (e.g. Schlenker and Lobell, 2010) or agroclimatic indicator approaches (Trnka et al., 2011; Rötter et al., 2013a). Regional differences with regard to expected climate changes and their impacts on shifts in crop suitability and yields are highlighted and discussed.

Observed weather data indicate that global warming is causing changes in rainfall patterns and increasing the frequency and severity of extreme events such as heat waves and drought (Trenberth, 2011; Schiermeier, 2011; Coumou and Rahmstorf, 2012; Field et al., 2012; WMO, 2013). Such changes are also projected by climate models for future conditions (Meehl et al., 2007; Rummukainen 2012, 2014; Sloth Madsen et al., 2012). As of yet, there is no clear or wellestablished understanding of the relationship between global warming and enhanced climatic variability (see Rummukainen, 2014). However, increased climatic variability, as well as more frequent extreme weather events - particularly their impacts on crop yields and production (Schlenker and Lobell, 2010; Hatfield et al., 2011) - would increase risks to food production (Rötter et al., 2012a, 2013a; Williams, 2012) and farm income (Wheeler and von Braun, 2013).

Therefore, we pay special attention to the capability and limitations of current biophysical assessment approaches and modelling tools for capturing impacts of variability and extremes of weather on crop yields (Rötter et al., 2011a), and report on recent progress in this respect (e.g. Challinor et al., 2005; Rötter et al., 2011b; Asseng et al., 2011; Tao and Zhang, 2013; Sanchez et al., 2014).

Following a brief overview of how crop simulation models - the most widely used biophysical assessment tools (e.g. White et al., 2011) - are commonly applied in CC impact assessments, we present a range of selected CC impacts for key crops and regions, with a focus on the European Union (EU-27). Beginning with production trends of the past, we move to shifts in future production possibilities and relative crop yield changes under alternative projections of future climate, and conclude this overview for Europe with expected shifts in future crop production potentials and implications for global trade and food security.

The presentation of selected key impacts is followed by a detailed discussion of various uncertainties. These are not restricted to uncertainties related to biophysical models, but also include other sources of uncertainty, such as that originating from climate models, from downscaling or regionalizing climate model outputs and from several of the other "unknowns" regarding technology development and other socio-economic factors (Rötter et al., 2012a; 2013b). We conclude with suggestions for improvement of biophysical assessment methodology and modelling tools (see green box at centre of Figure 1a).

Specific objectives of this chapter are as follows:

1. To present current biophysical assessment methodology and discuss its shortcomings and recent developments;

2. To present recent results from different studies of CC impacts on key crops - for Europe as a whole and for its various subregions; 


\section{figure $1 a-b$}

Main components of climate change impact assessment methodology for agriculture (a) and uncertainty and error propagation along the biophysical model chain (b) [(b) modified from Wilby \& Dessai (2010) and KLIWAS, unpublished)]

a
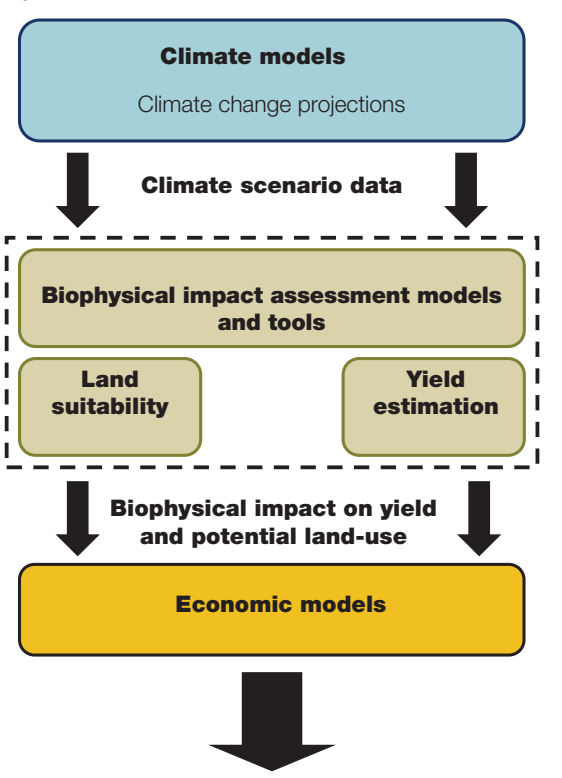

Impact on food production and land-use etc.

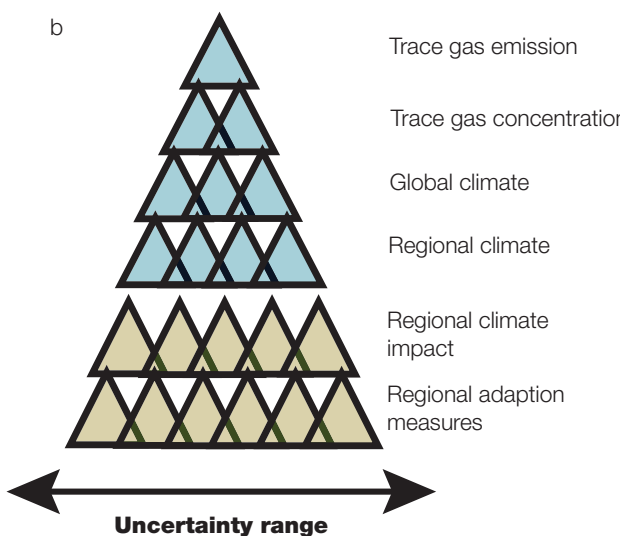

Uncertainty range
3. To discuss potential implications of these impact projections for European key crops in terms of global trade and food security; and

4. To discuss uncertainties, with particular focus on biophysical impact projections, and describe necessary improvements in methodology and projections.

While we will concentrate on the biophysical part of the CC impact assessment methodology (Figure 1a), we also include an overview of stateof-the art climate projections for Europe, including regional variations (Section 1.2). Section 2 presents the different approaches to biophysical assessment of CC impacts, discusses their strengths and weaknesses, and describes recent advancements. Section 3 deals with selected impacts for key crops, in terms of CC effects on land suitability for their cultivation as well as on yield and yield stability. Section 4 deals with uncertainties and provides an overview of the degree and relative importance of the various sources of uncertainty (Figure 1b) inherent to the impact projections at different scales. Finally, Section 5 gives recommendations for future research.

\subsection{Climate change projections for Europe}

\section{Climate change projections and their inherent uncertainties}

Changes in climate are the result of changes in greenhouse gas (GHG) concentrations and other external forcing factors, which are largely dependent on future anthropogenic emissions. The projections of climate models for changes in climatic variables attributable to a given external 
forcing are uncertain for a number of reasons, including the incompleteness of climate models (e.g. certain processes are not taken into account), parameters that are difficult to estimate and, to a considerable degree, unforced natural variability (Rummukainen, 2012; 2014).

Shortcomings and uncertainties with respect to climate modelling have been widely discussed (see Christensen et al., 2007; Boberg et al., 2012; Rummukainen, 2012). General Circulation Models, also called Global Climate Models (GCMs), have been applied to project the responses of the climate (i.e. changes in temperature, precipitation and other climatic variables) to increased GHG emissions in the atmosphere. In order to assess climate model uncertainty, multiclimate model datasets have been collected in huge international efforts such as the Coupled Model Intercomparison Project (CMIP). The fourth Intergovernmental Panel on Climate Change (IPCC) assessment report (AR4), released in 2007, utilized the multiclimate model dataset CMIP3 (Meehl et al., 2007), which included simulations by over 20 GCMs for several emissions or climate forcing scenarios. There are numerous different GCMs, each using different numerical formulations and physical parameterizations of the atmosphere and its phenomena (Rummukainen, 2014). Whether based directly on GCMs or on climate scenario data that have been downscaled statistically (Wilby et al., 2004) or dynamically (through Regional Climate Models, or RCMs) (Rummukainen, 2010), climate projections generally show similar projected temperature or precipitation changes - i.e. positive, negative or not evident. However, the exact magnitude of change varies widely when considering the outcome from ensembles of multiple models. Much of that variation can be attributed to discrepancies in internal variability simulated by the different models; however, the magnitude of change generally increases with higher emissions and over time.

When using the mean of the outcomes of climate model ensemble simulations for impact projections, it is important to keep in mind that, while means reveal the similarities of the various models and their CC projections, outliers (i.e. the worst and best cases) should not be ignored, as they illustrate the (plausible) extreme responses. The best choice for a given impact study, therefore, is not to rely on the ensemble mean plus the single most extreme outliers in both directions. Instead, if feasible, the multimodel mean should be complemented by a number of individual projections that can delineate the model spread in the most relevant output variables for the particular study (Rötter et al., 2013a; Rummukainen, 2014).

The change in global mean temperature observed so far amounts to around $+0.8^{\circ} \mathrm{C}$ since pre-industrial time. Increases in global mean temperature projected for the 2050s by IPCC (2007) as compared with the 2000s are between 0.5 and $3^{\circ} \mathrm{C}$ when considering different emission scenarios, climate models, and assumptions on feedbacks; when considering warming since pre-industrial time, the projected increase is 1 to $3.5^{\circ} \mathrm{C}$. Taking into account that observed GHG emission pathways currently follow the high-end emission scenarios (Peters et al., 2013), and given the 20-40 years lag time in effective climate forcing of present-day emissions, it is very likely that projected changes will exceed the international target of $2^{\circ} \mathrm{C}$ which was agreed upon by the United Nations Framework Convention on Climate Change (UNFCCC) to avoid disastrous impacts. Regarding global precipitation changes, it has been suggested that the precipitation increase will be around 2 percent for each degree of warming (Rummukainen, 2014).

However, global climate response to the various forcings is not uniform. While warming will occur overall, some regions will warm more than others, and some may considerably exceed the global mean change.

In the recently released fifth IPCC assessment report (AR5), new sets of scenarios have been

2 Feedback mechanisms of the earth-atmosphere system frequently incorporate very complex processes with much detail that cannot be exactly described by or incorporated in climate change models and require simplification. Hence, climate change models employ (different) assumptions depending on how they simplify/represent certain processes. 
defined, including Representative Concentration Pathways (RCPs) ${ }^{3}$. This has resulted in a new $\mathrm{CC}$ dataset with a larger range of climate model simulations, called CMIP5 (Taylor et al., 2012; Peters et al., 2013). A one-to-one comparison of the new RCPs with the former Special Report on Emissions Scenarios (SRES) family of emission scenarios is not possible; however, there are generally large similarities between the climate sensitivities of SRES and RCPs. For example, temperature changes and spatial distribution patterns under SRES A2 are quite similar to those under RCP8.5 (Knutti and Sedlacek, 2013).

\section{Regional changes within Europe}

Based on simulation from CMIP5 for RCP4.5, Rummukainen (2014) describes how projected changes during the twenty-first century in annual mean temperature and precipitation at the global level vary considerably by region. For Europe, regional variations in temperature change vary by factors ranging from 1 (implying change equal to global change) in the northwestern parts of Europe, to 2.5 in the northeastern parts. For precipitation, the factors of change relative to the global mean ranged from no change (in southern parts) to 1.5 (in the northeastern parts). In terms of precipitation change, this confirms a rule of thumb for CC projections, which suggests that "wet gets wetter" and "dry gets drier" (Rummukainen, 2014).

According to Deser et al. (2012), in many parts of the world regional-scale changes in climate are not only formed by global drivers, but also strongly affected by modifications of regional circulation patterns (Lamb, 1995). As for climate model predictions on changes in circulation patterns

3 Representative Concentration Pathways (RCPs) are four greenhouse gas concentration trajectories adopted by the IPCC for its fifth Assessment Report (AR5) (Moss et al., 2008). The pathways describe four possible climate futures represnting a broad range of possible levels of greenhouse gases expected to be emitted in the years to come. The four RCPs, RCP2.6, RCP4.5, RCP6, and RCP8.5 are named after a possible range of radiative forcing values in the year 2100 relative to pre-industrial values $(+2.6,+4.5,+6.0$, and +8.5 Watts $/ \mathrm{m} 2$, respectively) (Weyant et al., 2014). and associated climatic variability, for some time it has been suggested by many GCM studies that there will not be major shifts in variability (IPCC, 2007). Large-scale variability patterns that strongly influence weather conditions and represent the internal variability of the climate system in Europe include, for instance, the North Atlantic Oscillation and the Arctic Oscillation (Rummukainen, 2014). While most projections have suggested that these circulation patterns will remain in place, recently it has been postulated that the retreat of Arctic sea ice (poorly predicted by most climate models) could influence atmospheric circulation such that it would tend towards more "meridionality" or meridional patterns (Lamb, 1995) ${ }^{4}$. This would particularly affect the mid-latitudes of the northern hemisphere, producing more extreme winters characterized by prolonged cold spells and summers characterized by more extended droughts, flooding and heat waves (Francis and Vavrus, 2012).

Analysis of results from the CMIP3 climate model ensemble on temperature-related extreme events indicates that, generally, daily minimum (Tmin) and maximum (Tmax) temperature changes are in line with average temperatures (Tmean). However, there are also distinct deviations, such as Tmin experiencing the largest change (i.e. more warming) in the winter of the Boreal climatic zone, meaning that the colder end of the distribution warms up more than the warmer end. Similarly, Tmax shows the largest change during the summer months in the continental and Mediterranean climatic zones of Europe (Orlowsky and Seneviratne, 2012).

The scatter plots presented in Figure 2 illustrate changes in temperature and precipitation for different seasons (i.e. winter, Dec.-Feb. and

4 There is a meridian atmospheric circulation dominated by the Hadley circulation of the tropical atmosphere with mean upwelling near the equator, poleward flow aloft, subsidence in the subtropics and equatorward return flow near the surface. This circulation transports heat poleward within the tropics but becomes much weaker in middle latitudes and does little heat transport there (Marshall and Plumb, 2007). 


\section{figure 2}

Changes in winter (December-February) and summer (June-August) temperature and precipitation in northern Europe (10W-40E, 48-75N; top panels), southern Europe (10W-40E, 30-48N; middle panels) and northern hemisphere land areas (bottom panels) for the period 2030-2049 relative to 1961-1990 from three datasets of climate model projections: the "Grand ensemble" probabilistic projection for the A1B scenario

(Harris et al., 2010), ENSEMBLES RCMs and their driving GCM simulations (Deque et al., 2011) and GCM simulations used by the IPCC from the CMIP3 dataset (Meehl et al., 2007).

(Reprinted with permission from Taylor \& Francis; source: Rötter et al., 2012a)
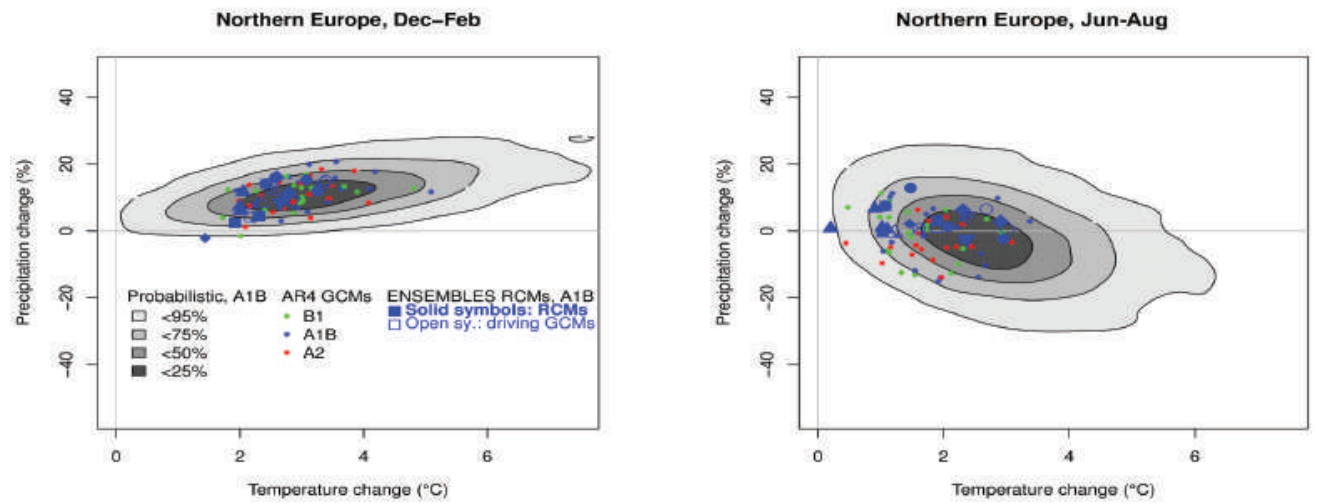

Southern Europe, Dec-Feb
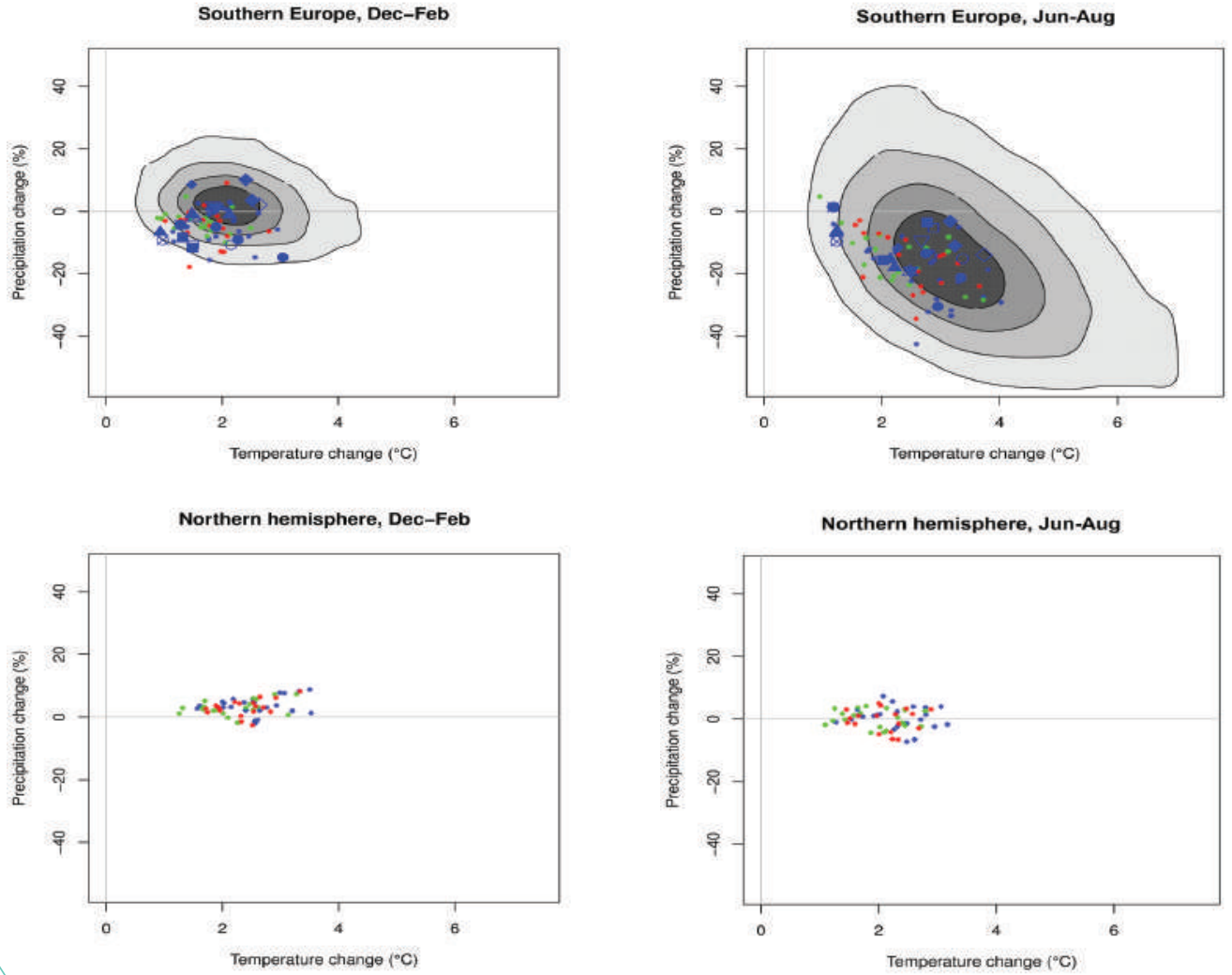
summer, Jun.-Aug.). Those for northern and southern Europe are based on the ENSEMBLES project (Harris et al. 2010) hemisphere are based on individual GCM runs from the CMIP3 dataset (Meehl et al., 2007).

Output from 11 different RCMs has recently been presented by Sloth Madsen et al. (2012). Although they show similarities in terms of the strongest temperature and precipitation changes for broad regions in Europe, the specific spatial patterns of change can still be quite different in certain subregions. This also applies, though to a much lesser extent, if the same "parent" GCM has been the common source for different RCMs (Sloth Madsen et al., 2012).

As presented by Sloth Madsen et al. (2012) for the European continent, CC projections for the period 2030-2050 vary widely, depending on the emissions scenarios and GCMs or RCMs considered. The general tendency, however, consistent with many studies, is to project that conditions will become wetter and warming will be stronger in northern Europe than in southern Europe or the northern hemisphere. This general picture is confirmed by probabilistic projections made for the SRES A1B scenario, based on ENSEMBLES RCMs, as well as by GCM runs based on CMIP3 (Figure 2). Even though thermal growing seasons will be extended, projected increases in the frequency of heavy rains, heat waves and drought (Christensen et al., 2007) may lead to higher variability in crop performance (Trnka et al., 2011; Trnka et al., 2014).

5 The ENSEMBLES project is 5-year funded project by the European Commission, which aims to provide probabilistic estimates of climatic risk through grouped ("ensemble") integrations of Earth system models in which the uncertainties noted here are explicitly incorporated.

\section{Climate change impact assessment methodology for agriculture}

\subsection{Different approaches to assessment}

Current projections of CC impacts on crop yields and food production are almost entirely based on outcomes from process-based crop simulation models (Parry et al., 2004; Challinor et al., 2009; White et al., 2011; Müller and Robertson, 2014). However, for early impact assessments (e.g. Goudriaan et al., 1990), agroclimatic indices, such as "effective temperature sum" were applied to analyse the broad-scale sensitivity of agriculture to $\mathrm{CC}$ and to determine shifts in agroclimatic suitability for given crops under different CC scenarios; among other crops, this was shown for maize and wheat in Europe (Carter et al., 1991). Over time a suite of biophysical impact assessment methods and models has been developed for analysing $\mathrm{CC}$ effects on land suitability and productivity of agricultural crops (Nix, 1985; Rötter et al., 1995; Harrison and Butterfield, 1996; Schlenker and Roberts, 2009; Lobell and Burke, 2010; Lobell et al., 2011; Trnka et al., 2011, 2014; Challinor, 2011; Rötter et al., 2013a).

Here we describe three basic approaches, as well as combinations among these, or with other techniques and classification schemes:

a. Agroclimatic indices

b. Statistical crop weather models

c. Crop simulation models

a. Application of the agroclimatic index approach, in combination with environmental zoning for Europe, has been presented by Trnka et al. (2011), using 11 indices (selected from a large set of potential indices) to characterize climatic suitability and risks to the production of major crops, and their shifts under different CC scenarios. In this analysis, performed for 86 stations distributed over Europe, Trnka et al. 
found that, for high-end CC scenarios (higher values for radiative forcings), agroclimatic conditions deteriorate in many zones, in terms of increased drought stress and shortening of the active growing season. The projections showed a marked need for adaptive measures in most zones, particularly for increasing soil water availability or drought resistance of crops. Rainfed agriculture was found likely to be affected by more climate-related risks and the number of extremely unfavourable years in many climate zones was projected to increase; this would result in higher interannual yield variability, constituting a considerable challenge for adaptation of crops and cropping systems. Recent applications of the agroclimatic index approach at national level have been reported by Hakala et al. (2012), Lalic et al. (2013) and Rötter et al. (2013a). The latter authors used the approach to identify areas most prone to CC risks (i.e. heat and drought), and subsequently applied crop simulation modelling to evaluate alternative adaptation options in these areas. Trnka et al. (2014) recently detailed an approach for wheat cultivation in Europe under CC, explicitly considering multiple climate-related stress occurrences.

b. Crop-climate or crop-weather models based on empirical statistical approaches, most often on multiple regression analysis, have a long tradition (Nix, 1985). With seed yield or biomass yield as the dependent variable, models often contain a number of independent variables that represent temperature or rainfall characteristics over a certain time span during the crop growth cycle, or a variety of indices derived from weather data and interpreted in agricultural terms. Statistical crop models have been applied to detect the influence of climate of the recent past on crop production trends (e.g. Lobell et al., 2011) and they are increasingly applied to predict crop yield responses to CC, although usually restricted to time horizons that do not reach too far into the future (Schlenker and Roberts, 2009;
Lobell and Burke, 2010; Lobell and Gourdji, 2012). An advantage of statistical crop yield models is that they take into account the effect of all kinds of yield-limiting factors (e.g. heat and water stress) and yield-reducing factors (such as weeds, pests and diseases, ozone levels, etc.). However, a disadvantage is that these yield-influencing factors usually cannot be separated from each other and are lumped together, which makes them less suitable for evaluating alternative adaptation options. For this reason, they are useful primarily for assessing CC impacts under actual farmers' conditions that are characterized by suboptimum management.

c. Process-based crop simulation models are currently the most widely used tools for predicting crop productivity under $\mathrm{CC}$, and they are applied from field to global scale (Angulo et al., 2013; Nelson et al., 2013; Rosenzweig et al., 2013; Müller and Robertson, 2014). Their advantage over statistical models is the ability to explicitly take into account interactions of genotype by environment by management (GxExM) and to quantify the relative effects of individual factors on crop development, growth and final yield. A range of crop simulation models of various levels of complexity exists; however, even the relatively simple, most widely used crop simulation models (sometimes called summary models) suffer from high data demand in terms of calibration and validation, which restricts their meaningful application to a limited number of crops and regions. Lack of data for model testing also makes it impossible to make use of the results from a large number of output variables; often only a few outputs can be utilized with confidence.

Particular capabilities and limitations of crop simulation models with respect to assessing $\mathrm{CC}$ effects on crop yields, including their role in integrated assessment methodology, are briefly presented here. The major shortcomings of the 
various approaches of current biophysical impact assessment methodology in relation to information demands are presented in Section 2.2.

Process-based crop growth simulation models were developed in the 1960s (de Wit, 1965). They differ in complexity - i.e. level of detail in which biophysical processes (e.g. phenology, photosynthesis, respiration, transpiration and soil evaporation) are simulated - and in which yield constraints are explicitly taken into account - i.e. just crop characteristics, temperature and solar radiation (as needed for simulations of potential production) or including water and nutrient-limited productivities as well (van Ittersum and Rabbinge, 1997).

The more complex cropping system models are able to integrate processes of carbon and nitrogen and detailed water balance components (evapotranspiration, soil moisture, deep percolation, etc.) from planting to maturity, and can provide estimates of final yield and biomass production as well as daily values of crop and soil components during the crop growth cycle (van Ittersum et al., 2003). Only a few models also cover dynamics of phosphorus and estimates of GHG fluxes. Also quite rare are models that cover crop-weed interactions, damage by pests and pathogens (Savary et al., 2006).

In fact, there is no fully deterministic crop simulation model widely used for practical applications such as CC impact assessment at field/farm or higher aggregation levels. The less detailed the process model and - usually - the larger the spatial extent it is targeting, the more empirical relationships are incorporated. If a complex process like photosynthesis by crop canopies is simplified and reduced to such an extent that only a few parameters are sufficient in a crop model to mimick the influence of temperature and irradiation on gross assimilation in a crop model, the model itself becomes less generic and usually requires local or region-specific data for statistically deriving robust values for those key (such as radiation use efficiency, RUE); likewise, the larger the spatial extent (pixel size) of the basic calculation units used in either the crop models or climate models, the more certain detailed data (be it soil data or climatic variables) need to be aggregated or generalized - and the more data gaps usually occur that make it then impossible to retain detailed process descriptions - but rather resort to simplifications that again result in replacement of physically based process descriptions by statistically derived empirical relationships. This rule of thumb is not restricted to crop simulation models but also applies to climate models (see Rummukainen, 2010; 2014).

For this reason, we find a wide range of crop models that are semi-empirical - i.e. they combine deterministic elements based on biophysical, chemical and ecophysiological principles with a number of empirical parameterizations (e.g. setting a fixed fraction for run-off instead of simulating its underlying processes, such as infiltration, soil water flows, etc. in detail). Simplifying and parameterizing processes in this way requires crop- or regionspecific calibration and validation.

Given the capabilities and specific limitations of each individual biophysical impact assessment approach - agroclimatic index, statistical model or crop simulation model - it has been suggested that a combination of these different approaches would be fruitful (Challinor, 2011). However, to date, application of such a combination approach is still rare (e.g. Rötter et al., 2013a).

In this paper, we briefly characterize current biophysical models and assessment tools that are part of state-of-the-art integrated CC impact assessment methodology for agriculture (e.g. Nelson et al., 2014; Figure 3). As mentioned previously, despite their limitations, crop simulation models are the tools most widely used at present as part of integrated CC impact assessments at different scales. Figure 3 illustrates the state-ofthe-art methodology applied in a recent global study on CC effects on agriculture (Nelson et al., 2014) by means of a modelling chain comprising global-scale climate models, gridded crop models and economic models to estimate changes in crop yield, cultivation area, food consumption and trade. The various implications of using "imperfect crop models" in the integrated assessment methodology are further discussed in the next 


\section{figure 3}

State-of-the-art agricultural impact modelling chain, from climate to crop and economic effects. Abbreviations: Temp, temperature; Prec, precipitation;

Cons, consumption. (Reprinted with permission from the National Academy of Sciences of the United States of America; source: Nelson et al., 2014)
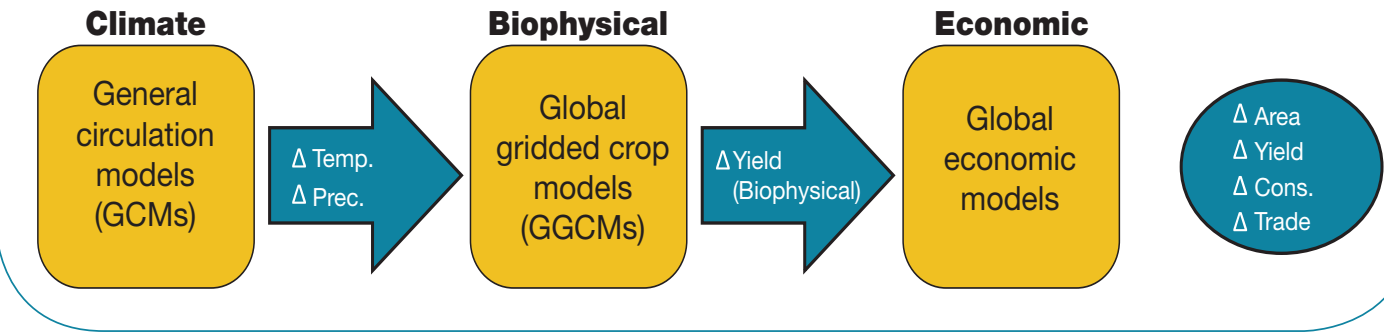

section (Section 2.2) as well as in the discussion of uncertainties (Section 4).

\subsection{Major shortcomings}

Shortcomings in the current methodology and tools for assessing biophysical impacts of CC on agriculture and food security have been identified and described (e.g. Rötter et al., 2011a; 2013b; White et al., 2011; Asseng et al., 2013; Rosenzweig et al., 2013; Wheeler and von Braun, 2013). These shortcomings basically originate from two facts: i) existing biophysical models were not developed for the unprecedented rate and magnitude of currently projected CC and thus are likely not to represent the expected novel interrelations with agro-ecosystem processes; and ii) there is increasing demand for specific requirements by integrated assessment tools. The latter can be illustrated by the challenge in Europe to sustainably intensify agricultural production under CC (Soussana et al., 2012), as formulated by the Modelling European Agriculture with Climate Change for Food Security (MACSUR) project. "Key questions to be addressed are how to increase agricultural production and Europe's share in global food supply security while concurrently reducing greenhouse gas (GHG) emissions from agriculture" (Rötter et al., 2013b, p.556); in other words, "what land and water resources, efficiency gains, technologies, investments and institutional settings are required" to substantially increase Europe's agricultural production by 2050 without increasing GHG emissions.

This implies that present-day Integrated Assessment Modelling (IAM) for agriculture under CC, whether at farm, regional or supranational scale, will demand that many biophysical output variables be considered simultaneously. To estimate the consequences of CC and management practices, apart from crop yields, models need to provide data on effects of the production process on environmental indicators such as nitrogen leaching, GHG emissions and water use (e.g. Eckersten et al., 2001; Rötter et al., 2013b; Müller and Robertson, 2014). Figure 3 shows only a rough schematic of integrated assessment, to which several environmental and socio-economic dimensions would need to be added.

Furthermore, when considering not only food production trends in the long term, but also the different dimensions of food security - i.e. stability, access and utilization, as well as food supply - at different temporal and spatial scales (Howden et al., 2007; Wheeler and von Braun, 2013), additional critical shortcomings of the biophysical and integrated impact assessment methodology are revealed. These include: 
a. The lack of a comprehensive, well-tested methodology for the assessment of multiple risks to crop production under CC. Given that changes in the means, variability and extremes of climate variables can imply changes in several of the relevant climateinduced risks that affect the growing conditions and yield formation of various food crops simultaneously (see Trnka et al., 2011; 2014), it is necessary to account for not only heat and drought stress (as considered in some crop models) but also shifts in risks imposed by, for example, late frost, heavy rains that produce water-logging, or unfavourable precipitation, leading to yield losses during harvest time (Rötter et al., 2013b). In the MACSUR project, Trnka et al. (2014) began addressing this issue, using agroclimatic indicator approaches in combination with new climate projections from the CMIP5 ensemble.

b. With very few exceptions, most studies on the biophysical impacts of CC on crop production are incomplete. Usually, studies either address CC impacts on relative yield change for some key crops in their current cultivation areas, or analyse shifts in biophysical potential and risks for cultivation of a predefined set of different crops or crop groups, without simultaneously using crop models to estimate yields. In the ideal case, both types of studies should be combined, so that assessment of biophysical potential and relative yield changes is further linked with economic evaluation of a wide range of adaptation measures (not just changes in sowing dates, cultivar choice or irrigation) (see Rickards and Howden, 2012).

c. The fact that most CC impact assessments neglect to capture short-term climate variability has a number of implications for their usefulness to address and quantify CC impacts on the different dimensions of food security, whether food supply stability or access (for further discussion, see below, and Section 3.5). Probably the most critical shortcoming is emphasizing the influence of emission scenario uncertainty, climate model uncertainty or impact model uncertainty on the outcome of final impact projections while failing to account for the effects of short-term variability on food production and food security. It is well-established that a reliable and affordable supply of food is central to human well-being and the stability of societies (von Braun, 2008). However, CC is likely to reduce regional and global food security and the stability of agrifood systems because of increased short-term variability in supply (Lobell and Gourdji, 2012; Wheeler and von Braun, 2013). The situation becomes especially critical if food supply shortages occur simultaneously in several important agricultural regions, as has sometimes been the case in recent years - e.g. 2007 and 2010 (Williams, 2012; Willenbockel, 2012; Lobell and Gourdij, 2012; lizumi et al., 2013).

However, methodologies for assessing CC impacts on global and regional food supply have paid surprisingly little attention so far to capturing short-term variability occurring simultaneously at different locations (Williams, 2012). In addition, crop simulation models and other assessment tools have not been sufficiently suited to reliably capture climate variability and extremes and their impact on food production at regional and global scales (Wheeler et al., 2000; Rötter et al., 2011a; Lobell and Gourdij, 2012; Lobell et al., 2013; Wheeler and von Braun, 2013). Such information is required to effectively guide formulation of trade and climate policies and inform decisionmaking on adaptation strategies at different levels of organization and different spatial scales (farm household, district, country, etc.). This research gap will require specific attention in the near future.

Figure 4 illustrates the development of impact projection results over time, from 1990s to present, using a few examples. The more recent CC impact projections for wheat and maize in Europe show less spread than earlier projections; this is probably largely the result of more consistent methodology, including choice of emissions and climate scenarios and better standards in impact model applications. 


\section{figure 4}

Development of reported wheat and maize yields over time based on studies published in the 1990s (A) (based on four studies)*, 2000s (B) (based on six studies)*

and 2010s (C) (based on four studies) ${ }^{\star}$, expressed as (a) percentage difference from reference yield levels and

(b) absolute yields for selected regions. Note that the reported yields for central Europe (Austria, Czech Republic,

Hungary) are related to impacts of changed climatic variables only, whereas for northwest Europe

(United Kingdom, northwest France, BeNeLux) and southern Europe (Spain, Italy, Greece) both climate change

and $\mathrm{CO}_{2}$ effects were considered. Box boundaries indicate the 25th and 75th percentiles; the line within

the box marks the median; whiskers below and above the box extend to 1.5 times the height of the box.

Points are outliers that do not fall within the whiskers and asterisks are extreme outliers having values more than three times the height of the boxes
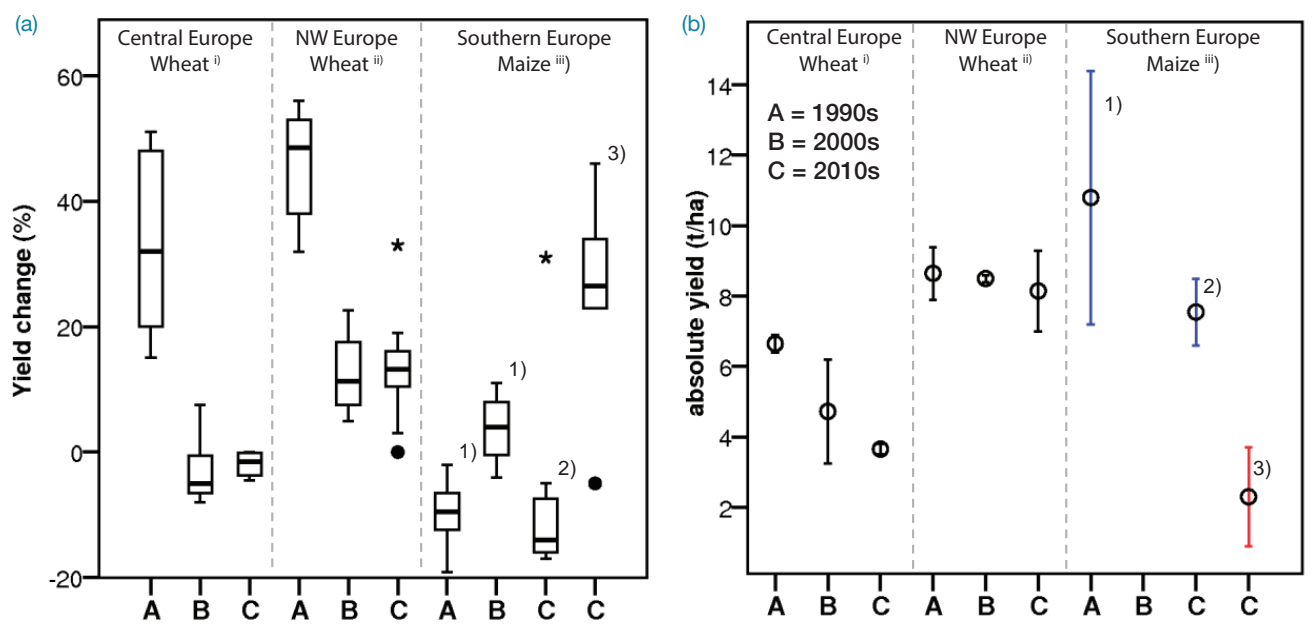

i) Basci et al. (1991), Alexandrov et al. (2002), Eltzinger et al. (2003), Hermans et al. (2010)

ii) Favis-Mortlock et al. (1991), Ghaffari et al. (2002), Gibbons \& Ramsden (2008), Semenov (2009), Hermans et al. (2010), Wu et al. (2011), Supit et al. (2012).

iii) Iglesias \& Minguez (1997), Kapetanaki \& Rosenzweig (1997), Gianna-kopoulos et al. (2009), Supit et al. (2012), Bocchiola et al. (2013).

1) Irrigated maize yields

2) Potential maize yields

* References to these studies are given as Figure Legends i-iii.
3) Rainfed maize yields

\subsection{Recent progress}

Over the last 20 years, considerable progress has been made in using field experiments on crop models to test a wider range of crops and growing conditions as the foundation for $\mathrm{CC}$ assessments. This progress is indicated by numerous publications on the topic; the intensity of publication has increased exponentially during the last five to seven years. An important advance in CC assessments over the last two decades has been the inclusion of elevated atmospheric carbon dioxide $\left(\mathrm{CO}_{2}\right)$ routines in crop models and testing these with open-top and free air $\mathrm{CO}_{2}$ enrichment (FACE) experimental data. While there is still some debate regarding whether the effect of elevated $\mathrm{CO}_{2}$ on cereal growth is overestimated, there are several studies showing that simulations are in line with FACE experiments. Additional advances in CC assessments include: modelling of a wider range of crops (e.g. grapevines); including nutrients other than nitrogen in simulation models (e.g. phosphorus uptake and response); considering the sensitivity of crop growth and transpiration to soil salinity; and simulating ozone effects, waterlogging and heat stress (Asseng et al., 2011, 
Lobell et al., 2013, Teixeira et al., 2013). Another major development has been more work on crop modelling for large areas, in particular making fairly detailed crop models operational for use at regional (Tao et al., 2009) and global scales (e.g. Bondeau, 2007).

However, substantial progress will still be needed in data gathering, improvement of crop models and other impact assessment techniques in order to meet the demands for integrated assessments at different scales. In both the Agricultural Model Intercomparison and Improvement Project (AgMIP) and MACSUR projects, efforts are underway in this direction.

\subsection{Current use of crop simulation for assessing effects of climate and adaptation}

Many factors will shape future crop productivity, including changes in climate and atmospheric concentration of $\mathrm{CO}_{2}$ and other gases such as ozone, as well as improvements in agronomic management and technology (adaptation).

However, in most biophysical impact assessment studies of CC on crop production, only a few factors influencing crop yields are addressed. These are: changes in climatic variables (most notably temperature and precipitation); $\mathrm{CO}_{2}$ concentration; and, to a lesser extent, technical development or adaptation options (White et al., 2011).

Before discussing the ways these factors are usually treated in simulation model-based impact assessment studies, we offer here a brief account of how knowledge of modelled processes regarding some critical factors and their interactions has developed.

Experimental progress has enabled researchers to incorporate and evaluate atmospheric $\mathrm{CO}_{2}$ concentration impact functions within crop models. Combined with temperature and water balance routines, this has enabled crop simulation techniques to be used for CC impact assessments (Asseng et al., 2011; Lobell et al., 2013; Teixeira et al., 2013). Three different approaches have been used to simulate the photosynthesis response to increasing $\mathrm{CO}_{2}$ concentrations (see Kersebaum and Nendel, 2014). Effects on transpiration are seen as an empirical reduction in transpiration with enhanced $\mathrm{CO}_{2}$ or by a reduction in stomatal conductance (Tubiello and Ewert, 2002). Crop models have been widely tested using FACE experiments and with elevated $\mathrm{CO}_{2}$ in open-top chambers (Ewert et al. 1999; Nendel et al., 2009).

All crop models consider temperature effects on various ecophysiological processes, including phenology, light utilization, photosynthesis and respiration, dry matter allocation to different plant organs and evapotranspiration. However, as of yet, very few models consider heat stress effects with maximum temperatures above certain thresholds e.g. accelerated leaf senescence or effects on floret mortality /spikelet fertility of various cereals (see discussion below).

All widely applied crop models include consideration of water balance and the impact of crop water shortage. However, there are distinct differences in how various models treat the simulation of soil water dynamics (van Ittersum et al., 2003). Only a few models consider excess water and oxygen stress impacts on crop growth (e.g. Supit et al., 1994). An increasing number of models include the impact of crop nitrogen stress on crop growth and nitrogen use efficiency (e.g. Kersebaum, 2007).

Most crop model-based CC impact studies deal with several of the factors below, but for a fairly limited number of crops and regions (White et al., 2011).

\section{Temperature}

Temperature increases have multiple effects on crop growth and yield formation depending on the crop growth stage in which they occur. Higher temperatures usually accelerate rates of crop development, resulting in a shortened growing period, and typically - but not always - in lower crop yields (e.g. Nonhebel, 1996; Batts et al., 1997; Hatfield, 2011). Increased temperatures can prolong the vegetation period and reduce frost 
risk, particularly in regions where crop cultivation is currently limited by low temperatures (Trnka et al., 2011, 2014; Rötter et al., 2013a). On the other hand, higher temperatures during sensitive crop growth stages can cause heat stress, which can have various effects (and, as mentioned above, is still only incorporated in a few crop simulation models). For example, temperature thresholds of $32-36{ }^{\circ} \mathrm{C}$ for a few hours around flowering (threshold depending on crop/crop cultivar) may strongly affect floret mortality/spikelet fertility, resulting in yield damages and losses, dependent on the frequency and intensity of the stress - as has been reported for wheat, groundnut, sunflower, maize and rice (Porter and Gawith, 1999;

Challinor et al., 2005, Moriondo et al., 2011b; Teixeira et al., 2012; Sanchez et al., 2014; Matsui, 1997; Wheeler et al., 2000). In the case of cereals like wheat it has been found that heat stress with maximum temperatures above certain thresholds - e.g. above $34^{\circ} \mathrm{C}$ - accelerates leaf senescence and hence hastens maturity even more than the mean temperature effect on phenology alone (Asseng et al., 2011). Elevated temperatures also increase the vapour pressure deficit between air and leaf, which leads to increased transpiration rates and causes a decline in water-use efficiency (Ray et al., 2002). Furthermore, crops respond to very high vapour pressure deficit by closing their stomates, with the effect that net photosynthesis is reduced. Finally, warmer temperatures can stimulate or negatively affect photosynthesis, depending on the crop-specific temperature optimum and current temperature regime (Porter and Semenov, 2005; Sanchez et al., 2014).

\section{Precipitation}

Changes in precipitation can be either positive or negative, depending on the current weather regime and the extent and direction of the change. Increased precipitation can reduce drought-related production risks in areas that suffer from water stress under current conditions. On the other hand, too much rainfall can degrade soil conditions by reducing the soil oxygen content. Moreover, the projected increase of precipitation, such as during winter and spring in northern latitudes, is expected to substantially increase nitrogen leaching, surface runoff and soil erosion from agricultural fields; this has been shown, for example, in the simulations of Eckersten et al. (2001).

\section{$\mathrm{CO}_{2}$ concentration}

Increased atmospheric $\mathrm{CO}_{2}$ concentration affects crop growth and biomass accumulation in two ways. First, it enhances the $\mathrm{CO}_{2}$ fixation rate of C3 crops, with the effect that photosynthesis and therefore biomass accumulation are stimulated. Second, elevated ambient $\mathrm{CO}_{2}$ reduces stomatal conductance in both C3 and C4 crops (see chapter 2 section 2.a for a definition of C3/C4 crop types), which leads to a lower transpiration rate and therefore increased water-use efficiency (Ainsworth and Long, 2005). Due to the $\mathrm{CO}_{2}$ fertilization effect, yields of C3 and C4 crops are expected to increase by $10-20$ percent and 0-10 percent, respectively (Ainsworth et al., 2004; Gifford, 2004; Long et al., 2004) and at about 550 ppm $\mathrm{CO}_{2}$ concentration, production of aboveground biomass in pastures is expected to increase by 10 percent (Nowak et al., 2004).

\section{Agrotechnology}

Improvements in management and technology have increased crop productivity markedly over the last half of the twentieth century (see also Section 3.1). Lobell and Gourdij (2012) showed that yields of major crops have risen fairly linearly at the global scale, mainly as a result of optimizing nitrogen fertilizer input, more effective weed and disease control, extended irrigation and crop cultivar improvements through breeding. The remaining question is whether this trend will continue.

With a few exceptions (e.g. Sacks and Kucharik, 2011; Palosuo et al., 2013; Tao and Zhang, 2013b), crop simulation modelling has not yet been applied to systematically analyse the effect of technology change on historical yield trends or to project future yields. According to Matthews et al. (2013), crop modelling could make a substantial contribution in numerous areas. For 
example, it could be used to evaluate adaptation options for crops under CC - e.g. quantifying how current crops/cultivars will perform in the future, suggesting how breeding efforts should be targeted to better match crop cultivars to future climates, or recommending how management practices for crops and cropping systems should be changed to improve crop performance under CC.

The potential of crop modelling for supporting breeding efforts or to evaluate various adaptation options has not been at all exploited to date - nor have meaningful combinations of crop simulation modelling with statistical modelling or other techniques (Rötter et al., 2013b).

\section{Selected impacts for key crops and regions}

In this section, we provide an overview of production trends of the recent past and then move on to describe key impacts of CC on crop production potentials and yields - considering the main factors influencing land suitability and crop yields. Our focus is on effects of changes in temperature, precipitation and $\mathrm{CO}_{2}$ concentration, and on discrepancies in the impact projections, mainly due to climate model and emission scenario uncertainty. We also examine the influence of technology development, and summarize the shares of the various factors in affecting future crop productivity. Although the primary focus is on biophysical impacts of CC, we also discuss the possible implications of the overall results for Europe on global food trade and food security.

\subsection{Production trends - past and near future projections}

The most widely grown cereals in the European Union (EU-27) are wheat and barley, which in 2011 occupied areas of approximately 26 million hectares and 12 million hectares, respectively (Figure 5a). While the production area for wheat has increased continuously since the 1980s, cultivation of barley has shown a continuous decrease since the 1980s. The area cultivated with maize has remained more or less stable over the last five decades, fluctuating between 8 and 10 million hectares. A remarkable reduction has been observed in the cultivation area for potatoes, with a decrease from 8 million hectares cultivated in 1961 to 2 million hectares in 2011. A similar trend, though less strong, can also be seen for sugar beet (Figure 5b).

In general, average crop yields in Europe have increased continuously over the last half of the twentieth century. For the last decade or more, however, there have been clear signs with respect to many crops and regions that this trend is not likely to continue and that the linear yield growth rate is slowing down. Figure 5 (c and d) shows that the increase in barley and wheat yields has weakened since the beginning of the 2000s, while oat yields reached their maximum in the middle of the 1980s and have stagnated or even decreased since then. Yields for maize and sugar beet, however, have continued to grow nearly linearly. In the case of maize, this could partly be explained by its higher temperature optimum for photosynthesis rate $\left(\sim 23^{\circ} \mathrm{C}\right)$ (Bird et al., 1976). Furthermore, the cultivation area of irrigated maize has increased steadily in the main production regions in France, Italy Spain and Greece (Eurostat, 2010), with the effect that the risk of soil-water deficits caused by dry spells has been lowered. The increase in sugar beet yields has been induced primarily by structural changes in the production sector. The Common Market Organization reform of 2006 has led to a further geographical concentration of sugar beet production, with a shift to regions where the soil and climatic conditions are most favourable for growing beets. In fact, more than 85 percent of the total sugar beet production of the EU-27 in 2010 originated in the so-called "beet belt," including areas in Austria, Belgium, Czech Republic, France, Germany, the Netherlands, Poland and the United Kingdom (Agrosynergie, 2011).

There are also considerable differences in yield levels between European countries, as shown for wheat in Figure 5e. The highest wheat 


\section{figure 5}

Production area $(\mathrm{a}, \mathrm{b})$ and yields (c, d) for key crops in the European Union (EU-27), and wheat yields (e) and wheat production area (f) for some of the major wheat-producing countries in the European Union (FAOSTAT, 2014)

a)

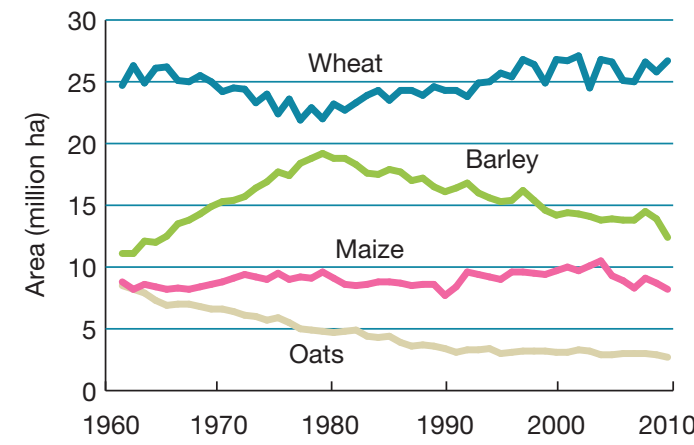

c)

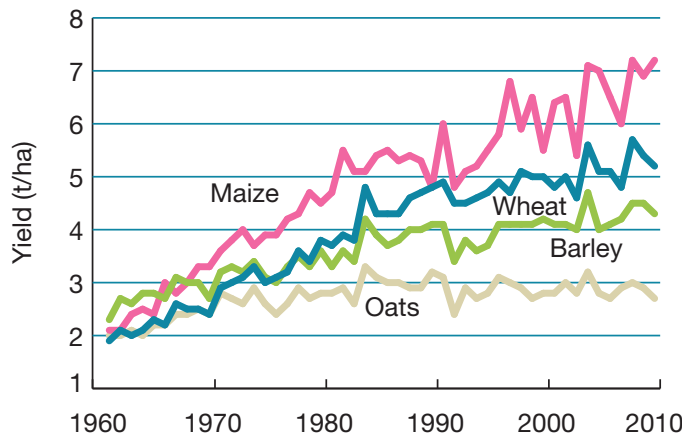

e)

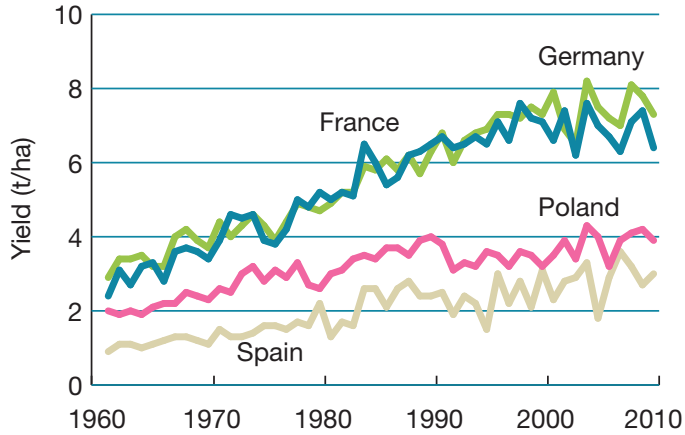

b)

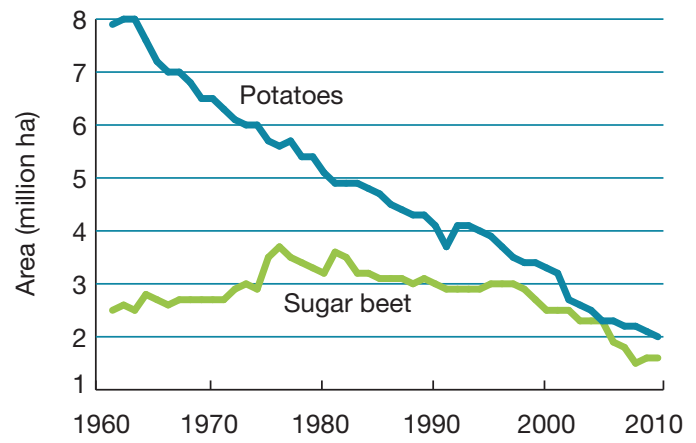

d)

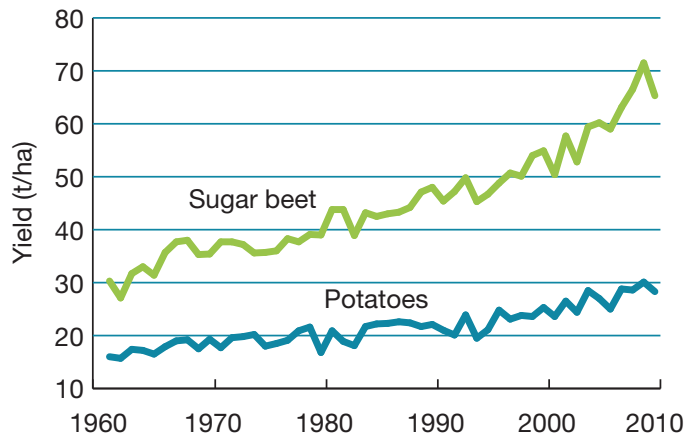

f)

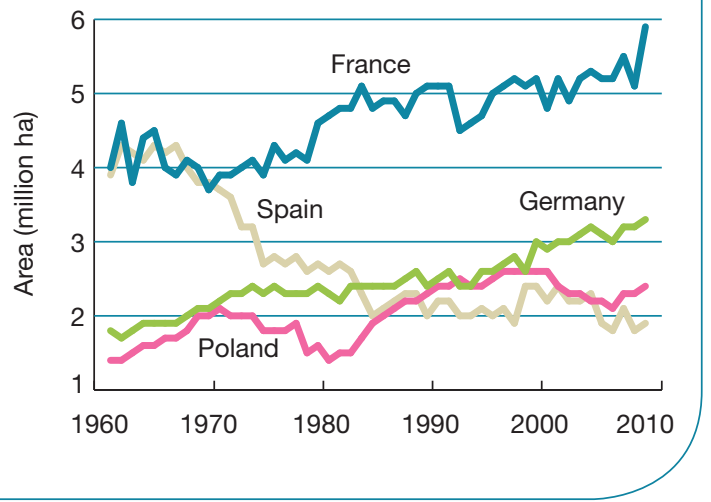


productivity is achieved in the western parts of Europe, including France, the United Kingdom, Ireland, Germany, Denmark and the BE-NE-LUX countries (i.e. Belgium, Netherlands, Luxembourg), with average yields ranging from 7 to 9 tonnes per hectare over the last decade. On the other hand, average wheat yields remain under 4 tonnes per hectare in southern Europe (e.g. Spain) and eastern Europe (e.g. Poland).

\subsection{Future shifts in production possibilities (suitability)}

The distribution of agricultural cropping areas is characterized by a high spatiotemporal variability. For example, in the short term, cultivation of a given crop will increase if the cost-price ratio has been favourable in the previous year. In addition, there are long-term trends, such as increase in the cultivation area of biofuel crops (e.g. maize, rapeseed) in response to increased and continued subsidies (see also Section 3.1). Shifts in the distribution of cropping areas are usually determined by the interaction of biophysical factors - including climate, soils and topography and socio-economic factors (Britz et al., 2011). Among these factors, $\mathrm{CC}$ is expected to have a considerable impact on European agriculture and land use (Olesen and Bindi, 2002; Hermans et al., 2010). Elsgaard et al. (2012) analysed the impact of changes in temperature and precipitation on land suitability for crop cultivation and provided model-based estimates of the distribution of selected cereals, including maize, wheat and oat, for an area reaching from southern France to central Finland $\left(45-65^{\circ} \mathrm{N}\right)$. According to this study, the cultivation area of maize is expected to increase in all parts of this area, expanding particularly towards northern Europe, including Denmark, Sweden and Finland. In these Nordic countries, growing conditions for agricultural crops are expected to improve, because of climate warming leading to a longer growing season (see also Trnka et al., 2011; Odgaard et al., 2011; Rötter et al., 2012a; Rötter et al., 2013a). The same extension towards northern latitudes is also anticipated for wheat, with higher cropping shares in the Nordic and Baltic countries. However, the wheat cultivation area is expected to decline in southern and eastern parts of Europe, including France, Hungary and Romania, because drier and hotter summers in these countries in the future will limit crop growth there (Trnka et al., 2011). Further south, the Mediterranean areas are at particular risk of drought during spring and summer (see Figure 2), reducing the potential for rainfed production. The area cultivated with oats is expected to decrease in the current production centres in southern Finland and mid-Sweden, although for areas in the Nordic countries with no oat cultivation currently, the cropping share is projected to increase (Elsgaard et al., 2012).

To our knowledge, a comprehensive study on shifts in production potentials that considers expected future trends of the various influential biophysical and socio-economic factors, their interaction at multiple scales (farm, regional, global) and also the resultant impact on shifts in distribution of cropping areas, has not yet been attempted (Wheeler and von Braun, 2013).

\subsection{Projections of relative crop yield change under future climate scenarios}

\section{Global and European perspectives}

A wide range of local and global impact studies have quantified the effects of changes in climate and $\mathrm{CO}_{2}$ on future crop productivity (e.g. Rosenzweig and Parry, 1994; Wolf and van Oijen, 2003; Parry et al., 2004; Nelson et al., 2009, 2010). At a global scale, crop productivity is expected to decrease in many regions of the world if the $\mathrm{CO}_{2}$ fertilization effect is not taken into account. According to a recent study conducted by Müller and Robertson (2014), which did not take the $\mathrm{CO}_{2}$ effect into account, average global wheat yields could be reduced by up to 20 percent, assuming a high-end RCP (RCP8.5; see Figure 6). Estimated yield losses for maize are even higher, 


\section{figure 6}

Relative changes in rainfed wheat productivity as projected by DSSAT (top) and

LPJmL (bottom) for the HadGEM2-ES (left) and IPSL-CM5A-LR (right) climate scenarios for the RCP8.5 emission scenario. Dark gray areas are currently not used for cultivation of rainfed wheat (Portmann et al., 2010).

(Reprinted with permission from John Wiley \& Sons; source: Müller and Robertson, 2014)

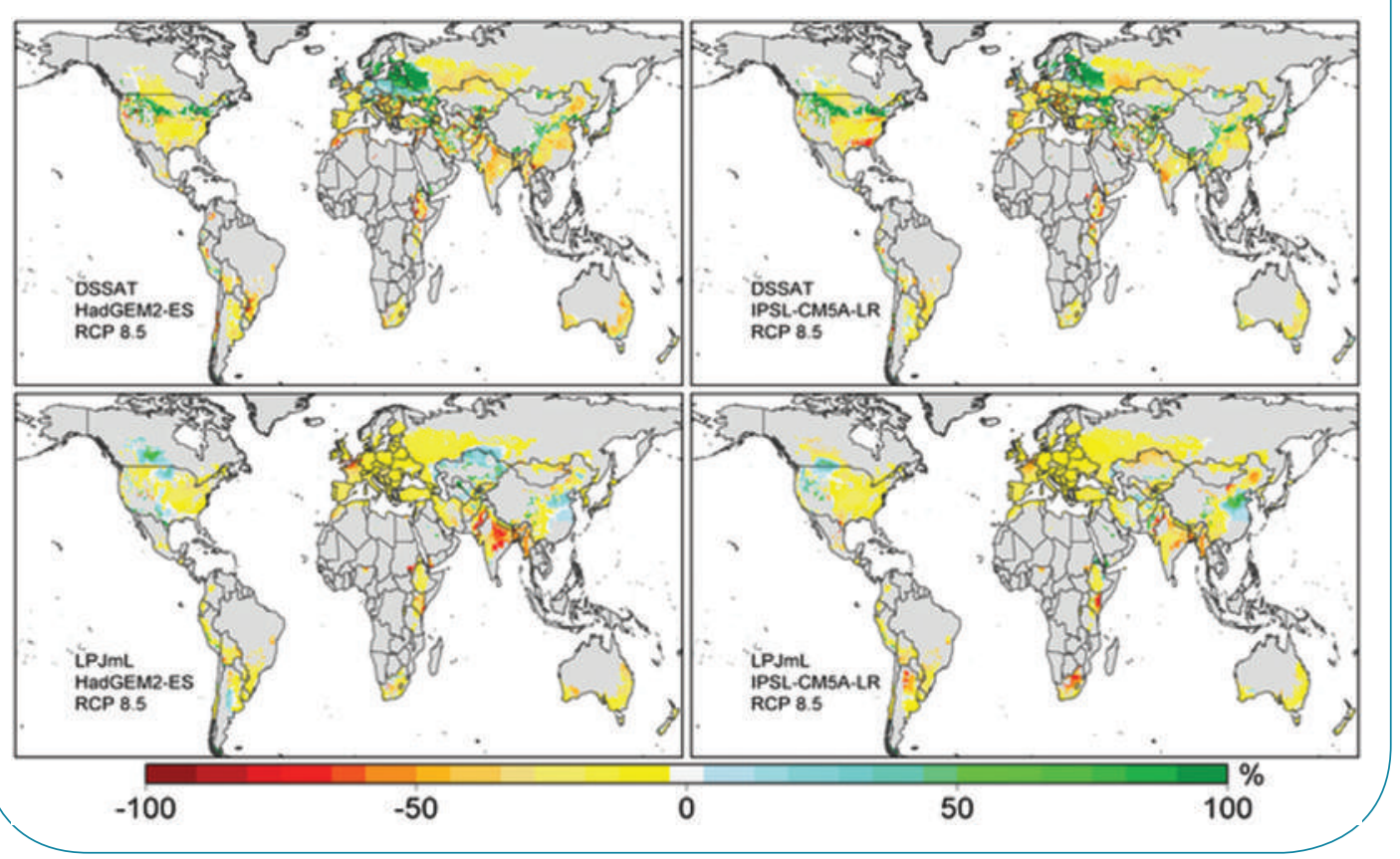

\section{figure 7}

Impacts of climate change (CC) on European wheat yields at mid-century (2050s)

with/without taking $\mathrm{CO}_{2}$ effects $\left(\mathrm{CO}_{2}\right)$ and progress in technology (technical progr.)

into account. (Compiled from results of the following studies: Angulo et al., 2013; Hermans et al., 2010;

Ewert et al., 2005; Harrison and Butterfield, 1996

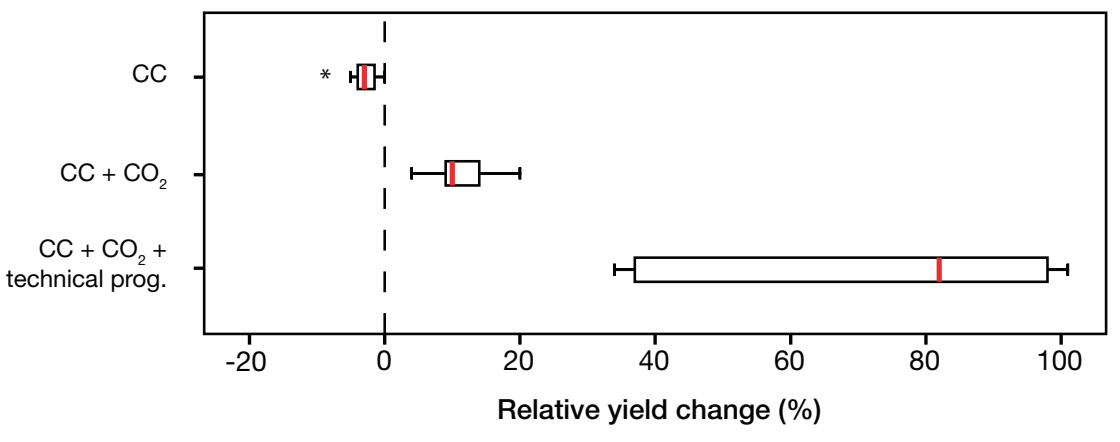


ranging from 30 to 34 percent. Even if farmers can adapt to CC by adjusting their management practices, such as planting decisions and choices among available cultivars, Deryng et al. (2011) found that, at the global scale, yield projections for spring wheat (-4 to $-12 \%)$ and maize (-6 to $-18 \%)$ would remain negative. Negative impacts of $\mathrm{CC}$ could be mitigated by the benefits of elevated $\mathrm{CO}_{2}$ concentration, specifically in the mid- and highlatitude areas, and in East and Southeast Asia. However, even in this case, average global crop yields were expected to decrease slightly, by 0 to 5 percent (Parry et al., 2004). As mentioned in Section 1.2, although SRES emission scenarios are not directly comparable to the new RCPs, they both span a similar range of alternative future emission scenarios (except for the lowend emissions pathway, RCP2.6). According to Knutti and Sedlacek (2013), climate sensitivity of high-end RCP8.5 (as applied in Müller and Robertson, 2014; see Figure 6), is fairly similar to that of SRES A2. From a global perspective, Europe as a whole will be relatively little affected by CC. Most studies for 2050 indicate that, overall, the effects of changes in climate and $\mathrm{CO}_{2}$ concentration will lead to positive impacts on crop production. This general picture is supported by the various global projections presented by Müller and Robertson (2014; Figure 6) as well as by various previous studies (e.g. Rosenzweig and Parry, 1994; Fischer et al., 2005; Nelson et al., 2010). Increases in crop yield and production are expected to be slightly to moderately positive in northern and western Europe, neutral to slightly positive in the central and eastern parts, and slightly negative to neutral for southern Europe (Olesen and Bindi, 2002; Easterling et al., 2007; Bindi and Olesen, 2011). However, for a given time horizon (e.g. 2050), the various studies show considerable differences in the spatial patterns of projected crop yield gains or losses, as well as in the rates of change, dependent on the choice of climate model, emission scenario (or concentration pathway) and impact model (see Section 3.3). According to Rummukainen (2014) and Hawkins and Sutton (2009), climate projection uncertainty is particularly high for the near term (up to 20 years), especially for regional projections, because of the enormous amount of uncertainty resulting from internal variability of the climate system. Overall climate projection uncertainty drops for lead times of 20-50 years, as climate model uncertainty decreases faster than emissions scenario uncertainty increases. Ultimately, total climate projection uncertainty rises again, due to rapidly increasing scenario uncertainty (about GHG emissions, land-use change, socio-economic development). This should be kept in mind when interpreting the various impact projections presented in Sections 3.2-3.4. The robustness and level of certainty of impact models also varies, and decreases with increasing distance from the present situation - i.e. with more deviation from conditions for which they were initially built and evaluated. This is self-evident for the empiricalstatistical crop-weather models (Lobell and Burke, 2010), but has been found for process-based crop simulation models as well - e.g. in a model intercomparison with the largest ensemble of wheat models to date (Asseng et al., 2013).

In order to provide an indication of the effects and relative importance of $\mathrm{CC}, \mathrm{CO}_{2}$, and technological progress on crop production in Europe, we synthesized the results from various European-wide studies for wheat yields by midcentury (Figure 7). Considering CC only, impacts are slightly negative to neutral; including $\mathrm{CO}_{2}$ effects turns the picture slightly positive (around $+10 \%$ for most studies). Considering technological progress/adaptation makes the biggest difference, resulting in high yield gains, although with a huge range of uncertainty. In the following section we illustrate the influence of different change variables, as well as that of using different climate models on the projected impacts.

\section{Europe and its subregions}

\section{Effects of climate variables only}

For Europe, yield projections are slightly negative if only CC impacts are considered (see Figures 
7 and 8) but, as shown for wheat in Figure 7, the magnitude of yield losses, ranging from 0 to 10 percent, is not as severe as for other world regions. Nevertheless, there are areas in Europe where the impacts of CC can have significant negative yield effects, as can partly be seen in southern Europe (Figure 8a). Increased temperatures and drier conditions can reduce rainfed wheat yields in those areas by up to 30 percent, as reported for southern Spain and the central regions of France. Projections for regions in Italy and Greece are also negative and yields are expected to decrease by 10 to 20 percent. On the other hand, beneficial effects of CC are expected in central, eastern and northern Europe, where wheat yields in most areas are likely to increase by 10 to 30 percent. Similar geographical patterns of projected yield reductions and gains can be observed for potato (Figure 8d) and grass (Figure 8g), with expected increases in northern Europe (just for potatoes), central and eastern Europe (for potatoes and grass) and reductions in western and southern Europe.

\section{Effects of climate variables and $\mathrm{CO}_{2^{*}}$} When the fertilization effect of $\mathrm{CO}_{2}$ is added to the projections, net impacts become positive at European scale, as shown for wheat in Figure 7. Ewert et al. (2005), for example, projected increases in wheat yields of 9 to 14 percent (EU15+2) by 2050, assuming a relative yield increase of 0.08 percent per unit ppm increase in $\mathrm{CO}_{2}$ concentration. Simulations at country scale (Supit et al., 2012) support those findings (Figure 9a-c). However, there are areas in southern Spain (Iglesias and Minguez, 1997; Iglesias et al., 2011), France (Hermans et al., 2010) and Italy (Tubiello et al., 2000; Farina et al., 2010; Ferrise et al., 2011) where elevated $\mathrm{CO}_{2}$ concentration cannot compensate for the yield reductions caused by CC (see Figure 8b, e, h). Projections for rainfed maize show higher variability and are more dependent on the CC scenario under consideration. Degree and spatial patterns of yield changes (Figure 9d-f) differ strongly according to choice of climate model and the resultant climate projection. While the average yield projections for rainfed maize, based on the output from three different climate models, indicate either no significant change or yield reduction in most parts of western, central and eastern Europe, they show increases in southern Europe (Figure 9d). Yield projections based on GCM mpi_echam5 are positive for southern and western Europe and for Poland (Figure 9e). On the other hand, projections based on GCM ipsl_cm4 (Figure 9h) turn sharply negative for nearly all of Europe, showing yield declines of more than 30 percent for Spain, France and southeastern Europe. Exceptions are Italy and the United Kingdom, where yields are likely to increase by 10 to 20 percent. It is important to keep in mind that for mid-century projections, as presented in Figures 8 and 9, the effect of climate model uncertainty exceeds the uncertainty of emissions scenarios (SRES A1 and B1).

\section{Effects of climate variables, $\mathrm{CO}_{2}$ and technology}

A sharp increase in crop yields can be observed when also taking the effects of technical improvements into consideration (see Figure 7 and Figure 8c, f, i). According to a study on European wheat yields conducted by Ewert et al. (2005), which incorporates the effects of technology development, wheat yields (in EU15+2) are likely to increase between 37 and 100 percent around 2050, depending on the scenario-specific pace of progress in agrotechnology development (Figure 7). Ewert et al. (2005) define the latter as comprising improvements in crop management (e.g. improved machinery, pesticides, knowledge of farmers) and plant breeding. The results of Hermans et al. (2010) indicate that incorporation of technological progress clearly overrules the influence of all other factors (Figure 8c, f, i).

Finally, we present results from regional impact studies, to illustrate similarities and discrepancies in impact projections for some main commodities (Table 1).

The regional CC impact projections for wheat underline the general picture drawn for Europe: Higher yields are reported for regions in 


\section{figure 8}

Impact of climate change on European wheat (a-c), potato ( $d-f)$ and grass ( $g-i)$ yields, expressed as percentage difference relative to current yields (2005) for the year 2050 with climate change projected by the ukmo_hadcm3 climate model under

the A1 scenario taking into consideration climate change $(\mathrm{a}, \mathrm{d}, \mathrm{g})$, climate change and elevated $\mathrm{CO}_{2}$ concentration (b,e,h) and climate change, elevated $\mathrm{CO}_{2}$ concentration and technical progress (c,f,i). (Illustration based on data from Hermans et al., 2010; source: Supplementary data, Appendix C)
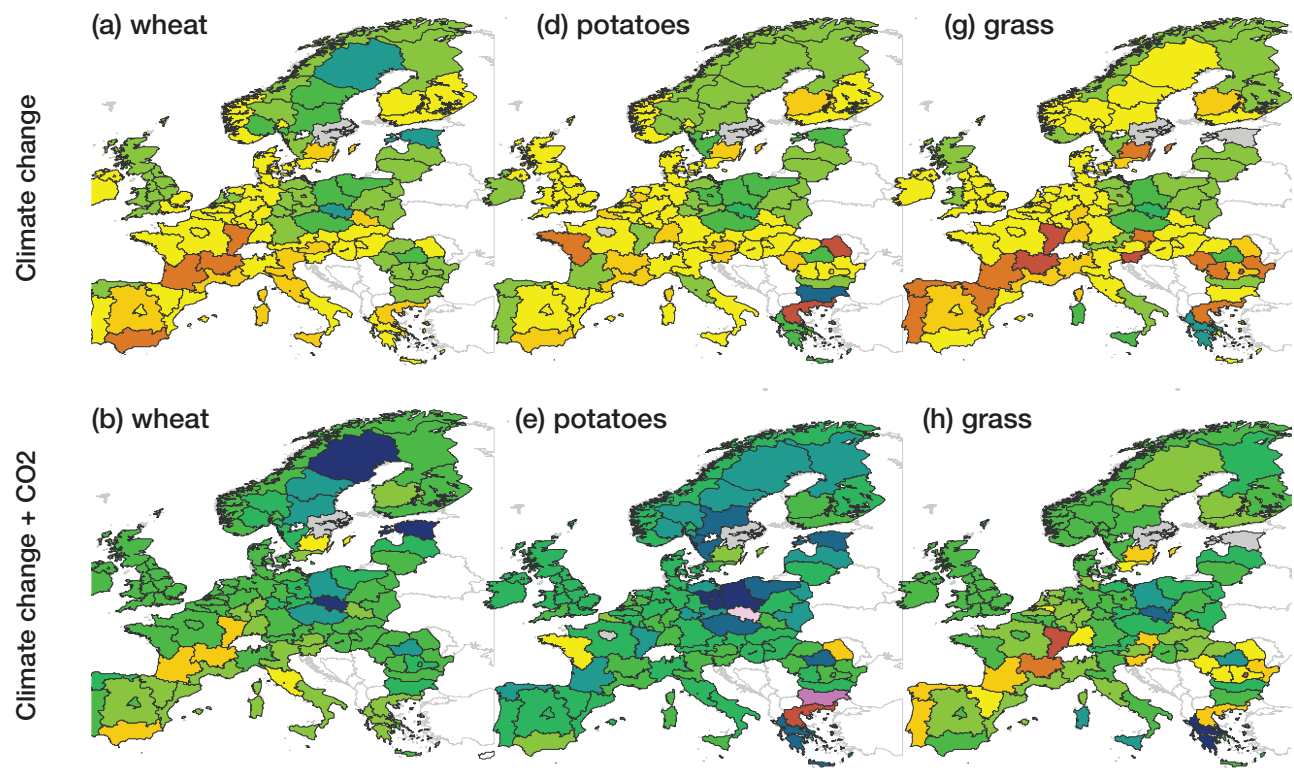

\section{(e) potatoes}

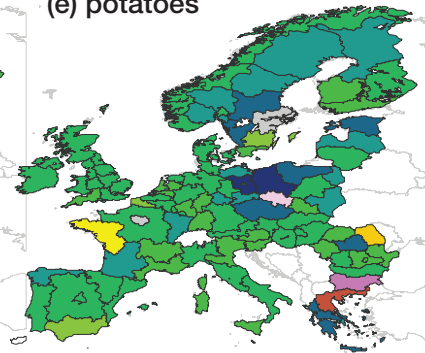

\section{(h) grass}
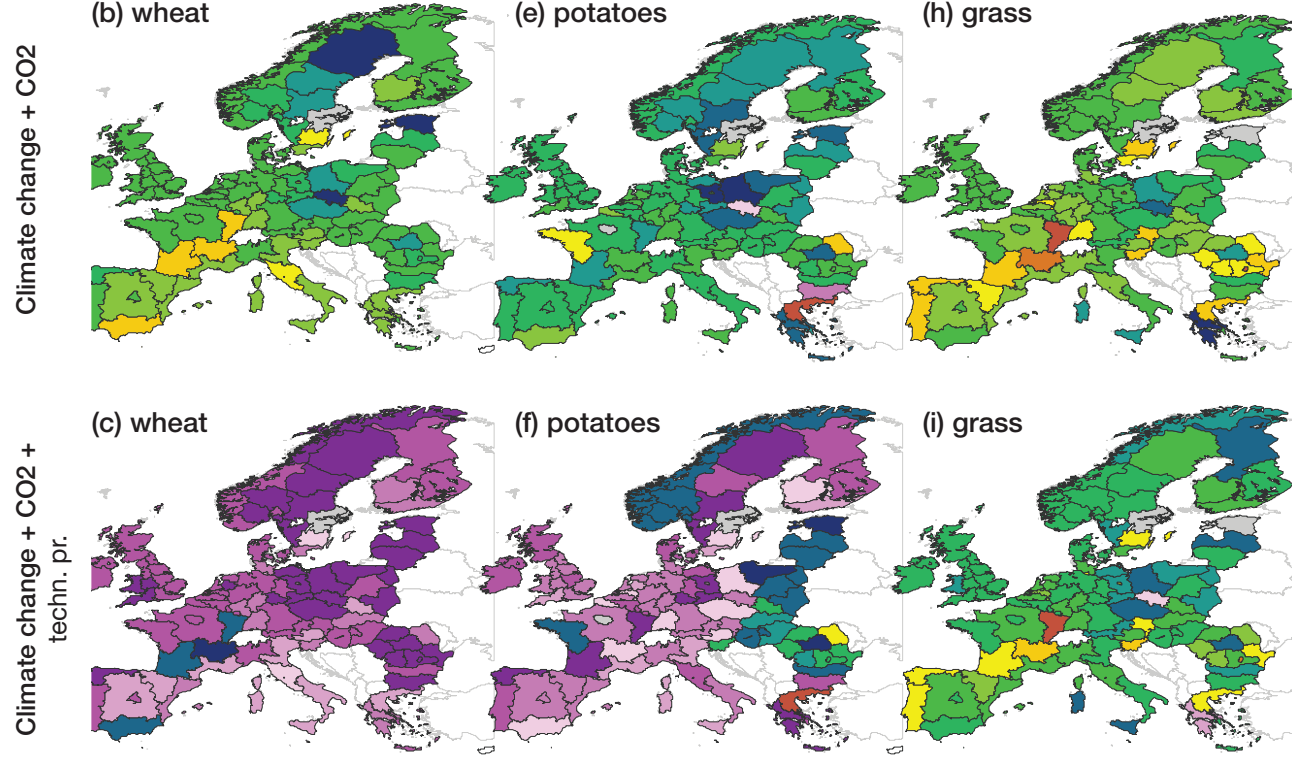

relative yield change (\%)

Calc. most likely biased

\begin{tabular}{|l|l|l|l|l|l|l|l|llllll|l|l|}
\hline & & & & & & & & & & & & & & \\
\hline$<-30$ & -30 & -20 & -10 & 0 & 10 & 20 & 30 & 40 & 50 & 60 & 70 & 80 & 90 & $100>100$
\end{tabular}




\section{figure 9}

Changes in wheat $(a-c)$ and rainfed maize $(d-f)$ dry matter yields relative to the

baseline period (1990-2008) for three climate change projections under the

B1 emission scenario in EU-27: Multi-model mean (MMM) of climate models ipsl_cm4,

miroc3.2 (medium resolution), mpi_echam5 (a,d,g), mpi_echam5 (b,e,h) and ipsl_cm4 (c,f,i).

Future yields are centred around 2050 (2040-2060) and $\mathrm{CO}_{2}$ effects are taken into account as described in Supit et al. (2012). (Illustration based on data from Supit et al., 2012; Source: Supplementary data, Tables S1-S12)
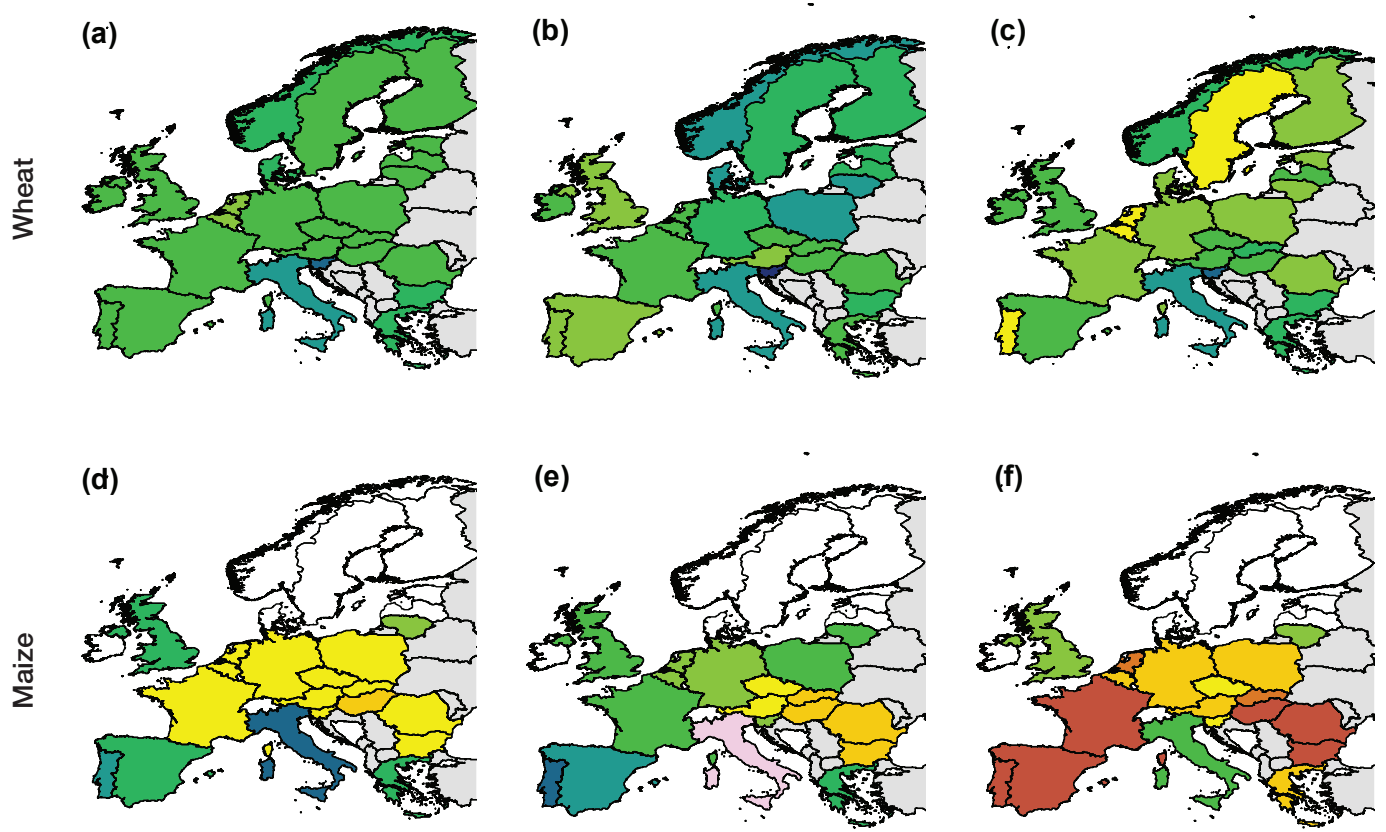

relative yield change (\%) 


\section{table 1}

Relative yield changes derived from regional impact studies for selected crops and countries representing northern (Denmark), western (United Kingdom), central (Austria), eastern (Bulgaria) and southern (Italy) Europe, taking the effects of climate change and elevated $\mathrm{CO}_{2}$ concentration into consideration

\begin{tabular}{llccccccc}
\hline Country & $\begin{array}{c}\text { Projected } \\
\text { time } \\
\text { horizon }\end{array}$ & \multicolumn{2}{c}{ Wheat } & \multicolumn{2}{c}{ Barley } & Maize & Source \\
\hline & & $\begin{array}{c}\text { Reference } \\
\text { yield } \\
(\mathrm{t} / \mathrm{ha})\end{array}$ & $\begin{array}{c}\text { yield } \\
\text { change } \\
(\%)\end{array}$ & $\begin{array}{c}\text { Reference } \\
\text { yield } \\
(\mathrm{t} / \mathrm{ha})\end{array}$ & $\begin{array}{c}\text { yield } \\
\text { change } \\
(\%)\end{array}$ & $\begin{array}{c}\text { Reference } \\
\text { yield } \\
\text { (t/ha) }\end{array}$ & $\begin{array}{c}\text { yield } \\
\text { change } \\
(\%)\end{array}$ \\
\hline Denmark & $2051-2070$ & 5.8 & $9-19$ & $4.1^{1}$ & $-35-24$ & n.a. & n.a. & (a) \\
\hline UK & $2041-2070$ & 9.7 & $17-29$ & $5.9^{1}$ & $-3-10$ & n.a. & n.a. & (b) \\
\hline Austria & $2007-2038$ & 6.3 & -5 & $4.9^{1}$ & -10 & 10.9 & -4 & (c) \\
\hline Bulgaria & $2040-2069$ & 6 & $14-45$ & n.a. & n.a. & $7^{3}$ & $-21-6$ & (d) \\
\hline Italy & $\begin{array}{l}\text { End of the } \\
\text { century }\end{array}$ & 5.2 & $-15-0$ & $4.6^{2}$ & $-33-11$ & $9.2^{3}$ & $-24--9$ & (e) \\
\hline
\end{tabular}

1) spring barley, 2) winter barley, 3) irrigated, n.a. not available

(a) Doltra et al. (2012), (b) Gibbons \& Ramsden (2008), (c) Strauss et al. (2012), (d) Alexandrov \& Hoogenbaum (2000),

(e) Tubiello et al. (2000)

northern Europe (Denmark) and western Europe (United Kingdom), with increases of between 9 to 19 percent and 17 to 29 percent, respectively. In addition, the remarkable increase in projected yields for locations in Bulgaria (up to 45\%) corresponds with the results of studies conducted at coarser scale (see Figure 8b, 9a-c); so does the decrease reported for an area in northern Italy.

Regional projections for barley and maize are predominantly negative across Europe. Barley yields are likely to decrease in Austria, Denmark and Italy, although the upper (positive) end of the yield range in Italy was simulated for late-maturing cultivars. Such cultivars can counterbalance the risk of potential crop yield reduction caused by accelerated phenological development in a warmer climate (Tubiello et al., 2000) if they are not exposed to increased drought risk. The projected decreases in maize yields were primarily caused by a shorter growing period, due to accelerated phenological development under increased air temperatures (Alexandrov and Hoogenbaum, 2000; Tubiello et al., 2000). It should be borne in mind that the projected yields for Italy and Bulgaria correspond to irrigated maize and thus are not directly comparable with the rainfed maize projections presented in Figure 9d-f.

\subsection{Projections of future crop production potential (yields and suitability)}

Based on the results from assessing shifts in biophysical land suitability for the cultivation of arable crops and grassland, in combination with crop yield simulations and other crop yield models, we can conclude that, for Europe as a whole, future crop production potential would increase under CC. Positive changes prevail for northern and central Europe, but there are some risks for reduced production potential in the Mediterranean. There is considerable agreement that climatic suitability will improve for crop cultivation under CC in many parts of Europe, regardless of the assessment method. Overall, improved cultivation conditions are projected based on simple agroclimatic indices and phenology models, or by using more complex biophysical classification 
systems, (Section 3.2; Carter et al., 1991; Metzger et al., 2008; Elsgaard et al., 2012). The same projections apply for combined approaches with crop simulation or other crop yield estimation models (e.g. Rötter et al., 1995; Ewert et al., 2005; Hermans et al., 2010). Recently, however, this generally positive picture has been questioned by some studies that explicitly consider climate scenarios which include anticipated changes in variability and more frequent (and at times more severe) extreme events (e.g. Gibbons and Ramsden, 2008; Trnka et al., 2011, 2014; Semenov and Shewry, 2011; Rötter et al., 2011b, 2013a). Results from such studies suggest considerable challenges for adapting agricultural systems to CC in many parts of Europe.

Working Group II of IPCC concluded in AR4 that agricultural production will be reduced in developing countries primarily if global warming remains below $3^{\circ} \mathrm{C}$ (Easterling et al., 2007). However, later studies have suggested higher risks. For instance, it has been suggested that the trends already observed, of increased climatic variability along with more frequent and severe extreme weather events (Field et al., 2012), will continue or even become stronger under progressive CC. This would lead to faster and more severe yield reductions across the world than previously anticipated (Lobell et al., 2011). Some of these yield reductions are related to the sensitivity of crops when certain upper temperature thresholds are exceeded (see Section 2.4). In reality, often both severe heat and drought (e.g. during certain times of the day) are responsible for non-linear, negative impacts on yield. Apart from heat and drought, effects of intensive precipitation and flooding on plant physiological processes (e.g. oxygen stress) and soil processes (e.g. nitrate leaching, soil erosion) may significantly reduce crop yields. All these effects, which are induced by increased climatic variability, are not adequately captured by most current crop simulation models, although they are usually taken into account by statistical crop yield models. A higher proportion of statistical modelling in CC impact assessments may be one reason for more pessimistic projections in recent years; other reasons include gradual improvement of crop simulation models towards more sensitivity with regard to extremes.

\subsection{Potential implications for trade and food security}

Food price crises in the last years have made it clear that food security cannot be solved solely by more equitable food distribution; accelerating the rate of gains in crop yields and food production capacity is needed simultaneously (Soussana et al., 2012). Currently, at global scale, primary food produced is sufficient and a high percentage of food is wasted, but expected dietary changes and population growth call for substantial increases in food production. Of course, one major cause of hunger and insufficient access to food is poverty, which means that people in low-income countries are particularly vulnerable to CC risks. Generally, questions regarding the impacts of global CC on agricultural production and the capacity of agriculture to adapt (Howden et al., 2007) and to effectively contribute to mitigation through "climatesmart agriculture" (Smith and Olesen, 2010) have become increasingly important as the window of opportunity for an effective response to $\mathrm{CC}$ is closing.

When comparing CC impacts on crop production from a global perspective to a European perspective, it is clear that Europe will remain relatively well-off under CC in terms of production and yield potential for most food crops. Given the favourable current cultivation conditions in many of the temperate climatic zones of Europe, in conjunction with the high adaptive capacity of European farmers - as compared with the risky production environments of many agricultural regions of the tropics and subtropics (Hillel and Rosenzweig, 2013) - it is expected that the projected future production potential (especially in northwestern Europe) is likely to increase.

Furthermore, given projections regarding Europe's demographic development and availability of agricultural land reserves (admittedly unequally 
distributed within Europe), compared with many other parts of the world, it would be relatively easy to take additional land into cultivation (at lower environmental cost than anywhere else) if the need should arise (see Rötter et al., 1995; Rabbinge and van Diepen, 2000; Eijckhout et al., 2007). The question remains whether the good indications for future agricultural production potential could serve as "buffer capacity," enabling Europe to substantially increase its contribution to global food security under CC. Good and up-to-date information on this issue is scarce, and a thorough investigation and sound discussion of this question is urgently needed. However, this goes far beyond the scope of the current review.

It is expected that the total domestic demand for cereals is likely to grow in the European Union (Msangi and Rosegrant, 2011; Bruinsma, 2012) mainly as the result of increased demand for cereals as feedstock for bioenergy production and animal use. At the same time, various projections also indicate that the increased production potential, if fully utilized, could overcompensate the growth in domestic demand. As a rough guide, the bottom line in these future scenarios for 2050 is that Europe could have a higher share in global cereal trade. Figure 10 schematically illustrates the actual European cereal net trade and one rough projection of the future potential (2050), by comparing the total domestic production and demand for cereals.

One important issue relevant for future food security is the likely increasing instability of agrifood systems and the short-term variability of the food supply (Lobell and Gourdji, 2012; Wheeler and von Braun, 2013). To a large extent, this can be attributed to a gradual increase in climateinduced adverse events and risks for agriculture (Rötter et al., 2012a). This issue has not yet been properly addressed in any biophysical or bioeconomic CC impact assessments, not even in the most recent global studies (e.g. Nelson et al., 2014; and various chapters in this volume). As shown by observed weather data, global warming is already causing changes in rainfall patterns and increasing the frequency and severity of extreme events (Trenberth, 2011; Coumou and Rahmstorf, 2012; Field et al., 2012; WMO, 2013), and climate model projections suggest that such changes will continue in the future (Meehl et al., 2007; Rummukainen 2012, 2014).

Most critical in terms of enhanced shortterm climatic variability for agriculture and global food security are those periods in which food supply shortages occur simultaneously in several important agricultural regions, as has been the case in recent years - such as 2007 and 2010 (Williams, 2012; Willenbockel et al., 2012; Lobell and Gourdij, 2012; lizumi et al., 2013).

The ways in which conditions of food supply and demand and commodity prices change at the global level is essential information for all farmers; the crucial level for CC adaptation and mitigation is the farm, where the final decisions on agricultural production and resource management are taken (Lehtonen et al., 2010; Mandryk et al., 2012; Rötter et al., 2013b).

Realizing sustainable agriculture at both farm and regional levels requires new integrative assessment approaches and tools that link analyses between global and local scales (Figure 11). According to a recent review of research gaps in CC risk and agricultural impact assessment in Europe (FACCE-MACSUR ${ }^{6}$ ), missing elements are robust agro-ecosystem models (AEMs) and farming system models (FSMs) that can be combined with sound socio-economic data and meaningful future scenarios to model farmers' decisions on adaptation and mitigation strategies (Bezlepkina et al., 2011; Rivington et al., 2007).

In addition to improving methodologies and tools for informing adaptation, it is important that analyses of possible effects of the most promising adaptation strategies and supportive policy responses for global trade and food security also take into account the various uncertainties that cannot be attributed to biophysical and bioeconomic modelling of CC impacts, but are related to the various assumptions underlying scenarios of socio-economic development.

6 http://www.macsur.eu/ 


\section{figure 10}

Current European (EU-27) total demand and production of cereals (FAOSTAT, 2014)

and projected potential future cereal demand and production (by 2050) illustrating production surpluses and export potential. Future demand is projected to increase by 35\% relative to the year 2000 (see von Braun, 2008;

Msangi and Rosegrant, 2011) and future production is projected to increase by $50 \%$ until 2050

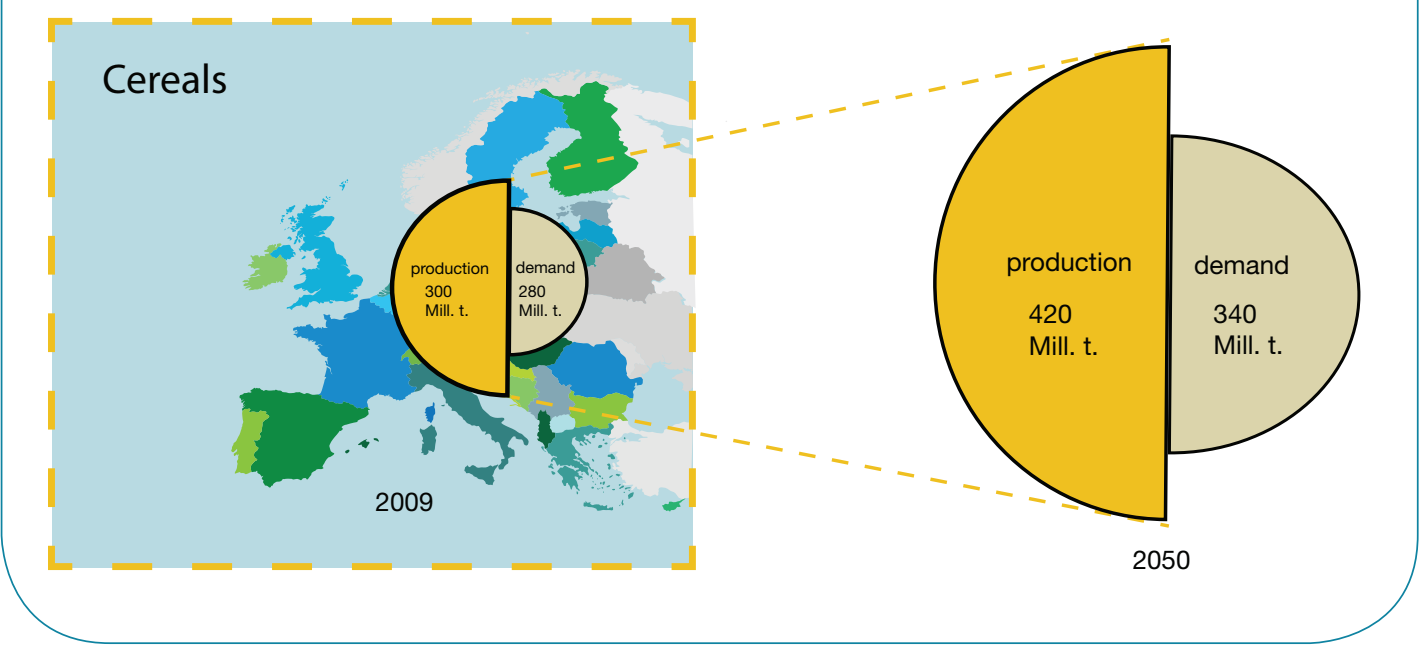

\section{Discussion of uncertainties}

In this section we first provide an overview of the various uncertainties involved in CC impact projections. This is followed by a discussion of their relative importance, and examination of uncertainty that is numerical and can be quantified, with a couple of known "unknowns".

Figure $1 \mathrm{~b}$ attempts to illustrate schematically the propagation of uncertainties and errors in CC impacts along the impact modelling chain. Figure 1 does not explicitly include "socio-economic scenario uncertainty," which is usually large and increases more rapidly into the future the longer the time horizon. Such scenario uncertainty in turn results in uncertainty in GHG emission scenarios, which are used in GCMs that have their own inherent uncertainties (Räisänen and Räty, 2012; Rummukainen, 2012, 2014). As GCMs (usually with grid boxes of 150 to $200 \mathrm{~km}$ resolution) are too coarse for agricultural impact assessments, statistical or dynamic downscaling methods (e.g. $\mathrm{RCMs}$ ) must be applied in order to produce climate scenario data as input for impact models such as crop simulation models or other techniques for estimating suitability and productivity for agricultural crops and livestock. However, these impact models come with their own uncertainties (Walker et al. 2003; Palosuo et al., 2011; Asseng et al., 2013). Eventually, results from biophysical impact models are fed into global/ regional economic and trade models or bioeconomic farm type or regional land use models, creating a further dimension of uncertainty, finally resulting in a considerable uncertainty range. This has previously been labelled the "uncertainty cascade" (Jones, 2000).

Summarizing the scientific-technical challenges for crop modelling, Rötter et al. (2011a) identified impact uncertainty analysis as one of four research areas that should be addressed to overcome deficiencies of current impact assessment methodologies. One of the main goals of $\mathrm{CC}$ impact assessments is to give a thorough account to decision-makers (risk managers) of the level of certainty of model-based impact simulations. 
In addition to quantifying uncertainties in climate projections and downscaling (see above, and Sections 1.2 and 2.2; Rötter et al., 2012a), several other sources of uncertainty must be acknowledged, including discrepancies in simulating climate impacts by different impact models. Such impact model-related uncertainty has been shown to constitute a considerable share of overall uncertainty in projections of CC impacts on crop production (Palosuo et al., 2011; Rötter et al., 2012a; Asseng et al., 2013; Eitzinger et al., 2013). Asseng et al. (2013) even found that crop model uncertainty exceeded climate model uncertainty for the climate scenarios considered in that study. Earlier studies (e.g. Mearns et al., 1999) also highlighted the relatively high importance of crop model uncertainty. On the other hand, other studies have found that uncertainties in climate projections have even greater importance (e.g. lizumi et al., 2011).

There are basically three ways of evaluating uncertainty in models, including crop models:

1. The first approach - the traditional one is through comparison of simulated and observed values, with the assumption that past errors are representative of the uncertainty in future simulations; this commonly done for crop models (Wallach et al., 2013). A major difficulty with this approach in the context of IAM of future climate effects is that past errors may not be representative of future errors.

2. A second approach is to evaluate the contribution of specific sources of error to model uncertainty (Walker et al., 2003; Palosuo et al., 2011). The major effort in this respect has been to evaluate the effects of uncertainty in model parameter values on uncertainty in predictions, through sensitivity analysis or by using a Bayesian approach (deductive reasoning based on probabilistic outcomes) (for example, Wallach et al., 2012). While this approach makes it possible to evaluate errors for new conditions, it does not take into account uncertainties in model formulation.

3. The third approach is through the use of ensembles of models (Rötter et al., 2011; Asseng et al., 2013). Renewed efforts have been made recently to use crop model intercomparisons to reveal uncertainties (e.g. in COST action 7347, AgMIP and MACSUR projects). Discrepancies between models can be assumed to represent uncertainty in both model formulation and parameterization, specific to each context simulated. This approach is easily extended to cascades of models (for example, climate models feeding climate projections into crop models, and the latter feeding relative yield changes into economic models), and therefore is particularly well suited to IAM. For example, Asseng et al. (2013) used ensembles of both GCMs and crop models to evaluate the uncertainty in future yields, and to apportion the overall uncertainty to contributions from uncertainty in GCMs and uncertainty in crop models. Recent studies by Tao et al. (2009) and lizumi et al. (2011) combined an ensemble of GCMs with a Bayesian approach to model parameterization, in order to obtain multiple climate scenarios and model parameter combinations. This was done in an attempt to determine the relative importance of uncertainties in CC impact assessments stemming from climate projections and crop models, respectively, and to analyze probabilities of yield outputs. lizumi et al. (2011) found that the uncertainties of projected yield impacts for rice grown in different regions of Japan stemmed, in most cases, from climate projections, but that the relationship between crop model and climate projection uncertainty also varied considerably among regions.

\footnotetext{
The European Cooperation in Science and Technology (COST) Action 734 'Impacts of Climate change and Variability on European Agriculture', http://www.cost734.eu
} 


\section{figure 11}

Scales and levels of organization and their interactions in integrated assessments of climate change impacts on agricultural production and food security

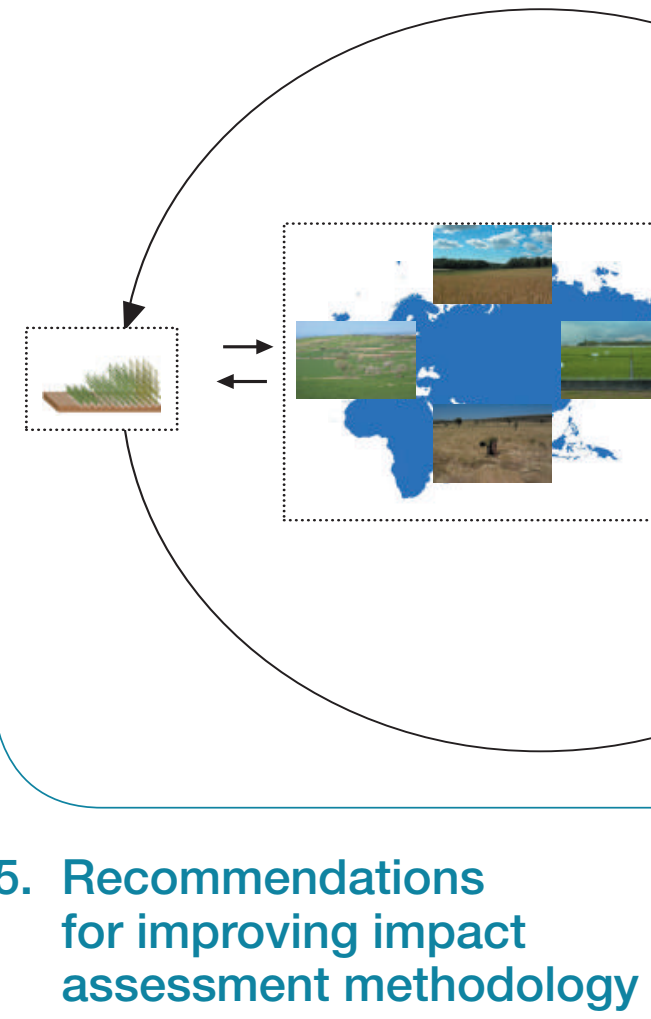

The presentation of outcomes from various studies on key impacts for selected key crops and agricultural regions in Europe has shown that, while there is often good agreement on the direction of impact, there are also considerable discrepancies regarding the magnitude of impact and the spatiotemporal patterns of change. The crop modelling component of FACCE MACSUR recently launched a study with the objective of examining the present state of crop modelling for assessing CC risks to food production. The study's emphasis is on the use of crop models as part of IAM (Ewert et al., forthcoming.

Preliminary results of that investigation indicate that, while there has been considerable progress in modelling CC impacts on crops, this largely reflects the improved sensitivity of crop models to CC factors, in particular to climate extremes and their interaction with various crop growth and development processes (e.g. Asseng et al., 2013; Lobell et al., 2013). Many other aspects required for a detailed CC risk assessment for European agriculture and food security (see www.macsur.eu; Rötter et al., 2013b) are less well represented. Considerable gaps still exist between the variety of data and information demanded by IAM and what crop models can offer.

The lesson to be learned from this and other reviews is that it is necessary to put substantial efforts into improving crop simulation and other biophysical and bio-economic impact assessment techniques concurrently (see also other chapters in this volume). It is highly unlikely that such challenges can be met by individual research groups. Rather, concerted international efforts are required to guide the process of improving crop models and other biophyscial impact assessment techniques for further use in bio-economic 
modelling, for integrated assessments at farm level, and through regional, national and global IAMs.

The current approach of using processbased biophysical impact models across scales, assessment variables and crop management options needs further study and possibly revision. Alternative methods, such as agroclimatic indices approaches (Trnka et al., 2011) combined with crop modelling (Rötter et al., 2013a), or a combination of empirical-statistical and crop simulation modelling (van Oort et al., 2012; Rötter et al., 2013b), may be promising and should be explored further.

Finally, for some reason, methodologies for assessing CC impacts on global and regional food supply have paid little attention to capturing shortterm variability occurring simultaneously at different locations, nor have crop simulation models and other assessment tools been made sufficiently fit to reliably capture climate variability and extremes, and their impact on food production at regional and global scale (Wheeler et al., 2000; Rötter et al., 2011b; Lobell and Gourdij, 2012; Lobell et al., 2013; Wheeler and von Braun, 2013). Biophysical and bio-economic CC impact assessment methodologies and tools need to be further developed, to allow integrated studies of such situations at multiple scales, from farm to global level and back, for ex ante evaluation of alternative adaptation responses in various iterations (as indicated schematically in Figure 11).

Such information is needed to guide formulation of trade and climate policies and inform decision-making on adaptation strategies at different levels of organization and spatial scales (farm household, district, country, etc.).

\section{References}

Agrosynergie- European Economic Interest Grouping. 2011. Evaluation of Common Agricultural Policy measures applied to the sugar sector. Short Summary, 8 pp.
Ainsworth, E., A. Rogers, R. Nelson, \& S. Long. 2004. Testing the source-sink hypothesis of down-regulation of photosynthesis in elevated $\mathrm{CO}_{2}$ in the field with single gene substitutions in Glycine max. Agricultural and Forest Meteorology, 122: 85-94.

Ainsworth, E. \& S. Long. 2005. What have we learned from 15 years of free-air $\mathrm{CO}_{2}$ enrichment (FACE)? A meta-analytic review of the responses of photosynthesis, canopy properties and plant production to rising $\mathrm{CO}_{2}$. New Phytologist, 165: 351-371.

Alexandrov, V. \& G. Hoogenboom. 2000. The impact of climate variability and change on crop yield in Bulgaria. Agricultural and Forest Meteorology, 104: 315-327.

Alexandrov, V., J. Eitzinger, V. Cajic, \& M. Oberforster. 2002. Potential impact of climate change on selected agricultural crops in northeastern Austria. Global Change Biology, 8: 372389.

Angulo, C., R. Rötter, A. Lock, A. Enders, S. Fronzek, \& F. Ewert. 2013. Implication of crop model calibration strategies for assessing regional impacts of climate change in Europe. Agricultural and Forest Meteorology, 170: 32-46.

Asseng, S., I. Foster, \& N. Turner. 2011. The impact of temperature variability on wheat yields. Global Change Biology, 17: 997-1012.

Asseng, S., F. Ewert, C. Rosenzweig, J. Jones, J. Hatfield, A. Ruane, K. Boote, P. Thorburn, R.P. Rötter, D. Cammarano, N. Brisson, B. Basso, P. Martre, P. Aggarwal, C. Angulo, P. Bertuzzi, C. Biernath, A. Challinor, J. Doltra, S. Gayler, R. Goldberg, R. Grant, L. Heng, J. Hooker, L. Hunt, J. Ingwersen, R. Izaurralde, K. Kersebaum, C. Müller, S. Kumar, C. Nendel, G. O'Leary, J. Olesen, T. Osborne, T. Palosuo, E. Priesack, D. Ripoche, M. Semenov, I. Shcherbak, P. Steduto, C. Stöckle, P. Stratonovitch, T. Streck, I. Supit, 
F. Tao, M. Travasso, K. Waha, D. Wallach, J. White, J. Williams \& J. Wolf. 2013. Uncertainties in assessing food security under climate change. Nature Climate Change, 3: 827-832.

Bacsi, Z., P. Thornton, \& J. Dent. 1991. Impacts of future climate change on Hungarian crop production: An application of crop growth simulation models. Agricultural Systems, 37: 435450.

Batts, G., J. Morison, R. Ellis, P. Hadley \& T. Wheeler. 1997. Effects of $\mathrm{CO}_{2}$ and temperature on growth and yield of crops of winter wheat over four seasons. European Journal of Agronomy, 7: 43-52.

Bezlepkina, I., P. Reidsma, S. Sieber \& K. Helming. 2011. Integrated assessment of sustainability of agricultural systems and land use: Methods, tools and applications. Agricultural Systems, 104(2): 105-109.

Bindi, M. \& J. Olesen. 2011. The responses of agriculture in Europe to climate change. Regional Environmental Change, 11: 151-158.

Boberg, F. \& J. Christensen. 2012. Overestimation of Mediterranean summer temperature projections due to model deficiencies. Nature Climate Change, 2: 433-436.

Bocchiola, D., E. Nana \& A. Soncini. 2013. Impact of climate change scenarios on crop yield and water footprint of maize in the Po valley of Italy. Agricultural Water Management, 116: 50-61.

Bondeau, A., P. Smith, S. Zaehle, S. Schaphoff, W. Lucht, W. Cramer, \& D. Gerten. 2007. Modelling the role of agriculture for the 20th century global terrestrial carbon balance. Global Change Biology, 13: 679-706.

Britz, W., P. Verburg \& A. Leip. 2011. Modelling of land cover and agricultural change in Europe: combining the CLUE and CAPRI-Spat approaches. Agriculture, Ecosystems \& Environment, 142: 4060.

Bruinsma, J. 2012. European and Central Asian agriculture towards 2030 and 2050. Policy Studies on Rural Transition, No. 2012-1. FAO, Rome.

Carter, T., J. Porter \& M. Parry. 1991. Climatic warming and crop potential in Europe: Prospects and uncertainties. Global Environmental Change, 1: 291-312.

Challinor, A., T. Wheeler, P. Craufurd \& J. Slingo. 2005. Simulation of the impact of high temperature stress on annual crop yields. Agricultural and Forest Meteorology, 135: 180-189.

Challinor, A., T. Wheeler, D. Hemming \& H. Upadhyaya. 2009. Ensemble yield simulations: crop and climate uncertainties, sensitivity to temperature and genotypic adaptation to climate change. Climate Research, 38: 117-127.

Challinor A. 2011. Agriculture: forecasting food. Nature Climate Change, 1: 103-104.

Christensen, J., B. Hewitson, A. Busuioc, A. Chen, X. Gao, R. Held, R. Jones et al. 2007. Regional climate projections. In: S. Solomon, ed. Climate Change 2007: The Physical Science Basis. Cambridge University Press, Cambridge, pp. 847940.

Coumou, D. \& S. Rahmsdorf. 2012. A decade of weather extremes. Nature Climate Change, 2: 491 496.

Déqué, M., S. Somot, E. Sanchez-Gomez, C. Goodess, D. Jacob, G. Lenderink, \& O. Christensen. 2012. The spread amongst ENSEMBLES regional scenarios: Regional Climate Models, driving General Circulation Models and interannual variability. Climate Dynamics, 38: 951 964. 
Deryng, D., W. Sacks, C. Barford, \& N. Ramankutty. 2011. Simulating the effects of climate and agricultural management practices on global crop yield. Global Biochemical Cycles, 25: GB2006, doi:10.1029/2009GB003765.

Deser, C., A. Philipps, V. Bourdeette, \& H. Teng. 2012. Uncertainty in climate change projections: the role of internal variability. Climate Dynamics, 38 : 527-546. Doi: 10.1007/s00382-010-0977-x.

de Wit, C., 1965. Photosynthesis of leaf canopies. Wageningen, The Netherlands: PUDOC.

Doltra, J., M. Lagdsmann \& J. Olesen. 2012. Impacts of projected climate change on productivity and nitrogen leaching of crop rotations in arable and pig farming systems in Denmark. Journal of Agricultural Science, 152(1) 75-92.

Easterling, W., P. Aggarwal, P. Batima, K. Brander, J. Bruinsma, L. Erda et al. 2007. Food, fibre and forest products. In: M.L. Parry, O.F. Canziani, J.P. Palutikof, P.J. v. d. Linden \& C.E. Hanson, eds. Climate change 2007: impacts, adaptation and vulnerability. Contribution of Working Group II to the Fourth Assessment Report of the Intergovernmental Panel on Climate Change. Cambridge, UK: Cambridge University Press, pp. 273-313.

Eckersten, H., K. Blombäck, T. Kätterer \& P. Nyman. 2001. Modelling C, N, water and heat dynamics in winter wheat under climate change in southern Sweden. Agriculture Ecosystems \& Environment, 142: 6-17.

Eijckhout, B., H. van Meijl, A. Tabeau \& T. van Rheenen. 2007. Economic and ecological consequences of four European land-use scenarios. Land Use Policy, 24: 562-575.

Eitzinger, J., M. Stastna, Z. Zalud \& M. Dubrovsky. 2003. A simulation study of the effect of soil water balance and water stress on winter wheat production under different climate change scenarios. Agricultural Water Management, 61:195-217.

Eitzinger, J., S. Thaler, E. Schmid, F. Strauss, R. Ferrise, M. Moriondo, M. Bindi, T. Palosuo, R.P. Rötter, K. Kersebaum, J. Olesen, R. Patil, L. Şaylan, B. Çaldag, \& O. Çaylak, 2013. Sensitivities of crop models to extreme weather conditions during flowering period demonstrated for maize and winter wheat in Austria. The Journal of Agricultural Science, 151: 813-835.

Elsgaard, L., C. Børgesen, J. Olesen, S. Siebert, F. Ewert, P. Peltonen-Sainio, R.P. Rötter \& A. Skjelvåg. 2012. Shifts in comparative advantages for maize, oat and wheat cropping under climate change in Europe. Food Additives \& Contaminants: Part A, 29: 1514-1526.

Eurostat. Agriculture-Farm structure 2010. [online]. Available from http://appsso.eurostat.ec.europa. eu/nui/show.do?dataset=ef_poirrig\&lang=en.

Ewert, F., M. Van Oijen \& J. Porter. 1999. Simulation of growth and development processes of spring wheat in response to $\mathrm{CO}_{2}$ and ozone for different sites and years in Europe using mechanistic crop simulation models. European Journal of Agronomy, 10: 231-247.

Ewert, F., M. Rounsevell, I. Reginster, M. Metzger \& R. Leemans. 2005. Future scenarios of European agricultural land use. I. Estimating changes in crop productivity. Agriculture, Ecosystems and Environment, 107: 101-16.

Ewert, F., R. Rötter, M. Bindi, H. Webber, M. Trnka, K. Kersebaum, J. Olesen, M. van Ittersum, S. Janssen, M. Rivington, M. Semenov, D. Wallach, J. Porter, D. Stewart, J. Verhagen, T. Gaiser, T. Palosuo, F. Tao, C. Nendel, P. Roggero, L. Bartosova, S. Asseng, (2014). Crop modelling for integrated assessment of risk to food production from climate change. Environmental Modelling \& Software (in review). 
Ewert, F., M. van Ittersum, I. Bezlepkina,

O. Therond, E. Andersen, H. Belhouchette,

C. Bockstaller, F. Brouwer, T. Heckelei,

S. Janssen, R. Knapen, M. Kuiper, K. Louhichi,

O. Alkan, K. Olsson, N. Turpin, J. Wery, J. Wien,

\& J. Wolf. 2009. Methodology for enhanced

flexibility of integrated assessment in agriculture.

Environmental Science \& Policy, 12(5): 546-561.

FAOSTAT. Agricultural production 2014. [online].

Available from http://faostat.fao.org.

Farina, R., G. Seddaiu, R. Orsini, E. Steglich, P. Roggero \& R. Francaviglia. 2011. Soil carbon dynamics and crop productivity as influenced by climate change in a rainfed cereal system under contrasting tillage using EPIC. Soil \& Tillage Research, 112: 36-46.

Favis-Mortlock, D., R. Evans, J. Boardman \& T. Harris. 1991. Climate change, winter wheat yield and soil erosion on the English South Downs. Agricultural Systems, 37: 415-33.

Ferrise, R., M. Moriondo \& M. Bindi. 2011. Probabilistic assessments of climate change impacts on durum wheat in the Mediterranean region. Natural Hazards and Earth System Sciences, 11: 1293-1302.

Field, C., V. Barros, T. Stocker, D. Qin, D. Dokken, K. Ebi, M. Mastrandrea, K. Mach, G. Plattner, S. Allen, M. Tignor, \& P. Midgley. (eds.), 2012. Managing the Risks of Extreme Events and Disasters to Advance Climate Change Adaptation. A Special Report of Working Groups I and II of the Intergovernmental Panel on Climate Change (IPCC). Cambridge University Press, Cambridge, UK, and New York, NY, USA, 582 pp.

Fischer, G., M. Shah, F. Tubiello \& $H$. van Velthuizen. 2005. Socio-economic and climate change impacts on agriculture: an integrated assessment, 1990-2080. Philosophical Transactions of the Royal Society B, 360: 20672083.
Francis, J. \& S. Vavrus. 2012. Evidence linking Arctic amplification to extreme weather in midlatitudes. Geophysical Research Letters, 39: L06801.

Ghaffari, A., H. Cook \& H. Lee. 2002. Climate change and winter wheat management: $\mathrm{A}$ modelling scenario for South-Eastern England. Climatic Change, 55: 509-539.

Giannakopoulos, C., P. le Sager, M. Bindi, M. Moriondo, E. Kostopoulou \& C. Goodess. 2009. Climatic changes and associated impacts in the Mediterranean resulting from a $2^{\circ} \mathrm{C}$ global warming. Global and Planetary Change, 68: 209224.

Gibbons, J., S. Ramsden. 2008. Integrated modelling of farm adaptation to climate change in East Anglia, UK: Scaling and farmer decision making. Agriculture, Ecosystems and Environment, 127: 126-134.

Gifford, R. 2004. The $\mathrm{CO}_{2}$ fertilising effect - does it occur in the real world? New Phytologist, 163: 221-225.

Goudriaan, J. 1990. Primary productivity and $\mathrm{CO}_{2}$. In: J. Goudriaan, H. Van Keulen \& H.H. Van Laar, eds. The greenhouse effect and primary productivity in European agro-ecosystems. Pudoc, Wageningen, The Netherlands, pp. 23-25.

Hakala, K., L. Jauhiainen, S. Himanen, R. Rötter, T. Salo \& H. Kahiluoto. 2012. Sensitivity of barley varieties to weather in Finland. The Journal of Agricultural Science, 150: 145-160.

Harris, G., M. Collins, D. Sexton, J. Murphy, \& B. Booth. 2010. Probabilistic projections for 21st century European climate. Natural Hazards and Earth System Sciences, 10: 2009-2020.

Harrison, P. \& R. Butterfield. 1996. Effects of climate change on Europe-wide winter wheat and sunflower productivity. Climate Research, 7: 225-241. 
Hatfield, J., K. Boote, B. Kimball, L. Ziska, R. Izaurralde, D. Ort. et al. 2011. Climate impacts on agriculture: Implications for crop production. Agronomy Journal, 103(2): 351-370.

Hawkins, E. R. \& Sutton. 2009. The potential to narrow uncertainty in regional climate predictions. Bulletin of the American Meteorological Society, 90: 1095-1107.

Hermans, C., I. Geizendorffer, F. Ewert, M. Metzger, P. Vereijken, G. Woltjer, \& A. Verhagen. 2010. Exploring the future of European crop production in a liberalised market, with specific consideration of climate change and the regional competitiveness. Ecological Modelling, 221: 2177-2187

Hillel, D. \& C. Rosenzweig (eds.) 2013. Handbook of Climate Change and Agroecosystems. Global and regional aspects and implications. Imperial College Press, London, 301 pp.

Howden, S., J. Soussana, F. Tubiello, N. Chhetri, M. Dunlop \& H. Meinke. 2007. Adapting agriculture to climate change. Proceedings of the National Academy of Sciences of the United States of America (PNAS), 104: 19691-19696, doi:10.1073/ pnas.0701890104.

Iglesias, A. \& I. Minguez. 1997. Modelling cropclimate interactions in Spain: Vulnerability and adaptation of different agricultural systems to climate change. Mitigation and Adaptation Strategies for Global Change, 1: 273-288.

Iglesias, A., R. Mougou, M. Moneo \& S. Quiroga. 2011. Towards adaptation of agriculture to climate change in the Mediterranean. Regional Environmental Change, 11, Suppl. 1: 159-166.

lizumi, T., M. Yokozawa \& M. Nishimori. 2011. Probabilistic evaluation of climate change impacts on paddy rice productivity in Japan. Climatic Change, 107: 391-415. lizumi, T., M. Yokozawa, G. Sakurai, M. Travasso, V. Romanernkov, P. Oettli, T. Newby, Y. Ishigooka \& J. Furuya. 2013. Historical changes in global yields: major cereal and legume crops from 1982 to 2006. Global Ecology and Biogeography. doi: 10.1111/ geb.12120.

IPCC 2007. Climate change 2007. The Physical Science Basis. Cambridge University Press, Cambridge, 996 pp.

Jones, R. 2000. Managing uncertainty in climate change projections: Issues for impact assessment. Climatic Change, 45(3-4): 403-419.

Kapetanaki, G. \& C. Rosenzweig. 1997. Impact of climate change on maize yield in central and northern Greece: A simulation study with CERESMAIZE. Mitigation and Adaptation Strategies for Global Change, 1: 251-271.

Kersebaum, K. 2007. Modelling nitrogen dynamics in soil-crop systems with HERMES. Modelling water and nutrient dynamics in soil-crop systems, Springer, The Netherlands, pp. 147-160.

Kersebaum, K. \& C. Nendel. 2014. Site-specific impacts of climate change on wheat production across regions of Germany using different $\mathrm{CO}_{2}$ response functions. European Journal of Agronomy, 52: 22-32.

KLIWAS, Klima, Wasser, Schifffahrt, http://www.kliwas.de

Knutti, R. \& J. Sedlacek. 2013. Robustness and uncertainties in the new CMIP5 climate model projections. Nature Climate Change, 3: 369-373.

Lalic, B., J. Eitzinger, D. Mihailovic, S. Thaler \& M. Jancic. (2013): Climate change impacts on winter wheat yield change - which climatic parameters are crucial in Pannonian lowland? Journal of Agricultural Science; 151(6): 757-774. 
Lamb, H. 1995. Climate, history, and the modern world. 2nd edition. Routledge, New York, USA, pp. 433.

Lehtonen, H., R. Rötter, T. Palosuo, T. Salo, J. Helin, Y. Pavlova \& H. Kahiluoto. 2010. A modelling framework for assessing adaptive management options of Finnish agrifood systems to climate change. Journal of Agricultural Science, 2(2): 3-16.

Lobell, D. \& M. Burke. 2010. On the use of statistical models to predict crop yield responses to climate change. Agricultural and Forest Meteorology, 150: 1443-1452.

Lobell, D., W. Schlenker \& J. Costa-Roberts. 2011. Climate trends and global crop production since 1980. Science, 333: 616-620.

Lobell, D. \& S. Gourdji. 2012. The Influence of Climate Change on Global Crop Productivity. Plant Physiology, 160: 1686-1697.

Lobell, D., G. Hammer, G. McLean, C. Messina, M. Roberts \& W. Schlenker. 2013. The critical role of extreme heat for maize production in the United States. Nature Climate Change, 3: 497-501.

Long, S., E. Ainsworth, A. Rogers \& D. Ort. 2004. Rising atmospheric carbon dioxide: plants FACE the future. Annual Review of Plant Biology, 55: 591-628.

Mandryk, M., P. Reidsma \& M. van Ittersum. 2012. Scenarios of long-term farm structural change for application in climate change impact assessment. Landscape Ecology, 27: 509-27.

Marshall J. \& A. Plumb (2007). Circulation of the Atmosphere and Ocean: an introductory text. Massachusetts Institute of Technology January 28, 2007.

Matsui, T., O. Namuco, L. Ziska \& T. Horie. 1997. Effects of high temperature and $\mathrm{CO}_{2}$ concentration on spikelet sterility in indica rice. Field Crops Research, 51: 213-219.

Matthews, R., M. Rivington, S. Muhammed, A. Newton \& P. Hallett. 2013. Adapting crops and cropping systems to future climates to ensure food security: The role of crop modelling. Global Food Security, 2: 24-28.

Mearns, L., T. Mavromatis, E. Tsvetsinskaya, C. Hays \& W. Easterling. 1999. Comparative responses of EPIC and CERES crop models to high and low resolution climate change scenarios. Journal of Geophysical Research, 104 (D6):66236646.

Meehl, G., C. Covey, K. Taylor, T. Delworth, R. Stouffer, M. Latif et al. 2007. The WCRP CMIP3 multimodel dataset - A new era in climate change research. Bulletin of the American Meteorological Society, 88: 1383-1394.

Metzger, M., R. Bunce, R. Leemans \& D. Viner. 2008. Projected environmental shifts under climate change: European trends and regional impacts. Environmental Conservation, 35: 64-75.

Moriondo, M., C. Giannakopoulos \& M. Bindi. 2011. Climate change impact assessment: the role of climate extremes in crop yield simulation. Climatic Change, 104: 679-701.

Moss, R., M. Babiker, S. Brinkman, E. Calvo, T. Carter, J. Edmonds, I. Elgizouli, S. Emori, L. Erda, K. Hibbard, R. Jones, M. Kainuma, J. Kelleher, J. Lamarque, M. Manning, B. Matthews, J. Meehl, L. Meyer, J. Mitchell, N. Nakicenovic, B. O'Neill, R. Pichs, K. Riahi, S. Rose, P. Runci, R. Stouffer, D. van Vuuren, J. Weyant, T. Wilbanks, J. van Ypersele, and M. Zurek. 2008. Towards New Scenarios for Analysis of Emissions, Climate Change, Impacts, and Response Strategies. Geneva: Intergovernmental Panel on Climate Change. p. 132. 
Msangi, S. \& M. Rosegrant. 2011. World agriculture in a dynamically changing environment: IFPRI's long-term outlook for food and agriculture. In: P. Conforti, ed. Looking Ahead in World Food and Agriculture: Perspectives to 2050, FAO, Rome.

Müller, C. \& R. Robertson. 2014. Projecting future crop productivity for global economic modelling. Agricultural Economics, 45: 37-50.

Nelson, G., M. Rosegrant, J. Koo et al. 2009. Climate change: impact on agriculture and costs of adaptation. Food Policy Report. International Food Policy Research Institute, Washington DC.

Nelson, Gerald C., M. Rosegrant, A. Palazzo, I. Gray, C. Ingersoll, R. Robertson, S. Tokgoz, T. Zhu, T. Sulser, C. Ringler, S. Msangi, and L. You (2010). Food Security, Farming, and Climate Change to 2050: Scenarios, Results, Policy Options. Research Monographs. International Food Policy Research Institute, Washington D.C.

Nelson, G., H. Valin, R. Sands, P. Havlík, H. Ahammad, D. Deryng et al. 2014. Climate change effects on agriculture: Economic responses to biophysical shocks. Proceedings of the National Academy of Sciences 111: 3274-3279.

Nendel, C., K. Kersebaum, W. Mirschel, R. Manderscheid, H. Weigel, \& K. Wenkel. 2009. Finding a suitable $\mathrm{CO}_{2}$ response algorithm for crop growth simulation in Germany. Crop Modeling and Decision Support, 30-43.

Nix, H. 1985. Agriculture. In: R. Kates, J. Ausubel, \& M. Berberian, eds. Climate Impact Assessment. Studies of the Interaction of Climate and Society (Scope 27), John Wiley \& Sons, Chichester. pp. 105-130.

Nonhebel, S. 1996. Effects of temperature rise and increase in $\mathrm{CO}_{2}$ concentration on simulated wheat yields in Europe. Climatic Change, 34: 73-90.
Nowak, R., D. Ellsworth \& S. Smith. 2004. Tansley review: functional responses of plants to elevated atmospheric $\mathrm{CO}_{2}$ - Do photosynthetic and productivity data from FACE experiments support early predictions? New Phytologist, 162: 253-280.

Odgaard, P., T. Dalgaard \& J. Svenning. 2011. Climatic and non-climatic drivers of spatiotemporal maize-area dynamics across the northern limit for maize production-a case study from Denmark. Agriculture, Ecosystems \& Environment, 142: 291302.

Olesen, J. \& M. Bindi. 2002. Consequences of climate change for European agricultural productivity, land use and policy. European Journal of Agronomy, 16: 239-262.

Orlowsky, B. S. Seneviratne. 2012. Global changes in extreme events: Regional and seasonal dimension. Climatic Change, 110: 669-696.

Palosuo, T., K. Kersebaum, C. Angulo, P. Hlavinka, M. Moriondo, J. Olesen et al. 2011. Simulation of winter wheat yield and its variability in different climates of Europe: A comparison of eight crop growth models. European Journal of Agronomy, 35: 103-114.

Palosuo, T., R. Rötter, H. Lehtonen, P. Virkajärvi \& T. Salo. 2013. How to assess climate change impacts on farmers' crop yields? Impacts World 2013 Conference Proceedings. Potsdam, Potsdam Institute for Climate Impact Research, pp: 327334. DOI: 10.2312/pik.2013.001

Parry, M., C. Rosenzweig, A. Iglesias, M. Livermore \& G. Fischer. 2004. Effects of climate change on global food production under SRES emissions and socio-economic scenarios. Global Environmental Change, 14: 53-67.

Peters, G., R. Andrew, T. Boden, J. Canadell, P. Ciais, C. Le Quéré, G. Marland, M. Raupach \& C. Wilson. 2013. The challenge to keep global 
warming below $2^{\circ} \mathrm{C}$. Nature Climate Change, 3: 4-6.

Porter, J. \& M. Gawith. 1999. Temperatures and the growth and development of wheat: a review. European Journal of Agronomy, 10: 23-36.

Porter, J. \& M. Semenov. 2005. Crop responses to climatic variation. Philosophical Transactions of the Royal Society B, 360: 2021-2035.

Porter, J., J-F Sousanna, E. Fereres,

S. Long, F. Mohren, P. Peltonen-Sainio, and J. von Braun. 2013. European Perspectives: An agronomic science plan for food security in a changing climate. Chapter 5 In: D. Hillel \& C. Rosenzweig, eds. A Handbook of climate change and Agroecosystems: Global and Regional Aspects and Implications. Imperial College Press, London, pp. 73-84.

Portmann, F., S. Siebert \& P. Döll. 2010.

MIRCA2000-Global monthly irrigated and rainfed crop areas around the year 2000: A new highresolution data set for agricultural and hydrological modeling. Global Biogeochemical Cycles, 24: Gb1010.

Rabbinge, R. \& C. Van Diepen. 2000. Changes in agriculture and land use in Europe. European Journal of Agronomy, 13 (2/3): 85-99.

Räisänen, J. \& O. Räty. 2012. Projections of daily mean temperature variability in the future: crossvalidation tests with ENSEMBLES regional climate simulations. Climate Dynamics, doi: 10.1007/ s00382-012-1515-9

Ray, J., R. Gesch, T. Sinclair \& L. Allen. 2002. The effect of vapor pressure deficit on maize transpiration response to a drying soil. Plant Soil, 239: 113-121.

Rickards, L. \& S. Howden. 2012. Transformational adaptation: agriculture and climate change. Crop and Pasture Science, 63: 240-250.
Rivington, M., K. Matthews, G. Bellocchi, K. Buchan, C. Stockle \& M. Donatelli. 2007. An integrated assessment approach to conduct analyses of climate change impacts on wholefarm systems. Environmental Modelling Software, 22: 202-210.

Rosenzweig, C. \& M. Parry. 1994. Potential impact of climate change on world food supply. Nature, 367: 133-138.

Rosenzweig, C., J. Jones, J. Hatfield et al. 2013. The Agricultural Model Intercomparison and Improvement Project (AgMIP): Protocols and pilot studies. Agricultural and Forest Meteorology, 170: 166-182.

Rötter, R., F. Veeneklaas \& C. van Diepen. 1995. Impacts of changes in climate and socio-economic factors on land use in the Rhine basin: projections for the decade 2040-49. Proceedings, International Conference of Climate Change Research, Maastricht 6-9 December 1994, Elsevier, Amsterdam, The Netherlands.

Rötter, R. \& S. van De Geijn. 1999. Climate change effects on plant growth, crop yield and livestock. Climatic Change, 43: 651-681.

Rötter, R., T. Carter, J. Olesen \& J. Porter. 2011 a. Crop-climate models need an overhaul. Nature Climate Change, 1: 175-177.

Rötter, R., T. Palosuo, N. Pirttioja, M. Dubrovsky, T. Salo, S. Fronzek et al. 2011b. What would happen to barley production in Finland if global warming exceeded $4^{\circ} \mathrm{C}$ ? A model-based assessment. European Journal of Agronomy, 35: 205-214.

Rötter, R., J. Höhn \& S. Fronzek. 2012a.

Projections of climate change impacts on crop production: A global and a Nordic perspective. Acta Agriculturae Scandinavica, Section A - Animal Science, 62: 166-180. 
Rötter, R., T. Palosuo, K. Kersebaum et al. 2012b. Simulation of spring barley yield in different climatic zones of Northern and Central Europe. A comparison of nine crop models. Field Crops Research, 133: 23-36.

Rötter, R., J. Höhn, M. Trnka, S. Fronzek, T. Carter \& H. Kahiluoto. 2013a. Modelling shifts in agroclimate and crop cultivar response under climate change. Ecology and Evolution, 3: 41974214.

Rötter, R., F. Ewert, T. Palosuo, M. Bindi, K. Kersebaum, J. Olesen, M. Trnka, M. van Ittersum, S. Janssen, M. Rivington, M. Semenov, D. Wallach, J. Porter, D. Stewart, J. Verhagen, C. Angulo, T. Gaiser, C. Nendel, P. Martre \& A. de Wit. 2013b. Challenges for agro-ecosystem modelling in climate change risk assessment for major European crops and farming systems. Impacts World 2013 Conference Proceedings. Potsdam, Potsdam Institute for Climate Impact Research, pp: 555-564. DOI: 10.2312/pik.2013.001.

Rummukainen, M. 2010. State-of-the-art with regional climate models. WIREs Climate Change, 1: 82-96.

Rummukainen, M. 2012. Changes in climate and weather extremes in the 21st century. WIRES Climate Change, 3: 115-129. Doi: 10.1002/ wcc. 160 .

Rummukainen, M. 2014. Climate projections for 2050. In: J. Fuhrer \& P. Gregory, eds. Climate Change Impact and Adaptation in Agricultural Systems. CABI.

Sacks, W. \& C. Kucharik. 2011. Crop management and phenology trends in the U.S. corn belt: Impacts on yields, evapotranspiration and energy balance. Agricultural and Forest Meteorology, 151: 882-894.
Sanchez, B., A. Rasmussen \& J. Porter, 2014. Temperatures and the growth and development of maize and rice: A review. Global Change Biology, 20: 408-417. Doi: 10.1111/gcb.12389.

Savary, S., Teng, P., L. Willocquet \& F. Nutter Jr. 2006. Quantification and modeling of crop losses: a review of purposes. Annual Review of Phytopathology, 44: 89-112.

Schiermeier, Q., 2011. Extreme measures. Nature, 477: 148-149.

Schlenker, W. \& M. Roberts. 2009. Nonlinear temperature effects indicate severe damages to U.S. crop yields under climate change. Proceedings of the National Academy of Sciences of the United States (PNAS), 106(37): 1559415598.

Schlenker, W. \& D. Lobell. 2010. Robust negative impacts of climate change on African agriculture. Environmental Research Letters, 5: 014010.

Semenov, M. 2009. Impacts of climate change on wheat in England and Wales. Journal of the Royal Society Interface, 6: 343-350.

Semenov, M. \& N. Halford. 2009. Identifying target traits and molecular mechanisms for wheat breeding under a changing climate. Journal of Experimental Botany, 60: 2791-804.

Semenov, M. \& P. Shewry. 2011. Modelling predicts that heat stress, not drought, will increase vulnerability of wheat in Europe. Scientific Reports, 1: 66. doi:10.1038/srep00066.

Sloth M., C. Fox Maule, N. MacKellar, J. Olesen \& C. Hesselbjerg. 2012. Selection of climate change scenario data for impact modelling. Food Additives \& Contaminants: Part A, 29:1502-1513.

Smith, P. \& J. Olesen. 2010. Synergies between the mitigation of, and adaptation to, climate 
change in agriculture. Journal of Agricultural Science, 148: 543-552.

Soussana, J.-F., E. Fereres, S. Long, F. Mohren, R. Pandya-Lorch, P. Peltonen-Sainio et al. 2012. A European science plan to sustainably increase food security under climate change. Global Change Biology, 18: 3269-3271.

Strauss, F., E. Schmid, E. Moltchanova, H. Formayer \& X. Wang. 2012. Modeling climate change and biophysical impacts of crop production in the Austrian Marchfeld region. Climate Change, 111: 641-664.

Supit, I., A. Hooijer \& C. Van Diepen. 1994. System description of the WOFOST 6.0 crop simulation model implemented in CGMS, vol. 1: Theory and Algorithms, Luxembourg: Joint Research Centre, Commission of the European Communities.

Supit, I., C. van Diepen, A. de Wit, J. Wolf, P. Kabat, B. Baruth et al. 2012. Assessing climate change effects on European crop yields using the Crop Growth Monitoring System and a weather generator. Agricultural and Forest Meteorology,164: 96-111.

Tao, F., Z. Zhang, J. Liu \& M. Yokozawa. 2009. Modelling the impacts of weather and climate variability on crop productivity over a large area: A new super-ensemble-based probabilistic projection. Agricultural and Forest Meteorology, 149: 1266-1278.

Tao, F. \& Z. Zhang. 2013a. Climate change, hightemperature stress, rice productivity, and water use in eastern China: A new superensemblebased probabilistic projection. Journal of Applied Meteorology and Climatology, 52: 531-551.

Tao, F. \& Zhang, Z. 2013b. Climate change, wheat productivity and water use in the North China Plain: A new super-ensemble-based probabilistic projection. Agricultural and Forest Meteorology, 170: 146-165.
Taylor, K., R. Stouffer, \& G. Meehl. 2011. A summary of the CMIP5 experiment design. [online] Available from http://cmip-pcmdi.lnl.gov/cmip5/ docs/Taylor_CMIP5_design.pdf

Teixeira, E., G. Fischer, H. van Velthuizen, C. Walter \& F. Ewert. 2012. Global hot-spots of heat stress on agricultural crops due to climate change. Agricultural and Forest Meteorology, 170: 206215.

Trenberth, K. 2011. Changes in precipitation with climate change. Climate Research, 47: 123.

Trnka, M., J. Olesen, K. Kersebaum, A. Skjelvag, J. Eitzinger, B. Seguin et al. 2011. Agroclimatic conditions in Europe under climate change. Global Change Biology, 17: 2298-2318.

Trnka, M., R. Rötter, M. Ruiz-Ramos, K. Kersebaum, J. Olesen \& M. Semenov. 2014. Adverse weather conditions for wheat production in Europe will become more frequent with climate change. Nature Climate Change, 4: 637-643.

Tubiello, F., M. Donatelli, C. Rosenzweig \& C. Stockle. 2000. Effects of climate change and elevated $\mathrm{CO}_{2}$ on cropping systems: model predictions at two Italian locations. European Journal of Agronomy, 13: 179-89.

Tubiello, F. \& F. Ewert. 2002. Simulating the effects of elevated $\mathrm{CO}_{2}$ on crops: approaches and applications for climate change. European Journal of Agronomy, 18: 57-74.

van Ittersum, M. \& R. Rabbinge. 1997. Concepts in production ecology for analysis and quantification of agricultural input-output combinations. Field Crops Research, 52: 197-208.

van Ittersum, M., P. Leffelaar, H. van Keulen, M. Kropff, L. Bastiaans \& J. Goudriaan. 2003. On approaches and applications of the Wageningen crop models. European Journal of Agronomy, 18: 201-234. 
van Oort, P., B. Timmermans \& A. van Swaaij. 2012. Why farmers' sowing dates hardly change when temperature rises. European Journal of Agronomy, 40: 102-111.

von Braun, J. 2008. Food price crisis isn't over. Nature, 456: 701-702.

Walker, W., P. Harremoës, J. Rotmans, J. van der Sluijs, M. van Asselt, P. Janssen \& M. von Krauss.2003. Defining uncertainty: a conceptual basis for uncertainty management in modelbased decision support. Integrated Environmental Assessment and Management, 4: 5-17.

Wallach, D., F. Brun, N, Keussayan, B. Lacroix \& J. Bergez. 2012. Assessing the uncertainty when using a model to compare irrigation strategies. Agronomy Journal, 104: 1274-1283.

Wallach, D., D. Makowski, J. Jones \& F. Brun. 2013. Working with Dynamic Crop Models: Methods, Tools and Examples for Agriculture and Environment. Academic Press/Elsevier. London, UK/ San Diego, USA.

Weyant, J., C. Azar, M. Kainuma, J. Kejun, N. Nakicenovic, P. Shukla, E. La Rovere and G. Yohe. 2009. Report of 2.6 Versus 2.9 Watts/ m2 RCPP Evaluation Panel. Geneva, Switzerland: IPCC Secretariat.

Wheeler, T., P. Craufurd, R. Ellis, J. Porter \& P. Prasad. 2000. Temperature variability and the yield of annual crops. Agriculture, Ecosystems \& Environment, 82: 159-167.

Wheeler, T. \& J. von Braun. 2013. Climate change impacts on global food security. Science, 341: 508-513.

White, J., G. Hoogenboom, B. Kimball \& G. Wall. 2011. Methodologies for simulating impacts of climate change on crop production. Field Crops Research, 124: 357-368.
Wilby, R., S. Charles, E. Zorita, B. Timbal, P. Whetton \& L. Mearns. 2004. Guidelines for use of climate scenarios developed from statistical downscaling methods. IPCC Supporting Material, available from the DDC of IPPC TGCIA.

Wilby, R. \& S. Dessai. 2010. Robust adaptation to climate change. Weather, 65: 180-185.

Willenbockel, D. 2012. Extreme weather events and crop price spikes in a changing climate: Illustrative global simulation scenarios. Oxfam research report. Oxford, Oxfam GB.

Williams, J. 2012. Competition and efficiency in international food supply chains. Improving food security. Earthscan Food and Agriculture, Routledge, New York, U.S.A., pp. 260.

Wolf, J. \& M. Van Oijen. 2003. Model simulation of effects of changes in climate and atmospheric $\mathrm{CO}_{2}$ on tuber yield potential of potato (cv. Bintje) in the European Union. Agriculture, Ecosystems \& Environment, 94(2): 141-157.

World Meteorological Organization (WMO) 2013. The global climate 2001-2010. A decade of climatic extremes. Summary report. WMO-No 1119, World Meteorological Organization, Geneva, Switzerland, $15 \mathrm{pp}$.

Wu, L., A. Shepherd \& D. Chadwick. 2011. Quantify response of crop systems to future climate change using SPACSYS model. Aspects of Applied Biology, 107: 57-62. 
chapter 5

\section{Page}

1. Introduction

1.1 Population 150

1.2 Income $\quad 150$

$\begin{array}{ll}1.3 \text { Agriculture } & 150\end{array}$

2. Climate and climate models $\quad 150$

2.1 Precipitation $\quad 150$

2.2 Temperature $\quad 155$

3. DSSAT Crop Model Results 156

3.1 Rainfed maize 158

$\begin{array}{ll}3.2 \text { All crops } & 161\end{array}$

4. Impact model results $\quad 165$

4.1 Maize $\quad 165$

4.2 Sorghum 166

4.3 All crops 170

$\begin{array}{ll}4.4 \text { Malnutrition } & 171\end{array}$

5. Conclusions 172

5.1 Essential points for policy-makers $\quad 173$

$\begin{array}{ll}\text { References } & 174\end{array}$

Citation

Thomas, T. and M. Rosegrant. 2015. Climate change impact on key crops in Africa: Using crop models and general equilibrium models to bound the prediction, In: Climate change and food systems: global assessments and implications for food security and trade, Aziz Elbehri (editor). Food Agriculture Organization of the United Nations (FAO), Rome, 2015. 


\section{chapter 5}

\section{Climate change impact on key crops in Africa: Using crop models and general equilibrium models to bound the predictions}

Timothy Thomas and Mark Rosegrant ${ }^{1}$

\section{main chapter messages}

- By examining the detailed climate productivity change maps, it is possible to identify climate hotspots (areas with future significant losses) and climate opportunities (areas with future gains).

- On average, climate change across the globe will have negative effects on productivity which, together with increasing global demand, will drive prices higher. In response to the higher prices, farmers will spend more on inputs and investments to increase productivity. This second-order effect will then lead to some crops to increase in yield sufficiently well to have higher yields than without climate change.
- Because there is reasonable uncertainty as to the impact of climate change on temperature and rainfall in any specific location, policies will need to be flexible and adaptable, so as not to overcommit to any one solution.

- For successful agricultural adaptation to climate change, researchers will need to work together with farmers to develop new crop varieties and livestock breeds - along with supporting agronomic and husbandry methods, extension services and mechanisms for scaling up and out.

\footnotetext{
${ }^{1}$ International Food Policy Research Institute (IFPRI)
} 


\section{Introduction}

A global emissions of anthropogenic greenhouse gases (GHGs) continue relatively unabated, their impact on climate is already being felt. Furthermore, the acceleration of climate change in coming years is virtually assured, due at least in part to the long half-lives of most GHGs. While many of the impacts on people are projected to be modest in the short run (with the exception of increased frequency and intensity of extreme weather events), the adverse consequences are expected to accelerate as climate change accelerates.

Climate change is likely to affect the agricultural sector more than any other sector, which means that populations that depend most on agriculture could be the ones most adversely affected. This is especially true in most African countries. Many of these countries have limited resources to prepare for and adapt to climate change, or to recover from adverse climate shocks.

In order to help African policy-makers, researchers, non-governmental organizations (NGOs) and donors to better plan and prepare for climate change impacts, national level studies were recently undertaken ${ }^{2}$. These studies provide spatially-refined analyses of the impacts of climate on key crops, along with additional analysis that

2 These national level studies were published by the International Food Policy Research Institute (IFPRI) in the form of three monographs on agricultural adaptation to climate change in Africa: one for West Africa (Jalloh et al., 2013); one for East Africa (Waithaka et al., 2013); and one for Southern Africa (Hachigonta et al., 2013). These were produced in partnership with several regional institutes: Conference des Responsables de Recherche Agronomique Africains (CORAF - Conference of the Agricultural Research Leaders in West and Central Africa), Association for Strengthening Agricultural Research in Eastern and Central Africa (ASARECA), and Food, Agriculture and Natural Resources Policy Analysis Network (FANRPAN), and with support from the Consultative Group on International Agricultural Research (CGIAR) research programme on Climate Change, Agriculture and Food Security (CCAFS) and the Federal Ministry for Economic Cooperation and Development, Germany. examines global trends and other factors that are changing with the climate, including gross domestic products (GDP), populations, and agricultural technology development and use. These studies were reported separately for West, East, and Southern Africa. Figure 1 shows the regions covered in this chapter, along with other regions of Africa.

Each study analyzed the range of plausible impacts of climate change by the year 2050, focusing almost entirely on annual crops. Studies used both crop models and global partial equilibrium models, informed by four different climate models and three socio-economic scenarios. In some of the studies on countries in which the livestock sector is important, authors highlighted some key aspects of this sector, using secondary literature.

Two approaches were used to study the impact of climate change on agriculture. The first was to apply the Decision Support System for Agrotechnology Transfer (DSSAT) crop modelling software (Jones et al., 2003) to climate model data, to see how crop yields of major crops would be affected by climate change, not accounting for market effects, technological changes or adaptation. The second was to use a large global partial equilibrium model focusing on food and agriculture, the International Model for Policy Analysis of Agricultural Commodities and Trade (IMPACT), to account for population growth and GDP growth in demand, as well as to consider the supply response, as affected by both climate change and technological change.

For the DSSAT crop models, the goal was to compare crops grown in the typical weather of the period 1950 to 2000 with crops grown in weather expected to be typical in 2050. The studies used climate data from four different general circulation models (GCMs - also referred to as "climate models") so that conclusions would be drawn from a range of scientifically validated possibilities. These models were among those recognized by the Intergovernmental Panel on Climate Change (IPCC) in their Fourth Assessment Report (AR4). These analyses used downscaled climate data 


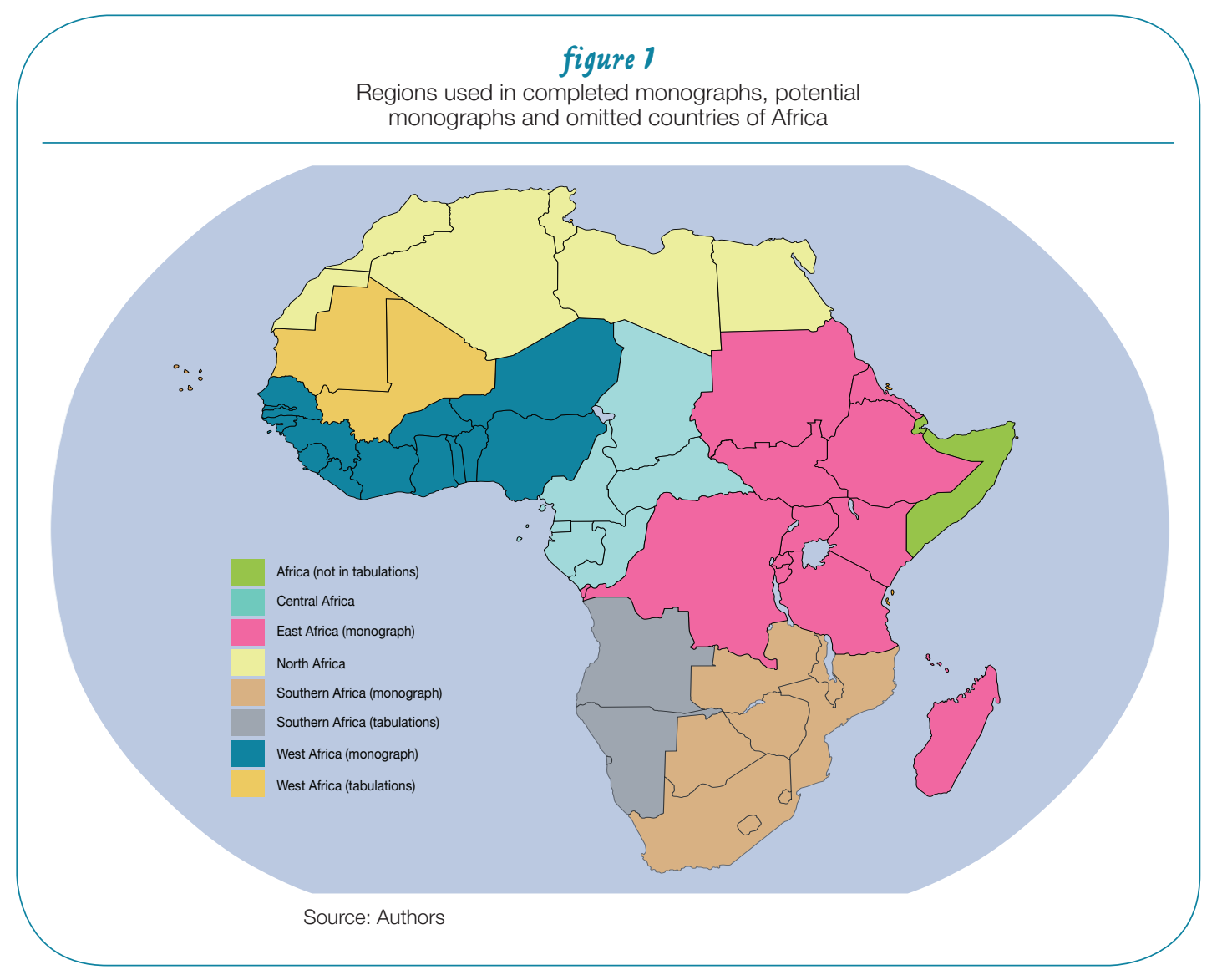

(Jones et al., 2009), with climate data taken approximately every ten kilometres.

The second approach used in these studies worked with IMPACT, a global partial equilibrium food and agricultural model. The authors used estimates for three different GDP and population scenarios (optimistic, pessimistic, and baseline) and four different climate models. The IMPACT model incorporates assumptions about exogenous technological change for agricultural production, so the predictions for yields are much more optimistic than with the crop model approach, which does not allow for technological change. The biophysical impacts of climate change on crop yield from the DSSAT model are incorporated into alternative scenarios in the IMPACT model, in order to assess the effect of climate change when market adjustments are also included.
This paper draws heavily on material presented in the three regional overview chapters of the monographs (Jalloh et al., 2013; Waithaka, et al., 2013; Hachigonta et al., 2013), along with material generated in support of the monographs but which may not have appeared in the final publications. For those wishing to gain a deeper understanding of the methodology used in the studies (and thus of the results presented here), please see the methodology chapter in one of the monographs, such as Nelson et al. (2013).

Although national and subnational results are not entirely ignored in this chapter, its focus is primarily on regional statistics (i.e. for East Africa, West Africa, and Southern Africa).

The chapter is organized as follows: First, key trends are reviewed in order to better understand the forces of change that influence the projections 
and conclusions for 2050. In particular, projections for population, GDP and levels of agricultural production are presented. Then methodologies for climate models are presented, followed by the crop model results for climate change impacts and IMPACT model results. Key policy recommendations are then briefly presented in the conclusions.

\subsection{Population}

Table 1 presents regional summaries of population growth, which is one of the leading drivers of food demand, along with data for leading countries in each region.

East Africa is projected to have the fastest population growth, with the median variant projected to grow at around 2.0 percent annually. This is followed by West Africa, with the median variant projected to grow at around 1.8 percent annually, and Southern Africa, projected to grow at 1.4 percent annually.

The reason Southern Africa is projected to grow more slowly is largely because South Africa, which in 2008 made up slightly more than one-third of the region in terms of population, is projected to grow at only 0.4 percent annually. Its low variant scenario actually projects a negative population growth rate.

Nigeria's population represents more than half of the population of West Africa, and almost 20 percent of the population of all three regions, so it has a large influence on all of the regional statistics presented for West Africa.

With such large population growth rates projected across the three regions, demographic changes will present formidable challenges to policy-makers in the areas of employment, housing, water, health and issues of food security. These challenges will be in addition to any challenges presented by climate change.

\subsection{Income}

The second key driver of food demand is measured as GDP per capita. Table 2 shows that the GDP per capita for Southern Africa is approximately six times higher than West Africa. East Africa and West Africa have similar GDP per capita values, though West Africa's is around 13 percent higher than in East Africa. However, the projected growth rates of GDP per capita suggest that they will even out, with West Africa having the highest projected growth, followed by East Africa and then Southern Africa.

\subsection{Agriculture}

The most important crops for each region, based on crop area harvested, are presented in Table 3. Maize, sorghum and millet occupy the highest crop areas for all of Africa, but with considerable variation across regions. Maize is the most significant crop in Southern Africa, and ranks fourth in West Africa. Sorghum ranks a close second, although it is of relatively low importance (fifth) in Southern Africa. Millet is ranked third - in first place in West Africa but fourth in Southern Africa.

Only Southern Africa is dominated by a single crop, maize, which occupies almost twice the area as the second through fifth ranked crops. Both East Africa and West Africa have more diverse cropping areas, although maize and sorghum together form a significant portion of crop area for East Africa.

\section{Climate and climate models}

\subsection{Precipitation}

Figure 2 shows mean annual precipitation for the 1950 to 2000 period. Steep declines in precipitation are seen moving northwards through the Sahelian zone towards the Sahara in North 
table 1

Population in 2008, and projected population in 2050 (millions)

\begin{tabular}{|c|c|c|c|c|}
\hline \multirow[t]{3}{*}{ Name } & \multirow{3}{*}{$\begin{array}{l}2008 \\
\text { WDI }\end{array}$} & \multicolumn{3}{|c|}{2050} \\
\hline & & Low & Median & High \\
\hline & & \multicolumn{3}{|c|}{ United Nations } \\
\hline West Africa & 287604 & 545233 & 618835 & 697456 \\
\hline Benin & 8662 & 19402 & 21982 & 24744 \\
\hline Burkina Faso & 15209 & 36189 & 40830 & 45757 \\
\hline Cote d'Ivoire & 20591 & 37845 & 43373 & 49350 \\
\hline Gambia, The & 1660 & 3292 & 3763 & 4270 \\
\hline Ghana & 23351 & 39660 & 45,213 & 51163 \\
\hline Guinea & 9833 & 21131 & 23975 & 27025 \\
\hline Guinea-Bissau & 1575 & 3147 & 3555 & 3990 \\
\hline Liberia & 3793 & 7730 & 8841 & 10040 \\
\hline Mali & 12711 & 24941 & 28260 & 31792 \\
\hline Niger & 14669 & 52568 & 58216 & 64156 \\
\hline Nigeria & 151319 & 254129 & 289083 & 326395 \\
\hline Senegal & 12211 & 22814 & 26102 & 29620 \\
\hline Sierra Leone & 5560 & 10904 & 12446 & 14100 \\
\hline Togo & 6459 & 11481 & 13196 & 15054 \\
\hline Southern Africa & 135054 & 208209 & 241513 & 277655 \\
\hline Angola & 18021 & 37224 & 42267 & 47675 \\
\hline Botswana & 1905 & 2335 & 2758 & 3220 \\
\hline Lesotho & 2017 & 2056 & 2491 & 2970 \\
\hline Malawi & 14278 & 32019 & 36575 & 41456 \\
\hline Mozambique & 21781 & 38268 & 44148 & 50480 \\
\hline Namibia & 2114 & 3076 & 3588 & 4141 \\
\hline South Africa & 48687 & 47536 & 56802 & 67051 \\
\hline Swaziland & 1168 & 1463 & 1749 & 2061 \\
\hline Zambia & 12620 & 25302 & 28957 & 32870 \\
\hline Zimbabwe & 12463 & 18930 & 22178 & 25731 \\
\hline East Africa & 340843 & 678634 & 773746 & 875639 \\
\hline Burundi & 8074 & 13006 & 14846 & 16814 \\
\hline Congo, DR & 64205 & 130013 & 147512 & 166249 \\
\hline Eritrea & 4996 & 9458 & 10787 & 12198 \\
\hline Ethiopia & 80713 & 152720 & 173811 & 196245 \\
\hline Kenya & 38534 & 74187 & 85410 & 97541 \\
\hline Madagascar & 19111 & 37155 & 42693 & 48694 \\
\hline Rwanda & 9721 & 19498 & 22082 & 24829 \\
\hline Sudan & 41348 & 66140 & 75884 & 86371 \\
\hline Tanzania & 42484 & 95884 & 109450 & 124020 \\
\hline Uganda & 31657 & 80573 & 91271 & 102678 \\
\hline
\end{tabular}




\section{table 2}

GDP per capita in 2008, and projected for 2050 (constant 2000 US dollars)

\begin{tabular}{|c|c|c|c|c|}
\hline \multirow[t]{3}{*}{ Name } & \multirow{3}{*}{$\begin{array}{l}2008 \\
\text { WDI }\end{array}$} & \multicolumn{3}{|c|}{2050} \\
\hline & & Low & Median & High \\
\hline & & \multicolumn{3}{|c|}{ Projections } \\
\hline West Africa & 324 & 808 & 1697 & 3174 \\
\hline Benin & 359 & 149 & 1397 & 2539 \\
\hline Burkina Faso & 263 & 791 & 1428 & 2579 \\
\hline Cote d'Ivoire & 530 & 1536 & 3401 & 6265 \\
\hline Gambia, The & 374 & 750 & 1724 & 3162 \\
\hline Ghana & 327 & 988 & 2724 & 4975 \\
\hline Guinea & 417 & 1456 & 2876 & 5234 \\
\hline Guinea-Bissau & 128 & 683 & 835 & 2140 \\
\hline Liberia & 148 & 347 & 394 & 1594 \\
\hline Mali & 295 & 1122 & 2108 & 3818 \\
\hline Niger & 180 & 559 & 637 & 1671 \\
\hline Nigeria & 487 & 684 & 1364 & 2491 \\
\hline Senegal & 530 & 1362 & 3055 & 5602 \\
\hline Sierra Leone & 262 & 378 & 1410 & 2566 \\
\hline Togo & 245 & 660 & 1438 & 2653 \\
\hline Southern Africa & 1957 & 2682 & 5892 & 11852 \\
\hline Angola & 1357 & 3548 & 4002 & 8378 \\
\hline Botswana & 4440 & 3686 & 25628 & 48646 \\
\hline Lesotho & 525 & 1850 & 3166 & 6279 \\
\hline Malawi & 165 & 656 & 744 & 2488 \\
\hline Mozambique & 365 & 1186 & 1812 & 2885 \\
\hline Namibia & 2692 & 4082 & 14239 & 26654 \\
\hline South Africa & 3764 & 5409 & 15473 & 29941 \\
\hline Swaziland & 1559 & 2709 & 8026 & 15455 \\
\hline Zambia & 387 & 1791 & 2454 & 4254 \\
\hline Zimbabwe & NA & 1326 & 1539 & 5296 \\
\hline East Africa & 287 & 565 & 1161 & 1780 \\
\hline Burundi & 111 & 569 & 973 & 1450 \\
\hline Congo, DR & 99 & 277 & 440 & 715 \\
\hline Eritrea & 147 & 505 & 955 & 1379 \\
\hline Ethiopia & 190 & 323 & 720 & 1037 \\
\hline Kenya & 464 & 543 & 2255 & 3286 \\
\hline Madagascar & 271 & 654 & 1195 & 1741 \\
\hline Rwanda & 313 & 468 & 1583 & 2268 \\
\hline Sudan & 532 & 320 & 372 & 680 \\
\hline Tanzania & 362 & 1013 & 1310 & 2416 \\
\hline Uganda & 348 & 1156 & 2563 & 3667 \\
\hline $\begin{array}{l}\text { Source: WDI from V } \\
\text { Adaptation to Clima } \\
\text { population data fror }\end{array}$ & $\begin{array}{l}\text { 09). Proj } \\
\text { ject (Wo } \\
\text { lations (U }\end{array}$ & $\begin{array}{l}\text { uted usir } \\
\text { Millenniur }\end{array}$ & $\begin{array}{l}\text { om the World } \\
\text { ssessment (2 }\end{array}$ & \\
\hline
\end{tabular}


table 3

Top five crops per region, ranked by harvested area (ha), mean 2006-2008

\begin{tabular}{lccccr}
\hline East Africa & \multicolumn{2}{c}{ Southern Africa } & \multicolumn{2}{c}{ West Africa } \\
\hline Crop & Hectares & Crop & Hectares & Crop & Hectares \\
Sorghum & 9893208 & Maize & 9199950 & Millet & 16002237 \\
\hline Maize & 9367883 & Cassava & 2015384 & Sorghum & 14288715 \\
\hline Millet & 3622654 & Groundnuts & 1073603 & Cow peas & 10297759 \\
\hline Beans & 3512688 & Millet & 988690 & Maize & 7747435 \\
\hline Cassava & 3474208 & Sorghum & 848518 & Rice & 5725947 \\
\hline Source: FAOSTAT (FAO 2010) & & & & \\
\end{tabular}

Africa as well as moving towards the coast of Botswana. High rainfall areas are noted among the tropical forests of the Democratic Republic of Congo, the eastern coast of Madagascar, and several coastal locations in Central Africa and West Africa.

In the three monographs on agriculture and climate change in Africa, the authors used climate data from GCMs that had been produced for the IPCC AR4. Figure 3 shows changes in annual precipitation as projected by the four GCMs used in these studies (CNRM, CSIRO, ECHAM, and MIROC). These GCMs reflect assumptions of the IPCC's A1B scenario for GHG emissions (see notes for Figure). Table 4 augments the maps in Figure 3, tabulating the mean changes for each country and region by GCM.

According to the CNRM GCM, a few locations should expect a significant reduction in rainfall (a noteworthy exception being the southern half of Madagascar) but the Horn of Africa and much of coastal Central Africa should anticipate significant increases in rainfall. This is in contrast to the CSIRO GCM, which shows very few locations experiencing significant increases in rainfall. Much of the Atlantic coast of Africa is projected to become significantly drier.

The ECHAM GCM projects that most of Southern Africa will become significantly drier under climate change. At the same time, much of Central Africa and parts of the interior of East Africa are projected to become wetter. Some of

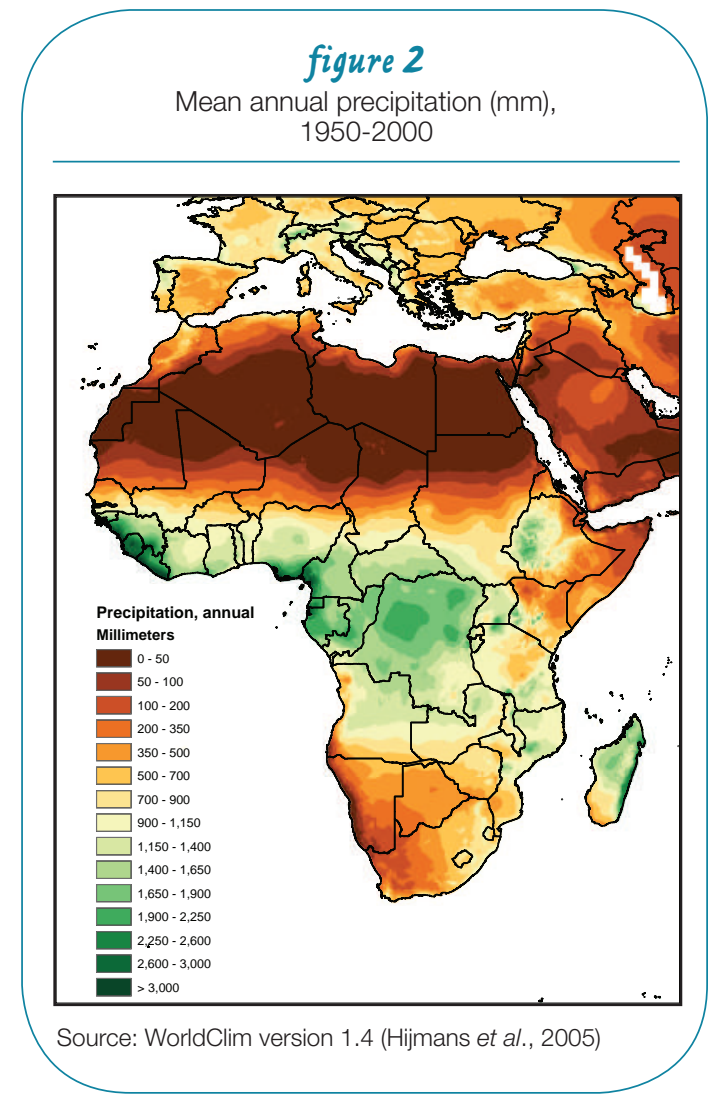

the steepest declines in rainfall are projected by the MIROC GCM. These occur in coastal portions of central Africa and the southern coast of West Africa. 


\section{figure 3}

Change in mean annual rainfall (mm), from 19502000 climate to 2050 climate
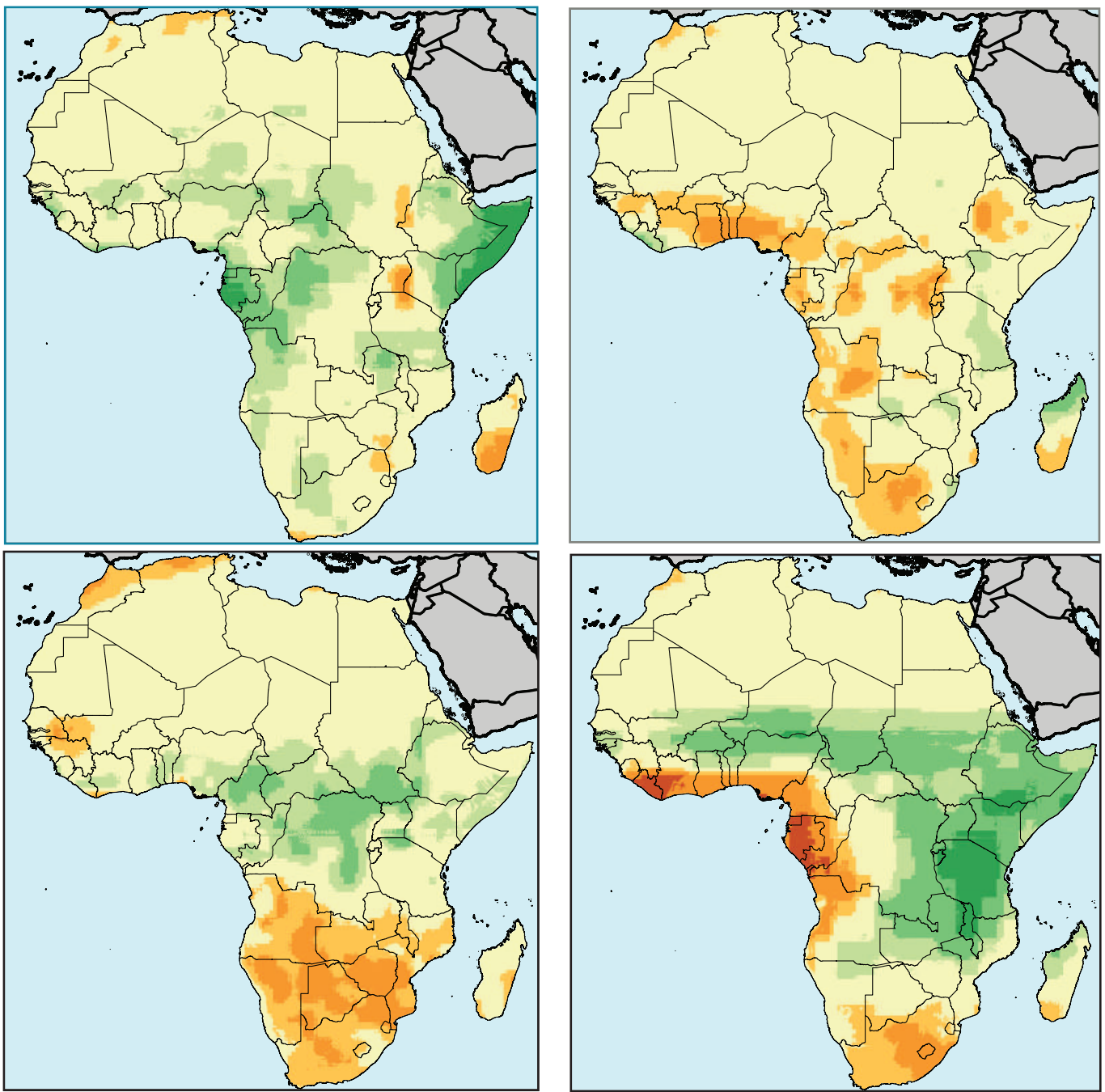

Source: Authors' calculations based on Jones, Thornton and Heinke (2009)

Notes: Model predictions for A1B scenario and 4 AR4 GCMs: CNRM (top left); CSIRO (top right); ECHAM (bottom left; and MIROC (bottom right). A1B = greenhouse gas emissions scenario that assumes fast economic growth, a population that peaks mid-century, and the development of new and efficient technologies, along with a balanced use of energy sources; CNRM-CM3 = National Meteorological Research Centre-Climate Model 3; CSIRO = climate model developed at the Australia Commonwealth Scientific and Industrial Research Organisation; ECHAM $5=$ fifth-generation climate model developed at the Max Planck Institute for Meteorology (Hamburg); GCM = general circulation model; MIROC = Model for Interdisciplinary Research on Climate, developed by the University of Tokyo Center for Climate System Research 
table 4

Average change in annual rainfall ( $\mathrm{mm}$ ), climate of 2000-2050

\begin{tabular}{lrrrrlrrrr}
\hline Country/Region & CNR & CSI & ECH & MIR & Country/Region & CNR & CSI & ECH & MIR \\
\hline East Africa & 32 & -7 & 39 & 100 & West Africa & 30 & -23 & -1 & 22 \\
\hline Sudan & 20 & 10 & 37 & 70 & Benin & 11 & -89 & 45 & 49 \\
\hline Ethiopia & 72 & -35 & 41 & 141 & Cape Verde & -3 & -4 & -12 & 12 \\
\hline Eritrea & 37 & 3 & 38 & 67 & Gambia & 24 & -20 & -33 & 67 \\
\hline Kenya & 64 & 26 & 47 & 184 & Mauritania & 2 & -7 & -12 & 6 \\
\hline Tanzania & 25 & 31 & 11 & 214 & Burkina Faso & 46 & -46 & -16 & 114 \\
\hline Uganda & -53 & -20 & 64 & 153 & Cote d'lvoire & 31 & -38 & 25 & -127 \\
\hline D. R. Congo & 55 & -43 & 64 & 61 & Ghana & 2 & -103 & 25 & -54 \\
\hline Rwanda & 2 & -63 & 10 & 197 & Guinea & 46 & -45 & -44 & -12 \\
\hline Burundi & -20 & -57 & 1 & 209 & Guinea-Bissau & 48 & -35 & -29 & 83 \\
\hline Madagascar & -62 & 20 & -22 & 14 & Liberia & 14 & 72 & 22 & -236 \\
\hline Southern Africa & 24 & -28 & -82 & -2 & Mali & 28 & -12 & -18 & 39 \\
\hline South Africa & 9 & -57 & -81 & -89 & Niger & 47 & 5 & -2 & 75 \\
\hline Botswana & 19 & -17 & -104 & -9 & Nigeria & 50 & -57 & 35 & 28 \\
\hline Lesotho & -15 & -53 & -54 & -161 & Senegal & 14 & -20 & -46 & 36 \\
\hline Swaziland & -9 & 51 & -94 & -54 & Sierra Leone & 28 & 12 & 17 & -84 \\
\hline Namibia & 32 & -54 & -88 & -10 & Togo & -10 & -120 & 48 & -21 \\
\hline Angola & 48 & -57 & -74 & -28 & & & & &
\end{tabular}

Source: Authors' calculations based on Jones, Thornton, and Heinke (2009)

Notes: All values are based on the A1B SRES scenerio, which is a greenhouse gas emissions scenario that assumes fast economic growth, a population that peaks mid-century and the development of new and efficient technologies, along with a balanced use of energy sources; CNR is an abbreviation for CNRM-CM3, which is a GCM from the National Meteorological Research Centre-Climate Model 3; CSI is an abbreviation for CSIRO, which is a climate model developed at the Australia Commonwealth Scientific and Industrial Research Organisation; ECH is an abbreviation for ECHAM 5, which is a fifth-generation climate model developed at the Max Planck Institute for Meteorology (Hamburg); GCM = general circulation model; MIR is an abbreviation for MIROC, which is a GCM and is short for the Model for Interdisciplinary Research on Climate, developed bythe University of Tokyo Center for Climate System Research.

Generally, the models suggest that East Africa will become wetter and Southern Africa will become drier, while the results for West Africa are mixed.

\subsection{Temperature}

In all the models, temperature is projected to increase, but by different amounts across models. The distribution of temperature in the climate of 1950-2000 is shown in Figure 4, which indicates the mean daily maximum temperature for the warmest month. As expected, temperatures are higher moving northwards across the Sahelian zone towards the Sahara. Coastal areas tend to be cooler, especially along the Mediterranean Sea, but also quite noticeably along the Atlantic Coast from Southern Africa through Central Africa to the southern coast of West Africa. Highlands are noticeably cooler.

Figure 5 shows the changes in mean daily maximum temperature for the warmest month according to each of the four GCMs used in the analysis. Temperature changes by country and region are shown in Table 5. 


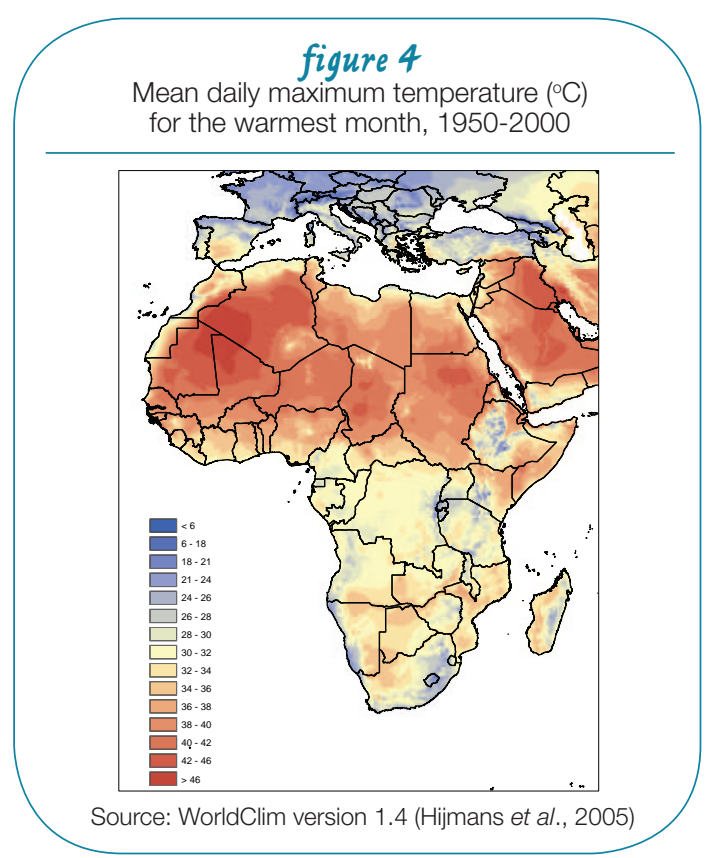

Some of the most extreme temperature increases are found in the ECHAM GCM. When averaged by region, this always proves to be the hottest model but the increases are particularly strong in this GCM for Southern Africa. When combined with the drying trend that was shown previously, this suggests that if the ECHAM model proves to be accurate, Southern Africa may be the hardest hit in terms of rainfed crop production.

MIROC also shows some extreme temperature increases, but these tend to be focused in North Africa, and in the northern portions of West Africa. While the calculations for West Africa according to this GCM appear to present challenges for cropping, much of the extreme temperature increase appears in parts of the region which are already too dry for rainfed crops. This is a mitigating factor, as well, for Southern Africa in the ECHAM model, because the highest temperature increases are also in very dry areas.

The CSIRO GCM generally predicts relatively modest temperature increases. This is especially the case for East Africa and large portions of West Africa.

Finally, the CNRM GCM resembles the ECHAM GCM, except in Southern Africa, where it is more moderate in its projections for temperature increases.

Considering all the models together, Southern Africa is projected generally to be the hardest hit in terms of temperature increases.

\section{DSSAT Crop Model results}

DSSAT is a crop modelling software package that was used in the three monographs on climate change impacts on agriculture in Africa on which this chapter is based. The crops analysed in those monographs using DSSAT are maize, wheat, rice, soybeans, groundnuts and sorghum. DSSAT takes into account soil characteristics and weather, as well as crop variety and farming practices.

DSSAT has its own daily weather data generator, which was applied in the study. For each month, climate data were provided, consisting of mean precipitation, number of rainy days, solar radiation, mean daily high temperature, and mean daily low temperature. From these data, the software programme stochastically generates daily weather data that are based on the monthly statistics.

Using the daily data for the climate of 1950 to 2000 , thirty years of weather were simulated, and yields were computed for each of those years, taking the average of weather outcomes. The same procedure was applied for each GCM, to generate climate assumptions for the year 2050. The mean yield results were compared, gridcellby-gridcell, to determine how yields would change between 2000 and 2050 as a result of climate change.

In this particular analysis, it was assumed that there would be no adaptation. This implies that the model did not allow for changing cultivars or fertilizer regimens or, in the case of rainfed crops, for switching to some kind of water supplementation, such as irrigation.

The analysis focused on 10 kilometre gridcells for East and Southern Africa, and 30 kilometre gridcells for West Africa (except for sorghum, which was done at 10 kilometre resolution). In the case of East Africa, a grid was overlaid 


\section{figure 5}

Change $\left({ }^{\circ} \mathrm{C}\right)$ in mean daily maximum temperature for the warmest month, 2000-2050
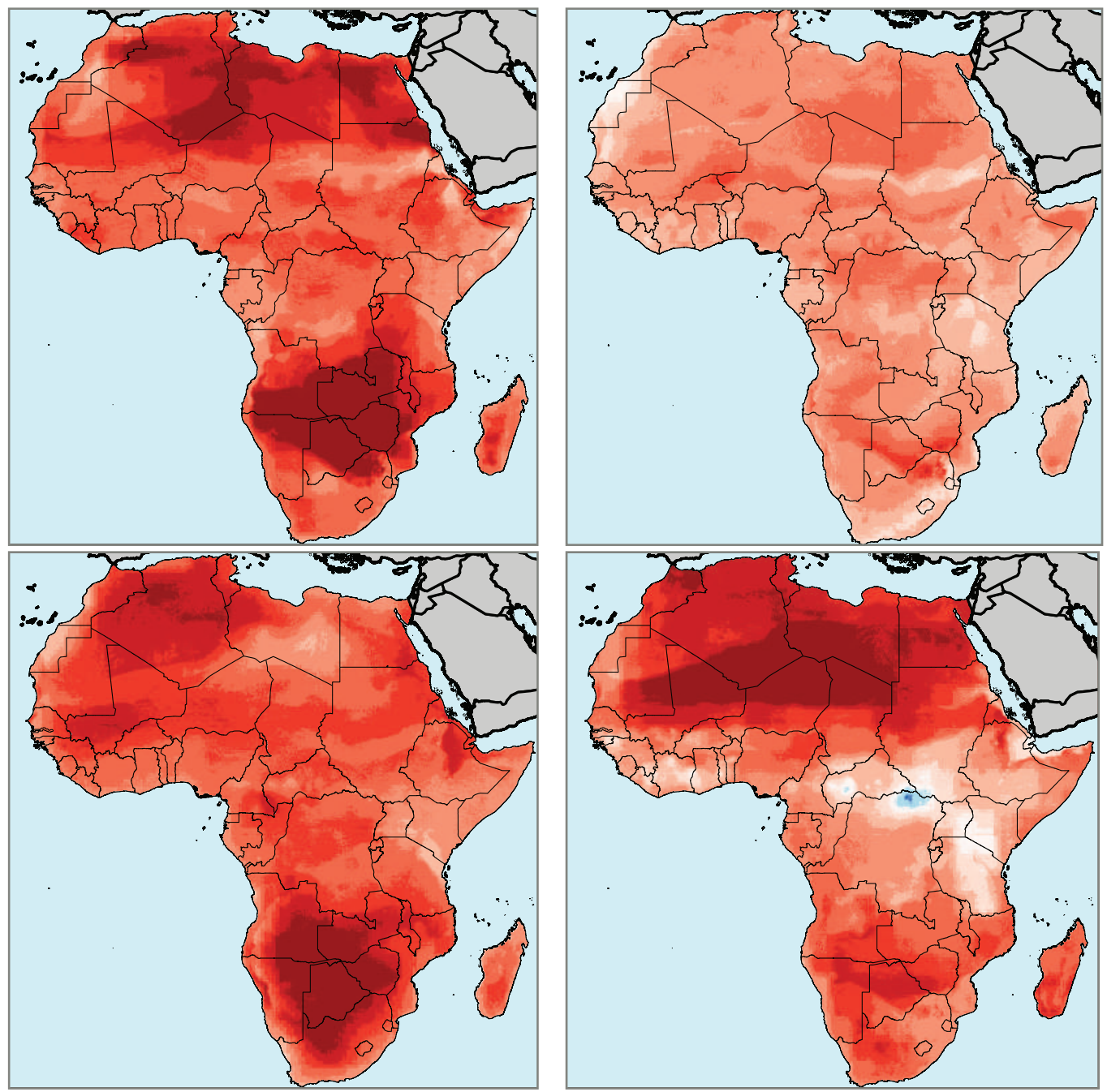

Source: Authors' calculations based on Jones, Thornton, and Heinke (2009)

Notes: Model predictions for A1B scenario and 4 AR4 GCMs: CNRM (top left); CSIRO (top right); ECHAM (bottom left; and MIROC (bottom right). A1B = greenhouse gas emissions scenario that assumes fast economic growth, a population that peaks mid-century and the development of new and efficient technologies, along with a balanced use of energy sources; CNRM-CM3 = National Meteorological Research Centre-Climate Model 3; CSIRO = climate model developed at the Australia Commonwealth Scientific and Industrial Research Organisation;

ECHAM 5 = fifth-generation climate model developed at the Max Planck Institute for

Meteorology (Hamburg); GCM = general circulation model; MIROC = Model for Interdisciplinary Research on Climate, developed by the University of Tokyo Center for Climate System Research.

Results for the CNRM (top left), CSIRO (top right), ECHAM (bottom left), and MIROC (bottom right) GCMs 
table 5

Average change $(\mathrm{oC})$ in mean daily maximum temperature for the warmest month, 2000-2050

\begin{tabular}{llllllllll}
\hline Country/Region & CNR & CSI & ECH & MIR & Country/Region & CNR & CSI & ECH & MIR \\
\hline East Africa & 2.1 & 1.3 & 2.1 & 1.5 & West Africa & 2.2 & 1.5 & 2.3 & 2.0 \\
\hline Sudan & 2.2 & 1.2 & 2.2 & 1.7 & Benin & 2.1 & 1.6 & 2.0 & 1.4 \\
\hline Ethiopia & 1.9 & 1.4 & 2.0 & 1.3 & Cape Verde & 1.8 & 0.8 & 1.6 & 1.8 \\
\hline Eritrea & 2.1 & 1.2 & 2.1 & 1.4 & Gambia & 2.0 & 1.3 & 2.1 & 1.6 \\
\hline Kenya & 1.8 & 1.2 & 1.9 & 1.1 & Mauritania & 2.4 & 1.5 & 2.4 & 2.8 \\
\hline Tanzania & 2.1 & 1.1 & 2.1 & 1.2 & Burkina Faso & 2.1 & 1.6 & 2.4 & 1.4 \\
\hline Uganda & 2.1 & 1.3 & 2.1 & 1.1 & Cote d'Ivoire & 2.2 & 1.4 & 2.0 & 1.1 \\
\hline D. R. Congo & 2.0 & 1.4 & 2.2 & 1.6 & Ghana & 2.2 & 1.5 & 1.9 & 1.2 \\
\hline Rwanda & 2.1 & 1.3 & 2.1 & 1.5 & Guinea & 2.2 & 1.5 & 2.4 & 1.4 \\
\hline Burundi & 2.2 & 1.3 & 2.2 & 1.5 & Guinea-Bissau & 2.0 & 1.4 & 2.1 & 1.4 \\
\hline Madagascar & 2.0 & 1.3 & 1.7 & 2.1 & Liberia & 2.2 & 1.2 & 1.8 & 1.4 \\
\hline Southern Africa & 2.2 & 1.7 & 2.7 & 1.9 & Mali & 2.3 & 1.7 & 2.6 & 2.4 \\
\hline South Africa & 2.0 & 1.8 & 2.4 & 2.0 & Niger & 2.2 & 1.5 & 2.4 & 2.3 \\
\hline Botswana & 2.4 & 2.0 & 3.2 & 2.0 & Nigeria & 2.1 & 1.4 & 2.0 & 1.3 \\
\hline Lesotho & 2.1 & 1.6 & 2.3 & 1.8 & Senegal & 2.1 & 1.4 & 2.3 & 1.7 \\
\hline Swaziland & 1.8 & 1.3 & 2.0 & 1.5 & Sierra Leone & 2.2 & 1.3 & 2.0 & 1.4 \\
\hline Namibia & 2.3 & 1.9 & 2.8 & 2.2 & Togo & 2.2 & 1.6 & 1.9 & 1.4 \\
\hline Angola & 2.2 & 1.6 & 2.7 & 2.1 & & & & & \\
\hline Malawi & 2.1 & 1.4 & 2.5 & 1.6 & & & & & \\
\hline Zambia & 2.2 & 1.4 & 2.9 & 1.6 & & & & & \\
\hline Zimbabwe & 2.3 & 1.7 & 2.8 & 1.7 & & & & & \\
\hline Mozambique & 2.0 & 1.4 & 2.2 & 1.7 & & & & & \\
\hline & & & & & & & & & \\
\hline
\end{tabular}

Source: Authors' calculations based on Jones, Thornton, and Heinke (2009)

Notes: All values are based on the A1B SRES scenerio, which is a greenhouse gas emissions scenario that assumes fast economic growth, a population that peaks mid-century and the development of new and efficient technologies, along with a balanced use of energy sources; CNR is an abbreviation for CNRM-CM3, which is a GCM from the National Meteorological Research Centre-Climate Model 3; CSI is an abbreviation for CSIRO, which is a climate model developed at the Australia Commonwealth Scientific and Industrial Research Organisation; ECH is an abbreviation for ECHAM 5, which is a fifth-generation climate model developed at the Max Planck Institute for Meteorology (Hamburg); GCM = general circulation model; MIR is an abbreviation for MIROC, which is a GCM and is short for the Model for Interdisciplinary Research on Climate, developed by the University of Tokyo Center for Climate System Research

onto the map forming a collection of squares of $10 \times 10$ kilometres. Yield was computed for the values at the centre of each square.

\subsection{Rainfed maize}

Rainfed maize is one of the crops grown widely across all three regions of Africa that were considered in the monographs. It will be the main focus of this paper.

\section{East Africa}

Figure 6 shows the rainfed maize areas in East Africa, using IFPRI's Spatial Production Allocation Model (SPAM) dataset for 2000. SPAM takes agricultural statistical information from national datasets, using provinces, districts, or any other level of aggregation that is available. It then uses geographic datasets on land cover, irrigation, roads and cities, along with national expert information on production technologies, to distribute agricultural activities, including estimates of yields and areas harvested. 
Figure 6 indicates where rainfed maize is currently cultivated, and where crop model analysis was utilized. The DSSAT crop model was applied to cells containing at least 30 ha of a crop, out of a total of approximately 8500 ha per gridcell. Analysis was likewise applied within a few pixels of the gridcells that were selected for analysis by the "30 hectare" rule. Note the areas of no data $(<1$ ha) where maize is no longer cultivated, which will most likely remain the case in the future.

Figure 7 shows the results of this analysis using crop models combined with climate models. This Figure focuses on the areas of East Africa where maize is mostly grown. Significant regional variations as well as variations between GCMs were observed, as shown in Figure 7. Overall, the models suggest a slight positive change in production of rainfed maize due to climate change in East Africa, although certain countries will do better than others. Generally, Uganda appears to be consistently adversely affected in terms of maize production, while the impact in Ethiopia is mostly positive.

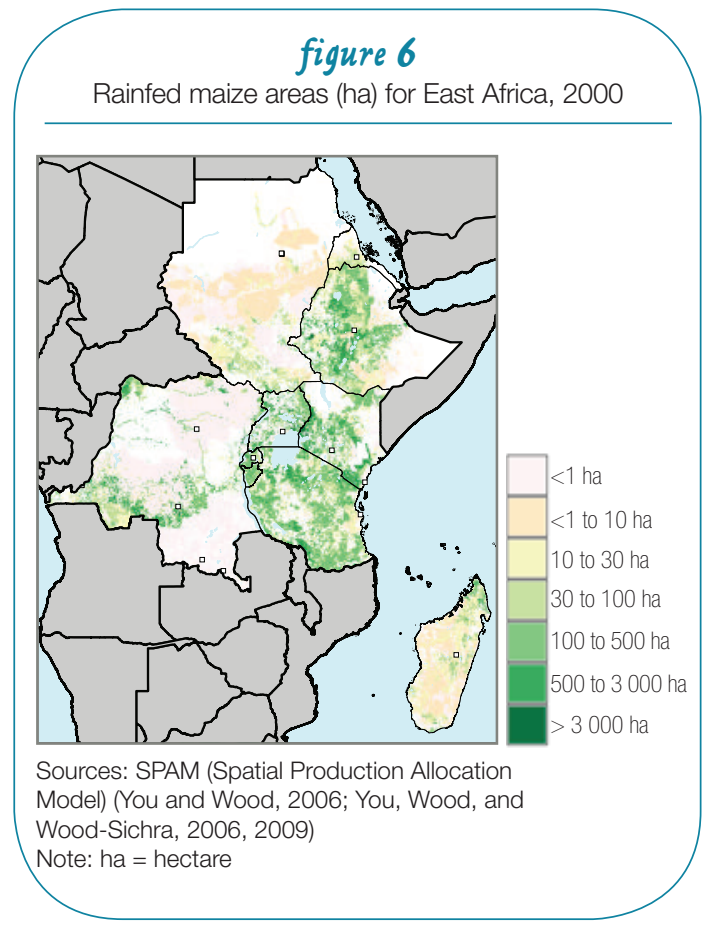

The ECHAM model seems to be the most pessimistic of the four in terms of rainfed maize productivity, with significant yield reduction visible across southern Tanzania and the central parts of Ethiopia.

\section{Understanding and interpreting Crop Model} Maps (an application to rainfed maize in East Africa)

By examining the detailed climate productivity change maps, it is possible to identify climate hotspots (areas which are projected to suffer large losses) and climate opportunities (areas which may have large gains or areas that were previously unsuitable but can become suitable for crop production at some point).

Climate hotspots are areas that will become unproductive (shown in red) or have high yield losses (shown in dark orange) as a result of climate change. These only qualify as "hotspots" if they are the main crop in terms of income or consumption for those growing them. One GCM, the CNRM model, concludes that the area in western Kenya is one of those hotspots. Because the other GCMs are more optimistic about production in that location, the area is considered to be a possible hotspot. But if the CNRM GCM proved, over time, to be accurate, then farmers in that location would be under severe hardship, which would make that particular region of Kenya a legitimate hotspot.

Climate hotspots require special attention, because unless farmers find tools with which to adapt, they will likely become impoverished, possibly inducing climate migration - either to towns and cities, or to areas seen to present climate opportunities.

Climate opportunities are those areas that could come into production (shown in blue) or have significant yield increases (shown in dark green) as a result of climate change. The models appear to be generally in agreement in the central part of Kenya, with the appearance of new areas for producing rainfed maize. Climate opportunities are generally the result of one of two possibilities: first, that rainfall has increased in an area where rainfall had been too low to sustain production; or second, 


\section{figure 7}

Change (\%) in rainfed maize yield for East Africa due to climate change, 2050, A1B scenario

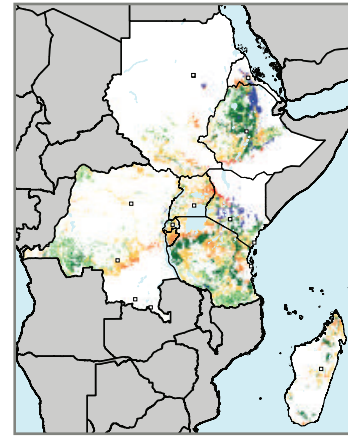

Source: Authors

Notes: Left to right: results for the CNRM, CSIRO, ECHAM, and MIROC GCMs

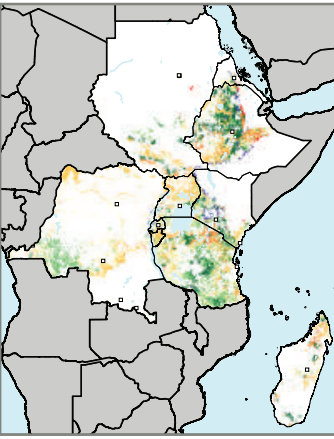

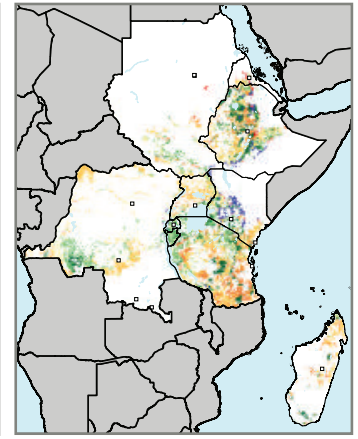

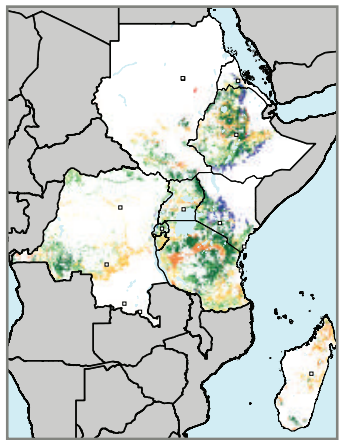

Baseline area lost

Yield lost $>25 \%$ of baseline Yield lost $5 \%$ to $25 \%$ of baseline Yield change within $5 \%$ of baseline Yield gain $5 \%$ to $25 \%$ of baseline Yield gain $>25 \%$ of baseline

New area gained that temperature has risen to a point that an area that might have been too cold to produce the crop will now be sufficiently warm. This latter possibility is generally found in higher elevations.

While climate opportunities may present truly good opportunities, both to farmers and to society, some of these areas may not be without additional challenges. For example, some of these areas may be in protected forests or game reserves or on slopes of hills or mountains, and what might be a climate opportunity could also be a potential tourism or environmental disaster.

These areas may also present fresh avenues for social conflict if climate migration induces people of one ethnicity to move into an area traditionally occupied by people of another ethnicity. Furthermore, ethnicity aside, these areas might previously have been considered commons, or even privately owned but unused land, and new settlers might cause property rights conflicts to arise in cases where laws are not explicit or easily enforced.

All of the possibilities demonstrated in the climate productivity change maps developed from crop modelling suggest several avenues for policy-makers to consider, depending on what the analysis shows and on existing legal and social structures.

If climate hotspots are identified, some kind of intervention would likely improve the outcome for the people living in those areas. Some possibilities include:

- Investment in agricultural research, to develop new varieties of crops currently grown, identify alternative crops that are acceptable to the farmers and their families or develop new farming techniques for the area that will help farmers to continue to grow their current crop (e.g., small-scale water harvesting in areas that will be affected by declining precipitation).

- Coordination between agricultural research and extension and advisory services, to help make farmers aware of any technological solutions developed.

- Support for developing rural enterprises in the affected area to engage farmers in new approaches for income-generating activities.

- Assistance to farmers moving to a more suitable location;

- $\quad$ And, in some cases, investment in irrigation. 
If climate opportunity areas are identified, further analysis need to be performed to determine any additional concerns about impacts on environmentally sensitive areas. Points to consider are a) strengthening protection for environmentally sensitive areas; and b) strengthening or clarifying property rights issues.

\section{Southern Africa}

Figure 8 shows areas where rainfed maize is grown in Southern Africa. Much of the western portion of South Africa and all but the northernmost part of Namibia do not currently cultivate maize, but it is otherwise grown throughout most of the region.

Figure 9 shows yield change maps for rainfed maize for the areas of highest maize concentration in Southern Africa. Analysis across all the models indicates that yields will be adversely affected in most of South Africa, but the expected impacts are more positive than negative in Zambia and Zimbabwe.

The results from the ECHAM model appear to be more negative in their outlook than results for the other models - most notably in northern Mozambique, but also in South Africa.

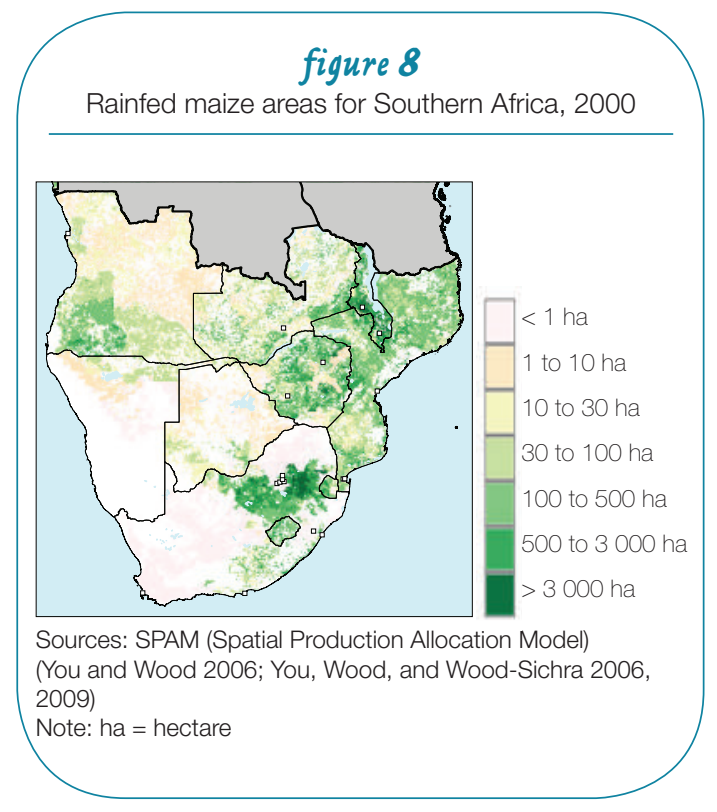

In both the ECHAM and MIROC models, areas will become unproductive in Botswana and Angola, and also in northern Namibia according to the ECHAM model.

Potential new areas that might become productive, which are found across all models, include parts of Lesotho and part of South Africa just northeast of Lesotho. These all appear to be elevated areas.

\section{West Africa}

Figure 10 shows estimated areas of rainfed maize for West Africa from the SPAM model. Most of the maize is grown south of the Sahel although it is not grown on the western coast of the region, except in and around Gambia.

Figure 11 shows productivity changes of rainfed maize resulting from the crop model analysis of the climate models. These results are focused on the areas of highest maize concentration in West Africa.

With the possible exception of the CNRM GCM, the models show productivity losses across the entire southern coastal area of West Africa (Figure 11). The maps in this Figure indicate some areas of yield increase across Burkina Faso and southern Mali, and a slight amount in northern Nigeria. Finally, there appears to be a band in the north of SudanoSahel zone (shown in red) in which cultivation of rainfed maize will probably cease to be feasible. It is likely that temperature increase will be the main driver of this change, making it too warm to cultivate maize.

\subsection{All crops}

\section{East Africa}

Table 6 presents productivity changes from climate change, based on the crop model analysis in East Africa. Computations were done using weighted averages and applying harvested areas of the respective crops from the SPAM model as weights.

Rainfed sorghum, wheat, and soybeans, along with irrigated rice, are unequivocal losers under 


\section{figure 9}

Change (\%) in rainfed maize yield for Southern Africa due to climate change, 2050, A1B scenario
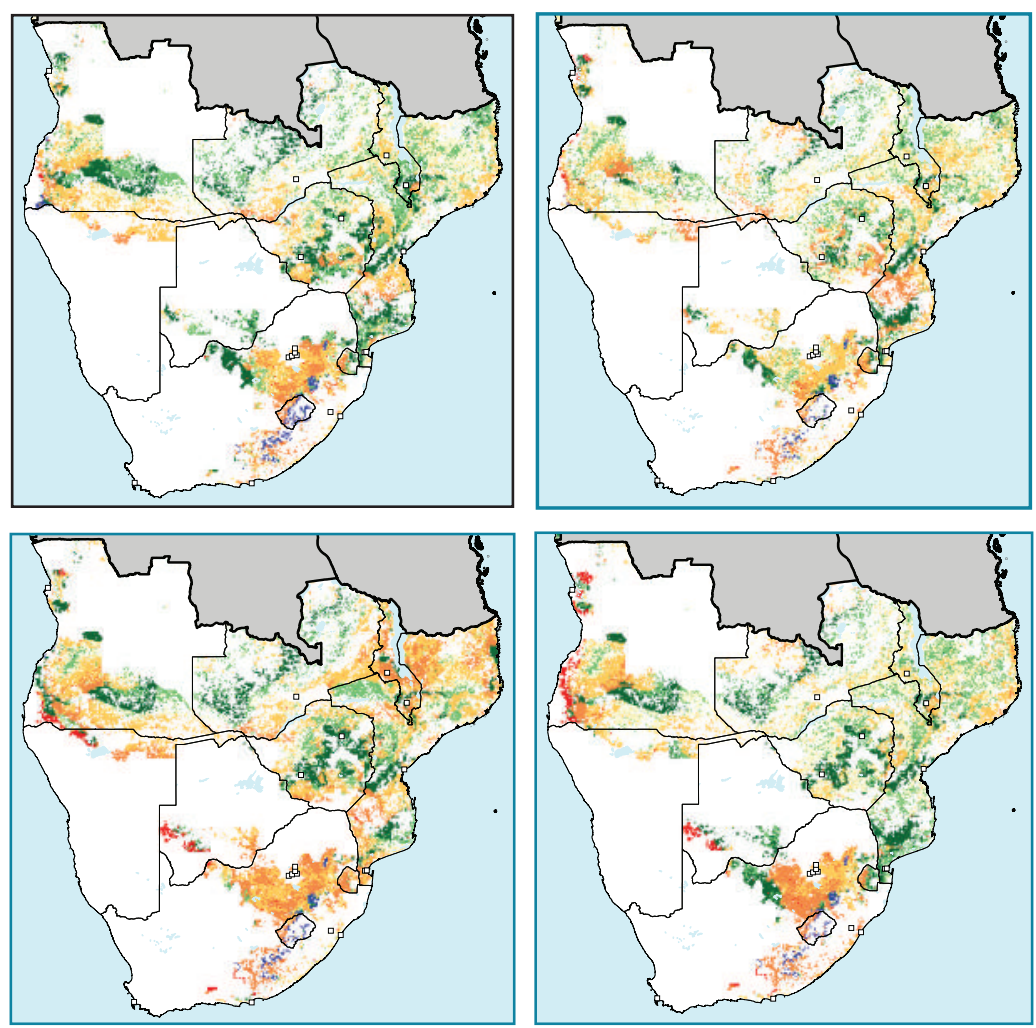

Baseline area lost

Yield lost $>25 \%$ of baseline

Yield lost $5 \%$ to $25 \%$ of baseline Yield change within $5 \%$ of baseline Yield gain 5\% to 25\% of baseline

Yield gain $>25 \%$ of baseline

New area gained

Source: Authors

Notes: Results for the CNRM (top left), CSIRO (top right),

ECHAM (bottom left), and MIROC (bottom right) GCMs

\section{table 6}

Yield changes (\%) for various crops in East Africa as a result of climate change, 2000 - 2050

\begin{tabular}{lccrrr}
\hline Water & Crop & CNRM & CSIRO & ECHAM & MIROC \\
\hline Rainfed & Groundnuts & -8.3 & 1.9 & 2.4 & 11.6 \\
\hline Rainfed & Maize & 1.5 & 2.5 & -1.7 & -18.7 \\
\hline Irrigated & Rice & -19.7 & -10.4 & -17.3 & 6.7 \\
\hline Rainfed & Rice & 2.2 & 2.8 & -7.4 & -0.5 \\
\hline Rainfed & Sorghum & -15.5 & -6.0 & -15.9 & -10.6 \\
\hline Rainfed & Soybeans & -21.4 & -10.0 & -16.1 & -10.1 \\
\hline Irrigated & Wheat & 1.7 & -12.9 & -13.8 & -7.9 \\
\hline Rainfed & Wheat & -6.2 & -5.4 & & \\
\hline Source: Authors & & & & &
\end{tabular}




\section{figure 10}

Rainfed maize areas (ha) for West Africa, 2000
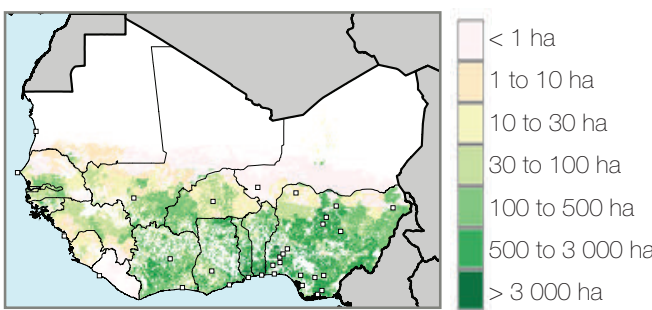

Sources: SPAM (Spatial Production Allocation Model) (You and Wood, 2006; You, Wood, and Wood-Sichra, 2006, 2009)

Note: ha $=$ hectare climate change in the region. All models confirm that rainfed rice will improve in productivity. Results for all other crops are mixed; rainfed maize and groundnuts will increase in productivity under climate change, while irrigated wheat will decline in productivity.

Any negative impact of climate change on irrigated crops is attributable to temperature increases. Yield reductions for rainfed crops could be attributed, depending upon the particular crop, to either rainfall reductions or temperature increases. For East Africa, most models show steady or increased annual rainfall; however, in some areas, growing season rainfall might decline despite rising annual rainfall.

\section{figure 11}

Change (\%) in rainfed maize yield for West Africa due to climate change, 2050, A1B Scenario
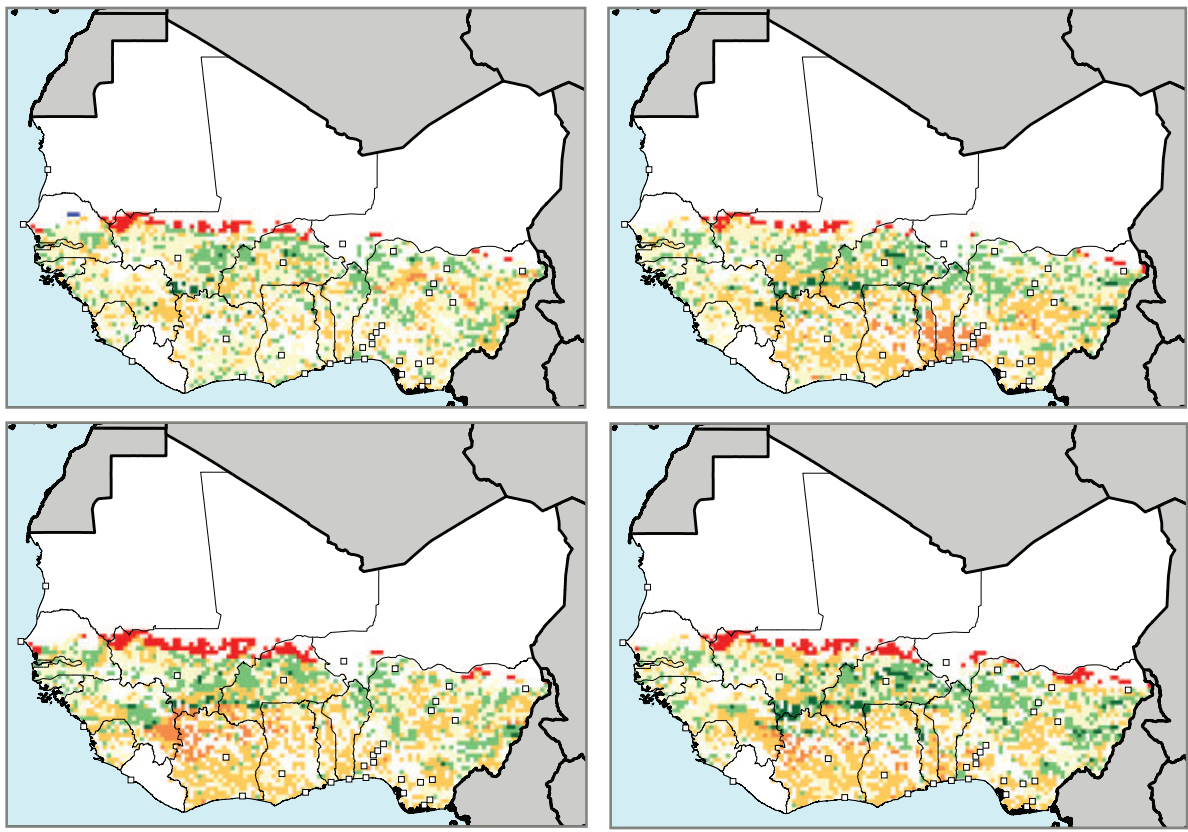

Source: Authors

Notes: Top to bottom: results for the CNRM, CSIRO,

ECHAM, and MIROC GCMs

Baseline area lost

Yield lost $>25 \%$ of baseline Yield lost $5 \%$ to $25 \%$ of baseline Yield change within $5 \%$ of baseline Yield gain 5\% to 25\% of baseline

Yield gain $>25 \%$ of baseline

New area gained 


\section{table 7}

Yield changes (\%) for various crops in Southern Africa as a result of climate change, 2000-2050

\begin{tabular}{lccccc}
\hline Water & Crop & CNRM & CSIRO & ECHAM & MIROC \\
\hline Rainfed & Groundnuts & 1.7 & 3.3 & -5.7 & 2.1 \\
\hline Irrigated & Maize & -5.6 & -3.1 & -2.8 & -4.0 \\
\hline Rainfed & Maize & -1.6 & -2.8 & -12.9 & -4.0 \\
\hline Rainfed & Rice & -0.6 & 0.1 & -0.4 & -1.6 \\
\hline Rainfed & Sorghum & -5.8 & -4.6 & -10.4 & -4.8 \\
\hline Rainfed & Soybeans & -15.4 & -12.8 & -24.7 & -7.3 \\
\hline Irrigated & Wheat & -5.1 & -5.1 & -7.1 & -3.8 \\
\hline Rainfed & Wheat & 18.5 & 18.3 & 11.0 & -6.1 \\
\hline Source: Authors & & & & & \\
\hline
\end{tabular}

\section{table 8}

Yield changes (\%) for various crops in West Africa as a result of climate change, 2000-2050

\begin{tabular}{|c|c|c|c|c|c|}
\hline Water & Crop & CNRM & CSIRO & ECHAM & MIROC \\
\hline Rainfed & Groundnuts & -5.8 & -7.7 & -9.2 & 0.3 \\
\hline Rainfed & Maize & -2.3 & -8.1 & -6.0 & -4.9 \\
\hline Irrigated & Rice & -19.9 & -12.4 & -20.0 & -18.2 \\
\hline Rainfed & Rice & 4.4 & 0.5 & 0.9 & 1.0 \\
\hline Rainfed & Sorghum & -15.9 & -9.5 & -14.8 & -13.0 \\
\hline Rainfed & Soybeans & -1.5 & -8.4 & -1.6 & -14.2 \\
\hline Irrigated & Wheat & -37.8 & -10.9 & -28.5 & -14.3 \\
\hline
\end{tabular}

\section{table 9}

World price changes (\%), 2000-2050

\begin{tabular}{lccccc}
\hline Crop & $\begin{array}{c}\text { MIROC } \\
\text { A1B }\end{array}$ & $\begin{array}{c}\text { MIROC } \\
\text { B1 }\end{array}$ & $\begin{array}{c}\text { CSIRO } \\
\text { A1B }\end{array}$ & $\begin{array}{c}\text { CSIRO } \\
\text { B1 }\end{array}$ & $\begin{array}{c}\text { No climate } \\
\text { change }\end{array}$ \\
\hline Rice & 83 & 87 & 85 & 82 & 54 \\
\hline Wheat & 121 & 106 & 99 & 93 & 66 \\
\hline Maize & 209 & 165 & 156 & 145 & 103 \\
\hline Sweet potatoes \& yams & 141 & 96 & 156 & 120 & 60 \\
\hline Cassava & 78 & 50 & 64 & 42 & 18 \\
\hline Sugar cane & 125 & 113 & 108 & 103 & 77 \\
\hline Sorghum & 115 & 104 & 110 & 104 & 82 \\
\hline Millet & 8 & 8 & 14 & 13 & 8 \\
\hline Groundnuts & 35 & 33 & 37 & 33 & 13 \\
\hline
\end{tabular}

Source: Based on analysis conducted for Nelson et al. (2010)

Note: The price changes are from the baseline economic-demographic scenario 


\section{Southern Africa}

Table 7 shows regional tabulations of productivity changes for various crops based on the crop model results for Southern Africa. Rainfed rice is generally predicted to be unchanged. Rainfed maize is mostly negatively affected, though moderately so, except in the ECHAM model. ECHAM was the model which predicted the largest temperature increases.

Rainfed wheat shows yield increases because it is grown mostly in colder areas, and a temperature increase under such circumstances could boost productivity (Table 7). Rainfed soybeans and rainfed sorghum both show yield losses, probably as a result of temperature increases stressing these crops in the currently cultivated areas.

\section{West Africa}

Table 8 shows the weighted tabulations of productivity change for crops grown in West Africa, based on the crop model analysis. Only rainfed rice shows positive change. Yield reductions for rainfed maize and groundnuts are less than 10 percent, with an average of around 5 percent, and rainfed soybeans show around 6 percent reduction.

Overall, rainfed sorghum shows large yield reductions in all regions of Africa. Irrigated rice and irrigated wheat have large yield reductions, with wheat having larger reductions than rice. Yield productivity losses for irrigated crops are the result of temperature increases.

\section{IMPACT model results}

The IMPACT model is a global partial equilibrium food and agricultural model. Three different economic-demographic scenarios were examined using the IMPACT model: 1) pessimistic, with high population growth and low GDP per capita growth scenario for the world; 2) optimistic, with low population growth, high income scenario; and 3) baseline, which is between the two.

Yield results from four climate model/ Special Report on Emissions Scenarios (SRES) combinations: CSIRO A1B, CSIRO B1, MIROC
A1B, and MIROC B1 were incorporated. SRES scenarios are IPCC predictions for how the world might evolve in terms of technology, governance and responsiveness to curbing emissions of GHGs. $\mathrm{B} 1$ is a lower emission scenario than A1B.

The units in IMPACT are countries, rather than the gridcells used in the crop models. The IMPACT model works by solving global supply and demand equations. One of the important questions that the IMPACT modelling approach attempts to answer is whether the world will produce sufficient food to feed the growing population, which will generally earn greater incomes. The results indicate that it will, but the demand for food will drive food prices higher relative to the price of other goods.

Table 9 shows the price changes projected by the IMPACT model between 2000 and 2050. Of all the food commodities, the world price of maize is projected to have the highest increase, doubling without climate change, and tripling according to one of the climate models. Millet prices will have the most minimal change, rising only 8 percent in three of the five climate scenarios evaluated.

Depending on which scenario is analysed, the maize price increase is followed by sweet potatoes and yams for MIROC A1B and CSIRO B1; sugar cane for MIROC B1; sweet potatoes and maize show the same level of price change under CSIRO A1B. Under no climate change scenario, sorghum top the price increase (Table 9).

\subsection{Maize}

In most of the graphs presented in this section, the economic-demographic scenarios are represented by three different colours. In each bar on the graph, we include only the results expected with climate change; the X's indicate the cases in which we have assumed no climate change. As in Table 9, the four climate model/SRES scenario combinations are CSIRO A1B, CSIRO B1, MIROC $\mathrm{A} 1 \mathrm{~B}$, and MIROC B1.

Important issues to note are: whether there is much variation between climate models (sometimes the bars are very flat, indicating little 
variation); where the "no climate change" results are relative to the "climate change" results; whether there is great variation between economicdemographic scenarios; and whether values change very much through time.

\section{East Africa}

Figure 12 shows that, on average, maize yield will increase by around 60 percent between 2010 and 2050, although there is fairly large variation between the "good" climate model and the "bad" climate model. Very little variation is seen between economic-demographic scenarios. Climate change seems to be mostly favourable for yields of maize in East Africa, given that the X's for the no climate change scenario are located at the bottom range of the bars on the yield graph.

Harvested areas appear to rise slightly and then fall slightly, denoting that the impact on production is predictable - that is, with production increasing rapidly in the early years, then tapering off.

\section{Southern Africa}

Yield is projected to increase by around 50 percent between 2010 and 2050 in Southern Africa (Figure 13), which is not significantly different than the 60 percent projected for East Africa. However, the range of yields over all climate models is very small compared to those observed for East Africa. A slightly steeper decline in harvested area devoted to maize was also noted, which would result in production actually falling slightly, on average, after 2040.

\section{West Africa}

Figure 14 shows the projections for maize production in West Africa. Yield changes are remarkably similar to those of the other two regions, with yields over the period growing between 50 and 60 percent. Similar to the case for East Africa, the harvested area appears to rise and then fall, both ever so slightly. This results in a production level that is relatively flat after 2040.

\subsection{Sorghum}

For sorghum, biophysical changes in yield and area attributable to climate change are based on the percentage changes for maize, since sorghum and maize are very similar crops, and since the sorghum model in DSSAT had not been run globally in time for the results to be included in IMPACT.

\section{East Africa}

In Figure 15, sorghum yields under climate change are projected to rise around 90 percent between 2010 and 2050. Unlike in the case of maize, the areas expand steadily by around 30 percent. The yields and area changes will result in sorghum production changes of around 150 percent.

Sorghum prices, unlike those for maize, are projected to be relatively flat, with a modest increase of 20 percent. Still, the climate-impacted prices will be higher than the prices without climate change.

\section{Southern Africa}

Sorghum yields more than doubled in Southern Africa which is even greater than the gains expected in East Africa. There is little variation in yield among climate models and between models with or without climate change in Southern Africa. On the other hand, a fairly high variation in yield was noted between climate models in East Africa.

Harvested area is projected to rise by around 30 percent in Southern Africa. The end result would be almost a tripling in production between 2010 and 2050.

\section{West Africa}

In Figure 17, sorghum in West Africa is between the projected levels for East Africa and Southern Africa. The yield almost doubles, with a small to moderate variation between climate models. Harvested area expands by around 20 percent, with total production rising by close to 150 percent. 


\section{figure 12}

Projections for maize production in East Africa, 2010-2050
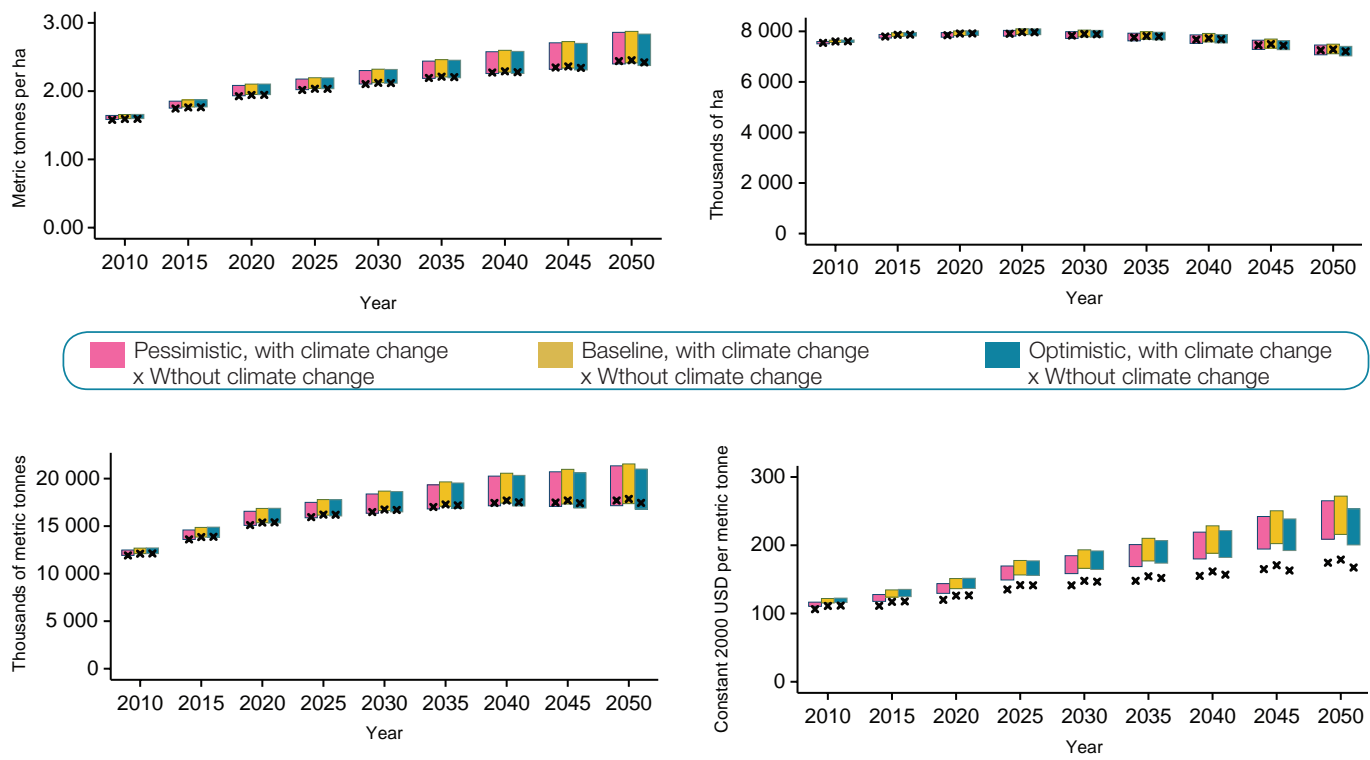

Source: Based on analysis conducted for Nelson et al. (2010)

Notes: Yield (top left); area (top right); production (bottom left); price (bottom right)

\section{figure 13}

Projections for maize production in Southern Africa, 2010-2050
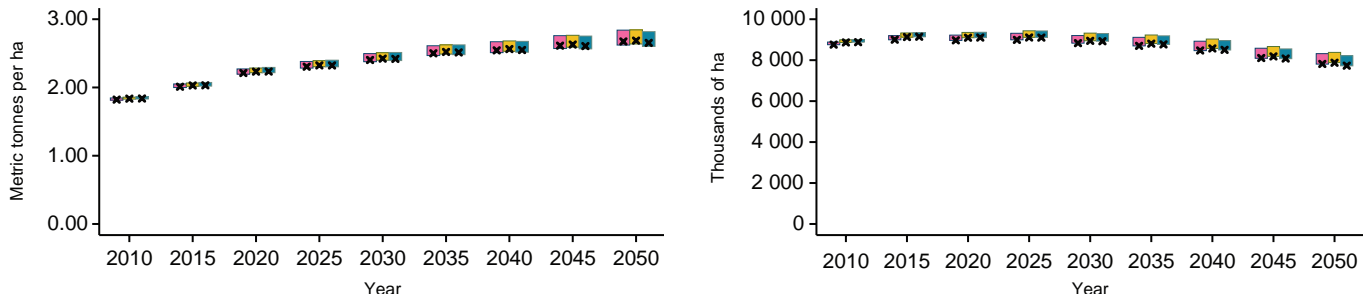

Pessimistic, with climate change

$x$ Wthout climate change
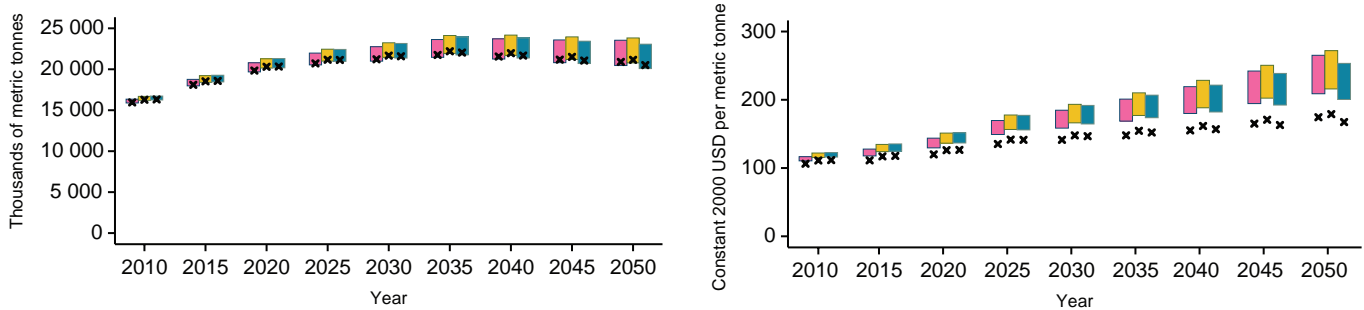

Source: Based on analysis conducted for Nelson et al. (2010)

Notes: Yield (top left); area (top right); production (bottom left); price (bottom right) 


\section{figure 14}

Projections for maize production in West Africa, 2010-2050
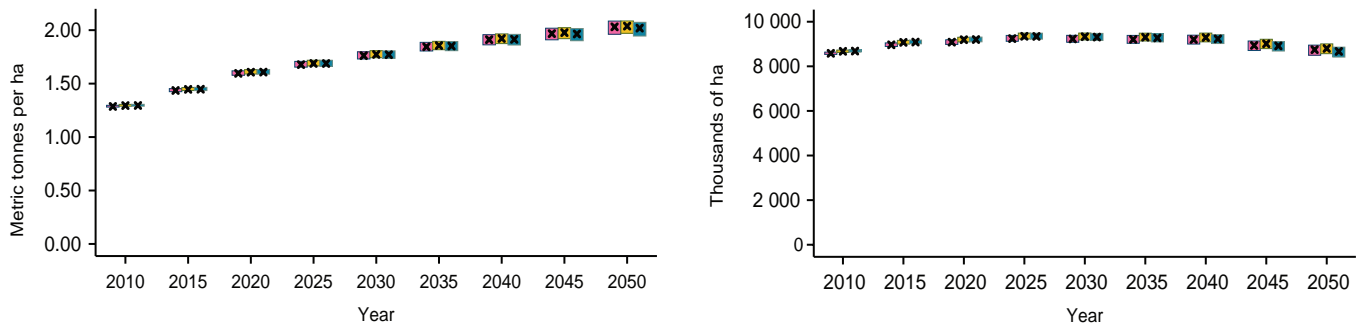

Pessimistic, with climate change

Baseline, with climate change

Optimistic, with climate change $x$ Wthout climate change $x$ Wthout climate change $x$ Wthout climate change
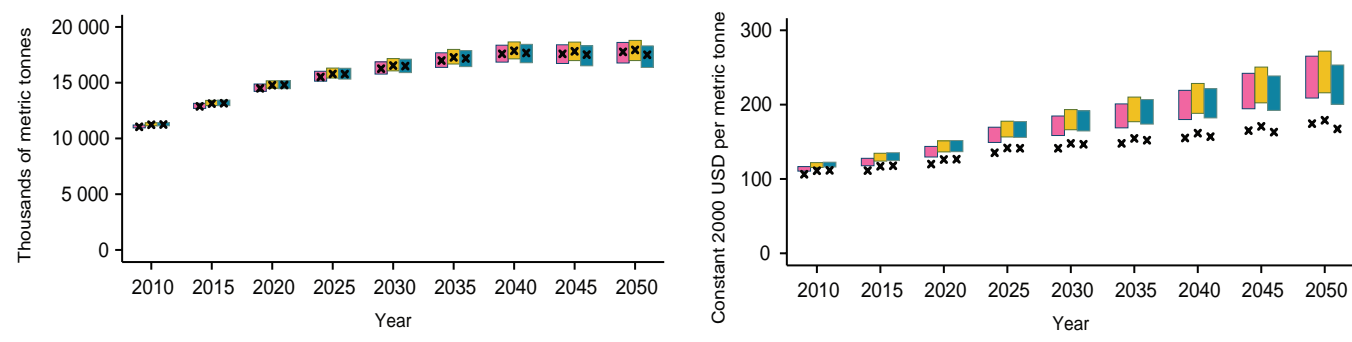

Source: Based on analysis conducted for Nelson et al. (2010)

Notes: Yield (top left); area (top right); production (bottom left); price (bottom right)

\section{figure 15}

Projections for sorghum production in East Africa, 2010-2050
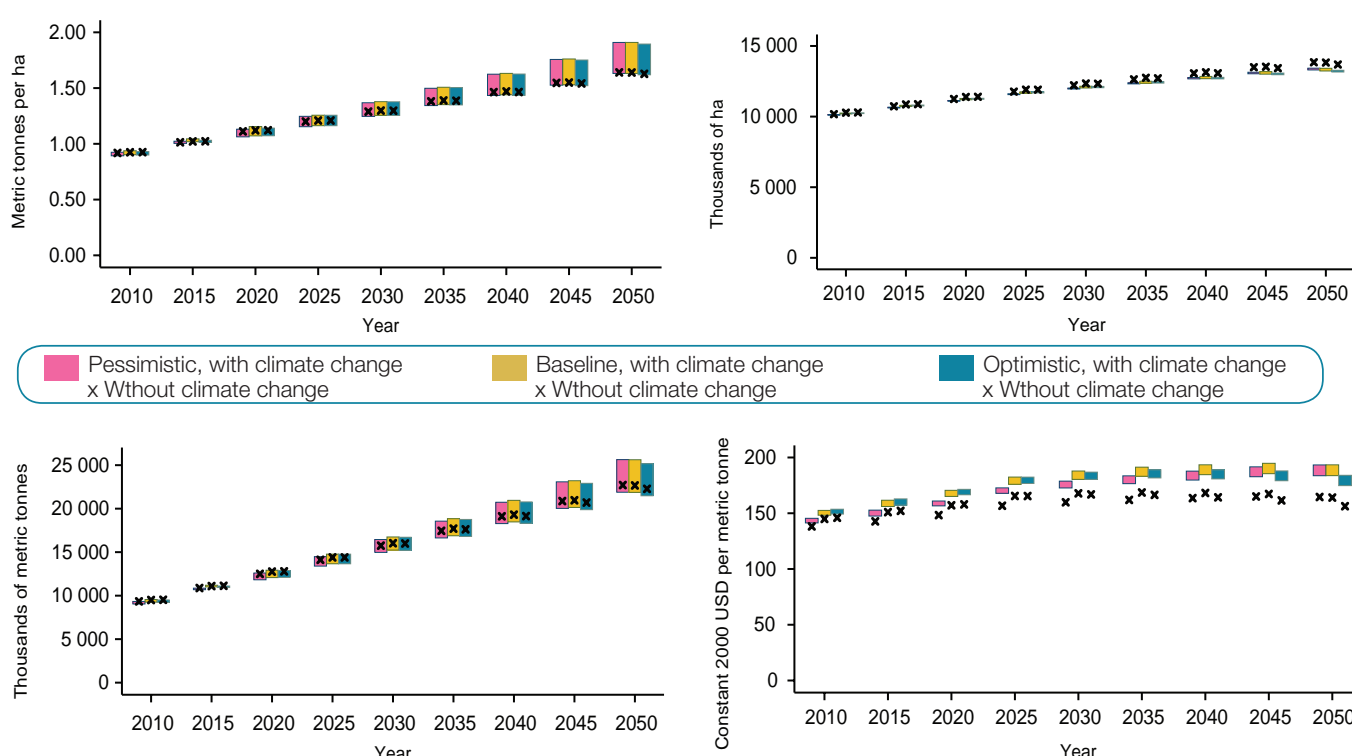

$$
\text { Year }
$$

Optimistic, with climate change $x$ Wthout climate change

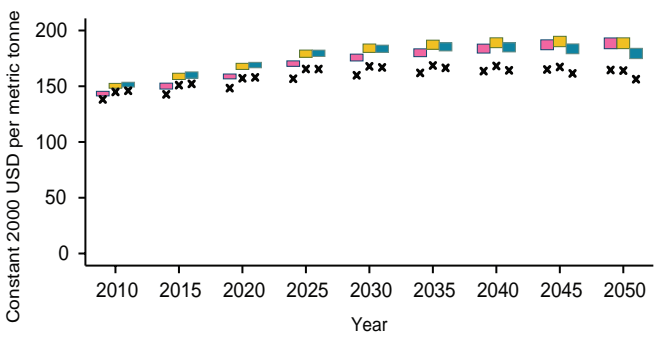

Source: Based on analysis conducted for Nelson et al. (2010)

Notes: Yield (top left); area (top right); production (bottom left); price (bottom right) 


\section{figure 16}

Projections for sorghum production in Southern Africa, 2010-2050
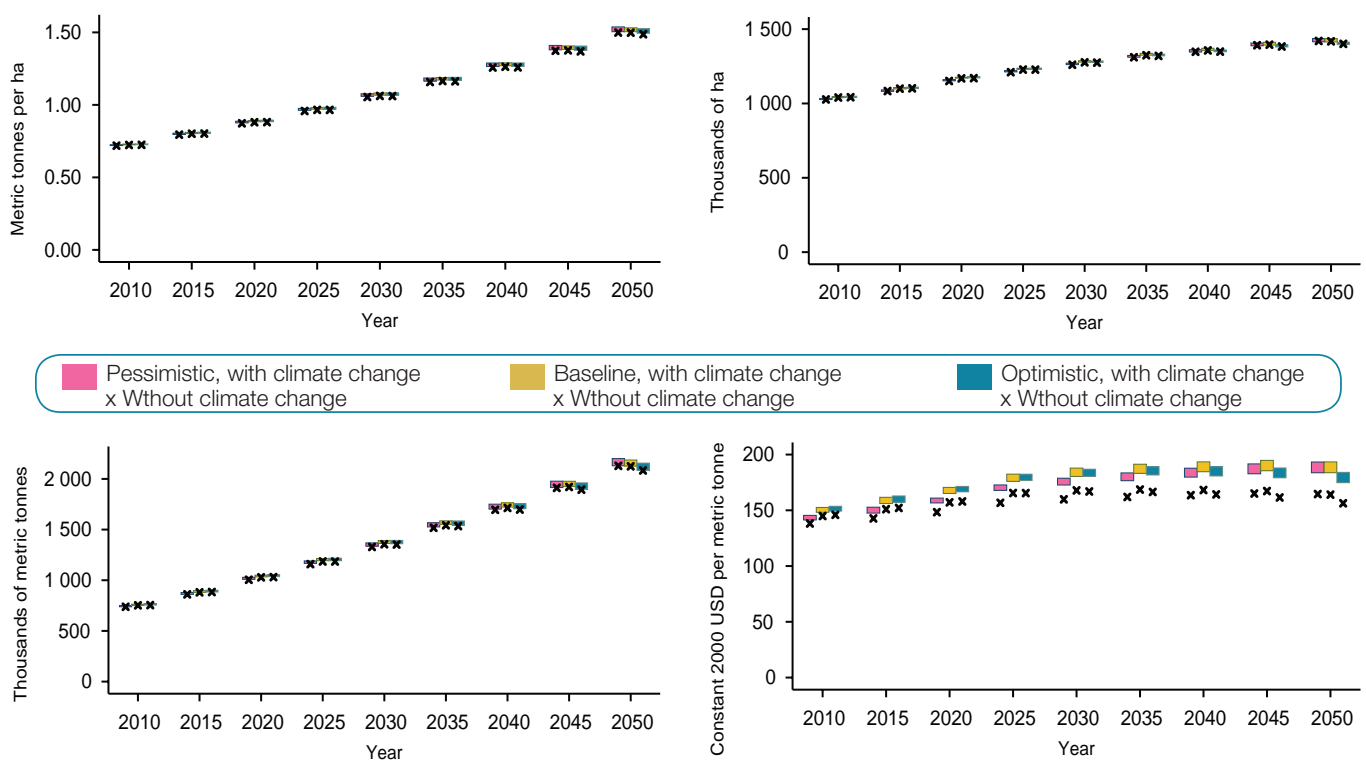

Source: Based on analysis conducted for Nelson et al. (2010)

Notes: Yield (top left); area (top right); production (bottom left); price (bottom right)

\section{figure 17}

Projections for sorghum production in West Africa, 2010-2050
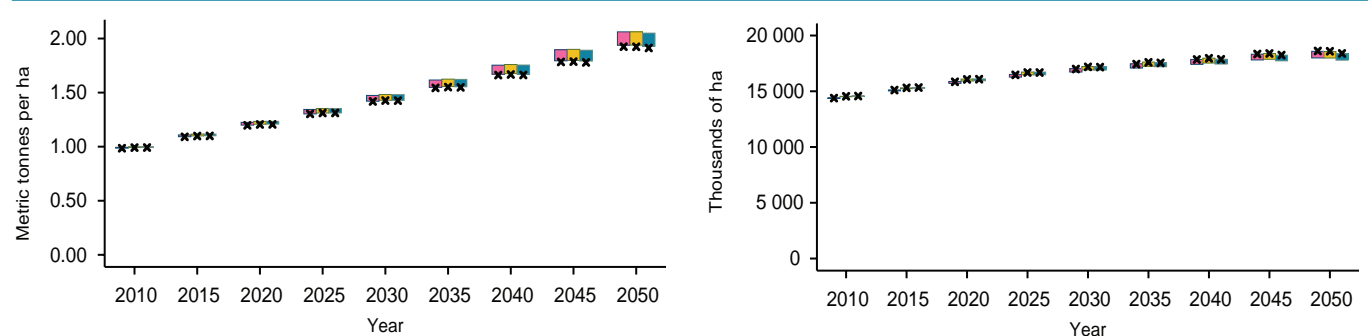

$$
\begin{array}{ll}
\begin{array}{l}
\text { Pessimistic, with climate change } \\
\mathrm{x} \text { Wthout climate change }
\end{array} & \begin{array}{l}
\text { Baseline, with climate change } \\
\mathrm{x} \text { Wthout climate change }
\end{array}
\end{array}
$$

Optimistic, with climate change $x$ Wthout climate change
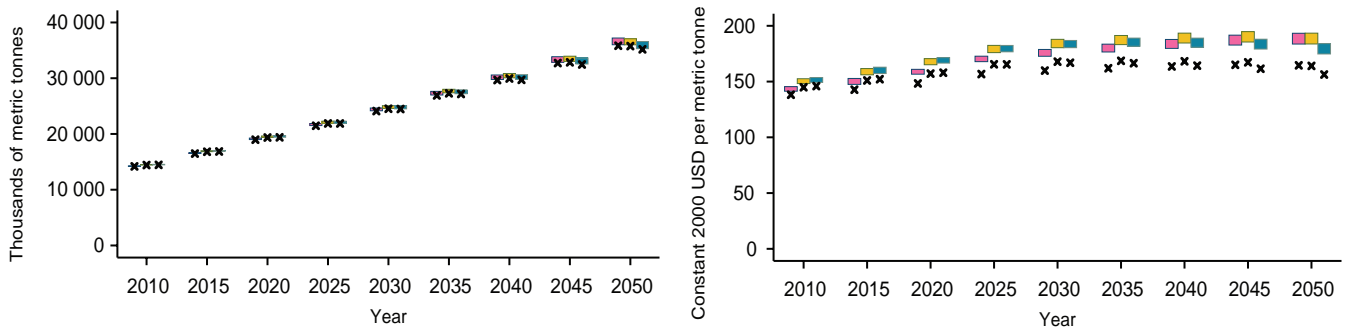

Source: Based on analysis conducted for Nelson et al. (2010)

Notes: Yield (top left); area (top right); production (bottom left); price (bottom right) 
table 10

Change (\%) in productivity, East Africa, 2010-2050, IMPACT model

\begin{tabular}{|c|c|c|c|c|c|}
\hline Crop & $\begin{array}{c}\text { No Climate } \\
\text { Change }\end{array}$ & $\begin{array}{c}\text { CSIRO } \\
\text { A1B }\end{array}$ & MIROC A1B & $\begin{array}{c}\text { CSIRO } \\
\text { B1 }\end{array}$ & $\begin{array}{c}\text { MIROC } \\
\text { B1 }\end{array}$ \\
\hline Cassava & 54.7 & 46.1 & 51.4 & 53.0 & 47.7 \\
\hline Groundnuts & 12.9 & 15.8 & 23.5 & 16.5 & 21.6 \\
\hline Maize & 54.0 & 51.1 & 73.5 & 54.7 & 62.7 \\
\hline Millet & 137.7 & 139.9 & 163.8 & 134.4 & 147.0 \\
\hline Rice & 120.1 & 136.6 & 140.3 & 136.5 & 137.4 \\
\hline Sorghum & 77.4 & 83.0 & 111.6 & 75.5 & 90.7 \\
\hline $\begin{array}{l}\text { Sweet potatoes } \\
\text { and yams }\end{array}$ & 161.3 & 145.0 & 188.2 & 162.9 & 179.2 \\
\hline Wheat & 128.6 & 119.1 & 127.2 & 123.3 & 118.9 \\
\hline
\end{tabular}

Source: Based on analysis conducted for Nelson et al. (2010)

Note: Values are for the baseline economic-demographic scenario

\subsection{All crops}

Table 10 summarizes the productivity changes for a number of crops analysed for East Africa, based on the IMPACT model. It includes the no climate change scenario as well as four climate change scenarios.

The highest productivity gains were observed for sweet potatoes and yams, with more than a 160 percent increase expected between 2010 and 2050 (Table 10). This is followed by millet and rice. The lowest productivity gains are anticipated for groundnuts, followed by cassava and maize.

Averaging the results across climate models, it appears that productivity for many crops in East Africa will be higher with climate change than without. This is not attributable to direct impacts of climate on yields, at least not in some of the cases. The direct impacts of climate change on some crops in East Africa are presented in Table 6.

On average, climate change across the globe will have negative effects on productivity, which will drive prices higher (Table 9). In response to the higher prices, farmers will endeavor to increase productivity - for example, through increased use of fertilizers. This second-order effect will then lead to some crops that were adversely affected by climate change to increase in yield sufficiently well to have higher yields than without climate change. We would not expect this to be universally true - it would be unrealistic to expect that all farmers across the globe would be able to increase their yields to that degree in response to a price rise. But in Africa, where fertilizer use is low, it is plausible that a significant and sustained price rise could lead to farmers spending more on inputs such as fertilizer, leading to a rise in productivity.

In Table 10, productivity is projected to be higher in East Africa under climate change for groundnuts, maize, millet, rice, sorghum, and sweet potatoes and yams; however, climate change is anticipated to have a negative impact on cassava and wheat.

Table 11 shows the same type of results found in Table 10, except the projections are for Southern Africa. Millet is anticipated to have by far the largest productivity gains between 2010 and 2050 , increasing by almost 250 percent. This is followed, in a distant second place, by cotton, which is projected to increase by more than 150 percent. Cassava is projected to have the lowest productivity gains among the crops for Southern Africa. 


\section{table 11}

Change (\%) in productivity, Southern Africa, 2010-2050, IMPACT model

\begin{tabular}{|c|c|c|c|c|c|}
\hline Crop & $\begin{array}{c}\text { No Climate } \\
\text { Change }\end{array}$ & $\begin{array}{c}\text { CSIRO } \\
\text { A1B }\end{array}$ & $\begin{array}{c}\text { MIROC } \\
\text { A1B }\end{array}$ & $\begin{array}{c}\text { CSIRO } \\
\text { B1 }\end{array}$ & MIROC B1 \\
\hline Cassava & 26.9 & 27.9 & 42.0 & 29.0 & 39.5 \\
\hline Cotton & 155.3 & 165.3 & 175.1 & 155.6 & 176.5 \\
\hline Groundnuts & 47.2 & 51.6 & 51.6 & 50.6 & 55.4 \\
\hline Maize & 46.3 & 48.6 & 53.3 & 44.2 & 52.5 \\
\hline Millet & 243.4 & 243.1 & 255.6 & 247.5 & 248.5 \\
\hline Potatoes & 49.4 & 53.1 & 53.4 & 53.7 & 52.4 \\
\hline Rice & 119.8 & 109.7 & 115.2 & 114.1 & 102.6 \\
\hline Sorghum & 107.0 & 108.7 & 109.9 & 107.8 & 108.7 \\
\hline Soybeans & 61.6 & 48.9 & 58.1 & 47.7 & 64.3 \\
\hline Sugar cane & 60.2 & 62.3 & 66.5 & 63.2 & 66.5 \\
\hline
\end{tabular}

Source: Based on analysis conducted for Nelson et al. (2010)

Note: Values are for the baseline economic-demographic scenario

Comparing the no climate change scenario to the average productivity changes of the four climate models, it appears that climate change will be beneficial, on average, to cassava, cotton, groundnuts, maize, millet, potatoes, sorghum, and sugar cane, but will be detrimental, on average, to rice and soybeans. In the East African case study model, higher prices resulting from the projected negative impact of climate change on yields stimulates increased use of fertilizer, which then leads to higher yields.

For most of the crops shown in Table 11, yields are higher under the MIROC climate model than under the CSIRO climate model. Since this was not always the case - as in Table 7, which shows the results of the crop models - it may be that this phenomenon is the result of global impacts of climate change on prices. We see from the price changes shown in Table 9 that global prices tend to be higher in the MIROC model than in the CSIRO model.

Table 12 shows the same type of results as in Tables 10 and 11, with a focus on West Africa. The B1 scenario (a lower GHG emissions scenario) generally predicts much higher yields than results based on the A1B scenarios (Table 12). As is often the case, the yields in the A1B scenario are lower than the no climate change scenario, while the yields in the B1 scenario are higher than the no climate change scenario. This is seen for cassava, cotton, groundnuts, soybeans, and sweet potatoes and yams.

In some cases, we also note the price-stimulus effect, reflected in the MIROC yields being higher than CSIRO yields (with the exception of soybeans).

\subsection{Malnutrition}

Table 13 shows calculations from the IMPACT model for the number of malnourished children under five years of age, and their share in all children under five years of age. In all regions, the number and share of children who are malnourished will be higher with climate change than without climate change.

Both the number and share of malnourished children should fall in each region between 2010 and 2050. This appears to be primarily an income effect, with increased incomes enabling people to more than compensate for food price increases. However, despite the drop in malnutrition rates through time, the projected malnutrition shares 


\section{table 12}

Change (\%) in productivity, West Africa, 2010-2050, IMPACT model

\begin{tabular}{|c|c|c|c|c|c|}
\hline Crop & $\begin{array}{l}\text { No Climate } \\
\text { Change }\end{array}$ & CSIRO A1B & MIROC A1B & $\begin{array}{c}\text { CSIRO } \\
\text { B1 }\end{array}$ & $\begin{array}{c}\text { MIROC } \\
\text { B1 }\end{array}$ \\
\hline Cassava & 49.5 & 35.5 & 37.2 & 55.5 & 62.5 \\
\hline Cotton & 90.9 & 71.4 & 76.5 & 89.1 & 85.2 \\
\hline Groundnuts & 42.0 & 35.4 & 43.9 & 41.1 & 47.3 \\
\hline Maize & 57.4 & 53.0 & 59.8 & 55.9 & 58.7 \\
\hline Millet & 147.2 & 151.9 & 176.2 & 147.5 & 156.2 \\
\hline Rice & 89.3 & 87.5 & 89.1 & 89.1 & 89.7 \\
\hline Sorghum & 94.1 & 95.5 & 106.3 & 95.2 & 99.4 \\
\hline Soybeans & 81.5 & 80.0 & 77.7 & 84.6 & 78.5 \\
\hline $\begin{array}{l}\text { Sweet potatoes } \\
\text { and yams }\end{array}$ & 73.5 & 48.1 & 49.1 & 72.3 & 84.0 \\
\hline
\end{tabular}

Source: Based on analysis conducted for Nelson et al. (2010)

Note: Values are for the baseline economic-demographic scenario

\section{table 13}

Number and percent of malnourished children under five in Africa, 2010 and 2050, IMPACT model

\begin{tabular}{|c|c|c|c|c|c|c|c|}
\hline \multirow[t]{3}{*}{ Region } & \multirow[t]{3}{*}{ Scenario } & \multicolumn{2}{|c|}{2010} & \multicolumn{4}{|c|}{2050} \\
\hline & & \multirow[b]{2}{*}{ Number } & \multirow[b]{2}{*}{ Percent } & \multicolumn{2}{|c|}{$\begin{array}{l}\text { No climate } \\
\text { change }\end{array}$} & \multicolumn{2}{|c|}{$\begin{array}{l}\text { Average of max and } \\
\text { min of } 4 \text { GCM -SRES } \\
\text { scenarios }\end{array}$} \\
\hline & & & & Number & Percent & Number & Percent \\
\hline \multirow[t]{2}{*}{ East Africa } & Baseline & 20991 & 34.3 & 18931 & 24.2 & 21077 & 27.0 \\
\hline & Optimistic & 20975 & 34.3 & 13968 & 20.4 & 15858 & 23.2 \\
\hline \multirow{2}{*}{$\begin{array}{l}\text { Southern } \\
\text { Africa }\end{array}$} & Baseline & 4894 & 24.6 & 3570 & 15.2 & 4288 & 18.2 \\
\hline & Optimistic & 5024 & 25.3 & 1671 & 8.2 & 2264 & 11.2 \\
\hline \multirow[t]{2}{*}{ West Africa } & Baseline & 15157 & 31.0 & 12415 & 20.9 & 13913 & 23.4 \\
\hline & Optimistic & 14733 & 30.2 & 7615 & 15.1 & 8949 & 17.1 \\
\hline
\end{tabular}

Source: Based on analysis conducted for Nelson et al. (2010)

in 2050 still appear to be high in the baseline economic-demographic scenario, and even for the optimistic scenario in East Africa.

\section{Conclusions}

This paper summarizes key results at a regional level from three recently published monographs on impacts of climate change on agriculture.

The results show great geographical variation in climate change effects on agriculture, and indicate that, while most direct climate change impacts will be negative, there will be positive impacts on yields in some areas with projected increases in precipitation, and in some elevated areas that will be able to be cultivated due to warmer temperatures. 
As shown in the IMPACT results, global increases in income and population and constraints on productivity growth will cause real crop prices to rise - and this is more notably the case with climate change than without. Between price increases spurring farmers to use more inputs to increase yield, and general technological improvements in crops, yields will rise. In many cases in Africa, the price effect will lead yields to rise even more under climate change than they would have done without. This seemingly counterintuitive result is due to the negative climate change impacts on crop yields in much of the rest of the world, which will boost world crop prices enough to counterbalance the direct effects of climate change on crop yields in Africa.

\subsection{Essential points for policy-makers}

- Good agricultural policy for today will also be helpful for the future

Climate change is incremental, so one way of seeing things is to understand that climate change is already happening. What can improve agricultural productivity now? Not only will this help farmers adapt to climate change already being experienced, but it will put them on the road to future adaptation as well.

- Researchers will need to work together with farmers to develop new crop varieties and livestock breeds - along with supporting agronomic and husbandry methods, extension services and mechanisms for scaling up and out

In many cases, this will require a shift in budget priorities, and the sooner the shift, the better. New varieties take quite a long time to develop and test. Varieties that can adapt to climate change ten years from now need to start being developed today.
- Institutions and policies in agriculture need to be redesigned to be more flexible and robust across a range of possible future climates, and diverse outcomes across ecozones

There is sufficient disagreement between equally valid climate models that scientists are unable to specify how climate will impact a village or district or an ecozone. As a result, it is important not to overcommit resources to a specific climate outcome that may not even materialize, but rather to calibrate investments in response to evolving changes over time and to create a menu of options for farmers as well as policy-makers.

- In some, but not all, countries, severe productivity losses will be experienced in some parts of the country while productivity gains will be experienced in other parts, creating pressure for migration

While this needs further study, it also suggests that laws in the areas of property rights and protection of environmentally sensitive areas may need to be examined and improved. In these cases, higher investments in rural infrastructure would also facilitate climate change adaptation. 


\section{References}

FAO (Food and Agriculture Organization of the United Nations). 2010. FAOSTAT Database on Agriculture. Rome.

Hachigonta, S., G. Nelson, T. Thomas \& L. Sibanda, eds. 2013. Southern African Agriculture and Climate Change: A Comprehensive Analysis. IFPRI Research Monograph. Washington: International Food Policy Research Institute.

Hachigonta, S., G. Nelson, T. Thomas \& L. Sibanda. 2013. Overview, in Southern African Agriculture and Climate Change: A Comprehensive Analysis, Hachigonta, S. et al., eds. Washington: IFPRI.

Hijmans, R., S. Cameron, J. Parra, P. Jones \& A. Jarvis. 2005. Very High Resolution Interpolated Climate Surfaces for Global Land Areas, International Journal of Climatology 25: 1965-1978.

Jalloh, A., M. Faye, H. Roy-Macauley, P. Sérémé, R. Zougmoré, T. Thomas \& G. Nelson. 2013. Overview, in West African Agriculture and Climate Change: A Comprehensive Analysis, Jalloh, A. et al., eds. Washington: IFPRI.

Jalloh, A., G. Nelson, T. Thomas, R. Zougmoré \& H. Roy-Macauley, eds. 2013. West African Agriculture and Climate Change: A Comprehensive Analysis. IFPRI Research Monograph. Washington: International Food Policy Research Institute.

Jones, J., G. Hoogenboom, C. Porter, K. Boote, W. Batchelor, L. Hunt, P. Wilkens, U. Singh, A. Gijsman \& J. Ritchie. 2003. The DSSAT Cropping System Model, European Journal of Agronomy 18 (3-4): 235-265.

Jones, P., P. Thornton \& J. Heinke. 2009. Generating Characteristic Daily Weather Data Using Downscaled Climate Model Data from the IPCC's Fourth Assessment. Project report. Nairobi, Kenya: International Livestock Research Institute.
Millennium Ecosystem Assessment. 2005. Ecosystems and Human Well-being: Synthesis. Washington, DC: Island Press.

Nelson, G., A. Palazzo, D. Mason-d'Croz, R. Robertson \& T. Thomas. 2013. Methodology, in West African Agriculture and Climate Change: A Comprehensive Analysis, Jalloh, A. et al., eds.

Nelson, G., M. Rosegrant, A. Palazzo, I. Gray, C. Ingersoll, R. Robertson, S. Tokgoz, Tingju Zhu, T. Sulser, C. Ringler, S. Msangi, and L. You. 2010. Food Security, Farming, and Climate Change to 2050: Scenarios, Results, Policy Options. Washington, DC: International Food Policy Research Institute.

UNPOP (United Nations Department of Economic and Social Affairs-Population Division). 2009. World Population Prospects: The 2008 Revision. New York.

Waithaka, M., G. Nelson, T. Thomas \& M. Kyotalimye, eds. 2013. East African Agriculture and Climate Change: A Comprehensive Analysis. IFPRI Research Monograph. Washington: International Food Policy Research Institute.

Waithaka, M., T. Thomas, M. Kyotalimye \& G. Nelson. 2013. Overview, in East African Agriculture and Climate Change: A Comprehensive Analysis, Waithaka, M. et al., eds. Washington: IFPRI.

World Bank. 2009. World Development Indicators. Washington, DC. . 2010. Economics of Adaptation to Climate Change: Synthesis Report. Washington, DC.

You, L., \& S. Wood. 2006. An Entropy Approach to Spatial Disaggregation of Agricultural Production. Agricultural Systems 90 (1-3): 329-347.

You, L., S. Wood \& U. Wood-Sichra. 2006. Generating Global Crop Distribution Maps: 
From Census to Grid. Paper presented at the International Association of Agricultural Economists

Conference in Brisbane, Australia, August 11-18.

2009. Generating Plausible Crop

Distribution and Performance Maps for Sub-

Saharan Africa Using a Spatially Disaggregated

Data Fusion and Optimization Approach.

Agricultural Systems 99 (2-3): 126-140. 
chapter 6

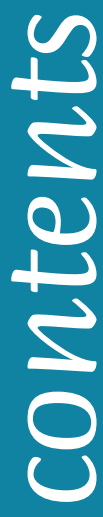

1. Introduction

178

2. Methodology 179

2.1 Climate scenarios $\quad 179$

2.2 Biophysical impact modelling 180

2.3 Economic impact modelling $\quad 183$

$\begin{array}{ll}\text { 3. Results } & 187\end{array}$

3.1 Livestock sector developments without climate change

3.2 Climate change impact on livestock markets $\quad 190$

3.3 Land management adaptation $\quad 193$

3.4 Livestock sector adaptation $\quad 195$

4. Conclusions 196

$\begin{array}{ll}\text { References } & 197\end{array}$

Citation

Havlik, P., D. Leclère, H. Valin, M. Herrero, E. Schmid, J-F Soussana, C. Müller and M. Obersteiner. 2015. Global climate change, food supply and livestock production systems: A bioeconomic analysis, In: Climate change and food systems: global assessments and implications for food security and trade, Aziz Elbehri (editor). Food Agriculture Organization of the United Nations (FAO), Rome, 2015. 


\title{
chapter 6
}

\section{Global climate change, food supply and livestock production systems: A bioeconomic analysis}

\author{
Petr Havlík ${ }^{a}$, David Leclère ${ }^{a}$, Hugo Valin ${ }^{a}$, Mario Herrerob, \\ Erwin Schmidc, Jean-Francois Soussana ${ }^{\mathrm{d}}$, Christoph Müllere, \\ Michael Obersteinera1
}

\section{main chapter messages}

- Climate change impacts on crop and grass yields are projected to have only small effect on global milk and meat production by 2050 , which remains under any climate scenario within $+/-2$ percent of the projected production without climate change.

- Depending on the scenario, the climate change effects can be more pronounced at the regional scale. In sub-Saharan Africa, the effects are both the most uncertain and potentially the most severe; e.g. ruminant meat production could increase by 20 percent but it could also decrease by 17 percent.

- The effects on regional consumption are less pronounced because the impacts of climate change are mostly buffered through international trade. Virtually all the negative effects are smaller than 10 percent.

- Adjustment in the production systems structure will be an important adaptation measure. Grass yields benefit more (or are hurt less) from climate change than crop yields. Climate change would hence favour the grazing systems, leading potentially to a change in the current trend towards more intensive systems.

- Depending on the impact scenario, optimal adaptation strategies can go in opposite directions. Efforts to decrease this uncertainty must go hand in hand with search for robust strategies effective under many different climate futures.

Authors are affiliated with: (a) International Institute for Applied Systems Analysis, Austria; (b) Commonwealth Scientific and Industrial Research Organization, Australia; (c) University of Natural Resources and Life Sciences, Vienna, Austria; (d) French National Institute for Agricultural Research (INRA), Paris, France; and (e) Potsdam Institute for Climate Impact Research (PIK), Germany. 


\section{Introduction}

L _ivestock are the source of 33 percent of the protein in human diets, and continued population and economic growth could double the total demand for livestock products by 2050 (Alexandratos and Bruinsma, 2012). Currently, 30 percent of global land area is already being used for livestock rearing (Steinfeld et al., 2006), which means that substantial efficiency gains will be required to satisfy the rising demand within the physical constraints related to land, and, to some extent, water (Doreau et al., 2012). At the same time, global mean surface temperature is projected to rise by $0.4-2.6^{\circ} \mathrm{C}$ by 2050 , and the contrast in precipitation between wet and dry regions and between wet and dry seasons will also increase according to the Intergovernmental Panel on Climate Change (IPCC) $5^{\text {th }}$ Assessment Report (2013). Climate change will have multiple impacts on livestock, from heat stress to livestock diseases to feed quality and availability (Thornton et al., 2009). The objective of this chapter is to assess how the impacts of climate change on crop and grass yields will influence the global livestock sector from now to 2050, and to explore the potential for adaptation through transitions in livestock production systems, which have been identified as an efficient adaptation mechanism to address future challenges, even in the absence of climate change (Havlík et al., 2014).

Global economic assessments of climate change impacts on agriculture over the last couple of years have experienced an unprecedented boom. In 2007, Schmidhuber and Tubiello (2007) could state that most global assessments relied on a single modelling framework, represented by the International Institute of Applied Systems Analysis (IIASA)'s Agro-ecological zones (AEZ)/ Basic Linked System (BLS) (Fischer et al., 2005). During the past year, however, a coordinated climate change impact and adaptation model intercomparison exercise has been implemented within the Agricultural Model Intercomparison and Improvement Project (AgMIP)/ Inter-Sectoral Impact Model Intercomparison Project (ISI-MIP), which combines nine global economic models with five global gridded crop models (Nelson et al., 2014a). However, the effects of climate change on fodder availability remain under-researched (Wheeler and Reynolds, 2013). Most of the studies, including the recent model intercomparison, have considered climate change impacts only on crop yields. In the past, climate change effects on grassland productivity were taken into account in only two models, Future Agricultural Resources Model (FARM) (Darwin, 2004) and Emissions Predictions and Policy Analysis (EPPA) (Reilly et al., 2007). Both models represented the whole livestock sector as an aggregate single activity and the potentially important effects of changes in grass yields on ruminant sectors were blurred by climate change impacts on crops as the main feedstuff for pigs and poultry. For this chapter, we implement the Global Biosphere Management Model (GLOBIOM), a global partial equilibrium agricultural and forestry sector model with detailed livestock sector representation, to provide a new view on this topic (Havlík et al., 2013; Havlík et al., 2014).

GLOBIOM (Havlík et al., 2011) represents agricultural production at a spatial resolution going down to $5 \times 5$ minutes of $\operatorname{arc}^{2}$. Crop and grassland productivities for current and future climate scenarios are estimated at this resolution by means of biophysical process-based models, such as Environmental Policy Integrated Climate (EPIC) (Williams, 1995). Livestock representation follows a simplified version of the Seré and Steinfeld (1996) production system classification. This approach recognizes differences in feed base and productivity between grazing and mixed crop-livestock production systems across different agro-ecological zones (arid, humid, temperate/ highlands). Parameters for the model were obtained from a recently published global livestock production systems dataset (Herrero et al., 2013). GLOBIOM allows for endogenous shifts

260 arcminutes correspond to 1 degree 
of livestock between the different production systems based on their relative profitability. The model has been implemented for climate change impact assessments in the past, both individually (Mosnier et al., 2014) and as part of the AgMIP/ISIMIP model intercomparison, but it is in this chapter that climate change impacts on grasslands are included for the first time.

Future climate development is highly uncertain and the large differences in impact assessments provided by crop or vegetation models add to this uncertainty (Asseng et al., 2013; RamirezVillegas et al., 2013; Challinor et al., 2014; Rosenzweig et al., 2014). The ISI-MIP project results (www.isi-mip.org) that were made available to impact modellers downscaled and bias-corrected climate change scenarios, based on the results of the Coupled Model Intercomparison Project (CMIP). Subsequently, a database of global, spatially explicit, modelled climate change impacts across different sectors has been created (Warszawski et al., 2013). These datasets make it possible, in principle, to account for the uncertainties inherent in climate change impact assessments. We have identified the most important sources of uncertainty to be: use of a particular crop/grass growth model; and assumptions about the strength of the carbon dioxide $\left(\mathrm{CO}_{2}\right.$ fertilization effect. These two aspects will be systematically treated throughout our study.

\section{Methodology}

The assessment provided in this chapter follows a sequential approach. First, climate change scenarios quantified by general circulation models (GCMs) are selected, then results of these scenarios are used as input to biophysical process-based models to assess the impacts on crop and grass yields, and finally these models are used as input for the economic model to project the effects of climate change on the agricultural sector as a whole. In the next sections, we will present these three steps in detail.

\subsection{Climate scenarios ${ }^{3}$}

The most recent generation of climate change scenarios available at the time of this study corresponds to the fifth phase of the Coupled Model Intercomparison Project (CMIP5)

(Taylor et al., 2011). In this project, more than 50 climate models were used to simulate four emission scenarios (Representative Concentration Pathways, or RCPs). The four RCPs cover a range of "radiative forcing" in the year 2100, going from 2.6 to $8.5 \mathrm{~W} / \mathrm{m}^{2}$ (Vuuren et al., 2011). Depending on the climate model, these levels of radiative forcing would spread the global temperature increase above pre-industrial levels, from below $1{ }^{\circ} \mathrm{C}$ for RCP2.6 to about $7{ }^{\circ} \mathrm{C}$ for RCP8.5, the median across the models for the latter RCP being just below $5{ }^{\circ} \mathrm{C}$ (Rogelj et al., 2012). For this analysis, we will focus on RCP8.5 for three reasons: first, because this scenario shows best what the future challenges of climate change could be; second, because together with the "present climate" scenario, it allows for judgment about the intermediate emission pathways; and finally, because the recent emission developments exceed even the RCP8.5 emission levels for the relevant years (Peters et al., 2013).

The ISI-MIP provided impact modellers with spatially interpolated and bias-corrected climate datasets for all four RCPs and for five GCMs (GFDL-ESM2M, HadGEM2-ES, IPSLCM5A-LR, MIROC-ESM-CHEM, NorESM1-M) selected to span the CMIP5 range of global mean temperature changes and relative precipitation changes (Warszawski et al., 2013). Of the five GCMs, ISI-MIP retained HadGEM2-ES as the

3 The scenarios reported in this study were developed as part of a European Union-funded FP7 project called "An integration of mitigation and adaptation options for sustainable livestock production under climate change" (ANIMALCHANGE) (Grant 266018)

4 "radiative forcing" is linked to the $\mathrm{CO}_{2}$ concentration measured in part per million value or ppmv. The higher the $\mathrm{CO}_{2}$ concentration, the higher the radiative forcing which in turn raises the radiative energy reaching the earth's surface and causes the average earth temperature to increase 
reference model, and we do the same in this chapter. Under RCP8.5, HadGEM2-ES projects a global temperature increase for 2050 of about $2.5^{\circ} \mathrm{C}$ and an average increase in precipitation of about 3 percent. This ranks HadGEM2-ES as the hottest and driest of the five models, with potentially the most negative effects on agricultural production. The spatial distribution of the change in temperature and precipitation is presented in Figure 1. The temperature increases follow the typical spatial pattern, with higher increases in the north. Reductions in precipitation are projected to affect large parts of Australia, Brazil and Europe, the southwest part of the United States of America, and parts of Africa and the Near East.

\subsection{Biophysical impact modelling}

Climate scenarios need to be translated into impacts on crop and grass yields. In general, two approaches are available: biophysical processbased (mechanistic) models; or statistical models (Porter et al., 2014). However, as described by these authors, it is difficult for the statistical models to represent the direct effect of elevated $\mathrm{CO}_{2}$, which makes them less suitable for long-term assessments. These models have also never been applied to assess climate change impacts on grass productivity at the global scale, and therefore can be ruled out as an option for our study. Two different approaches exist for implementation of crop growth models at global scale: the models can be run for a limited number of specific sites, and the results extrapolated to the areas not directly covered; or the crop models can be run on a more or less detailed spatial grid for each relevant pixel. For purposes of this chapter we adopt the second option.

Our preferred crop growth model is EPIC (Williams, 1995), which is a standard component of the model cluster around the economic model GLOBIOM. EPIC is a long-established crop growth model and, in addition to crop simulations, it has been applied to forage yield projections (Izaurralde et al., 2011). However, EPIC has been designed to model managed grasslands. Globally, large areas of pasture are managed very extensively and their composition is close to natural biomes. The climate change impacts on potentially species-rich and highly heterogeneous natural rangelands can then be very different from those on intensively managed grasslands consisting of a few selected species at most. Therefore, we considered using the output of one of the global vegetation models developed to

\section{figure 1}

Absolute changes in annual mean temperature $\left({ }^{\circ} \mathrm{C}\right.$, left) and annual mean precipitation (mm/day, right), from 1980-2010 to 2035-2065 for the HadGEM2-ES model under RCP8.5

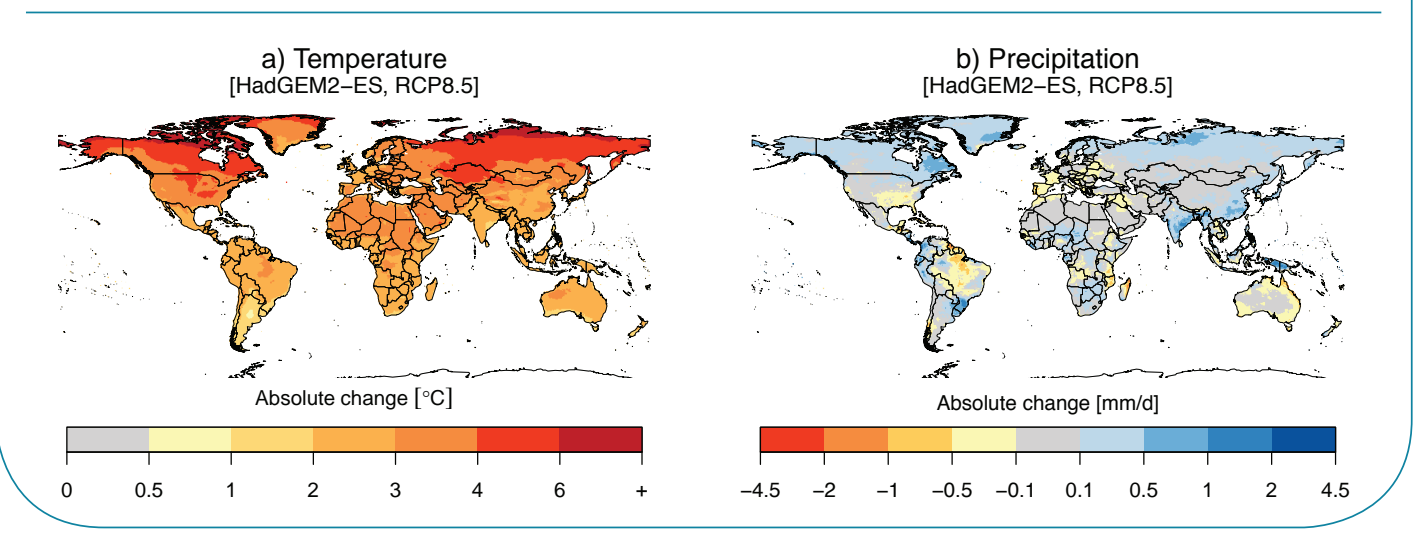


simulate natural terrestrial vegetation, as discussed in Friend et al. (2013) within the ISI-MIP framework. These models simulate climate change impacts on vegetation in terms of change in the net primary productivity (NPP). Their limitation is that the results reported by these models at $0.5^{\circ} \times 0.5^{\circ}$ resolution do not distinguish between different vegetation types, and hence the change in NPP cannot be directly associated with grasslands unless they cover a large majority of the pixel. Our analysis showed that such usable pixels do not provide sufficient coverage over the globe, so the results of the global vegetation models as provided in the fast track phase of ISI-MIP were not suitable for our purposes. However, we found that the climate change impacts on managed grasslands reported by Lund-Post-Jena Dynamic Global Vegetation Model with managed Land (LPJmL) (Müller and Robertson, 2014) showed similar patterns to the climate change impacts on natural vegetation simulated with the global vegetation module of LPJmL, for areas where sufficient cover by grasslands allowed for comparison between the two modules. Because the managed grassland simulations by LPJmL provide sufficient coverage at the global scale, we decided to use them as the model most closely representing natural grasslands. LPJmL also provides simulation results for major agricultural crops. For reasons of consistency, we decided to use the LPJmL grassland simulations together with the LPJmL crop yield simulations. Thus, two alternative model set-ups are used for representing the climate change impacts on crop and grass productivity - one entirely based on EPIC and the other on LPJmL. In addition to exploiting the complementarities between the two models, this approach also makes it possible to deal with the uncertainties inherent in the use of crop models, given that, at global scale, LPJmL is a rather optimistic model and EPIC a rather pessimistic one - in particular, when the direct effects of elevated $\mathrm{CO}_{2}$ concentrations are considered (Rosenzweig et al., 2014).

The pure climate change impacts on crop and grass yields as simulated by the two models for RCP8.5 and the five ISI-MIP GCMs for 2050 relative to 2000 are shown in Figure 2 . These results include the direct effect of elevated $\mathrm{CO}_{2}$. The regional aggregates are calculated as averages from the spatially explicit results based on crop and management system distribution as of 2000, using either the Spatial Production Allocation Model (SPAM) dataset from the International Food Policy Research Institute (IFPRI) (You and Wood, 2006) or the current grassland distribution calculated from Global Land Cover 2000 (GLC2000) and feed requirements as described in Havlík et al. (2014). The definitions of the ten large regions that, for presentation purposes, aggregate the $30 \mathrm{GLOBIOM}$ regions are provided in the Annex, Table A1. The EPIC simulations indicate that crop yields would fall by 6 percent globally, while grass yields would increase by 14 percent. The LPJmL model projects much more positive effects of climate change, increasing overall crop yields by 23 percent on average, and grass yields by 50 percent. The pattern of systematically more positive (or less negative) effects of climate change on grass yields as compared to crop yields applies for EPIC in all the aggregate world regions. The prediction is similar for the LPJmL model, with the notable exception of Latin America, where the crop yields would increase by 41 percent on average, while grass yields would only increase by 8 percent. The climate change impacts on yields calculated by LPJmL provide a more optimistic picture compared with EPIC across all the regions except in the case of grass yields in Europe, where the average values from both crop models are similar, and for the Near East \& North Africa, where EPIC shows a slightly more significant grass yield increase than LPJmL. Although there is a wide variation in the results of each individual crop model across the GCMs, the domain of results of one crop model rarely overlaps with the domain of results of the other model.

The extent to which the full $\mathrm{CO}_{2}$ fertilization effect will materialize in the real world remains highly uncertain (Tubiello et al., 2007). Therefore, for the selected GCM - HadGEM2-ES - we have also considered the climate change impacts with 


\section{figure 2}

Relative climate change impacts on crop and grass yields as projected by EPIC and LPJmL for five GCMs retained for the fast track phase of ISI-MIP, with full direct effects of elevated $\mathrm{CO}_{2}$ concentration for 2050 compared with 2000 in \%

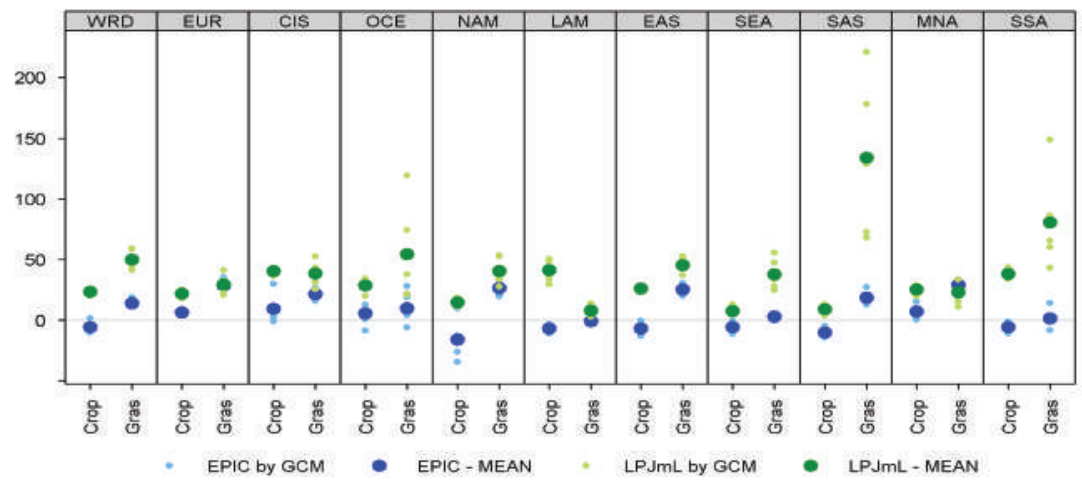

constant $\mathrm{CO}_{2}$ concentrations corresponding to 2000 levels of 370 ppm in LPJmL (or 2005 levels of $380 \mathrm{ppm}$ in EPIC). The effect of the assumption about $\mathrm{CO}_{2}$ fertilization on the crop model results is presented in Figure 3. With $\mathrm{CO}_{2}$ fertilization activated, EPIC and LPJmL simulate for crop yields a global decrease of 10 percent and an increase of 24 percent, respectively. The predicted grass yields for EPIC and LPJmL call for increases of 12 percent and 45 percent, respectively. However, ignoring the $\mathrm{CO}_{2}$ fertilization effect leads to substantially different results. In this case, crop yields in LPJmL would increase by only 5 percent, and according to EPIC, they would fall by 20 percent. The contrast at global scale is the most pronounced for grass yields projected by LPJmL; whereas they would increase by 45 percent with $\mathrm{CO}_{2}$ fertilization activated, they are nearly stagnant (+7 percent) without the $\mathrm{CO}_{2}$ fertilization effect. Looking at the regional results, crop yields projected by LPJmL are higher than those projected by EPIC, even without the effect of $\mathrm{CO}_{2}$ fertilization. However, the $\mathrm{CO}_{2}$ fertilization effect seems to play a very important role in grass yield projections by LPJmL. In some regions, such as North America or Eastern Asia, removing the $\mathrm{CO}_{2}$ fertilization effect turns LPJmL from a rather optimistic model, projecting substantial yield improvements, into a more pessimistic model, projecting decreases in yields. In general, LPJmL is more responsive to the $\mathrm{CO}_{2}$ fertilization assumption than EPIC.

The differences between EPIC and LPJmL models in terms of the simulated effects of climate change and atmospheric $\mathrm{CO}_{2}$ concentration are the result of significant differences in the type and parameterization of biophysical processes accounted for by the two models, as well as differences in their input data regarding soil and management assumptions. The EPIC model accounts for more factors co-limiting biomass accumulation (such as stresses from heat or from soil state with respect to oxygen, aluminum, and bulk density), while LPJmL considers only water and sub-optimal temperature stresses. LPJmL is thus expected to be more optimistic with respect to impacts of changes in climate and $\mathrm{CO}_{2}$. However, the models also differ in their representation of fundamental processes such as light utilization (i.e. spatially homogeneous radiation-use efficiency for EPIC vs. detailed and spatially heterogeneous photosynthesis and respiration for LPJmL), evapotranspiration (Penman-Montheith vs. Priestley-Taylor 


\section{figure 3}

Relative climate change impacts on crop and grass yields as projected by EPIC and LPJmL for HadGEM2-ES with full direct effects of elevated $\mathrm{CO}_{2}$ concentration $\left(\mathrm{WTCO}_{2}\right)$ and without any direct effects of $\mathrm{CO}_{2}\left(\mathrm{WOCO}_{2}\right)$ for 2050 compared with 2000 in \%

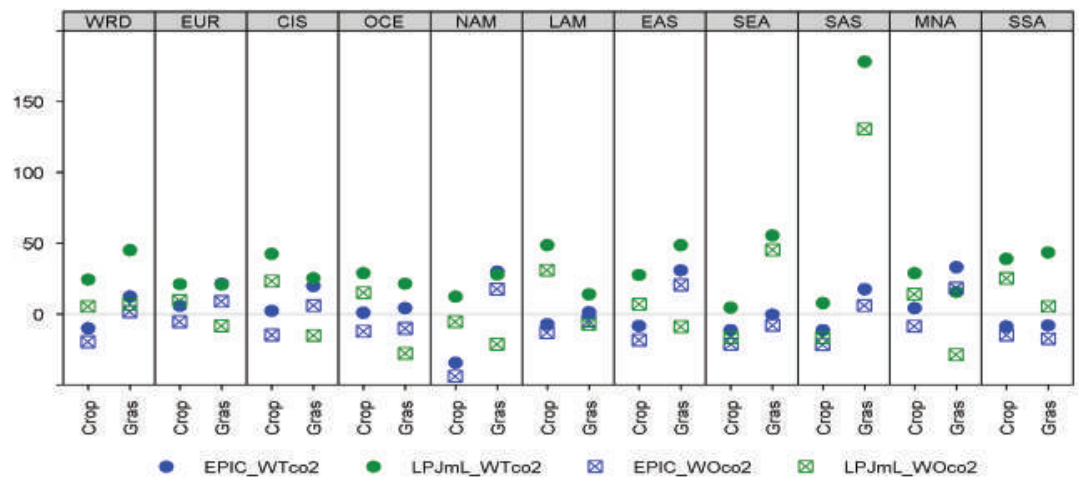

approaches for EPIC and LPJmL, respectively) and crop phenology, as well as soil, water and nutrient dynamics and yield formation. These differences significantly blur expectations with respect to model output differences, even without accounting for changes in $\mathrm{CO}_{2}$. Differences in accounting for $\mathrm{CO}_{2}$ effects add further complexities; in the EPIC model, $\mathrm{CO}_{2}$ increases light utilization and water transpiration efficiencies homogenously across space, whereas in LPJmL these factors can have highly contrasted spatial responses. Management assumptions further differentiate the two models. LPJmL does not account for nutrient stress as a factor limiting biomass accumulation, but only parameterizes management intensity to mimic current management systems (Fader et al., 2010). EPIC accounts for the stress related to nutrient availability and takes into account spatially heterogeneous levels of nitrogen application rates for crops (representing current management systems). For grassland this effect should not be large, as we assumed low nitrogen stress in EPIC simulations, but assumptions regarding grassland harvest and grazing efficiencies differ significantly. In EPIC, a high and homogeneous harvest efficiency (70 percent) was considered for grassland, without specific effects of mowing regimes. However, in LPJmL, an intensive mowing system is assumed, in which mowing is triggered by phenology and biomass thresholds. While such assumptions may not be representative for both models in many parts of the world, the LPJmL model suggests that accelerated phenology under global warming and higher biomass production could lead to amplified effects on harvested biomass, as additional harvest events could become possible.

Given these results and the number of analysed scenarios, and considering the trade-off between exhaustiveness and ease of presentation, we decided to focus this chapter on results for the two different crop models and the two assumptions on $\mathrm{CO}_{2}$ fertilization for just a single GCM. This approach makes it possible to capture the most important uncertainties among the five climate change scenarios, including the current climate as a benchmark. The scenarios are summarized in Table 1.

\subsection{Economic impact modelling}

The first economic assessments of climate change impacts on the global agricultural sector appeared 
table 1

Climate change impact scenarios

\begin{tabular}{lllll}
\hline & Radiative forcing & GCM & Crop model & $\begin{array}{c}\text { CO }_{2} \\
\text { concentration }\end{array}$ \\
\hline Present climate & Current & HadGEM2-ES & EPIC & current \\
\hline EPIC_WTco 2 & RCP8p5 & HadGEM2-ES & EPIC & RCP8p5 \\
\hline LPJmL_WTco 2 & RCP8p5 & HadGEM2-ES & LPJmL & RCP8p5 \\
\hline EPIC_WOCO ${ }_{2}$ & RCP8p5 & HadGEM2-ES & EPIC & current \\
\hline LPJmL_WOco & RCP8p5 & HadGEM2-ES & LPJmL & current \\
\hline
\end{tabular}

over twenty years ago. At that time, three modelling efforts in this area were launched, more or less simultaneously. The first global assessment used Static World Policy Simulation (SWOPSIM) (Kane et al., 1992; Reilly et al., 1994), a partial equilibrium model developed by the Economic Research Service at the United States Department of Agriculture (USDA). By that time, GCMs had already provided projections of future climate to models for crop growth, which in turn calculated the estimated changes in crop yields. These changes were finally implemented in economic models as exogenous crop yield shifters. However, the Economic Research Service at the USDA then switched to a second approach for climate change impact modelling, based on the FARM model (Darwin and Kennedy, 2000; Darwin, 2004). FARM was a computable general equilibrium model based on a geographic information system. FARM adopted a completely different approach to representing impacts of climate change on production activities. The FARM model divided land endowments into six land classes, characterized by soil temperature and length of growing season. As a result of climate change, distribution of land across the different classes was changing. This approach made it possible to account for effects on crop yields and also on pasture and forest productivity; in addition to FARM, it was used in World Trade Model with Climate-Sensitive Land (WTMCL) (Juliá and Duchin, 2007). This approach also accounted for changes in runoff and the resulting changes in water supply for irrigation.
However, the model was highly aggregated in terms of regions and sectors. While SWOPSIM divided the world into 13 regions and differentiated between 20 agricultural commodities, FARM, as implemented in 1995, represented the world in 8 regional aggregates, and agriculture was split into only two sectors - crops and livestock. The third modelling approach among the early attempts relied on the general equilibrium model BLS, developed at IIASA. Initially, the climate change impacts on crop production were based on crop model simulations using the International Benchmark Sites Network for Agrotechnology Transfer (IBSNAT) of the International Consortium for Agricultural Systems Applications (ICASA). The simulations covered 124 sites in 18 countries and then extrapolated to other parts of the world through derived yield transfer functions (Fischer et al., 1994; Rosenzweig and Parry, 1994; Parry et al., 1999; Parry et al., 2004). Later on, the climate change impact module has been replaced by the AEZ framework of the Food and Agriculture Organization of the United Nations (FAO)-ILASA (Fischer et al., 2005; Tubiello and Fischer, 2007). The BLS model divides the world into 34 countries/ regions and aggregates global agricultural production into nine sectors, with the rest of the economy aggregated in a single sector. The model has been extensively used for climate change impact analysis for more than a decade.

Since 2007, global climate change impact assessments focusing on the agricultural sector have inspired an increasing number of 
economic models. The EPPA model developed at Massachusetts Institute of Technology (MIT) used the Terrestrial Ecosystem Model (TEM) to derive changes in crop, pasture and forest productivity (Reilly et al., 2007; Reilly et al., 2013). The Global Trade Analysis Project (GTAP) and its variants were implemented later; these usually relied on literature reviews or existing datasets for the climate change impact parameters (Lee, 2009; Hertel et al., 2010; Calzadilla et al., 2013). Recently, several influential studies on climate change impacts and the costs of adaptation were carried out at IFPRI with the International Model for Policy Analysis of Agricultural Commodities and Trade (IMPACT) model, which derived the climate change impact parameters from detailed Decision Support System for Agrotechnology Transfer (DSSAT) simulations (Nelson et al., 2009, 2010; Rosegrant et al., 2014). The widespread interest in this topic among the global economic modelling teams was expressed in the coordinated model intercomparison project, co-organized by AgMIP and ISI-MIP, in which nine global economic models jointly analysed climate change impacts on the agricultural sector based on the most recent climate change impact projections by five global gridded crop models (Nelson et al., 2014a; Nelson et al., 2014b).

In this study we use GLOBIOM (Havlík et al., 2011). This model had been implemented for climate change impact assessments in the past, both individually (Mosnier et al., 2014 Leclère et al., (in press) Climate change induced transformations of agricultural systems: insights from a global model Environ. Res. Lett.) and as part of AgMIP/ ISI-MIP. GLOBIOM is a partial equilibrium model covering the agricultural and forestry sectors including the bioenergy sector - which is used for analysing medium to long-term exploratory and policy oriented scenarios. The model divides the world into 30 economic regions, in which a representative consumer by region is modeled through a set of isoelastic demand functions. The spatial resolution of the supply side relies on the concept of Simulation Units, which are aggregates of 5 to 30 arc minutes pixels (or from $1 / 12$ to $1 / 2$ degree) that belong to the same altitude, slope, and soil class, and to the same country. For crops, grass and forest products, Leontief production functions covering alternative production systems are calibrated based on biophysical models, such as EPIC (Williams, 1995). For this study, the supply side spatial resolution is aggregated to $2^{\circ} \times 2^{\circ}$ (about $200 \times 200 \mathrm{~km}$ at the equator). Economic optimization is based on the spatial equilibrium modelling approach (Takayama and Judge 1971). The price-quantity equilibrium is computed using the method of McCarl and Spreen (1980) at the regional level. The model is calibrated to FAOSTAT activity levels as of the year 2000, and is then recursively calculated in 10 year intervals of time.

GLOBIOM includes a particularly detailed representation of the global livestock sector (Havlík et al., 2013; Havlík et al., 2014). The model distinguishes between dairy and other bovines, dairy and other sheep and goats, pigs and poultry, with further distinctions between laying hens and broilers. Livestock production activities are defined in several alternative production systems adapted from Seré and Steinfeld (1996) as follows: grassbased (arid - LGA, humid - LGH, temperate/ highlands - LGT), mixed crop-livestock (arid - MRA, humid - MRH, temperate/highlands - MRT), urban (URB) and other (OTH), for ruminants; smallholder and industrial production for monogastrics. For each species, production system and region, a set of input-output parameters is calculated, based on the approach by Herrero et al. (2013). Feed rations are defined as consisting of grass, stover, feed crops aggregates and other feedstuff. Outputs include four meat types, milk and eggs, as well as environmental factors (manure production, nitrogen excretion, and greenhouse gas emissions). The initial distribution of livestock across the systems is based on Robinson et al. (2011). Switching among the production systems allows for feedstuff substitution and for intensification or extensification of livestock production.

Furthermore, six land cover types are distinguished: cropland, grassland, short-rotation tree plantations, managed forest, unmanaged forest and other natural vegetation. Depending on the relative profitability of the individual activities 
and the constraints on recursivity, the model can switch from one land cover type to another. Comprehensive accounting of greenhouse gas for agriculture and land use change is also implemented in the model. Detailed descriptions of these accounts and additional background information are provided in Valin et al. (2013).

Climate change impacts on crop and grass yields are implemented in GLOBIOM as changes relative to the year 2000 values at the Simulation Unit level. Eighteen globally important crops, which cover about 75 percent of total harvested area as reported by FAOSTAT, are represented explicitly in the model (Barley, Dry beans, Cassava, Chick pea, Corn, Cotton, Groundnut, Millet, Oil palm, Potatoes, Rapeseed, Rice, Sorghum, Soybeans, Sugar cane, Sunflower, Sweet potatoes, and Wheat). All of them, except for Oil palm, are individually parameterized with EPIC for four management systems - subsistence, low-input commercial, high-input and irrigated. The initial distribution of crops and systems for the year 2000 is based on IFPRI's SPAM (You and Wood, 2006). The EPIC model provides not only information about yields but also the corresponding nitrogen and irrigation water requirements. Climate change impact simulations are conducted for three management systems - subsistence (used also for the low-input commercial system), high-input and irrigated. In the high-input management system, nitrogen fertilization is automatically adjusted to the changes in requirements by crops in response to climate change. In the irrigated systems, the levels of both nitrogen and water for irrigation are adjusted in response to climate change. Furthermore, the dates of operations such as sowing are adapted to the climate. For Oil palm, an average value is used - calculated from the climate change impacts on groundnuts, rice, soybeans and wheat - following the protocol of Müller and Robertson (2014). LPJmL provides climate change impact simulations individually for 11 major crops and for two management systems rainfed and irrigated. The yields for the remaining seven crops are derived analogically from those 11 crops. The relative changes in yields from the single LPJmL rainfed system are used for all three GLOBIOM rainfed systems. Nitrogen and irrigation water requirements are adjusted proportionally to the yields, as are phosphorus requirements and production costs, for both EPIC and LPJmL climate change simulations. In GLOBIOM, the extent and distribution of grasslands are determined based on GLC2000 and livestock feed requirements. Grass productivity levels in the year 2000 are taken from EPIC for regions with intensive or semi-intensive grassland management and from CENTURY (Parton et al., 1987; Parton et al., 1993) for regions with extensive rangelands. Climate change impact on grasslands is captured through shifts in relative productivity calculated for managed grasslands by both EPIC and LPJmL, as discussed above.

Marginal adaptation to climate change, in terms of input level or adjustments of operation dates is implicit in the crop model results as mentioned above. GLOBIOM models additional mechanisms which can mitigate the effects of climate change on the agricultural sector. In addition to relocating production activities within or across the various regions to exploit new comparative advantages between locations and individual production activities, a major adaptation mechanism represented in GLOBIOM is switching between different production systems. In the crop sector, this can take the form of shifting some of the production from the rainfed system to the irrigated system in response to increased droughts. In the livestock sector, it generally involves shifting ruminants from grazing systems to mixed crop-livestock systems or vice versa, changes which can play an important role in the future livestock sector development (Havlík et al., 2013; Havlík et al., 2014). The ruminant diets differ widely in their composition across the production systems (Figure 4). For instance, in arid zones, an average of 90 percent of the ruminant diet in grazing systems (LGA) is composed of grass, but grass does not even constitute 50 percent of the diet for ruminants in mixed systems (MRA). It follows that climate change impacts on grass yields may substantially alter the relative competitiveness 


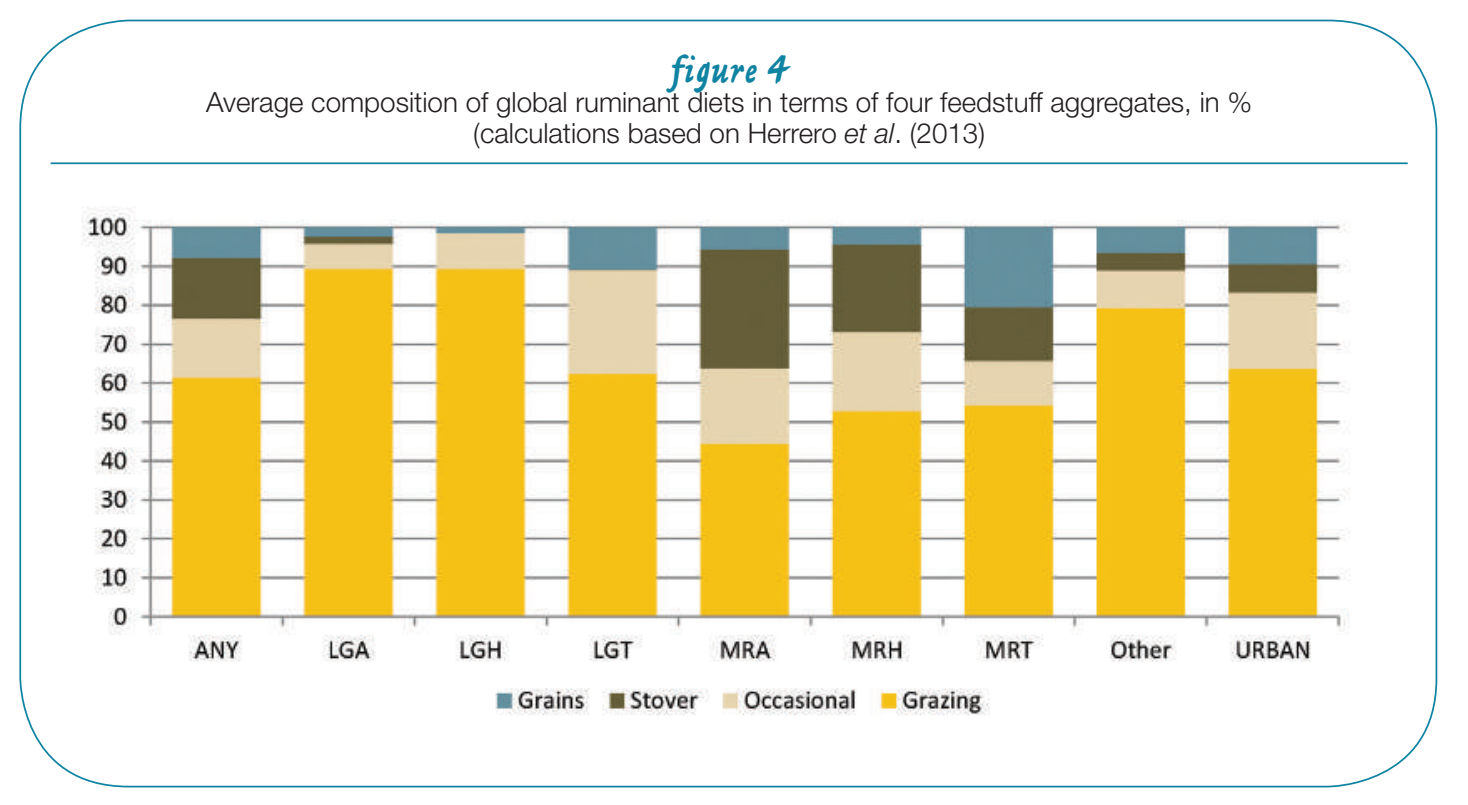

of the different systems and hence the overall outcome for the livestock sector.

Only one set of socio-economic drivers is used for all the climate scenarios in this study. Gross domestic product (GDP) and population projections correspond to the SSP2 - the Middle of the Road scenario out of the five Shared Socio-economic Pathways (SSPs) (O'Neill et al., 2014). The impact of future technological change on crop yields and feed conversion efficiencies has been calculated from past relationships observed between crop yields and GDP, and has been transposed for the livestock sector based on past rates of feed conversion efficiency gains at global level (Herrero, M., Havlík, P., McIntire, J., Palazzo, A. and Valin, H. 2014. African Livestock Futures: Realizing the Potential of Livestock for Food Security, Poverty Reduction and the Environment in Sub-Saharan Africa. Office of the Special Representative of the UN Secretary General for Food Security and Nutrition and the United Nations System Influenza Coordination (UNSIC), Geneva, Switzerland, 118 p.). Global future consumer preferences are captured in the income elasticities of the demand functions used in this chapter, which have been calibrated to the FAO projections by Alexandratos and Bruinsma (2012) (Valin et al., 2014).

\section{Results}

Climate change impacts on crop and grass yields will trigger a series of adjustments in the global agricultural system, which is trying to buffer the negative effects and exploit the new opportunities. Here we first briefly present our projections of livestock sector development up to 2050 without climate change, and then discuss how these developments could be altered through climateinduced crop and grass yield changes. In a final step, we analyse the adaptation mechanisms at play in the area of land management and in the livestock sector.

\subsection{Livestock sector developments without climate change}

Demand for milk is projected to almost double globally (+91 percent) between 2000 and 2050 (Figure A1 in the Annex). The fastest growth is expected to occur in South Asia, sub-Saharan Africa and Southeast Asia (+230-250 percent). In absolute terms, half of the new demand is projected to come from South Asia (+255 million tonnes), followed by Latin America 
(+67 million tonnes). Regional production is mostly projected to follow the increases in local demand, leaving a minor role for international trade. The noticeable exception is South Asia, which is projected to increase production by "only" 183 percent, leading to a gap of 50 million tonnes, which will need to be covered through imports. Europe and Oceania would remain the only major exporters. At the global scale, the price of raw milk would increase by only 4 percent by 2050 . Even at the regional level, the price increase would remain below 10 percent, except for the Near East \& North Africa and sub-Saharan Africa, where the prices are projected to rise by about 20 percent.

Demand for ruminant meat is projected to increase globally at almost the same rate as milk demand (+90 percent). The fastest increases are projected to occur in sub-Saharan Africa (+269 percent) and Southeast Asia (+255 percent). In absolute terms, however, the largest increase is projected to occur in East Asia (+14 million tonnes), followed closely by Latin America and sub-Saharan Africa. On the opposite end of the scale, total demand is projected to increase by only about 10 percent in Europe and North America. Ruminant meat production is projected to increase the most noticeably in Latin America and East Asia - by 18 and 14 million tonnes, respectively. Latin America is also projected to become the most important ruminant meat exporter, at 5.7 million tonnes per year by 2050, whereas the second largest exporter, Oceania - whose export rate is rather stagnant would supply the global market with about half that volume, at 2.8 million tonnes. Imports are projected to rise most dramatically in the Near East \& North Africa and in sub-Saharan Africa, reaching 2.9 and 2.7 million tonnes, respectively. China's rising demand is projected to be satisfied by local production, leaving imports close to the historical level of 1.4 million tonnes per year. Ruminant meat prices are projected to rise globally by 15 percent between 2000 and 2050, although they are actually projected to decrease slightly for all regions except South Asia, the Near East \& North Africa and sub-Saharan Africa, where they would rise by 145 percent, 46 percent, and 40 percent, respectively.
Finally, demand for meat from monogastrics is projected to increase by 104 percent between 2000 and 2050. The fastest increases are projected for South Asia (+1300 percent), sub-Saharan Africa (+547 percent) and the Near East \& North Africa (+289 percent). In terms of volume, the largest increase would still occur in East Asia, up to 37 million tonnes between 2000 and 2050, followed by Latin America, at 29 million tonnes, and South Asia, at 28 million tonnes. Most of the demand would be satisfied through local production, except in sub-Saharan Africa and South Asia, which are projected to be importing about 30 percent of their total demand by 2050. China is still projected to be importing about one million tonnes, but this would represent just 1 percent of its total demand. Meat prices for monogastrics are projected to increase only marginally at the global scale, with the exception of South Asia, where they are projected to rise more than 120 percent.

As mentioned earlier, the income elasticities of our demand functions have been calibrated to the FAO projections by Alexandratos and Bruinsma (2012). Hence, it comes as no surprise that the commodity demand projections presented above are similar to the FAO projections; our projection for total milk demand is only 6 percent higher, for ruminant meat demand it is 4 percent higher, and for monogastric meat demand it is just 2 percent higher than FAO projections for 2050. At the regional level, the discrepancies in projections are larger, for both demand and supply. This has an effect on the level of agreement between our projected net trade and the FAO projections. However, given the difference in approaches for producing the two sets of projections, even the net trade values are often reasonably comparable. The major exception to this is South Asia; our projections indicate that this region will have to satisfy an increasingly large amount of its livestock product demand from imports, in particular for dairy products, while the FAO projects net trade to remain close to the current levels.

By the year 2000, the largest share (22 percent) of ruminants, measured in tropical livestock units (TLU - equivalent of $250 \mathrm{~kg}$ body weight), had 


\section{figure 5}

Livestock numbers distributed by livestock production systems for 2000, 2030 and 2050 in million (mio) TLUs. (RUMI - ruminants, BOVI - bovines, SHGT - small ruminants,

BOVDh - bovines dairy herd, BOVOh - bovines other herd, SGTDh small ruminants dairy herd, SGTOh - small ruminants other herd)

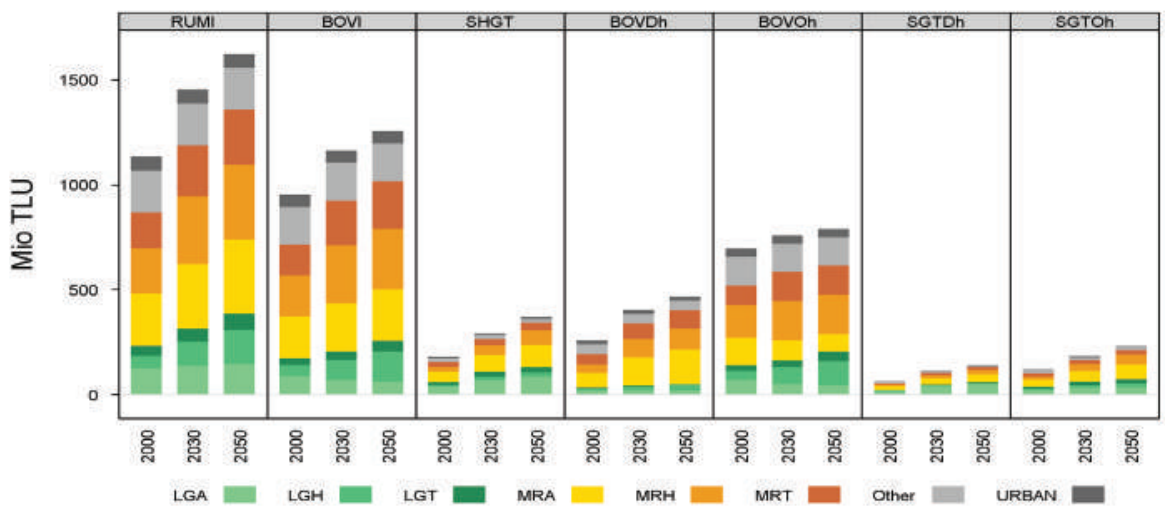

\section{figure 6}

Land cover change between 2000 and 2050 in million (mio) hectares.

(CrpLnd - cropland, GrsLnd - grassland, PltFor - energy plantations, Forest - managed and unmanaged forest, NatLnd - other natural land)

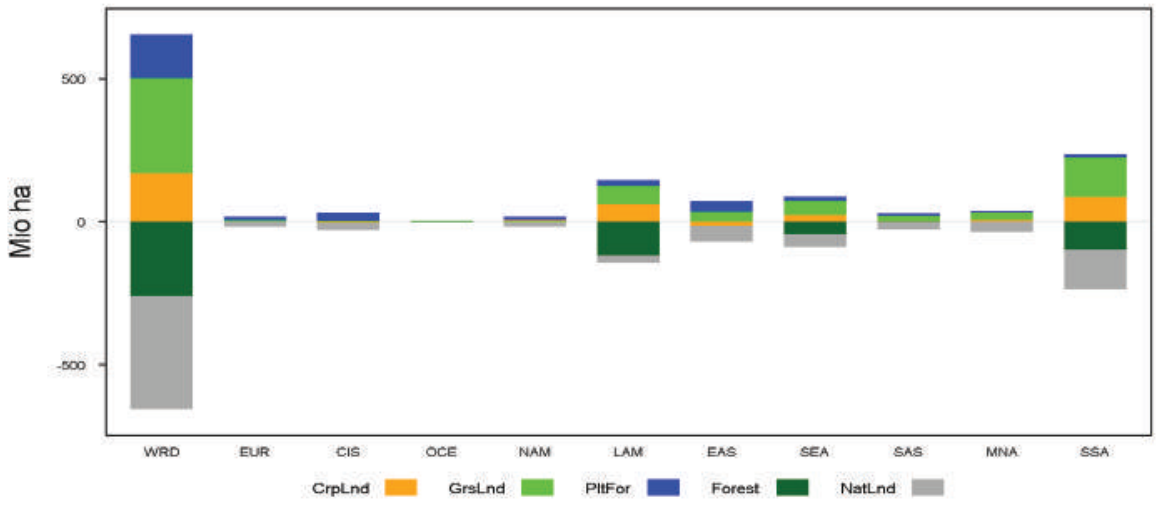

been reared in mixed arid systems, followed by mixed humid systems (19 percent) and other systems (18 percent). Only 20 percent of all ruminants were in the grazing systems (Figure 5). The number of ruminants is projected to increase by 43 percent between 2000 and 2050. This is approximately half of the projected increase in milk and ruminant meat production, indicating substantial productivity gains over this period. The largest increases in the numbers of animals are expected in humid systems, driven by the continued boom in Latin America; 144 million TLUs in the mixed humid system and 105 million TLUs in the grazing humid system.

The additional agricultural production will also come partly from cultivated land expansion. Global 


\section{figure 7}

Relative climate change impacts on livestock production compared with the present climate scenario (presclim) by 2050 in \%. (ALMILK - bovine and small ruminant milk, RMMEAT - bovine and small ruminant meat, MGMEAT - pig and poultry meat)

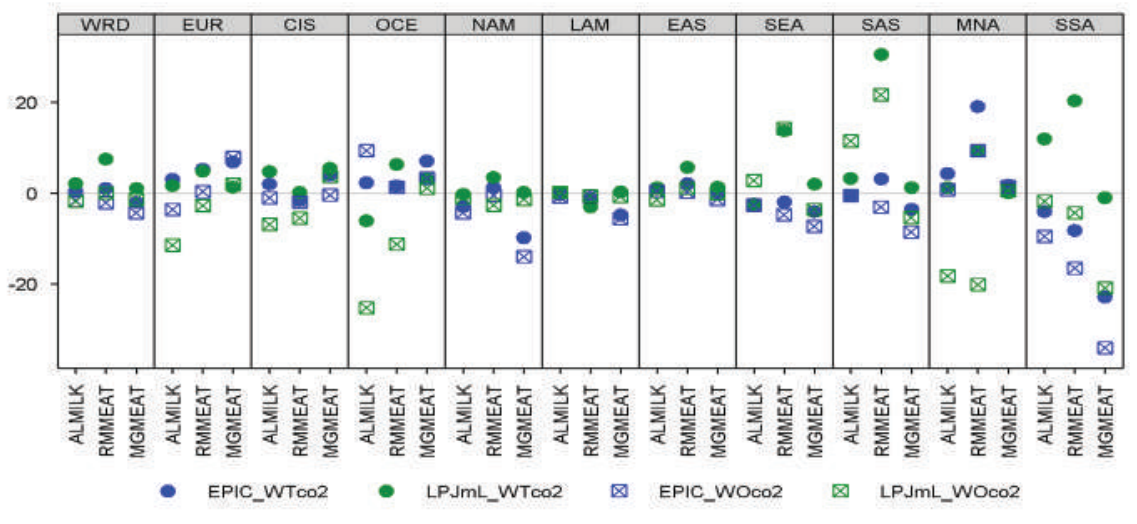

croplands are projected to expand by 170 million hectares, and grasslands by 331 million hectares (Figure 6). The largest expansion of both cropland and grassland is projected for sub-Saharan Africa, Latin America, and Southeast Asia. Significant grassland expansion is also projected for Eastern Asia and for the Near East \& North Africa.

\subsection{Climate change impact on livestock markets}

Climate change impacts on crop and grass yields are projected to have only minimal effect on global milk and meat production by 2050 , which remains within $+/-2$ percent of the projected production without climate change (Figure 7). The only two exceptions are as follows: ruminant meat production increases by 7.5 percent under the yields projected with $L P J \mathrm{~mL}$, taking into account the $\mathrm{CO}_{2}$ fertilization effect; and monogastric meat production decreases by 4.3 percent under the yields projected with EPIC without the $\mathrm{CO}_{2}$ fertilization effect. These results reflect the climate change impacts presented in Figure 3: grass yields projected globally by LPJmL with $\mathrm{CO}_{2}$ fertilization benefit most from climate change - grass being the most important feedstuff for ruminant meat production; and crop yields projected by EPIC without $\mathrm{CO}_{2}$ fertilization experience the most severe negative impacts of climate change - crops being the major feedstuff for monogastrics in commercial systems.

Depending on the scenario, the climate change effects can be more pronounced at the regional level. In three regions - the former Union of Soviet Socialist Republics (USSR), Eastern Asia and Oceania - the climate change effect on livestock production remains within $+/-10$ percent under all the different yield impact projections. Two regions may experience strong increases in production in response to climate change - South Asia and Southeast Asia. Both regions could react to the large positive grass yield effects projected by LPJmL by increasing ruminant production; e.g. with the yields projected by LPJmL with $\mathrm{CO}_{2}$ fertilization, ruminant meat production in South Asia in 2050 would be higher by 30 percent with climate change than without climate change. Other regions - Europe, Northern America, and Oceania are expected to experience significant negative effects on livestock production in at least one of the yield scenarios. In Oceania, in particular, the pessimistic grass yield projections resulting from 


\section{figure 8}

Climate change impacts on net trade by 2050 in '000 tonnes. (ALMILK - bovine and small ruminant milk, RMMEAT bovine and small ruminant meat, MGMEAT - pig and poultry meat)
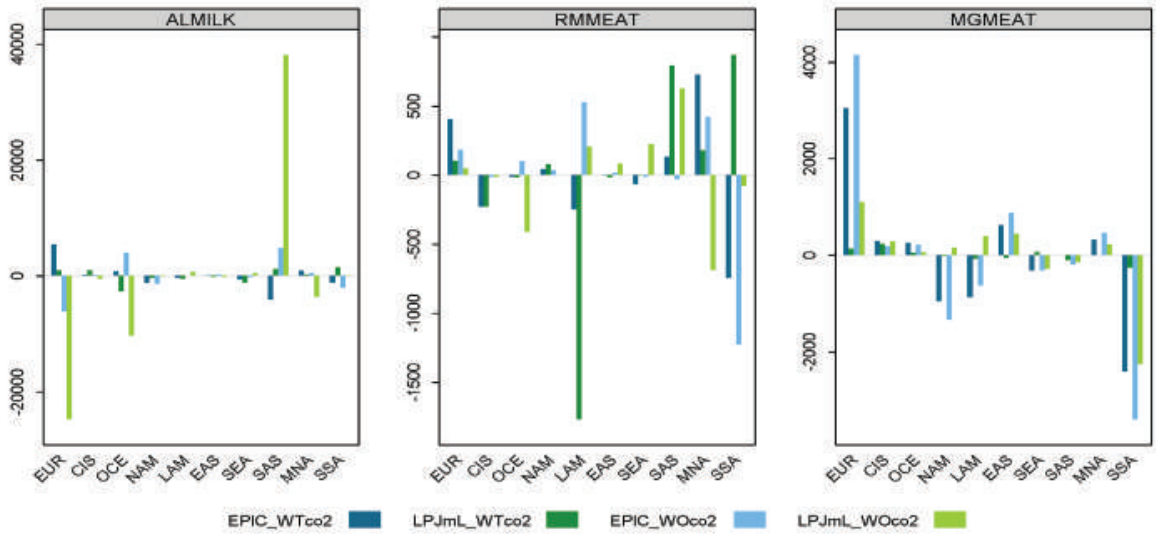

reduced precipitation could lead to a 25 percent decrease in milk production under the LPJmL yields without $\mathrm{CO}_{2}$ fertilization, compared with the current climate scenario. The climate effects seem to be the most uncertain in the Near East \& North Africa and in sub-Saharan Africa. For instance, in the Near East \& North Africa, the change in ruminant meat production attributable to climate change varies by +/-20 percent, depending on the yield scenario. In sub-Saharan Africa, the effects are the most uncertain and potentially the most severe; ruminant production could increase by 20 percent but it could also decrease by 17 percent, and all yield scenarios except for LPJmL with $\mathrm{CO}_{2}$ fertilization would lead to monogastric meat production falling by more than 30 percent.

The model scenario analysis confirms this approach confirms that there is a generally positive relationship between changes in crop yields and monogastric production, and between changes in grass yields and ruminant production. This link is the strongest with respect to changes in grass yields and ruminant meat production. This can be explained by the fact that grass represents a substantial share of the meat ruminant diet, and that adaptation options in grassland management are limited.
The relationship between grass yields and changes in milk production provides a good illustration of the complex interactions present in the global livestock sector. For instance, Oceania shows two cases of counterintuitive behavior with this respect. On the one hand, grass (and crop) yields decrease in projections by EPIC without $\mathrm{CO}_{2}$ fertilization and milk production increases, and on the other hand, grass (and crop) yields increase in projections by LPJmL with $\mathrm{CO}_{2}$ fertilization, and milk production decreases. Oceania is projected to be the second largest milk exporter by 2050; therefore, its local production depends on the supply in other regions. Under the EPIC scenario without $\mathrm{CO}_{2}$ fertilization, supply of milk from Europe - which is projected to be the largest exporter by 2050 - decreases, as does milk production in sub-Saharan Africa and North America, and this gap is filled by the increased production in Oceania (Figure 8). Similarly, under yields projected by LPJmL with $\mathrm{CO}_{2}$ fertilization, milk production increases in some of the importing regions - such as South Asia and sub-Saharan Africa - which reduces the demand for milk exports from Oceania, and leads to reduced production. However, another reason why change in grass yields is not a good predictor for change in 
milk production is the level of importance of crops in dairy ruminant diets; e.g. the decrease in milk production in North America, despite grass yield increases under the EPIC yield scenarios, can be attributed to substantial crop yield decreases under the same scenarios.

Rates of regional pig and poultry meat production do not show a strong connection to climate change impacts on crop yields but some regular patterns can be identified with respect to the different crop models. EPIC projects an overall deterioration in crop yields as a consequence of climate change. Under the EPIC scenarios, most regions behave as expected - i.e. they decrease meat production if crop yields decrease, and increase production if the climate change effect on yields is positive. Some regions also increase production when their crop yields decrease, particularly under the scenario without $\mathrm{CO}_{2}$ fertilization. Under that scenario, many regions including North America - are very negatively affected, which creates a comparative advantage for regions that are less affected, such as Europe and Oceania. LPJML projects mostly positive effects of climate change on crops and, under these scenarios, monogastric meat production is less reactive to the crop yield change, because of low responsiveness of demand to price reduction of these commodities. Sub-Saharan Africa is an outlier under all but the most favourable yield scenario - LPJmL with $\mathrm{CO}_{2}$ fertilization. Absolute crop yields in the reference case without climate change are very low, so even if climate change impacts are positive, such as under the LPJmL scenario without $\mathrm{CO}_{2}$ fertilization, production in the pig and poultry sector decreases, as the impact on absolute yield is much smaller than in other parts of the world.

The effects on regional consumption are less pronounced than the effects on production because the impacts of climate change are partly buffered through international trade, as discussed above. The strongest negative effects correspond to a reduction of consumption by 12 percent (Figure 9). This occurs in the area of North America monogastric meat consumption under the worst crop yield scenario coming from the EPIC projections without $\mathrm{CO}_{2}$ fertilization. The other region that experiences a similar consumption decrease in one of the livestock commodities is the Near East \& North Africa, where the strong grass yield reduction in the projections by LPJmL

\section{figure 9}

Relative climate change impacts on livestock product consumption compared with the present climate scenario (presclim) by 2050 in \%. (ALMILK - bovine and small ruminant milk, RMMEAT - bovine and small ruminant meat, MGMEAT - pig and poultry meat)

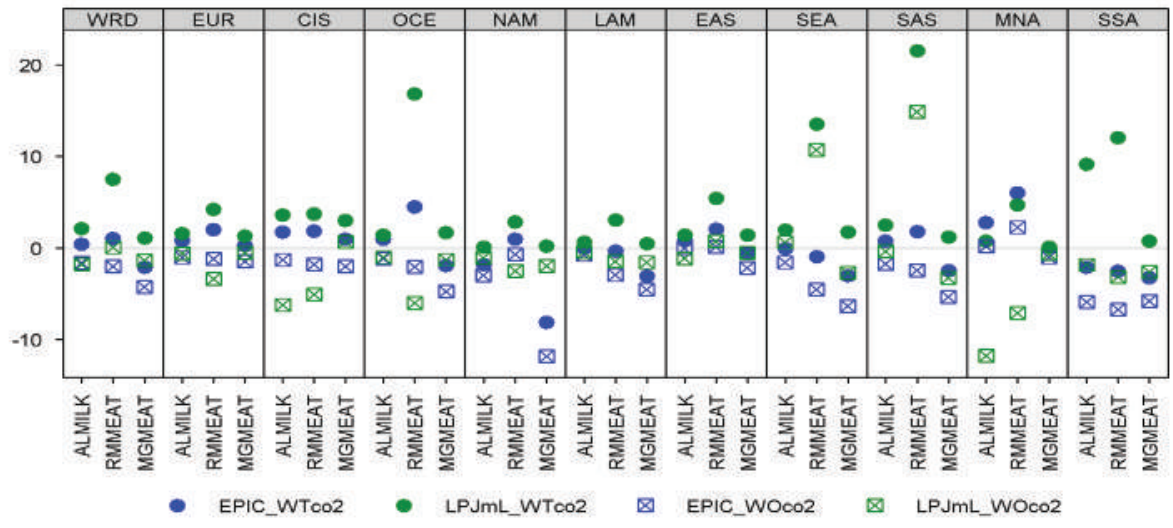




\section{figure 10}

Relative climate change impacts on livestock product prices compared with the present climate scenario (presclim) by 2050 in \%. (ALMILK - bovine and small ruminant milk, RMMEAT - bovine and small ruminant meat, MGMEAT - pig and poultry meat)

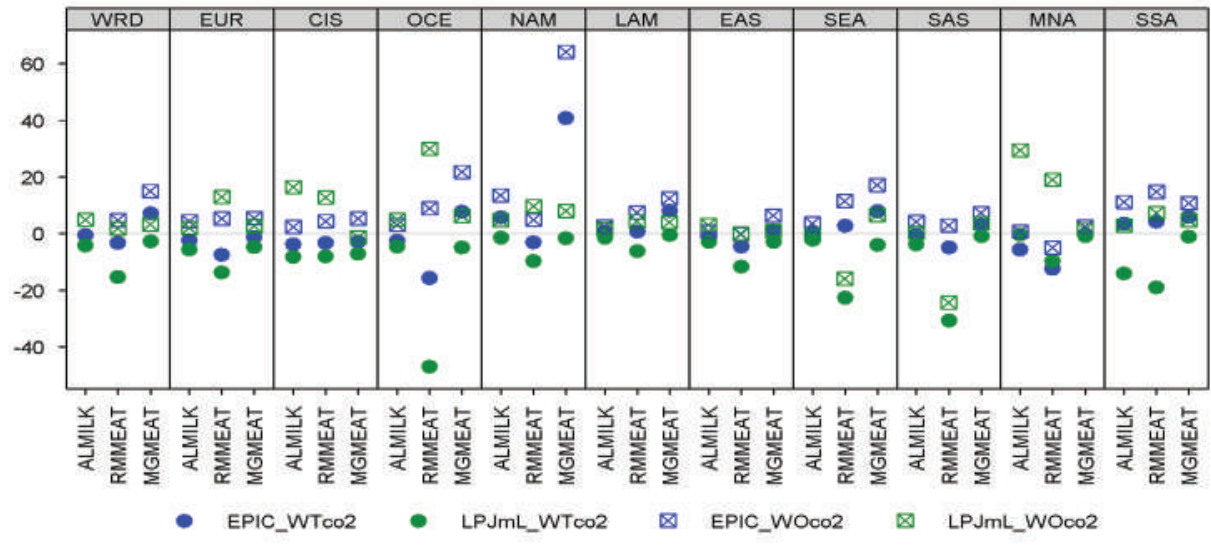

without $\mathrm{CO}_{2}$ fertilization leads to a substantial drop in milk consumption. Any other negative effects are smaller than 10 percent. Even sub-Saharan Africa, which is projected to experience a fall in production by up to 34 percent, depending on the scenario and the commodity, would see its consumption decreasing by at most 7 percent compared with the scenario without climate change. As can be expected, these mostly small changes in consumption go hand in hand with modest changes in commodity prices (Figure 10). The only case where the prices are projected to exceed 30 percent compared with the no climate change yield scenario is that of monogastric meat in North America, where the strong negative effect on crop yields meets up with the price inelastic demand.

From the perspective of food availability, it will be more important to control developments in the crop sector, because crops are the source of about 80 percent of all food energy consumption. However, the loss of energy availability barely exceeds $50 \mathrm{kcal} / \mathrm{cap} /$ day, except under the yield scenario projected by EPIC without $\mathrm{CO}_{2}$ fertilization. The climate change effect on overall food availability is systematically positive under the yield scenario projected by LPJmL with $\mathrm{CO}_{2}$ fertilization.

\subsection{Land management adaptation}

In response to climate change impacts on yields, GLOBIOM allows for adaptation through changes in the management system and relocation of production to more or less productive land within and across countries, which will result in changes in aggregate regional or global yields (YILD). GLOBIOM also allows for adaptation through adjustments in the total area devoted to a given activity. The results, summarized in Figure A2 in the Annex, show that GLOBIOM tends to compensate for yield decreases caused by negative climate change effects, while positive climate change effects lead to extensification (crop area expansion in previously marginal lands or substitution with other activities) and to final yields lower than projections based on pure climate shock. An example of effective adaptation is in North America, where the EPIC crop yield projections without $\mathrm{CO}_{2}$ fertilization lead to the most severe negative impact - a 44 percent decrease - but autonomous adaptation buffers a third of this impact, leading to a final yield decrease of only 30 percent. At the other extreme, one of the most positive effects is projected for the former USSR by LPJmL with $\mathrm{CO}_{2}$ fertilization - a 


\section{figure 11}

Land cover change due to climate change by 2050 in million hectares.

(CrpLnd - cropland, GrsLnd - grassland, PItFor - energy plantations, Forest - managed and unmanaged forest, NatLnd - other natural land)

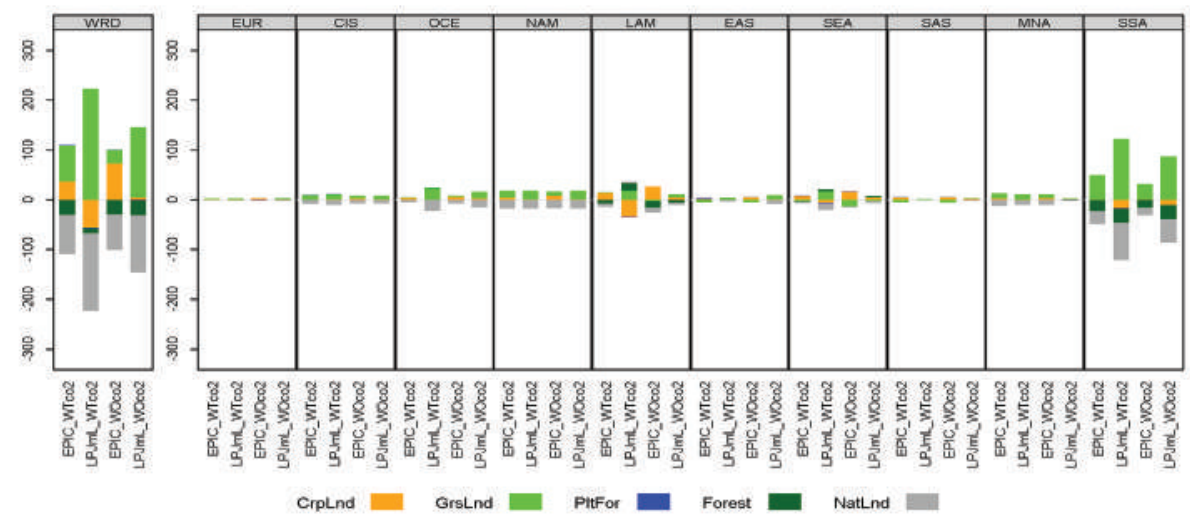

42 percent increase - but the final aggregate crop yield is only 15 percent higher compared with the present climate scenario. We can see also cases where overall positive effects may lead to slightly negative yields after adaptation. This is due to changes in the composition of the crop aggregate as some crops are favoured or disadvantaged by the climate change more than others. Relocation of production to lower-yielding crops may also lead to aggregate crop yield decrease through a composition effect. The autonomous yield adjustment can buffer about 50 percent of the pure climate change effect, on average, as indicated by the slope of the trend line, which is 0.48 . The aggregate area response has a negative slope, meaning that the model tends to expand the crop area in regions and scenarios where crop yields are affected negatively, and decrease the crop area when crop yields are affected positively. This outcome complements the results presented in Nelson et al., (2014a), which considered individual crops or just small crop aggregates. In these cases, GLOBIOM, unlike the other models, tends to expand the areas of particular crops that are affected positively by climate change, at the expense of crops affected negatively. The overall effect on crop production does not have a strong indicator. The negative effects are, in general, buffered through management change or area expansion, while the positive effects tend to be evened out, through extensification or crop area reduction.

The adapted regional grass yields are the direct result of livestock relocation to more or less productive land because, in the current version of GLOBIOM, no adaptation through grassland management is considered, and because reported yields are calculated as weighted averages, with the area of utilized grasslands in each pixel used as the weight. It is clear that livestock relocation within a given region has very little potential to buffer negative climate change impacts. Positive climate change impacts most often lead to expansion of grasslands into less productive areas, which then leads to a less than proportional increase in grass productivity compared with climate shock. The strength and direction of this effect is similar to the changes in crop yield. There is no significant relationship between the grass yield shock and the grassland area expansion which in turn leads to lack of relationships between the yield shock and grass production as between the yield shock and total yield change. 


\section{figure 12}

Climate change impact on ruminant numbers across the different livestock productions systems by 2050 in million TLUs

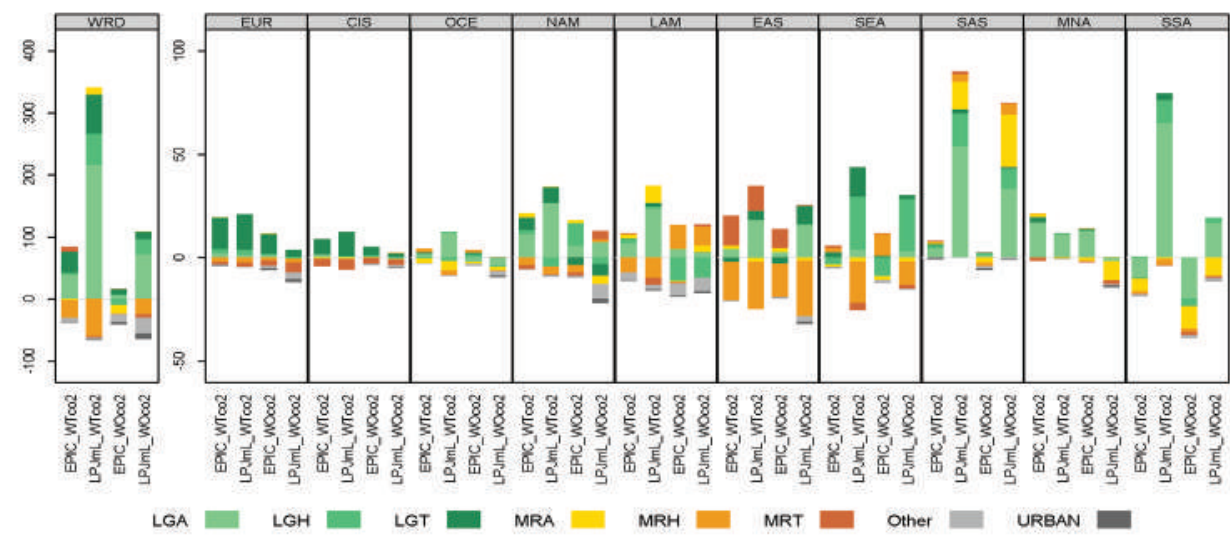

These adjustments lead, overall, to minor land cover changes (Figure 11). The most significant land cover changes occur in sub-Saharan Africa in response to the new opportunities created by increases in grass productivity in yield scenarios by LPJmL. In this region the grassland increases by up to 122 million hectares, mostly at the expense of other natural land. This counterintuitive result comes mostly from the fact that sub-Saharan Africa - which, under other yield scenarios, is a net importer of bovine meat improves its competitiveness through the positive climate change impacts on grass yields and even becomes a small net exporter. However, since the beef production in Africa is very land-intensive, the area expansion is not accompanied by crop area reduction in other regions. Hence, the LPJmL impact scenarios lead to the globally largest losses of natural land.

\subsection{Livestock sector adaptation}

The major mechanism for adaptation to yield changes due to climate change in the livestock sector is a change in the composition of animal diets. In our modelling framework, this occurs through changes in allocation of the animals between grazing systems and systems relying on supplementation of the diets by crop-based feeds (mixed systems). Figure 12 shows that the relatively more positive impacts of climate change on grass yields compared with crop yields would translate to expansion of ruminants reared in the grazing systems, partly at the expense of ruminants in the mixed systems. For instance, under grass yields projected by LPJmL with $\mathrm{CO}_{2}$ fertilization, 38 percent of ruminants globally would be reared in grazing systems by 2050, although it was only 20 percent in 2000 , and would be just 24 percent in 2050 without climate change. This development would be the most significant for the dairy bovines. Without climate change, the share of dairy bovines reared in grazing systems is projected to further decrease, from the already low 13 percent in 2000 to 11 percent in 2050, but under the grass yield change projected by LPJmL with $\mathrm{CO}_{2}$ fertilization, 30 percent of all dairy bovines would be reared in grazing systems. Such developments would present a substantial alteration of the current trends.

Except for Europe, the former USSR and Oceania, all regions are very sensitive to the grass yield projections. The region most affected by this uncertainty is South Asia, where LPJmL 
projects grass yield increases by 178 percent and 130 percent, with and without $\mathrm{CO}_{2}$ fertilization, respectively. This leads to a large increase in bovine numbers in the mostly arid grazing systems. These developments contrast with the climate change impact scenarios in EPIC, under which the numbers of ruminants are not substantially different from the scenario without climate change. Ruminant production in sub-Saharan Africa is also highly sensitive to the yield projections. As in South Asia, a large expansion of ruminant numbers is projected to occur in the arid grazing systems under the yield scenario by LPJmL. Disagreement with the results from the EPIC scenarios is particularly large for sheep.

The differences in total livestock numbers and in the distribution of livestock across production systems are more pronounced than the differences in total production and its distribution across the systems. While the total number of ruminants under the yield scenario projected by LPJmL with $\mathrm{CO}_{2}$ fertilization would be 17 percent higher than without climate change, the total ruminant protein production would be only 4 percent higher. This is due to the fact that most of this expansion would occur in relatively low-yielding regions, and in very unproductive, arid grazing systems (LGA).

Overall ruminant meat production is very closely related to climate impacts on grass yields. This is also true for distribution of production across the systems (Figure A1 in the Annex). The difference in the percentage of animals in the grazing systems with and without climate change is most directly related to the change in grass yields for the bovine meat herd. Overall, climate change is likely to increase the share of ruminants in grazing systems, as it is projected to occur in 30 out of 40 combinations of ten regions and four yield scenarios.

\section{Conclusions}

This study provides the most detailed global assessment of climate change impacts on the livestock sector available so far, accounting not only for changes in crop yields but also for changes in grass productivity. This type of analysis is generally subject to large uncertainties along the entire chain, from climate and crop models, through assumptions about the strength of some mechanisms that are still not well understood, such as the effects of $\mathrm{CO}_{2}$ fertilization, up to the uncertainties inherent in the economic models (Nelson et al., 2014a). Uncertainties within the chain of biophysical modelling of climate change impacts on crops have been well documented in Rosenzweig et al. (2014) and the issue of uncertainty is even more relevant to grass yield projections, where reference data are less available for model development and evaluation. In this report, we have considered two different crop models and two different assumptions about the effects of $\mathrm{CO}_{2}$ fertilization - not attempting to cover the whole spread of uncertainty but rather to illustrate the challenge.

We have obtained several important results that appear fairly robust across the scenarios. First, our results coincide with the vast body of literature showing that, regardless of the scenario chosen, the effects of climate change on the agricultural sector in general, and on the livestock sector in particular, would remain fairly small on the global scale by 2050, as illustrated by projected price changes mostly being contained within a range of $+/-10$ percent. Second, international trade could buffer the majority of negative production shocks so that the impacts on consumption remain limited. Finally, because grass yields tend to benefit more (or to be hurt less) from climate change than crop yields, climate change would favour increasing the number of ruminants in the grazing systems, representing a rebalancing in the general trend towards more intensive systems projected without climate change (Havlík et al., 2014). This last finding is also in agreement with previous studies (Jones and Thornton, 2009; Thornton et al., 2011).

However, some regions remain more vulnerable than the others. South Asia and subSaharan Africa are the regions with potentially 
the most severe - but also the most uncertain effects. For instance, the generally robust shift towards grazing systems is valid for South Asia and sub-Saharan Africa under only two of the four climate impact scenarios. This level of uncertainty makes it difficult to engage in investments that would steer the sector in a particular direction, and substantial reductions in uncertainty are not expected in the near future (Ramirez-Villegas et al., 2013). Therefore, adaptation strategies that would be appropriate under a large set of future climate and climate impact scenarios need to be elaborated.

Although this study takes an important step forward in analysing climate change impacts on livestock production, it does not cover effects other than quantitative impacts on feed supply. Altered climate will cause changes in not only the quantity but also the quality of the forage. Heat stress may limit the capacity of the animals to fully benefit from the increased grass availability. In addition, the spread of disease may represent an unprecedented challenge. All these factors may make the impact of climate change on the livestock sector worse than what is projected here. On the other hand, although our modelling approach includes a high level of flexibility through the autonomous adjustments in the livestock production structure, it does not consider other potential adaptation options, such as changes in grassland management or development of new livestock production systems, and hence may overestimate the negative effects. Besides the long-term "trend" impacts of climate change discussed so far, a major challenge may come from increased climate volatility (Wheeler and von Braun, 2013). The effects may be particularly severe in the livestock sector, where, for instance, forage failure in one year can have long lasting effects because of the constraints it imposes on herd dynamics (Mosnier et al., 2009).

In conclusion, this study shows that, contrary to the findings by Reilly et al. $(2007,2013)$, there is strong relationship between grass yield changes and livestock production, and that climate change impacts on grasslands will substantially shape the future of the livestock sector and will be a factor in determining the optimal adaptation strategies. Further research in this area is of the utmost importance for the whole food system.

\section{References}

Alexandratos, N. and J. Bruinsma. 2012. World Agriculture Towards 2030/2050: The 2012 Revision. ESA Working Paper. Food and Agriculture Organization of the United Nations (FAO), Rome.

Asseng, S., F. Ewert, C. Rosenzweig, J. Jones, J. Hatfield, A. Ruane, K. Boote, P. Thorburn, R. Rotter, D. Cammarano, N. Brisson, B. Basso, P. Martre, P. Aggarwal, C. Angulo, P. Bertuzzi, C. Biernath, A. Challinor, J. Doltra, S. Gayler, R. Goldberg, R. Grant, L. Heng, J. Hooker, L. Hunt, J. Ingwersen, R. Izaurralde, K. Kersebaum, C. Muller, S. Naresh Kumar, C. Nendel, G. O'Leary, J. Olesen, T. Osborne, T. Palosuo, E. Priesack, D. Ripoche, M. Semenov, I. Shcherbak, P. Steduto, C. Stockle, P. Stratonovitch, T. Streck, I. Supit, F. Tao, M. Travasso, K. Waha, D. Wallach, J. White, J. Williams, J. Wolf. 2013. Uncertainty in simulating wheat yields under climate change. Nature Clim. Change 3, 827-832.

Calzadilla, A., K. Rehdanz, R. Betts, P. Falloon, A. Wiltshire and R. Tol. 2013. Climate change impacts on global agriculture. Climatic Change 120, 357-374.

Challinor, A., P. Martre, S. Asseng, P. Thornton, F. Ewert. 2014. Making the most of climate impacts ensembles. Nature Clim. Change 4, 77-80.

Darwin, R. 2004. Effects of Greenhouse Gas Emissions on World Agriculture, Food Consumption, and Economic Welfare. Climatic Change 66, 191-238.

Darwin, R. and D. Kennedy. 2000. Economic effects of $\mathrm{CO}_{2}$ fertilization of crops: transforming changes 
in yield into changes in supply. Environmental Modeling \& Assessment 5, 157-168.

Doreau, M., M. Corson, S. Wiedemann. 2012. Water use by livestock: A global perspective for a regional issue? Animal Frontiers 2, 9-16.

Fader, M., S. Rost, C. Müller, A. Bondeau, D. Gerten. 2010. Virtual water content of temperate cereals and maize: Present and potential future patterns. Journal of Hydrology 384, 218-231.

Fischer, G., K. Frohberg, M. Parry and C. Rosenzweig. 1994. Climate change and world food supply, demand and trade: Who benefits, who loses? Global Environmental Change 4, 7-23.

Fischer, G., M. Shah, F. Tubiello and $H$. van Velhuizen. 2005. Socio-economic and climate change impacts on agriculture: an integrated assessment, 1990-2080. Philosophical Transactions of the Royal Society B: Biological Sciences 360, 2067-2083.

Friend, A., W. Lucht, T. Rademacher, R. Keribin, R. Betts, P. Cadule, P. Ciais, D. Clark, R. Dankers, P. Falloon, A. Ito, R. Kahana, A. Kleidon, M. Lomas, K. Nishina, S. Ostberg, R. Pavlick, P. Peylin, S. Schaphoff, N. Vuichard, L. Warszawski, A. Wiltshire, F. Woodward, 2013. Carbon residence time dominates uncertainty in terrestrial vegetation responses to future climate and atmospheric $\mathrm{CO}_{2}$. Proceedings of the National Academy of Sciences.

Havlík, P., U. Schneider, E. Schmid, H. Böttcher, S. Fritz, R. Skalský, K. Aoki, S. Cara, G. Kindermann, F. Kraxner, S. Leduc, I. McCallum, A. Mosnier, T. Sauer, M. Obersteiner. 2011. Global land-use implications of first and second generation biofuel targets. Energy Policy 39, 5690-5702.

Havlík, P., H. Valin, M. Herrero, M. Obersteiner, E. Schmid, M. Rufino, A. Mosnier, P. Thornton, H. Böttcher, R. Conant, S. Frank, S. Fritz, S. Fuss,
F. Kraxner, A. Notenbaert. 2014. Climate change mitigation through livestock system transitions. Proceedings of the National Academy of Sciences.

Havlík, P., H. Valin, A. Mosnier, M. Obersteiner, J. Baker, M. Herrero, M. Rufino and E. Schmid. 2013. Crop Productivity and the Global Livestock Sector: Implications for Land Use Change and Greenhouse Gas Emissions. American Journal of Agricultural Economics 95, 442-448.

Herrero, M., P. Havlík, H. Valin, A. Notenbaert, M. Rufino, P. Thornton, M. Blümmel, F. Weiss, D. Grace and M. Obersteiner. 2013. Biomass use, production, feed efficiencies, and greenhouse gas emissions from global livestock systems. Proceedings of the National Academy of Sciences.

Hertel, T., M. Burke and D. Lobell. 2010. The poverty implications of climate-induced crop yield changes by 2030. Global Environmental Change 20, 577-585.

Izaurralde, R., A. Thomson, J. Morgan, P. Fay, H. Polley, J. Hatfield. 2011. Climate Impacts on Agriculture: Implications for Forage and Rangeland Production All rights reserved. No part of this periodical may be reproduced or transmitted in any form or by any means, electronic or mechanical, including photocopying, recording, or any information storage and retrieval system, without permission in writing from the publisher. Agron. J. 103, 371-381.

Jones, P. and P. Thornton. 2009. Croppers to livestock keepers: livelihood transitions to 2050 in Africa due to climate change. Environmental Science \& Policy 12, 427-437.

Juliá, R. and F. Duchin, F. 2007. World trade as the adjustment mechanism of agriculture to climate change. Climatic Change 82, 393-409.

Kane, S., J. Reilly and J. Tobey. 1992. An empirical study of the economic effects of climate change on world agriculture. Climatic Change 21, 17-35. 
Leclère D, Havlík P, Fuss S, Schmid E, Mosnier A, Walsh B, Valin H, Herrero M, Khabarov N and Obersteiner $M$ (in press) Climate change induced transformations of agricultural systems: insights from a global model Environ. Res. Lett.

Lee, H.-L., 2009. The impact of climate change on global food supply and demand, food prices, and land use. Paddy Water Environ 7, 321-331.

Mosnier, A., M. Obersteiner, P. Havlík, E. Schmid, N. Khabarov, M. Westphal, H. Valin, S. Frank and F. Albrecht. 2014. Global food markets, trade and the cost of climate change adaptation. Food Security 6, 29-44.

Mosnier, C., J. Agabriel, M. Lherm and A. Reynaud. 2009. A dynamic bio-economic model to simulate optimal adjustments of suckler cow farm management to production and market shocks in France. Agricultural Systems 102, 77-88.

Müller, C. and R. Robertson. 2014. Projecting future crop productivity for global economic modeling. Agricultural Economics 45, 37-50.

Nelson, G., H. Valin, R. Sands, P. Havlík, H. Ahammad, D. Deryng, J. Elliott, S. Fujimori, T. Hasegawa, E. Heyhoe, P. Kyle, M. Von Lampe, H. Lotze-Campen, D. Mason d'Croz, H. van Meijl, D. van der Mensbrugghe, C. Müller, A. Popp, R. Robertson, S. Robinson, E. Schmid, C. Schmitz, A. Tabeau and D. Willenbockel. 2014a. Climate change effects on agriculture: Economic responses to biophysical shocks. Proceedings of the National Academy of Sciences 111, 3274-3279.

Nelson, G., D. van der Mensbrugghe, H. Ahammad, E. Blanc, K. Calvin, T. Hasegawa, P. Havlik, E. Heyhoe, P. Kyle, H. Lotze-Campen, M. von Lampe, D. Mason d'Croz, H. van Meijl, C. Müller, J. Reilly, R. Robertson, R. Sands, C. Schmitz, A. Tabeau, K. Takahashi, H. Valin and D. Willenbockel. 2014b. Agriculture and climate change in global scenarios: why don't the models agree. Agricultural Economics 45, 85-101.
O’Neill, B., E. Kriegler, K. Riahi, K. Ebi, S. Hallegatte, T. Carter, R. Mathur and D. Vuuren. 2014. A new scenario framework for climate change research: the concept of shared socioeconomic pathways. Climatic Change 122, 387-400.

Parry, M., C. Rosenzweig, A. Iglesias, G. Fischer and M. Livermore. 1999. Climate change and world food security: a new assessment. Global Environmental Change 9, Supplement 1, S51-S67.

Parry, M., C. Rosenzweig, A. Iglesias, M. Livermore and G. Fischer. 2004. Effects of climate change on global food production under SRES emissions and socio-economic scenarios. Global Environmental Change 14, 53-67.

Parton, W., D. Schimel, C. Cole, D. Ojima. 1987. Analysis of Factors Controlling Soil Organic Matter Levels in Great Plains Grasslands1. Soil Sci. Soc. Am. J. 51, 1173-1179.

Parton, W., J. Scurlock, D. Ojima, T. Gilmanov, R. Scholes, D. Schimel, T. Kirchner, J. Menaut, T. Seastedt, E. Garcia Moya, A. Kamnalrut, J. Kinyamario. 1993. Observations and modeling of biomass and soil organic matter dynamics for the grassland biome worldwide. Global Biogeochemical Cycles 7, 785-809.

Peters, G., R. Andrew, T. Boden, J. Canadell, P. Ciais, C. Le Quere, G. Marland, M. Raupach and C. Wilson. 2013. The challenge to keep global warming below 2 [deg]C. Nature Clim. Change 3, 4-6.

Ramirez-Villegas, J., A. Challinor, P. Thornton, A. Jarvis. 2013. Implications of regional improvement in global climate models for agricultural impact research. Environmental Research Letters 8, 024018.

Reilly, J., N. Hohmann, S. Kane. 1994. Climate change and agricultural trade: Who benefits, who loses? Global Environmental Change 4, 24-36. 
Reilly, J., S. Paltsev, B. Felzer. X. Wang,

D. Kicklighter, J. Melillo, R. Prinn, M. Sarofim, A. Sokolov and C. Wang. 2007. Global economic effects of changes in crops, pasture, and forests due to changing climate, carbon dioxide, and ozone. Energy Policy 35, 5370-5383.

Reilly, J., S. Paltsev, K. Strzepek, N. Selin, Y. Cai, K. Nam, E. Monier, S. Dutkiewicz, J. Scott, M. Webster and A. Sokolov. 2013. Valuing climate impacts in integrated assessment models: the MIT IGSM. Climatic Change 117, 561-573.

Rogelj, J., M. Meinshausen, and R. Knutti. 2012. Global warming under old and new scenarios using IPCC climate sensitivity range estimates. Nature Clim. Change 2, 248-253.

Rosenzweig, C., J. Elliott, D. Deryng, A. Ruane, C. Müller, A. Arneth, K. Boote, C. Folberth, M. Glotter, N. Khabarov, K. Neumann, F. Piontek, T. Pugh, E. Schmid, E. Stehfest, H. Yang, J. Jones. 2014. Assessing agricultural risks of climate change in the 21st century in a global gridded crop model intercomparison. Proceedings of the National Academy of Sciences 111, 3268-3273.

Rosenzweig, C. and M. Parry. 1994. Potential impact of climate change on world food supply. Nature 367, 133-138.

Schmidhuber, J. and F. Tubiello. 2007. Global food security under climate change. Proceedings of the National Academy of Sciences 104, 19703-19708.

Seré, C. and H. Steinfeld. 1996. World Livestock Production Systems: Current status, issues and trends. FAO Animal Production And Health Paper FAO, Rome.

Taylor, K., R. Stouffer and G. Meehl. 2011. An Overview of CMIP5 and the Experiment Design. Bulletin of the American Meteorological Society 93, 485-498.
Thornton, P., P. Jones, P. Ericksen and A. Challinor. 2011. Agriculture and food systems in subSaharan Africa in a $4^{\circ} \mathrm{C}+$ world. Philosophical Transactions of the Royal Society A: Mathematical, Physical and Engineering Sciences 369, 117-136.

Thornton, P., J. van de Steeg, A. Notenbaert and M. Herrero. 2009. The impacts of climate change on livestock and livestock systems in developing countries: A review of what we know and what we need to know. Agricultural Systems 101, 113-127.

Tubiello, F., J. Amthor, K. Boote, M. Donatelli, W. Easterling, G. Fischer, R. Gifford, M. Howden, J. Reilly and C. Rosenzweig. 2007. Crop response to elevated $\mathrm{CO}_{2}$ and world food supply: A comment on "Food for Thought..." by Long et al., Science 312:1918-1921, 2006. European Journal of Agronomy 26, 215-223.

Tubiello, F. and G. Fischer. 2007. Reducing climate change impacts on agriculture: Global and regional effects of mitigation, 2000-2080. Technological Forecasting and Social Change 74, 1030-1056.

Valin, H., P. Havlík, A. Mosnier, M. Herrero, E. Schmid and M. Obersteiner. 2013. Agricultural productivity and greenhouse gas emissions: trade-offs or synergies between mitigation and food security? Environmental Research Letters 8, 035019.

Valin, H., R. Sands, D. van der Mensbrugghe, G. Nelson, H. Ahammad, E. Blanc, B. Bodirsky, S. Fujimori, T. Hasegawa, P. Havlik, E. Heyhoe, P. Kyle, D. Mason-D'Croz, S. Paltsev, S. Rolinski, A. Tabeau, H. van Meijl, M. von Lampe and D. Willenbockel. 2014. The future of food demand: understanding differences in global economic models. Agricultural Economics 45, 51-67.

Vuuren, D., J. Edmonds, M. Kainuma, K. Riahi, A. Thomson, K. Hibbard, G. Hurtt, T. Kram, V. Krey, J-F. Lamarque, T. Masui, M. Meinshausen, N. Nakicenovic, S. Smith, S. Rose. 2011. The 
representative concentration pathways: an overview. Climatic Change 109, 5-31.

Warszawski, L., K. Frieler, V. Huber, F. Piontek, O. Serdeczny, J. Schewe. 2013. The Inter-Sectoral Impact Model Intercomparison Project (ISI-MIP): Project framework. Proceedings of the National Academy of Sciences.

Wheeler, T. and C. Reynolds. 2013. Predicting the risks from climate change to forage and crop production for animal feed. Animal Frontiers 3, 36-41.

Wheeler, T. and J. von Braun. 2013. Climate Change Impacts on Global Food Security. Science 341, 508-513.

Williams, J. 1995. The EPIC model. In:

Singh, V.P. (Ed.), Computer Models of Watershed Hydrology. Water Resources Publications, Highlands Ranch, Colorado, pp. 909-1000.

You, L. and S. Wood. 2006. An entropy approach to spatial disaggregation of agricultural production. Agricultural Systems 90, 329-347. 


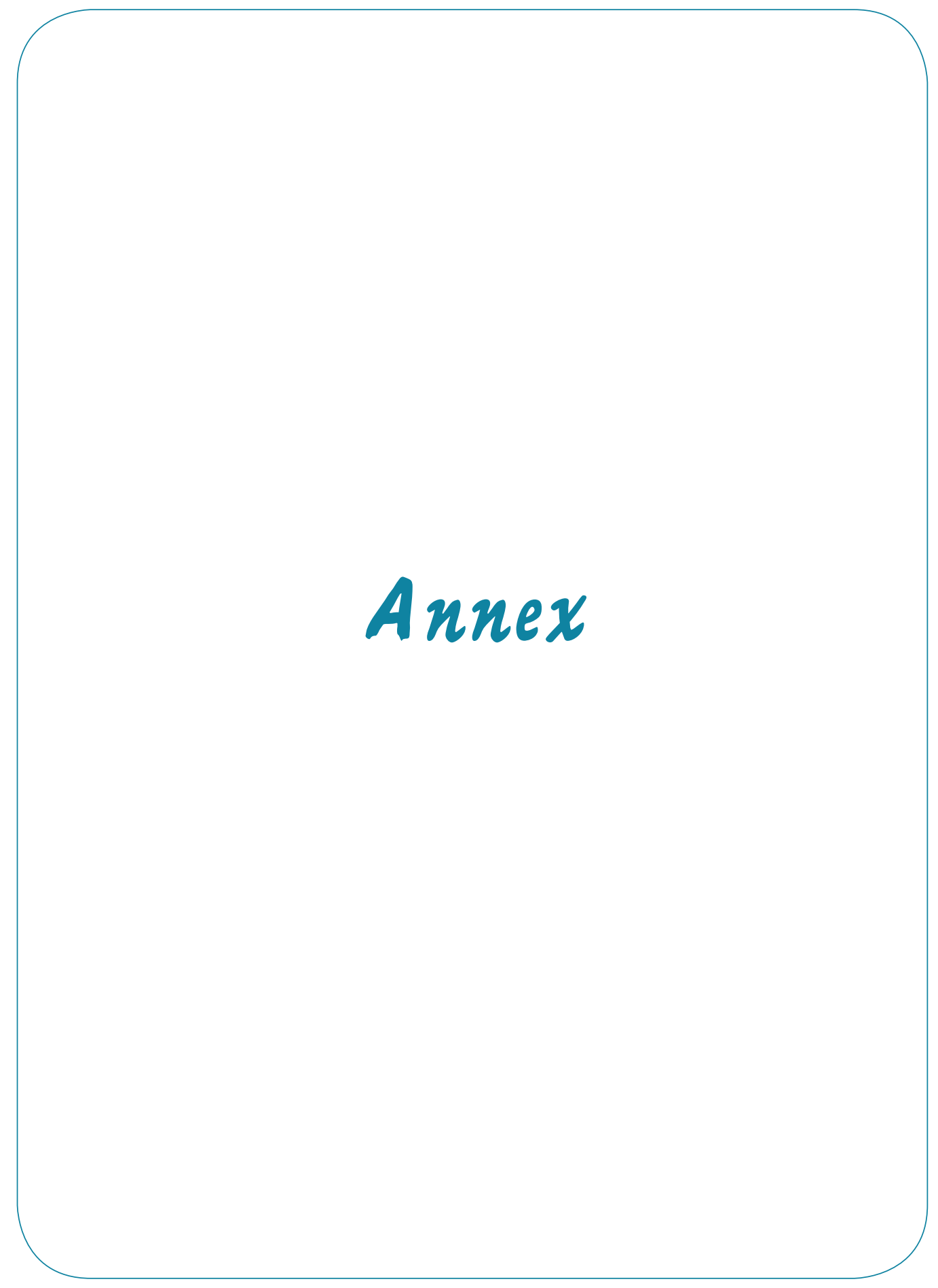




\section{figure A1}

Relationship between the pure climate change impact on crop and grass yields (YEXO) and livestock production (Supply) relative to the scenario with present climate (presclim) by 2050 in \% (ALMILK - bovine and small ruminant milk, RMMEAT - bovine and small ruminant meat, MGMEAT - pig and poultry meat)
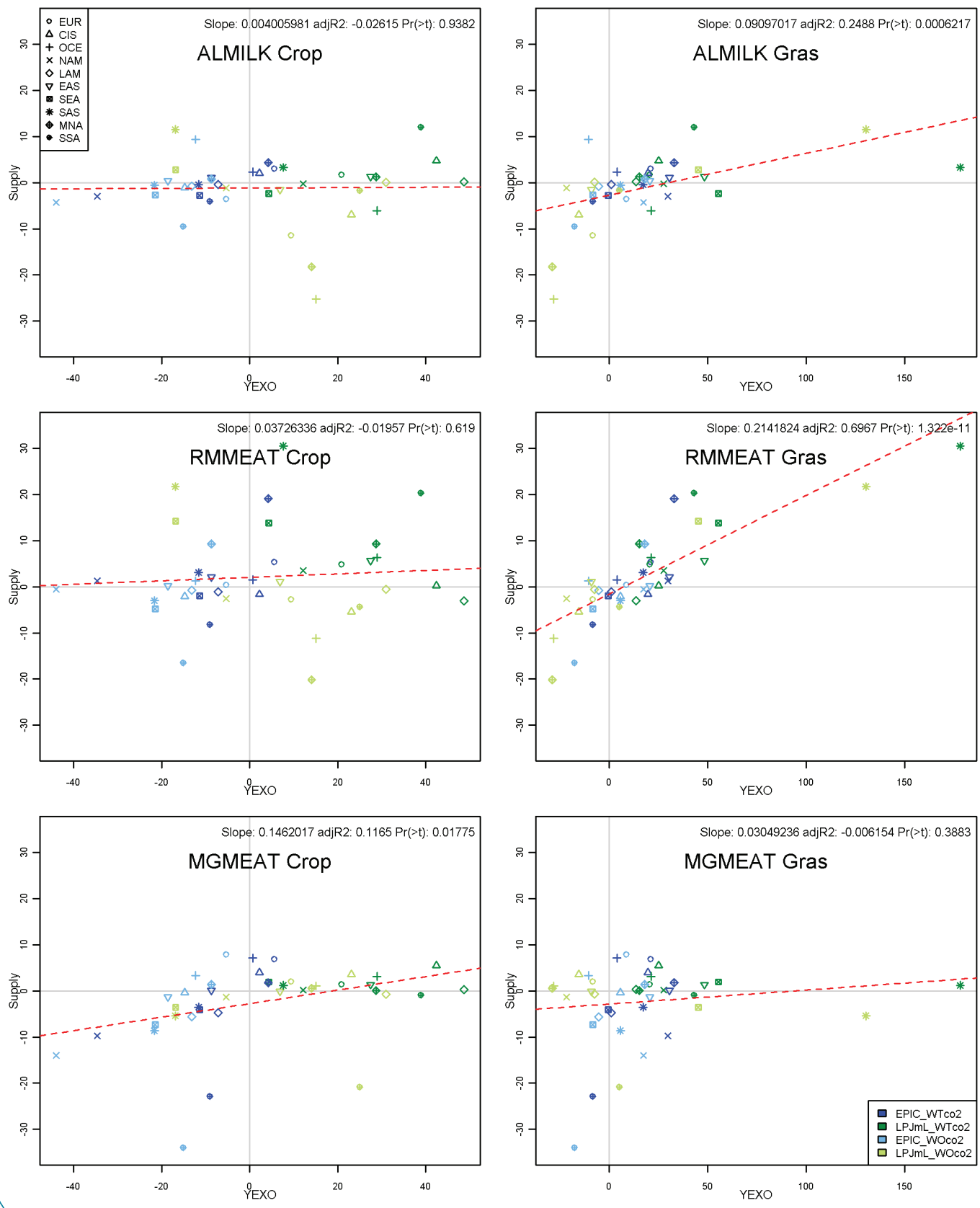


\section{figure $A 2$}

Transmission of the pure climate change impact on crop (Crop) and grass (Gras) yields (YEXO) through autonomously adapted yields (YILD) and areas (Area) on total production relative to the scenario with present climate (presclim) by 2050 in \%
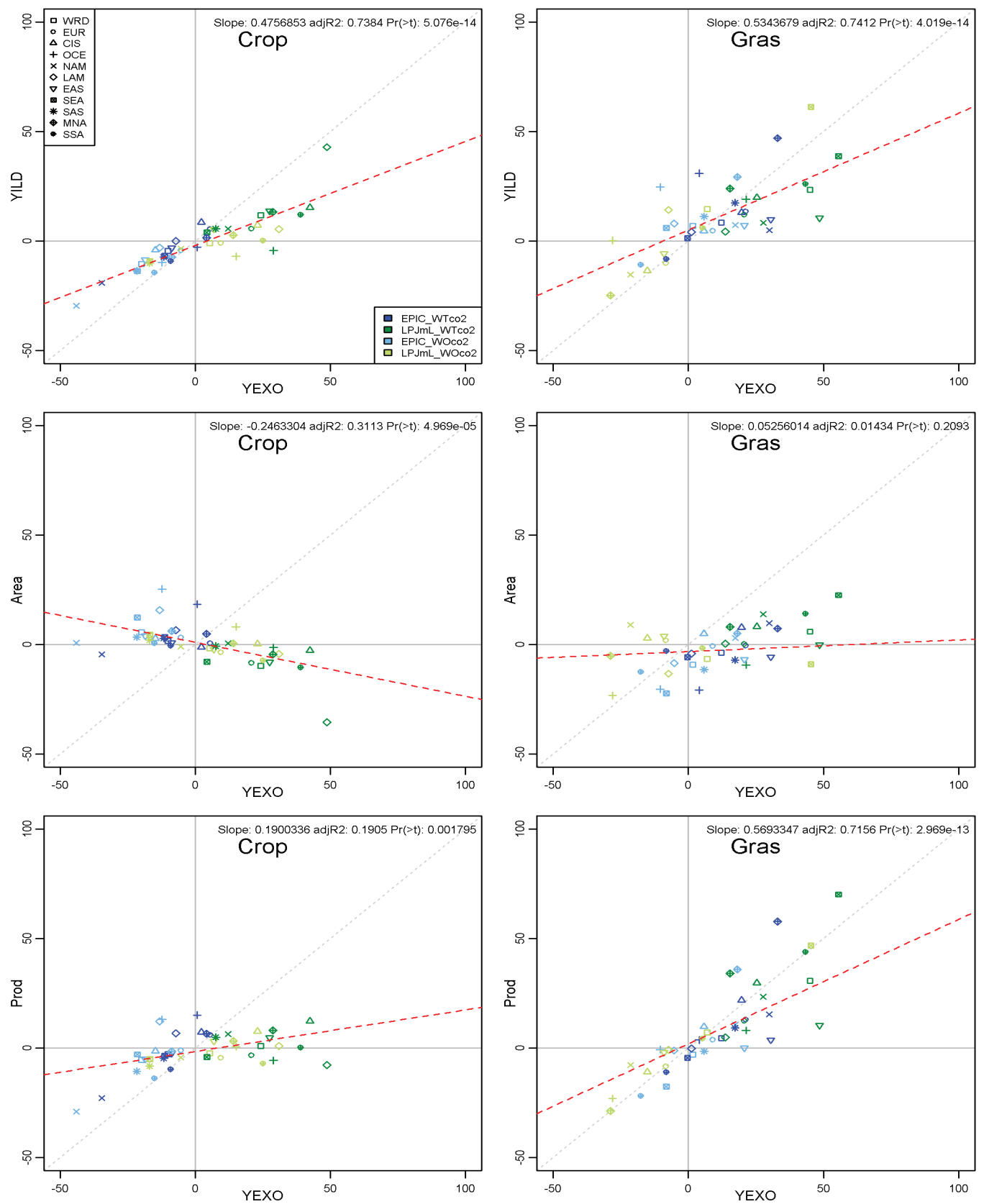


\section{figure $A 3$}

Change in distribution of ruminant numbers across the livestock productions systems as compared with the present climate scenario (presclim) by 2050 in million TLUs. (BOVI - bovines, SHGT - small ruminants, BOVDh - bovines dairy herd, BOVOh bovines other herd)

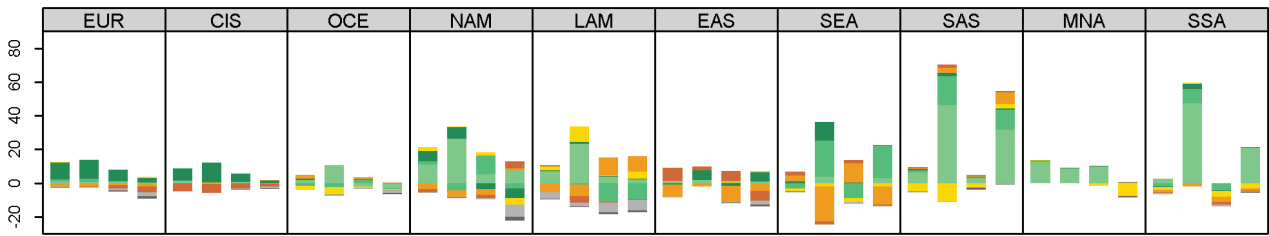

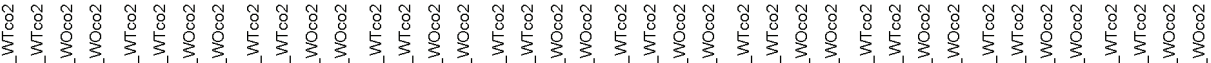

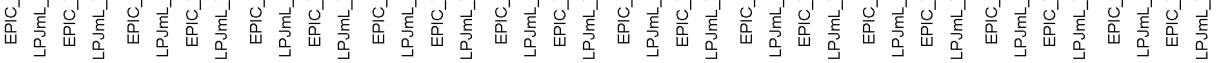
SHGT

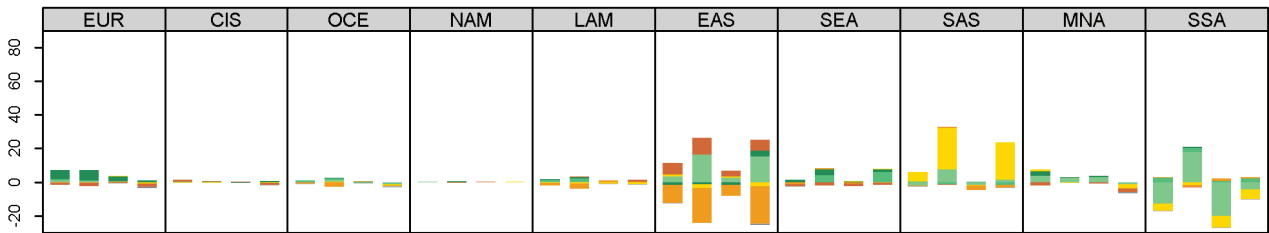

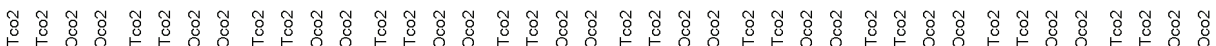

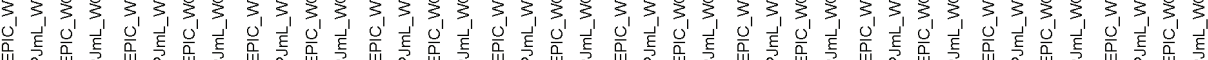

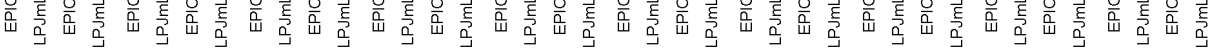

BOVDh

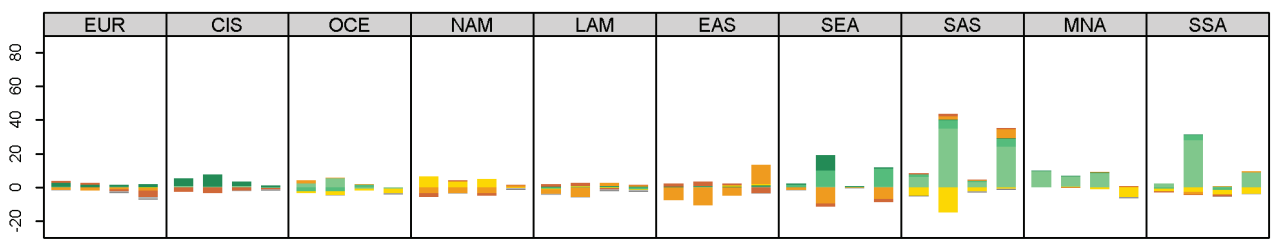

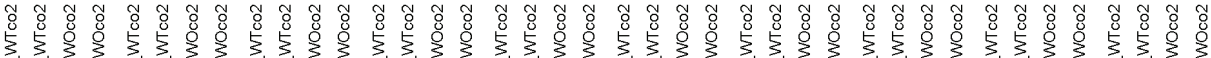

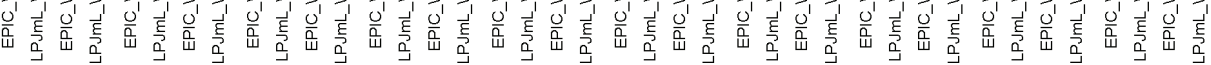

Bovoh

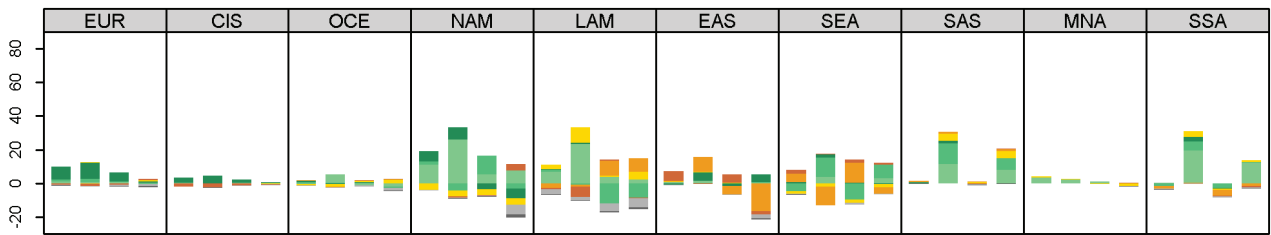

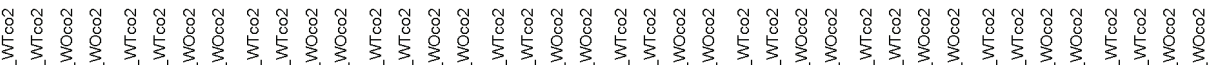

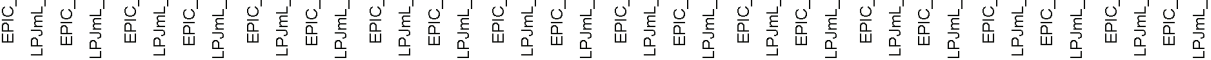

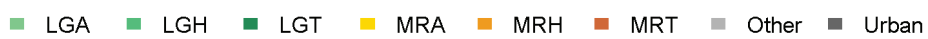




\section{figure A4}

Relationship between the pure climate change impact on grass yields (YEXO) and the share of ruminants reared in grazing systems (LG_SHR) relative to the scenario with present climate (presclim) by 2050 in \%. (RUMI - bovines and small ruminants, BOVI - bovines, BOVDh - bovine dairy herd, BOVOh - bovines other herd)
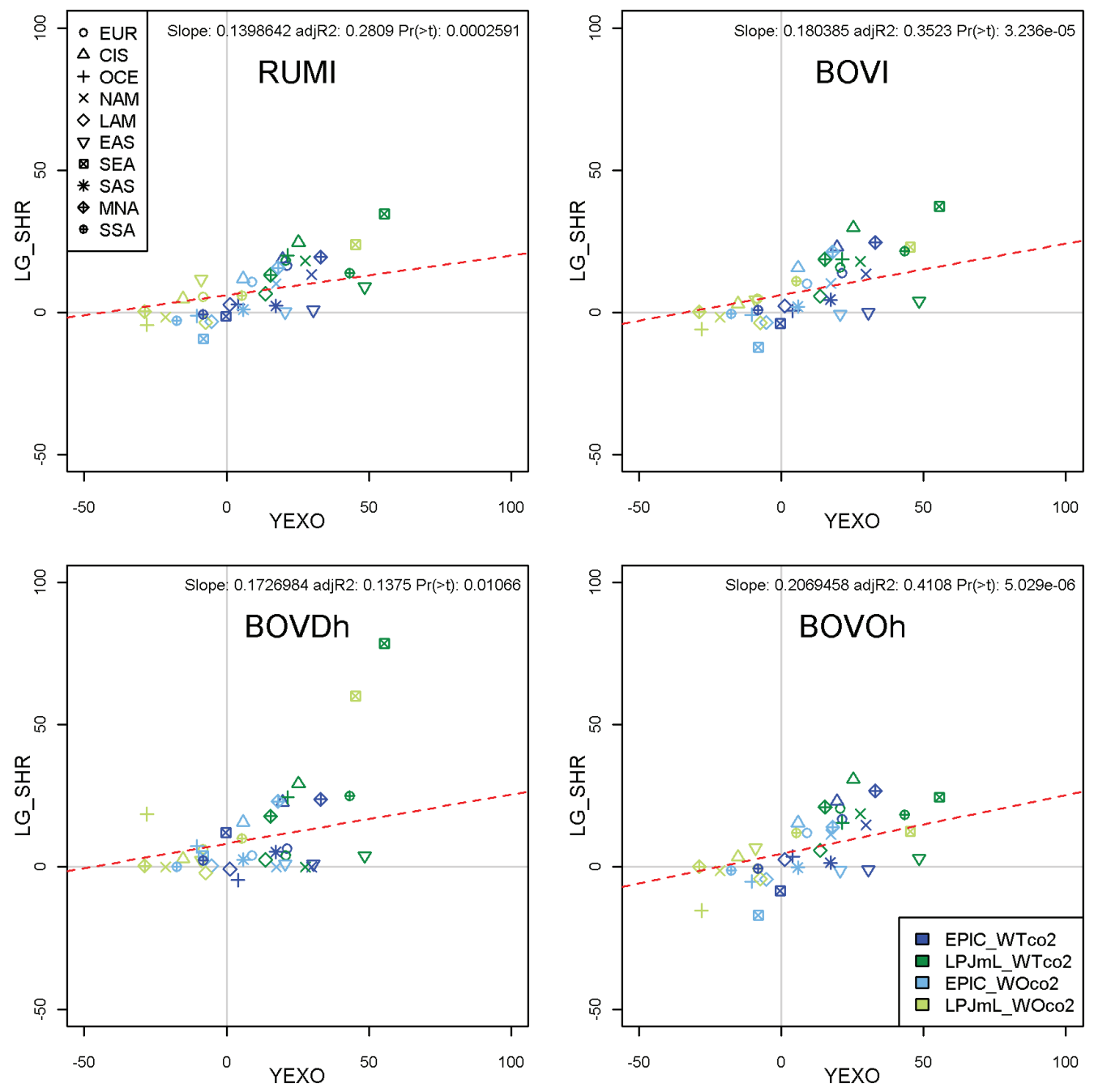


\section{table $A 1$}

List of GLOBIOM regions

\begin{tabular}{|c|c|c|}
\hline Macro region & Model regions & Countries \\
\hline \multirow{7}{*}{ Europe (EUR) } & EU Baltic & Estonia, Latvia, Lithuania \\
\hline & EU Central East & $\begin{array}{l}\text { Bulgaria, Czech Republic, Hungary, Poland, Romania, } \\
\text { Slovakia, Slovenia }\end{array}$ \\
\hline & EU Mid West & $\begin{array}{l}\text { Austria, Belgium, Germany, France, Luxembourg, } \\
\text { Netherlands }\end{array}$ \\
\hline & EU North & Denmark, Finland, Ireland, Sweden, United Kingdom \\
\hline & EU South & Cyprus, Greece, Italy, Malta, Portugal, Spain \\
\hline & RCEU & $\begin{array}{l}\text { Albania, Bosnia and Herzegovina, Croatia, Macedonia, } \\
\text { Serbia-Montenegro }\end{array}$ \\
\hline & ROWE & Gibraltar, Iceland, Norway, Switzerland \\
\hline Former USSR (CIS) & Former USSR & $\begin{array}{l}\text { Armenia, Azerbaijan, Belarus, Georgia, Kazakhstan, } \\
\text { Kyrgyzstan, Moldova, Russian Federation, Tajikistan, } \\
\text { Turkmenistan, Ukraine, Uzbekistan }\end{array}$ \\
\hline \multirow[b]{2}{*}{ Oceania (OCE) } & ANZ & Australia, New Zealand \\
\hline & Pacific Islands & $\begin{array}{l}\text { Fiji Islands, Kiribati, Papua New Guinea, Samoa, } \\
\text { Solomon Islands, Tonga, Vanuatu }\end{array}$ \\
\hline \multirow{2}{*}{ North America (NAM) } & Canada & Canada \\
\hline & United States of America & United States of America \\
\hline \multirow{4}{*}{ Latin America (LAM) } & Brazil & Brazil \\
\hline & Mexico & Mexico \\
\hline & RCAM & $\begin{array}{l}\text { Bahamas, Barbados, Belize, Bermuda, Costa Rica, } \\
\text { Cuba, Dominica, Dominican Republic, El Salvador, } \\
\text { Grenada, Guatemala, Haiti, Honduras, Jamaica, } \\
\text { Nicaragua, Netherland Antilles, Panama, St Lucia, St } \\
\text { Vincent, Trinidad and Tobago }\end{array}$ \\
\hline & RSAM & $\begin{array}{l}\text { Argentina, Bolivia, Chile, Colombia, Ecuador, Guyana, } \\
\text { Paraguay, Peru, Suriname, Uruguay, Venezuela }\end{array}$ \\
\hline \multirow{3}{*}{ Eastern Asia (EAS) } & China & China \\
\hline & Japan & Japan \\
\hline & South Korea & South Korea \\
\hline \multirow{2}{*}{ Southeast Asia (SEA) } & RSEA OPA & $\begin{array}{l}\text { Brunei Daressalaam, Indonesia, Singapore, Malaysia, } \\
\text { Myanmar, Philippines, Thailand }\end{array}$ \\
\hline & RSEA PAC & $\begin{array}{l}\text { Cambodia, Democratic People's Republic of Korea, Lao } \\
\text { People's Democratic Republic, Mongolia, Viet Nam }\end{array}$ \\
\hline
\end{tabular}




\section{table A1 (cont'd.)}

List of GLOBIOM regions

\begin{tabular}{|c|c|c|}
\hline Macro region & Model regions & Countries \\
\hline \multirow[b]{2}{*}{ South Asia (SAS) } & India & India \\
\hline & RSAS & $\begin{array}{l}\text { Afghanistan, Bangladesh, Bhutan, Maldives, Nepal, } \\
\text { Pakistan, Sri Lanka }\end{array}$ \\
\hline \multirow[t]{2}{*}{$\begin{array}{l}\text { Middle East \& North Africa } \\
\text { (MNA) }\end{array}$} & $\begin{array}{l}\text { Middle East and North } \\
\text { Africa }\end{array}$ & $\begin{array}{l}\text { Algeria, Bahrain, Egypt, Iran, Iraq, Israel, Jordan, } \\
\text { Kuwait, Lebanon, Libya, Morocco, Oman, Qatar, Saudi } \\
\text { Arabia, Syria, Tunisia, United Arab Emirates, Yemen }\end{array}$ \\
\hline & Turkey & Turkey \\
\hline \multirow{5}{*}{ Sub-Saharan Africa (SSA) } & Congo Basin & $\begin{array}{l}\text { Cameroon, Central African Republic, Democratic } \\
\text { Republic of Congo, Equatorial Guinea, Gabon }\end{array}$ \\
\hline & Eastern Africa & Burundi, Ethiopia, Kenya, Rwanda, Tanzania, Uganda \\
\hline & South Africa & South Africa \\
\hline & Southern Africa (Rest of) & $\begin{array}{l}\text { Angola, Botswana, Comoros, Lesotho, Madagascar, } \\
\text { Malawi, Mauritius, Mozambique, Namibia, Swaziland, } \\
\text { Zambia, Zimbabwe }\end{array}$ \\
\hline & West and Central Africa & $\begin{array}{l}\text { Benin, Burkina Faso, Cape Verde, Chad, Cote d'Ivoire, } \\
\text { Djibouti, Eritrea, Gambia, Ghana, Guinea, Guinea } \\
\text { Bissau, Liberia, Mali, Mauritania, Niger, Nigeria, } \\
\text { Senegal, Sierra Leone, Somalia, Sudan, Togo }\end{array}$ \\
\hline
\end{tabular}





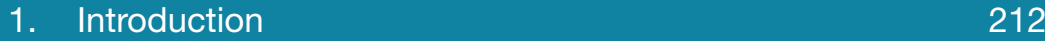

2. Historical trends of grain production and trade 213

2.1 Decline in agriculture in 1991-2001 213

2.2 Recovery trends in 2002-2013 215

3. Short-term weather variability and land dynamics 219

4. Impacts of climate change on grain production 222

5. Outlooks for grain production and export 229

6. Conclusions 235

$\begin{array}{ll}\text { References } & 237\end{array}$

Citation

Lioubimtseva, E., N. Dronin and A. Kirilenko. 2015. Grain production trends in the Russian Federation, Ukraine and Kazakhstan in the context of climate change and international trade, In: Climate change and food systems: global assessments and implications for food security and trade, Aziz Elbehri (editor). Food Agriculture Organization of the United Nations (FAO), Rome, 2015. 


\section{chapter 7}

\section{Grain production trends in the Russian Federation, Ukraine and Kazakhstan in the context of climate change and international trade}

\section{Elena Lioubimtseva1, Nicolai Dronin ${ }^{2}$ and Andrei Kirilenko ${ }^{3}$}

\section{main chapter messages}

- Russian Federation, Ukraine, and Kazakhstan (RUK) together are very likely to surpass the European Union and the United States within the next few years in total grain exports. However, official government goals of boosting grain and meat production by 2020 s are unlikely to be fully reached by the three countries.

n- High grain exports from RUK have been primarily driven by reduced domestic demand than by increased productivity. The latter remains below the historical trend and is still much lower than officially projected. Future use of abandoned arable lands for cropping remains uncertain and unlikely, given that abandoned lands in 1990's are marginal with very low potential productivity.
- Climate change scenarios suggest that the grain production potential in RUK may increase due to a combination of winter temperature increase, extension of the growing season, and yieldenhancing $\mathrm{CO} 2$ fertilization; however the most productive semi-arid zone could suffer a dramatic increase in drought frequency.

- Uncertainty about future grain production outlook in RUK region in relation to climate change require more refined modelling on crop yield impacts, land-use and land cover trends and their future impacts on GHG emissions. Also critical are future socio-economic changes including development pathways of infrastructure, financial systems, land market development and alignments between WTO requirements and agricultural subsidies.

\footnotetext{
${ }^{1}$ Geography and Planning Department, Grand Valley State University, Michigan, USA

2 School of Geography, Moscow State University, the Russian Federation

${ }^{3}$ Department of Earth System Science and Policy, University of North Dakota, USA
} 


\section{Introduction}

C

limate change and variability increase

the frequency and amplitude of regional crop shortfalls and create an impact on agriculture and food systems all over the world (Adams et al., 1998; Parry et al., 2004, Easterling et al., 2007). Geographic patterns of food production are directly affected by climatic variables such as temperature and precipitation and the frequency and severity of extreme events (Tebaldi et al., 2006; Rosenzweig and Tubiello, 2007). Climate change may also change the types, frequencies and intensities of various crop and livestock pests, the availability and timing of irrigation water supplies, and the severity of soil erosion (Adams et al., 1998), while the rising carbon dioxide $\left(\mathrm{CO}_{2}\right.$ concentration might influence crops' photosynthetic activity and wateruse efficiency (Antle et al., 2004).

By the middle of the twenty-first century, world population is expected to reach 9.6 billion (United Nations 2013). This growth is projected to occur primarily in developing countries, where dependency on cereal imports is already high and is likely to increase. International trade will play an important role in fulfilling this increase in food demand. Trade flows and prices may become increasingly volatile and unpredictable as a result of changing geographic patterns of agroecological potential in different regions. In the context of an increasingly interconnected global economy and the increasing interdependence of food trading partners, climate change - along with other global changes (such as rapid land use and land cover changes and increasing consumption of water and energy resources) is likely to contribute to increasing food prices and overall instability of the global food market. Understanding the magnitude of expected changes is crucial to developing adaptation and mitigation measures as well as more productive and resilient food systems to meet the challenge of food security at national, regional and global levels. The tradeoff between mitigation for climate change through increase of carbon sink to natural vegetation and meeting the increasing food demand adds additional challenges.

The grain-growing belt of Central Eurasia, shared by the Russian Federation, Ukraine and Kazakhstan, extends almost $20000 \mathrm{~km}$, from the Carpathian Mountains to the Amur River valley in the Russian Far East, and offers significant underutilized grain production potential. These three countries of the former Union of Soviet Socialist Republics (USSR) have recently reemerged as leading grain exporters; their share in the global grain exports rose from 1 percent in 1991 to 18 percent in 2013 (Liefert et al., 2013; FAOSTAT 2013). Understanding impacts of climate change on the future productivity of this region is essential for predicting its potential as a major grain supplier in the future. The recent growth in grain exports from the Russian Federation, Ukraine and Kazakhstan has been driven by a combination of multiple factors, including structural changes in their agricultural sectors, economic recovery of the region after the deep decline of the 1990s, and relatively favourable weather conditions (Liefert et al., 2013; Lioubimtseva et al., 2013; Dronin and Kirilenko, 2013). Several studies based on coupling climate and crop models indicate that the agro-ecological potential of the grainproducing zone of Central Eurasia may increase due to warmer temperatures, longer growing seasons, decrease of frosts and positive impact of higher atmospheric concentrations of $\mathrm{CO}_{2}$ on crops (Pegov, 2000; Fischer et al., 2005), while other modelling experiments project the decline of agricultural potential due to increasing frequency of droughts (Alcamo et al., 2007; Dronin and Kirilenko, 2008). Economic scenarios driven by climate and crop models are extremely uncertain as they fail to capture multiple environmental, social, economic, and institutional factors (Lioubimtseva and Henebry, 2012).

This paper is a combination of an extensive bibliographic review and our own computations of potential changes in grain production in the Russian Federation, Ukraine and Kazakhstan considering impacts of climate change, international trade, and agricultural policy changes. 
We examine historical trends since the collapse of the USSR and future outlooks for grain production and export potential by the Russian Federation, Ukraine and Kazakhstan in the context of physical and economic effects of climate change on the Central Eurasian grain belt.

Section 2 examines structural changes in the agriculture sectors of the Russian Federation, Ukraine and Kazakhstan that have led to changing their role from net importers to major net exporters of grain. There is a general consensus that dramatic economic and policy changes over the past few decades have had a significantly higher impact on grain production than climate variability and change (Liefert et al., 2013; Lioubimtseva et al., 2013), although socioeconomic and biophysical changes may overlap, partly masking each other's effects (Dronin and Kirilenko, 2013). This section discusses the turning points in the changing trends of this region's arable area, productivity, and exports of the major cereal crops.

While agricultural statistics provide critical information about land-use dynamics and yields, remote sensing offers a complementary perspective on land changes. Section 3 provides a brief discussion of the recent short-term weather variations and land cover changes in the graingrowing regions of the Russian Federation, Ukraine and Kazakhstan, derived from remote sensing data.

Section 4 provides a detailed review of historical climate trends and scenarios of climate change and grain productivity based on a review of previous experiments and our own simulations of agro-ecological changes and their impact on future yields. Section 5 outlines and discusses our three bio-economic scenarios of the future grain production and export potential of the Russian Federation, Ukraine and Kazakhstan: "Federal Program", "Historical Trend", and "Historical Trend Plus Climate", and discusses likelihoods of each of them. The concluding section identifies the major knowledge gaps and provides some recommendations for future research.

\section{Historical trends of grain production and trade}

\subsection{Decline of agriculture in 1991-2001}

The steppe and forest-steppe belt of Ukraine, the Russian Federation and Kazakhstan was "the bread basket" of the USSR. During the last 30 years of its existence, the USSR increased its cereal production from 119 million tonnes in 1961 to 155 million tonnes in 1991, with a maximum production of more than 170 million tonnes in 1980 (Lioubimtseva, 2010). In the 1950s the growth of grain production was driven by the expansion of arable lands (the "Virgin Lands Campaign"), but during the following years the area of cereal cultivation contracted slightly and the growth was the result of increasing productivity. Despite significant efforts to increase yields through the "agriculture intensification" programme, by the end of its existence, the USSR's yields were significantly lower compared with other major cereal producers and lower than they are now (Table 1). In addition, in its effort to satisfy growing standards of food consumption, the USSR launched a shift to a livestock sector at the beginning of 1970s that caused a growing grain imbalance in the country.

Although grain production grew between 1970 and 1990, the role of USSR grain exports declined significantly during that time because of increasing domestic consumption. The USSR wheat exports reached a maximum of 8.5 million tonnes per year in 1971 but declined steadily during the 1980s to less than 0.5 million tonnes in 1991. Increasing cereal production could not keep up with increasing domestic needs (both for livestock feed and human consumption) and wheat imports rose from 0.4 million tonnes in 1969 to 20 million tonnes in 1991 (FAOSTAT 2013).

The collapse of the USSR and the Council for Mutual Economic Assistance (COMECON) in 1991 began a period of drastic transition from state-controlled to market-driven economies 
table 1

The top wheat producers in 1991 and in 2012

\begin{tabular}{lcccc}
\hline & \multicolumn{2}{c}{ Wheat yields t/ha } & \multicolumn{2}{c}{ Wheat production, metric tonnes } \\
\hline China & 1991 & 2011 & 1991 & 2011 \\
\hline USSR & 4.2 & 4.8 & 95953781 & 117410000 \\
\hline Russia & 1.5 & & 71991008 & 56239990 \\
\hline Ukraine & & 2.3 & & 22323600 \\
\hline Kazakhstan & 3.4 & 53890000 & 22732000 \\
\hline USA & 4.6 & 1.7 & 31945600 & 25261400 \\
\hline Canada & 2.6 & 2.9 & 10557400 & 27410076 \\
\hline Australia & 1.6 & 3.0 & 2916823 & 5690043 \\
\hline Brazil & 1.6 & 2.0 & & \\
\hline Source: (FAOSTAT 2013) & & 2.7 & & \\
\hline
\end{tabular}

across Eastern Europe and Central Asia that has resulted in fundamental transformation of their agricultural systems and land use. These transitional economies went through a stage of catastrophic decline in 1991 to 2000. The "Free Market" reforms of the 1990s made a heavy impact on the economy of the former USSR. Deterioration of the agriculture sector contributed to an overall economic decline. For instance, from 1991 to 2001, gross domestic product (GDP) in the Russian Federation, Ukraine and Kazakhstan declined by 65-67 percent (UNData 2013), average life expectancy declined from 69 to 65 years, and male life expectancy in rural areas of the Russian Federation declined from 61 to 53 years (Prishchepov et al., 2013). This economic and social crisis was particularly pronounced in rural regions, where state support of agriculture ended and rural development ceased almost entirely (Prishchepov et al., 2013). The major changing trends in the 1990s were the disintegration of the centrally planned institutions and existing agricultural policies, uncertainties about the legal status of land, sharp declines of agricultural subsidies and other forms of governmental support (Lioubimtseva and Henebry, 2012). Producer support estimates from the Organisation for Economic Cooperation and Development (OECD) for the Russian Federation, Ukraine and Kazakhstan indicate substantial positive support for farmers up to 1991, which then fell almost to zero in the following few years (OECD-FAO 2008). As the subsidies declined, the high cost of imported herbicides, fungicides and insecticides caused farmers to cut back on their use (Lerman et al., 2004). Fertilizer use fell by 85 percent in the Russian Federation and Ukraine and by almost 90 percent in Kazakhstan between 1990 and 2000 and total grain production fell by more than 50 percent during the same period of time (FAOSTAT 2013). Between 1990 and 2000, investments in the Russian Federation's agricultural sector declined from USD 39 billion to USD 2 billion (Prishchepov et al., 2013) and the area of land under cereals was reduced from 65 million to 50 million hectares (Liefert et al., 2009a). According to the Food and Agriculture Organization of the United Nations (FAO), the use of arable lands in the Russian Federation, Ukraine and Kazakhstan together dropped from 200 million hectares in 1991 to 177 million hectares in 2003 (FAOSTAT 2013), which constituted a withdrawal of 23 million hectares or 12 percent of the arable lands in 1991 (Lioubimtseva and 
Henebry, 2012), although even these numbers may be underestimated. Statistics in the Russian Federation for cultivated areas (ROSSTAT, 2013) and remote sensing data suggest that abandoned cropland area in the Russian Federation alone constitutes up to 40 million hectares, significantly more than reported by FAO land resource statistics (Shierhorn et al., 2010; Prishchepov et al., 2013). Given that there was almost no change in rural population of the country (UniSIS 2013), labour productivity in agriculture dropped by 30 percent in the Russian Federation. It is notable that in other countries of Eastern Europe, such as Czech Republic and Slovakia, even though the total production decreased, the labour productivity in agriculture has been increasing; in Hungary, for instance, the agricultural production has doubled (Rozelle and Swinnen, 2000).

The loss of state subsidies also increased feed and production costs and reduced profitability for livestock enterprises. As prices for meat products increased, consumer demand declined, thus establishing a downward spiral that continued throughout the decade (Lioubimtseva and Henebry, 2012). Livestock inventories and demand for forage both continued to decline. Between 1992 and 2006, the Russian Federation lost almost half of its meat production: the number of cattle dropped from almost 20 million to 10.3 million; the number of pigs fell from more than 36.3 million to 18.7 million; and the number of sheep dropped from 20 million to 7 million (FAOSTAT 2013). In Kazakhstan, 33.9 million sheep were in stock in 1992, but by 1999 that number had dropped 75 percent, to 8.6 million (Lioubimtseva and Henebry, 2009). In addition, shrinking livestock inventories in all three countries caused the demand for feedgrain to plummet, which led to a 76 percent drop in barley area (Lioubimtseva, 2010). The increasing inability of large agricultural enterprises to maintain livestock operations, largely because of inefficient management and the inability to secure adequate supplies of feed, resulted in increased dependence on smaller household farms to satisfy demands for meat (Welton, 2011). Furthermore, the involvement of investor groups in agricultural production has had an impact on livestock numbers. Many farmers who entered agreements with investment firms killed off their herds because livestock was not quickly profitable and not as attractive to investors. For example, in Kazakhstan, due to the loss of incentives to keep the herds, two-thirds of the sheep population was lost between 1995 and 1999 (Lioubimtseva and Henebry, 2012). The drop in livestock inventories led in turn to a drop in demand for feedgrain and pastures across the region. Although the free fall in livestock inventories has slowed since 2000, large industrial farms have been shifting away from livestock and towards crop production (loffe et al., 2012) and livestock inventories continued to decrease, particularly in the areas with extensive herding, such as Central Asia, Kazakhstan, and semi-arid and arid zones of the Russian Federation (Lioubimtseva and Henebry, 2009, 2012). Between 1991 and 2001, meat production in the Russian Federation, Ukraine and Kazakhstan declined by 50 percent (OECD 2002).

The economy-wide decline and the collapse of the agriculture sector have caused fundamental changes in the trade structure. Following the declines in demand and in purchasing power, wheat imports in the Russian Federation fell from 18.9 million tonnes in 1992 to only 0.3 million tonnes in 2002, a decrease of over 98 percent (FAOSTAT 2013).

\subsection{Recovery trends in $2002-2013$}

By the end of the 1990s, the majority of Russian and Western experts did not see much evidence of success from ongoing market reforms in Russian agriculture, suggesting instead that the stagnating agriculture sector would be dominated by former collective farms, which would be undergoing transformation into large cooperative units (Zogoleva, 1997; Osborne and Trueblood, 2002; Miloserdov, 2006). This "Anti-Free Market" scenario was expected to limit labour productivity in agriculture (Prosterman et al., 1999). Despite this negative outlook, fast growth of agriculture 
in the 2000s has made the Russian Federation the leading grain exporter. The free fall in the agricultural production of the Russian Federation, Ukraine and Kazakhstan had slowed down by 2000 and signs of recovery have been observed in all three countries since 2002 , clearly coinciding with economy-wide recovery of the entire region. Some experts believe that the tipping point for Russian agriculture occurred in the year 2000 (von Cramon-Taubadel, 2002). With the exception of several years with unfavourable weather (such as an anomalously rainy 2003 and severe droughts in 2010 and 2012), cereal production has rebounded in all three countries. Since 2000, the Russian Federation has had several outstanding harvests and, on average, grain yields are also showing signs of improvement. However, the yields still remain below the 1991 levels and are much lower than potential yields for this region; in 2010, wheat yields were only 2.6 tonnes/ hectare (t/ha) in Ukraine, $1.9 \mathrm{t} /$ ha in the Russian Federation, and $0.7 \mathrm{t} /$ ha in Kazakhstan, much lower numbers compared with $7.0 \mathrm{t} /$ ha in France, 4.7 t/ha in China, and 3.1 t/ha in the United States (Lioubimtseva et al., 2013). Although weather remains a very important determinant for grain yield, improvements in crop management practices fueled by the growing state subsidies have also contributed to the recent increase and stabilization of wheat and barley yields (Uzun et al., 2012; Liefert, 2013).

During the Soviet period, growth was essentially driven by extensive conversion of marginal lands to agriculture, but in the more open economy of the 2000s, marginal arable lands grew unprofitable and were gradually abandoned even under high grain demand (Liefert et al., 2009b). Unlike in the 1970s and 1980s, the increase of agricultural production in the 2000s was not based on land expansion. On the contrary, the area under cereals continued to shrink, from 50 million hectares in 1996-2000 to 45 million hectares in 2001-2008 (FAOSTAT 2013). In 2008, the area under cereals in the Russian Federation increased marginally (by 5 percent), driven by the record high world grain prices of USD 400-450 per metric tonne. The Russian Federation declared agriculture to be a national priority area in 2005 and increased federal support for agricultural development from USD 2.6 billion in 2006 to USD 5.2 billion in 2008 (EBRD-FAO 2008). Despite the increase in level of overall support given to agricultural producers, federal support as a share of total farm receipts remained relatively low (15 percent in the Russian Federation and 12 percent in the Russian Federation and Ukraine, compared with 55 percent in Japan, 33 percent in the EU and 16 percent in the United States) (Lioubimtseva and Henebry, 2012). Due to recovery of some agricultural subsidies and at least partial success of reforms, fertilizer and machinery use have increased during the past few years. The use of mineral fertilizer has tripled since 1999 in Kazakhstan and doubled in the Russian Federation and Ukraine, but current application rates represent only a fraction of the amounts applied in the late 1980s (Lioubimtseva and Henebry, 2012). A return to the 1980s application rates is unlikely - and unnecessary, as they were frequently excessive. Between 1996-2000 and 2001-2008, the yields grew from $1.3 \mathrm{t} /$ ha to $1.83 \mathrm{t} /$ ha (FAOSTAT 2013).

The share of harvested land under various major crops has changed in a different way (Figure 1). Wheat has been the primary cereal crop in terms of area harvested and shows a slight increase in harvested area after half a century of decline that followed the Virgin Lands expansion campaign (Table 2). Barley has been a significant secondary crop, but declines in area harvested started in the mid-1970s and accelerated through the mid-1990s. Rye, which is largely restricted to the Russian Federation, has declined substantially since 1991, and shows no evidence of recovery. Maize continues to be a minor crop regionally, but the harvested area has been increasing steadily since the mid-1990s, particularly in Ukraine (Lioubimtseva et al., 2013).

In the Russian Federation, the first result of the privatization reform of 1992 was the emergence of 280000 private farmer households by 1995 . However, these first private farms held only five percent of arable lands, while 


\section{figure 1}

Trends of harvested land under various major cereal crops

WHEAT

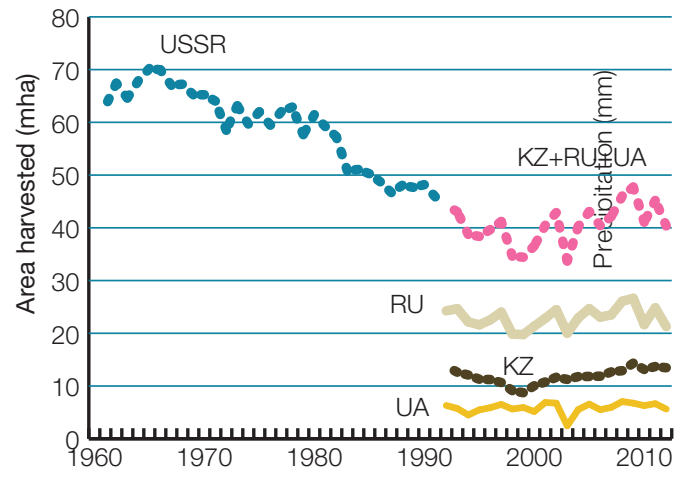

MAIZE

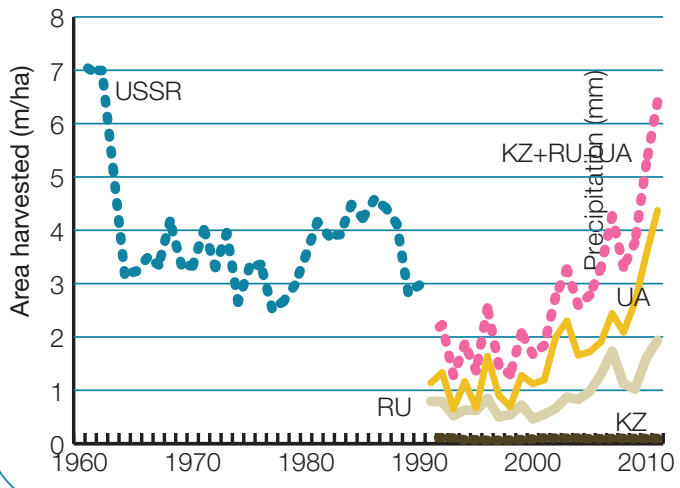

BARLEY

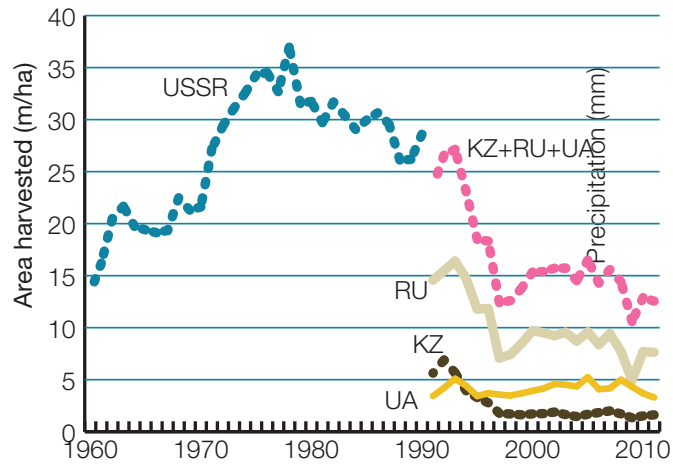

RYE

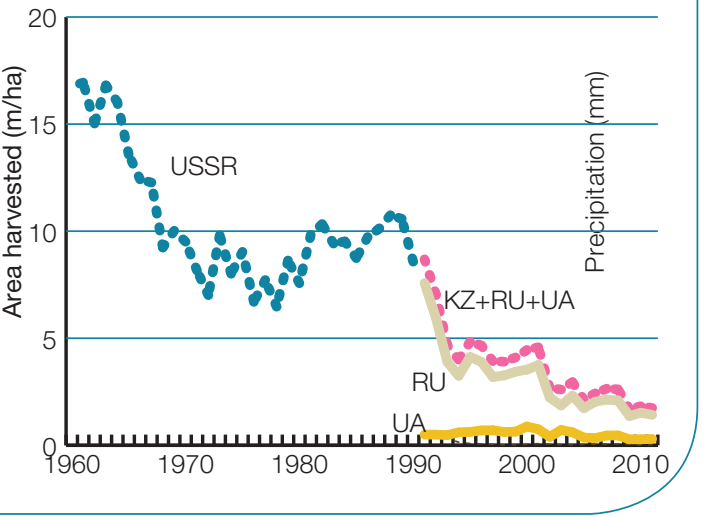

\section{table 2}

The area under wheat and mean wheat yield for Kazakhstan, Russia and Ukraine (FAOSTAT, 2014)

\begin{tabular}{lcccccc}
\hline \multirow{2}{*}{$\begin{array}{l}\text { Time } \\
\text { period }\end{array}$} & \multicolumn{3}{c}{ Area harvested (th. $\mathbf{~ k m}^{2}$ ) } & \multicolumn{3}{c}{ Yield (t/ha) } \\
\cline { 2 - 7 } & Kazakhstan & $\begin{array}{c}\text { Russian } \\
\text { Federation }\end{array}$ & Ukraine & Kazakhstan & $\begin{array}{c}\text { Russian } \\
\text { Federation }\end{array}$ & Ukraine \\
\hline $1991-1995$ & 124 & 232 & 55 & 0.82 & 1.64 & 3.19 \\
\hline $1996-2000$ & 100 & 215 & 58 & 0.85 & 1.59 & 2.41 \\
\hline $2001-2005$ & 115 & 230 & 56 & 1.02 & 1.95 & 2.72 \\
\hline $2006-2010$ & 130 & 242 & 63 & 1.07 & 2.15 & 2.86 \\
\hline
\end{tabular}

FAOSTAT, 2014. http://faostat.fao.org, last accessed 13 April 2014 


\section{figure 2}

Percentage of land under crops in year 2000 in Kazakhstan, Russia and Ukraine (Ramankutty et al., 2008)

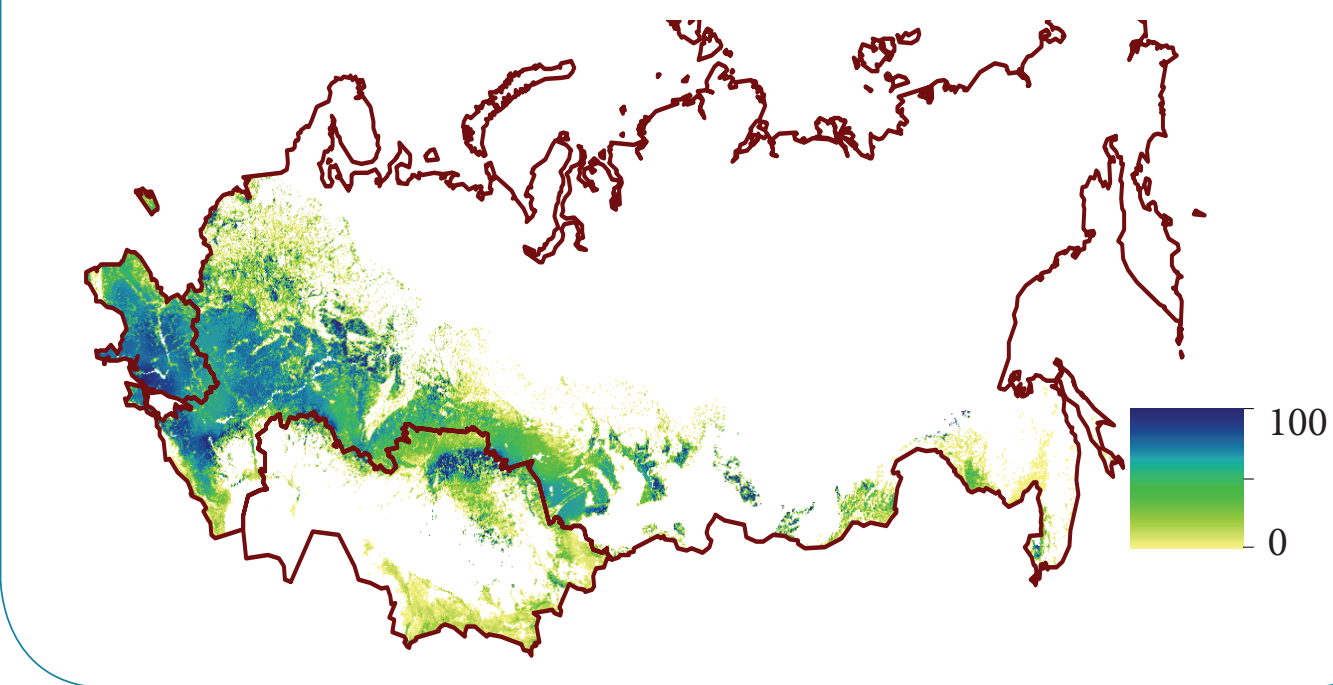

collective farms - slightly reorganized kolkhozy and sovkhozy - still prevailed (Csaki and Lerman, 1997; Prosterman et al., 1999). These collective farms owned 108 million hectares, which were formally privatized by managers of the collective farms. About 40 percent of these lands belonged to elderly people. According to the survey of farm managers conducted by the Rural Development Institute, no change or very little change had occurred in the way of governance of the farms compared with the Soviet period (Prosterman et al., 1999). While ineffective cooperative units inherited from reformed kolkhozes and sovkhozes still produce a significant share of grain in the country (Brock et al., 2008), many experts believe that the increased yields since 2000 resulted from the growth of large, vertically integrated agro-industrial holdings (Serova 2007; Uzun et al., 2012). This growth started at the end of the 1990s, when some banks, oil companies, and similar large businesses started investing in agriculture, primarily in the steppe and forest-steppe zones of the Russian Federation (Smelansky, 2003), where large-scale intensive agriculture is possible (Figure 2). The new businesses brought a significant increase in investments, new technologies and contemporary management to a number of collective farms in the most productive regions of the country (Serova, 2007). According to the Institute of Agricultural Market Studies (IKAR), in 2002 the agro-industrial holdings were already producing 10 percent of grain, 25 percent of meat, and 70 percent of sunflower oil in the Russian Federation (http://www.vedomosti.ru Ivanova, May 26, 2003). A thorough discussion of agro-industrial production has been published by Uzun et al. (2012).

In 2005, the Russian Federation's government designated agriculture a primary industry for receiving federal support and during the following two years federal support for agriculture increased by 52 percent (adjusted for inflation) (Liefert et al., 2009a,b). In 2009, the Russian Federation's government created the United Grain Company, which has become the main federal agent for the grain market, with the goals of supporting grain producers, increasing competitiveness of grain exports and improving grain production infrastructure. 
Another noteworthy recent trend in the agricultural land use of this region has been a significant increase in oilseeds production (sunflower, rapeseed, soybean, safflower and cotton), mainly at the expense of cereals and forage. For example, between 2001 and 2012, sunflower seed production increased from 2.7 to 8 million tonnes in the Russian Federation and from 2.3 to 8.3 million tonnes in Ukraine, rapeseed production grew from 0.1 to 1 million tonnes in the Russian Federation and from 0.1 to 1.3 million tonnes in Ukraine, and soybean production rose from 0.3 to 1.8 million tonnes in the Russian Federation and from 0.06 to 2.4 tonnes in Ukraine (FAOSTAT 2013). These shifts indicate a response to global market signals and are linked to the higher profitability of oilseed crops. It is likely that this trend will continue into the future and it may have a negative impact on the potential for grain production.

The livestock industry has become another priority area for federal support. Throughout the 1990s, livestock numbers were reduced dramatically, leading to a 55 percent reduction in milk and meat production (OECD 2002). This actually had a positive effect on food security; a lower demand for feedgrain has resulted in more grain production available for domestic food use, even though the yields continued to be depressed (annual grain production in 2001-2008 was 83 million tonnes, compared with 103 million tonnes between 1987 and 1990). In 2007, the Federal Program of Agricultural Development and Regulation of Markets for Agricultural Produce, Raw Materials, and Food for 2008-2012 was accepted. The goal of the Program was to increase production of meat and poultry by 32.9 percent (in live weight; all numbers are for 2012 compared with 2006). The target numbers for 2012 were 11.4 million tonnes for meat and poultry and 37 million tonnes for milk production. The main vehicles of the Program were federal subsidies and protection for producers from cheap meat imports.

As a result, meat production in the Russian Federation has grown remarkably (Welton, 2011) so that the Program's goals were exceeded
(Table 2), although not in all sectors. The higher growth rates for pork and poultry production are explained by both their higher level of development in the USSR and their faster return on investment compared with beef, due to their shorter production cycle (Welton, 2011). This impressive growth was accompanied by an equally impressive increase in labour productivity, by 80 percent for poultry and 50 percent for pork production (Table 3). It is noteworthy that federal support for these sectors of agriculture is very high, even in comparison with the most developed countries (Table 4). On the other hand, the impressive federal support for animal husbandry between 2008 and 2012 had almost no effect on beef and milk production (Table 4). After the collapse of the USSR, dairy cattle remained the main source of beef (Gosudarstvennaya programma.., 2012). Domestic beef production has not been profitable for most farms; in 2011 the average profitability of the sector was only -24 percent, compared with 22.6 percent for pork and 10.2 percent for poultry production (O hode y resultatah realizacii.., 2012). According to experts in the Russian Federation, profitability should be at least 25 percent to make growth of these sectors stable (Rau, 2009).

The fast growth of animal husbandry in the second half of the 2000s had little impact on the positive balance of grain supply in the Russian Federation. The impressive grain exports combined with low internal meat and dairy production resembled the agricultural sector of the late period of the Tsarist Russia in the nineteenth century, as during both periods the positive balance of grain supply was largely based on poor development of livestock production and low internal demand, rather than on high yields.

\section{Short-term weather variability and land dynamics}

Although economic and institutional changes have probably been the dominant factors influencing recent grain production trends in post-Soviet 


\section{table 3}

Livestock production (tonnes): Federal Program goals vs. actual data

\begin{tabular}{llrrrrc}
\hline \multicolumn{1}{c}{ Commodity } & $\mathbf{2 0 0 8}$ & $\mathbf{2 0 0 9}$ & $\mathbf{2 0 1 0}$ & $\mathbf{2 0 1 1}$ & $\mathbf{2 0 1 2}$ \\
\hline \multirow{2}{*}{ Goal } & Poultry and meat (live weight) & 8950 & 9520 & 10100 & 10750 & 11400 \\
\cline { 2 - 7 } & Milk production & 33000 & 34000 & 35000 & 36000 & 37000 \\
\hline \multirow{2}{*}{ Actual } & Poultry and meat (live weight) & 9331 & 9972 & 10553 & 10965 & 11621 \\
\cline { 2 - 7 } & Milk production & 32362 & 32570 & 31847 & 31646 & 31831 \\
\hline
\end{tabular}

Source: Federal Program ...., 2007; ROSSTAT, 2013

table 4

Meat, eggs and dairy production in 2008-2012 to 1990 (percentage)

\begin{tabular}{lccccr}
\hline Commodity & $\mathbf{2 0 0 8}$ & $\mathbf{2 0 0 9}$ & $\mathbf{2 0 1 0}$ & $\mathbf{2 0 1 1}$ & $\mathbf{2 0 1 2}$ \\
\hline Cattle & 36.9 & 36.2 & 35 & 35.3 & 35 \\
\hline Pigs & 42.2 & 45 & 44.9 & 45 & 49.2 \\
\hline Birds & 61.3 & 65.7 & 68.1 & 71.7 & 75 \\
\hline Beef & 40.9 & 40.2 & 39.9 & 37.5 & 58 \\
\hline Milk & 58.1 & 58.5 & 57.2 & 67.8 & 57.3 \\
\hline Pork & 58.7 & 62.3 & 158 & 178 & 72.2 \\
\hline Poultry & 123 & 142 & 85.5 & 86.6 & 89.5
\end{tabular}

Source: Federal Program ...., 2007; ROSSTAT 2013

\section{table 5}

Federal subsidies for poultry production, USD per metric tonne of final product

\begin{tabular}{lcccr}
\hline Countries & $\mathbf{1 9 9 5}$ & $\mathbf{2 0 0 0}$ & $\mathbf{2 0 0 5}$ & $\mathbf{2 0 1 0}$ \\
\hline Russia & 430 & 350 & 473 & 1126 \\
\hline EU & No Data & 240 & 398 & 426 \\
\hline Canada & 222 & 7 & 29 & 301 \\
\hline USA & 10 & 1 & 0 & 1 \\
\hline
\end{tabular}

Source: Borodin et al., 2013

transitional economies, agricultural production is also highly sensitive to inter-annual climate variability, as expressed in growing season weather. Multiple studies have debated the relative roles of agricultural policy changes, weather variability and climate change in the performance of agriculture in Central Eurasia during various historical periods (loffe et al., 2012; Lioubimtseva and Henebry,
2012; Wright et al., 2012; Liefert et al., 2013). Detailed analysis of climate variability and policy changes in the Russian Federation in the twentieth century can be found in Dronin and Bellinger (2005). Furthermore, Dronin and Kirilenko (2013) examined the relative roles of climate and state agricultural policies affecting production of cereals using statistical yield modelling and found a tight 
correlation between actual and weather-explained yields. Their study suggested that weather changes had a significant effect on yields in the Russian Federation between 1958 and 2010, with the residual yield variability explained by large-scale changes in agricultural policies at the state level. The continental climate of the Central Eurasian grain belt results in volatile weather conditions for grain production, especially in terms of rainfall. The productivity of grain crops (winter wheat in the European parts of the Russian Federation and Ukraine, spring wheat and barley in Kazakhstan and in the Russian Federation east of the Volga River) depends strongly on spring and summer precipitation, which is particularly important during the critical phases of wheat growth, such as bushing and earring. The second major climatic constraint is temperature; for example, dry cold winters often kill winter wheat crops, but high summer temperatures, above $33^{\circ} \mathrm{C}$, damage crops and reduce production of spring wheat and barley.

Grain yields for the Russian Federation, Ukraine and Kazakhstan were very low every year between 1994 and 2000 - with the exception of a good yield in 1997 - mostly as the result of unfavourable weather. However, grain production was high every year between 2001 and 2013, except for the plunges in 2003, 2010 and 2012 (FAOSTAT 2013; Liefert et al., 2013). Again, the main driver for high yields was favourable weather, with only a few exceptions. The summer of 2010 featured an extraordinary heat wave, with the region experiencing the warmest July since at least 1880 and numerous locations breaking all-time maximum temperature records (Dole et al,. 2011).

The heat wave and extreme drought of summer 2010 affected all major grain-producing areas of the former USSR (Lioubimtseva et al., 2013). The government declared a state of emergency in 27 agricultural regions and a total of 43 regions were affected, with over 24 million hectares of crops destroyed (Welton, 2011). This area accounted for 17 percent of the total crop area and included almost 25000 farms. The 2010 heat wave cut grain yield in the Russian Federation by a third, the potato harvest by 25 percent and vegetables by 6 percent (FAOSTAT 2013). More than 25 percent of all crops were destroyed and many small dairy farmers were forced to slaughter their cattle as fodder prices increased rapidly in response to the heat wave. There are four main grain- producing regions in the Russian Federation: Central, South, Volga and Siberia. Of these, the Volga region which is the largest producer - was the most severely hit by the drought, seeing its annual harvest drop by more than 70 percent, while the Central region's production dropped by 54 percent. Overall, the harvest was down about one-third compared with the previous year (Welton, 2011). Although the 2012 summer temperatures in this region were not as high as in 2010, persistent droughts have continued during the past three years throughout the entire grain-producing belt of Central Eurasia.

Both weather variability and institutional changes have had observable impacts on land surface phenology of the region, captured by a time series of satellite imagery. Land surface phenology studies the timing and magnitude of seasonal patterns in the vegetated land surface as observed at spatial resolutions that are very coarse relative to individual plants. In the absence of obscuring clouds, the vegetated land surface is readily viewed from space because of the strong contrast in green plants between the near infrared and red portions of the electromagnetic spectrum. Green plants are very bright in the near infrared, scattering upwards of a third of incident radiation, but very dark in the red, absorbing more than 90 percent of incoming light. The Normalized Difference Vegetation Index (NDVI) exploits this spectral contrast ${ }^{4}$.

$4 \mathrm{NDVI}$ is calculated as follows: NDVI = (NIR-RED)/ (NIR+RED), where RED and NIR stand for the spectral reflectance measurements acquired in the red and near-infrared regions, respectively (Tucker et al., 1991). Vigorously growing healthy vegetation has low red light reflectance and high near-infrared reflectance, and hence, high NDVI values. Increasing positive NDVI values indicate increasing amounts of green vegetation. NDVI values near zero and decreasing negative values indicate non-vegetated features such as barren surfaces (rock and soil), snow, ice and clouds. 
Time series of NDVI data provide additional information about land surface phenology changes that can be caused either by land use changes or climatic variability and change, as well as growing season weather. Several studies based on analyses of NDVI and other vegetation indices derived from satellite imagery found an evidence of gradual increase of the length of growing season and overall increase of green vegetation cover across Eurasia (Bogaert et al,. 2001; deBeurs and Henebry, 2004; Lioubimtseva, 2007; Kariyeva and van Leewuven, 2011; Wright et al., 2012). Satellite imagery indicates that, while North America shows a fragmented pattern of NDVI change, Eurasia exhibited a persistent increase in growing season NDVI over a broad contiguous swath of land (Zhou et al., 2001; Bogaert et al., 2001). This greening trend has been attributed partially to institutional and land-use changes (DeBeurs and Henebry, 2004; Prishchepov et al., 2013) and partially to climate change and variability (DeBeurs and Henebry, 2008; Propastin and Kappas, 2008). Propastin and Kappas (2008), for instance, show that from March to May, greening increased in 65 percent of cropland pixels, and decreased in only 2 percent of the pixels; 73.5 percent of variation is explained by the change in spring temperature.

The signs of agricultural decline in the 1990s were sufficiently strong across the Russian Federation, Ukraine and Central Asia to be captured by NDVI and other vegetation indices derived from coarse resolution remote sensing data, such as AVHRR (Advanced Very High Resolution Radiometer) as well as more detailed satellite imagery, e.g. Moderate Resolution Imaging Spectroradiometer (MODIS) and Landsat (de Beurs and Henebry, 2004; Kariyeva and van Leeuwen, 2011; Prishchepov et al., 2013). A recent study of the agricultural conditions and NDVI trends in the grain belt between 2001 and 2010 by Wright et al. (2012) has revealed strong divergence between areas within and outside of the Chernozem zone. The agricultural sector has been disintegrating since at least 1991 in the marginal areas outside of the highly fertile
Chernozem zone, where productivity was always low. In contrast, agriculture in the Chernozem area is vigorous and NDVI series show no evidence of agricultural decline (de Beurs et al., 2012; loffe et al., 2012). Combining analyses of NDVI trends and land-cover changes, Wright et al. (2012) found a pattern of increasing greenness associated with agricultural abandonment (i.e. cropland to grassland) in the southern range of the Eurasian grain belt coinciding with statistically significant negative NDVI trends and likely driven by regional drought. In the northern range of the grain belt they found an opposite tendency towards agricultural intensification; in this case, represented by land-cover change from cropland mosaic to pure cropland, and also associated with statistically significant negative NDVI trends.

\section{Impacts of climate change on grain production}

A credible projection of grain production should include a physically based or statistical yield model, taking into account not only the changes in demand or technologies, but also variability of agricultural climates in the country and frequency of extreme weather conditions such as droughts, soils and other external parameters. Multiple authors have estimated the impact on yields of changes in one or a few of these parameters. Agricultural production is highly sensitive to interannual climate variability as expressed in growing season weather. Climate change is likely to have multiple effects on potential productivity and yields, such as: effects of elevated $\mathrm{CO}_{2}$ on plant growth, water-use efficiency and yields; effects of increased temperature; extension of the growing season; effects of increase of precipitation in some areas and decrease in others; effects of increased frequency and intensity of extreme events; and increased risk of weed invasion, insect pests and diseases.

Global Climate Models (GCMs) are the most advanced tools currently available for simulating the response of the global climate system to 
increasing greenhouse gas concentrations. The climate modelling scenarios suggest that, compared with the late Soviet Union period of the 1980s, the temperature in the grain-producing areas of the Russian Federation, Ukraine and Kazakhstan will increase by $1.5-1.8^{\circ} \mathrm{C}$ by the 2020 s and by $2.2-3.9^{\circ} \mathrm{C}$ by the 2050s, with the greatest increase in winter (Mitchell et al., 2002; Lioubimtseva and Henebry, 2009; 2012; Dronin and Kirilenko, 2013). Despite significant differences in the range of changes among the scenarios produced by different models, most studies tend to agree that summer precipitation is likely to decline all over the region and winter precipitation is projected to increase in parts of Western Russia and Siberia (Dronin and Kirilenko, 2008; Lioubimtseva and Henebry, 2012).

In order to evaluate impacts of climate change on the grain belt of Central Eurasia, we have computed the twentieth century temperature and precipitation trends for Kazakhstan, the Russian Federation and Ukraine by fitting a linear regression model to the 1901-2000 mean temperature and precipitation of these three countries. The historical climate data for the countries were retrieved from University of Eastern Anglia's Tyndall Centre for Climate Change Research (TYN) country average (CY) database 1.1 (Mitchell et al., 2003). Temperature trends are similar for the Russian Federation and Ukraine $\left(0.08^{\circ} \mathrm{C} /\right.$ decade), with a higher trend in Kazakhstan $\left(0.14^{\circ} \mathrm{C} /\right.$ decade). These changes were accompanied by precipitation increases of 0.7, 4.6 and $3.5 \mathrm{~mm} /$ decade in Kazakhstan, the Russian Federation and Ukraine, respectively. Over the last three decades of the twentieth century, these changes accelerated, with the temperature trend increasing to $0.37^{\circ} \mathrm{C} /$ decade in Kazakhstan, 0.32 ${ }^{\circ} \mathrm{C} /$ decade in the Russian Federation and $0.23^{\circ} \mathrm{C} /$ decade in Ukraine, with higher changes in winter (1.30, 0.81 and $0.73{ }^{\circ} \mathrm{C} /$ decade, respectively) and considerably lower warming in summer (0.33, 0.25 and $0.35^{\circ} \mathrm{C} /$ decade, respectively). During the last three decades of the twentieth century, the increasing precipitation trend continued in Kazakhstan $(2.1 \mathrm{~mm} /$ decade) and the Russian
Federation (2.8 $\mathrm{mm} /$ decade), but was reversed in Ukraine (-3.7 mm/decade). While in Kazakhstan, summer precipitation has increased, in Ukraine and the Russian Federation it has declined.

Observed trends exhibit a high level of spatial heterogeneity, especially in the Russian Federation. While on average the temperatures have become $1.29^{\circ} \mathrm{C}$ warmer over the past 100 years (1907-2006 - compared with $0.74^{\circ} \mathrm{C}$ global warming over the same period) (National communication, the Russian Federation, 2010), the warming trend was higher in Eastern Siberia and in the north of the European part of the country, with lesser warming in the intensive agriculture zone located in the south of the European part of the Russian Federation (NOAA GISS Surface Temperature Analysis, http://data. giss.nasa.gov/gistemp/). Similarly, the highest changes in precipitation were observed in the eastern part of the country in the spring season. There is considerable uncertainty in the data on precipitation trends, especially over the entire twentieth century, due to low density of the observational network (National communication, the Russian Federation 2010). In the agricultural region of northern Kazakhstan, the warming trend is higher compared with the entire country, especially in winter, and is accompanied by increasing winter and decreasing summer precipitation (National communication, Kazakhstan, 2009). Higher temperatures lead to a greater effective temperature sum (ETS, measured as a sum of growing-degree days with base temperature of $10^{\circ} \mathrm{C}$ ), a longer vegetative period, and to shifts in phenology. In extra-tropical regions, multiple studies demonstrated a lengthening of the growing season by approximately 10-20 days in the last few decades, mostly as the result of an earlier spring (Linderholm, 2006). In Europe, the growing season has extended by 3.5 days $/ \mathrm{C}$ over the last 30 years of the twentieth century (Menzel et al,. 2006). In the principal agricultural areas of the Russian Federation, the length of the period with temperatures above $10{ }^{\circ} \mathrm{C}$ (associated with the growing period) was increasing by 2.3-2.7 days per decade in central Chernozem, northern 


\section{figure 3}

Climate change impacts on temperature $(T)$ and precipitation $(P)$ change compared to the base period for 2020 s and 2050s. The data present the mean of four CMIP-3 GCM integrations under IPCC SRES A1FI scenario
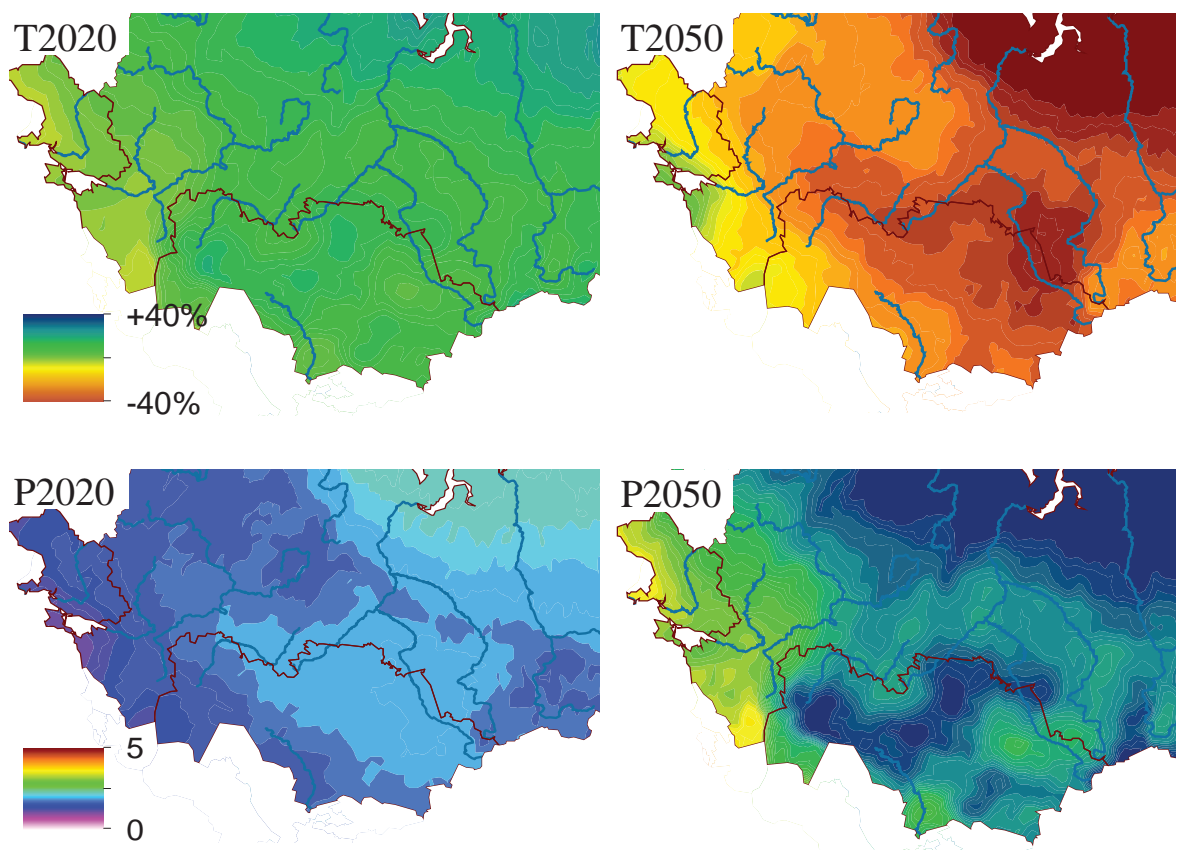

Caucasus, and western Siberian regions, and by 0.2-0.7 days per decade in the Ural and Povolzhie regions (Sirotenko et al., 2007). The highest increase in ETS, over $120^{\circ} \mathrm{C}$ per decade, was observed in Ukraine, with $57-77^{\circ} \mathrm{C}$ per decade growth in central Chernozem, northern Caucasus, and western Siberian regions, and lower growth or even decrease in the Ural and Povolzhie regions (Sirotenko et al., 2007).

We estimated projected future changes of climate over the territory of Kazakhstan, the Russian Federation and Ukraine in the 2020s and 2050s as deviations from the base values at the end of the Soviet period (1980s); the base period was selected for compatibility with earlier projections of climate change impacts on agriculture in the Russian Federation (Alcamo et al., 2007). The following parameters were computed as mean values from the ensemble of four GCMs (CGCM2, CSIROmk2, ECHam4 and DOE PCM): the change in annual and warm period temperature and precipitation; potential evapotranspiration; and growing degree days at base temperature of $10^{\circ} \mathrm{C}$ (GDD10). We computed the values of each parameter for the entire territory of interest, divided into $0.5^{\circ}$ geographical latitude and longitude cells with a regular grid (Figure 3). The values for each country were then combined as a weighted mean with weights equal to percentage of agricultural lands in each cell (Table 6).

In the 2020s, the temperature increase in all three countries - with lower increase in Ukraine (Figure 3) - would be followed by a correspondent increase in potential evapotranspiration, by 15-18 percent. The increase in precipitation, by 3-6 percent in the Russian Federation and Kazakhstan and by 0-2.3 percent in Ukraine, can partially compensate for an increased water deficit; however, the increase in precipitation is projected mostly for the cold part of the year, with 


\section{table 6}

Change of climate parameters for four IPCC SRES scenarios for the 2020s and 2050s, in comparison with the late USSR period (1980s). An ensemble mean for four GCMs (CGCM2, CSIROmk2, ECHam4, and DOE PCM) is shown

\begin{tabular}{|c|c|c|c|c|c|c|c|c|}
\hline TIME & Country & Scenario & T ann. & P ann. & T warm & P warm & PET & GDD10 \\
\hline \multirow{12}{*}{$2020 s$} & \multirow{4}{*}{ Kazakhstan } & $\mathrm{A} 1$ & 1.6 & 4.7 & 1.8 & 2.2 & 17 & 244 \\
\hline & & $\mathrm{A} 2$ & 1.7 & 5.0 & 1.8 & 1.0 & 15 & 244 \\
\hline & & B1 & 1.7 & 4.8 & 1.8 & 1.3 & 16 & 250 \\
\hline & & B2 & 1.9 & 5.6 & 1.9 & 0.6 & 17 & 277 \\
\hline & \multirow{4}{*}{ Russia } & $\mathrm{A} 1$ & 1.5 & 3.0 & 1.5 & 0.6 & 17 & 218 \\
\hline & & $\mathrm{A} 2$ & 1.6 & 3.4 & 1.5 & 0.3 & 16 & 215 \\
\hline & & B1 & 1.5 & 3.5 & 1.6 & 0.6 & 18 & 225 \\
\hline & & B2 & 1.8 & 4.2 & 1.7 & 0.7 & 18 & 247 \\
\hline & \multirow{4}{*}{ Ukraine } & $\mathrm{A} 1$ & 1.3 & 1.0 & 1.3 & -1.3 & 17 & 236 \\
\hline & & $\mathrm{A} 2$ & 1.3 & 0.3 & 1.3 & -1.6 & 15 & 237 \\
\hline & & B1 & 1.3 & 2.3 & 1.4 & -0.1 & 16 & 238 \\
\hline & & B2 & 1.6 & 1.8 & 1.5 & -0.7 & 17 & 271 \\
\hline \multirow{12}{*}{$2050 s$} & \multirow{4}{*}{ Kazakhstan } & $\mathrm{A} 1$ & 3.9 & 11.1 & 4.2 & 5.4 & 42 & 617 \\
\hline & & $\mathrm{A} 2$ & 3.5 & 10.4 & 3.6 & 2.2 & 33 & 528 \\
\hline & & B1 & 2.7 & 8.0 & 2.9 & 2.3 & 28 & 424 \\
\hline & & B2 & 3.2 & 9.4 & 3.3 & 1.1 & 31 & 484 \\
\hline & \multirow{4}{*}{ Russia } & $\mathrm{A} 1$ & 3.5 & 7.1 & 3.6 & 1.5 & 45 & 549 \\
\hline & & $\mathrm{A} 2$ & 3.2 & 7.0 & 3.1 & 0.7 & 34 & 462 \\
\hline & & B1 & 2.5 & 5.8 & 2.6 & 1.0 & 31 & 383 \\
\hline & & B2 & 3.0 & 7.1 & 2.9 & 1.2 & 32 & 434 \\
\hline & \multirow{4}{*}{ Ukraine } & $\mathrm{A} 1$ & 3.1 & 2.4 & 3.1 & -3.0 & 42 & 584 \\
\hline & & $\mathrm{A} 2$ & 2.7 & 0.6 & 2.7 & -3.3 & 33 & 501 \\
\hline & & B1 & 2.2 & 3.7 & 2.2 & -0.2 & 28 & 403 \\
\hline & & B2 & 2.6 & 3.0 & 2.6 & -1.3 & 30 & 468 \\
\hline
\end{tabular}

Note: The climate parameters are as follows: change in annual temperature ( $\mathrm{C} C$ ) $[T$ ann.], precipitation (percentage) [P ann.], change in warm period (April through September) temperature $[T$ warm] and precipitation [P warm], change in annual potential evapotranspiration (percentage) [PET], and and change in ETS base $10^{\circ} \mathrm{C}\left({ }^{\circ} \mathrm{C}\right)[\mathrm{GDD} 10$

a considerably smaller warm period increase in the Russian Federation and Kazakhstan and even some decrease in Ukraine. The ETS is projected to grow by approximately $250{ }^{\circ} \mathrm{C}$, roughly following these observations.

Food security studies frequently employ Dynamic Global Vegetation models (DGVMs) and crop simulation models driven by climate change projections, combined with economic models (Pegov, 2000; Golubev and Dronin, 2004; Fischer et al., 2005; Schmidhuber and Tubiello, 2007; Alcamo et al., 2007; Dronin and Kirilenko, 2008; 2013). A DGVM is a computer programme that simulates shifts in potential vegetation and the associated biogeochemical and hydrological cycles as a response to shifts in climate. Such models use time series of climate data and, given constraints of latitude, topography and 
soil characteristics, simulate monthly or daily dynamics of ecosystem processes. Crop models are crop-specific computer programmes that allow a user to estimate crop growth and yield as a function of weather conditions and management scenarios. Several studies based on analysis of agro-ecological scenarios indicate that the Russian Federation, Ukraine and Kazakhstan might be among the greatest beneficiaries of expansion of suitable croplands due to increasing winter temperatures, a longer frost-free season, $\mathrm{CO}_{2}$ fertilization effect and projected increases in wateruse efficiency by agricultural crops - as well as possible, though uncertain, increases in winter precipitation projected by some AtmosphereOcean General Circulation Models (AOGCMs) (Fischer et al., 2005). For example, the International Institute for Applied Systems Analysis (IIASA)/ Basic Linked System (BSL) models driven by the Hadley Centre climate prediction model 3 (HadCM3) climate change scenarios suggest that, as a result of regional climate changes by 2080 , the total area with agro-ecological constraints could decrease, and the potential for rainfed cultivation of major food crops could increase in the Russian Federation (primarily due to temperature increase and the $\mathrm{CO}_{2}$ fertilization effect on C3 plants) (Fischer et al., 2002). A study by Pegov et al., (2000) suggests that grain production in the Russian Federation may double, due to a northward shift of agricultural zones. Other modelling studies, however, indicate that the predicted shift of agro-ecological zones is unlikely to result in increasing agricultural productivity. Alcamo et al. (2007) and Dronin and Kirilenko (2008) have shown that, although large portions of the Russian Federation might increase their agricultural potential under warming scenarios, agriculture in the most productive Chernozem zone in the Russian Federation and Ukraine, between the Black and the Caspian Sea, could suffer a dramatic increase in drought frequency. This region is the main commercial producer of wheat and any declines in productivity would be detrimental to exports (Lioubimtseva and Henebry, 2012). The Global Assessment of Security (GLASS) model computes a considerable decrease of cereal yields in the most productive parts of the Russian Federation (Golubev and Dronin, 2004). Even though cereals will grow in the more humid central and northern regions, the average yield in the Russian Federation will decrease considerably because of a severe increase in droughts in the most productive regions. At its extreme, in Stavropolsky Krai, the key agricultural region of the northern Caucasus, potential cereal production would decrease by 27 percent in the 2020s and by 56 percent in the 2070s. In contrast, the yield of cereals in the central region will not change much, whereas yields in the northern regions will increase significantly. However, this latter increase would contribute little to the total grain production of the country.

A longer and warmer growing period generally would allow northward expansion of intensive agriculture. Globally, agriculture in the Russian Federation could gain the greatest benefit from a warmer climate if the increase in ETS is considered separately from other factors. Warmer temperatures shift the area of the country that is bioclimatically suitable for agriculture as much as $600 \mathrm{~km}$ northward (by the 2080s, under highemission scenarios) with an increase in production of up to 1.5-2 times (Pegov et al., 2000). It will also allow introduction of new or more productive crops. For example, accepting the ETS $=850{ }^{\circ} \mathrm{C}$ isoline roughly limiting the cultivation area of corn for grain (Carter et al., 1991), which includes almost the entire territory of Kazakhstan and Ukraine and crosses the Russian Federation just south of Moscow, the $250^{\circ} \mathrm{C}$ change in ETS by the 2020s (compared with 1980s climate - see Table 6) expands the potential corn cultivation area up to $400 \mathrm{~km}$ north in the Russian Federation. Considering more realistic scenarios, with limitations on both temperature and precipitation, the area potentially suitable for agriculture may increase by 64 percent (Fischer et al., 2005).

On the other hand, the best agricultural lands in the Russian Federation, Ukraine and Kazakhstan (Figure 4A) coincide with the zone of limited water availability and are more limited 


\section{figure 4}

Climate change impacts on the factors limiting agriculture: growing degree days

base $10{ }^{\circ} \mathrm{C}(\mathrm{GDD})$ and Thornthwaite's aridity index (Aridity), for the current (1970-2000) climate (A) and projections for the 2020s (B) and 2050s (C). The projections combine mean GDD and aridity computed for five CMIP-3 GCM projections under the

IPCC SRES A1FI scenario
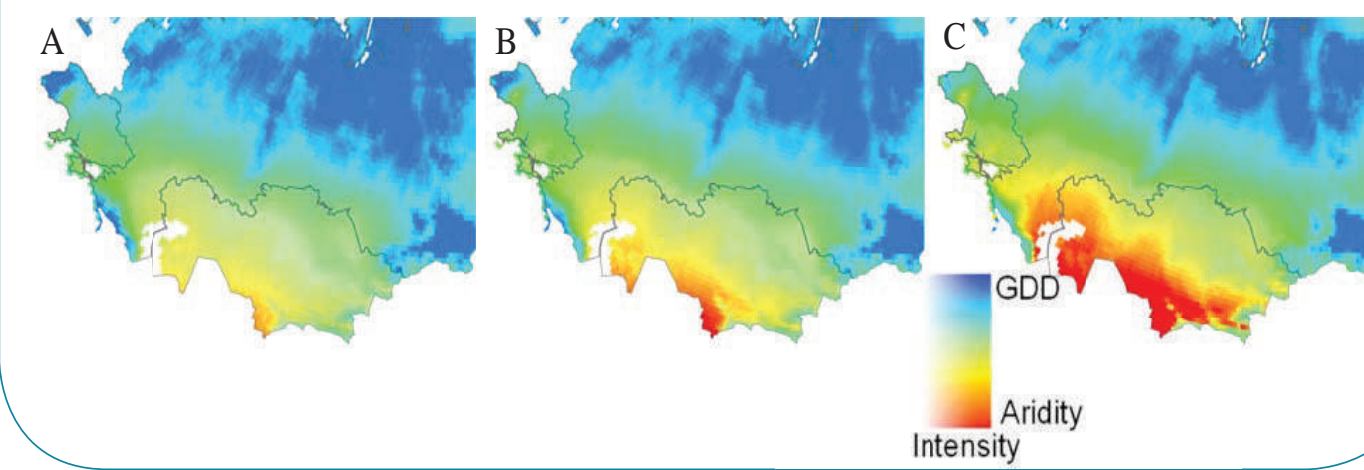

Aridity

Intensity

by precipitation levels $(322 \mathrm{~mm}$ for agricultural lands in Kazakhstan, $507 \mathrm{~mm}$ for the Russian Federation and $547 \mathrm{~mm}$ for Ukraine) than by temperatures (Figure 4A). Droughts regularly occur in this region (Table 6). Over the last three decades, the frequency of drought in the main agricultural regions of the Russian Federation has increased (Gruza et al., 1999; Spinoni et al., 2013). On these lands, a longer and warmer growing season may affect soil moisture, decreasing yields and leading to higher incidence of drought (Alcamo et al., 2007; Figure 4B, 4C). Limited land availability and soil fertility outside of Chernozem areas (Stolbovoi and McCallum, 2002) make it highly unlikely that the shift of agriculture to the boreal forest zone will ever compensate for crop losses caused by increasing aridity in the current zone of intensive agriculture. Decreasing availability of soil moisture is especially important for the main grain-growing regions of the Russian Federation and Ukraine, which in the past have been subjected to droughts every third year on average (Khomyakov et al., 2005). Without expansion of agricultural lands, increased temperatures combined with minor changes in precipitation, which are projected by the majority of GCMs for the steppe regions of the Russian Federation, Ukraine and Kazakhstan (Figure 4) will lead to a 6-9 percent reduction in grain production on average (Alcamo et al., 2007).

These simulations do not take into account any effects on yields from higher aerial $\mathrm{CO}_{2}$ concentrations. "Carbon fertilization" directly affects yields by increasing photosynthetic production (Smith et al., 2000). Higher $\mathrm{CO}_{2}$ concentrations may also indirectly affect yields in water-deficit conditions by decreasing plants' water requirements. Both direct and indirect effects are significantly more pronounced for C3 plants, such as wheat. The earlier laboratory studies demonstrated a very high carbon fertilization effect, with 19 to 31 percent increased wheat yield under a 550 ppm $\mathrm{CO}_{2}$ concentration (Long et al., 2006). On average, across several species and under unstressed conditions, recent data analyses find that, compared with current atmospheric $\mathrm{CO}_{2}$ concentrations, crop yields would increase at 550 ppm $\mathrm{CO}_{2}$, in the range of 10-20 percent for C3 crops and 0-10 percent for C4 crops (IPCC 2007). However, the results obtained for the Russian Federation with physically explicit models based on these data - e.g., by Sirotenko et al. (1997) - are likely to overestimate the related increase in global yields (Ainsworth, 2008). The Free Air-Enrichment Experiments (FACE) suggest that outside the highly artificial conditions of a 
test enclosure the carbon fertilization effect is significantly lower, with a mean yield increase of 12 percent for wheat (Long et al., 2006) and no response for $\mathrm{C} 4$ plants, such as corn. The fertilization effect is more pronounced under water stress (18 percent) than under good watering conditions (8 percent) (Ainsworth, 2008). Note, however, that the results of FACE experiments are highly variable over the test plots, with no data available for the region of interest. Temperature and precipitation changes in future decades are likely to modify, and possibly limit, direct $\mathrm{CO}_{2}$ fertilization effects on crops and other plants. For instance, high temperature during flowering may lower $\mathrm{CO}_{2}$ effects by reducing grain number, size and quality (Caldwell et al., 2005). Increased temperatures may also reduce $\mathrm{CO}_{2}$ effects indirectly, by increasing water demand. Rainfed wheat grown at $450 \mathrm{ppm} \mathrm{CO}_{2}$ demonstrated yield increases with temperature increases of up to $0.8^{\circ} \mathrm{C}$, but declines with temperature increases beyond $1.5^{\circ} \mathrm{C}$; additional irrigation was needed to counterbalance these negative effects (Xiao et al., 2005). The ongoing discussion of the role of carbon fertilization effect in future yields (see e.g. Ainsworth, 2008) contains very different estimates of $\mathrm{CO}_{2}$ fertilization impact on future food security.

Complicating the estimates of yield enhancement under increased $\mathrm{CO}_{2}$ concentration, the progressive nitrogen limitation (PNL) effect may decrease production on a longer time scale (Luo et al., 2004) without additional nitrogen input or a reduction of nitrogen loss. Furthermore, yield enhancement would be counteracted by the negative effect from increased ozone concentrations in the troposphere (Long et al., 2005). These and other effects of modifications in climate and chemical composition of the atmosphere increase the uncertainty of future yield estimations.

The physically based models discussed above attempt to project future yields by simulating major physical processes affecting photosynthesis, hydrology, availability of nutrients and other parameters affecting crop production at a local (e.g., DSSAT - Jones et al., 2003), regional (e.g.,
APEX - Gassman et al., 2010) or global (e.g., GAEZ - Fischer et al., 2002) level. For the region of interest, Alcamo et al. (2007) used a modified GAEZ model (Fischer et al., 2002) to find the response of multiple crops to GCM-projected 2020s, 2050s and 2080s changes in temperature and precipitation and to estimate the impacts of climate change on water and food security. They found a general decline in the potential climaterelated yield for the majority of analysed model integrations, with a correspondent decrease in food and water security. Furthermore, Dronin and Kirilenko (2010) combined these results with a simple model of food trade between regions and analysed the capacity for adaptation to increasing yield variability. While their analysis took into account the possibility of replacing some cultivars with others better suited for changing climate, they did not consider any change in yields due to progress in technology and management.

The statistical models attempt to use the historical yields in different years (time series), areas (cross-sections) or across both time and space (panels) to build a regression model, with temperature, precipitation and other parameters of climate used as predictor variables. While the physically based models are much more complex and require estimation of multiple parameters during the process of calibration, much simpler statistical models may demonstrate similar accuracy (Lobell and Burke, 2010). The additional benefit, which could also be a weakness of statistical models, is that local non-climatic conditions such as soils, management practices and technological advancement are intrinsically included in the model. For example, Dronin and Kirilenko (2013) used a statistical model to analyse the historical yields in The Russian Federation from 1958 to 2010, attempting to explain the difference between the reported yield and the sum of climatic (explained by the weather) yield and multiyear trend as a result of agrotechnological progress. The variations of harvest adjusted for weather and management improvements were considered in connection with the policies during key periods of agriculture in the Russian 
Federation: the "Virgin Lands" campaign (end of 1950s); Kosygin-Liberman initiatives (late 1960s); Brezhnev's stagnation era (late 1970s-early 1980s); Gorbachev's "Perestrojka" (1985-1991); and land privatization and price liberalization (1990s). They found a long-term trend of $\sim 1.15$ percent yield increase annually, which they attributed to longterm technological change.

To estimate future climate-related yield changes in the region of interest, we used a dynamic yield model by Alcamo et al. (2007) and a statistical model by Dronin and Kirilenko (2013). Both models were limited in coverage to the Russian Federation territory; for this reason, we estimated corresponding changes in Ukraine and Kazakhstan by computing the changes in yields in the adjacent agricultural zones of the Russian Federation. For Kazakhstan, this zone included Chelyabinskaya, Kurganskaya, Omskaya, and Tumenskaya Oblasts, and for Ukraine, Belgorodskaya, Kurskskaya, Lipetskskaya, Rostovskaya, and Voronezhskaya Oblasts and Stavropolsky Kray. For the territory of the Russian Federation, the dynamic and statistical models both show similar patterns in yield change, generally with a small reduction or an increase in yield for the Russian Federation and Ukraine and larger reductions for Kazakhstan (Table 7). Since the statistical model may poorly represent the yield outside the range of the historical climatic envelope, in the next section we base our assessments on the results of the dynamic model (Alcamo et al., 2007), while assuming the historical long-term technology-related trends in yields found by Dronin and Kirilenko (2013).

\section{Outlooks for grain production and export}

The outlooks for grain production and export are typically based on analyses of the recent agricultural trends, agricultural and economic policies, and assumptions about improvements of technology, infrastructure, and management techniques. They do not usually take into account climate change scenarios. The Federal Program of Agricultural Development and Regulation of Markets for Agricultural Produce, Raw Materials, and Food for 2013-2020 (Gosudarstvennaya programma razvitiya..., 2012) set new targets for the agriculture sector of the Russian Federation focusing on: (1) increased export potential; and

\section{table 7}

Estimated wheat yield change from 1980s to 2020s (percentage) attributable to temperature and precipitation shift alone, as simulated by dynamic (D, see Alcamo et al., 2007) and statistical (S, see Dronin and Kirilenko, 2013) yield models. Notice that for this time period the pattern of climate change is similar for $\mathrm{A} 1 \mathrm{FI}$ and $\mathrm{A} 2$ scenarios

\begin{tabular}{lcccc}
\hline Scenario & Model & Kazakhstan & Russia & Ukraine \\
\hline A1FI & S & 78.9 & 91.6 & 97.3 \\
\cline { 2 - 5 } & D & - & - & - \\
\hline A2 & S & 75.9 & 90.1 & 97.1 \\
\hline B1 & D & 96.8 & 94.0 & 78.5 \\
\hline B2 & S & 80.4 & 90.8 & 98.0 \\
\hline
\end{tabular}

Sources: ERBD, 2008 ; IKAR, 2009 ; Liefert et al., 2013 ; Rau, 2012 ; FAOSTAT, 2013 ; Babkin, 2013,

Schierhorn et al., 2012 


\section{table 8}

Summary of published wheat production trends and outlooks

\section{Cereal production, million tonnes, selected years}

$\begin{array}{llllll}1998 & 2002 & 2005 & 2008 & 2010 & 2012\end{array}$

Outlooks for cereal production, million tonnes

\begin{tabular}{|c|c|c|c|c|}
\hline $\begin{array}{l}\text { IKAR } \\
\text { for } \\
2016\end{array}$ & $\begin{array}{l}\text { IKAR } \\
\text { for } \\
2019\end{array}$ & $\begin{array}{l}\text { USDA } \\
\text { for } \\
2021\end{array}$ & $\begin{array}{c}\text { EBRD } \\
\text { maximum } \\
\text { potential }\end{array}$ & $\begin{array}{l}\text { Road } \\
\text { Map } \\
2020\end{array}$ \\
\hline
\end{tabular}

\begin{tabular}{|c|c|c|c|c|c|c|c|c|c|c|c|}
\hline & & & & & & & & & \multicolumn{3}{|c|}{ scenario } \\
\hline Russia & 46 & 84 & 77 & 106 & 59 & 69 & 98 & 125 & 100 & 126 & 295.6 \\
\hline Ukraine & 25 & 46 & 37 & 53 & 39 & 46 & 44 & $\mathrm{Na}$ & 59 & 75 & na \\
\hline Kazakhstan & 6 & 16 & 14 & 15 & 12 & 15 & 22 & $\mathrm{Na}$ & na & 29 & na \\
\hline Total & 77 & 146 & 128 & 174 & 110 & 130 & 164 & & & 230 & na \\
\hline
\end{tabular}

(2) increased food security based on reliance on internal meat and dairy production. In the view of the authors, the numerical targets set under this program $^{5}$ are overly optimistic based on unrealistic productivity gains assumptions (2.5 percent annual growth rate for grains). In 2008, despite record high prices for grain on the world market (up by USD 400-450/tonne), the area under cereals increased by only 5 percent in the Russian Federation. During the Soviet period, much marginal land had been ploughed but it was then abandoned in the 1990s and its cultivation is still unprofitable regardless of high prices for grain (Liefert et al., 2009a). The national report summarizing realization of the prior Federal Program as of 2011 shows that the area under cereals decreased slightly in the Russian Federation in 2008-2011 (O hode y resultatah ... 2012).

In fact, the high growth rates are based on expert estimates of potential yields, which are projected to exceed the current yields by hundreds of percentage points. For example, the European Bank for Reconstruction and Development (EBRD)

5 Average annual grain production under the Program is set to increase to 115 million tonnes, with overall export potential estimated at 30 million tonnes. Meat and poultry production to go up to 14.07 million tonnes in live weight, and milk production up to 38.2 million tonnes which translates into increased consumption from 69.1 to $73.2 \mathrm{~kg} /$ per capita for dairy and from 247 to $259 \mathrm{~kg} /$ per capita for meat, and an increase in exports of pork and poultry, up to 200000 and 400000 tonnes, respectively. estimated the maximum potential grain production in the Russian Federation at 126 million tonnes (EBRD-FAO, 2008). These estimates are based on the assumption that since the agroclimatic conditions in the Russian Federation are similar to those in Canada, the Russian Federation can increase its average yields from $1.86 \mathrm{t} / \mathrm{ha}$ (20082012) to the current level of yields in Canada (3.54 t/ha). Similarly, the Russian Institute for the Agrarian Market Studies has projected that in 2019, grain production in the Russian Federation will reach 125 million tonnes and grain export will be about 45-50 million tonnes (Schierhorn, et al., 2012). According to a projection by the Russian Federation's Ministry of Agriculture, by 2020, grain production could reach 120-130 million tonnes, which would allow export of 30 to 40 million tonnes of grain (Schierhorn et al., 2012). Perhaps the least convincing among these outlooks is the "Road Map of Agricultural Development in the Russian Federation by 2020" published by Babkin (2013), which projects a 214 percent increase in grain production from 2011 to 2020, up to 295.6 million tonnes, which would require a 13.5 percent annual growth in grain production.

We have developed more realistic growth projections, taking into account changes in management practices and technology, as well as the changes of climate in the main agricultural regions of the Central Eurasian grain belt.

One simple, albeit frequently used, approach to estimating future yields employs a linear 
regression model with climate parameters (usually temperature and precipitation) as predictors, assuming other parameters to be constant (e.g. Lobell et al., 2009). The next step would be to analyse time series, attempting to explain the observed long-term yield trends with the change in technology and management practices and shortterm variations with climate.

Historically, the long-term rate of grain yield increase has demonstrated surprisingly little variability. To the best of our knowledge, Obukhov (1927) was the first to publish a statistical analysis of the historical trends of yields in the Russian Federation. Obukhov computed the linear trend for six different crops based on the 1883-1914 yield statistics, estimating a 1.1 percent annual yield increase (8 kg/ha) with the "yield norm" (potential yield not accounting for weather variability) of 0.57 t/ha in 1883 and 0.82 t/ha in 1914. Another study of the historical change in yield (Wheatcroft, 1977) analysed the 1885-1940 yield data and found a lower annual trend of 0.87 percent $(7 \mathrm{~kg} / \mathrm{ha})$, presumably due to significant agriculture fallback during the periods of World War I, Civil War, and experiments in economics in the 1920s. Dronin and Kirilenko (2013) applied the same approach to analyse the 1958-2010 grain crops and found a 1.15 percent annual increase trend $(1.6 \mathrm{~kg} / \mathrm{ha})$. Similarly, despite drastic changes in economics, the 1980-2010 yields demonstrate a 1.15 percent increase on average.

While the twentieth century's long-term trend in yield can be explained by technological changes, a future scenario of grain balance should also take climate change into account. We have already described the potential future reduction in yield, mainly due to restricted water availability. Combined with a realistic rate of yield increase attributable to technological changes, however, higher yields can be projected. For example, a 6 percent decrease in potential grain yield in the Russian Federation in the 2020s due to climate change (Alcamo et al,. 2007), combined with a 1.15 percent agrotechnological yield increase trend (Dronin and Kirilenko 2013) would result in a 35 percent yield increase over the 1980s-2020s period.
For the purpose of this study we have accepted the historical yield trend as a conservative estimate of future yield growth in the Russian Federation and suggest the following three scenarios of future yield growth due to changes in technology and management:

I. Federal Program projection: 2.5 percent annual yield growth.

II. Historical Trend ("business as usual"): 1.15 percent annual yield growth.

III. Historical Trend Plus Climate: 1.15 percent annual yield growth plus climate change.

Table 9 shows the current (2008-2010) and future (2020) grain balance for the Russian Federation according to these three scenarios. The Federal Program projections show a significant increase in the amount of extra grain after meeting the requirements of human consumption, livestock and industry, indicating a surplus which can be exported. However, even projections under the conservative Historical Trend scenario indicate that a significant amount of grain can be exported.

While the cereal production in the Russian Federation, Ukraine and Kazakhstan is projected to increase, domestic demands are likely to grow at a much slower rate (see Tables 9-11). Populations of all three countries are projected to decline and the regional per capita incomes are expected to continue growing, with consumer diets shifting away from cereals. With appropriate policies, this combination of rising prices and demand on the international market and moderate domestic demand is likely to benefit export opportunities for the Russian Federation, Ukraine and Kazakhstan.

On the other hand, when the impact of climate change is taken into account, meeting the Federal Program goals of increasing meat production is possible only if grain exports are reduced more than 50 percent. However, we suggest that even the 2008-2012 rates of meat production are not sustainable. First, the most successful sector, poultry production, has already approached the level of demand (3.8 million tonnes - cf. 3.2 million tonnes produced in 2010). The increase in poultry 


\section{table 9}

Current (2008-2010) and future (2020) grain balance (million tonnes) for Russian Federation, according to the Federal Program (I), Historical Trend (II) and Historical Trend Plus Climate scenarios (III)

\begin{tabular}{lrrrr}
\hline Item & $\mathbf{2 0 0 8 - 2 0 1 0}$ & \multicolumn{2}{c}{ 2020 scenarios } & III \\
\cline { 3 - 5 } & & I & II & 10.8 \\
\hline Beginning stocks & 13.8 & 13.9 & 99.0 & -93 \\
\hline Production & 88.4 & 115 & 0.4 & 0.4 \\
\hline Import & 1.6 & 0.4 & 113.2 & $102.2-105.2$ \\
\hline Total production & 103.8 & 129.2 & 26.0 & 26.0 \\
\hline Food and industry & 24.7 & 26.0 & 12.0 & 12.0 \\
\hline Seeds & 11.8 & 12.0 & 42.0 & 42.0 \\
\hline Feed & 35.6 & 42.0 & 80.0 & 80.0 \\
\hline Total consumption & 72.1 & 80.0 & 33.2 & $22.2-25.2$ \\
\hline Production-consumption & 31.7 & 49.2 & 14.0 & $2.9-5.9$ \\
\hline Export & 16.0 & 30.0 & 8.5 & 8.5 \\
\hline Intervention fund & 7.2 & 8.5 & 10.8 & 10.8 \\
\hline Ending stocks & 8.5 & 10.8 & & 90 \\
\hline
\end{tabular}

Notes: The 2020 grain production (115 million tonnes), export (30 million tonnes), intervention fund (8.5 million tonnes) and grain imports ( 0.3 percent from the grain production and stocks) are based on the Federal Program of Agricultural Development and Regulation of Markets for Agricultural Produce, Raw Materials, and Food for 2013-2020 (Gosudarstvennaya programma razvitiya... 2012). The current grain production in the table (88.4 million tonnes) is based on the 2008-2010 mean, which is slightly higher than the current grain production (85.2 million tonnes) in the Federal Program. The estimates of food, feed, seeds and industry requirements are found in several Russian sources (see, for example, Altukhov, 2013). The size of ending stocks for Russia is recommended to be 10.8-10.9 million tonnes with 50 percent reliability and 13.4-13.7 million tonnes with 60 percent reliability (Altukhov, 2013).

production is thus possible only for export, but this option is limited due to competition from the United States and other countries, where cheaper corn is used for feed compared with more expensive wheat used in the Russian Federation (Welton, 2011). Domestic protection measures will be effective only in the case of poultry, while pork and beef production will meet higher competition with imports since the Russian Federation joined the World Trade Organization (WTO) in 2012 (Kiselev, 2013). Currently, the agricultural protectionist policies are based on veterinary standards, but after they are lifted, some experts in the Russian Federation warn that an unprecedented volume of pork imports will immediately enter the Russian market. ${ }^{6}$ While the Federal Program aims to

6 http://chickeninfo.ru/perspectivnoe_zhivotnovodstvo/ ptitsevodstvo-segodnya/hvatit-li-rossiyanam-myasa-- increase both beef and milk production, this is a very challenging task due to limited availability of fodder and increasing competition with imports of meat from Brazil, Argentina and Uruguay, which are currently the main beef exporters to the Russian Federation. With a limit on trade-distorting support and without the ability to raise customs duties above bound levels, the Russian Federation is likely to depend on beef imports for a long period to come (Kiselev and Romashkin, 2012).

Accession to the WTO will therefore not allow the Russian Federation to implement its policy of substituting relatively low-cost beef imports with domestic beef production. This will have a positive influence on grain exports. Grain export and livestock breeding are competitors, and success 
in grain exports does not automatically lead to an increase in meat production. If there is a choice between exporting grain or allocating it for the livestock sector (i.e. poultry), the former option has the advantage because of the attractiveness of earning hard currency. ${ }^{7}$ We suggest that the demand for feedgrain will increase at a slower rate, compared with the Federal Program's goals, leaving more grain for export. A recent report on agriculture in the Russian Federation by Salputra et al. (2013) used an econometric model to suggest similar projections for 2020-2025. These included: a decrease in beef production with a corresponding increase in imports to meet growing demand; an increased import of pork to address the gap between the fast growth of demand and slow growth of production; and a fast growth of poultry production, exceeding the internal demand. While the authors concluded that the Russian Federation will retain its position as a grain exporter, they also predicted a conservative increase in grain yields combined with some contraction in the area under cereals in favour of more profitable sunflower production (Salputra et al., 2013). The Federal Program's predicted demand for feedgrain is based on the assumption of further improvement of productivity of the livestock sector. The Program suggests that, if approximately 3.6 tonnes of grain was needed in 2008-2011 for production of 1 tonne of meat (live weight), then in the 2020s only 3 tonnes of grain would be required to produce 1 tonne of meat. (Altukhov, 2013).

During the past 20 years, Ukraine and Kazakhstan have both demonstrated very similar changing trends in agricultural production and exports, comparable to those occurring in the Russian Federation. Therefore, we assume that the scenarios formulated for the Russian Federation

7 For example, in 2012, the Russian Federation enjoyed good harvest of cereals (71 million tonnes) but an article in a Russian newspaper "Nezavisimaya" ("Independent") from 7 November 2012 stated that the chairman of the flour milling union of the Russian Federation had warned about a possible deficit of grain in spring of 2013 because of excessive export of grain in autumn of 2012 . may also be valid for Ukraine and Kazakhstan. The initial 1990s policies of price liberalization and privatization were followed by a chronic deep crisis in agriculture. In the early 2000s, a huge increase in government support and the emergence of large, vertically integrated agro-industrial holdings led to a rapid agriculture recovery, but evidence indicates that in recent years, grain surplus was achieved mainly as a result of favourable weather and low internal demand for feedgrain. Thus, both Ukraine and Kazakhstan seek their fortunes by boosting grain export; however, this is limited by the current state of infrastructure. Nevertheless, both countries have ambitious goals of becoming major world grain exporters, while reaching selfsufficiency in meat production (Programma po razvitiju agropromyshlennogo...2012).

The targets for 2020 s grain production in both countries are based on the maximum potential productivity for a given climate. For example, the EBRD-FAO (2008) estimates that grain yields in Ukraine could increase from $2.6 \mathrm{t} / \mathrm{ha}$ to $7.0 \mathrm{t} / \mathrm{ha}$ (thus attaining the level of yields in France), while the Ukrainian officials call for achieving 90 percent of West European yield levels by 2020. ${ }^{8}$ Similarly, according to the EBRD maximum potential scenario, Kazakhstan's yields can increase to the level of Australia's, from $1.16 \mathrm{t} /$ ha to $1.9 \mathrm{t} / \mathrm{ha}$. Note that EBRD-FAO projections were intended only to demonstrate full agro-ecological potential of the region, without taking into consideration other factors. In addition, none of these outlooks takes into account the impacts of climate change.

For Ukraine, annual production of 72 million tonnes of grain would require 4.6 percent annual growth; however, the historical trend has been 1.35 percent. Similarly, the EBRD projections for Kazakhstan would require a 4.5 percent annual grain yield growth, but the yield trends in the arid steppes of Eurasia have not exceeded

8 According to Nikolay Prisyazhnuk, the Minister of Agricultural Policy and Food: "Reaching the level of 90 percent of the yield of developed countries, while keeping the existing area, will provide an additional 30 million tonnes of production." http://www.proagro. com.ua/news/ukr/4081864.html 


\section{table 10}

Current (2008-2010) and future (2020) grain balance (million tonnes) for Ukraine, according to the Federal Program (I), Historical Trend (II) and Historical Trend Plus Climate scenarios (III)

\begin{tabular}{|c|c|c|c|c|}
\hline \multirow[t]{2}{*}{ Item } & \multirow[t]{2}{*}{$2009-2011$} & \multicolumn{3}{|c|}{2020 scenarios } \\
\hline & & I & II & III \\
\hline Beginning stocks & 4.5 & 5.6 & 5.6 & 5.6 \\
\hline Production & 46.0 & 72.0 & 52.6 & $41.3-45.2$ \\
\hline Import & 0.1 & 0.1 & 0.1 & 0.1 \\
\hline Total production & 50.6 & 77.7 & 58.3 & $46.9-50.9$ \\
\hline Food & 6.4 & 6.0 & 6.0 & 6.0 \\
\hline Seeds & 4.0 & 4.0 & 4.0 & 4.0 \\
\hline Feed & 15.1 & 18.0 & 18.0 & 18.0 \\
\hline Total consumption & 25.5 & 28.0 & 28.0 & 28.0 \\
\hline Production/consumption & 25.1 & 49.7 & 30.3 & $18.9-22.9$ \\
\hline Export & 18.8 & 41.0 & 21,6 & $10.2-14.2$ \\
\hline Intervention fund & - & 3.1 & 3.1 & 3.1 \\
\hline Ending stocks & 6.3 & 5.6 & 5.6 & 5.6 \\
\hline
\end{tabular}

Notes: The 2020 grain production (72.0 million tonnes) and export (41.0 million tonnes or more) are frequently cited by Ukrainian media with a reference to the Ministry of Agricultural Development and Food. On the consumption side, foodgrain demand is declining from 46 to 43 million tonnes due to projected decline of Ukrainian population. Grain for seeds estimates are based on 0.27 t/ha average seed requirements for Russia (Altukhov, 2013). It is likely that the sown area under cereals will not change significantly in Ukraine. In any case, Ukrainian officials have called on farmers to keep the sown area under grain. * We expect some growth in feed demand because of an existing trend for increase of meat production. Since no official projection for 2020 feed demand is available, we calculate feed requirements from total internal consumption demand for grain (28 million tonnes), food (6 million tonnes) and seeds (4 million tonnes). The internal consumption of grain at 28 million tonnes is believed to guarantee food security of Ukraine (Rynok zenovyh 2013). Estimate of grain reserve reaching 5.6 million tonnes is based on FAO's recommendation to reserve at least 20 percent of annual grain consumption (Rau, 2012).

* http://news.mail.ru/inworld/ukraina/ua_center/109/economics/15594169/

0.48 percent during the past 60 years. Due to the lack of grain production statistics at the regional (subnational) level for Ukraine and Kazakhstan prior to 1991, we have calculated historical trends for these countries using analogous data from the adjacent parts of the Russian Federation. For Ukraine we used data for the Central Black Earth region and North Caucasus. For Kazakhstan, the closest analogy is the southern fringe of Western Siberia. The scenarios of future grain balances of Ukraine and Kazakhstan are summarized in Tables 9 and 10. The official 2020 goals (scenario I) are unlikely to be achievable, as they assume a much higher than historical rate of annual yield growth. Meanwhile, a conservative scenario (scenario II) still indicates a sizable grain surplus, which is comparable to current volumes of grain export, while meeting internal feed demand compatible with the goals for increased meat production. However, meeting the goals for expanded grain export is possible only through reductions in meat production.

Combined with climate change (scenario III), the conservative scenario (scenario II) discussed above becomes less plausible. Reduction to below the current grain yield level will lead to intensified competition between grain exports and meat production. By the 2020s, the world cereal trade is projected to increase 17 percent, to 328 million tonnes (OECD/FAO 2011). The official targets for 
grain production and exports show the RUK region (the Russian Federation, Ukraine and Kazakhstan) supplying close to 30 percent of all grain exports (Table 11), justifying the idea of developing the RUK Grain Pool, first announced in 2009 and still being considered by the parties. However, the conservative scenario II would reduce the RUK share of exports to 12 percent, which is close to the current state, and taking climate change into account would further diminish it to merely 6 percent. Slow growth (in the Russian Federation) or stagnation (in Ukraine and Kazakhstan) of grain production combined with high variability of yields in future climate would reduce the prospects of the RUK Grain Pool countries to influence the world grain market.

\section{Conclusions}

The Russian Federation, Ukraine and Kazakhstan have become leading producers and exporters of grain, particularly wheat. Projections by several national and international agencies (Table 8) suggest that within the next few years these three countries together are very likely to surpass the European Union and the United States in terms of total grain exports and wheat exports. However, estimates of different agencies differ greatly from each other. For example, the United States Department of Agriculture (USDA) projects that, by 2021, total grain and wheat exports from the Russian Federation and Ukraine will rise by 93 percent and 76 percent, respectively, relative to average annual volumes during 2006-2010, and that this region would supply 22 percent of the world's total grain exports and 29 percent of wheat exports (Liefert et al., 2013). In contrast, the outlook by the Food and Agricultural Policy Research Institute - lowa State University (FAPRIISU) (2010) projects much slower growth of grain production and exports for this region.

These outlooks and scenarios are generally based on extension of the recent export and production trends, as well as several assumptions made by various authors, such as favourable weather conditions, benefits of climate change, improvement of agricultural policies, continuous improvement of management techniques and infrastructure and the possibility of recultivating previously abandoned arable lands. Given the many uncertainties about these factors, such assumptionbased projections need to be treated with caution.

The recent growth of exports from these three countries has been driven primarily by three factors: a) favourable temperature and precipitation regimes in 2002-2009, compared with the previous ten years (Liefert et al., 2009b; 2013); b) grain surplus caused by the relatively low domestic demand for grain; and c) significant increase of investments in agriculture and increase of agricultural subsidies, resulting in the growth in productivity in grain and livestock production in the second part of the period (2010-2012).

Comparison of production and export trends, however, also clearly indicates that high grain exports from the Russian Federation, Ukraine and Kazakhstan have been driven primarily by low domestic demand rather than significant increase in productivity. Future recultivation of the abandoned arable lands remains uncertain and unlikely, given that most of the marginal land abandoned in the 1990s had very low potential productivity.

A sequence of years with favourable weather conditions (2002-2009) was followed by severe droughts in 2010-2012. Total grain production by the Russian Federation, Ukraine and Kazakhstan dropped from the record high 174 million tonnes in 2008 to the meager 110 million tonnes in 2010 and 130 million tonnes in 2012, due to the persistent drought. Such short-term weatherrelated fluctuations do not provide any valid base for production scenarios and need to be viewed in a much longer-term context of climatic variability and trends.

Agro-ecological projections driven by climate change scenarios suggest that the grain production potential in the Russian Federation, Ukraine and Kazakhstan may increase due to a combination of winter temperature increase, extension of the growing season, and $\mathrm{CO}_{2}$ fertilization effect on agricultural crops; however, 


\section{table 11}

Current (2008-2010) and future (2020) grain balance (million tonnes) for Kazakhstan, according to the Federal Program (I), Historical Trend (II) and Historical Trend Plus Climate scenarios (III)

\begin{tabular}{lcccc}
\hline Item & $\mathbf{2 0 0 6 - 2 0 0 9}$ & \multicolumn{2}{c}{ 2020 scenarios } & III \\
\cline { 3 - 5 } & & I & II & 13.0 \\
\hline Beginning stocks & 11.3 & 13.0 & $19.0^{*}$ & $14.1-18.4$ \\
\hline Production & 18.3 & 28.0 & 0.1 & 0.1 \\
\hline Import & 0.1 & 0.1 & 35.1 & $27.2-31.4$ \\
\hline Total production & 29.7 & 41.1 & 5.7 & 5.7 \\
\hline Food and industry & $4.4+0,4$ & 5.7 & 2.6 & 2.6 \\
\hline Seeds & 2.7 & 2.6 & 6.0 & 6.0 \\
\hline Feed & 3.5 & 6.0 & 0.6 & 0.6 \\
\hline Losses & 0.6 & 0.6 & 14.9 & 14.9 \\
\hline Total consumption & 11.6 & 14.9 & 20.2 & $13.9-16.5$ \\
\hline Production-consumption & 18.1 & 26.2 & 7.2 & $0.9-3.5$ \\
\hline Export & 4.9 & 13.2 & 13.0 & 13.0 \\
\hline Ending stocks & 12.9 & 13.0 & & 13.0 \\
\hline
\end{tabular}

Notes: In contrast to Ukraine and Russia, Kazakhstan has not published its 2020 grain production goals. Since Scenario I is based on the EBRD-FAO (2008) maximum potential production of grain using the climate analogue method, we calculated yield increase based on mean yields in Australia, from 1.16 t/ha to 1.9 t/ha by 2016 . On the consumption side, we estimated that the demand for foodgrain will increase by 20 percent following population growth from 15.6 million in 2008 to 18.7 million in 2020. The 2013-2020 Kazakhstan Agricultural Program calls for a reduction in area under cereals in favour of forage and technical crops. However, this crop replacement has had a slow start, with no more than 2-3 percent reduction in area under cereals last year (Moldashev, 2013). The Program also projects an increase in internal demand for each category of meat (beef, lamb, horsemeat, and broiler chicken), targeting self-sufficiency in meat consumption and an increase in beef exports of 150 thousand tonnes by 2020. Total meat production is projected to increase by 71 percent, from 0.7 million tonnes in 2009 to 1.2 million tonnes in 2020, with corresponding increase in feedgrain demand (Programma po razvitiju.. 2012).

\section{table 12}

Current (2008-2010) and future (2020) grain export (million tonnes) in Russia, Ukraine and Kazakhstan, according to the official goals (I), Historical Trend (II) and Historical Trend Plus Climate scenarios (III). Note that model projections for (III) are given for SRES A2 and B2; compare with Tables 9, 10, and 11, where a range is given for model projections

\begin{tabular}{|c|c|c|c|c|c|}
\hline \multirow[t]{3}{*}{ Country } & \multirow[t]{3}{*}{ 2008-2010 } & \multicolumn{4}{|c|}{2020 scenarios } \\
\hline & & \multirow[t]{2}{*}{ I } & \multirow[t]{2}{*}{ II } & \multicolumn{2}{|c|}{ III } \\
\hline & & & & SRES/B2 & SRES/A2 \\
\hline Russia & 16.0 & 30.0 & 10.9 & 2.9 & 5.9 \\
\hline Ukraine & 18.8 & 41.0 & 21.6 & 14.2 & 10.2 \\
\hline Kazakhstan & 4.9 & 13.2 & 7.2 & 0.9 & 3.5 \\
\hline Total export & 39.7 & 84.2 & 39.7 & 18.0 & 19.6 \\
\hline
\end{tabular}


the most productive semi-arid zone could suffer a dramatic increase in drought frequency. In view of these projections, further research is needed to evaluate vulnerability of grain production to future climate change and to determine suitable adaptation measures. If projected climatic changes are slow enough that adaptations to the new climatic conditions can go along with the normal cycle of equipment replacement, the costs of adaptations might be relatively low. These responses include selection of new cultivars, introduction of new crops, early planting, changes in crop mixture and crop rotation, change in land and water management practices, new pest and disease control techniques, etc. However, if climate change is accelerated, as projected by GCMs for this century, reactive adaptations may carry much higher costs and planned adaptations may be required (Dronin and Kirilenko, 2011).

The following sources of uncertainty need to be further examined in order to produce more reliable grain production outlooks:

- Level of uncertainty associated with climate change scenarios.

- Lack of regional data on $\mathrm{CO}_{2}$ fertilization effect on crops and their water-use efficiency.

- Errors associated with land statistics and uncertainties associated with land cover trends derived from satellite imagery.

- Impacts of proposed recultivation of previously abandoned marginal lands on future greenhouse gas emissions, considering that recultivation would decrease current levels of carbon sequestration.

- Uncertainties associated with future political, social and economic changes in the RUK countries and their future agricultural policies.

- Uncertainties about the future development pathways of infrastructure, financial systems, land market development and future alignment between WTO requirements and agricultural subsidies.

Development of effective and sustainable food-production strategies in the Russian
Federation, Ukraine and Kazakhstan requires further basic, applied and translational research in several areas:

- More accurate modelling of climate change and its impacts on water resources and agroecological systems at the regional scale.

- FACE and laboratory experiments to improve understanding of $\mathrm{CO}_{2}$ fertilization on agricultural crops.

- Modelling of probability and frequency of extreme events, such as droughts, heat waves, wildfires, frosts and floods;

- Modelling human vulnerability and adaptations to climate change.

- Research on how adaptation measures can be incorporated into ongoing activities such as land-use planning, water resource management, drought and heat wave early warning and diversification of agriculture.

Our analysis shows that the ambitious goals of boosting grain and meat production by the 2020s, recently articulated by the governments of the three countries, are unlikely to be accomplished. However, the overall outlook is optimistic. The conservative "business as usual" scenario and the model GCM-based projections all indicate that the Russian Federation, Ukraine and Kazakhstan will be able to increase their meat production while maintaining grain production surplus similar to the current level.

\section{References}

Adams, R., B. Hurd, S. Lenhart, \& N. Leary, 1998. Effects of global climate change on agriculture: an interpretative review. Climate Research 11: 1930.

Alcamo, J., N. Dronin, M. Endejan, G. Golubev \& A. Kirilenko. 2007. A new assessment of climate change impacts on food production shortfalls and water availability in Russia. Global Environmental Change 1 (3 4): 429-444. 
Altukhov, A. 2013. Ustojchivost' zernovogo khozyajstva i rynka zerna - osnova ikh razvitiya. Kheloprodukty, 2013, № 9. pp. 4-10. In Russian: Алтухов А.И. 2013. Устойчивость зернового хозяйства и рынка зерна - основа их развития. Хлебопродукты, № 9. С. 4-10.

Antle, J., S. Capalbo, E. Elliott \& K. Paustian. 2004. Adaptation, spatial heterogeneity, and the vulnerability of agricultural systems to climate change and $\mathrm{CO}_{2}$ fertilization: an integrated assessment approach. Climatic Change 64(3): 289-315.

Babkin, K. 2013. Dorozhnaya karta razvitiya sel'skogo khozyajstva Rossii do 2020 goda (Road map of development of agriculture in Russia to 2020). Moskovskij ekonomicheskij forum, 20-21 marta 2013.

Borodin, K., M. Prokopiev \& A. Strokov. 2013. In Russian: Бородин К.Г., Прокопьев М.Г., Строков A.С. Оценка перспектив развития отечественного рынка мяса птицы в условиях присоединения России к ВТО. Проблемы прогнозирования, 2013, № 2. C.68-75.

Bogaert, J., L. Zhou, C. Tucker, R. Myneni \& R. Ceulemans. 2002. Evidence for a persistent and extensive greening trend in Eurasia inferred from satellite vegetation index data. Journal of Geophysical Research 107, (D11), 10.1029/2001JD001075, 2002.

Brock, G., M. Grazhdaninova, Z. Lerman \& V. Uzun. 2008. Technical efficiency in Russian agriculture. In: Lerman, Z. and Lanham, M.D., eds. Russia's agriculture in transition. Lexington Books. pp. 353-372.

Caldwell, C., S. Britz \& R. Mirecki. 2005. Effect of temperature, elevated carbon dioxide, and drought during seed development on the isoflavone content of dwarf soybean [Glycine max (L.) Merrill] grown in controlled environments. Journal of Agricultural and Food Chemistry 53: 1125-1129.
Carter, T., M. Parry, \& J. Porter. 1991. Climatic change and future agroclimatic potential in Europe. International Journal of Climatology 11(3): 251-269.

Csaki, C. \& Z. Lerman. 1997. Land reform and farm restructuring in East Central Europe and CIS in the 1990s: Expectations and achievements after the first five years. European Review of Agricultural Economics 24(3-4): 428-452.

de Beurs, K. \& G. Henebry. 2004. Land surface phenology, climatic variation, and institutional change: Analyzing agricultural land cover change in Kazakhstan. Remote Sensing of Environment 89(4): 497-509.

de Beurs, K. \& G. Henebry. 2008. Northern Annular Mode effects on the land surface phenologies of Northern Eurasia. Journal of Climate 21: 4257 4279.

Dole, R., M. Hoerling, J. Perlwitz, J. Eischeid, P. Pegion, T. Zhang, X-W. Quan, T. Xu \& D. Murray. 2011. Was there a basis for anticipating the 2010 Russian heat wave? Geophysical Research Letters 38: 10.1029/2010GL046582.

Dronin, N. \& E. Bellinger. 2005. Climate dependence and food problems in Russia (19001990). The interaction of climate and agricultural policy and their effect on food problems. CEU Press, Budapest-New York, 366 p.

Dronin, N. \& A. Kirilenko. 2008. Climate change and food stress in Russia: what if the market transforms as it did during the past century? Climatic Change 86: 123-150.

2010. Climate change, food stress, and security in Russia. Regional Environmental Change 11(1): 167-178.

2013. Weathering the Soviet Countryside: The Impact of Climate and Agricultural Policies on Russian Grain Yields, 1958 
2010. The Soviet and Post-Soviet Review 40(1): 115143.

Easterling, W., P. Aggarwal, P. Batima, K. Brander, L. Erda, S. Howden, A. Kirilenko, J. Morton, J-F. Soussana, J. Schmidhuber \& F. Tubiello. 2007: Food, fiber and forest products. In Parry, M.L., Canziani, O.F., Palutikof, J.P., van der Linden, P.J. \& Hanson, C.E., eds., Climate Change 2007: Impacts, Adaptation and Vulnerability. Contribution of Working Group II to the Fourth Assessment Report of the Intergovernmental Panel on Climate Change, Cambridge University Press, Cambridge, UK, 273-313.

EBRD-FAO, 2008. Grain production and export potential in CIS countries. Fighting food inflation through sustainable investment. European Bank for Reconstruction and Development/ Food and Agriculture Organization, London, 8 p.

FAOSTAT, 2013. Food and Agriculture Organization Statistics. http://www.fao.faostat.org, last access December 2013.

Fisher G., M. Shah \& H. van Velthuizen. 2002. Climate Change and Agricultural Vulnerability. International Institute for Applied Systems Analysis, Vienna, $152 \mathrm{p}$.

Fischer G., M. Shah, F. Tubiello \& H. van Velhuizen. 2005. Socio-economic and climate change impact on agriculture: an integrated assessment, 19902080. Philosophical Transactions of Royal Society B 360: 2067-2083.

Jones, J., G. Hoogenboom, C. Porter, K. Boote, W. Batchelor, L. Hunt, P. Wilkens, U. Singh, A. Gijsman \& J. Ritchie. 2003. DSSAT Cropping System Model. European Journal of Agronomy 18: 235-265.

Gassman, P., J. Williams, X. Wang, A. Saleh, E. Osei, L. Hauck, R. Izaurralde \& J. Flowers. 2010. Policy Environmental EXtender (APEX) Model: An Emerging Tool for Landscape and Watershed
Environmental Analyses. Transactions of the ASABE 53(3): 711740.

Golubev, G. \& N. Dronin. 2004. Geography of droughts and food problems in Russia (1900 2000). Report of the international project on global environmental change and its threat to food and water security in Russia. Center for Environmental Systems Research, Kassel.

Gosudarstvennaya programma razvitiya.., 2012, in Russian: Государственная программа развития сельского хозяйства и регулирования рынков сельскохозяйственной продукции, сырья и продовольствия на 2013 - 2020 годы. М.: Минво сельского хозяйства Российской Федерации, 2012. 204 c. (The Federal Program of Agricultural Development and Regulation of Markets for Agricultural Produce, Raw Materials, and Food for 2013-2020), Moscow, 2012.

Gruza, G., E. Rankova, M. Bardin, et al. 1999. In Russian: Груза Г.В., Ранкова Е.Я., Бардин М.Ю., Рочева Е.В., Платова Т.В. Самохина О.Ф., Соколов Ю.Ю. Рачкулик О. Изменения климата 1998. Обзор состояния и тенденции изменения климата России. Институт глобального климата и экологии. М., 1999.

Linderholm, H. 2006. Growing season changes in the last century. Agricultural and Forest Meteorology 137(1 2): 1-14.

IKAR 2013: Institute for Agricultural Market Studies, Russia. http://www.ikar.ru/eng/, last access December 2013.

loffe, G., T. Nefedova \& K. de Beurs. 2012. Land abandonment in Russia: the case of two oblasts. Eurasian Geogr Econ 53(4): 527-549. doi:10.2747/1539-7216.53.4.527.

Kariyeva, J. 2010. Land Surface Phenological Responses to Land Use and Climate Variation in a Changing Central Asia. Dissertation, University of Arizona, Tucson, AZ. 
Kariyeva, J. \& W. van Leewuven. 2011.

Environmental Drivers of NDVI-Based Vegetation Phenology in Central Asia. Remote Sensing 3(2): 203-246; doi:10.3390/rs3020203.

Kiselev, S. \& R. Romashkin. 2012. Possible Effects of Russia's WTO Accession on Agricultural Trade and Production; ICTSD Programme on Agricultural Trade and Sustainable Development; Issue Paper No. 40; International Centre for Trade and Sustainable Development, Geneva, Switzerland, www.ictsd.org.

Kiselev, S. 2013. In Russian: Киселев С. Влияние вступления в ВТО на сельское хозяйство и продовольственный сектор в России. ФАО Региональное бюро по Европе Центральной Азии. 2013 Июль.

Khomyakov, P., V. Kuznetsov \& V. Konyshev. 2001. In Russian: Хомяков П.М., Кузнецов В.И, Конышев В.Н. Влияние глобальных изменений климата на функционирование экономики и здоровье населения России. М.: Ленадат, 2001, 424 с.

Liefert, W., O. Liefert, \& M. Shane. 2009a. Russia's Growing Agricultural Imports: Causes and Outlook. Outlook Report No WRS-09-04, Washington, DC, Economic Research Service, USDA. http://www. ers.usda.gov/Publications/WRS0904/.

Liefert, W., O. Liefert, \& E. Serova. 2009b. Russia's transition to major player in world agricultural markets. Choices 24(2): 1.

Liefert, O., W. Liefert \& E. Luebehusen. 2013. Rising Grain Exports by the Former Soviet Union Region. Causes and Outlook. A Report from the Economic Research Service, USDA, February 2013, WHS-13A-01, February 2013, www.ers. usda.gov.

Lioubimtseva, E., 2007. Possible changes in the carbon budget of arid and semi-arid Central Asia inferred from land-use/landcover analyses during 1981-2001. In Lal, R., Suleimenov, M.,
Stewart, B.A., Hansen, D.O. \& Doraiswami, P., eds. Climate Change and Terrestrial Carbon Sequestration in Central Asia, Taylor \& Francis, London, pp.441-451.

Lioubimtseva, E. \& G. Henebry. 2009. Climate and environmental change in arid Central Asia: Impacts, vulnerability, and adaptations. Journal of Arid Environments 73(11): 963977.

Lioubimtseva, E. 2010. Global food security and grain production trends in Central Eurasia: do models predict a new window of opportunity? National Social Science Journal 41(1): 154-165.

Lioubimtseva, E. \& G. Henebry. 2012. Grain production trends in Russia, Ukraine and Kazakhstan: new opportunities in increasingly unstable world? Frontiers of Earth Science 6(2): 157-166. doi:10.1007/s11707-012-0318-y.

Lioubimtseva, E., K. de Beurs \& G. Henebry. 2013. Grain production trends in Russia, Ukraine and Kazakhstan in the context of the global climate variability and change. In Younos, T. \& Grady, C.A., eds., Climate Change and Water Resources, The Handbook of Environmental Chemistry. Vol. 25, 2013, XVIII, 221 p. Berlin, Heidelberg: Springer.

Lobell, D. \& M. Burke. 2010. On the use of statistical models to predict crop yield responses to climate change. Agricultural and Forest Meteorology 150 (11): 1443-1452.

Lobell, D. 2009. Crop Responses to Climate: Time-Series Models. Crop Response to Climate: Ecophysiological Models. In Lobell, D.B. \& Burke, M.B., eds., Climate Change and Food Security: Adapting Agriculture to a Warmer World, Springer.

Lobell, D., M. Burke, C. Tebaldi, M. Mastrandrea, W. Falcon \& R. Naylor. 2008. Prioritizing Climate Change Adaptation Needs for Food Security in 2030. Science 319(5863): 607-610. 
Long S., E. Ainsworth, A. Leakey, J. Nösberger \& D. Ort. 2006. Food for thought: lower-thanexpected crop yield stimulation with rising $\mathrm{CO}_{2}$ Concentrations. Science 312: 1918-1921.

Long, S., E. Ainsworth, A. Leakey \& P. Morgan. 2005. Global food insecurity. Treatment of major food crops with elevated carbon dioxide or ozone under large-scale fully open-air conditions suggests recent models may have overestimated future yields. Philosophical Transactions of the Royal Society B: Biological Sciences, 360(1463): 2011-2020.

Luo, Y., B. Su, W. Currie, J. Dukes, A. Finzi, U. Hartwig \& C. Field. 2004. Progressive nitrogen limitation of ecosystem responses to rising atmospheric carbon dioxide. Bioscience 54(8): 731-739.

Mendelsohn, R., W. Morison, M. Schlesinger \& N. Andronova. 2000. Country-specific market impact of climate change. Climatic Change 45(3-4): 553-569.

Menzel, A., T. Sparks, N. Estrella, E. Koch, A. Aasa, R. Ahas, K. Alm-Kublers, P. Bissoll, O. Braslavska, A. Briede, F. Chmielewski, Z. Crepinsek, Y. Curnel, A. Dahl, C. Defila, A. Donnelly, Y. Filella, K. Jatczak, F. Mage, A. Mestre, O. Nordli, J. Penuellas, P. Pirinen, V. Remisova, H. Scheifinger, M. Striz, A. Suznik, A. van Vliet, F. Wielgolaski, S. Zach \& A. Zust. 2006. European phenological response to climate change matches the warming pattern. Global Change Biology 12(10): 1365-2486.

Miloserdov, V. 2006. In Russian: Милосердов В. В. Экономические интересы и отношения. Екатеринбург: Изд-во УралГСХА, 2006, 92 с.

Mitchell, T., M. Hulme \& M. New. 2002: Climate data for political areas. Area 34: 109-112.

Modashev, A. 2012. In Russian: Молдашев, А. Социально-экономические аспекты повышения эффективности развития АПК Казахстана //
Устойчивое развитие сельского хозяйства Беларуси в новых условиях : (материалы IX Международной научно-практической конференции 20 сентября 2012 г.) / Республиканское научное унитарное предприятие "Институт системных исследований в АПК Национальной академии наук Беларуси”. Минск, 2013. - С. 111-114 .

National Communication Russia, 2010. Russia's fifth national communication to the Conference of the Parties of the United Nations Framework Convention on Climate Change. Ministry of Environment Protection, Moscow, 2010.

National Communication Kazakhstan, 2009. Kazakhstan's third, fourth, and fifth national communication to the Conference of the Parties of the United Nations Framework Convention on Climate Change. Ministry of Environment Protection, Astana, 2009.

O hode y resultatah ... 2012, in Russian: О ходе и результатах реализации в 2011 году государственной программы развития сельского хозяйства и регулирования рынков сельскохозяйственной продукции, сырья и продовольствия на 2008-2012 годы. Москва: Министерство сельского хозяйства Российской Федерации. 2012. 203 с.

Obukhov, V.M.1927. Dvizhenie urozhaev zernovyx kul'tur v byvshej Evropejskoj Rosiii v period1883-1915 (Dynamic of cereals harvests in the former European Russia in 1883-1915). Vliyanie neurozhaev na narodnoe khozyajstvo Rossii (Impact of poor harvest on national economy). Pod red. (ed) V.G.Gromana. Moskva: Rossijskaya assotsiatsiya nauhcno-issledovatel'skix institutov obshhestvennyx nauk, 1927, part 1.2840. (http://istmat.info/node/21586).

OECD 2002. Agricultural policies in transition, Paris: Centre for Co-operation with Economies in Transition, Organization for Economic Co-operation and Development, Paris: OECD Publishing. 
OECD-FAO 2008. OECD-FAO Agricultural Outlook 2008 2017. Paris: OECD Publishing.

OECD-FAO 2011. OECD-FAO Agricultural Outlook 2011-2020. Paris: OECD Publishing.

Osborne, S. \& M. Trueblood. 2002. Agricultural productivity and efficiency in Russia and Ukraine: building on a decade of reform. Market and Trade Economics Division, Economics Research Services, USDA, Agricultural Economics Report No.813.

Parry, M., C. Rosenzweig, A. Iglesias, V. Livermore \& G. Fischer. 2004. Effects of climate change on global food production under SRES emissions and socio-economic scenarios. Global Environmental Change 14(1): 53-67 doi:10.1016/j. gloenvcha.2003.10.008.

Pegov, S., D. Khomyakov \& P. Khomyakov. 2000 Vliyanie global'nyh izmenenii klimata na social'noecomomicheskoye polozheniye Rossii (Global change impact on socio-economical processes in Russia). In Kotlyakov, V.M., ed., Global'nye i regional'nye izmenenija klimata i ikh prirodnye i social'noehkonomicheskie posledstvija (global and regional climate change and its environmental and socioeconomical impacts). GEOS, Moscow, pp 60-69 (in Russian).

Prishchepov, A., D. Müller, M. Dubinin, M. Baumann \& V. Radeloff. 2013. Determinants of agricultural land abandonment in post-Soviet European Russia, Land Use Policy 30: 873884.

Programma po razvitiju agropromyshlennogo kompleksa v Respublike Kazakhstan na 20132020 gody, 2012: In Russian: Программа по развитию агропромышленного комплекса в республике Казахстан на 2013-2020 годы (Агробизнес-2020). Астана, 2012, 98 с.

Prosterman, R., L. Rolfes \& J. Duncan Jr. 1999. A Vision for Agricultural Land Reform in Russia. In: Farm profitability, sustainability and restructuring in Russia. Proceedings of the Workshop Held in Golitsyno, Moscow Region 1-2 October 1999, pp.120-140.

Rabbinge, R. \& C. van Diepen. 2000. Changes in agriculture and land use in Europe. European Journal of Agronomy 13 (2-3): 85-100.

Ramankutty, N., A. Evan, C. Monfreda, \& J. Foley. 2008. Farming the planet: 1. Geographic distribution of global agricultural lands in the year 2000, Global Biogeochemical Cycles 22, GB1003, doi:10.1029/2007GB002952.

Rau, V. 2012. In Russian: Раy B.В. Зерновой рынок России: от кризиса к возрождению. Проблемы прогнозирования, ИНП РАН, 2012, 2, 76-87.

Rau, V. 2009. In Russian: Pay, В. В. Аграрный сектор: Риски и шансы посткризисного развития Проблемы прогнозирования. - 2009. - N 1. - С. . 97-106.

ROSSTAT 2013 Федеральная служба государственной статистики http://www.gks.ru/ wps/wcm/connect/rosstat_main/rosstat/ru/

Rozelle, S. \& J. Swinnen. 2007. Transition and Agriculture. California Agricultural Experiment Station. Working Paper No. 00-021, October, 2000.

Rosenzweig, C. \& F. Tubiello. 2007. Adaptation and mitigation strategies in agriculture: an analysis of potential synergies. Mitigation and Adaptation Strategies for Global Change 12: 855-873,

Rynok zernovyh.., 2013. In Russian: Рынок зерновых культур в Украине в 2011/2012 маркетинговом году http://www.eba.com.ua/static/ members_reviews/Kreston_Grain_3_2013_RUS.pdf

Salputra, G., M. van Leeuwen, P. Salamon, T. Fellmann, M. Banse \& O. von Ledebur. 2013. The agri-food sector in Russia: current situation and market outlook until 2025. In T. Fellmann, T., Nekhay, 
O. \& M'barek, R., eds., Luxembourg: Publications Office of the European Union, 2013, 73 pp.

Schierhorn, F., D. Muller, A. Prishchepov \& A. Balmann. 2012. Grain potentials on abandoned cropland in European Russia. Paper prepared for presentation at the Annual World Bank Conference on Land and Poverty, World Bank, Washington, D.C., 23-26 April 2012,

Sedik, D., S. Sotnikov \& D. Wiesmann. 2003. Food security in Russia. FAO Economic and Social Development Paper 153, FAO. Rome, 114 pp.

Serova, E. 2007. Vertical integration in Russian agriculture. In Swinnen, J., ed., Global supply chains, standards and the poor: How the globalization of food systems and standards affects rural development and poverty, Wallingford, England: CAB International: pp. 188-206,

Sirotenko, O., H. Abashina \& V. Pavlova. 1997. Sensitivity of the Russian agriculture to changes in climate, $\mathrm{CO}_{2}$ and tropospheric ozone concentrations and soil fertility. Climatic Change 36: 217-232,

Sirotenko, O., G. Gruza, E. Rankova, E. Abashina \& V. Pavlova. 2007. Modern Climate-Related Changes in Heat Supply, Moistening, and Productivity of the Agrosphere in Russia. Russian Meteorology and Hydrology 32(8): 538546.

Smelansky, I. 2003. Biodiversity of Agricultural Lands in Russia: Current State and Trends. In Ladonina, N., Y. Gorelova \& D. Chernyakhovsky, eds., 2003. Moscow: IUCN. 2003. 52 p.

Smith, S., T. Huxman, S. Zitzer, T. Charlet, D. Housman, J. Coleman, L. Fenstermaker, J. Seemann \& R. Nowak. 2000. Elevated $\mathrm{CO}_{2}$ increases productivity and invasive species success in an arid ecosystem. Nature 408: 79 82,

Spinoni, J., G. Naumann, H. Carrao, P. Barbosa \& J. Vogt. 2013. World drought frequency, duration, and severity for 19512010 . International Journal of Climatology, DOI: 10.1002/joc.3875,

Stolbovoi, V. \& I. McCallum. CD-ROM land resources of Russia. IIASA, Laxenburg, Austria, 2002,

Tebaldi, C., K. Hayhoe, J. Arblaster \& G. Meehl. 2006. Going to the extremes: an intercomparison of model-simulated historical and future changes in extreme events. Climate Change 79(3-4): 185-211 doi:10.1007/s10584-006-9051-4.

Tucker, C., W. Newcomb, S. Los \& S. Prince. 1991. Mean and inter-year variation of growingseason normalized difference vegetation index for the Sahel 1981-1989. International Journal of Remote Sensing 12: 1113-1115,

United Nations, Department of Economic and Social Affairs, Population Division 2013. World Population Prospects: The 2012 Revision, Key Findings and Advance Tables. Working Paper No. ESA/PNWP.227.

UniSIS 2013. Unified Interdepartmental Statistical Information System (UniSIS) - http://www.fedstat. ru, accessed November 2013,

Uzun, V. 2005. Large and small business in Russian agriculture: adaptation to market. Comparative Economic Studies 47: 85-100,

Uzun, V., N. Shaigda \& V. Saraikin. 2012. In Russian: Узун В.Я., Шагайда Н.И., Сарайкин В.А., Агрохолдинги России и их роль в производстве зерна. В Исследования по политике перехода сельского хозяйства, \#2, 2012, 33 с.

von Cramon-Taubadel, S. 2002. Land reform in Russia. Economic Systems 26: 179 183,

Weigand, C. 2011. Wheat import projections towards 2050. Arlington: US Wheat Associates.

Welton, G. 2011.The Impact of Russia's 2010 Grain Export Ban, Oxfam Research Report, June 2011. 
Wheatcroft, S.1977. The significance of climatic and weather change on Soviet agriculture (with particular reference to the 1920s and the 1930s). Discussion papers. Soviet Industrialization Project Series. \#11, $48 \mathrm{P}$.

Wright, C., K. de Beurs \& G. Henebry. 2012.

Combined analysis of land cover change and NDVI trends in the Northern Eurasian grain belt. Frontier of Earth Science 6(2): 177 187. doi:10.1007/ s11707-012-0327-x,

Zhou, L., C. Tucker, R. Kaufmann, D. Slayback, N. Shabanov \& R. Myneni. 2001. Variations in northern vegetation activity inferred from satellite data of vegetation index during 1981 to 1999. Journal of Geophysical Research 106: 2006920083,

Zogolva, E.1997. In Russian: Жоголева Е. Е. Разработка приоритетов аграрной политики России: Дис. ... д-ра эконом. наук. М., 1997, 257, 

chapter 8

1. Introduction

2. Model and data

3. Simulation design 250

4. Simulation results $\quad 252$

$\begin{array}{ll}\text { 5. Conclusions } & 260\end{array}$

$\begin{array}{ll}\text { References } & 261\end{array}$

Citation

Chang, C-C., H-L Lee and S-H Hsu. 2015. The potential impact of climate changeinduced sea level rise on the global rice market and food security, In: Climate change and food systems: global assessments and implications for food security and trade, Aziz Elbehri (editor). Food Agriculture Organization of the United Nations (FAO),

Rome, 2015. 


\section{chapter 8}

The potential impact of climate change-induced sea level rise on the global rice market and food security in Asia

\section{Ching-Cheng Chang1', Huey-Lin Lee², Shih-Hsun Hsu}

\section{main chapter messages}

- Climate change affects food security in Asia not only through supply shortfalls of rice from extreme temperatures, frequent flooding or droughts, but also through sea-level-rise induced cross-border impact from land endowment losses in the low-lying zones.

- Global simulation results suggest that Viet Nam is likely to be hardest hit in terms of the agricultural extent loss to sea level rise, as most of its paddy rice is cultivated in the Mekong Delta flood zone. Thai-grown rice would only be able to partially supplement the potential shortfall.

- Model results also reveal two spillover effects on the global staple market. First, the wheat sector in Asia would be adversely affected due to land competition arising from local demand to secure the rice crop. Second, wheat- and coarse grain-growing regions outside Asia would reap some benefit from improved trade opportunities.

- Although rice is relatively less traded across borders, loss of agricultural land to sea level rise would widen the gap between rice supply and demand of the rice-consuming countries. This suggests a need to establish safety nets of food security in Asia that can address the heightened impact of future climate change.

\footnotetext{
${ }^{1}$ Institute of Economics, Academia Sinica, Taipei, Taiwan

2 Department of Economics, National Chengchi University, Taipei, Taiwan

${ }^{3}$ Department of Agricultural Economics, National Taiwan University, Taipei, Taiwan
} 


\section{Introduction}

C

limate change has already had a negative impact on Asia through extreme temperatures, frequent flooding and droughts, as well as sea level rise (SLR) and increased salinity of water supplies for rainfed agricultural areas. Church and White (2006) projected for the 35 Special Report on Emissions Scenarios (SRES) of the Intergovernmental Panel on Climate Change (IPCC) that global mean sea level could rise by up to one metre through the twenty-first century. The Fourth Assessment Report (AR4) of the IPCC projects that the global average sea level will rise by as much as 0.59 metre (in the A1FI scenario) by the end of the twenty-first century (2090-2099) relative to the level in 1980-1999 (IPCC, 2007, p.409, FAQ 5.1). The new summary report of IPCC's Fifth Assessment Report (AR5) for policy-makers reconfirms these projections with greater confidence "because of the improved understanding of the components of sea level, the improved agreement of processbased models with observations, and the inclusion of ice-sheet dynamic changes." (IPCC, 2013, p.23) IPCC AR5 warns that about 70 percent of coastlines worldwide are projected to experience sea level change (IPCC, 2013, p.24). Such climate change could bring complex, localized negative impacts for the food sector, especially for smallholders and subsistence farmers.

SLR is of particular concern for most Asian countries because their coastal areas - such as the mega-delta regions in East, South and Southeast Asia - have historically attracted human habitation. Farmers in Asian countries grow rice mostly along the river deltas and low-lying areas, which are prone to the SLR-induced flooding, storm surges and crop submergence that arrive with climate change. Examples of such areas are the Vietnamese Mekong Delta, Ganges-Brahmaputra, Irrawaddy and Chao Phraya (Wassmann et al., 2004). Unlike developed countries, most of the Asian rice-growing and rice-consuming economies, at their current stage of development, do not have spare funds and resources to brace for long-term
SLR and SLR-induced inundation and flooding. This could cause great concern regarding the food security of these populous countries, some of which rely on rice imports.

Most of the Asian countries are quite dependent on their domestic supplies of rice. The International Rice Commission (2003) indicates that Bangladesh, China, India, Indonesia, and Viet Nam are the major producers of rice, producing more than 70 percent of world volume. However, due to strong consumer preference towards particular rice varieties and qualities, world rice trade is low in volume, accounting for as little as 5 percent of global output. The Asian rice-producing countries tend to consume most of their own production. Nevertheless, Thailand and Viet Nam are able to export rice to, for example, neighbouring countries: Bangladesh, Indonesia, and the Philippines,.

Dasgupta et al. (2009) identified ten developing countries whose land areas are most exposed to the potential threat of a one-metre SLR: The Bahamas, Bangladesh, Belize, Cuba, The Gambia, Jamaica, Puerto Rico, Qatar, Taiwan, and Viet Nam. Among these hardest hit countries, Bangladesh, China, Taiwan, and Viet Nam and are rice-growing and rice-consuming countries. In an updated study by Dasgupta et al. (2011), ten additional countries were identified to be at risk for large increases in exposed agricultural area: Bangladesh, Cambodia, Colombia, Cuba, Egypt, Mexico, Mozambique, Pakistan, Sri Lanka, and Uruguay -among which Bangladesh, Cuba, Egypt, Mexico and Mozambique are rice-importing countries, while Combodia, Pakistan and Uruguay are rice-exporting countries (USDA, 2012).

Among Asian countries, Bangladesh, Indonesia, Malaysia, and the Philippines rely on imported rice. China and India are the two largest producers of rice in the world, but both countries consume the majority of their own rice production, contributing little for trade. SLR would cause significant concern with respect to food security for Asian countries. Using a partial equilibrium global rice trade model, Chen et al. (2012) investigated the potential impact of SLR combined with climate-induced crop yield change on global 
rice production and price. An estimated 1.6-2.73 percent reduction in global rice production was predicted, followed by an estimated 7.14-12.77 percent rise in global rice price. The study revealed that many key rice-consuming countries, including Bangladesh, Egypt, Japan, Myanmar and Viet Nam, are expected to be among the hardest hit by the effects of SLR.

The purpose of this study is to investigate how SLR would affect land-based agricultural production and trade. First, in contrast to previous studies, we take into account not only the impact of SLR-inflicted agricultural extent loss (supplyside impact), but also the changes in food demand due to market price economic growth (demand-side impact). Second, in contrast to the partial equilibrium approach by Chen et al., we use a global computable general equilibrium (CGE) model - the Global Trade Analysis Project (GTAP) model (Hertel, 1997) - in order to account for the substitution effects between rice and other food grains. Third, we use the GTAP Version 7 database (Narayanan and Walmsley, 2008) and the GTAP land-use database (Lee et al., 2009), which adopts the concept of agro-ecological zones (AEZ), as developed by the Food and Agriculture Organization of the United Nations (FAO, 2000) and Fischer et al. (2002). Fourth, for the potential SLR-inflicted agricultural extent loss, we draw on estimates from Dasgupta et al. (2009) regarding agricultural land loss due to a onemetre SLR as the land-input shock to the GTAP model.

The paper proceeds as follows: Section 2 introduces the GTAP model and our modifications in land-use modelling. Section 3 provides the simulation results of SLR impact on region-specific crop production, global food prices, and land-use change. Section 4 concludes the paper.

\section{Model and data}

The standard GTAP model allows all land-based sectors to compete for land according to relative land rents ${ }^{4}$. However, this model does not explicitly identify the suitability and viability of land for growing various crops. For a country with arable land located under diverse climate and terrain conditions, crop suitability of the land may diverge, and thus land-use change between sectors may be subject to temperature, precipitation and soil conditions of the particular locations. Therefore, we modify the GTAP model with the GTAP land-use database of Lee et al. (2009) so that transition of land between alternative uses is subject to crop suitability of land, which is implied by the terrestrial characteristics and weather conditions at the location of the land. We believe this modification describes the adjustment in agricultural land use more effectively and more realistically.

We combined the land-use database and version 7 of the GTAP database (Narayanan and Walmsley, 2008). The version 7 GTAP database is used as the benchmark equilibrium for global CGE simulations, which present transactions of commodities and services between sectors within and across countries/regions in 2004. Table 1 lists the 29 world countries/regions of our simulation. Table 2 shows the sector disaggregation, covering 17 production activities of the whole economy. Key food crops such as rice, wheat and other cereal grains, as well as processed food sectors, are disaggregated, while activities not directly linked with agricultural land are aggregated into energy, manufacturing and service sectors.

The GTAP land-use database is compiled following the AEZ approach developed jointly by FAO (2000) and Fischer et al. (2002). Arable land is classified into six categories by length of growing period. It is further defined in terms of three climatic zones (boreal, temperate, and tropical), which refer to the length of time within a year that the temperature is above $5^{\circ} \mathrm{C}$ and the soil moisture is sufficient for crop growth (Lee et al., 2009). However, irrigation is not accounted for in the AEZ methodology; the GTAP land-use model considers only the rainfed conditions of land resources.

4 Land rents refer to the market value of the output that equalizes the added cost of an additional unit of land. 
A two-level demand nested structure is identified within the AEZ-specific land demand by the agricultural sectors. We specify a large constant elasticity of substitution (CES) function of 20 between AEZs, so that land rents of all AEZs would change in the same direction and at very similar magnitude in response to exogenous shocks. This assumption also implies that production technology is the same across all AEZs, albeit with differentiated output levels.

The land supply is also AEZ-specific, with a three-level nested structure under the assumption of weak separability. For each tier, we specify a Constant Elasticity of Transformation (CET) function to govern the optimal allocation of land according to relative land rents payable by the land-using sectors. The bottom tier allocates the land between agricultural and forestry uses, while the middle tier allocates agricultural land between livestock husbandry and cropping activities. The top tier allocates land among alternative cropping activities $^{5}$.

\section{Simulation design}

We simulate the impact on global food supply, prices and land use, in combination with estimates by Dasgupta et al. (2009), as exogenous shocks to the GTAP model. Dasgupta et al. conducted a detailed geographic information system (GIS) analysis and overlaid satellite images of the world

5 Note that, in the current version of the model, land transition between agricultural and commercial plantation uses is specified as possible but limited. Conversion of natural lands to crops is possible in reality. However, there is no such information to benchmark the GTAP model to reflect the reality and so this is omitted in this study

table 1

Regions in the model

\begin{tabular}{lll|lll}
\hline No. & \multicolumn{1}{c}{ Code } & Region description & No. & \multicolumn{1}{c}{ Code } & Region description \\
\hline 1 & ANZ_Oceania & $\begin{array}{l}\text { Australia, New } \\
\text { Zealand \& Oceania }\end{array}$ & 16 & NorthAmerica & North America \\
\hline 2 & China & China and Hong Kong & 17 & Mexico & Mexico \\
\hline 3 & Japan & Japan & 18 & Argentina & Argentina \\
\hline 4 & SKorea & South Korea & 19 & CaribCentrAm & Central America \\
\hline 5 & Taiwan & Taiwan & 20 & Brazil & Brazil \\
\hline 6 & OtherEAsia & Other East Asia & 21 & Chile & Chile \\
\hline 7 & Cambodia & Cambodia & 22 & NSAmerica & Northern South \\
\hline 8 & Indonesia & Indonesia & 23 & EU27 & America \\
\hline 9 & SouthAsia & South Asia & 24 & OthEurope & European Union \\
\hline 10 & Myanmar & Myanmar & 25 & Russia_FSU & Other Europe \\
\hline 11 & Malay_Singap & Malaysia\& Singapore & 26 & MiddleEast & Former Soviet Union \\
\hline 12 & Philippines & Philippines & 27 & NAfrica & The Near East \\
\hline 13 & Thailand & Thailand & 28 & NoCstlAfrica & North Africa \\
\hline 14 & VietNam & Viet Nam & 29 & SAfrica & No Coastal Line Africa \\
\hline 15 & OtherSEAsia & Other South East Asia & & & South Africa \\
\hline & & & & & \\
\hline & & & & & \\
\hline
\end{tabular}


table 2

Sectors in the model

\begin{tabular}{ll|ll}
\hline No. Sectors & \multicolumn{1}{c}{ No. } & \multicolumn{1}{c}{ Sectors } \\
\hline 1 & Paddy rice & 10 & Processed meat products \\
\hline 2 & Wheat & 11 & Vegetable oil and fat \\
\hline 3 & Other cereal grains & 12 & Sugar \\
\hline 4 & Vegetables and fruits & 13 & Other processed food \\
\hline 5 & Oilseeds & 14 & Beverage and tobacco \\
\hline 6 & Sugar cane and beets & 15 & Coal, oil and gas \\
\hline 7 & Processed rice and flour & 16 & Other manufacture \\
\hline 8 & Animal products & 17 & Other services \\
\hline 9 & Forestry & & \\
\hline & & & \\
\hline
\end{tabular}

with data regarding agricultural extent (Globcover 2.1 dataset $\left.^{6}\right)$ of 84 coastal developing countries to map out the agricultural extent exposed to the threat of a one-metre SLR. We aggregate estimates by Dasgupta et al. into 24 developing countries/regions using land area shares as measures consistent with the region aggregation scheme of our GTAP land-use model.

Because the work of Dasgupta et al. (2009) does not assume any particular timing of the global mean SLR in projecting the extent of agricultural loss, we follow the IPCC's AR4 projections (Bindoff et al., 2007) and assume that adverse impact of a onemetre global mean SLR might occur as early as 2020. ${ }^{7}$ Figure 1 illustrates our simulation design.

$6 \quad$ The Globcover 2.1 dataset was produced by the European Space Agency with a resolution of $300 \mathrm{~m}^{\star} 300 \mathrm{~m}$, available at: http://www.esa.int/due/ionia/globcover. According to Dasgupta et al. (2009), there were three types of agricultural land in this dataset, but only the rainfed/irigated/ post-flooding cropland area was used in the mapping, which may lead to an underestimation of the impact on agricultural extent.

7 The IPCC AR5 projects that the likely range of global SLR by the year 2100 is 28 to $98 \mathrm{~cm}$ and the risk of exceeding $98 \mathrm{~cm}$ is considered to be $17 \%$ (IPCC, 2013). The AR5 also warns that, should sectors of the marine-based Antarctic ice sheets collapse, the sea level could rise by up to 1.2 to 1.5 metres during the twenty-first century. Therefore, our assumed impact of a one-metre SLR can be considered a severe case, but not as an upper limit.
To better simulate the SLR impact by 2020, we first update the 2004 GTAP version 7 database to present the 2020 benchmark equilibrium, with gross domestic product (GDP) and population growth forecasts under the IPCC scenario A2 of SRES. The SRES A2 assumes the highest projected population growth and thus is associated with the highest food demand. As illustrated in Figure 1, line E1E2 depicts the baseline growth trajectory of some variable - e.g. supply of a crop - from 2004 to 2020 under the SRES scenario A2.

To construct this baseline, we add regionspecific GDP and population growth forecasts by the International Institute for Applied Systems Analysis (IIASA, 2007a, 2007b) to the GTAP landuse model and gradually update the database to 2020 - i.e. point E2. The updated database then serves as the benchmark equilibrium for the second step; that is, to bring the supply-side shocks based on estimates by Dasgupta et al. (2009) of agricultural extent loss to a one-metre SLR for all regions. ${ }^{8}$

$8 \quad$ Note that the trade pattern changes driven by population and income growth can be reflected in the GTAP benchmark equilibrium, the base upon which we assess the cross-border impact of SLRinduced land endowment loss in the rice paddies. In reality, trade patterns may also change due to SLR itself and be much larger than the GTAP Armington 
The land endowment shock is brought into the second step of the simulation, as the regional agricultural extent loss to SLR. The scope of agricultural extent includes cropland and grazing land, so the land supply shocks pertain to the corresponding agricultural land-based sectors. All endogenous variables in our model will respond to such shocks and simultaneously reach a new equilibrium where demand equals supply for all commodities in all regions.

We then calculate the percentage of deviation for all endogenous variables (e.g. prices, supplies and demands) in the new equilibrium (point E3 in Figure 1) from those in the old one (point E2 in Figure 1). These deviation percentages measure the economic impacts of the agricultural extent loss due to SLR. We also assume that developing countries do not have coastal protection against SLR. For the five developed regions, given the lack of information from Dasgupta et al. (2009), we assume there is no agricultural extent loss. One justification for this assumption is that developed countries tend to have sufficient coastal protection (e.g. sea dykes) to ward off storm surges and SLR.

Figure 2 shows the magnitude of agricultural extent loss in percentage changes for the 29 regions, with most of the Asian rice-growing countries disaggregated. Viet Nam is hit the hardest by the 1-metre SLR, losing 7.14 perent of its agricultural extent. ${ }^{9}$ Other Asian rice-growing countries - for example, China, Indonesia, Myanmar and Taiwan - also lose 0.6-1.5 percent of their agricultural land to SLR. Calculations by Dasgupta et al. also indicate that agricultural activities of Asian developing countries are relatively more vulnerable to SLR than western countries.

parameters would suggest. However, the latter changes require additional modelling improvement and will be reserved for future research.

9 According to the recent FAO (2011) report, the mean sea level along the coastline of Viet Nam rose at a rate of $3 \mathrm{~mm}$ per year during 1993-2008, based on observations by tidal gauges in marine hydrometeorological stations. The IPCC AR4 projections are SLR of 65 to $100 \mathrm{~cm}$ into the end of the twenty-first century, relative to the 1980-1999 levels under the A1F1 scenario.
This is consistent with IPCC AR4 projections, which call for capacity enhancement to disaster risk reduction actions and adaptation in agriculture to climate change in Asian developing countries (particularly those in lower latitudes). ${ }^{10}$

\section{Simulation results}

Given the multitude of the numerical results from our simulation, we selected Viet Nam as an example in order to discuss and explain the results in detail, and refer to the relevant charts that show the impact magnitude of simulation results. Output of the land-based crop sectors (e.g., paddy rice, wheat and other grains) will be affected first. In the case of Viet Nam, paddy rice is grown in the low-lying river delta areas, such as the Mekong Delta region. SLR could easily diminish the paddy rice production capacity of Viet Nam; Table 3 shows rice production in Viet Nam reduced by 4.54 percent. However, given strong demand for Vietnamese rice-both domestically and from abroad-the SLR-inflicted shortfall in the Vietnamese rice supply would drive up the price of Vietnamese rice; Table 4 shows the price of Vietnamese paddy rice rising by 5.74 percent. The sugar cane price also rises, partly due to production loss from SLR as well as the fact that consumption is growing faster than production. This drives up land rents so that more land can be converted into sugar cane production to meet the market demand. ${ }^{11}$

The percentage change in land rent and land supply are shown in in Tables 5 and 6, respectively. The other land-based crop sectors would not be

10 Our main purpose is to highlight the cross-border impact of regionalized land endowment loss in the low-lying zones in Asia. This study does not take into account the crop yield responses to climate-induced temperature and precipitation changes. However, the simulation results would reveal the far-reaching spillover effects of the localized loss of land availability on the global staple market.

11 Sugar cane can be grown in all provinces of Viet Nam, including the drier regions of the south-central coast and Mekong Delta without irrigation, and the Red River Delta area in the north. 
figure 1

Simulation design

Variable under

investigation

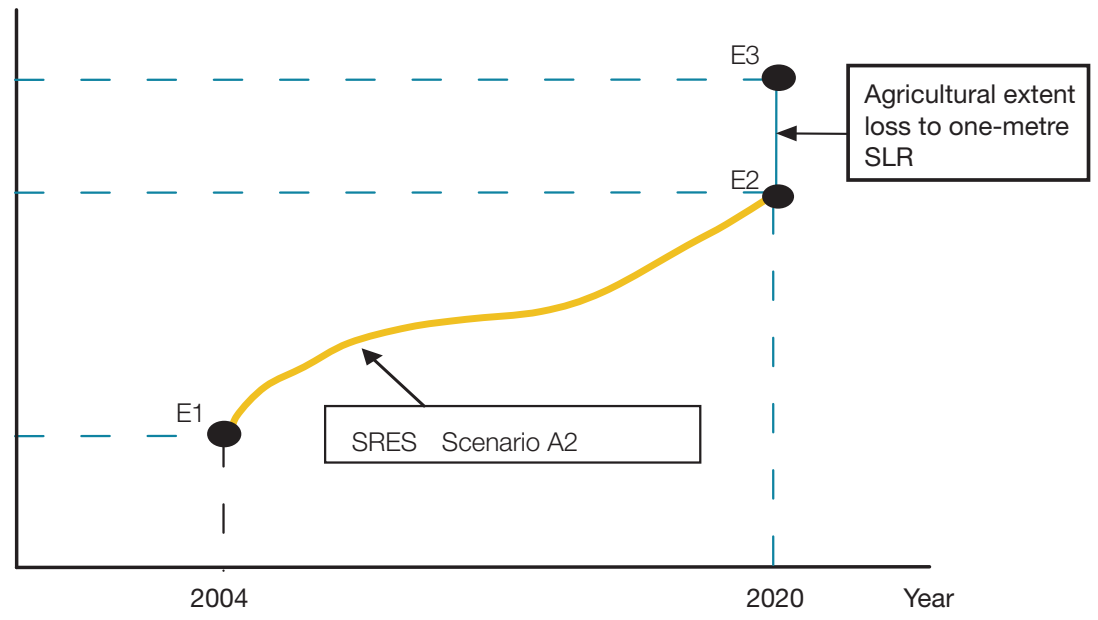

\section{figure 2}

Agricultural extent loss to 1-metre global mean sea-level rise, by region
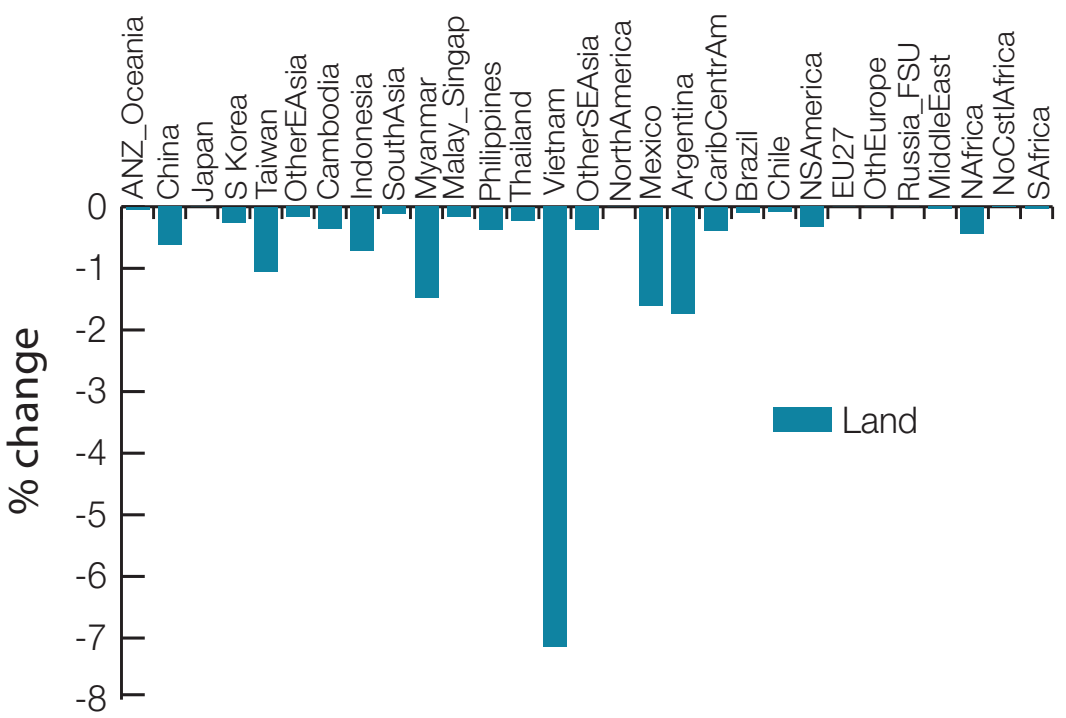

Land 


\section{table 3}

Percentage change in production of the crop sectors

\begin{tabular}{|c|c|c|c|c|c|c|}
\hline & & & & & & Unit \% \\
\hline & Rice & Wheat & $\begin{array}{l}\text { Other } \\
\text { grains }\end{array}$ & $\begin{array}{c}\text { Vegetables/ } \\
\text { fruits }\end{array}$ & Oilseeds & $\begin{array}{c}\text { Sugar cane/ } \\
\text { beets }\end{array}$ \\
\hline 1. ANZ_Oceania & 0.53 & 0.00 & 0.06 & 0.20 & 0.09 & 0.05 \\
\hline 2. China & -0.07 & -0.30 & -0.13 & -0.14 & -0.36 & -0.03 \\
\hline 3. Japan & 0.04 & 0.12 & 0.09 & 0.07 & 0.10 & 0.01 \\
\hline 4. S. Korea & -0.09 & -0.21 & -0.20 & -0.09 & -0.34 & 0.07 \\
\hline 5. Taiwan & -0.15 & -1.65 & -0.41 & -0.53 & 0.78 & -0.45 \\
\hline 6. Other E. Asia & 0.06 & -0.13 & -0.05 & -0.04 & -0.11 & -0.02 \\
\hline 7. Cambodia & -0.17 & -2.91 & -0.14 & -0.12 & -0.16 & -0.14 \\
\hline 8. Indonesia & -0.21 & -2.46 & -0.23 & -0.57 & -0.55 & -0.45 \\
\hline 9. SouthAsia & 0.02 & -0.04 & -0.02 & -0.03 & -0.03 & -0.04 \\
\hline 10. Myanmar & -0.58 & -1.71 & -1.31 & -1.44 & -1.30 & -0.68 \\
\hline 11. Malay_Singap & 0.08 & -1.07 & -0.01 & -0.06 & -0.05 & -0.11 \\
\hline 12. Philippines & 0.23 & -0.53 & 0.08 & -0.27 & -0.28 & -0.15 \\
\hline 13. Thailand & 0.03 & -0.31 & 0.00 & -0.12 & -0.15 & -0.04 \\
\hline 14. VietNam & -4.54 & -4.80 & -5.01 & -7.08 & -7.22 & -1.08 \\
\hline 15. OtherSEAsia & -0.16 & -0.67 & -0.19 & -0.29 & -0.32 & -0.16 \\
\hline 16. NorthAmerica & 0.59 & 0.11 & 0.07 & 0.18 & 0.13 & 0.02 \\
\hline 17. Mexico & -1.51 & -1.46 & -0.43 & -0.99 & -0.60 & -0.27 \\
\hline 18. Argentina & -0.80 & -1.28 & -0.80 & -0.88 & -1.12 & -0.34 \\
\hline 19. CaribCentrAm & 0.14 & -0.32 & -0.10 & -0.12 & -0.11 & -0.05 \\
\hline 20. Brazil & 0.11 & 0.25 & 0.04 & 0.08 & 0.15 & 0.00 \\
\hline 21. Chile & 0.13 & 0.03 & 0.05 & 0.15 & -0.02 & 0.02 \\
\hline 22. NSAmerica & -0.02 & -0.28 & -0.07 & -0.11 & -0.04 & -0.04 \\
\hline 23. EU27 & 0.78 & 0.10 & 0.04 & 0.12 & 0.16 & 0.02 \\
\hline 24. OthEurope & 0.79 & 0.06 & 0.03 & 0.08 & 0.13 & 0.00 \\
\hline 25. Russia_FSU & 0.37 & 0.05 & 0.02 & 0.08 & 0.13 & 0.01 \\
\hline 26. MiddleEast & 0.14 & 0.10 & 0.05 & 0.11 & 0.14 & 0.03 \\
\hline 27. NAfrica & 0.59 & -0.12 & -0.04 & -0.03 & -0.04 & -0.04 \\
\hline 28. NoCstlAfrica & 0.35 & 0.17 & 0.00 & 0.13 & 0.15 & 0.00 \\
\hline 29. S. Africa & 0.60 & 0.25 & 0.01 & 0.12 & 0.14 & 0.02 \\
\hline
\end{tabular}




\section{table 4}

Percentage change in market prices of the crop sectors

\begin{tabular}{|c|c|c|c|c|c|c|}
\hline & & & & & & Unit \% \\
\hline & Rice & Wheat & $\begin{array}{l}\text { Other } \\
\text { grains }\end{array}$ & $\begin{array}{c}\text { Vegetables/ } \\
\text { fruits }\end{array}$ & Oilseeds & $\begin{array}{c}\text { Sugar cane/ } \\
\text { beets }\end{array}$ \\
\hline 1. ANZ_Oceania & 0.23 & 0.10 & 0.12 & 0.15 & 0.13 & 0.11 \\
\hline 2. China & 0.59 & 0.30 & 0.46 & 0.54 & 0.44 & 0.54 \\
\hline 3. Japan & 0.03 & 0.04 & 0.04 & 0.03 & 0.05 & 0.02 \\
\hline 4. SKorea & 0.58 & 0.24 & 0.34 & 0.57 & 0.33 & 0.11 \\
\hline 5. Taiwan & 0.86 & 0.45 & 0.76 & 0.99 & 0.12 & 0.84 \\
\hline 6. OtherEAsia & 0.37 & 0.13 & 0.23 & 0.27 & 0.22 & 0.27 \\
\hline 7. Cambodia & 0.60 & 0.07 & 0.77 & 0.76 & 0.80 & 0.67 \\
\hline 8. Indonesia & 1.38 & 0.51 & 1.34 & 0.89 & 0.87 & 0.91 \\
\hline 9. SouthAsia & 0.28 & 0.16 & 0.23 & 0.23 & 0.23 & 0.23 \\
\hline 10. Myanmar & 2.33 & 0.72 & 1.30 & 1.11 & 1.31 & 2.10 \\
\hline 11. Malay_Singap & 0.58 & -0.03 & 0.37 & 0.38 & 0.35 & 0.38 \\
\hline 12. Philippines & 0.86 & 0.26 & 0.76 & 0.45 & 0.50 & 0.46 \\
\hline 13. Thailand & 0.64 & 0.15 & 0.45 & 0.44 & 0.38 & 0.44 \\
\hline 14. VietNam & 5.74 & 1.47 & 4.90 & 2.88 & 3.24 & 9.45 \\
\hline 15. OtherSEAsia & 0.70 & 0.17 & 0.62 & 0.54 & 0.50 & 0.54 \\
\hline 16. NorthAmerica & 0.28 & 0.09 & 0.08 & 0.14 & 0.11 & 0.10 \\
\hline 17. Mexico & 0.76 & 0.39 & 1.36 & 0.87 & 0.32 & 1.42 \\
\hline 18. Argentina & 0.63 & 0.47 & 0.62 & 0.71 & 0.52 & 0.94 \\
\hline 19. CaribCentrAm & 0.42 & 0.16 & 0.31 & 0.28 & 0.27 & 0.31 \\
\hline 20. Brazil & 0.11 & 0.13 & 0.08 & 0.10 & 0.09 & 0.07 \\
\hline 21. Chile & 0.16 & 0.11 & 0.10 & 0.22 & 0.29 & 0.11 \\
\hline 22. NSAmerica & 0.34 & 0.24 & 0.30 & 0.29 & 0.32 & 0.29 \\
\hline 23. EU27 & 0.11 & 0.03 & 0.03 & 0.04 & 0.04 & 0.02 \\
\hline 24. Other Europe & 0.13 & 0.03 & 0.02 & 0.04 & 0.08 & 0.01 \\
\hline 25. Russia_FSU & 0.19 & 0.05 & 0.04 & 0.06 & 0.09 & 0.03 \\
\hline 26. MiddleEast & 0.06 & 0.03 & 0.02 & 0.04 & 0.04 & 0.01 \\
\hline 27. NAfrica & 0.33 & 0.14 & 0.18 & 0.18 & 0.19 & 0.17 \\
\hline 28. NoCstlAfrica & 0.13 & 0.07 & 0.03 & 0.07 & 0.08 & 0.03 \\
\hline 29. SAfrica & 0.20 & 0.08 & 0.04 & 0.07 & 0.08 & 0.03 \\
\hline
\end{tabular}




\section{table 5}

Percentage change in land rents of the crop sectors

\begin{tabular}{|c|c|c|c|c|c|c|}
\hline & & & & & & Unit \% \\
\hline & Rice & Wheat & $\begin{array}{l}\text { Other } \\
\text { grains }\end{array}$ & $\begin{array}{l}\text { Vegetables/ } \\
\text { fruits }\end{array}$ & Oilseeds & $\begin{array}{c}\text { Sugar cane/ } \\
\text { beets }\end{array}$ \\
\hline 1. ANZ_Oceania & 1.91 & 0.68 & 0.84 & 1.14 & 0.90 & 0.81 \\
\hline 2. China & 3.03 & 2.49 & 2.90 & 2.86 & 2.34 & 3.12 \\
\hline 3. Japan & 0.28 & 0.46 & 0.38 & 0.33 & 0.42 & 0.20 \\
\hline 4. SKorea & 1.41 & 1.08 & 1.12 & 1.41 & 0.74 & 1.85 \\
\hline 5. Taiwan & 5.06 & 1.23 & 4.40 & 4.08 & 7.44 & 4.28 \\
\hline 6. OtherEAsia & 1.20 & 0.70 & 0.90 & 0.92 & 0.74 & 0.99 \\
\hline 7. Cambodia & 1.69 & -5.88 & 1.76 & 1.82 & 1.71 & 1.78 \\
\hline 8. Indonesia & 3.04 & -3.17 & 2.98 & 2.05 & 2.12 & 2.39 \\
\hline 9. SouthAsia & 0.82 & 0.66 & 0.70 & 0.69 & 0.68 & 0.67 \\
\hline 10. Myanmar & 4.97 & 1.82 & 2.95 & 2.57 & 2.95 & 4.67 \\
\hline 11. Malay_Singap & 1.40 & -1.77 & 1.16 & 1.03 & 1.04 & 0.89 \\
\hline 12. Philippines & 2.75 & 0.78 & 2.36 & 1.46 & 1.44 & 1.76 \\
\hline 13. Thailand & 1.64 & 0.69 & 1.54 & 1.21 & 1.13 & 1.44 \\
\hline 14. VietNam & 16.78 & 4.85 & 15.46 & 9.74 & 9.36 & 26.33 \\
\hline 15. OtherSEAsia & 1.51 & 0.12 & 1.43 & 1.17 & 1.08 & 1.52 \\
\hline 16. NorthAmerica & 1.90 & 0.74 & 0.66 & 0.90 & 0.78 & 0.52 \\
\hline 17. Mexico & 3.35 & 3.46 & 5.96 & 4.60 & 5.55 & 6.36 \\
\hline 18. Argentina & 4.81 & 3.65 & 4.82 & 4.63 & 4.04 & 5.93 \\
\hline 19. CaribCentrAm & 2.33 & 1.20 & 1.73 & 1.70 & 1.71 & 1.84 \\
\hline 20. Brazil & 0.97 & 1.28 & 0.80 & 0.91 & 1.05 & 0.72 \\
\hline 21. Chile & 1.17 & 0.94 & 0.97 & 1.21 & 0.79 & 0.91 \\
\hline 22. NSAmerica & 1.63 & 1.00 & 1.49 & 1.40 & 1.57 & 1.58 \\
\hline 23. EU27 & 2.01 & 0.53 & 0.41 & 0.58 & 0.65 & 0.35 \\
\hline 24. OthEurope & 1.93 & 0.32 & 0.26 & 0.37 & 0.48 & 0.19 \\
\hline 25. Russia_FSU & 1.08 & 0.30 & 0.22 & 0.37 & 0.49 & 0.20 \\
\hline 26. MiddleEast & 0.74 & 0.65 & 0.53 & 0.67 & 0.73 & 0.48 \\
\hline 27. NAfrica & 3.41 & 1.82 & 2.01 & 2.03 & 1.99 & 1.99 \\
\hline 28. NoCstlAfrica & 1.05 & 0.65 & 0.28 & 0.55 & 0.60 & 0.28 \\
\hline 29. SAfrica & 1.82 & 1.04 & 0.49 & 0.75 & 0.80 & 0.51 \\
\hline
\end{tabular}




\section{table 6}

Percentage change in land use of the crop sectors

\begin{tabular}{|c|c|c|c|c|c|c|}
\hline & & & & & & Unit \% \\
\hline & Rice & Wheat & $\begin{array}{l}\text { Other } \\
\text { grains }\end{array}$ & $\begin{array}{l}\text { Vegetables/ } \\
\text { fruits }\end{array}$ & Oilseeds & $\begin{array}{c}\text { Sugar cane/ } \\
\text { beets }\end{array}$ \\
\hline 1. ANZ_Oceania & 0.18 & -0.12 & -0.09 & -0.01 & -0.07 & -0.09 \\
\hline 2. China & -0.57 & -0.71 & -0.61 & -0.62 & -0.75 & -0.55 \\
\hline 3. Japan & -0.01 & 0.04 & 0.02 & 0.00 & 0.02 & -0.03 \\
\hline 4. SKorea & -0.25 & -0.33 & -0.33 & -0.25 & -0.42 & -0.14 \\
\hline 5. Taiwan & -0.87 & -1.82 & -1.03 & -1.11 & -0.27 & -1.06 \\
\hline 6. OtherEAsia & -0.09 & -0.22 & -0.17 & -0.16 & -0.21 & -0.15 \\
\hline 7. Cambodia & -0.37 & -2.26 & -0.35 & -0.33 & -0.36 & -0.35 \\
\hline 8. Indonesia & -0.56 & -2.12 & -0.58 & -0.81 & -0.80 & -0.73 \\
\hline 9. SouthAsia & -0.09 & -0.13 & -0.12 & -0.12 & -0.12 & -0.12 \\
\hline 10. Myanmar & -1.17 & -1.96 & -1.68 & -1.77 & -1.68 & -1.25 \\
\hline 11. Malay_Singap & -0.08 & -0.87 & -0.14 & -0.17 & -0.17 & -0.21 \\
\hline 12. Philippines & -0.14 & -0.64 & -0.24 & -0.47 & -0.47 & -0.39 \\
\hline 13. Thailand & -0.15 & -0.39 & -0.18 & -0.26 & -0.28 & -0.21 \\
\hline 14. VietNam & -6.50 & -5.30 & -6.84 & -8.26 & -8.36 & -4.12 \\
\hline 15. OtherSEAsia & -0.34 & -0.69 & -0.36 & -0.43 & -0.45 & -0.34 \\
\hline 16. NorthAmerica & 0.27 & -0.02 & -0.03 & 0.03 & 0.00 & -0.07 \\
\hline 17. Mexico & -2.08 & -2.06 & -1.43 & -1.77 & -1.53 & -1.33 \\
\hline 18. Argentina & -1.63 & -1.92 & -1.63 & -1.67 & -1.82 & -1.35 \\
\hline 19. CaribCentrAm & -0.24 & -0.52 & -0.39 & -0.40 & -0.40 & -0.36 \\
\hline 20. Brazil & -0.08 & 0.00 & -0.12 & -0.09 & -0.06 & -0.14 \\
\hline 21. Chile & -0.06 & -0.12 & -0.11 & -0.05 & -0.16 & -0.13 \\
\hline 22. NSAmerica & -0.28 & -0.44 & -0.31 & -0.34 & -0.29 & -0.29 \\
\hline 23. EU27 & 0.37 & 0.00 & -0.03 & 0.01 & 0.03 & -0.05 \\
\hline 24. OthEurope & 0.40 & 0.00 & -0.02 & 0.01 & 0.04 & -0.04 \\
\hline 25. Russia_FSU & 0.19 & 0.00 & -0.02 & 0.02 & 0.05 & -0.03 \\
\hline 26. MiddleEast & -0.01 & -0.03 & -0.06 & -0.03 & -0.01 & -0.07 \\
\hline 27. NAfrica & -0.10 & -0.49 & -0.44 & -0.44 & -0.45 & -0.45 \\
\hline 28. NoCst|Africa & 0.14 & 0.04 & -0.05 & 0.02 & 0.03 & -0.05 \\
\hline 29. SAfrica & 0.24 & 0.05 & -0.09 & -0.02 & -0.01 & -0.08 \\
\hline
\end{tabular}




\section{table 7}

Key statistics of global rice trade in GTAP database

\begin{tabular}{|c|c|c|c|c|c|c|}
\hline Ranking & 1st & $\begin{array}{c}\text { Share } \\
(\%)\end{array}$ & 2nd & $\begin{array}{c}\text { Share } \\
(\%)\end{array}$ & 3rd & $\begin{array}{c}\text { Share } \\
(\%)\end{array}$ \\
\hline \multicolumn{7}{|c|}{ Processed rice (pcr) } \\
\hline Exports & 13 Thailand: & 32.2 & 9 SouthAsia: & 22.4 & 14 VietNam: & 11.7 \\
\hline Output & 9 South Asia: & 27.6 & 2 China: & 20.2 & 3 Japan: & 18.3 \\
\hline \multicolumn{7}{|c|}{ Paddy rice (pdr) } \\
\hline Exports & 16 NorthAmerica: & 35.0 & 23 EU27: & 14.0 & 9 SouthAsia: & 12.6 \\
\hline Output & 9 SouthAsia: & 20.5 & 2 China: & 19.6 & 3 Japan: & 19.2 \\
\hline \multicolumn{7}{|c|}{ Wheat (wht) } \\
\hline Exports & 16 NorthAmerica: & 43.1 & 23 EU27: & 23.0 & 1 ANZ_Oceania: & 12.7 \\
\hline Output & 23 EU27: & 22.1 & 9 SouthAsia: & 21.9 & 16 NorthAmerica: & 11.5 \\
\hline \multicolumn{7}{|c|}{ Other grains (gro) } \\
\hline Exports & 16 NorthAmerica: & 44.5 & 23 EU27: & 23.2 & 18 Argentina: & 7.8 \\
\hline Output & 16 NorthAmerica: & 20.8 & 23 EU27: & 19.7 & 25 Russia_FSU: & 7.7 \\
\hline
\end{tabular}

able to contend with the rising land rent offered by the rice sector and thus the land would be transferred to rice cultivation. Among such sectors, the vegetables \& fruits and oilseeds sectors would be the most constricted, losing 6.84 percent and 8.36 percent of their land supply, respectively (Table 6). This also demonstrates the far-reaching influence of SLR-inflicted regional land loss in today's highly globalized world.

Due to the input-output relationship, the processed rice sector of Viet Nam faces the same fate as the rice sector: output would shrink and prices would rise, prompting domestic consumers to move away from rice. Moreover, Viet Nam ranks third among the world exporters of processed rice (see Table 7), and as much as 65 percent of Vietnamese processed rice is exported. The countries that import Vietnamese rice would be worse off due to the price rise of Vietnamese rice. Table 8 lists the top three import sources of processed rice in various importing countries.

Most of the countries rank Viet Nam and Thailand as their top importing sources of processed rice-which accounts for 64.7 percent of Vietnamese processed rice output and 49.2 percent of Thailand's. Thailand's land loss ( 0.15 percent) is not projected to be as serious as Viet Nam's (6.50 percent). Thai rice has been competing with Vietnamese rice in various Asian destinations - e.g. Indonesia, Malaysia, the Philippines and Singapore. In response to a shortfall of exported Vietnamese rice, Thai rice would supplement to meet the demand of these importing countries, which would also experience their own land loss because of SLR. Table 4 shows prices of Vietnamese rice rising 5.74 percent for paddy and 3.33 percent for processed rice under the impact of SLR, while Thai rice prices rise by only 0.64 percent and 0.51 percent for paddy and processed rice, respectively. This explains the slight increase in the output of Thai processed rice and paddy rice, given that Thailand itself would have lost 0.22 percent of its agricultural land to SLR.

According to the benchmark data of our model, the GTAP database, the Caribbean/Central America, the Near East, North Africa, Malaysia/ Singapore, and the Philippines are the top five importing regions for Vietnamese processed 


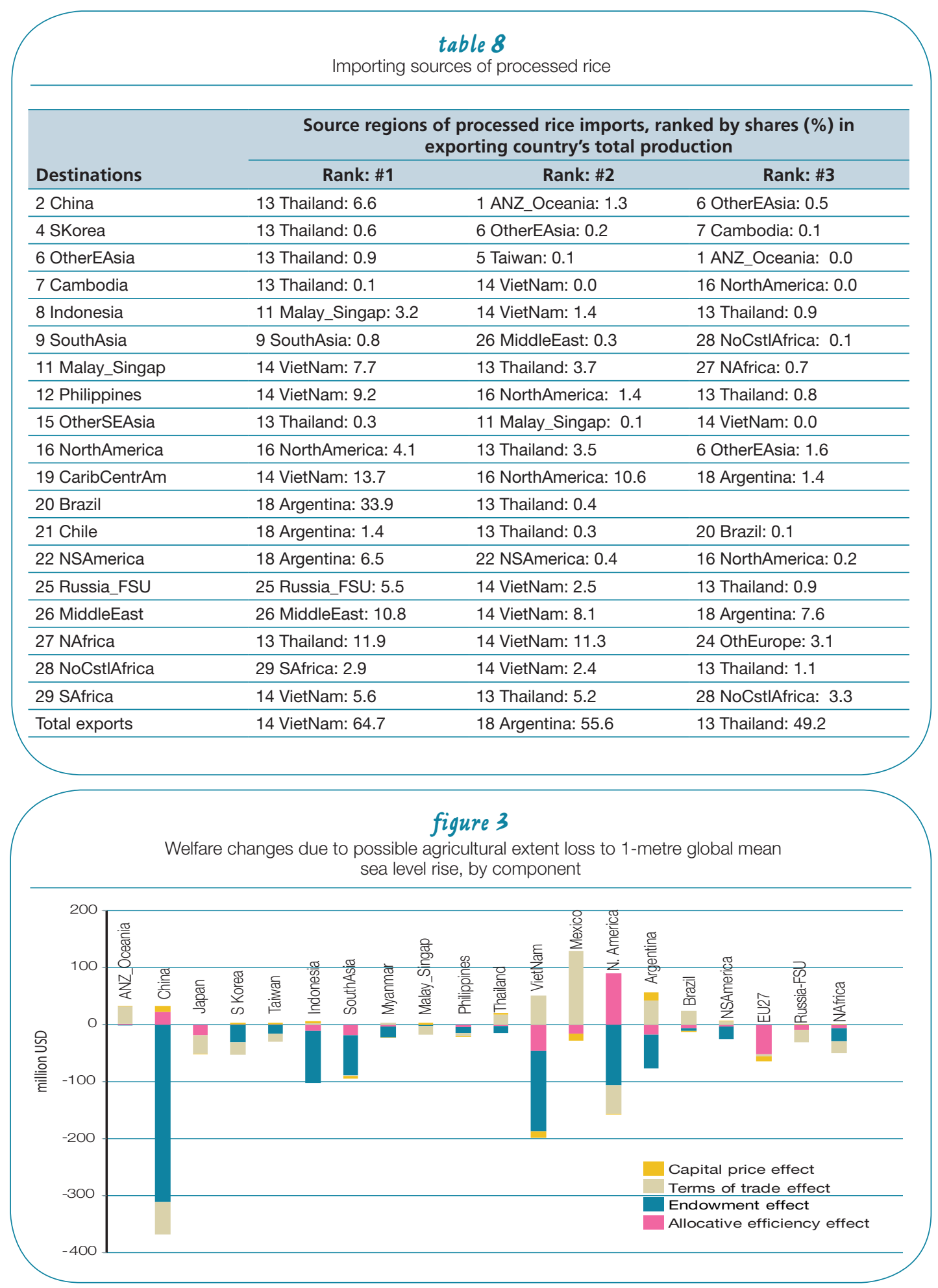


rice. This partially explains the negative terms of trade effect for these importing regions as we consider the key contributors to welfare change..$^{12}$ Figure 3 shows changes in welfare measured with equivalent variations (EV).

Rice-consuming developing countries would become worse off, while rice- and sugarproducing developed countries would become better off. Among the welfare-losing regions, China, Indonesia, South Asia and Viet Nam are the most negatively affected. The welfare results are shown in Figure 3 indicate that endowment effect accounts significantly for the projected welfare loss in these regions. Among the welfaregaining regions -Australia \& New Zealand (ANZ), Brazil, North America, Oceania, and Thailand improvements in the terms of trade contribute most to the projected welfare change of these regions. Price rises of their major crop exports (rice for Thailand, wheat for Brazil, grains for ANZ and North America) specifically promote the welfare gains. Argentina and Mexico are also key exporters of wheat and grains, following North America, the European Union, and Russia. Since a 1-metre SLR may claim as much as 1.5 percent of agricultural land in Argentina and Mexico, the negative endowment effects appear likely to be quite substantial. Argentina and Mexico therefore give

12 In the GTAP model simulation, the concept of equivalent variations (EV) is adopted to measure change in welfare. Huff \& Hertel (2000) proposed the breakdown of EV into the following seven categories of contributing effects:

(1) endowment effect: due to changes in availability of primary factors;

(2) technical efficiency effect: due to changes in the use efficiency of productive inputs;

(3) allocative efficiency effect: due to changes in allocation of resources, relative to pre-existing distortions;

(4) terms of trade effect: due to changes in export prices relative to import prices;

(5) capital price effect: due to changes in the relative prices of savings and investment;

(6) population effect: due to changes in population size; and

(7) distribution effect: due to changes in preference for the distribution of regional income between private consumption, government consumption and savings. way to the other wheat and grain exporters, e.g., Brazil, the European Union, and North America.

\section{Conclusions}

Understanding of past sea-level changes has been greatly improved since the IPCC AR4. In the IPCC AR5, under high unmitigated emission levels (RCP8.5), climate change is expected to raise global sea level between a half metre and one metre by the end of this century; the report has a high level of confidence that the rate of SLR is accelerating. In this study, we have modelled the potential effects of SLR with an approach that recognizes agro-ecological dissimilarities in land characteristics for agricultural purposes in a multiregional, multisectoral CGE model. The implications for agricultural production and trade diversion impact are also investigated. By considering crop suitability of land and region-differentiated agricultural extent loss, the framework of our economy-wide impact study is designed to provide a new perspective for the global concern regarding SLR and its socioeconomic consequences.

Our study provides an integrated economic assessment on rice in the global and regional context. Among Asian countries, Viet Nam is likely to be hit hardest, in terms of agricultural extent loss to SLR, because its cultivating zones of paddy rice, such as the Mekong Delta, are prone to inundation once the sea level rises. This will affect countries near and far that depend on Vietnamese rice exports, including Caribbean and Central America, Malaysia, the Near East, North Africa, Singapore, and the Philippines. Fortunately, Thai rice would be able to partially supplement the shortfall caused by the decline of Vietnamese rice exports. The wheat sector would also be adversely affected, though not directly, in the South Asian countries and China, where wheat is the second major staple crop. The Asian rice sector would draw more land away from wheat and other crop sectors due to land competition from a steadfast demand for the staple rice crop. Wheat- and grain-growing 
regions, such as Argentina, Australia/New Zealand, the European Union, North America, and Russia would thus reap the benefit of improved terms of trade because of the effect of SLR on the Asian rice-growing regions.

Although rice is relatively less traded across borders, loss of agricultural land to SLR, especially in lower-latitude Asian developing countries, would widen the gap between rice supply and demand of the rice-consuming countries. This suggests an urgent need to establish safety nets of food security in Asia. Particularly for agriculture of developing countries, sufficient efforts are also needed, in addition to poverty elimination, to brace for and adapt to climate change, so as to ensure their productivity and capacity of food supply.

The study represents the first attempt to analyze the sea level rise using a global CGE model that examines the relative impacts on several countries and combine supply, demand and trade effects. However, a fuller account of climate change impacts would require simulating the effects of projected temperature and precipitation changes along with the sea level rise. This, and refined assumptions about the scope for sea level rise at various projected future periods require additional research.

\section{References}

Bindoff, N., J. Willebrand, V. Artale, A. Cazenave, J. Gregory, S.Gulev, K. Hanawa, C. Le Quéré, S. Levitus, Y. Nojiri, C. Shum, L. Talley \& A. Unnikrishnan. 2007. Observations: Oceanic climate change and sea level. In Solomon, S., D. Qin, M. Manning, Z. Chen, M. Marquis, K. Averyt, M. Tignor \& H. Miller, eds. Climate Change 2007: The Physical Science Basis, pp. 385-431. Contribution of Working Group I to the Fourth Assessment Report of the IPCC, Cambridge, UK and New York, NY, USA, Cambridge University Press.

Brown, M. \& C. Funk. 2008. Food security under climate change. Science, 319(5863): 580-581.
Chen, C., B. McCarl \& C. Chang. 2012. Climate change, sea level rise and rice: global market implications. Climatic Change, 110(3): 543-560. (doi: 10.1007/s10584-011-0074-0).

Church, J. \& N. White. 2006. A 20th century acceleration in global sea-level rise. Geophysical Research Letter, 33, L01602. (doi: 10.1029/2005GL024826).

Dasgupta, S., B. Laplante, C. Meisner, D. Wheeler \& J. Yan. 2009. The impact of sea level rise on developing countries: A comparative analysis. Climatic Change, 93: 9-388.

Dimaranan, B. \& R. McDougall, eds. 2002. Global Trade, Assistance, and Protection: The GTAP 5 Data Base, West Lafayette, IN, USA, Center for Global Trade Analysis, Purdue University.

FAO. 2000. Land Cover Classification System: Classification Concepts and User Manual (with CDROM). Rome, FAO.

2007. The state of food and agriculture, 2007. Rome, FAO.

FAO \& IIASA. 2000. Global Agro-Ecological Zones (Global-AEZ CD-ROM) - 2000. Available at: http:// webarchive.iiasa.ac.at/Research/LUC/GAEZ/index. $\mathrm{htm}$

Fischer, G., H. van Velthuizen, M. Shah \& F. Nachtergaele. 2002. Global Agro-Ecological Assessment for Agriculture in the 21st Century: Methodology and Result. Research Report RR-02-02. Luxemburg, Austria, IIASA and FAO.

Hertel, T., ed. 1997. Global Trade Analysis: Modeling and Applications. New York, NY, USA, Cambridge University Press.

Hertel, T., H. Lee, S. Rose \& B. Sohngen. 2009. Modeling land-use related greenhouse gases and their mitigation potential. In Hertel, T., S. Rose \& 
R. Tol, eds. Economic Analysis of Land Use in Global Climate Change Policy, New York, NY, USA, Routledge.

Huff, K. \& T. Hertel. 2000. Decomposing welfare changes in the GTAP model. GTAP Technical Paper No.5, West Lafayette, IN, USA, Center for Global Trade Analysis, Purdue University.

International Rice Commission. 2003. Sustainable Rice Production for Food Security, Rome, Italy, FAO.

IPCC. 2000. Special report on emissions scenarios. In Nakicenovis, N. \& Swart R., eds. A Special Report of Working Group III of the Intergovernmental Panel on Climate Change (IPCC), Cambridge, UK, Cambridge University Press.

2001. Climate change 2001. Geneva, IPCC.

2001. Changes in sea level. In Houghton, J., D. Ding, M. Griggs, P. Noguer, X. Van der Linden, K. Dai \& C. Johnson, eds. Climate Change 2001: The Scientific Basis, pp. 639-694. Contribution of Working Group I to the Third Assessment Report of the Intergovernmental Panel, Cambridge, UK, Cambridge University Press.

2007. Observations: Ocean climate change and sea level. In Solomon, S., D. Qin, M. Manning, Z. Chen, M. Marquis, K. Averyt, M. Tignor \& H. Miller, eds. Climate Change 2007: The Physical Science Basis, Chapter 5, Contribution of Working Group I to the Fourth Assessment Report of the Intergovernmental Panel on Climate Change, Cambridge, UK and New York, NY, USA, Cambridge University Press.

2013. Summary for Policymakers. In

Stocker, T., D. Qin, G. Plattner, M. Tignor, S. Allen, J. Boschung, A. Nauels, Y. Xia, V. Bex \& P. Midgley, eds. Climate Change 2013: The Physical Science
Basis, Contribution of Working Group I to the Fifth Assessment Report of the Intergovernmental Panel on Climate Change, Cambridge, UK and New York, NY, USA, Cambridge University Press.

Lee, H. 2004. Incorporating agro-ecological zoned data into the GTAP framework. Paper presented at the Seventh Annual Conference on Global Economic Analysis, Washington, DC, The World Bank.

Lee, H., T. Hertel, S. Rose \& M. Avetisyan. 2009. An integrated global land use data base for CGE analysis of climate policy options. In Hertel, T., S. Rose \& R. Tol R., eds. Economic Analysis of Land Use in Global Climate Change Policy, New York, NY, USA, Routledge.

Narayanan, B. \& T. Walmsley. 2008. Global Trade, Assistance, and Production: The GTAP 7 Data Base, West Lafayette, IN, USA, Center for Global Trade Analysis, Purdue University.

Tol, R. 2002. Estimates of the damage costs of climate change. Part 1: Benchmark estimates. Environmental and Resource Economics, 21(1): 47-73.

USDA. 2012. World Rice Trade. Washington DC, Foreign Agricultural Service, United States Department of Agriculture (USDA).

Wassmann, R., N. Hien, C. Hoanh \& T. Tuong. 2004. Sea level rise affecting the Vietnamese Mekong Delta: Water elevation in the flood season and implications for rice production. Climatic Change, 66(1): 89-107. (doi:1023/ B:CLIM.0000043144.69736.b7). 



\section{chapter 9}

1. Introduction 266

2. Climatic zones suitable for banana production 267

3. Climate change impacts through 2070 on areas of climatic zones suitable for banana suitability

4. Climate change projections for 24 banana-growing areas in Latin America, Africa and Asia

5. Changes in potential productivity for 24 key banana-growing areas in Latin America, Africa and Asia for 2030, 2050 and 2070

5.1 Method to estimate banana GDD and TDU $\quad 275$

5.2 Method to estimate water deficit in bananas $\quad 280$

5.3 Results of calculations GDD, TDU and water deficit 280

6. Changes in leaf diseases for six key banana-growing sites in Latin America, Africa and Asia for 2030, 2050 and 2070

7. Changes at the margins - potential areas lost and gained for banana production in 2030, 2050 and 2070

8. Implications of climate change for global banana production

References

Citation

German Calberto, G., C. Staver and P. Siles. 2015. An assessment of global banana production and suitability under climate change scenarios, In: Climate change and food systems: global assessments and implications for food security and trade, Aziz Elbehri (editor). Food Agriculture Organization of the United Nations (FAO), Rome, 2015. 


\section{chapter 9}

\section{An assessment of global banana production and suitability under climate change scenarios}

\section{German Calberto ${ }^{1}$, Charles Staver², Pablo Siles ${ }^{3}$}

\section{main chapter messages}

- Even with temperature increases of $3^{\circ} \mathrm{C}$ by 2070 , conditions globally will continue to be highly favorable for banana production. Increasing annual temperatures will make conditions more favorable for banana production in the subtropics and in tropical highlands. Through 2070 land area suitable for bananas will increase by $50 \%$.

- Production cycles from planting to harvest will be shorter due to an accelerated rate of leaf emission, but water demand will increase by $12-15 \%$. Selected banana areas expected to surpass seasonal temperatures above $30^{\circ} \mathrm{C}$ may be lost for banana production by 2050 .

- Specific cultivar groups such as East African highland bananas merit special studies. Their special suitability to tropical highland conditions indicates that their cultivation area may expand to higher elevations. However, growers in lower elevation areas may need to substitute other cultivars as temperatures increase.

- Even though increasing temperatures are not unfavorable for banana, they may be unfavorable for perennial and annual crops with which bananas are often grown. Farm households growing crops such as coffee, with banana as a secondary crop, may abandon banana when they abandon coffee because of climate change.

- Additional analyses are needed to quantify the effects of extreme weather events and the implications for banana productivity and management. More analyses are also required to better understand the impacts on pest and disease dynamics for banana and tropical crops.

1 Bioversity International, Cali, Colombia - CGIAR Research Program on Climate Change, Agriculture and Food Security (CCAFS)

2 Bioversity International, Montpellier, France - CGIAR Research Program on Climate Change, Agriculture and Food Security (CCAFS)

3 CIAT, Managua, Nicaragua (previously Bioversity International, Turrialba, Costa Rica) 


\section{Introduction}

B anana and plantain are among the top ten crops globally in area, yield and calories, occupying seventh or eighth place depending on the category. The diverse set of cultivar groups making up banana and plantain are a source of income, food supply and dietary diversity for millions of rural and urban households throughout the tropics and subtropics. Banana is also a major export crop, the most widely consumed fruit, generating income and employment for millions of households. Unlike many other crops, which have crop cycles of 3-5 months, banana is a semi-perennial crop with a crop cycle nearly a year long under optimum conditions and even longer with lower temperatures or more erratic water supply. The vulnerability of the crop to climate change is an important consideration, demanding specific tools suited to banana growth habit and crop cycle.

Bananas and plantains figure among the top ten crops worldwide, ranking behind maize, rice, wheat, cassava, and potatoes, but ahead of sorghum, millet and sweet potatoes. The group comprising banana and plantain, unlike many of the other top ten crops, is made up of a diverse set of cultivar groups, each with a different genetic makeup, not just varieties of a single species. This diversity adds an additional dimension to any analyses of this crop. Nearly half of global production is the Cavendish group, which is the most important banana in world trade, followed by cooking bananas of diverse types, other dessert bananas and finally plantains (Table 1).

Although banana is considered a tropical crop, needing a uniform warm and rainy climate yearround, in practice bananas are grown throughout the tropics and subtropics. Bananas are found in

\section{table 1}

Banana production in tonnes by cultivar group and region for 2011

\begin{tabular}{|c|c|c|c|c|c|}
\hline \multirow[t]{2}{*}{ Tonnes } & \multicolumn{2}{|c|}{ Cooking bananas } & \multicolumn{2}{|c|}{ Dessert bananas } & \multirow[t]{2}{*}{ Total } \\
\hline & $\begin{array}{c}\text { Plantain AAB } \\
\text { group }\end{array}$ & $\begin{array}{c}\text { Highland } \\
\text { bananas }+\mathrm{ABB} \\
\text { + other } \mathrm{ABB} \\
+\mathrm{AAA}+\mathrm{AA}\end{array}$ & Cavendish & $\begin{array}{c}\text { Gros Michel \& } \\
\text { others }\end{array}$ & \\
\hline North America & 0 & 1000 & 8000 & 100 & 9100 \\
\hline South America & 5664779 & 416491 & 12479463 & 3927750 & 22488483 \\
\hline $\begin{array}{l}\text { Central } \\
\text { America }\end{array}$ & 783830 & 63835 & 7551531 & 81500 & 8480696 \\
\hline Caribbean & 1061898 & 669130 & 1125518 & 199930 & 3056476 \\
\hline $\begin{array}{l}\text { West and } \\
\text { Central Africa }\end{array}$ & 8981861 & 758796 & 2349174 & 485342 & 12575173 \\
\hline East Africa & 944716 & 12574031 & 2726439 & 874516 & 17119702 \\
\hline $\begin{array}{l}\text { North Africa \& } \\
\text { Middle East }\end{array}$ & 1031 & 135879 & 1969375 & 71871 & 2178156 \\
\hline Asia & 2130774 & 10726630 & 32034984 & 12942172 & 57834560 \\
\hline Oceania & 1286 & 530043 & 674681 & 259556 & 1465566 \\
\hline Europe & 2 & 20 & 422641 & 30 & 422693 \\
\hline World Total & 19570177 & 25875855 & 61341806 & 18842767 & 125630605 \\
\hline
\end{tabular}


southern Europe, northern Africa, Pakistan, northern India and China at their northern extreme and in Argentina, Paraguay, South Africa and Australia at their southern extreme. They are also grown in the tropics into mid-altitudes of higher than 1500 metres above sea level in the Andes, Himalayas, Kilimanjaro and the East African Highlands.

The production and consumption of the different groups vary geographically. Cavendish is concentrated in Asia and Latin America and the Caribbean, while cooking bananas are found primarily in Asia (India, Indonesia and the Philippines) and East Africa. Other dessert bananas are found primarily in Asia and Latin America. Plantains are concentrated in West and Central Africa and Latin America, but production is also found in East Africa and Asia.

The effects of climate change on agriculture have been proposed in terms of both productivity and the risk of disruption of production, with implications for food security and income for millions of households worldwide. The increase in average temperature that characterizes climate change is likely to generate an increase in the frequency and severity of extreme and moderate weather events resulting in additional episodic losses. This converts into increased vulnerability in agriculture over the medium and long term unless measures are taken to strengthen the resilience of production systems.

This study examines the effects of climate change on banana. The study also contributes to the global effort to build the response capacity of sectors linked to commodities of global importance. The study's main objectives are to:

1. Quantify the effects of climate change on growing conditions for banana globally;

2. Estimate the impacts of climate change on indicators of banana productivity;

3. Estimate the potential effects of climate change on the primary banana leaf disease;

4. Identify major changes in potential areas gained and lost in subtropical and tropical highlands and tropical lowlands due to climate change for 2030, 2050 and 2070.

\section{Climatic zones suitable for banana production}

To classify areas according to a range of suitability criteria for banana production, a spatial modelling procedure was developed and implemented in ArcGIS (Esri Inc.), using Esri Model Builder. Actual Mean Monthly Temperature and Precipitation (Spatial resolution: - 5 kilometre $(\mathrm{km})-2.5$ arc$\mathrm{min}$ ) were used for the global classification analysis found in the portal WorldClim (Hijmans et al., 2005).

Three categories of lands were identified in the initial round of analysis (see Table 2 for key temperature parameters for banana growth). Areas not suitable for banana production were defined as areas having three or more months with temperatures below $13^{\circ} \mathrm{C}$. Globally suitable areas were classified into tropical and subtropical banana production areas. Tropical areas have a relatively uniform average monthly temperature throughout the year, while subtropical areas were considered those which have a difference between the warmest and coolest months of greater than $8^{\circ} \mathrm{C}$ (as well as with fewer than three months below $\left.13^{\circ} \mathrm{C}\right)$.

For both the tropics and subtropics, subcategories were identified based on average annual temperature, total annual rainfall and length of the dry season (Table 4). A month is considered dry if it has less than $60 \mathrm{~mm}$ precipitation. Three categories of average annual temperature were identified: $13-18^{\circ} \mathrm{C}, 18-24^{\circ} \mathrm{C}$ and $>24^{\circ} \mathrm{C}$. While banana will survive in the $13-18^{\circ} \mathrm{C}$ range, leaf emission is very slow and a stem may take over two years to flower. Assuming no water limitations, in the $18-24{ }^{\circ} \mathrm{C}$ range, planting to harvest will generally take between 12 months and 24 months, while in the $>24^{\circ} \mathrm{C}$ range, a stem will produce a bunch in less than one year. For assessing total annual rainfall, four categories were proposed: $<900 \mathrm{~mm}, 900-1500 \mathrm{~mm}, 1500-2500 \mathrm{~mm}$ and $>2500 \mathrm{~mm}$. Depending on length of dry season, banana may suffer growth limitations at below $1500 \mathrm{~mm} /$ year of rainfall, while if rainfall is above 


\section{table 2}

Key temperature parameters for banana growth

\begin{tabular}{ll}
\hline Temperature $\left({ }^{\circ} \mathrm{C}\right)$ & \multicolumn{1}{c}{ Effect of temperature on banana growth } \\
\hline 47 & Thermal danger point, leaves die \\
\hline 38 & Growth stops \\
\hline 34 & Physiological heat stress starts \\
\hline 27 & Optimum mean temperature for productivity \\
\hline 13 & Minimum mean temperature for growth, field chilling \\
\hline 6 & Leaf chlorophyll destruction \\
\hline 0 & Frost damage, leaves die \\
\hline
\end{tabular}

this amount conditions for growth are more favourable. Two categories for length of dry season are used: three months or fewer with less than $60 \mathrm{~mm}$ of monthly rainfall (i.e. "dry") and more than three dry months. The combination of total annual rainfall and length of dry season provides an indication both of viability for banana growth without irrigation and of the conditions for leaf diseases. With fewer than three dry months and greater than $150 \mathrm{~mm} / \mathrm{month}$ of rainfall, banana grows well year-round without irrigation. Such conditions are also more favourable for leaf diseases.

Based on these parameters, the current suitability for banana cultivation can be mapped and quantified (Figure 1, Table 3). Currently across the globe the land area not suitable for banana 140 million square kilometres - is far larger than the tropical and subtropical lands suitable for banana. Potential banana lands in the subtropics and tropics are split about evenly, with around 40 million square kilometres in each climatic region.

For the subtropics, the vast majority of lands (36 million $\mathrm{km}^{2}$ ) receive less than $900 \mathrm{~mm}$ of rainfall annually (Figure 2, Table 5) and over half of these also experience annual temperatures between 13$18^{\circ} \mathrm{C}$. These lands are suitable for banana only with special practices. Around seven million square kilometres in the subtropics offer more favourable rainfall and temperature conditions for banana.

For the tropics, in terms of temperature, all lands are suitable except high elevations, which represent only about two million square kilometres (Table 5). Suitable areas in terms of temperature and rainfall, including the extremely wet zones with over $2500 \mathrm{~mm}$ rainfall, represent around 30 million square kilometres. This can be contrasted with a current area under banana and plantain production of 126000 square kilometres (calculated based on 10 tonnes/hectare approximate yield).

\section{Climate change impacts through 2070 on areas of climatic zones for banana suitability}

The impact of climate change on the land area for agroclimatic zones was also mapped and quantified using climate change projections based on data from the Climate Change, Agriculture and Food Security (CCAFS) data portal (Ramirez and Jarvis, 2008) with a resolution of five kilometres. Projections were done for 2030, 2050 and 2070, assuming scenario A2 and the average of 20 general circulation models (GCMs). Tropical and subtropical areas are combined in this analysis, although shown separately in Table 5 .

Over the projected period, the most important banana-growing areas will increase substantially in area (Figure 2). Zones 131, 231, 331 and 431 will all increase substantially in area. In each of 


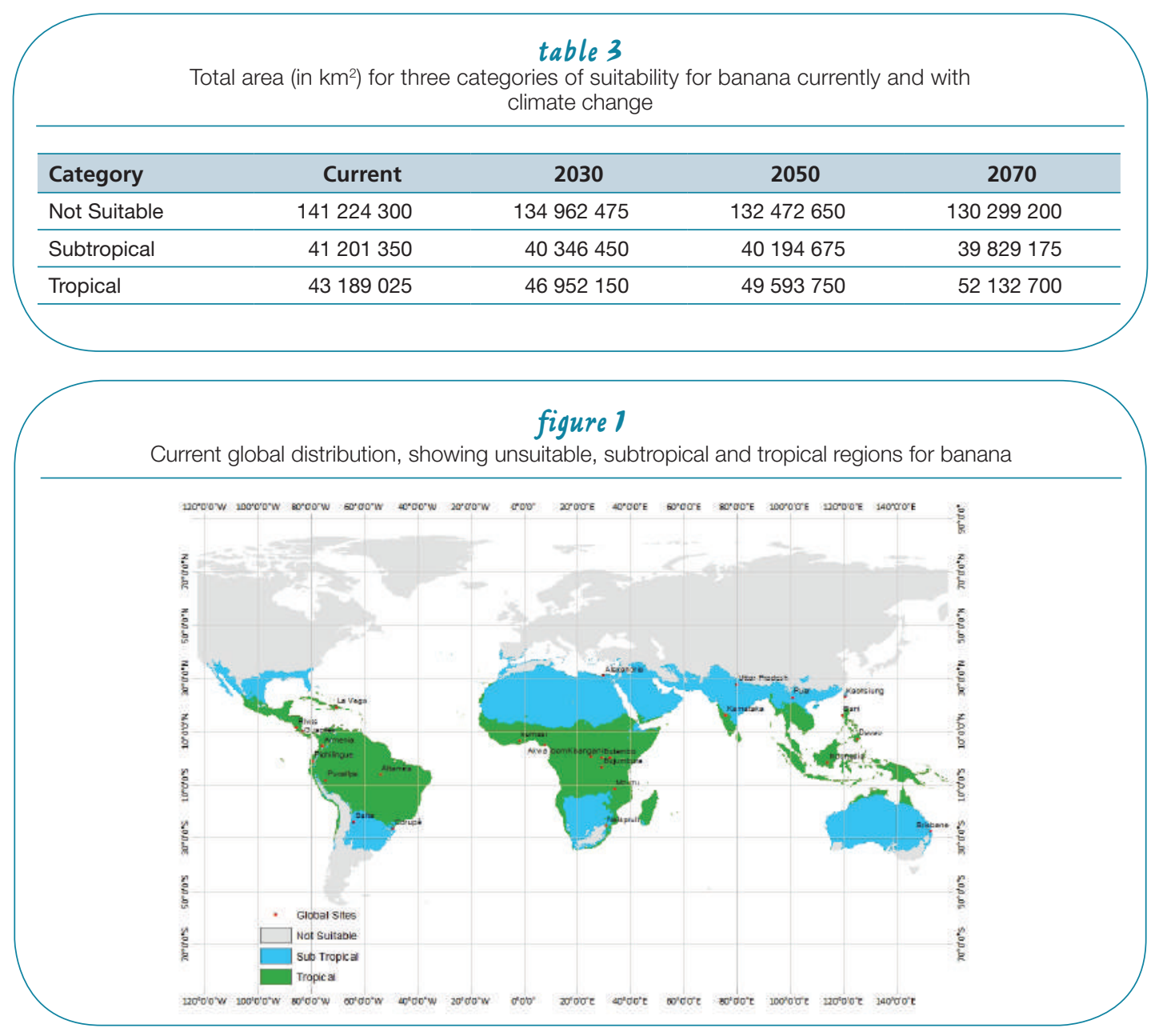

the rainfall regimes (represented by the first digit in Table 5), there is a decline in the areas with cooler temperatures (represented by second digit of $1\left(13-18^{\circ} \mathrm{C}\right)$ ) and an increase in higher temperatures (represented by second digit of 2 or $3\left(18-24^{\circ} \mathrm{C}\right.$ or $\left.>24^{\circ} \mathrm{C}\right)$ ). Table 5 also highlights a new category, 141 , to identify those areas which will be subject to excessively high temperatures ( $>35^{\circ} \mathrm{C}$ for at least three months per year). These areas first appear in 2050 and increase substantially by 2070 , although they make up only a small percentage of area suitable for banana.

This broad overview of suitability based on temperature and rainfall indicates that lands suitable for banana production will continue to be widely available for banana-growing in the subtropics and tropics even with climate change. However, there will be an increase in climatic zones with higher temperatures and the appearance of areas not suitable due to extended periods of extremely high temperatures. This suggests that if temperatures continue to increase beyond 2070, more areas in the tropics may be lost for banana production due to excessively high temperatures. 


\begin{tabular}{|c|c|c|c|c|c|c|c|c|}
\hline \multicolumn{9}{|c|}{$\begin{array}{c}\text { table } 4 \\
\text { Agroclimatic zones }\end{array}$} \\
\hline \multirow{3}{*}{$\begin{array}{l}>3 \text { dry } \\
\text { months } \\
\text { (1) }\end{array}$} & \multicolumn{4}{|c|}{$<900 \mathrm{~mm}(1)$} & \multicolumn{4}{|c|}{$900-1500 \mathrm{~mm} \mathrm{(2)}$} \\
\hline & $\begin{array}{c}13-18^{\circ} \mathrm{C} \\
\text { (1) }\end{array}$ & $\begin{array}{c}18-24^{\circ} \mathrm{C} \\
(2)\end{array}$ & $\begin{array}{c}>24^{\circ} \mathrm{C} \\
\text { (3) }\end{array}$ & $\begin{array}{c}>35^{\circ} \mathrm{C} \\
(4)\end{array}$ & $\begin{array}{c}13-18^{\circ} \mathrm{C} \\
(1)\end{array}$ & $\begin{array}{c}18-24^{\circ} \mathrm{C} \\
\text { (2) }\end{array}$ & $\begin{array}{c}>24{ }^{\circ} \mathrm{C} \\
\text { (3) }\end{array}$ & $\begin{array}{c}>35^{\circ} \mathrm{C} \\
\text { (4) }\end{array}$ \\
\hline & 111 & 121 & 131 & 141 & 211 & 221 & 231 & 241 \\
\hline \multirow{3}{*}{$\begin{array}{c}<3 \text { dry } \\
\text { months } \\
\text { (2) }\end{array}$} & \multicolumn{4}{|c|}{$<900 \mathrm{~mm}(1)$} & \multicolumn{4}{|c|}{$900-1500 \mathrm{~mm} \mathrm{(2)}$} \\
\hline & $\begin{array}{c}13-18^{\circ} \mathrm{C} \\
\text { (1) }\end{array}$ & $\begin{array}{c}18-24^{\circ} \mathrm{C} \\
\text { (2) }\end{array}$ & $\begin{array}{c}>24^{\circ} \mathrm{C} \\
\text { (3) }\end{array}$ & $\begin{array}{c}>35^{\circ} \mathrm{C} \\
(4)\end{array}$ & $\begin{array}{c}13-18^{\circ} \mathrm{C} \\
\text { (1) }\end{array}$ & $\begin{array}{c}18-24^{\circ} \mathrm{C} \\
\text { (2) }\end{array}$ & $\begin{array}{c}>24{ }^{\circ} \mathrm{C} \\
\text { (3) }\end{array}$ & $\begin{array}{c}>35^{\circ} \mathrm{C} \\
(4)\end{array}$ \\
\hline & 112 & 122 & 132 & 142 & 212 & 222 & 232 & 242 \\
\hline \multirow{3}{*}{$\begin{array}{c}>3 \text { dry } \\
\text { months } \\
(1)\end{array}$} & \multicolumn{4}{|c|}{$1500-2500 \mathrm{~mm} \mathrm{(3)}$} & \multicolumn{4}{|c|}{$>2500 \mathrm{~mm} \mathrm{(4)}$} \\
\hline & $\begin{array}{c}13-18^{\circ} \mathrm{C} \\
(1)\end{array}$ & $\begin{array}{c}18-24^{\circ} \mathrm{C} \\
(2)\end{array}$ & $\begin{array}{c}>24{ }^{\circ} \mathrm{C} \\
(3)\end{array}$ & $\begin{array}{c}>35^{\circ} \mathrm{C} \\
(4)\end{array}$ & $\begin{array}{c}13-18^{\circ} \mathrm{C} \\
(1)\end{array}$ & $\begin{array}{c}18-24^{\circ} \mathrm{C} \\
(2)\end{array}$ & $\begin{array}{c}>24{ }^{\circ} \mathrm{C} \\
\text { (3) }\end{array}$ & $\begin{array}{c}>35^{\circ} \mathrm{C} \\
(4)\end{array}$ \\
\hline & 311 & 321 & 331 & 241 & 411 & 421 & 431 & 441 \\
\hline \multirow{3}{*}{$\begin{array}{c}<3 \text { dry } \\
\text { months } \\
\text { (2) }\end{array}$} & \multicolumn{4}{|c|}{$1500-2500 \mathrm{~mm}(3)$} & \multicolumn{4}{|c|}{$>2500 \mathrm{~mm}(4)$} \\
\hline & $\begin{array}{c}13-18^{\circ} \mathrm{C} \\
(1)\end{array}$ & $\begin{array}{c}18-24{ }^{\circ} \mathrm{C} \\
(2)\end{array}$ & $\begin{array}{c}>24^{\circ} \mathrm{C} \\
\text { (3) }\end{array}$ & $\begin{array}{c}>35^{\circ} \mathrm{C} \\
(4)\end{array}$ & $\begin{array}{c}13-18^{\circ} \mathrm{C} \\
(1)\end{array}$ & $\begin{array}{c}18-24^{\circ} \mathrm{C} \\
(2)\end{array}$ & $\begin{array}{c}>24^{\circ} \mathrm{C} \\
\text { (3) }\end{array}$ & $\begin{array}{c}>35^{\circ} \mathrm{C} \\
(4)\end{array}$ \\
\hline & 312 & 322 & 332 & 342 & 412 & 422 & 432 & 442 \\
\hline
\end{tabular}

\section{Climate change projections for 24 banana-growing areas in Latin America, Africa and Asia}

To further explore the implications of climate change for banana-growing, we identified 24 sites where banana is an important crop, located in contrasting climatic zones in Latin America, Africa and Asia (Table 7). Eight sites were chosen from each major continent, with no more than two sites per country. These sites represent 13 of the climatic zones in Table 5. They include seven subtropical sites, five tropical highland sites, six wet/dry tropical sites and six wet tropical sites (see Figures 3-6 for the different groupings and their projected climate change). For each site, changes in average temperature and monthly rainfall were projected for 2030, 2050 and 2070, using data from the CCAFS database portal (Ramirez and Jarvis, 2008) with a resolution of five kilometres. Projections assume scenario A2 and an average of 20 GCMs.

The subtropical sites (Figure 3) show a marked difference between a cooler season when minimum temperatures are as low as $10^{\circ} \mathrm{C}$ and a high sun season with elevated temperatures. Two sites have extremely high temperatures in the summer season - Salta, Argentina and Uttar Pradesh, India - with temperatures ranging above $40{ }^{\circ} \mathrm{C}$, especially for 2050 and 2070 . Rainfall is highly variable for the different sites. Some sites have highly uniform rainfall distribution from month to month, while others receive a major part of the annual rainfall in only a few months. The projections for the next decades show little major change in monthly rainfall distribution.

For the tropical highland sites (Figure 4), temperatures are quite uniform throughout the year, except for the site in China, which is a 


\begin{tabular}{|c|c|c|c|c|c|c|c|c|c|c|}
\hline \multirow[t]{2}{*}{ Value } & \multicolumn{5}{|c|}{ Subtropical } & \multicolumn{5}{|c|}{ Tropical } \\
\hline & Current & 2030 & 2050 & 2070 & & Current & 2030 & 2050 & 2070 & \\
\hline 0 & 0 & 1350 & 1750 & 1875 & + & & & & & \\
\hline 111 & 1907000 & 1202500 & 775525 & 542900 & - & 616725 & 382125 & 253025 & 183900 & - \\
\hline 112 & 4450 & 3375 & 12575 & 16950 & + & 3975 & 3400 & 1475 & 1275 & - \\
\hline 121 & 17749650 & 15634075 & 13442900 & 11594125 & - & 2495050 & 1638800 & 1234875 & 933800 & - \\
\hline 122 & 3400 & 1200 & 3050 & 17175 & + & 9700 & 2975 & 4225 & 3050 & - \\
\hline 131 & 16018350 & 21161325 & 25159125 & 28595100 & + & 4653925 & 5556050 & 6085825 & 6333975 & + \\
\hline 132 & 0 & 0 & 0 & 25 & + & 3600 & 5425 & 4950 & 5325 & + \\
\hline \multirow[t]{2}{*}{141} & 0 & 0 & 225 & 30700 & + & 0 & 0 & 0 & 17975 & + \\
\hline & 35682000 & 38002475 & 39393400 & 40796975 & + & 7783000 & 7588775 & 7584375 & 7479300 & - \\
\hline 211 & 251325 & 266700 & 241575 & 205875 & - & 326900 & 199475 & 126225 & 85100 & - \\
\hline 212 & 472000 & 229150 & 171200 & 159975 & - & 82800 & 57375 & 49450 & 50450 & - \\
\hline 221 & 1384225 & 1299950 & 1370450 & 1319475 & - & 4449025 & 2900100 & 2138425 & 1234025 & - \\
\hline 222 & 1067550 & 1580275 & 1842650 & 1962050 & + & 772075 & 355225 & 232675 & 151400 & - \\
\hline 231 & 1756375 & 2299825 & 2600575 & 3034800 & + & 6807200 & 8279450 & 8957925 & 9626725 & + \\
\hline \multirow[t]{2}{*}{232} & 24225 & 74700 & 168725 & 241200 & + & 601775 & 916975 & 943325 & 1065850 & + \\
\hline & 4956000 & 5750600 & 6395175 & 6923375 & + & 13400000 & 12708600 & 12448025 & 12213550 & - \\
\hline 311 & 89900 & 69950 & 51825 & 38025 & - & 78375 & 32575 & 17475 & 8650 & - \\
\hline 312 & 166950 & 106700 & 69300 & 51200 & - & 182175 & 109200 & 81500 & 63275 & - \\
\hline 321 & 760350 & 602375 & 521200 & 445975 & - & 1167375 & 561550 & 374200 & 275825 & - \\
\hline 322 & 808575 & 1237050 & 1491850 & 1707725 & + & 1669025 & 829525 & 620600 & 494750 & - \\
\hline 331 & 404525 & 764225 & 1087850 & 1372525 & + & 2930250 & 3813325 & 4377875 & 4755450 & + \\
\hline \multirow[t]{2}{*}{332} & 14425 & 25875 & 107600 & 250525 & + & 8185925 & 8539500 & 8319750 & 7963500 & - \\
\hline & 2245000 & 2806175 & 3329625 & 3865975 & + & 14213000 & 13885675 & 13791400 & 13561450 & - \\
\hline 411 & 17200 & 11725 & 8825 & 7275 & - & 800 & 2300 & 2525 & 1400 & + \\
\hline 412 & 3225 & 2625 & 2375 & 3150 & - & 98825 & 76000 & 64125 & 55375 & - \\
\hline 421 & 128850 & 103875 & 94850 & 86600 & - & 56125 & 41575 & 31275 & 25700 & - \\
\hline 422 & 31975 & 33625 & 39025 & 42600 & + & 792950 & 506150 & 393100 & 312050 & - \\
\hline 431 & 116025 & 190700 & 257125 & 317800 & + & 384025 & 421500 & 457500 & 494250 & + \\
\hline \multirow[t]{2}{*}{432} & 5750 & 21200 & 35600 & 50600 & + & 4830875 & 5115850 & 5422300 & 5686100 & + \\
\hline & 303000 & 363750 & 437800 & 508025 & + & 6164000 & 6163375 & 6370825 & 6574875 & + \\
\hline
\end{tabular}


figure 2

Map showing changing distribution for climatic zones for banana suitability (Table 4) A: Current, B: 2050

\section{A: Current}

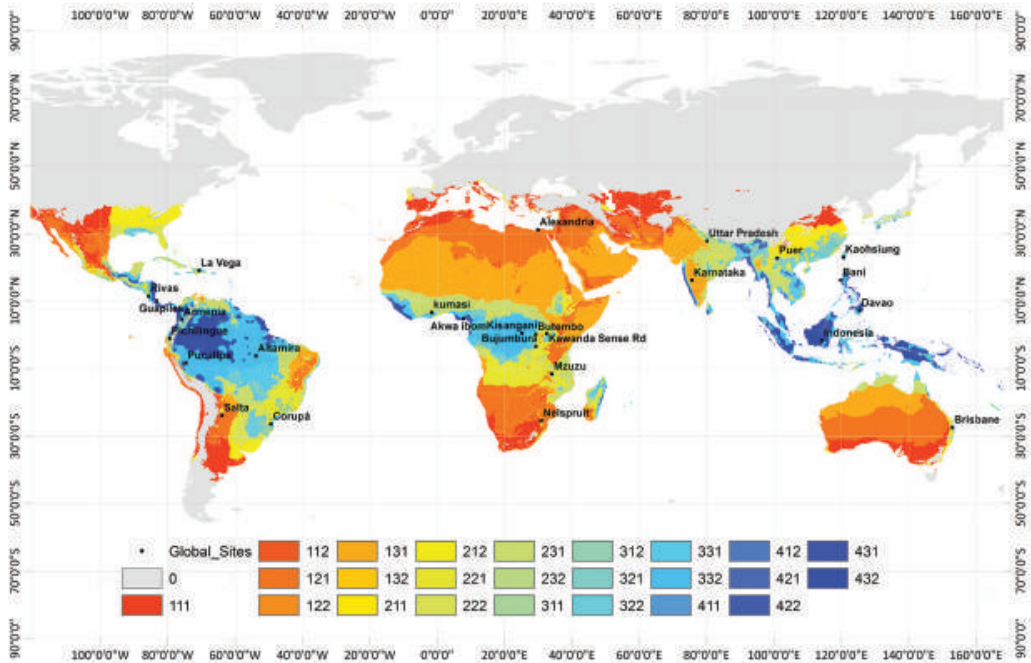

\section{B: 2050}

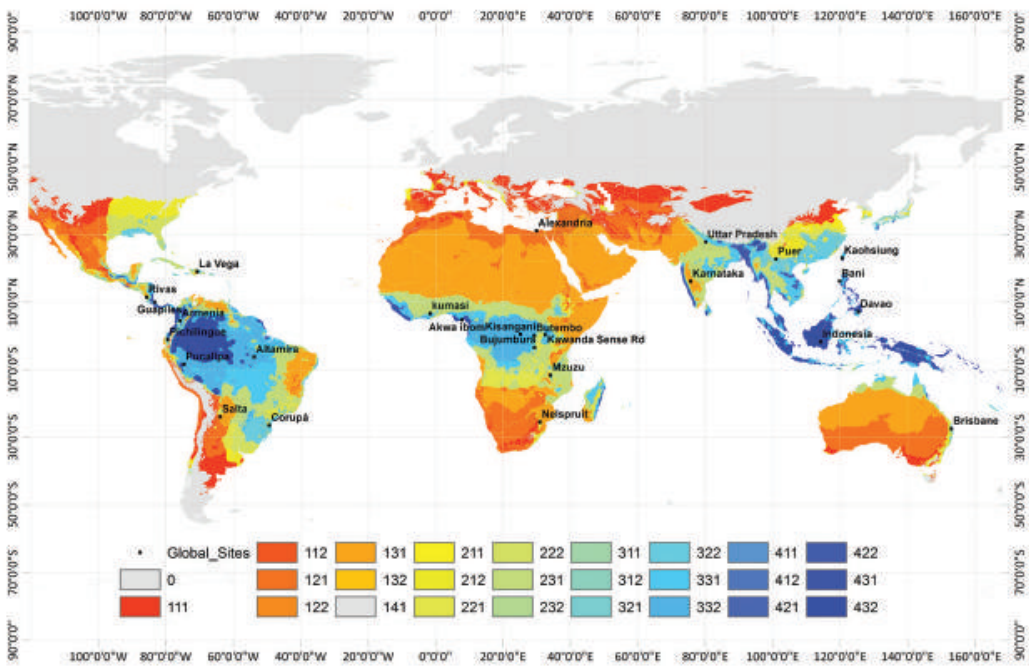


highland area (1300 metres above sea level), although subtropical in location. For the China site, winter temperatures are limiting for banana growth, although according to climate change projections, the winter cold will be moderated. Temperatures in the other sites - even by 2070 - range between 15 and $30{ }^{\circ} \mathrm{C}$, well within the acceptable parameters for banana growth. Several sites will shift to the agroclimatic zone which has temperatures $>24^{\circ} \mathrm{C}$. Rainfall distribution varies from site to site. Sites such as Kawanda, North Kivu and Armenia have no dry months, while the other sites have seasonal dry periods. The monthly rainfall distribution is not projected to change over the period studied.

For the remaining two blocks of sites, wet/ dry tropics (Figure 5) and wet tropics (Figure 6), average temperatures are projected to increase over the next 50 years by over $3{ }^{\circ} \mathrm{C}$, from $25^{\circ} \mathrm{C}$ to $28^{\circ} \mathrm{C}$, but remain largely within a favourable range of $25-30{ }^{\circ} \mathrm{C}$. Maximum temperatures will reach the danger zone for banana in the India site by 2070, although even for current production, occasional heat waves may cause damage to new banana plants and to emerging bunches. On average, rainfall is not highly variable, except for the sites in Central America and the Caribbean, where rainfall is projected to decline by 2050 and 2070 .

Five of the 24 sites will shift agroclimatic categories due to temperature change over the period from the present to 2070: Kawanda, Uganda; Butembo, Democratic Republic of the Congo (DRC); Mzuzu, Malawi; Salta, Argentina; and Armenia, Colombia (Table 6). These sites will shift from an $18-24{ }^{\circ} \mathrm{C}$ temperature range to a $>24^{\circ} \mathrm{C}$ temperature range. Three sites will shift the climatic zone to which they are mapped due to rainfall changes: Rivas, which will become drier; Kawanda, which is projected to become wetter; and La Vega. In La Vega several months hover right around the limit of $60 \mathrm{~mm} / \mathrm{month}$, which is considered the difference between a dry month and a wet month and thus changes the length of the dry season based on rainfall.

In summary, based on this analysis of 24 sites:

- All sites demonstrate the linear increase in temperatures - average as well as minimum and maximum temperatures - which has made climate change a concern for humankind.

- Only three sites show trends towards extremely high temperatures - two in India and one in Argentina - which may limit banana growth.

\section{table 6}

Shift in agroclimatic zone for sites showing change in category with climate change (other sites unchanged)

\begin{tabular}{|c|c|c|c|c|c|c|}
\hline Region & Country & Town & Current & 2030 & 2050 & 2070 \\
\hline Africa & Uganda & Kawanda & 222 & 222 & 322 & 332 \\
\hline Africa & DRC & Butembo & 312 & 322 & 322 & 322 \\
\hline Africa & Nigeria & Akwa Ibom & 432 & 432 & 432 & 432 \\
\hline Africa & Malawi & Mzuzu & 321 & 331 & 331 & 331 \\
\hline Africa & DRC & Kisangani & 332 & 332 & 332 & 332 \\
\hline America & Argentina & Salta & 121 & 121 & 131 & 131 \\
\hline America & Colombia & Armenia & 322 & 322 & 322 & 332 \\
\hline America & Dominican Rep. & La Vega & 222 & 221 & 221 & 221 \\
\hline America & Nicaragua & Rivas & 331 & 231 & 231 & 231 \\
\hline
\end{tabular}




\section{table 7}

Agroclimatic zone for selected sites grouped by zones

\begin{tabular}{|c|c|c|c|c|c|c|}
\hline Zone & Region & Country & $\begin{array}{l}\text { City/Prov- } \\
\text { ince }\end{array}$ & Town & Longitude & Latitude \\
\hline 121 & Africa & South Africa & Nelspruit & Nelspruit & 30.97 & -25.47 \\
\hline 121 & America & Argentina & Salta & Salta & -63.86 & -23.92 \\
\hline 131 & Asia & India & Bagalkot & Karnataka & 75.69 & 16.19 \\
\hline 222 & Africa & Uganda & Kampala & Kawanda & 32.52 & 0.41 \\
\hline 222 & America & $\begin{array}{l}\text { Dominican } \\
\text { Rep. }\end{array}$ & La Vega & La Vega & -70.71 & 19.06 \\
\hline 222 & $\begin{array}{l}\text { Australia \& } \\
\text { Oceania }\end{array}$ & Australia & Queensland & Brisbane & 153.02 & -27.47 \\
\hline 231 & Africa & Burundi & Bujumbura & Bujumbura & 29.36 & -3.38 \\
\hline 231 & Asia & India & Uttar Pradesh & Uttar Pradesh & 80.12 & 27.81 \\
\hline 232 & Africa & Ghana & Kumasi & Kumasi & -1.60 & 6.69 \\
\hline 312 & Africa & DRC & Kivu Norte & Butembo & 29.28 & 0.13 \\
\hline 321 & Africa & Malawi & Mzuzu & Mzuzu & 34.07 & -11.64 \\
\hline 321 & Asia & China & Yunnan & Puer & 100.99 & 22.78 \\
\hline 322 & America & Brazil & St. Catarina & Corupá & -49.30 & -26.44 \\
\hline 322 & America & Colombia & Quindío & Armenia & -75.72 & 4.53 \\
\hline 331 & America & Nicaragua & Rivas & Rivas & -85.64 & 11.51 \\
\hline 331 & America & Ecuador & Los Rios & Pichilingue & -79.46 & -1.10 \\
\hline 332 & Africa & DRC & Kisangani & Kisangani & 25.18 & 0.53 \\
\hline 332 & America & Peru & Ucayali & Pucallpa & -74.58 & -8.38 \\
\hline 332 & Asia & Philippines & Davao Region & Davao & 125.46 & 7.22 \\
\hline 421 & Asia & Taiwan & Kaohsiung & Kaohsiung & 120.66 & 23.06 \\
\hline 431 & Asia & Philippines & Bani & Bani & 119.86 & 16.24 \\
\hline 432 & Africa & Nigeria & Akwa Ibom & Akwa Ibom & 7.86 & 4.80 \\
\hline 432 & America & Costa Rica & Guapiles & Guapiles & -83.26 & 10.04 \\
\hline 432 & Asia & Indonesia & $\begin{array}{l}\text { Cent. } \\
\text { Kalimantan }\end{array}$ & Palangkaraya & 114.26 & -1.70 \\
\hline
\end{tabular}


- In most sites the rainfall distribution during the year and the amount of rainfall per month are quite stable from the present through 2030, 2050 and 2070. The sites in Central America and the Caribbean are projected to experience declines in monthly rainfall, while sites in Uganda and Burundi show a tendency to increase.

\section{Changes in potential productivity for 24 key banana-growing areas in Latin America, Africa and Asia for 2030, 2050 and 2070}

The analysis in the previous section is based on general growing conditions for banana and provides an overview of the effects of average climate change. Diverse tools have been used to convert the general requirements for growth into more quantified effects. For example, niche modelling, such as with Maxent, Bioclim and Ecocrop, has been used in many different crops. Ecocrop has been used in banana (van den Bergh et al., 2012). Models such as Ecocrop use annual data for temperature and rainfall which limits their applicability for crops that have a 12- month cycle and that may use irrigation.

To establish a quantitative index of the effects of changing temperature and water availability on banana growth, we developed a calculation using monthly temperature and rainfall. Leaf emission rate is a key variable in banana productivity, because the rate of leaf emission is closely correlated to the length of the vegetative cycle and the development time from one bunch to the next for each banana mat. Leaf emission rate is highly influenced by temperature and available water. Three calculations were carried out: 1) effect of temperature alone, measured by growing degree days (GDD); 2) thermal development units (TDU), in which GDD are reduced by excess or insufficient available soil water for optimum growth; and 3) water deficit, based on a water balance using natural rainfall and optimum crop needs. All three calculations were carried out for current conditions and 2030, 2050 and 2070.

\subsection{Method to estimate banana GDD and TDU}

The basic concept of GDD is that plant development will occur when temperatures exceed a base temperature and cease when a non-lethal maximum temperature is exceeded. GDD assigns a heat value to each day, then the values are added together to give an estimate of the amount of seasonal growth that banana plants have to achieved. If the temperature is only slightly above base temperature, few GDD are accumulated. If the temperature is just below the non-lethal maximum temperature, then a higher amount of GDD are accumulated. Depending on the unit of time of the calculations and the temperatures, the number of growing degree days are accumulated for the period. To estimate GDD for banana, monthly temperatures were used. A base temperature of $13^{\circ} \mathrm{C}$ was subtracted from the monthly average temperature to give an average GDD. If the average GDD were calculated to be a negative number that number was made equal to zero. If the mean monthly temperature exceeded $35^{\circ} \mathrm{C}$, then the GDD would be 0 , due to high temperatures (Thomas et al. 1998; Turner and Lahav, 1983). Monthly GDD were calculated by multiplying daily GDD calculated based on monthly temperatures by the number of days of each month and then summing GDD for each month for the year. The total number of GDD for the year was then converted to the number of leaves by dividing by $108^{\circ} \mathrm{C}$, the number of GDD needed to generate a new leaf. Some effect of photoperiod on GDD accumulation has been shown by Fortescue, Turner and Romero (2011), but that effect was not included in this analysis.

The calculation of number of leaves/year by means of TDU uses GDD reduced by the effects of water limitation. The relationship between TDU and GDD for a time period is: 


\section{figure 3}

Average monthly temperature and rainfall projections for subtropical banana-growing areas, using average values for 20 GCMs under scenario A2. A: Nelspruit (South Africa), B: Salta (Argentina), C: Brisbane (Australia), D: Uttar Pradesh (India), E: Corupá (Brazil), F: Kaohsiung (Taiwan)

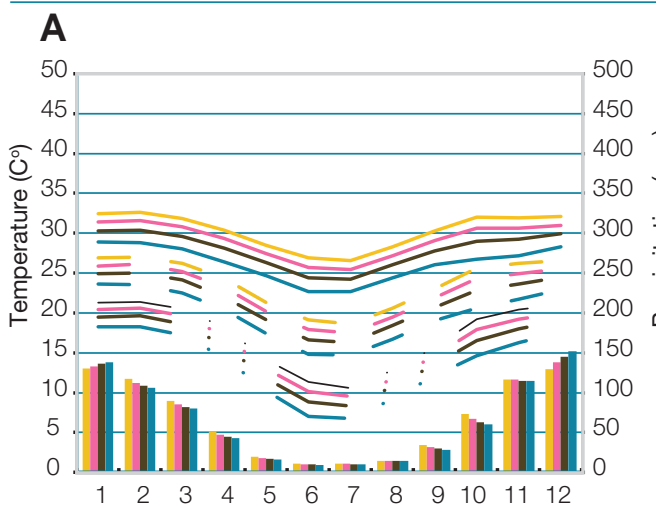

C

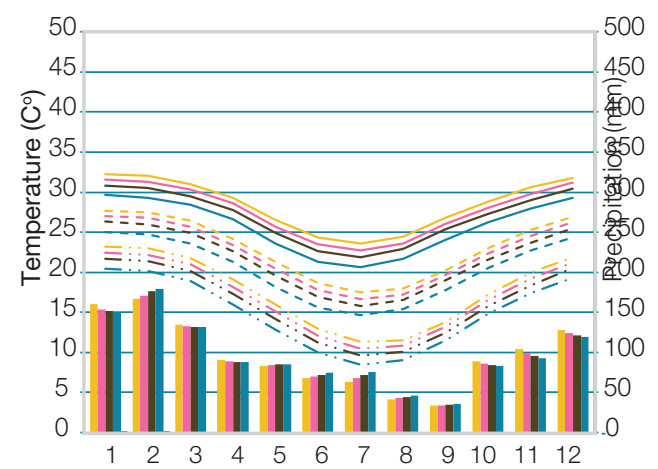

E
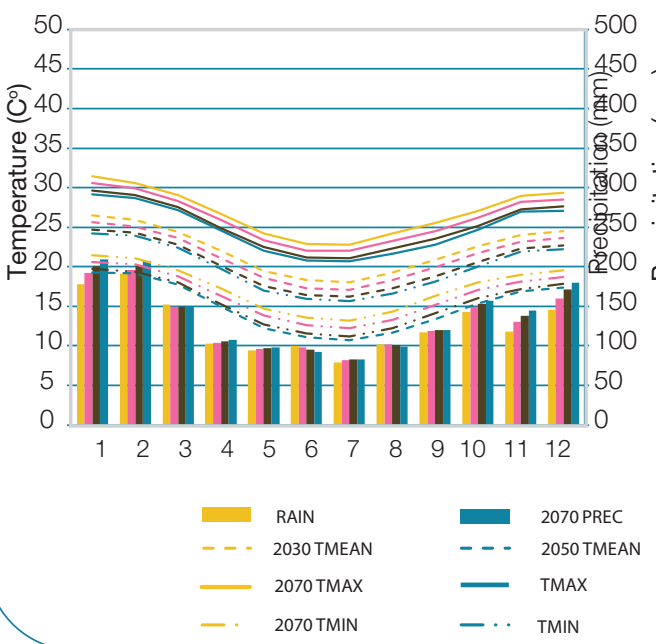

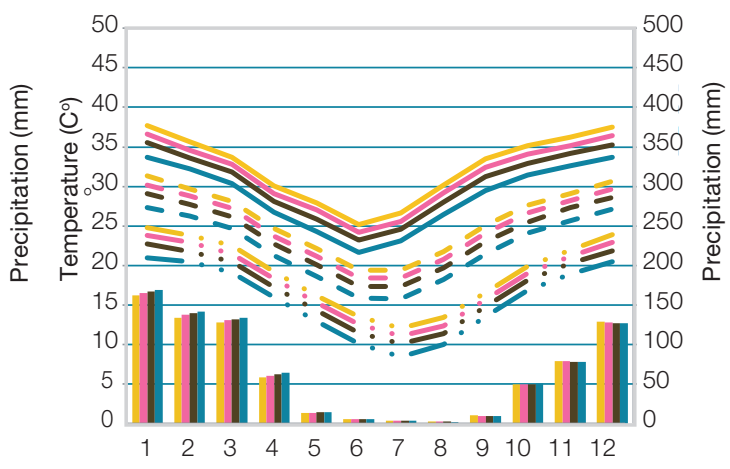

D

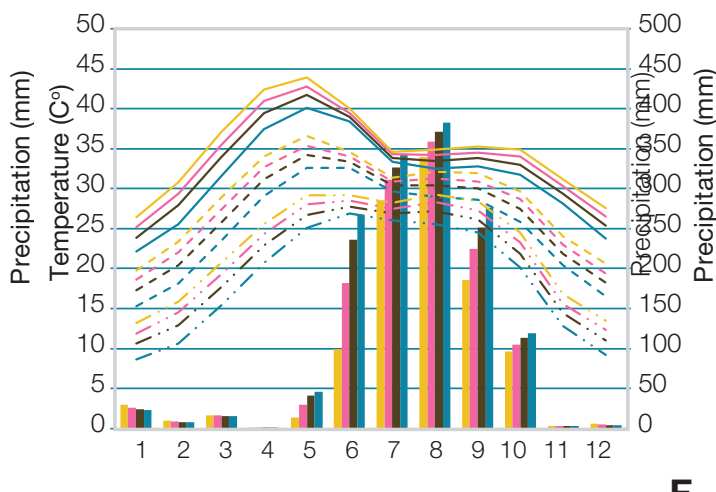

$\mathbf{F}$
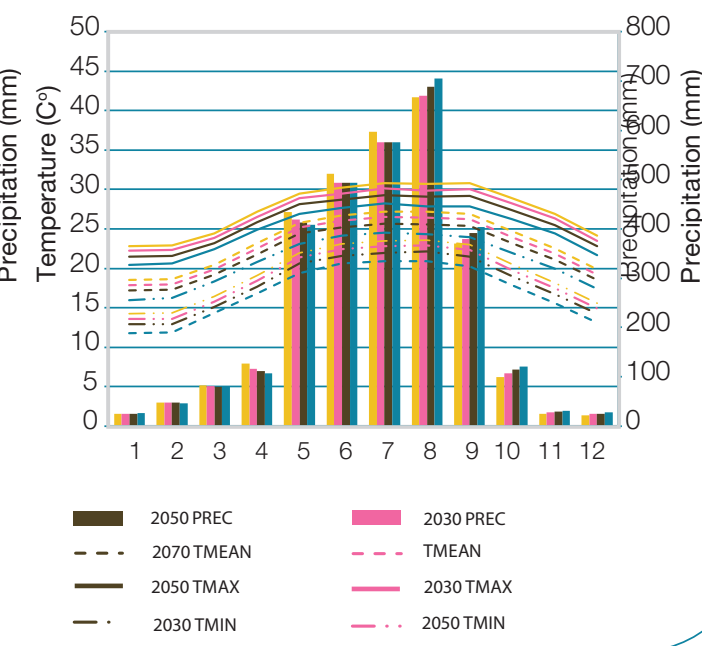


\section{figure 4}

Average monthly temperature and precipitation projections for highland tropical banana growing areas, using average values for 20 GCMs under scenario A2. G: Puer (China) subtropical highland, H: Kawanda (Uganda), I: Bujumbura (Burundi), J: North Kivu (DRC), K: Mzuzu (Malawi), L: Armenia (Colombia)
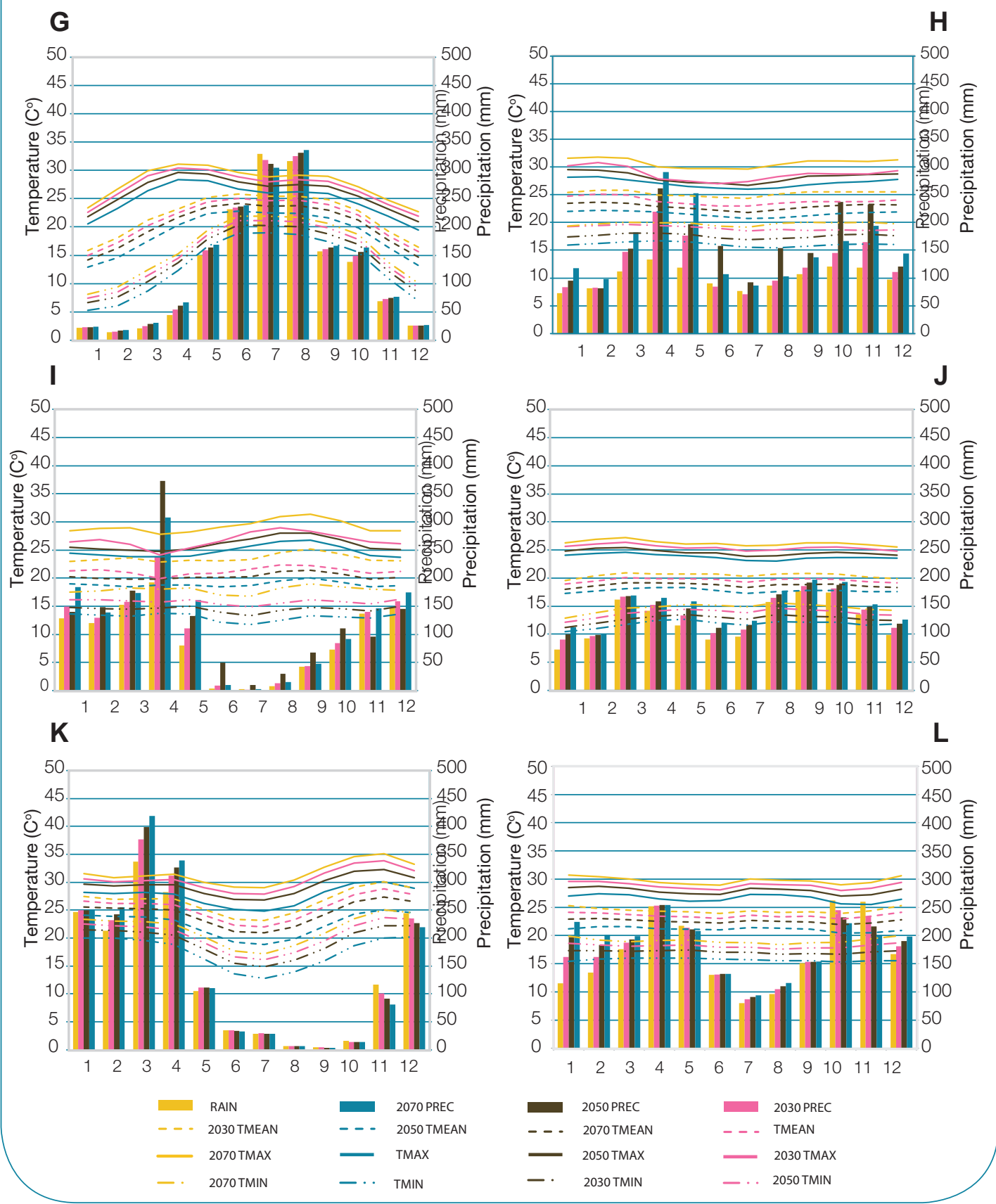


\section{figure 5}

Average monthly temperature and precipitation projections for wet/dry tropical banana-growing areas, using average values for 20 GCMs under scenario A2. M: Karnataka (India), N: La Vega (Dominican Republic), O: Kumasi (Ghana), P: Rivas (Nicaragua), Q: Pichilingue (Ecuador), R: Pucallpa (Perú)
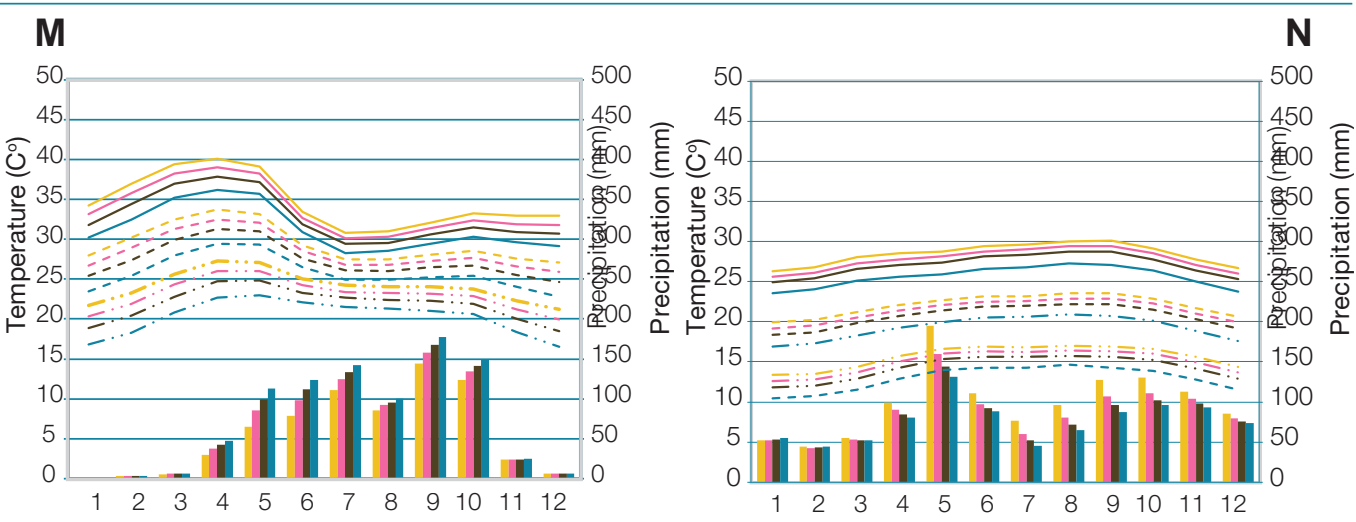

\section{0}
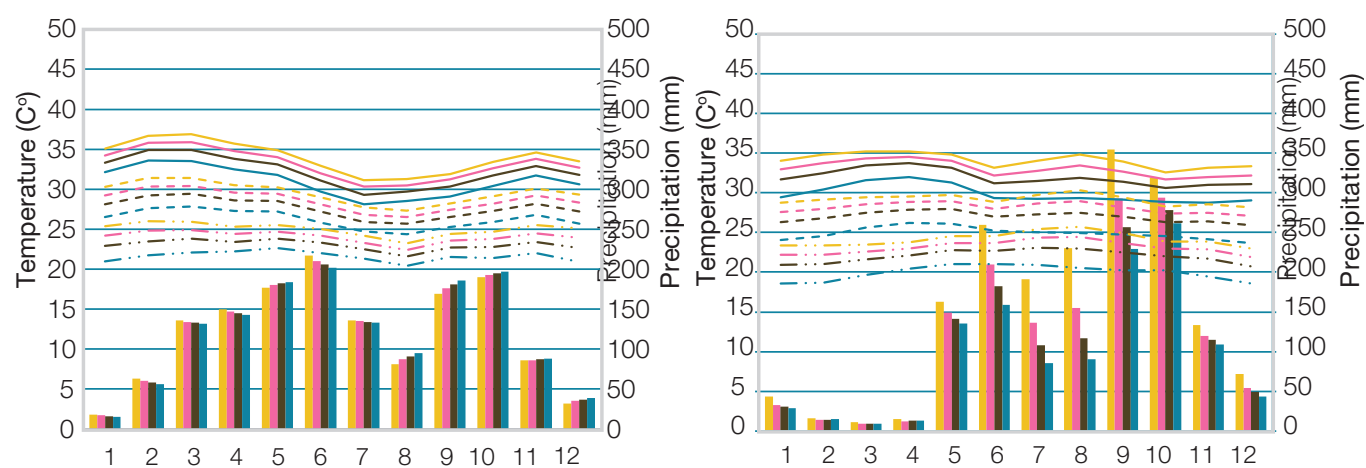

Q
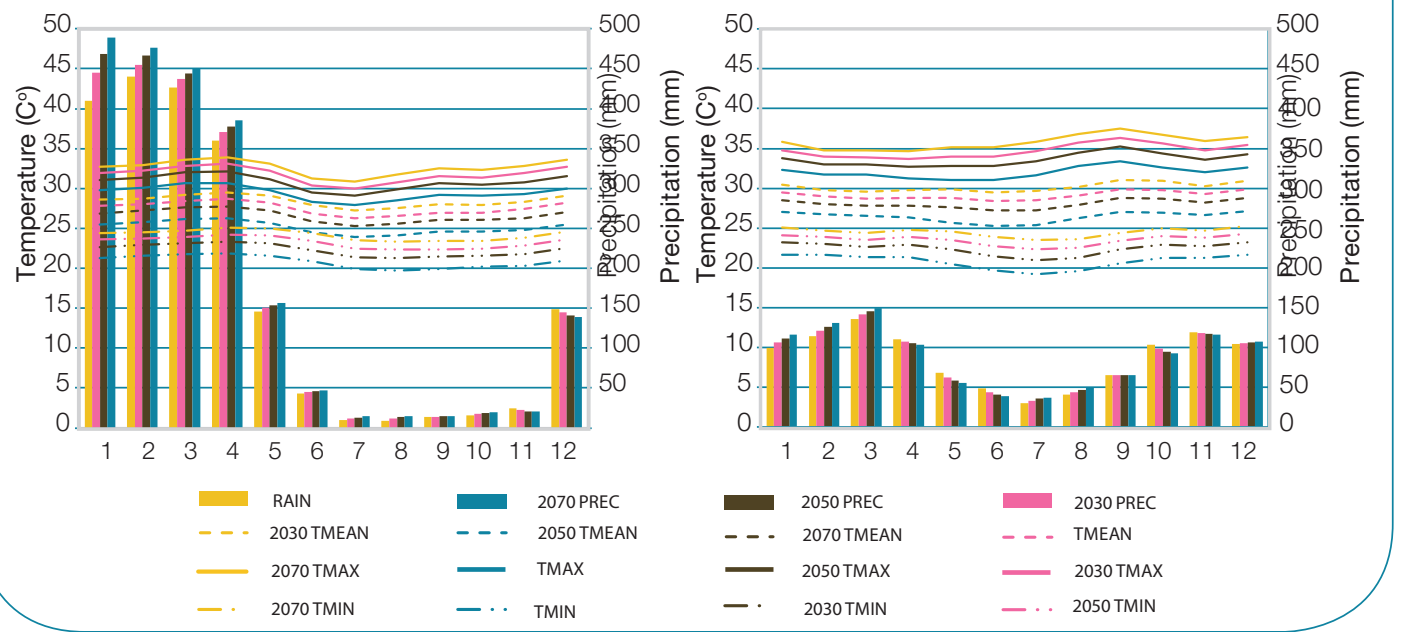


\section{figure 6}

Average monthly temperature and precipitation projections for wet tropical banana-growing areas, using average values for 20 GCMs under scenario A2. S: Guapiles (Costa Rica), T: Akwa Ibom (Nigeria),

U: Central Kalimantan (Indonesia, V: Davao (Philippines), W: Bani (Philippines), X: Kisangani (DRC)

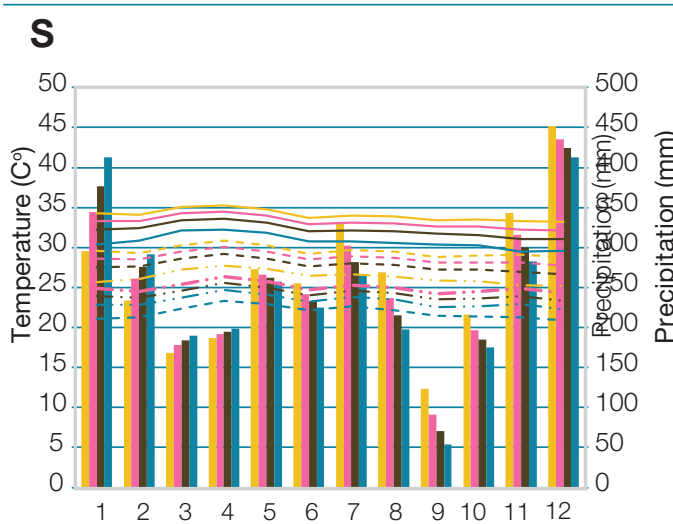

$\mathbf{U}$
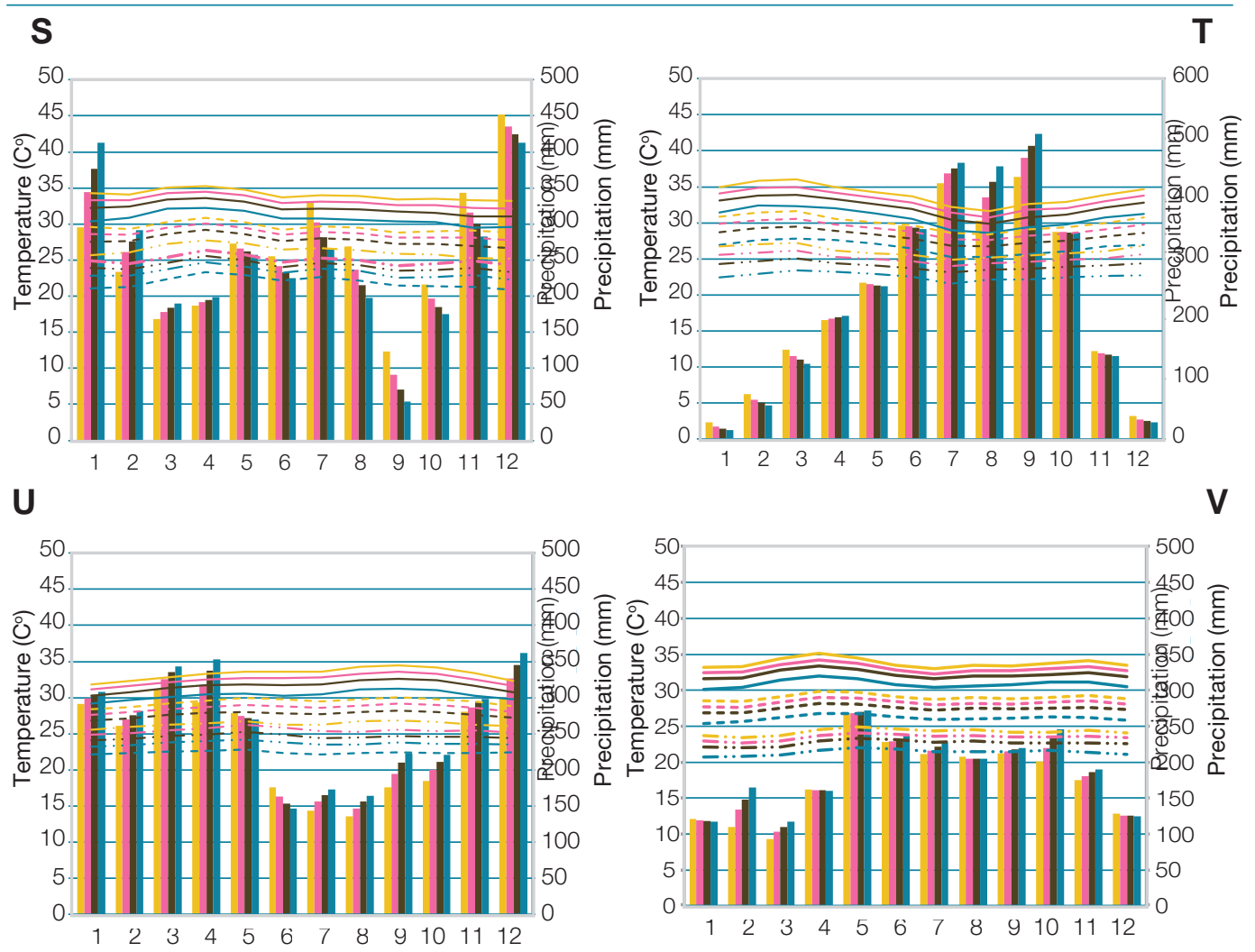

W
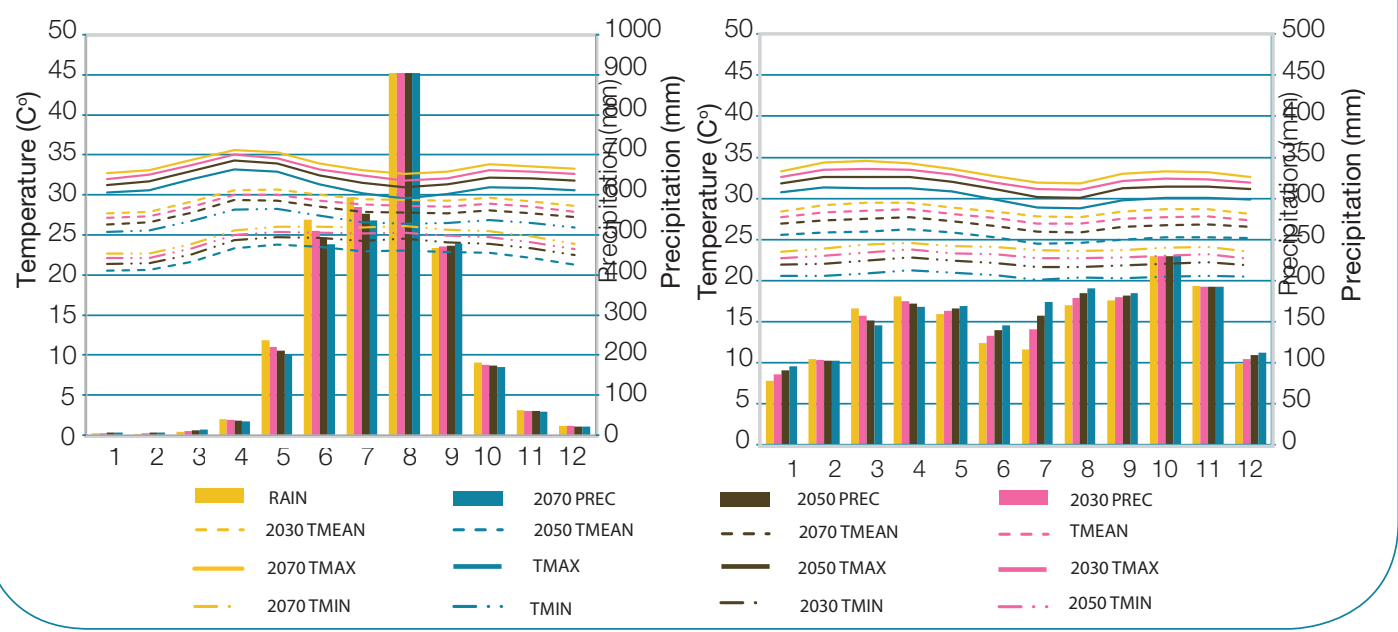


\section{$T D U=G D D * P f * W f\left({ }^{\circ} C d\right)$}

Where: $\boldsymbol{P f}$ is a scalar (0.0 to 1.0) for photoperiod and $\boldsymbol{W} \boldsymbol{f}$ is a scalar (0.0 to 1.0) for soil water balance. Pf was not taken into account in this study. The soil water balance $(\boldsymbol{W} \boldsymbol{f})$ was estimated monthly, from the ratio of rainfall/potential evaporation (Rain/PET), taking $\boldsymbol{W} f$ as 1.0 if the ratio fell between 1.0 and 1.1. If Rain/PET was above 1.1 then $\boldsymbol{W} \boldsymbol{f}=1+0.2(1-$ Rain/PET), allowing for a negative effect for excess of water (Fortescue et al., 2011).

\subsection{Method to estimate water deficit for bananas}

The irrigation water need or water deficit for banana was estimated on a monthly basis and calculated for the year as the difference between the crop water need and that part of the rainfall which can be used by the crop, known as effective rainfall. Actual evapotranspiration (AET) is the quantity of water that is removed from the soil due to evaporation and transpiration processes (Allen et al., 1998). AET is dependent on solar radiation and temperature as well as the vegetation characteristics, quantity of water available in the soil and soil hydrological properties (mainly soil water retention curves):

\section{AET $=$ Ksoil $*$ Kc $*$ PET $($ mm/month $)$}

Where: Ksoil $=$ reduction factor dependent on volumetric soil moisture content (0-1), $K c=$ banana crop coefficient dependent on the development of the crop (0.3-1.3). The crop coefficient $(K \boldsymbol{c})$ is used to estimate the crop water use for reference PET for different crops or vegetation types. A Kc value for banana of 1.15 was taken from the literature (Allen et al., 1998; Freitas, et al., 2008; Silva and Bezerra, 2009).

The effective rainfall in this study was estimated using an empirical formula from FAO/Water Resources, Development and Management Service (AGLW) based on analysis carried out for various climatic data (Clarke et al., 2001; Smith, 1992).
Both TDU and AET depend on an estimation of potential evaporation (PET). The Hargreaves model was chosen (Hargreaves and Allen, 2003), as it performed almost as well as the FAO Penman-Monteith model, but required less parameterization (Hargreaves and Allen, 2003; Trajkovic, 2007). To calculate PET, the Hargreaves model uses mean monthly temperature and global solar radiation at the surface, measured in units of water evaporation.

\subsection{Method to estimate water deficit for bananas}

The calculations for annual leaf emission based on GDD (Table 8) show the effects of the linear increase in temperature alone on total leaf emission for a 12-month period. From the present to 2070, GDD will increase by 30 percent, i.e. about 1000-1200 across all sites. This increase results from the increase in monthly average temperatures. This represents an increase in leaf emission of about 10 leaves, although a few sites show slightly lower increases. This increase represents more potential bunches/hectare per year. The site in Uttar Pradesh, India, is notable, since by 2070 , the site is no longer viable for banana based on an extended period of over three months with average temperatures of about $35^{\circ} \mathrm{C}$.

The calculation of leaf emission based on TDU takes into account not only the effects of temperature, but also the water limitations for rainfed production (Figure 7, Table 8). In those sites where total leaf emission continues to be limited by water, rather than temperature, leaf emission rates are stable or increase only slightly. In other sites with more uniform rainfall throughout the year, such as Kisangani, Corupá and Armenia, leaf emission increases by up to ten leaves over the 12-month period by 2070.

The differences between increases in leaf emission based on GDD and TDU highlight the importance of water availability in banana productivity. This is projected using a 
calculation of water deficit (Table 9). From the present through 2070, the increase in average temperature will result not only in an increased leaf emission potential and the accompanying increase in number of bunches, but also an increase in crop water demand to meet PET. The amount of water to be applied as irrigation to meet plant needs will increase by 12-15 percent over the period. The demands are higher for the drier sites than for sites with rainfall $>2500 \mathrm{~mm} /$ year.

\section{Changes in leaf diseases for six key banana- growing sites in Latin America, Africa and Asia for 2030, 2050, and 2070}

In addition to effects on leaf emission and water demand, average climate change may also affect the conditions for disease incidence and severity. The most important leaf disease, Mycosphaerella fijiensis or black leaf streak (BLS), was used as an indicator of the projected effect of climate change on banana pest management.

Six of the 24 sites were chosen for more detailed analysis based on the rainfall categories - three subtropical sites: Salta (121); Brisbane (222); and Puer (321), one tropical upland site: Kawanda (222) and two tropical sites: Pichilingue (331); and Davao (332).

To project the effect of changes in average climate on BLS, daily weather data are needed. The simulator program MarkSim works at a scale of 30 arc-seconds to simulate daily rainfall patterns from the database WorldClim (Hijmans et al., 2005). For each of the years 2030, 2050 and 2070, MarkSim was run ten times to generate daily rainfall patterns. These were then averaged to obtain a single daily rainfall pattern for the location. These daily patterns were then used in two calculations for BLS - velocity of evolution and state of evolution.
The velocity of evolution of BLS is linked to temperature. The minimum temperature for the germination of BLS is $12^{\circ} \mathrm{C}$, the optimal is $27^{\circ} \mathrm{C}$ and the maximum is $36^{\circ} \mathrm{C}$ (Porras and Perez, 1997). In general, the germination of conidia is optimal between $25^{\circ} \mathrm{C}$ and $30^{\circ} \mathrm{C}$ following a quadratic function type-response with an estimation of $26.5^{\circ} \mathrm{C}$ as an optimal temperature for germination. Additionally, almost 100 percent germination is presented after 24 hours (Jacome et al., 1991; Jacome and Schuh, 1992). For ascospore germination, the estimated optimal temperature is $25^{\circ} \mathrm{C}$ (Jacome et al., 1991; Jacome and Schuh, 1992). Ascospores and conidia have different responses to relative humidity. Ascospores germinate only when relative humidity is higher than 98 percent, while conidia germinate in a wider range of humidity (88 to 100 percent) (Jacome et al., 1991). The daily sum of development rates of evolution of BLS was calculated based on maximum and minimum daily temperature with a simple regression developed by Porras and Perez (1997).

The projected increase in temperatures at all six sites could be expected to result in increased growth rates for the germination tube of spores of $\mathrm{BLS}$ and more rapid disease development. As shown in Figure 8, response is variable by site, but in general by 2050 and 2070 the velocity of evolution is projected to increase.

A second approach to projecting the effect of average climate change on BLS is based on the state of evolution or advance of the disease. In general, leaf infection by BLS ascospores is not observed in the absence of leaf wetness. Infection by BLS conidia occurs at leaf wetness of between 0 to 18 hours. Leaf lesions appear 14 days after inoculation of plants subjected to 18 hours of leaf wetness (cited by Jacome and Schuh, 1992). In general, the development of BLS in the field can be monitored by the evolution of BLS in leaf four $(\mathrm{EE} 4 \mathrm{H})$ or leaf five $(\mathrm{EE} 5 \mathrm{H})$. Taking into account the 14-day delay before appearance of the disease, Perez et al. (2006) developed a model to predict the evolution state of EE4H based on the accumulated rainfall for 14 days five weeks before 


\section{table 8}

Total annual leaf emission based on temperature (GDD) and temperature and water (TDU)

\begin{tabular}{|c|c|c|c|c|c|c|c|c|c|c|}
\hline \multirow[t]{2}{*}{ Region } & \multirow[t]{2}{*}{ Country } & \multirow[t]{2}{*}{ Town } & \multicolumn{4}{|c|}{ GDD } & \multicolumn{4}{|c|}{ TDU } \\
\hline & & & Current & 2030 & 2050 & 2070 & Current & 2030 & 2050 & 2070 \\
\hline Africa & Uganda & Kawanda & 25 & 30 & 32 & 36 & 21 & 24 & 24 & 25 \\
\hline Africa & DRC & Butembo & 15 & 20 & 22 & 26 & 13 & 12 & 14 & 18 \\
\hline Africa & Burundi & Bujumbura & 34 & 38 & 39 & 44 & 24 & 21 & 19 & 23 \\
\hline Africa & Ghana & Kumasi & 39 & 44 & 46 & 50 & 29 & 32 & 35 & 35 \\
\hline Africa & Nigeria & Akwa Ibom & 41 & 46 & 47 & 50 & 27 & 28 & 29 & 33 \\
\hline Africa & Malawi & Mzuzu & 26 & 31 & 32 & 36 & 16 & 17 & 18 & 20 \\
\hline Africa & DRC & Kisangani & 37 & 42 & 44 & 48 & 35 & 40 & 41 & 44 \\
\hline Africa & South Africa & Nelspruit & 19 & 26 & 29 & 33 & 16 & 16 & 17 & 18 \\
\hline America & Brazil & Corupá & 20 & 25 & 27 & 31 & 18 & 21 & 24 & 27 \\
\hline America & Argentina & Salta & 27 & 31 & 34 & 37 & 16 & 18 & 19 & 19 \\
\hline America & Colombia & Armenia & 21 & 27 & 28 & 31 & 19 & 26 & 27 & 29 \\
\hline America & Costa Rica & Guapiles & 40 & 44 & 46 & 49 & 35 & 39 & 40 & 43 \\
\hline America & Dominican Rep. & La Vega & 14 & 18 & 19 & 21 & 21 & 24 & 24 & 26 \\
\hline America & Nicaragua & Rivas & 40 & 47 & 51 & 55 & 24 & 27 & 27 & 27 \\
\hline America & Peru & Pucallpa & 40 & 45 & 48 & 52 & 36 & 38 & 40 & 41 \\
\hline America & Ecuador & Pichilingue & 36 & 41 & 42 & 45 & 19 & 23 & 25 & 28 \\
\hline Asia & Taiwan & Kaohsiung & 24 & 26 & 27 & 29 & 13 & 15 & 17 & 16 \\
\hline Asia & India & Karnataka & 38 & 43 & 44 & 48 & 16 & 16 & 16 & 17 \\
\hline Asia & India & $\begin{array}{l}\text { Uttar } \\
\text { Pradesh }\end{array}$ & 35 & 41 & 42 & 0 & 17 & 19 & 19 & 0 \\
\hline Asia & Philippines & Davao & 39 & 43 & 44 & 47 & 35 & 37 & 38 & 41 \\
\hline Asia & Philippines & Bani & 42 & 47 & 48 & 49 & 17 & 17 & 19 & 18 \\
\hline Asia & Indonesia & Kalimantan & 40 & 44 & 46 & 49 & 35 & 37 & 40 & 42 \\
\hline Asia & China & Puer & 16 & 22 & 23 & 28 & 14 & 18 & 18 & 21 \\
\hline $\begin{array}{l}\text { Australia } \\
\text { \& Oceania }\end{array}$ & Australia & Brisbane & 22 & 26 & 28 & 32 & 20 & 23 & 25 & 26 \\
\hline
\end{tabular}




\section{figure 7}

Thermal Development Units (TDU) for current climate and projection for 2050, using average values for 20 GCMs under scenario A2. A: Current, B: 2050

\section{A: Current}

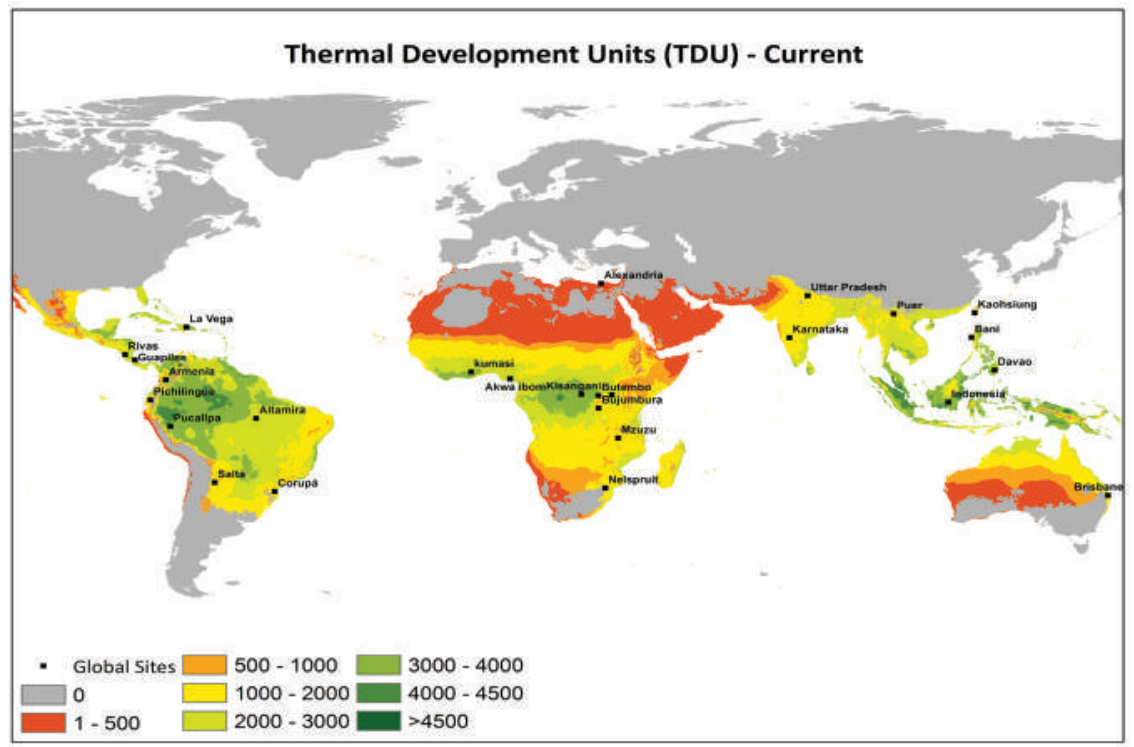

\section{B: 2050}

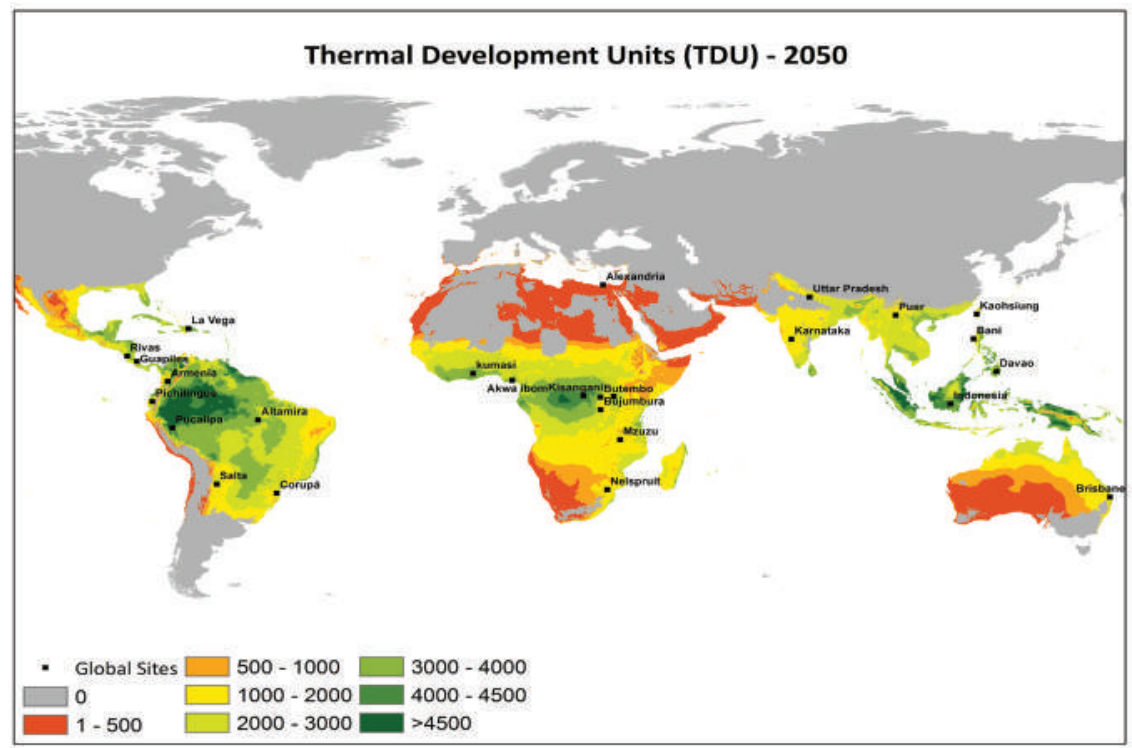




\section{table 9}

Banana water demand (AET) and deficit ( $\mathrm{mm} /$ year) for 24 banana-growing zones for current climate and projections

\begin{tabular}{|c|c|c|c|c|c|c|c|c|c|c|}
\hline \multirow[t]{2}{*}{ Region } & \multirow[t]{2}{*}{ Country } & \multirow[t]{2}{*}{ Town } & \multicolumn{4}{|c|}{ Crop Water Demand (AET) } & \multicolumn{4}{|c|}{$\begin{array}{c}\text { Water Deficit } \\
\text { (AET-effective rainfall) }\end{array}$} \\
\hline & & & Current & 2030 & 2050 & 2070 & Current & 2030 & 2050 & 2070 \\
\hline Africa & Uganda & Kawanda & 1743 & 1829 & 1899 & 1988 & 1077 & 1203 & 1312 & 1405 \\
\hline Africa & DRC & Butembo & 1525 & 1556 & 1614 & 1695 & 651 & 802 & 855 & 873 \\
\hline Africa & Burundi & Bujumbura & 1733 & 1806 & 1854 & 1942 & 996 & 1339 & 1432 & 1446 \\
\hline Africa & Ghana & Kumasi & 2026 & 2084 & 2095 & 2241 & 1154 & 1106 & 1104 & 1320 \\
\hline Africa & Nigeria & Akwa Ibom & 1678 & 1759 & 1806 & 1879 & 613 & 729 & 763 & 777 \\
\hline Africa & Malawi & Mzuzu & 1497 & 1546 & 1582 & 1664 & 642 & 699 & 710 & 734 \\
\hline Africa & DRC & Kisangani & 1852 & 2010 & 2078 & 2177 & 794 & 943 & 1046 & 1150 \\
\hline Africa & South Africa & Nelspruit & 1420 & 1550 & 1605 & 1686 & 992 & 1165 & 1215 & 1312 \\
\hline America & Brazil & Corupá & 1316 & 1347 & 1336 & 1399 & 358 & 350 & 397 & 391 \\
\hline America & Argentina & Salta & 1820 & 1858 & 1879 & 1985 & 1383 & 1360 & 1366 & 1458 \\
\hline America & Colombia & Armenia & 1586 & 1711 & 1702 & 1761 & 370 & 338 & 332 & 565 \\
\hline America & Costa Rica & Guapiles & 1879 & 1924 & 1940 & 2000 & 105 & 221 & 230 & 260 \\
\hline America & Dominican Rep. & La Vega & 1712 & 1808 & 1835 & 1893 & 1016 & 1113 & 1149 & 1231 \\
\hline America & Nicaragua & Rivas & 2062 & 2138 & 2206 & 2306 & 1043 & 1271 & 1418 & 1600 \\
\hline America & Peru & Pucallpa & 1995 & 2061 & 2090 & 2202 & 977 & 1104 & 1124 & 1241 \\
\hline America & Ecuador & Pichilingue & 1808 & 1859 & 1911 & 2048 & 844 & 837 & 866 & 954 \\
\hline Asia & Taiwan & Kaohsiung & 1352 & 1441 & 1462 & 1511 & 410 & 481 & 449 & 526 \\
\hline Asia & India & Karnataka & 2058 & 2097 & 2133 & 2169 & 1682 & 1757 & 1790 & 1786 \\
\hline Asia & India & Uttar Pradesh & 1887 & 2055 & 2078 & 2043 & 1300 & 1434 & 1428 & 1439 \\
\hline Asia & Philippines & Davao & 1892 & 2018 & 2046 & 2120 & 527 & 669 & 692 & 652 \\
\hline Asia & Philippines & Bani & 1849 & 1928 & 1946 & 1971 & 976 & 1033 & 1030 & 1087 \\
\hline Asia & Indonesia & Kalimantan & 1658 & 1741 & 1768 & 1883 & 196 & 281 & 324 & 434 \\
\hline Asia & China & Puer & 1716 & 1700 & 1753 & 1973 & 884 & 938 & 957 & 1119 \\
\hline $\begin{array}{l}\text { Australia } \\
\text { \& Oceania }\end{array}$ & Australia & Brisbane & 1355 & 1410 & 1464 & 1545 & 691 & 706 & 789 & 866 \\
\hline
\end{tabular}


the date of prediction and the average potential evapotranspiration two weeks before the date of prediction (Perez et al., 2006).

This latter approach to projecting the response of BLS to average climate change (Figure 9) indicates that there will probably be little change in the dynamic of BLS seasonally. The lines of different colours in the Figure largely overlap for each of the locations. Given that the rainfall distribution is not projected to change and that this calculation is based on wetness parameters, the disease will continue to be highly problematic in the rainy season and much less aggressive during drier periods of the year.

Bringing together the two calculations for BLS epidemiology and management, the following implications can be tentatively proposed. The period of the year when BLS is the most difficult to manage will remain the same - primarily the rainy season. The disease may become more aggressive, as the velocity of growth of the germination tube of the spores is projected to increase in response to temperature. However, this will only occur in the presence of leaf wetness.

\section{Changes at the margins - potential areas lost and gained for banana production in 2030, 2050 and 2070}

The shift among the different climatic zones for banana production globally provides a final view of the implications of climate change for the world's capacity to produce bananas. Based primarily on changes in average temperature, the world will continue to have large land areas which are suitable for banana production. We examine first the areas lost to production due to excessively high temperatures, then look at the trends for shifts from unsuitably cold temperatures to $13-18^{\circ} \mathrm{C}$ and from $13-18^{\circ} \mathrm{C}$ to $>24^{\circ} \mathrm{C}$ for each of the major continents (Table 10).
By 2070, projections indicate that certain areas in Africa and Asia will have at least three months with average monthly temperatures above $35^{\circ} \mathrm{C}$, conditions not suitable for banana production (Table 10). These areas are found in the interior of the Sahara and of India. No areas are projected to be lost in Latin America and the Caribbean.

On the other end of the scale - areas that are unsuitable due to extended cold periods below $13^{\circ} \mathrm{C}$ - there is a decline in all continents from the current status through 2070 (Table 10). Over five million square kilometres will shift out of the unsuitably cold category globally, with over 87 percent in Asia, 12 percent in Latin America and only very small areas in Africa.

The category of lands in the range of temperature from $13-18{ }^{\circ} \mathrm{C}$ will show an increase in potential banana-growing area based on lands shifting away from unsuitably cold, but will also lose lands due to a shift into the category $18-24{ }^{\circ} \mathrm{C}$. On balance, the lands in this latter category will decline by nearly four million square kilometres. Given the global nature of increasing temperatures, it can be assumed that all shifts are into the next higher temperature category. Shifts due to declining temperatures are unlikely, as are shifts of lands by two categories. The shifts into the $13-18^{\circ} \mathrm{C}$ range are quite equally distributed among the three continents. Combining gains and losses over the period of the projections, over nine million square kilometres total may be shifting into this category.

The category of lands in the range of temperature from $18-24{ }^{\circ} \mathrm{C}$ will show an increase based on lands shifting from 13$18^{\circ} \mathrm{C}$, but will also lose lands due to a shift of lands into the temperature range $>24^{\circ} \mathrm{C}$. Over the period of climate change projections done in this study, lands in the range of $18-24{ }^{\circ} \mathrm{C}$ will decline by nearly ten million square kilometres - over 60 percent in Africa, followed by 25 percent in Latin America and the Caribbean, with the remainder in Asia. More detailed studies would be useful, but 


\section{figure 8}

Sums of velocity of BLS evolution based on temperature.

A: Salta, (Argentina), B: Brisbane (Australia), C: Puer (China), D: Kawanda (Uganda), E: Pichilingue (Ecuador), F: Davao, (Philippines).

\section{A}

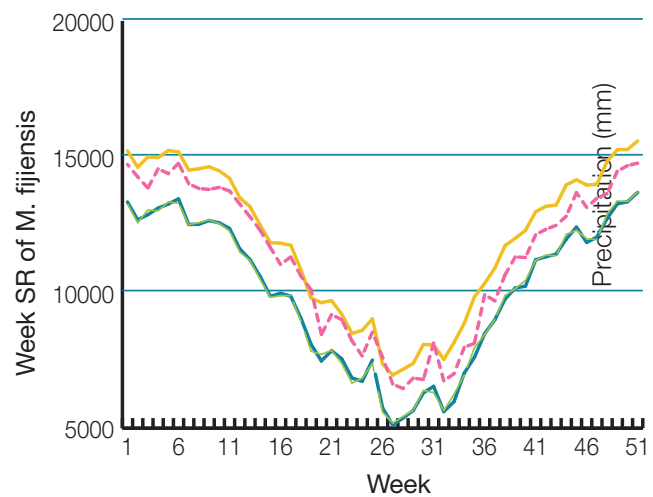

C

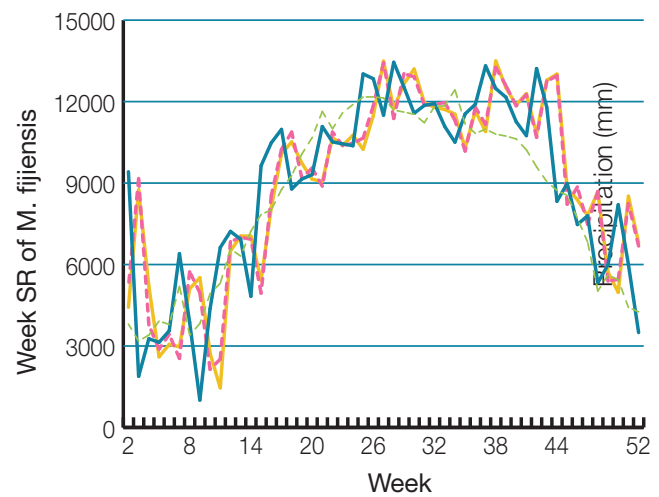

E

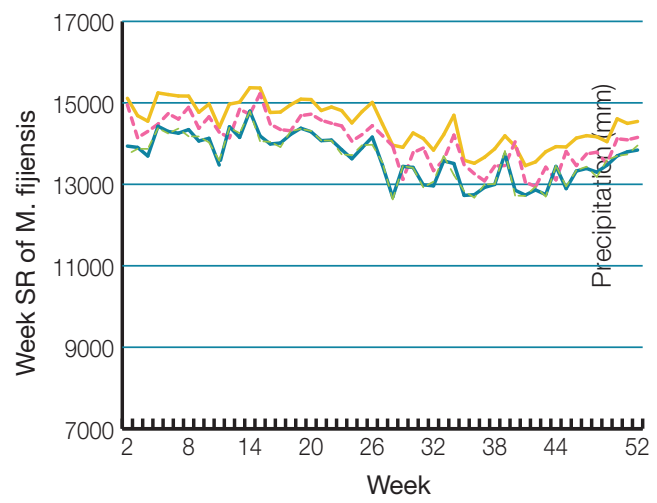

B
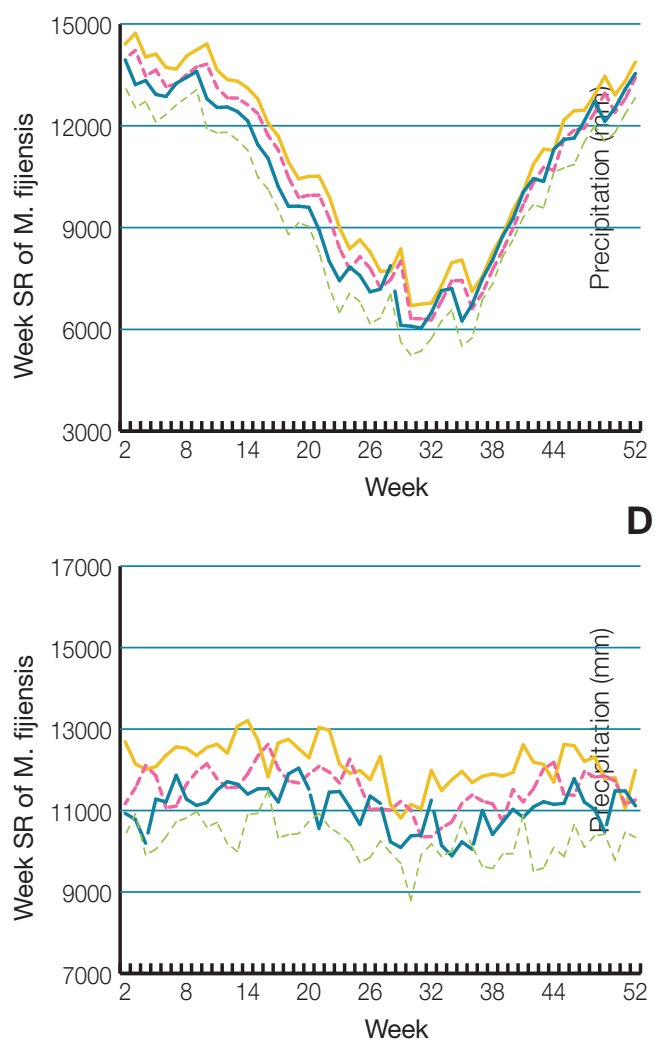

$\mathbf{F}$

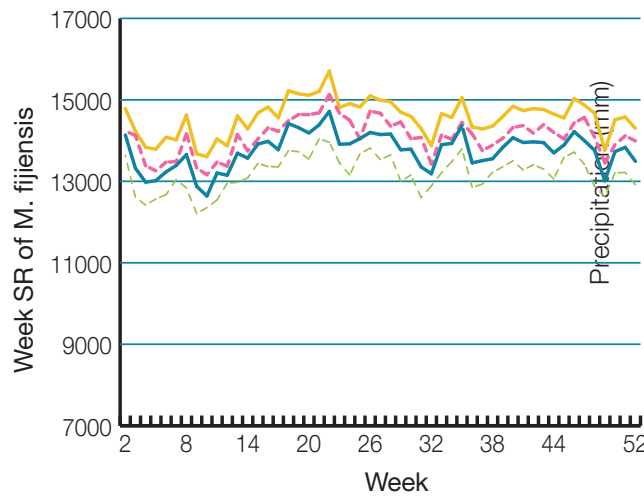




\section{figure 9}

State of BLS evolution based on precipitation and EVT. A: Salta (Argentina),

B: Brisbane, (Australia), C: Yunnan (China), D: Kawanda (Uganda),

E: Pichilingue (Ecuador), F: Davao (Phillipines)

A

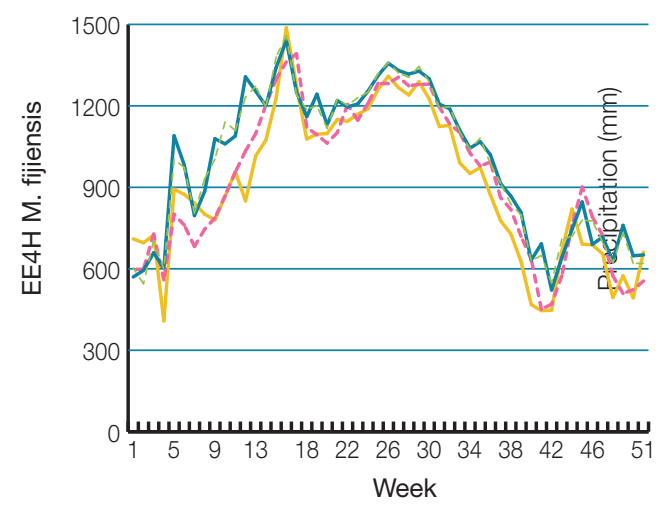

C

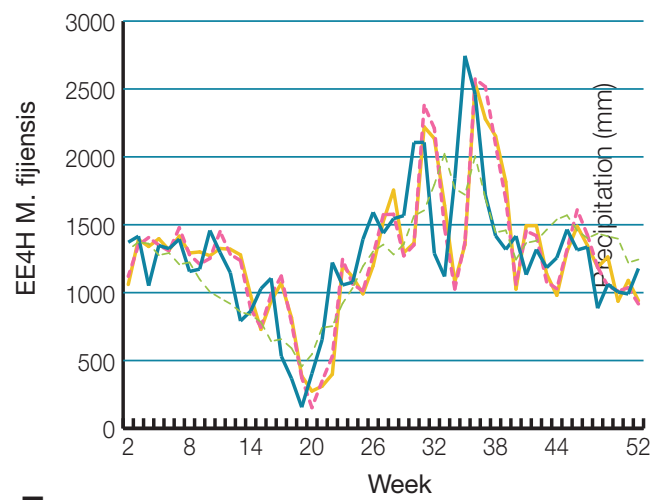

E

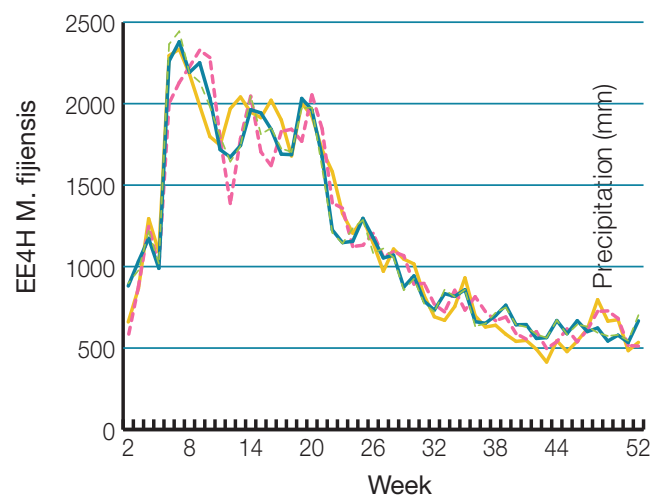

B
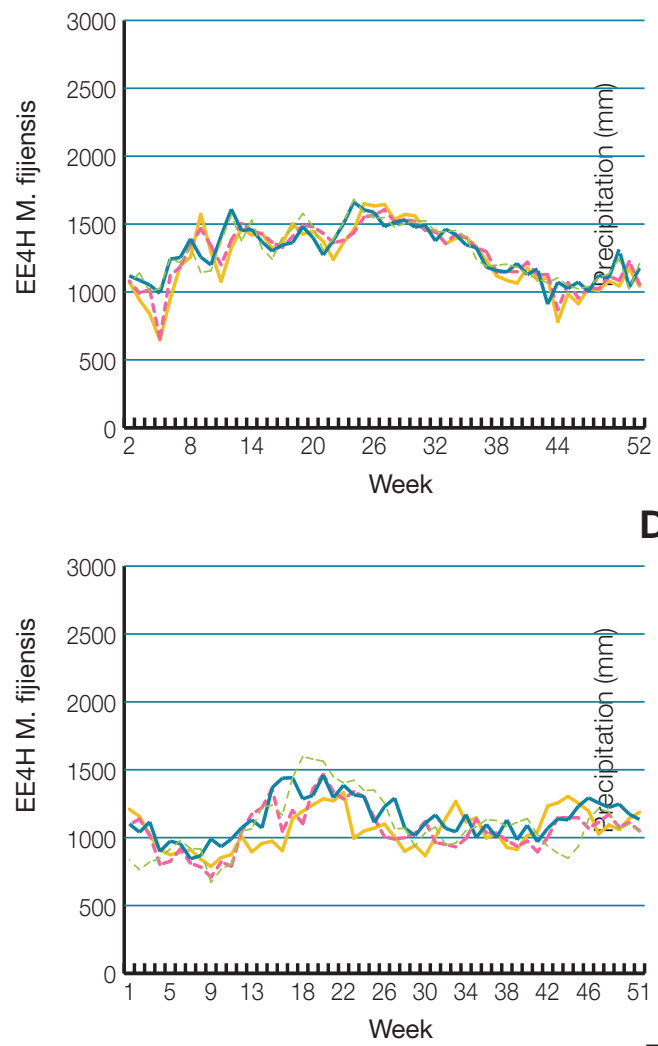

$\mathbf{F}$

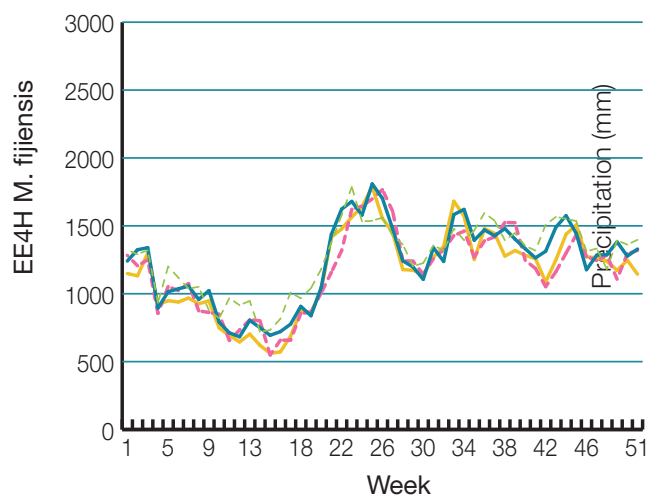


increasing temperatures in tropical highlands and in the subtropics are likely to be responsible for these projected changes. Several of the 24 sites reviewed earlier are projected to shift out of the 18$24^{\circ} \mathrm{C}$ range into more tropical zones.

The only category that will increase in area through 2070 is in the temperature range of $>24^{\circ} \mathrm{C}$. There will be an increase of nearly 50 percent globally for lands in this category, from 40 to 60 million square kilometers. This increase is primarily divided between Africa and Asia, with seven million square kilometres in each continent and the remainder in Latin America.

By 2070, the 60 million square kilometres of land area in the temperature category $>24^{\circ} \mathrm{C}$ will provide abundant land for banana production. In terms of available rainfall, 44 percent of this consists of dry lands with $<900 \mathrm{~mm}$ of annual rainfall (agroclimatic zones 131 and 132) (Table 11). Banana production under such conditions requires supplemental irrigation. Land surface in zones 231/232 and 331/332 comprises another 45 percent of the area in this category, divided roughly equally between the two zones. While these four zones represent the most favourable natural conditions for banana production globally, the climatic zone 331 stands out as the best of the four. With 1500-2500 mm annual rainfall and $<3$ months of dry season, banana plants will grow well throughout the year without additional irrigation. The area of land in this category is largely stable from current conditions to 2070, although for zones 231 and 332, land area will increase by 50 percent due to climate change (Table 11).

In summary, the effects of climate warming are clearly evident in this last analysis. The climatic zones with lower average annual temperatures are projected to lose land area on all three continents, while the land area in the zones with temperatures of $>24^{\circ} \mathrm{C}$ will increase. This change will favour potential banana productivity due to the increase in bunch number per hectare per year. The average temperature for potential banana lands in this zone is also likely to increase over the period of projections. Among the 24 sites analysed earlier, the lowland tropical areas showed an increase from $25^{\circ} \mathrm{C}$ to $28^{\circ} \mathrm{C}$, over the period of the projections. While banana productivity is favoured by this increase, the appearance of zones with excessive heat during certain periods of the year (three months $>35^{\circ} \mathrm{C}$ ) in both Asia and Africa indicates that climate warming must be addressed.

It is worth noting that bananas are often grown in mixed crops with perennials and annuals. Even if increasing temperatures are not unfavourable for banana, they may be unfavourable for the associated crops. We have also used the temperature parameters in this study based on the Cavendish variety. Other banana cultivars may have other critical parameters not yet established. In particular, the group of East African Highland cultivars is known to perform well at higher elevations. Farmers depending on this cultivar group may expand the upper limit in altitude for these cultivars as temperatures increase, but may need to switch cultivars at lower elevations where they are currently grown.

\section{Implications of climate change for global banana production}

The present study provides the basis for the following implications of climate warming on banana production and suitability globally:

- Growing conditions are suitable for banana in wide areas of the subtropics, the tropical highlands and the lowland tropics. A climatic zoning approach based on monthly temperatures, monthly rainfall and length of dry season provides the basis for quantifying the suitability of global land area for banana production. Although much of the global land surface is not suitable for banana-growing, the land area in two categories of annual temperature $-18-24{ }^{\circ} \mathrm{C}$ and $>24^{\circ} \mathrm{C}$ - with favourable rainfall, makes up about 37 million square kilometres. This stands in contrast to the 126000 square kilometres of land area currently occupied by banana and plantain. 
- According to global projections of climate change based on climatic zoning and the 24 selected sites representing important banana-growing zones, the area not suitable for growing banana will decrease over the period 2030, 2050 and 2070. Land area with lower productivity potential due to lower temperatures will decline, and land area characterized by temperatures $>24^{\circ} \mathrm{C}$ will increase. Calculations using leaf emission rate as an indicator of banana productivity indicate that, based on temperature alone, the leaf emission rate will increase by 10 leaves per year across most sites.

- The productivity of banana based on temperature and available water in the different agroclimatic zones and the 24 sites as measured by leaf emission rate will increase by 10 leaves per year only in the sites with abundant water yearround. In many other sites with a longer dry season only 4-6 additional leaves per year are likely in response to climate warming. The increased temperature that is associated with faster leaf emission rate will also be associated with an increased water demand of 10-15 percent across the sites as a result of increasing temperatures for the period through 2070.

- Black leaf streak, one of the most important leaf diseases of banana, may become more aggressive with increased temperatures, since the growth of the germination tube of spores accelerates with higher temperature. However, spore germination is primarily based on leaf wetness. The climate projections indicate that rainfall distribution on average will not change over the projection period for any of the 24 sites studied and therefore black leaf streak will continue to be a challenge during the rainy periods, just as it is currently.

- An overview of the shifts among different climatic zones showed that the climatic zones with lower average annual temperatures are projected to lose land area in all three continents, while the land area in the zones with temperatures $>24^{\circ} \mathrm{C}$ will increase. This change will favour potential banana productivity. The average temperature for potential banana lands in this zone is also likely to increase over the period of projections. Among the 24 sites analysed, the lowland tropical lands showed an increase in temperature from $25^{\circ} \mathrm{C}$ to $28^{\circ} \mathrm{C}$, over the period of the projections. While banana productivity is favoured by this increase, the appearance of zones with excessive heat during certain periods of the year (three months $>35^{\circ} \mathrm{C}$ ) in both Asia and Africa indicate that climate warming must be addressed.

- Even though increasing temperatures are not unfavourable for banana, they may be unfavourable for perennial and annual crops with which bananas are often grown. Farm households growing crops such as coffee, with banana as a secondary crop, may abandon banana when they abandon coffee because of climate change.

- $\quad$ The temperature parameters used in this study were based on Cavendish export banana. Other banana cultivar groups - in particular, the group of East African Highland cultivars - is known to perform well at higher elevations. This cultivar group may expand into higher altitudes as temperatures increase, but farmers may need to switch cultivars at the lower elevation range.

The implications summarized here are based on projections of average temperature and rainfall. Climate warming is also linked to increasing volatility of weather. Additional analyses are needed to quantify the type and frequency of weather events of moderate and extreme variability and the implications for banana productivity and management. 


\section{table 10}

Changes in suitability areas $\left(\mathrm{km}_{2}\right)$ for banana production by major temperature categories due to projected climate change through 2070 for three continents

\begin{tabular}{|c|c|c|c|c|c|c|c|c|}
\hline & & Current & 2030 & & 2050 & & 2070 & \\
\hline \multirow{4}{*}{ Unsuitable } & LAC & 3226450 & 2802200 & - & 2568425 & - & 2306525 & - \\
\hline & Africa & 109175 & 47075 & - & 28850 & - & 19100 & - \\
\hline & Asia & 22491675 & 20256675 & - & 18891200 & - & 17809400 & - \\
\hline & Total & 25827300 & 23105950 & - & 21488475 & - & 20135025 & - \\
\hline \multirow{4}{*}{$13-18^{\circ} \mathrm{C}$} & LAC & 3312150 & 2502875 & - & 2091125 & - & 1885300 & - \\
\hline & Africa & 1630625 & 860000 & - & 477000 & - & 235950 & - \\
\hline & Asia & 7589450 & 7210925 & - & 6838750 & - & 6485150 & - \\
\hline & Total & 12532225 & 10573800 & - & 9406875 & - & 8606400 & - \\
\hline \multirow{4}{*}{$18-24^{\circ} \mathrm{C}$} & LAC & 6675800 & 5313650 & - & 4783075 & - & 4318275 & - \\
\hline & Africa & 9639025 & 7213200 & - & 5519750 & - & 3616250 & - \\
\hline & Asia & 11119175 & 10331425 & - & 9989500 & - & 9580650 & - \\
\hline & Total & 27434000 & 22858275 & - & 20292325 & - & 17515175 & - \\
\hline \multirow{4}{*}{$24-35^{\circ} \mathrm{C}$} & LAC & 12406025 & 14892450 & + & 16068550 & + & 17001075 & + \\
\hline & Africa & 14843075 & 18070025 & + & 20164475 & + & 22291875 & + \\
\hline & Asia & 14059675 & 17297875 & + & 19375850 & + & 21184925 & + \\
\hline & Total & 41308775 & 50260350 & + & 55608875 & + & 60477875 & + \\
\hline \multirow{4}{*}{$\begin{array}{l}\text { Unsuitable } \\
\text { due to high } \\
\text { temperatures }\end{array}$} & LAC & 0 & 0 & & 0 & & 0 & \\
\hline & Africa & 0 & 0 & & 225 & + & 27125 & + \\
\hline & Asia & 0 & 0 & & 0 & & 21650 & + \\
\hline & Total & 0 & 0 & & 225 & + & 48775 & + \\
\hline
\end{tabular}

\section{table 11}

Global land area $\left(\mathrm{km}^{2}\right)$ for category of lands $>24^{\circ} \mathrm{C}$ under different rainfall regimes

\begin{tabular}{lrrrr}
\hline Climate category & Current & \multicolumn{1}{c}{$\mathbf{2 0 3 0}$} & \multicolumn{1}{c}{$\mathbf{2 0 5 0}$} & $\mathbf{2 0 7 0}$ \\
\hline 131 & 16354225 & 20460100 & 23591850 & 26378825 \\
\hline 132 & 3325 & 5250 & 4725 & 4950 \\
\hline 231 & 8055150 & 10132325 & 11109325 & 12206500 \\
\hline 232 & 583850 & 948275 & 1019725 & 1183700 \\
\hline 331 & 3270050 & 4555150 & 5441425 & 6103275 \\
\hline 332 & 7975475 & 8492200 & 8354475 & 8141575 \\
\hline 431 & 462200 & 604350 & 706675 & 803475 \\
\hline 432 & 4604500 & 5062700 & 5380675 & 5655575 \\
\hline
\end{tabular}




\section{References}

Allen, R., L. Pereira, D. Raes \& M. Smith. 1998.

Crop evapotranspiration: Guidelines for computing crop water requirements. FAO irrigation and drainage paper 56, FAO, Rome. 6541 p.

Clarke, D., M. Smith \& K. El-Askari. 2001. CropWat for Windows: user guide. IHE.

Fortescue, J., D. Turner, \& R. Romero, 2011. Evidence that banana (Musa spp.), a tropical monocotyledon, has a facultative long-day response to photoperiod. Functional Plant Biology, 38: 867-878.

Freitas, W., M. Ramos \& S. Costa. 2008. Demanda de irrigasao da cultura da banana na bacia do Rio Sao Francisco. Revista Brasileira de Engenharia Agricola e Ambiental. 12: 343-349.

FRUITROP, 2011. Direct from the markets. No 191. p. 5.

Hargreaves, G. \& R. Allen. 2003. History and evaluation of Hargreaves evapotranspiration equation. Journal of Irrigation and Drainage Engineering, 129: 53-63.

Hijmans, R., S. Cameron, J. Parra, P. Jones \& A. Jarvis. 2005. Very high resolution interpolated climate surfaces for global land areas. International Journal of Climatology, 25: 1965-1978.

Jacome, L. \& W. Schuh. 1992. Effects of leaf wetness duration and temperature of development of black Sigatoka disease on banana infected by Mycosphaerella fijiensis var. difformis. Phytopathology, 82: 515-520.

Jacome, L., W. Schuh \& R. Stevenson. 1991. Effect of temperature and relative humidity on germination and germ tube development of Mycosphaerella fijiensis var. difformis. Phytopathology, 12: 1480-1485.

Perez V., M. Mauri, M. Hernandez, A. Abreu \& G. Porras. 2006. Relaciones entre los factores climáticos y la velocidad de evolución de la Sigatoka Negra en bananos y plátanos. Memorias de XVII Reunión Internacional de ARCORBAT, 2: 702-709.

Porras, A. \& L. Pérez. 1997. Efecto de la temperatura sobre el crecimiento de los tubos germinativos de las ascosporas de Mycosphaerella spp. causantes de Sigatoka en banano. InfoMusa, 6(2): 27-31.

Ramirez, J. \& A. Jarvis. 2008. High resolution statistically downscaled future climate surfaces. International Center for Tropical Agriculture (CIAT), CGIAR Research Program on Climate Change, Agriculture and Food Security (CCAFS). Cali, Colombia.

Silva, E. \& F. Bezerra. 2009. Evapotranspiration and crop coefficients of banana at the Vale of Curu, CE, Brazil. Revista Ciencia Agronomica.

40: 203-210.

Smith, M. 1992. CROPWAT: A computer program for irrigation planning and management. FAO Irrigation and Drainage Paper 46, FAO. Rome, 1992.

Thomas, D., D. Turner \& D. Eamus. 1998. Independent effects of the environment on the leaf gas exchange of three banana (Musa sp.) cultivars of different genomic constitution. Scientia Horticulturae, 75: 41-57.

Trajkovic, S. 2007. Hargreaves versus PenmanMonteith under humid conditions. Journal of Irrigation and Drainage Engineering, 133: 38-42.

Turner, D. \& E. Lahav. 1983. The growth of banana plants in relation to temperature. Functional Plant Biology, 10: 43-53.

Van den Bergh, I., J. Ramirez, C. Staver, D. Turner, A. Jarvis \& D. Brown. 2012. Climate change in the subtropics: The impacts of projected averages and variability on banana productivity. Acta Hort. (ISHS) 928: 89-99. 


\section{chapter 10}

$\begin{array}{ll}\text { 1. Introduction } & 294\end{array}$

2. Modelling international trade 295

2.1 Modelling trade in a general equilibrium framework 295

2.2 Modelling trade in a partial equilibrium framework 297

3. Trade in agricultural commodities: Recent trends 298

4. Description of scenarios $\quad 299$

5. Implications for trade of the "socio-economic and climatic" scenarios

5.1 Agrifood trade in 2050 under scenario S1 301

5.2 Agrifood trade in 2050: A closer look at model agreement

5.3 Key drivers of trade: Degree of model agreement 304

5.4 Production-exports nexus: Degree of model agreement

6. Discussion and conclusions 308

$\begin{array}{ll}\text { References } & 309\end{array}$

Citation

Ahammad, H., E. Heyhoe, G. Nelson, R. Sands, S. Fujimori,T. Hasegawa, D. van der Mensbrugghe, E. Blanc, P. Havlik, H. Valin, P. Kyle, D. d'Croz, H. van Meill, C. Schmitz, H. Lotze-Campen, M. von Lampe and A. Tabeau. 2015. The role of international trade under a changing climate: Insights from global economic modelling, In: Climate change and food systems: global assessments and implications for food security and trade, Aziz Elbehri (editor). Food Agriculture Organization of the United Nations (FAO), Rome, 2015. 


\title{
chapter 10
}

\section{The role of international trade under a changing climate: Insights from global economic modelling ${ }^{1}$}

\author{
Helal Ahammad(a), Edwina Heyhoe ${ }^{(a)}$, Gerald Nelson ${ }^{(b)}$, \\ Ronald Sands ${ }^{(c)}$, Shinichiro Fujimori(d), Tomoko Hasegawa ${ }^{(d)}$, \\ Dominique van der Mensbrugghe ${ }^{(e)}$, Elodie Blanc(i), \\ Petr Havlik ${ }^{(9)}$, Hugo Valin(g), Page Kyle ${ }^{(h)}$, Daniel Mason d'Croz ${ }^{(i)}$, \\ Hans van Meij( $(0)$, Christoph Schmitz ${ }^{(k)}$, Herman Lotze-Campen ${ }^{(k)}$, \\ Martin von Lampe ${ }^{(1)}$, Andrzej Tabeau ${ }^{(0)}$
}

\section{main chapter messages}

- The likely impacts of future climate change and socio-economic drivers on international trade in agrifood commodities would vary depending on assumptions regarding how the future will evolve as encapsulated by 'scenarios'.

- The projected agrifood trade impacts are also likely to vary across economic models, depending on model types and underlying theoretical structures.

- To improve understanding on why simulated impacts differ across models under specific 'scenarios', results from a recent AgMIP (Agricultural Model Intercomparison and Improvement Project) economic modelling exercise are used, with particular focus on the agriculture sector.

- The analysis presented in this chapter suggests an increasing role for trade under future climate change but the extent of the change in agrifood trade varies substantially between models.

- Based on the insights from the analysis, a number of potential issues are recommended for future modelling and research.

1 This paper is part of a global economic model intercomparison activity undertaken as part of the AgMIP Project (www.agmip.org). The climate change drivers collectively known as MIP were provided as part of the ISI-MIP model comparison project (www.isi-mip.org). The socio-economic drivers were developed for the Shared Socioeconomic Pathways (SSP) as part of a new set of IPCC scenarios for analyses of climate impacts, adaptation and mitigation, and are available at the SSP data portal (https://secure.iiasa.ac.at/web-apps/ene/)

2 Authors affiliations are as follow: (a) Australian Bureau of Agricultural and Resource Economics and Sciences; (b) University of Illinois at Urbana-Champaign; (c) U.S. Department of Agriculture, Economic Research Service; (d) National Institute for Environmental Studies; (e) Global Analysis Project, Purdue University; (f) Massachusetts Institute of Technology; (g) International Institute for Applied Systems Analysis; (h) Pacific Northwest National Laboratory; (i) International Food Policy Research Institute; (j) LEl Part of Wageningen University; (k) Potsdam Institut für Klimafolgenforschung; (I) Organization for Economic Co-operation and Development. 


\section{Introduction}

nternational trade plays an important role in improving global wellbeing, by allowing comparative advantages to be exploited. Changing socio-economics can alter comparative advantages and trade flows, and so can climate change. In recent decades, the volume of agricultural trade has grown in response to growing populations and rising incomes, with geographical distribution of this trade favouring certain developing countries. In the future, climate change will potentially have an impact on land productivity globally, altering the relative productivity of land in one region compared with another (see, for example, Nelson et al., 2013). In other words, climate change can alter the volumes and patterns of international agrifood trade through its impacts on national comparative and competitive advantages arising from changes in production, transport and distribution chains (see, for example, WTO-UNEP, 2009). Therefore, while the socio-economic drivers of international trade are expected to remain important, climate change can also potentially alter future international competitiveness and agrifood trade patterns.

A number of studies (see, for example, Reilly and Hohmann, 1993; Hertel and Randhir, 2000; and Verburg et al., 2008; Nelson et al. 2010) have suggested that trade can facilitate "adaptation" to climate change in agriculture and food sectors. The term "adaptation" is amenable to multiple interpretations. To avoid any misinterpretation, trade as an adaptation option should be understood in the following context: climate change causes changes in comparative advantage and exploiting these changes will involve changes in trade flows. That is, changes in trade flows are an "endogenous" response or adaptation to climate change. All economic models considered in this chapter specify "endogenous" responses to changes in socio-economic and climate drivers. Many important research questions are concerned with identifying how much, where, and how different these responses will be, and there is no clear consensus that has yet emerged from the literature in this regard (see also OECD, 2012). Model projections are expected to differ across scenarios, due to differences in the underlying economic, demographic and technology assumptions, and also across models, due to differences in the underlying model structures and base-year databases.

In this chapter, the likely implications of some socio-economic and climate change drivers of trade are examined, using six scenarios involving two alternative assumptions about the socioeconomic drivers (GDP, population) with varying climate change impacts on agricultural productivity. These scenarios were designed for a recent AgMIP (Agricultural Model Intercomparison and Improvement Project) exercise, to examine how economic models responded to different kinds of shocks - socio-economic and climate (as well as bioenergy) - and to improve the understanding of why simulated impacts differ across models. AgMIP has brought together climate modellers, crop modellers and global economic modellers from across the world and provides a forum for comparison and improved understanding of model results under selected socio-economic and climatic scenarios. The global economic modelling group incorporates both partial equilibrium (PE) models of agriculture and food commodities and global general equilibrium (GE) models (von Lampe et al., 2014). The different models used in this joint analysis are described in Table $1 \mathrm{a}$.

This chapter presents a synthesis of modelling results for agrifood trade under the selected socioeconomic and climatic scenarios. In particular, the specific objectives of this study are to examine key trends and patterns in projected future agrifood trade under the different socio-economic and climate scenarios and, drawing on the results, to shed some light on the relative importance of socio-economic and climate drivers, as well as the characteristics of the models involved, all of which determine trade patterns.

The following section presents some of the key features of the global economic models that are being used to project international trade. 
Section 3 provides an overview of current trends in agrifood trade. Section 4 briefly describes the scenarios simulated for the AgMIP global economic modelling exercise. Section 5 presents and synthesises key agrifood trade results from participating models. The final section draws conclusions on the level of consistency between model results, identifies some key reasons for significant differences across models and suggests potential areas for future model comparison exercises.

\section{Modelling international trade}

Projections of agricultural trade are dependent on the characterization of trade in the models, which depends on the supply and demand responses specified within the models. These responses depend, in particular, on the capacity of regions to respond to changes in productivity, land-use change and changing input mix, and how price and income changes affect consumption. A series of papers offers some detailed assessment of the specifications of the supply side (Robinson et al., 2014), land use change (Schmitz et al., 2014) and the demand side (Valin et al., 2014) of the AgMIP models.

The specification of international trade varies significantly between model classes - i.e. GE and PE models, as well as between models within each model class. While these differences are important in understanding the model results, for brevity only the broad characteristics of GE and PE modelling of trade are described below. Interested readers are directed to AgMIP papers and/or can further explore individual model documentations cited earlier.

\subsection{Modelling trade in a general equilibrium framework}

All six GE models utilize the "Armington" approach to modelling international trade (Armington, 1969a, 1969b), which distinguishes domestically produced

\section{table 19}

Partial equilibrium and general equilibrium models used in this analysis

\begin{tabular}{|c|c|c|}
\hline Model category & Model name & Source \\
\hline \multirow{4}{*}{ Partial Equilibrium (PE) } & Global Change Assessment Model (GCAM) & Wise and Calvin, 2011 \\
\hline & Global Biosphere Management Model (GLOBIOM) & Havlík et al., 2011; 2013 \\
\hline & $\begin{array}{l}\text { International Model for Policy Analysis of } \\
\text { Agricultural Commodities and Trade (IMPACT) }\end{array}$ & Rosegrant et al., 2012 \\
\hline & $\begin{array}{l}\text { Model of Agricultural Production and its Impacts } \\
\text { on the Environment (MAgPIE) }\end{array}$ & Lotze-Campen et al., 2008 \\
\hline \multirow{6}{*}{ General equilibrium (GE) } & Asian Pacific Integrated Model (AIM) & Fujimori et al., 2012 \\
\hline & $\begin{array}{l}\text { Environmental Impact and Sustainability Applied } \\
\text { General Equilibrium (ENVISAGE) }\end{array}$ & van der Mensbrugghe, 2013 \\
\hline & Predictions and Policy Analysis (EPPA) & Paltsev et al., 2005 \\
\hline & Future Agricultural Resources Model (FARM) & (Sands et al., 2013) \\
\hline & Global Trade and Environmental Model (GTEM) & Ahammad and Mi, 2005 \\
\hline & $\begin{array}{l}\text { Modular Applied GeNeral Equilibrium Tool } \\
\text { (MAGNET) }\end{array}$ & Nowicki et al., 2009 \\
\hline
\end{tabular}


commodities from comparable commodities produced in other countries. ${ }^{3}$ By differentiating domestic goods from comparable imports, these models effectively allow for two-way trade flows, preventing the problem of over-specialization that would otherwise occur in computable general equilibrium (CGE) models while also conferring some market power on each open economy.

The two-way trade flows specified in these models can be described by means of a two-level nested constant elasticity of substitution (CES) function, representing a two-level budgeting and decision-making process. The first level distinguishes between imports and domestically produced goods and the second between imports from various sources.

The same "Armington" preference structure is adopted for each model agent: households, government and producers select from domestically produced goods and imports based on the same two-level budgeting and decisionmaking process. Total demand for imports for each commodity in an economy is the sum of imports by all model agents. Bilateral trade between all model regions is determined through a CES function, as seen in Equation 1.

$$
Q M S(i, r, s)=b(i, r) \cdot Q M(i, s) \cdot\left(\frac{P M S(i, r, s)}{P M(i, s)}\right)
$$

\section{where:}

- QMS is bilateral trade in commodity i from region $r$ to region $s$

- QM is demand for imports of commodity i by region $\mathrm{s}$

3 An alternative approach to modelling international trade in a GE model is to treat domestic commodities as identical to (or as perfect substitutes for) corresponding imports, and address the issue of complete production or import specialization when constant returns to scale prevail in production - for example, by assuming some sector-specific factors of production (see, for example, Taylor and Black, 1974; Clarete and Whalley, 1988).
- PMS is price of commodity i from region $r$ in region $s$

- PM is the average price of imports of commodity $i$ in region $s$

- $b$ is a parameter representing any exogenous preference shift

- $\alpha$ is elasticity of substitution (often referred to as the "Armington elasticity").

Total exports from all regions equal the sum of imports to all regions.

Armington (1969b) lists the characteristics that determine the size of the elasticity, including the commodity composition of trade (i.e. the level of homogeneity within the commodity class), the degree and nature of trade restrictions, the importance of long-term contracts and loyalty to particular sources. The size and diversity of the region can also affect elasticities. For example, the elasticity could be different for large diverse regions compared to single country regions.

One of the most established sets of Armington elasticity estimates is in the Global Trade Analysis Project (GTAP) database (Narayana et al., 2012). Most models used the GTAP database as a starting point for their Armington elasticity estimates (Table 1b). The most recent GTAP database (version 8) has Armington elasticities
Description of Armington elasticities from the CGE models

\begin{tabular}{ll}
\hline Model & \multicolumn{1}{c}{ Description of Armington } \\
\hline ENVISAGE & Higher than GTAP \\
\hline EPPA & Unmodified from GTAP \\
\hline FARM & Approximately those of GTAP \\
\hline GTEM & Unmodified from GTAP \\
\hline MAGNET & Unmodified from GTAP \\
\hline
\end{tabular}

Note: AIM is a CGE model that does not specify bilateral trade. Therefore, it has a single import/domestic Armington structure, rather than the nested approach adopted in other models. AlM specifies an Armington elasticity of 0.8 for all agrifood commodities across all regions. 
between imports and domestically produced goods ranging between 1.3 and 4.5 , depending on the level of homogeneity within the commodity class. The elasticity for wheat, for example, is approximately three times that of the "other coarse grains" commodity class. In the standard GTAP database, these elasticities are assumed to be the same for all regions. However, given any difference in a commodity class across regions, the same elasticity value for the class will represent varying levels of product differentiation (or degrees of substitutability) for the commodities in the class across regions. For example, a given elasticity value for the "other coarse grains" commodity class will mean a different degree of substitutability (that is, a different underlying or implied value of Armington elasticity) for corn for different regions, depending on the share of corn in the "other coarse grains" commodity class across regions.

As pointed out earlier, by treating the domestically produced commodity and the comparable commodities produced in other economies as heterogeneous, the Armington approach to modelling international trade confers some market power on each open economy. In other words, this approach allows changes in the international terms of trade of an economy to occur under a scenario simulation. Also, all AgMIP global GE models specify exchange rates. With the choice of particular price indexes - for example, gross domestic product (GDP) deflators - as the numeraires (relative to which all price changes are measured), model simulations will generate changes in real exchange rates. The changes in the international terms of trade and real exchange rates are features of the GE mechanisms that can have dominating effects on trade flows, as compared with PE modelling.

\subsection{Modelling trade in a partial equilibrium framework}

The four PE models assume that a commodity is homogenous regardless of where in the world it is produced and consumed - i.e. that there is a single world market for each commodity and that consumers do not have a preference for domestically produced commodities over imports. In modelling terms, these models specify net trade by region, rather than in two-way trade flows. In the PE models, trade is calculated as the residual of regional production and consumption, as specified in Equation 2.

(2)

$$
Q T=Q P-Q D-Q S
$$

where:

- $Q T$ = volume of net trade

- $\mathrm{QP}=$ domestic production of the commodity

- $Q D=$ domestic demand for the commodity

- QS = change in held stock of the commodity

The world price (PW) of a commodity is the equilibrating mechanism, such that when an exogenous shock is introduced in the model, PW will adjust and each adjustment is passed through to consumer and producer prices in each region. Producer and consumer prices differ from the PW by transport and other margins and by subsidy equivalents. Changes in domestic prices subsequently affect commodity supply and demand, necessitating their iterative readjustment until world supply and demand are in balance. The PW is set to ensure that global net trade equals zero, representing the market clearing condition, as shown in Equation 3.

\section{$\Sigma_{r} Q T=0$}

Thus, the net trade projections from these models are directly linked to the demand and supply functions, whereas imports and exports are linked to demand and supply functions, respectively, in the GE models. 


\section{Trade in agricultural commodities: Recent trends}

Over the past several decades, global agricultural trade has expanded in line with increasing populations, rising incomes, improved technologies and an expansion of agricultural lands. In broad terms, international agricultural trade tends to flow from countries with large, productive land resources and high rates of agricultural mechanization and investment to less-developed countries that are characterized by rising populations and limited productive capacity, such as in sub-Saharan Africa (Figures 1 and 2, USDA ERS, 2013a, 2013b). Some developing countries, such as Brazil and Argentina, export significant quantities of agricultural products. Conversely, some developed countries, such as Japan and Korea, are highly import-dependent.

Wheat is the most widely traded agricultural commodity, with exports totalling around 21 percent of world production (FAOSTAT 2013). Collectively, the European Union (EU), the United

\section{figure 1}

Exports by commodity and region, average over 5 years to 2009, million tonnes (Mt)

M

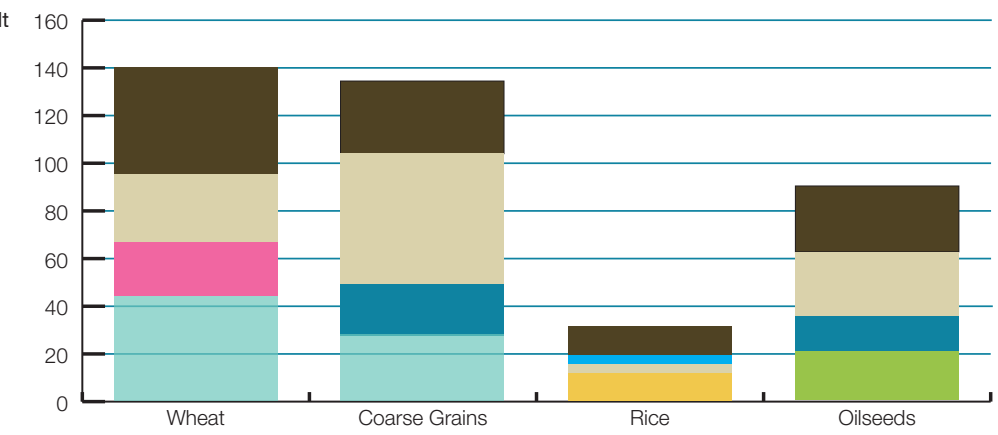

Brazil

Europe

India

United States

Southeast Asia

Rest of Latin American Former Soviet Union Rest of World

\section{figure 2}

Source: FAOSTAT 2013

Note: Trade data for Europe includes intra-EU trade

Imports by commodity and region, average over 5 years to 2009, million tonnes (Mt)

Mt

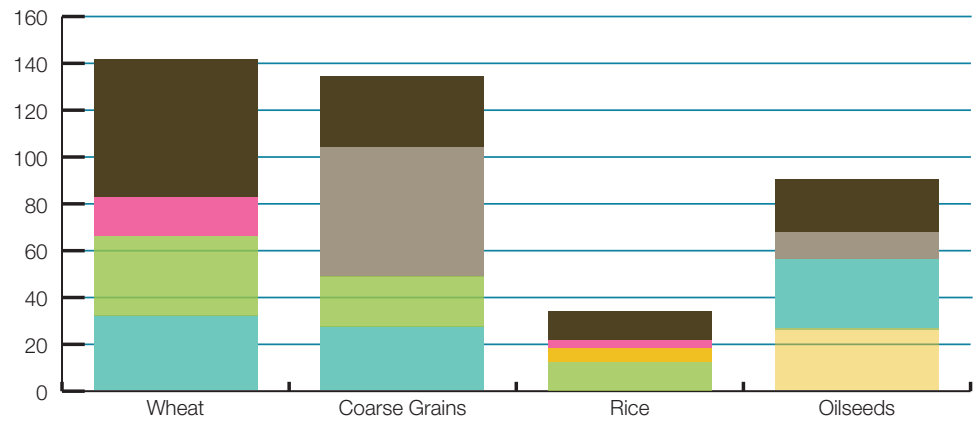

Rest of World

Source: FAOSTAT 2013

Note: Trade data for Europe includes intra-EU trade 
States of America, the former Soviet Union, Argentina, Australia and Canada account for around 90 percent of world exports. Trade in coarse grains (corn, barley, sorghum and oats) represents around 13 percent of global production. Corn is the main commodity, representing around three-quarters of global coarse grains production. The United States of America is the main exporter of coarse grains, followed by the EU and Latin America. The main importers of wheat and coarse grains are countries in Africa, the Middle East and North Asia. For both wheat and coarse grains, the EU appears to be both a major exporter and importer; however, this is a reflection of significant intra-EU trade (FAOSTAT 2013).

Rice is not heavily traded; exports account for only about 4 percent of global rice production (FAOSTAT 2013). Southeast Asia is the world's largest rice-exporting region, accounting for around 50 percent of world rice exports (Figure 1). Thailand and Viet Nam are the primary exporters, followed by Pakistan, the United States of America and India. The major importers of rice are other countries in Southeast Asia, sub-Saharan Africa, the Middle East and North Africa (FAOSTAT 2013, Figure 2).

Around 29 percent of world oilseed production is exported, with soybeans accounting for half of this trade (FAOSTAT 2013). The United States of America is the world's largest exporter, followed by Brazil and Argentina (which appears as part of Rest of Latin America in Figure 1). China is the world's largest importer of vegetable oil and oilseeds, India is a major importer of vegetable oil, and the EU is the largest importer of soybean meal and second largest importer of soybeans (FAOSTAT 2013).

Trade in meat consists of ruminant (sheep and cattle) and non-ruminant (pigs and poultry) meat and collectively accounts for about 5 percent of global production. The major exporters of meat are the United States of America, the EU, Brazil and Australia, while the major importers are Japan and the Republic of Korea, as well as China, Southeast Asia, the Middle East and North Africa and the former Soviet Union (FAOSTAT 2013).

Trade in dairy products represents around 9 percent of global dairy production. The main exporters of dairy products are the EU, Australia, New Zealand and the United States of America. The main importers are the Middle East and North Africa, China, Japan and the Republic of Korea (FAOSTAT 2013).

\section{Description of scenarios}

The AgMIP modelling group simulated eight scenarios, each one specified in terms of: socioeconomic characteristics (GDP and population); agricultural productivity (based on results of climate and crop modelling); and rate of biofuel penetration. Table 2 lists the key features of each scenario and the following paragraphs briefly describe them. These scenarios are described in more detail in von Lampe et al. (2014).

The socio-economic scenarios, SSP2 and SSP3, are the two of the shared socioeconomic pathways (SSP) developed for the Fifth Assessment Report (AR5) of the Intergovernmental Panel on Climate Change (IPCC). Broadly described, SSP2 reflects a world in which economic growth is reasonably rapid, sustained by relatively high productivity growth, clean technology development and an integrated global economy. The SSP3 scenario, on the other hand, reflects a world of high population growth in developing countries, combined with slower economic growth, representing a fragmented global economy.

The AgMIP scenarios S1 and S2 represent the SSP2 and SSP3 socio-economic pathways but no allowance has been made for the impacts of climate change on agricultural productivity (Table 2). The AgMIP scenarios S3 to S6 incorporate agricultural productivity affected by climate change, and are derived from a combination of outputs from climate and crop models assuming a Representative [greenhouse gas] Concentration Pathway (RCP) corresponding to a radiative forcing target of $8.5 \mathrm{w} / \mathrm{m}^{2}$ by 2100 . More specifically, for scenarios S3 through S6, most AgMIP modellers have implemented agricultural productivity changes generated 
table 2

Description of AgMIP scenarios

\begin{tabular}{llllll}
$\begin{array}{l}\text { Scenario } \\
\text { code }\end{array}$ & $\begin{array}{l}\text { Socio-economic } \\
\text { characteristics }\end{array}$ & \multicolumn{1}{c}{ RCP } & \multicolumn{1}{c}{$\begin{array}{c}\text { Climate } \\
\text { Model }\end{array}$} & $\begin{array}{c}\text { Crop } \\
\text { Model }\end{array}$ & \multicolumn{1}{c}{ Bioenergy } \\
\hline S1 & SSP 2 & Present climate & None & None & Model-specific \\
\hline S2 & SSP 3 & Present climate & None & None & Model-specific \\
\hline S3 & SSP 2 & RCP8.5 & IPSL-CM5A-LR & LPJmL & Model-specific \\
\hline S4 & SSP 2 & RCP8.5 & HadGEM2-ES & LPJmL & Model-specific \\
\hline S5 & SSP 2 & RCP8.5 & IPSL- CM5A-LR & DSSAT & Model-specific \\
\hline S6 & SSP 2 & RCP8.5 & HadGEM2-ES & DSSAT & Model-specific \\
\hline S7 & SSP 2 & Present climate & None & None & 1st-gen. ca. 6ExaJoule; no \\
\hline S8 & SSP 2 & & Nond-gen. (2050) & 1st-gen. ca. 6ExaJoule; 2nd- \\
\hline
\end{tabular}

though IMPACT modelling, using the outcomes of the climate models and crop models (Table 2). The only exception is MAgPIE, which has used its own endogenously derived technological change parameters (for details on the MAgPIE methodology, see Dietrich et al., 2013).

In simulating these scenarios, no trade policy reforms have been explicitly implemented. Land supply has been determined and implemented independently by individual modellers (Schmitz et al., 2014). Furthermore, the climate change scenarios (S3 through S6) have not accounted for $\mathrm{CO}_{2}$-fertilization effects of higher atmospheric concentration of carbon dioxide $\left(\mathrm{CO}_{2}\right)$. Many other factors, such as extreme events and seasonal variability, sea level rises, population health and labour productivity - through which climate change may affect agriculture and broader economies have not been considered. In terms of adaptation to climate change, no explicit measures have been considered other than price-driven "endogenous" responses to the input and output mix, supply and demand, and trade structures. In light of these omissions and model implications, the results should be read cautiously as first order approximation that require more follow up investigations where policy issues are factored in.

\section{Implications for trade of the "socio-economic and climatic" scenarios}

Various models that were included in the AgMIP model comparison exercise differ in their spatial resolution/economic regions and in the level of aggregation of various agricultural sectors, as well as in many other important aspects, such as international trade, as discussed earlier. For comparability of model results, however, the AgMIP exercise involved harmonization of agricultural commodity aggregates, spatial aggregates/ economic regions, key model variables and time period across models for reporting and analysis. Furthermore, with the "base" database for these models corresponding to different years, the reported results were re-based to 2005 as the common base year. For further details on the reporting protocol, processes and associated issues, see von Lampe et al., 2014 and also Nelson et al., 2013.

Given the focus of this paper and for the sake of brevity, the results presented and analysed in this section relate to the AgMIP scenarios S1 ("reference case"), S2 ("fragmented global economy") and an 
average of the four climate change scenarios (S3 to S6) including, where possible, error bars showing the maximum and minimum of the climate change scenarios. Also, we have focused only on the key trends and on the major exporting and importing economies or regions. A more comprehensive set of results is available from the authors on request.

\subsection{Agrifood trade in 2050 under Scenario S1 (the reference case)}

Figure 3 presents global exports of major agricultural commodities (wheat and rice) and commodity groups (coarse grains and oilseeds) in 2050 under Scenario S1, simulated by various GE models. (Projected exports from the PE models were not available as these models specify net trade and do not project exports and imports separately.) Exports of these commodities and commodity groups are projected to grow substantially by 2050 , relative to the common base year of 2005: by between 50 and 230 percent in the case of wheat; between 50 and 190 percent for rice; between 80 and 140 percent for coarse grains; and between 90 and 210 percent for oilseeds, depending on the model. ${ }^{4}$ Most models projected that today's

$4 \quad$ As already indicated, the base data sets of these largest exporters of rice, coarse grains and oilseeds would retain their dominance in the world export market in 2050. However, in the case of wheat, Canada is projected by most models to replace the former Soviet Union to become one of the top three exporters in the world.

Figure 4 shows the growth in global exports relative to the growth in global production of five commodities and commodity groups (wheat, rice, sugar, coarse grains and oilseeds) under Scenario S1, simulated by the GE models. The solid line indicates equal growth rates in exports and production. As can be seen, exports of most commodities are projected to grow marginally faster than production.

Not all models have simulated exports and imports separately (see Section 2). In what follows, we focus on net trade - measured as exports minus imports, with a positive net trade quantity meaning net exports and negative quantity means net imports.
models were not harmonized. With GE models drawing on different versions of the GTAP database and PE models calibrated to FAOSTAT data but with different starting years, it proved challenging to harmonize the base data across models and therefore that was not undertaken as part of this AgMIP exercise (Nelson et al., 2013). However, for reporting and analysis, the model results for selected variables, including trade variables, were re-based, post-simulation, to the common base year of 2005.

\section{figure 3}

Export by commodity and region in 2050 under Scenario S1, million tonnes (Mt)

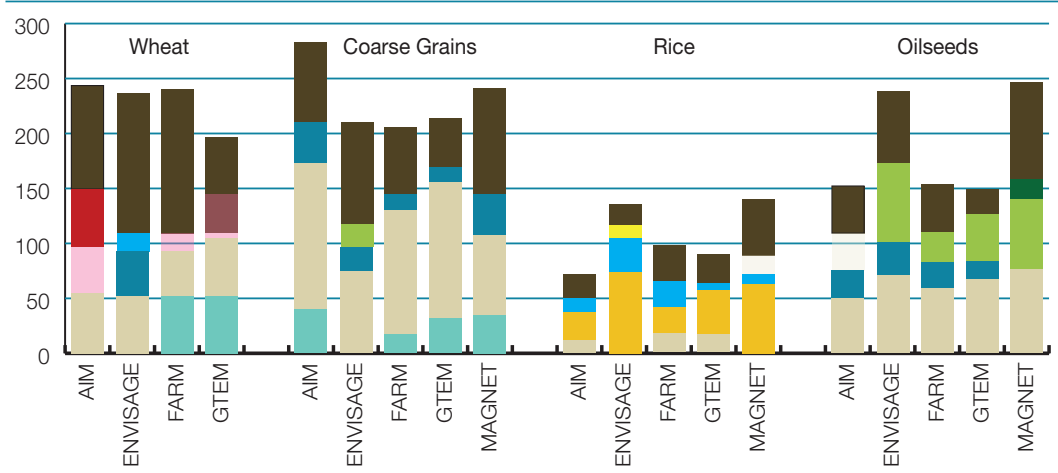

Source: AgMIP scenario results

Note: Results are only presented for GE models because PE models specify only net trade 


\section{figure 4}

Index of export and production growth in 2050 under Scenario S1

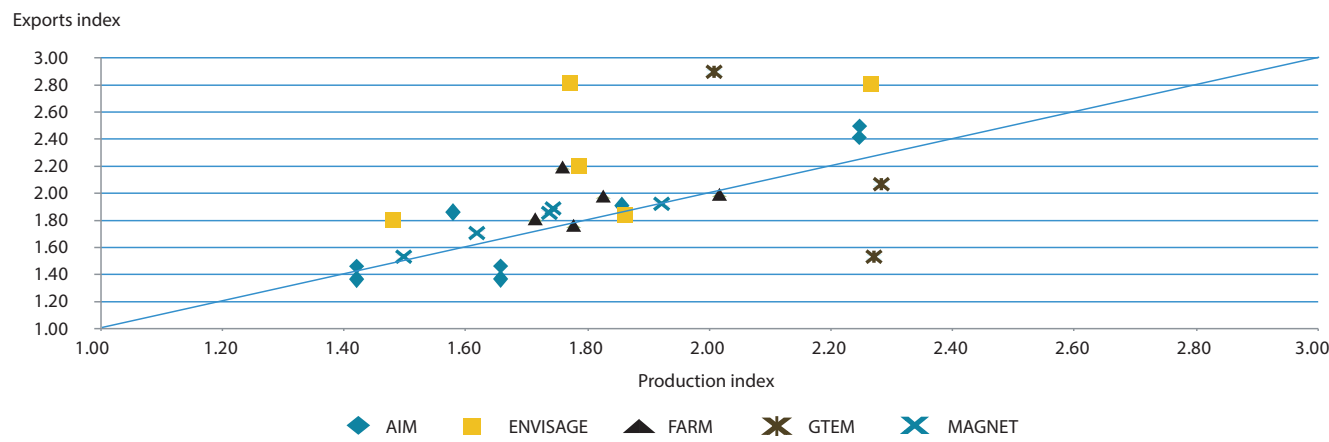

Source: AgMIP scenario results

Note: Results are only presented for GE models because PE models specify only net trade

Most models project that the historical net trade status of key regions will be maintained until 2050 under Scenario S1 (Table 3). Countries with large and productive land areas are projected by most models to remain key exporters and most of the less-developed countries are projected to be key importers of agrifood commodities.

According to most models, the United States of America and the former Soviet Union will remain net exporters in wheat, and the United States of America and Latin America will be net exporters in coarse grains at 2050. In the case of rice, Southeast Asia, the United States of America and India are projected to remain net exporting regions. The main net importers of wheat, rice and coarse grains are projected to be countries in the Middle East, North Africa and sub-Saharan Africa. The United States of America and Latin America are projected to remain net exporters in oilseeds, with China a net importer.

\subsection{Agrifood trade in 2050: A closer look at model agreement}

As discussed above, there is some agreement across models in terms of key exporters and importers by 2050. Here, we explore further agreement among models, focusing on net trade results for key commodities and trading countries.
Most models project that the United States of America will remain a significant net exporter of coarse grains and oilseeds under all AgMIP scenarios in 2050 (Figures 5 and 6). GCAM is the exception, projecting that the United States of America will become a net importer of coarse grains by 2050. This result in GCAM is primarily driven by the assumed corn ethanol production, which would increase corn demand by about 150 million tonnes per year between 2005 and 2050.

The agreement among models with regard to changes in net trade diminishes somewhat for the fast-growing developing economies. Some models project that China will become a net agricultural importer by 2050, whereas other models suggest that low population growth and rapid productivity growth will ensure that China remains a net exporter. Given its growing importance in the global economy, the results for China have a significant impact on global trade.

The projected net trade in coarse grains and oilseeds of China in 2050 are presented in Figures 7 and 8, respectively.

As can be seen from Figure 7, some models project that China will become a net importer of coarse grains by 2050. Others project that China will remain mostly self-sufficient for coarse grains, as in recent years, when net trade was less than 
table 3

Net importers and net exporters under Scenario S1 in 2050, by commodity

\begin{tabular}{|c|c|c|c|c|}
\hline Commodity & Net importer & No of models & Net exporter & No of models \\
\hline \multirow[t]{4}{*}{ Coarse grains } & China & 5 of 9 & Europe & 5 of 9 \\
\hline & Middle East; North Africa & & India & 7 of 8 \\
\hline & Sub-Saharan Africa & All & Rest of Latin America & 6 of 9 \\
\hline & & 6 of 9 & USA & 7 of 8 \\
\hline \multirow[t]{4}{*}{ Oilseeds } & China & 7 of 9 & Brazil & All \\
\hline & Europe & All & Rest of Latin America & All \\
\hline & India & 6 of 8 & Sub-Saharan Africa & 5 of 9 \\
\hline & & & USA & All \\
\hline \multirow[t]{4}{*}{ Rice } & Europe & 7 of 9 & China & 6 of 9 \\
\hline & Middle East; North Africa & All & India & 5 of 8 \\
\hline & Sub-Saharan Africa & All & Southeast Asia & 7 of 9 \\
\hline & & & USA & 6 of 8 \\
\hline \multirow[t]{4}{*}{ Wheat } & Europe & 5 of 9 & China & 5 of 9 \\
\hline & India & 5 of 8 & Former Soviet Union & 7 of 9 \\
\hline & Middle East; North Africa & All & USA & 7 of 8 \\
\hline & Sub-Saharan Africa & All & & \\
\hline
\end{tabular}

1 percent of domestic supply. For oilseeds, where net imports accounted for about 35 percent of domestic supply in the base year, the models also generally project this pattern to continue, with the exceptions of GCAM, MAgPIE, and MAGNET (Figure 8). However, GCAM projects that China will become a significant net exporter of both coarse grains and oilseeds by 2050.

Notable disagreement among models in projected net trade also appears in the case of rice trade in India (Figure 9). Currently, India is largely self-sufficient in rice. Most of the GE models project relatively small changes in its net rice trade by 2050. Interestingly, among the PE models, GCAM and GLOBIOM project that India will become a significant net importer by 2050, driven by an approximate doubling in food demand over this time, consistent with the assumed population and income growth. In contrast, despite similar assumed growth in food demand, IMPACT projects that India will become a net exporter in the S1 and S2 scenarios. This is because, compared with GCAM and GLOBIOM, IMPACT projects a relatively strong income-related shift from rice towards other commodities, predominantly dairy, wheat and sugar crops (not shown in Figure 9).

Consistent across models is the increasing import dependency of sub-Saharan Africa for staple commodities such as wheat, rice and coarse grains (Figures 10, 11 and 12). Figure 10 shows projections for net imports of wheat into sub-Saharan Africa in 2050, with IMPACT projecting larger and ENVISAGE and MAGNET projecting lower net imports, relative to other models. Sub-Saharan Africa currently imports a large volume of rice and all models project this situation to continue until 2050 (Figure 11). However, IMPACT among the PE models and 


\section{figure 5}

Net trade in coarse grains in 2050, the United States of America
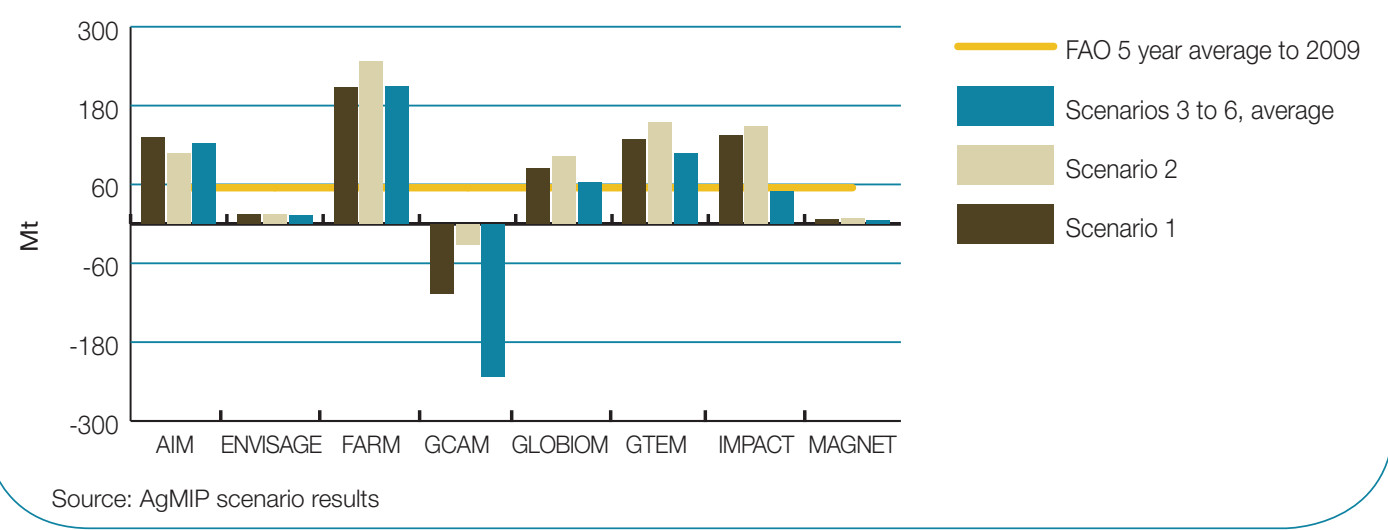

Source: AgMIP scenario results

\section{figure 6}

Net trade in oilseeds in 2050, the United States of America

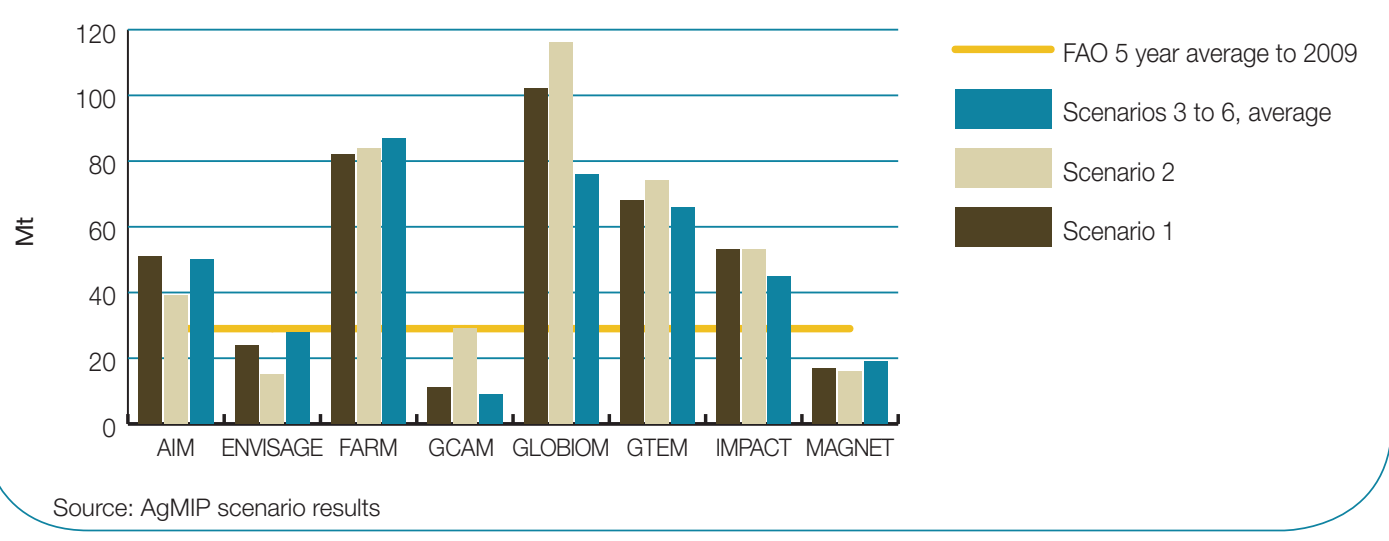

GTEM among the GE models project the largest net import volumes for all AgMIP scenarios under consideration. By 2050, most models project that net imports will make up between 30 and 50 percent of rice consumption in subSaharan Africa (with the highest rates projected by IMPACT). As for the coarse grains, a majority of the models suggest that sub-Saharan Africa will remain a net importer in 2050, with the PE models (particularly IMPACT and GCAM) projecting substantial import dependence (Figure 12).

\subsection{Key drivers of trade: Degree of model agreement}

Most of the projected changes in agrifood production and consumption, and thus changes in international trade in these commodities over the projection period, are driven by economic and population growth. Comparing results for scenarios S1 and S2 also gives some insights into likely implications of lower global economic growth and the distribution of global economic and population growth. While most models show 


\section{figure 7}

Net trade in coarse grains in 2050, China
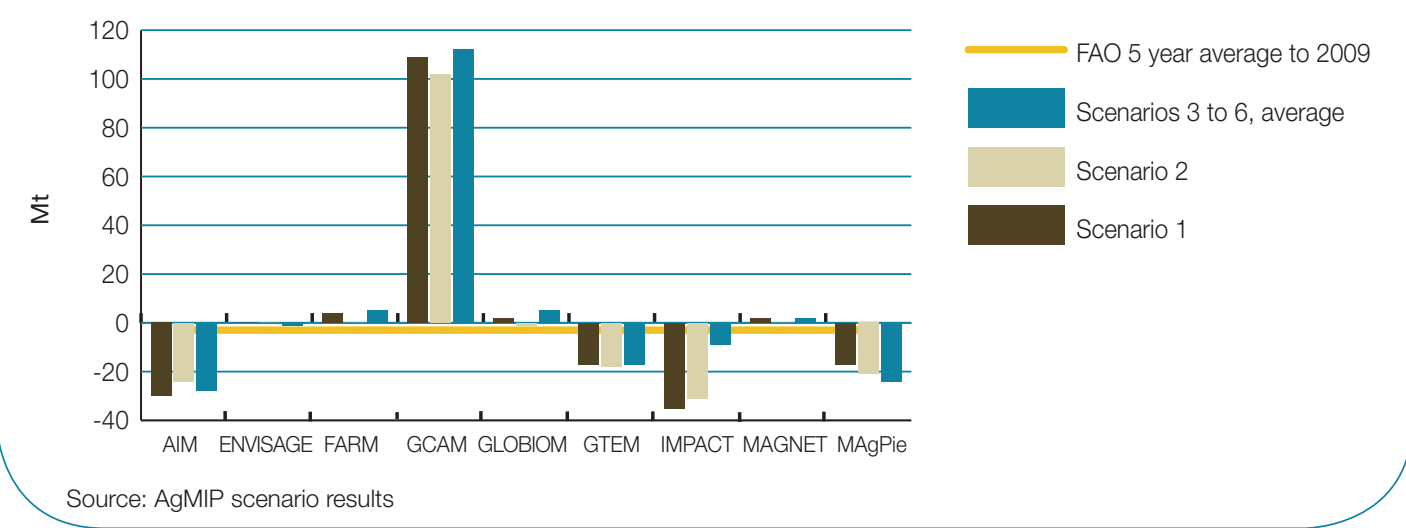

Source: AgMIP scenario results

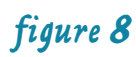

Net trade in oilseeds in 2050, China

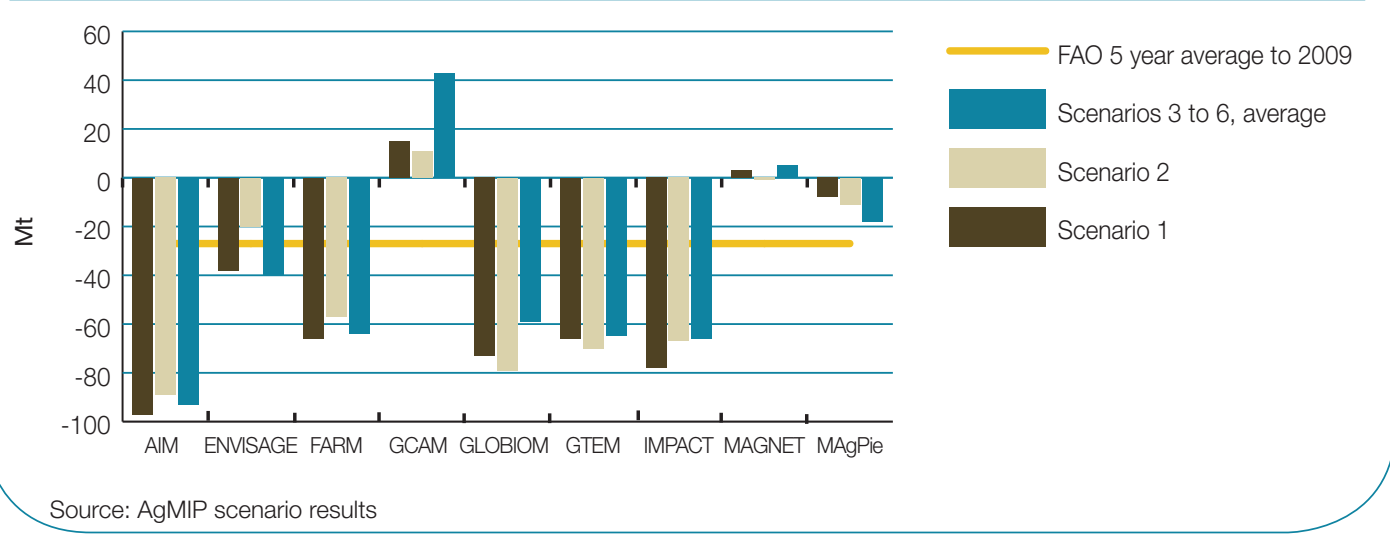

changes in net trade arising from the changes in key socio-economic drivers, i.e. GDP and population growth (Figures 5 through 12), the magnitude of the change in net trade varies across models. Furthermore, the direction of change is not uniform across models. For GCAM, changes from base-year trade patterns typically arise from relative forces of the assumed demand drivers i.e. changes in socio-economic drivers and future agricultural productivity, as well as biofuel mandates assumed for GCAM modelling. Model agreement in terms of direction of changes also seems to vary across commodities depending on the size of the net trade volumes in the initial years of the modelled period. More specifically, the degree of model disagreement is found to be high for small net trade volumes (for example, rice trade for India and coarse grains trade for China) compared to large net trade volumes (for example, coarse grains and oilseeds trade for the United States of America and wheat and rice trade for sub-Saharan Africa).

Another key production and trade driver, included in AgMIP scenarios 3 through 6, is 


\section{figure 9}

Net trade in rice in 2050, India
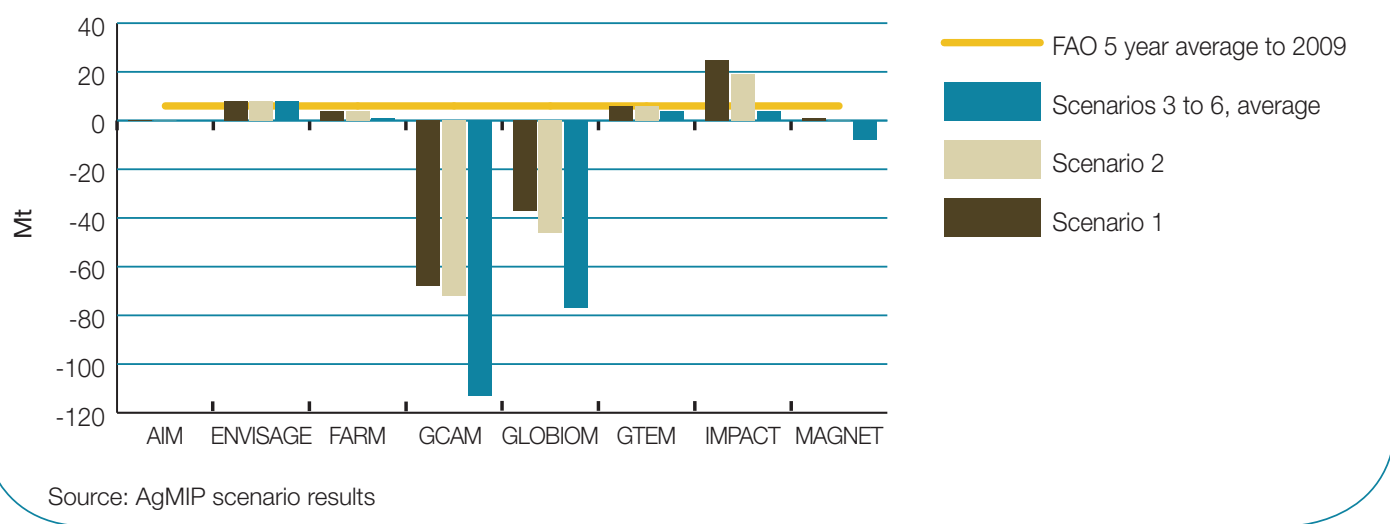

Source: AgMIP scenario results

figure 10

Net trade in wheat in 2050, sub-Saharan Africa
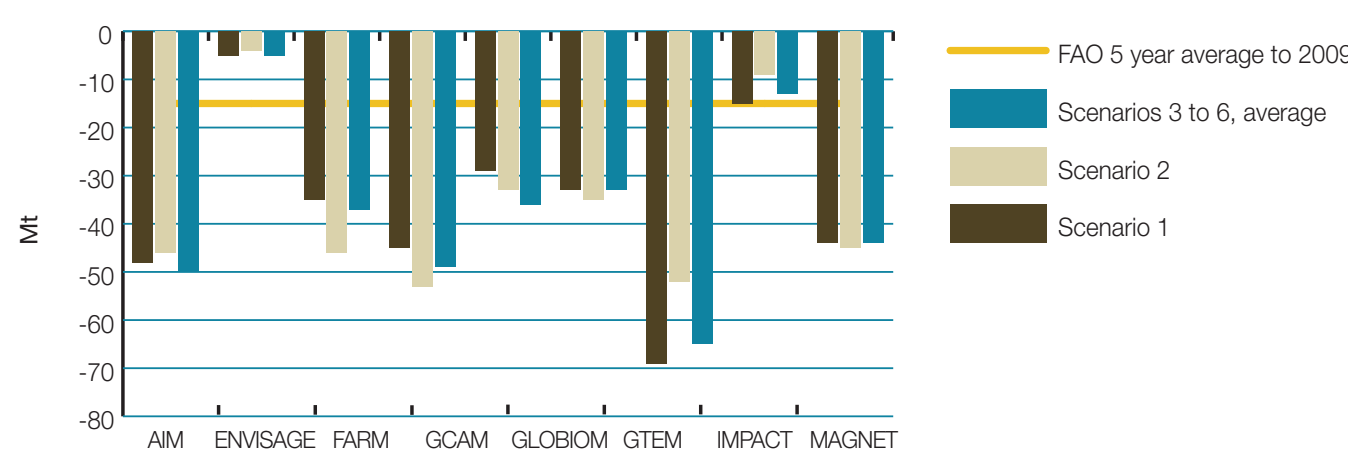

Source: AgMIP scenario results

climate change impact. ${ }^{5}$ While all models simulate reportable impacts on net trade (with varying

5 It is important to note that, although the implications of the socio-economic and climate change drivers for production and trade have been identified and analysed separately, the model results for the climate scenarios indeed represent outcomes of interactions between these two sets of drivers. In addition, impacts of climate change on GDP and/or population growth were not simulated, given the way the underlying scenarios were modelled. However, the models do generate impacts on food prices and consumption under various scenarios; these have been discussed extensively in von Lampe et al. (2014) and are therefore not repeated here. directions and magnitudes) associated with climate change, with the exception of a few cases, the models projected no change in the net trade status in 2050 of the key exporting and importing countries and commodities considered in Figures 5 through 12.

Most models have projected that climate change will have some negative effect on coarse grains and oilseeds exports from the United States of America (Scenarios S3 to S6 relative to Scenario S1, Figures 5 and 6). However, according to results from the crop models used in the AgMIP study, crop yields in the United States of America are 


\section{figure 11}

Net trade in rice in 2050, sub-Saharan Africa
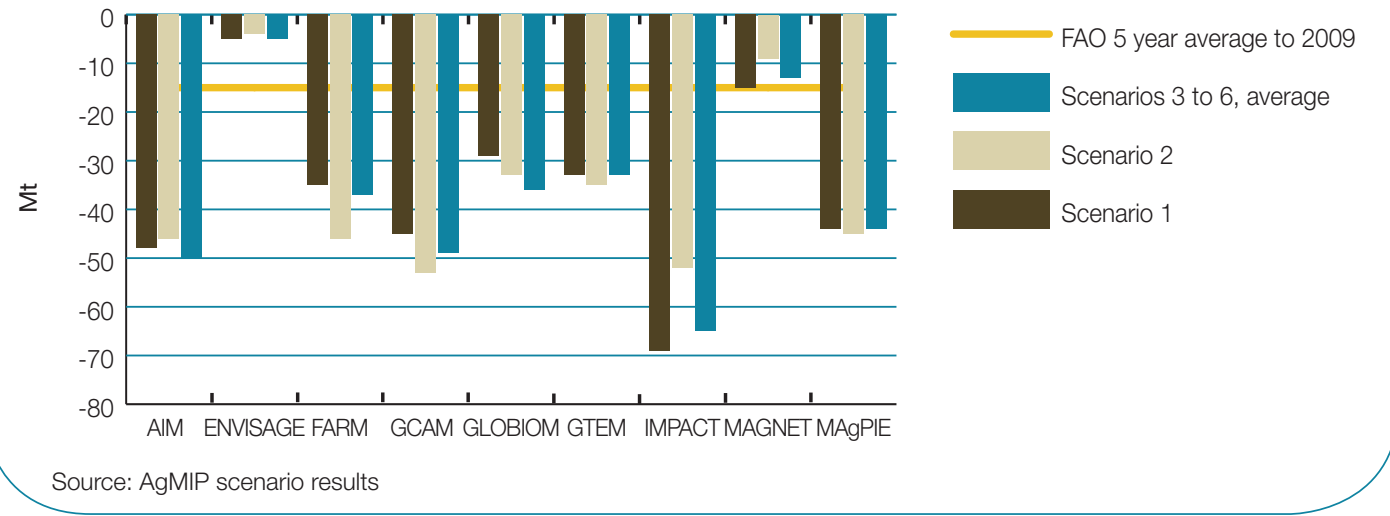

Source: AgMIP scenario results

\section{figure 12}

Net trade in coarse grains in 2050, sub-Saharan Africa
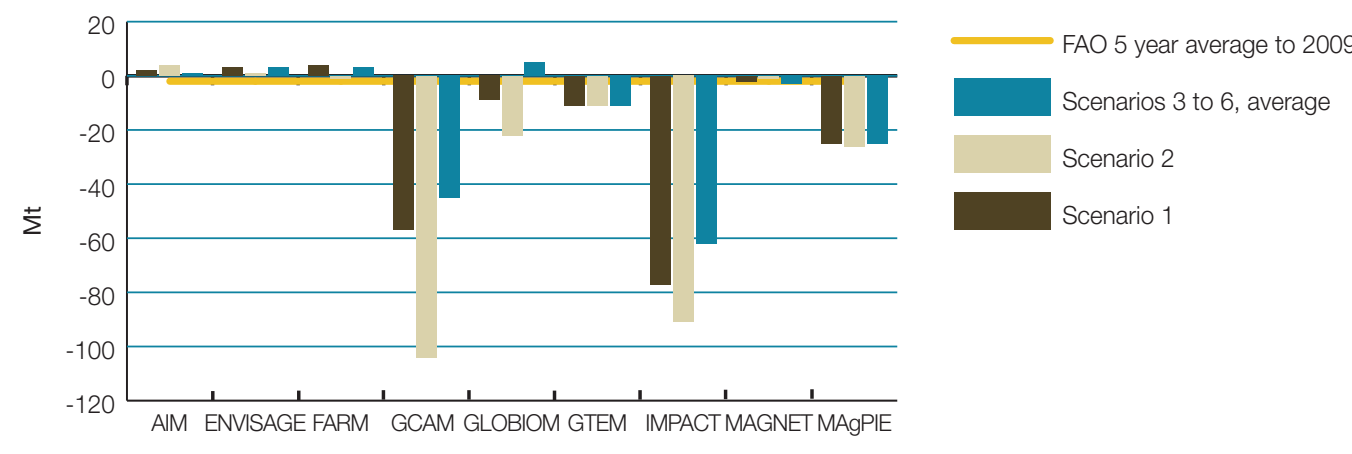

Source: AgMIP scenario results

generally less affected by climate change than in other countries/regions, and consequently the impacts on the net exports from the United States of America are also projected to be relatively small, with the exception of GCAM and IMPACT models for coarse grains, and GLOBIOM and GCAM models for oilseeds. According to most models, projected impact of climate change on Chinese trade in coarse grains and oilseeds will be a reduction in net imports (Scenarios S3 to S6 relative to Scenario S1, Figures 7 and 8). A majority of models suggest somewhat increased import dependency for rice and wheat in sub-Saharan
Africa (Scenarios S3 to S6 relative to Scenario S1, Figures 10 to 11).

The error bars in Figures 5 to 12 reflect the projected minimum and maximum net trade across Scenarios S3 to S6. All the PE models, apart from MAgPIE, show far larger variations in net trade across the various climate change scenarios than the GE models. This may be linked to the ways these two types of model specify international trade. 


\subsection{Production-exports nexus: Degree of model agreement}

Figure 13 shows the difference between Scenario $\mathrm{S} 2$ and Scenario S1 in the projected volumes of global production (on the horizontal axis) and exports (on the vertical axis) in 2050 for the following crop commodities: wheat, rice, coarse grains, sugar and oilseeds. Only results from GE models are considered, as PE models only consider net exports for modelled regions (and the global sum of net exports is zero). Modelling results presented show a positive correlation between projected changes in production and projected changes in exports. That is, if global production is projected to rise (or fall) by 2050 under Scenario S2 relative to Scenario $\mathrm{S} 1$, then exports are also projected to rise (or fall) by 2050 under Scenario S2 relative to Scenario S1, with the exception of MAGNET projections.

There is no consensus among models on whether global production and exports will be higher under Scenario S2 than under Scenario S1. Relative to Scenario S1, ENVISAGE projects strong declines in global production and exports under Scenario S2, whereas GTEM projects strongly rising production and exports. With faster population growth under Scenario S2 relative to Scenario S1, food consumption and production are expected to increase. A slower income growth under Scenario S2 relative to Scenario S1 would have the reverse effect for most goods. With relatively high income elasticities, slower income growth could drive declining food demand despite increasing population.

Figure 14 plots the projected changes in global production and exports for all modelled crops in 2050, similarly to Figure 13, but under climate change Scenarios S3 to S6 relative to Scenario S1. Each point in Figure 14 represents the likely impacts of climate change by 2050 on the production and exports of a particular crop projected by a particular GE model. Virtually all models project lower global production for all modelled crops under climate change. Most models project exports to decrease by much less than the projected decline in production or, interestingly, to increase against declining production under Scenarios S3 to S6 relative to Scenario S1. This seems to suggest an increasing role of trade under climate change.

\section{Discussion and conclusions}

The modelling results confirm that economic growth and population growth will continue to drive

figure 13

Changes in global production and export volumes in 2050: Scenario S2 relative to Scenario S1

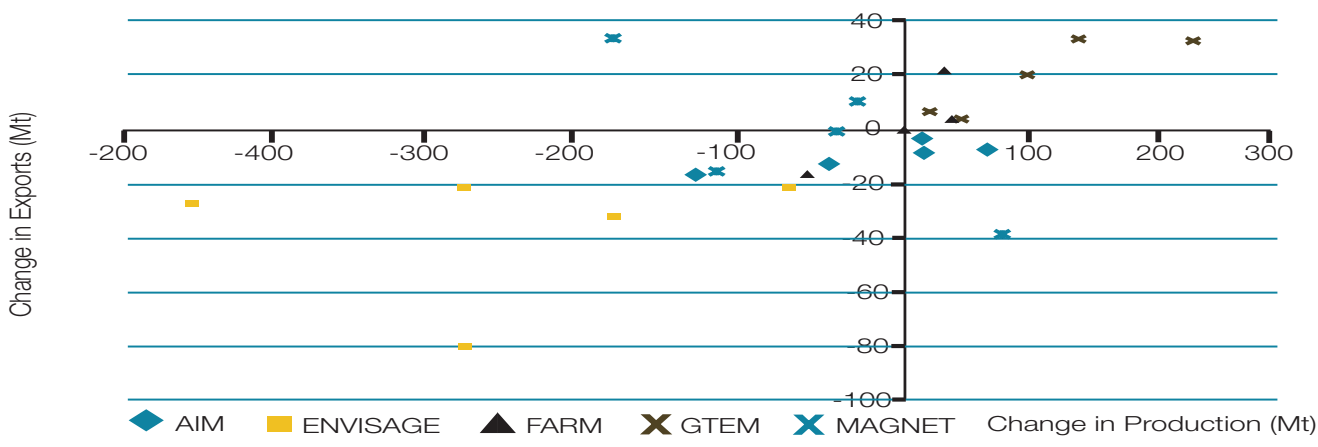

Source: AGMIP modelling results

Note: Results are only presented for GE models because PE models specify only net trade 


\section{figure 14}

Change in global production and export volumes in 2050: Scenario S3 to Scenario S6 relative to Scenario S1

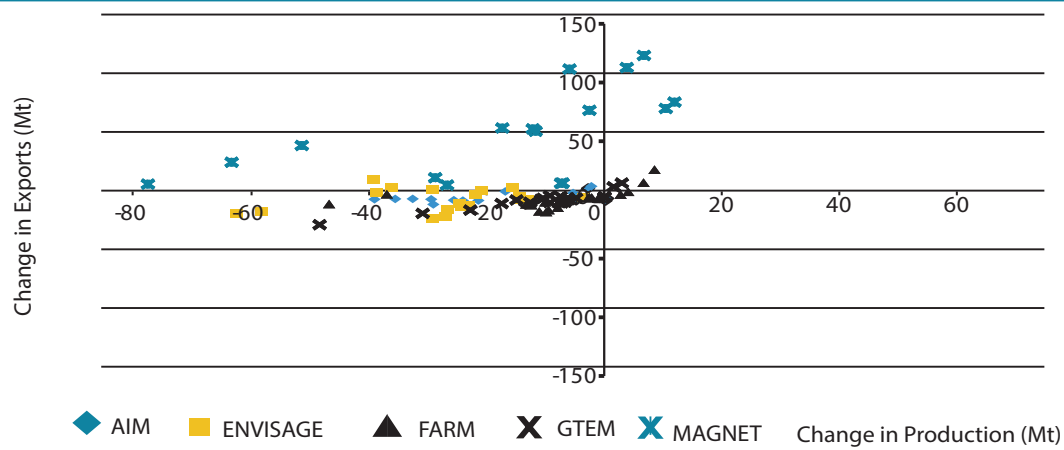

Source: AGMIP modelling results

Note: Results are only presented for GE models because PE models specify only net trade

international trade. Most models suggest that the net trade status of key exporting and importing countries/regions would remain the same in 2050 under various AgMIP scenarios considered in the paper, even when climate change is taken into account. However, the results have only focused on few important traded commodities and major exporters and importers.

There are significant differences across models in terms of projected trade in key commodities. The differences in model results seem to be somewhat heightened in cases of small trade volumes involving less-developed and/or fastdeveloping countries. For example, the projected capacity of China and India to meet domestic demand for key commodities varies significantly across models under the scenarios considered. A close assessment of land supply and land use would reveal additional reasons for the lack of model agreement.

PE models and GE models specify and treat trade differently, which seems to influence model results in many cases. In some cases, small initial values for trade can restrict its growth in GE models, to well below estimates from the PE models. In other cases, the "Armington" product differentiation assumption (or the lack of it) can lead to very large differences in projected trade patterns across models. This area of modelling warrants further investigation.
Despite the differences, modelling results in this chapter seem to suggest an enhanced role for international trade under climate change. Virtually all GE models project global production of key crops to be lower under climate change than otherwise. Most models also project exports to decrease by much less than the projected decline in production attributable to climate change. Some even project exports to increase against declining production due to climate change.

\section{References}

Ahammad, H., and R. Mi. 2005. "Land Use Change Modeling in GTEM: Accounting for forest sinks".Australian Bureau of Agricultural and Resource Economics. Presented at EMF 22: Climate Change Control Scenarios, Stanford University, California, 25-27 May, 2005.

Armington, P. 1969a. The geographic pattern of trade and the effects of price changes. IMF Staff Papers 16(2): 179-201.

1969b. A theory of demand for products distinguished by place of production. IMF Staff Papers 16(1):159-178. 
Clarete, R. \& J. Whalley. 1988. Interactions between trade policies and domestic distortions in a small open developing country. Journal of International Economics, 24: 345-358.

Dietrich, J., C. Schmitz, H. Lotze-Campen, A. Popp \& C. Müller. 2013. Forecasting technological change in agriculture - An endogenous implementation in a global land use model. Technological Forecasting and Social Change (online available), DOI: http://dx.doi. org/10.1016/j.techfore.2013.02.003.

FAOSTAT 2013. Food and Agriculture Organization of the United Nations, online database, accessed on 18 February at http://faostat.fao.org/site/291/ default.aspx

Fujimori, S., T. Masui \& Y. Matsuoka. 2012. AIM/ CGE [basic] manual. Discussion paper series, No. 2012-01, Center for Social and Environmental Systems Research, NIES, accessed February 2013 at http://www.nies.go.jp/social/dp/pdf/2012-01.pdf.

Havlík, P., U. Schneider, E. Schmid, H. Böttcher, S. Fritz, R. Skalský, K. Aoki, S. Cara, G. Kindermann, F. Kraxner, S. Leduc, I. McCallum, A. Mosnier, T. Sauer \& M. Obersteiner. 2011. Global land-use implications of first and second generation biofuel targets. Energy Policy, 39: 5690-5702.

Havlík, P., H. Valin, A. Mosnier, M. Obersteiner, J. Baker, M. Herrero, M. Rufino \& E. Schmid. 2013. Crop productivity and the global livestock sector: Implications for land use change and greenhouse gas emissions. American Journal of Agricultural Economics, 95: 442-448.

Hertel, T. \& T. Randhir. 2000. Trade liberalization as a vehicle for adapting to global warming. Agriculture and Resource Economics Review, 29(2): 1-14.

Lotze-Campen, H., C. Müller, A. Bondeau, S. Rost, A. Popp \& W. Lucht. 2008. Global food demand, productivity growth and the scarcity of land and water resources: a spatially explicit mathematical programming approach. Agricultural Economics, 39: 325-338.

Narayanan, B., A. Aguiar \& R. McDougall, eds. 2012. Global trade, assistance, and production: The GTAP 8 database. Center for Global Trade Analysis, Purdue University. Available online at: http://www.gtap.agecon.purdue.edu/databases/ v8/v8 doco.asp

Nelson, G., A. Palazzo, C. Ringler, T. Sulser \& M. Batka. 2009. The role of international trade in climate change adaptation, ICTSD-IPC Platform on Climate Change, Agriculture and Trade, Issue Paper No.4, International Centre for Trade and Sustainable Development, Geneva, Switzerland and International Food \& Agricultural Trade Policy Council, Washington DC, USA.

Nelson, G., M. Rosegrant, A. Palazzo, I. Gray, C. Ingersoll, R. Robertson, S. Tokgoz, T. Zhu, T. Sulser, C. Ringler, S. Msangi \& L. You. 2010. Food Security, Farming, and Climate Change to 2050. International Food Policy Research Institute, Washington, D.C., USA.

Nelson, G., H. Valin, R. Sands, P. Havlík, H. Ahammad, D. Derynge, J. Elliott, S. Fujimori, T. Hasegawa, E. Heyhoe, P. Kyle, M. von Lampe, H. Lotze-Campen, D. Mason-d'Croz, $H$. van Meijll, D. van der Mensbrugghe, C. Müller, A. Popp, R. Robertson, S. Robinson, E. Schmid, C. Schmitz, A. Tabeau \& D. Willenbock. 2013. Climate change effects on agriculture: Economic responses to biophysical shocks. Proceedings of the National Academy of Science, www.pnas.org/ cgi/doi/10.1073/pnas.1222465110

Nowicki, P., K. Hart, H. van Meijl, D. Baldock, M. Banse, J. Bartley, K. van Bommel, J. Helming, K. Jansson, T. Jansson, I. Terluin, K. van der Veen, P. Verhoog, D. Verburg \& G. Woltjer. 2009. Study on the impact of modulation. - Contract No. 30-CE-0200286/00-21. European Commission, 
Directorate-General Agriculture and Rural Development, Brussels.

OECD 2012. Global Food Security: Challenges for the Food and Agriculture System, TAD/CA/APM/ WP(2012)18, OECD, Paris.

Paltsev, S., J. Reilly, H. Jacoby, R. Eckaus, J. McFarland, M. Sarofim, M. Asadoorian \& M. Babiker. 2005. The MIT Emissions Prediction and Policy Analysis (EPPA) Model: Version 4, available at http://globalchange.mit.edu/research/ publications/697.

Reilly, J. \& N. Hohmann. 1993. Climate change and agriculture: The role of international trade. American Economic Review Papers and Proceedings, 83(2): 306-312.

Robinson, S., H. van Meijl, D. Willenbockel, H. Valin, S. Fujimori, T. Masui, R. Sands, M. Wise, K. Calvin, P. Havlik, D. Mason d'Croz, A. Tabeau, A. Kavallari, C. Schmitz, J. Dietrich \& M. von Lampe. 2014. Comparing supply-side specifications in models of global agriculture and the food system. Agricultural Economics (Special Issue on climate change impacts modelling), 45(1): 21-35.

Rosegrant, M.\& IMPACT Development Team (2012) International Model for Policy Analysis of Agricultural Commodities and Trade (IMPACT) Model Description, Washington DC.

Sands, R., H. Forster, K. Schumacher \& C. Jones. 2013. Bio-electricity and land use in the Future Agricultural Resource Model (FARM). in review at Climate Change for Special Issue on Technology Outcomes and Climate Policy Objectives.

Schmitz, C., H. van Meijl, P. Kyle, G. Nelson, S. Fujimori, A. Gurgel, P. Havlik, E. Heyhoe, D. Mason d'Croz, A. Popp, R. Sands, A. Tabeau, D. van der Mensbrugghe, M. von Lampe, M. Wise, E. Blanc, T. Hasegawa, A. Kavallari \& H. Valin. 2014. Land-use change trajectories up to 2050: insights from a global agro-economic model comparison. Agricultural Economics (Special Issue on climate change impacts modelling), 45(1): 69-84.

Taylor, L. \& S. Black. 1974. Practical general equilibrium estimation of resource pulls under trade liberalisation. Journal of International Economics, 4(1): 37-58.

USDA ERS (United States Department of Agriculture, Economic Research Service), 2013a. Crops (various), accessed on 18 February at http://www.ers.usda.gov/topics/crops.aspx

2013b. International Markets and Trade (various countries and regions), accessed on 26 February at http://www.ers.usda.gov/topics/ international-markets-trade/countries-regions/.

Valin, H., R. Sands, D. van der Mensbrugghe, G. Nelson, H. Ahammad, E. Blanc, Bodlrsky, S. Fujimori, T. Hasegawa, P. Havlik, E. Heyhoe, P. Kyle, D. Mason-D'Croz, S. Paltsev, S. Rolinski, A. Tabeau, H. van Meijl, M. von Lampe \& D. Willenbockel. 2014. The future of food demand: Understanding the differences in global economic models. Agricultural Economics (Special Issue on climate change impacts modelling), 45(1): 51-67.

Van der Mensbrugghe, D. 2013. The ENVironmental Impact and Sustainability Applied General Equilibrium (ENVISAGE) Model: Version 8.0, processed, FAO, Rome.

Verburg, R., G. Woltjer, A. Tabeau, B. Eickhout \& E. Stehfest. 2008. Agricultural Trade Liberalisation and Greenhouse Gas Emissions: A simulation study using GTAP-IMAGE modelling framework, LEI, The Hague.

von Lampe, M., D. Willenbockel, H. Ahammad, E. Blanc, Y. Cai, K. Calvin, S. Fujimori, T. Hasegawa, P. Havlik, E. Heyhoe, P. Kyle, H. Lotze-Campen, D. Mason-D'Croz, G. Nelson, R. Sands, C. Schmitz, A. Tabeau, H. Valin, D. van der Mensbrugghe \& H. van Meijl. 2014. Why do 
global long-term scenarios for agriculture differ? An overview of the AgMIP global economic model intercomparison. Agricultural Economics (Special Issue on climate change impacts modelling), 45(1): 3-20.

Wise, M. \& K. Calvin. 2011. GCAM 3.0 Agriculture and Land Use Modeling: Technical Description of Modeling Approach, accessed on 2 April at https://wiki.umd.edu/gcam/images/8/87/ GCAM3AGTechDescript12_5_11.pdf.

WTO (World Trade Organization) and UNEP (United Nations Environment Program) 2009. Trade and Climate Change, accessed on 23 May 2013 at https://www.wto.org/english/res e/booksp e/ trade climate change e.pdf. 



\section{chapter 11}

Page

$\begin{array}{ll}\text { 1. Introduction } & 316\end{array}$

$\begin{array}{ll}\text { 2. Climate change } & 317\end{array}$

3. Climate variability and agriculture 318

4. Impacts of climate change on food availability 319

4.1 Global studies of impacts on crop production and yield 321

4.2 Local, national and regional studies of impacts on crop production and yield

5. Impacts on food access, utilization and stability 323

6. Mitigation and adaptation in the agricultural sector 326

7. Understanding and working with uncertainty about climate change impacts on food security

8. Towards climate-compatible food policies 330

9. Conclusions 330

$\begin{array}{ll}\text { References } & 331\end{array}$

Citation

Wheeler, T. 2015. Climate change impacts on food systems and implications for climate-compatible food policies, In: Climate change and food systems: global assessments and implications for food security and trade, Aziz Elbehri (editor). Food Agriculture Organization of the United Nations (FAO), Rome, 2015. 


\section{chapter 11}

\section{Climate change impacts on food systems and implications for climate-compatible food policies}

\section{Tim Wheeler ${ }^{1}$}

\section{main chapter messages}

- Climate variability and change will add further stresses on a global food production system that needs to respond to future trends of increasing population, changes in diet and urbanisation.

- The impacts of climate change on food security will vary from one part of the world to another and hinder progress towards a world without hunger.
- The stability of whole food systems may be at risk under climate change, largely due to short term variability and extreme events in agricultural markets.

- Climate change risks to agricultural output, to food systems and for food security will increase over time and so should not be ignored by those making medium- and long-term planning decisions about food security. 


\section{Introduction}

T

he overall level of hunger in the world has been steadily falling since the widespread introduction of "green revolution" technologies brought more productive crop varieties and better agricultural technologies to large parts of Asia and elsewhere. The number of hungry people has fallen from an estimated 980 million globally in 1990-1992 to about 850 million in 2010-2012 (FAO, 2012). The boost to production resulting from adoption of green revolution varieties has also contributed to a long-term decline in global food prices. Areas of persistent hunger still remain; many of these are in parts of Africa (von Grebmer et al., 2012). However, recently much attention has been focused on looking ahead to the challenges of the feeding the world now and in the near future. How can the global food system cope over the coming decades with increases in the human population, changes in diet, climate change and greater demands on energy and water resources (Godfray et al., 2010), in addition to the challenges of food insecurity that already exist?

Food security is a broad concept, defined by the World Food Summit in 1996: food security "exists when all people, at all times, have physical and economic access to sufficient, safe and nutritious food to meet their dietary needs and food preferences for an active and healthy life" (FAO, 1996). Food security means more than just the production of food and encompasses aspects of food availability, access, utilization and stability (Box 1).

The effectiveness of the agricultural sector is only one among many influences that determine whether an individual, community or population is food-secure. However, when considering the potential impacts of climate change on global food security, agriculture is a key sector because it is inherently sensitive to climate variability and change, whether attributable to natural causes or to human activities. Climate change resulting from emissions of greenhouse gases is expected to exert a direct impact on crop production systems for food, feed

\section{box 1}

Food security

The formal definition of food security by the Food and Agricultural Organization of the United Nations (FAO) has the following four components:

1. Availability: availability of sufficient quantities of food of appropriate quality, supplied through domestic production or imports;

2. Access: access by individuals to adequate resources (entitlements) for acquiring appropriate foods for a nutritious diet;

3. Utilization: utilization of food through adequate diet, clean water, sanitation and health care to reach a state of nutritional well-being in which all physiological needs are met;

4. Stability: reliable access to adequate food at all times, for populations, households or individuals.

or fodder, affect livestock health, and alter the patterns and balance of trade of food products. The potential range and extent of indirect impacts on food security are large and will be factors in addition to direct impacts. All of these impacts will vary with the degree of warming and associated changes in rainfall patterns, and from one location to another. It is likely that climate variability and change will add further stresses on food production and food security in the future. This paper takes a broad view of the complex impacts of climate change on food security, with the aim of identifying robust conclusions based on research evidence to date. It also attempts to frame the existing evidence in a way that is accessible to those making policy decisions on climate change and food security, guided by the recognition that, despite 
the complexity and uncertainties of knowledge regarding climate change impacts on food security, it is necessary to make robust policy choices now, to better prepare for the challenges of climate change to food security in the future.

\section{Climate change}

Multiple observations have provided increasing evidence that the climate is changing. Many pieces of evidence support the conclusion that the Earth has warmed since pre-industrial time - i.e. the middle of the eighteenth century. Evidence ranges from direct measurements of climate (for example, Figure 1) to observations of change in the natural environment that correlate with a warming world (IPCC, 2007a). Global mean temperature has risen by $0.8^{\circ} \mathrm{C}$ since the 1850 s, with warming found in three independent temperature records over land and sea and in the ocean surface water (IPCC, 2007b).

The Berkeley Earth Surface Temperature project (BEST) (Richard, 2012) reassessed existing records of global temperature. The project was independent of any previous organizations that have analysed global warming, and used different methods. BEST analysed temperature measurements dating back to before the 1800s from sources around the world. The interim project findings were almost indistinguishable from previous records of global temperature (Figure 2). The BEST project concluded that "the global warming trend is real". The project also rejected concerns raised by some climate sceptics that the warming trend is dominated by an urban heat island effect, poor station quality and the risk of data selection bias.

Climate change can result from natural causes, from human activities, through the emission of greenhouse gases, such as carbon dioxide $\left(\mathrm{CO}_{2}\right)$, methane and nitrous oxides, and from changes in land use. $\mathrm{CO}_{2}$ levels in the atmosphere have gone up from about 284 ppm in 1832 to 395 ppm in 2013 (Tans and Keeling, 2013; www.esrl.noaa. gov/gmd/ccgg/trends/global.html). Fundamental physics indicates a clear theoretical link between more greenhouse gases in the atmosphere and increased global warming. The key question for scientists is whether or not the warming observed since pre-industrial times can be largely attributed to human activities.

Three independent reviews since 2007 have found strong evidence for human causes of climate change. The headline findings are:

- "Most of observed increase in globally averaged temperature since the mid-20th

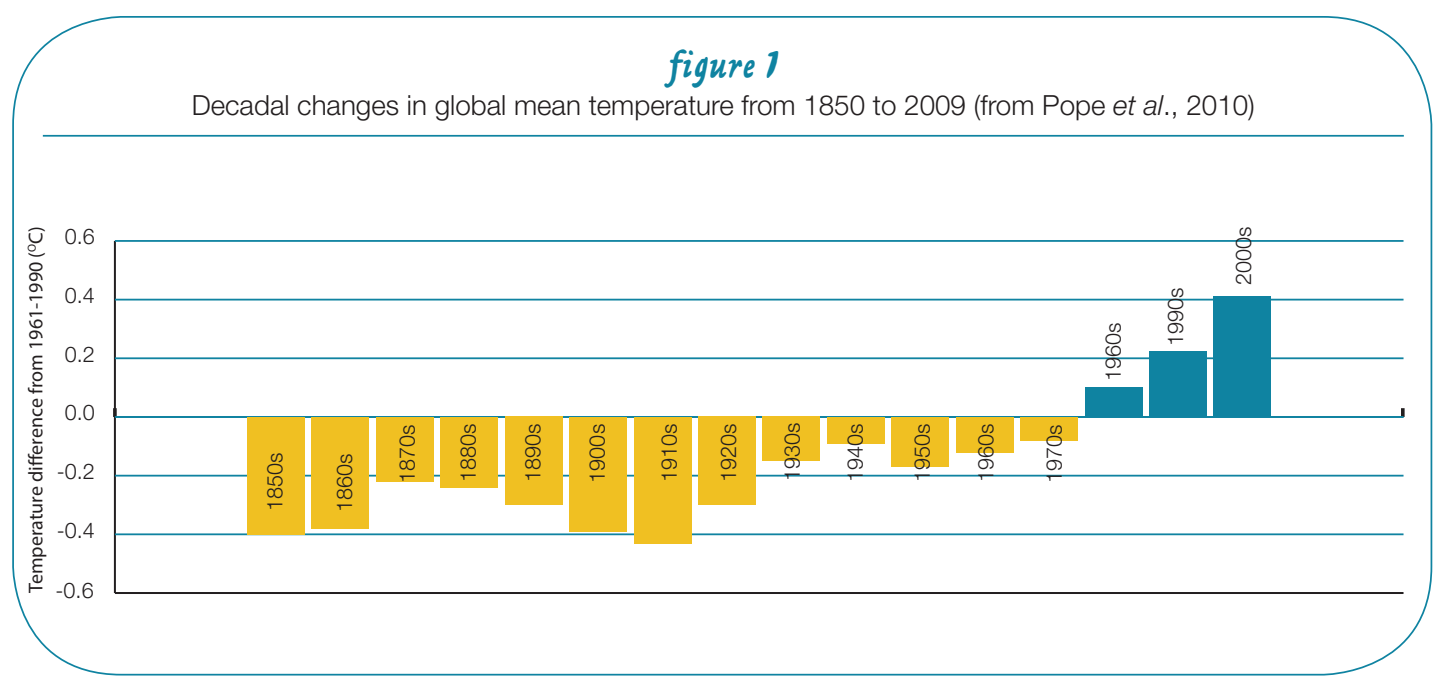


century is very likely (more than a $90 \%$ chance) due to observed increase in anthropogenic greenhouse gas concentrations", Intergovernmental Panel on Climate Change (IPCC, 2007, WG1).

- "There is strong evidence that the warming of the Earth over the last half-century has been caused largely by human activity, such as the burning of fossil fuels and changes in land use", The Royal Society (2010).

- "A strong, credible body of scientific evidence shows that climate change is occurring, is caused largely by human activities, and poses significant risks for a broad range of human and natural systems", United States National Science Academy (2010).

A recent study by Huber and Knutti (2012) reported that at least three-quarters of the temperature rise observed in the past 60 years is due to human activity and that natural climate variability is extremely unlikely to have contributed more than one-quarter of the observed global warming. The study findings reinforce previous reports that greenhouse gases, in particular $\mathrm{CO}_{2}$, are the main cause of recent global warming. It calculated a net warming value of $0.5^{\circ} \mathrm{C}$ (since the 1950s), which is very close to the actual observed temperature rise of $0.55^{\circ} \mathrm{C}$. The study was also able to model the contribution of solar radiation, commonly cited by climate sceptics as the cause of global warming. Solar radiation only contributed around $0.07^{\circ} \mathrm{C}$ of the recent warming. This study produces even higher confidence that humaninduced causes dominate the observed global warming.

Finally, the IPCC $5^{\text {th }}$ Assessment Report, published recently, concluded that "there is a clear human influence on the climate" and that "it is extremely likely that human influence has been the dominant cause of observed warming since 1950" (IPCC, 2013a).

\section{Climate variability and agriculture}

Agriculture is sensitive to variability in weather and climate (principally rainfall and temperature) at a range of time and spatial scales, as evidenced from observations of crop plants, the behaviour of soft commodity prices and the productivity of the entire agricultural sector.

In many monsoon-affected regions of the world, clear, large-scale correlations are seen between seasonal rainfall and national crop yields and even gross national products (GNPs). For example, between 1966 and 1990, the total

\section{figure 2}

Decadal land-surface average temperature (from Richard, 2012; Figure at http://www.bbc.co.uk/news/science-environment-15373071

Temperature anomaly $\left({ }^{\circ} \mathrm{C}\right)$

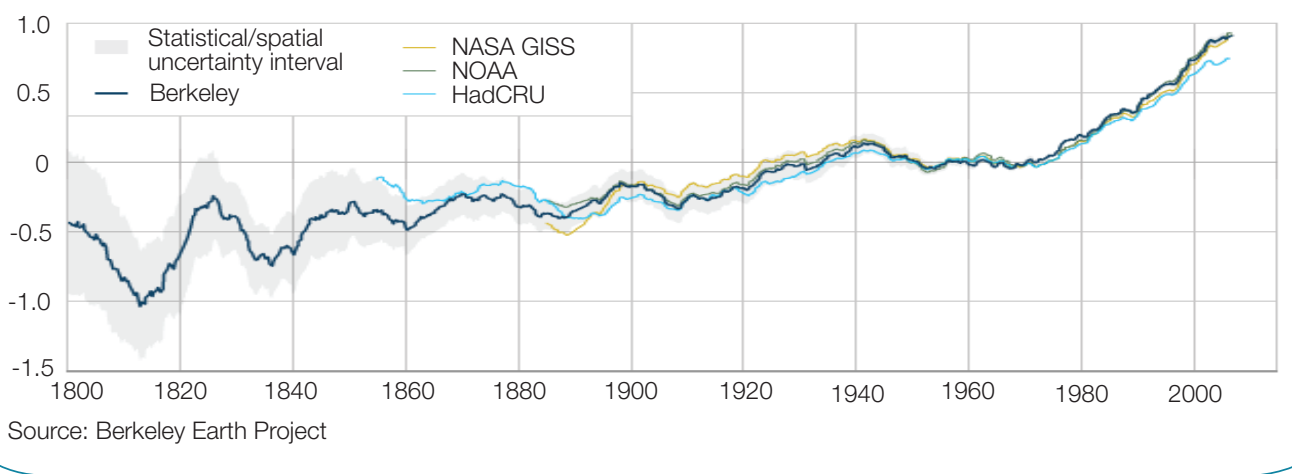


average annual monsoon rain over all of India varied from about $450 \mathrm{~mm}$ to over $1200 \mathrm{~mm}$. Over the same period, the yield of groundnut, an oilseed crop, varied from $600 \mathrm{~kg} / \mathrm{ha}$ to over 1200 $\mathrm{kg} / \mathrm{ha}$ as a country average. Within these country averages considerable variation in rainfall and yield existed, from state to state and from one district to another. Challinor et al. (2004) analysed these spatial and temporal patterns and found that just over half (52\%) the variation in crop yield over this time period and from one district to another in India could be attributed to variability in the total monsoon rains alone (Figure 3). There is a simple, large-scale, coherent correlation between variability in rainfall and crop yield in India, demonstrating the importance of that simple metric of climate in India for rainfed crop production. Such large-scale patterns can even be found between rainfall and GDP growth in countries where the agricultural sector represents a large share of national income. For example, de Jong (2005) found an association between rainfall variability and GDP growth over an 18-year period in Ethiopia (Figure 4). Given such examples of the sensitivity of agriculture to natural variability in climate, it is not surprising that there are many potential ways in which climate change due to human influences could also have an impact on agriculture and food security.

\section{Impacts of climate change on food availability}

Much of the early literature on the impacts of climate change on food availability focused on direct effects on crop plants. Increasing the concentration of $\mathrm{CO}_{2}$, one of the main greenhouse gases, enhances the productivity of most crops, due to enhanced rates of photosynthesis (Drake et al., 1997). This boost to productivity is apparent for all crops that use the C3 photosynthetic pathway ${ }^{2}$, such as wheat, barley, rice and soybean. Reviews of hundreds of plant studies found an average yield gain of 33 percent for these crops (Kimball et al., 1983). Although there is some disagreement about whether the full extent of these benefits to crops can always be found under field conditions (Long et al., 2006), we can expect increasing $\mathrm{CO}_{2}$ to benefit the productivity of most food crops, pasture grasses and feed crops.

There are, however, a number of important crops that have a different response to elevated $\mathrm{CO}_{2}$. Maize, sorghum, millet and sugar cane use the C4 photosynthetic pathway. The leaf photosynthetic rates of $\mathrm{C} 4$ plants are not substantially enhanced by elevated concentrations

2 See chapter, section 2.3 for a detailed definition of C3 and C4 pathways.

\section{figure 3}

Patterns of seasonal rainfall (left, cm) and yield of groundnut (right, kg ha-1) in India from 1966 to 1990
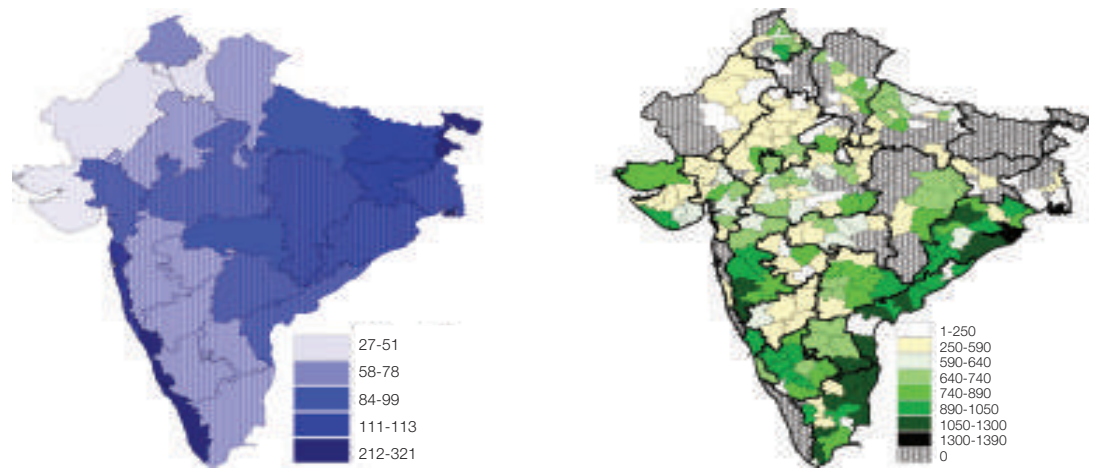

Source: Challinor et al., 2004) 


\section{figure 4}

Variation in GDP growth with total seasonal rainfall variation in Ethiopia

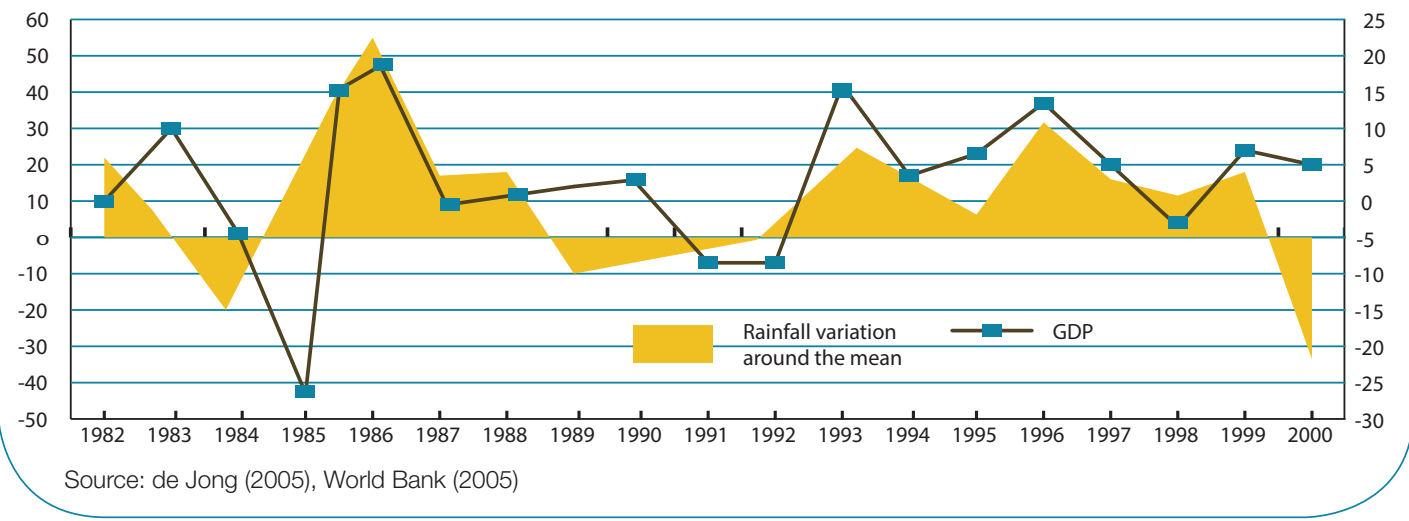

of $\mathrm{CO}_{2}$; yield gains in these plants grown under elevated $\mathrm{CO}_{2}$ are much more modest than for $\mathrm{C} 3$ plants - for example, no yield change is observed for maize (Long et al., 2006). There is a small improvement in the efficiency of water use for both $\mathrm{C} 3$ and $\mathrm{C} 4$ crops under enhanced $\mathrm{CO}_{2}$ conditions.

Warmer temperatures affect the rate at which crops grow and develop, and potentially affect the survival of plants and seeds at extremes of temperature. The duration from sowing to flowering to crop harvest is determined by temperature regime and by day-length (Craufurd and Wheeler, 2009). In a warmer climate, we expect the areas where crops are grown to shift northwards in the northern hemisphere and southwards in the southern hemisphere. Where the appropriate genetic material is available, farmers at a particular location can adapt to these changes using new varieties or crops with longer durations; that is, with higher thermal requirements for crop development. Where longer-season varieties cannot be used, crop yields will decline with warmer temperatures because less radiation will be captured and used for crop yield in seasons of shorter duration. For example, an analysis of more than 20000 variety trials of maize across Africa found that, for each degree day spent above $30^{\circ} \mathrm{C}$, final maize yield was reduced by 1 percent under optimal rainfed conditions and by 1.7 percent under drought conditions (Lobell et al., 2011). In the future, with a shift to adapted varieties, some of the negative impacts of warmer temperature can be partly offset, although there are important differences among the world's major crops - such as between C3 and C4 crops, and between crops grown in temperate and tropical latitudes. For example, a synthesis of adaptation studies of wheat yield found that adaptation counteracted the equivalent of 4.5 to $5^{\circ} \mathrm{C}$ of warming in the mid to high latitudes, but only 1.5 to $3^{\circ} \mathrm{C}$ at low latitudes (Easterling et al., 2007). Beyond these values of temperature warming, the impacts of climate change exceed adaptive capacity.

Extremes of hot temperature will become more frequent under climate change (Figure 5). Even without any changes in the distribution of daily temperature, a warmer mean distribution will increase the frequency of extremely hot days. Increased climate variability, which is expected under climate change, will further increase the frequency of extreme temperatures. Where extremely hot days coincide with a sensitive stage of crop development, such as flowering, we find dramatic decreases in seed or grain yields (Wheeler et al., 2000). For example, an increase in maximum temperature above $30^{\circ} \mathrm{C}$ reduced the seed set of rice cultivar IR64 by 7 percent per degree increase in heat stress (Jagadish et al., 2007). What is 


\section{figure 5}

Changes in wheat yields over a range of temperature changes with (green lines) and without (red lines) adaptation and at two latitude ranges (from Easterling et al., 2007)

(c) Wheat, mid- to high-latitude

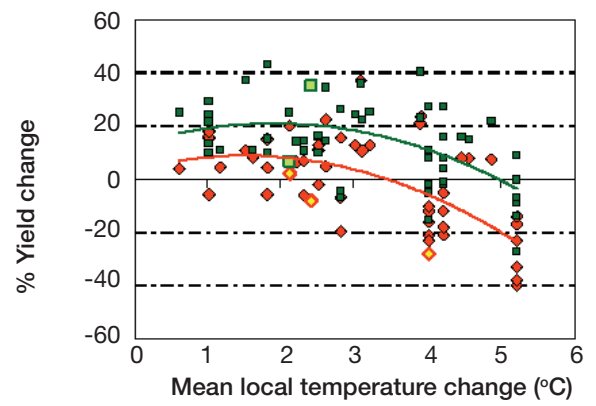

(d) Wheat, low latitude

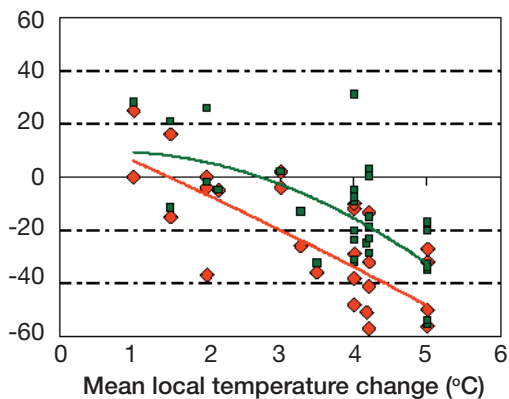

less well understood is how these extremely hot temperatures may affect the quality of seeds and grains for food processing (Madan et al., 2012) or for animal feed.

\subsection{Global studies of impacts on crop production and yield}

The first attempts to examine the potential impacts of various scenarios of climate change on crop productivity were done using simulations at single sites. A crop model simulation would usually compare the output of a run of years under current climate conditions with a set of simulations using the current climate plus a change derived from a climate change scenario. Rosenzweig and Parry (1994) produced the first global assessment of the potential impacts of climate change scenarios on crops. They used the output of three General Circulation Models (GCMs), each with high temperature sensitivity (warming of $4-5.2^{\circ} \mathrm{C}$ ) and run with twice the baseline atmospheric $\mathrm{CO}_{2}$ equivalent concentrations. They used crop models for wheat, maize, soybean and rice, ran the simulations at 112 sites in 18 countries and aggregated the output to a national level by combining the climate change yield signal with crop production statistics. The projected change in crop yield varied with climate model and in different parts of the world. Most of the scenarios showing increases in yield were simulated in northern Europe, while yield change was negative across most of Africa and South America (Rosenzweig and Parry, 1994; Figure 6a).

Since 1994, more complete knowledge of the effects of climate on crop plant physiology has been gained and incorporated into crop simulation models, the simulation methods for impact studies are more advanced and the computing power and datasets to run global simulations have improved. As a consequence, more studies of the impacts of climate change on crop yield and production at a global scale have been published. Landmark studies include those by Cline (2007), Parry et al. (2004) and most recently the World Bank (World Bank, 2010; Figure 6b). These studies used different techniques for estimating climate change impacts; the study by Cline, using Ricardian statistical economic models, was quite different in method from the others, which used more traditional crop simulation model approaches.

Despite these differences in method and the 16-year period over which these studies were conducted, the general pattern of change in crop productivity has remained the same across all four global studies, although the magnitude of crop 
impacts varies at global scale. In general, crop yields experience more negative impact across many parts of the tropics, compared with higher latitudes where yield impacts can be positive, especially in the northern hemisphere. Precise projections vary according to the climate model scenario used and the time scale over which the projection is done - with simulations becoming more negative further into the future; however, the broad-scale pattern of climate change impacts has been consistent over the 20 years or so of research. It seems reasonable to conclude that there is a robust and coherent pattern of impacts of climate change on crop productivity, and most likely on food availability, at a global scale.

Within this consistent broad-scale pattern of climate change impacts on food availability it is also clear that many of the negative impacts occur in developing countries, where there is already a high level of food insecurity. Wheeler and von Braun (2013) showed a close spatial association between the global distribution of negative impacts on crops and areas where food insecurity is high, as quantified by the International Food Policy Research Institute (IFPRI) Global Hunger index (Von Grebmer et al., 2012). A number of concerns for food security underlie this simple association. Many negative impacts on crops are projected in areas where current climate conditions are already marginal (hot or dry) for productive cultivation of crops. In addition, technologies and farm management systems that could aid adaptation to negative climate change impacts are absent or underutilized in many developing countries, where direct climate impacts are projected to be greatest. Such considerations led Wheeler and von Braun (2013) to suggest that climate change impacts will hinder progress towards a world without hunger.

Studies of crop yield impacts under climate change across Africa and South Asia have recently been the subject of a systematic review (Knox et al., 2012). Systematic methods for summarizing research evidence are rare in the field of agricultural research; they are found more commonly in the health and medical literature. Knox et al. (2012) reviewed 1144 existing studies of the impacts of climate change on a selection of crops (wheat, maize, sorghum, millet, rice, cassava and sugar cane) in Asian and African countries. Systematic review protocols require that each study be screened against a strict set of inclusion criteria. Of the initial studies, 52 were selected for metaanalysis on the basis of strict quality criteria. The projected average mean change in yield of all crops across both regions was -8 percent by the 2050s. Across Africa, yields changed by -17 percent for wheat, -5 percent for maize, -15 percent for sorghum and -10 percent for millet. Across South Asia yields changed by -16 percent for maize and -11 percent for sorghum under climate change averaged over studies examining projections from 2020 to 2080. The magnitude of yield impacts increased over this period. No mean change in yield was detected for rice, possibly because most of the simulations in Asia were of rice grown in paddies, which would tend to minimize any signal from changes in rainfall.

Within these mean yield impacts, Knox et al. (2012) were able to identify some common features of different impact methods. For example, variation in the projected mean yield change for all crops was smaller in studies that used an ensemble of more than three GCMs. Complex simulation studies using biophysical crop models showed the greatest variation in mean yield changes. The authors concluded that evidence of the impact of climate change on crop productivity in Africa and South Asia is robust for wheat, maize, sorghum and millet but is inconclusive, absent or contradictory for rice, cassava and sugar cane.

\subsection{Local, national and regional studies of impacts on crop production and yield}

The impacts of climate change are expected to vary from one part of the world to another and to change over time. Consideration of local contexts within the large-scale global trends discussed in the previous section is important for providing information to farmers and their advisers seeking 
to adapt to these new challenges, because many adaptation actions are undertaken at the farm or national scale. Global estimates generally simulate the impacts of changes in mean seasonal temperature and monthly rainfall on crop yields, whereas the evidence from crop experiments suggests that it is the extremes of climate, which are often local, that will have the most severe impact on crop productivity (Wheeler et al., 2000). More detailed crop simulations, possible at country and regional scales, could also consider these finer time scales of weather extremes.

National scale assessments of the impacts of climate change on crops can potentially use information with finer resolution on climate, soils, and topography for crop simulation. This is especially relevant for large countries such as China, as its large natural climate variability adds a further level of uncertainty to projections. For example, interannual variation in the East Asian summer monsoon and the El Niño Southern Oscillation account for 14 percent and 16 percent, respectively, of the variation in maize yields from year to year (Tao et al., 2004), and national maize yields decline by 5 percent during an El Niño phase (Tao et al., 2004). Changes in some climate parameters, principally temperature and precipitation, during the last fifty years (Wang et al., 2004; Zhai et al., 1999) may have already advanced the harvest date of crops in China (Dong et al., 2009).

Much finer grid scales of 5-20 km place even greater limits on the skill of predictive science than national and global scales. Additional uncertainties arise from: the method by which the output of global-scale climate models is downscaled; whether input data (such as crop, soils, typography and management information) are available across the domain for crop simulation at this scale; and general questions about the skill of the simulation methods across a fine-scale domain. It is not surprising that the sheer complexity of food production systems at a very fine scale makes them difficult to reproduce in numerical models.

A simple visual comparison of fine-scale projections of climate change impacts for maize crops in East Africa illustrates the challenges of coping with uncertainty (Figure 7; Thornton et al., 2009). This projection gives fine-scale information that is completely absent from projections at the broad scale (Figure 6). However, comparison of different fine-scale impact studies often shows disagreement in both the signal and magnitude of the simulated changes in crop productivity at any one location. Of course, as in global studies, each regional study varies in terms of data inputs and simulation methods used, and so in a sense these studies reflect the uncertainty space for crop impacts under climate change at these fine scales. One further level of analysis is needed to help with the interpretation of small-scale impacts: a test of how well these fine-scale simulations compare with observations in the current climate. Such tests of model skill are found in some studies at the global scale - for example, Osborne et al. (2012).

\section{Impacts on food access, utilization and stability}

Climate change impacts on food access, utilization and stability are often less direct than those on food availability; however, these dimensions of food security do have strong links to climate change. Perhaps because the impacts are more indirect, the evidence is less well-developed for these dimensions of food security. Wheeler and von Braun (2013) reviewed the evidence of food security impacts of climate change following publication in 1990 of the first IPCC report. They concluded that studies of the impacts of climate change on the food availability dimension of food security dominated the evidence base, with 70 percent of publications on this single dimension alone. Wheeler and von Braun (2013) summarized the main indirect effects of climate change on food access, utilization and stability as described in the following paragraphs.

Access to food depends on levels of household and individual income. Two approaches have been used to assess the impacts of climate change on access to food: top-down models 


\section{figure 6}

Global Global impacts of climate change on crop productivity from simulations published in 1994 (top, from Rosenzweig and Parry, 1994) and in 2010 (bottom, from World Bank, 2010)
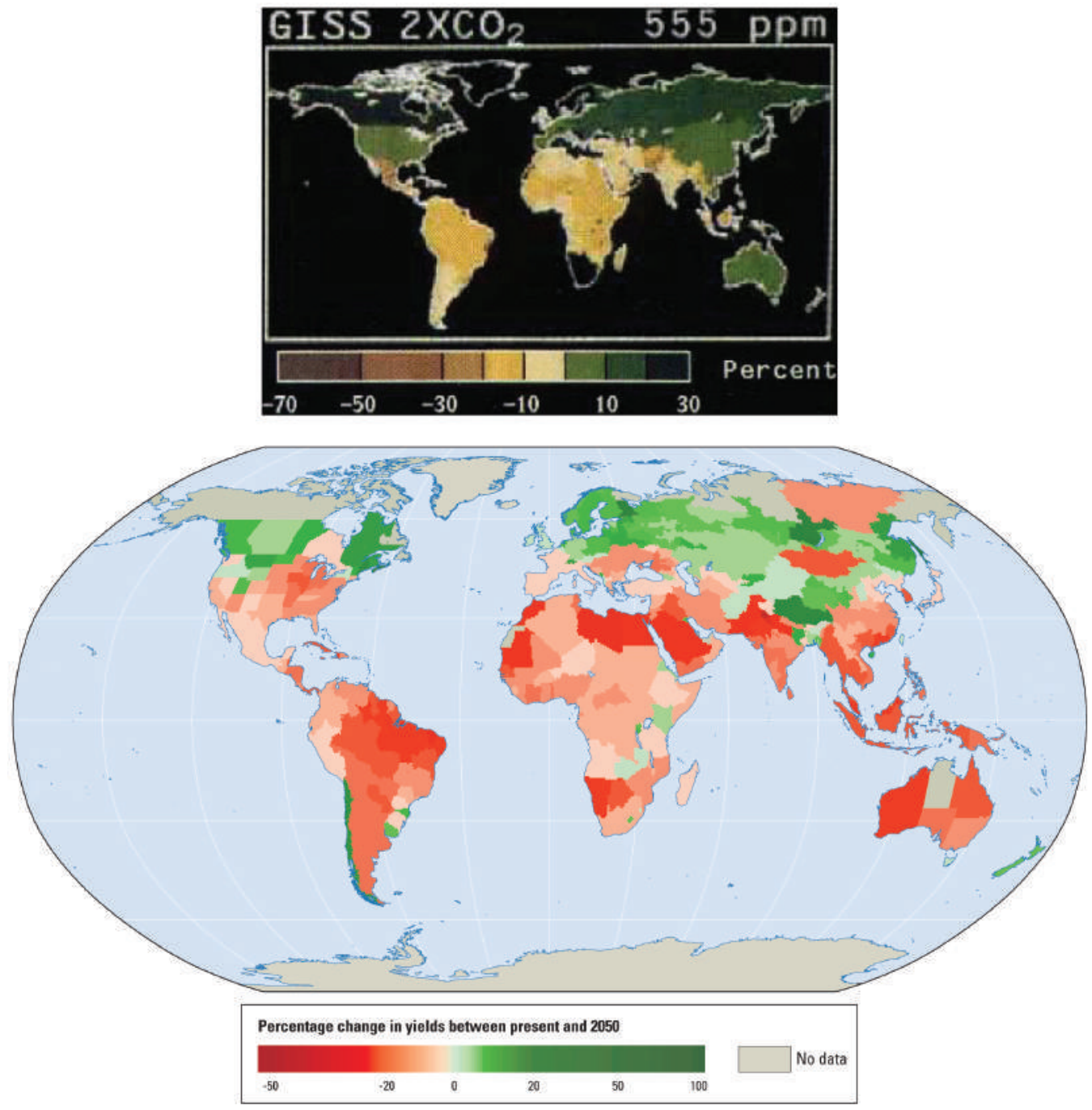
that attempt to link macro shocks to household level responses and adaptation outcomes; and community and household level studies that try to assess climate change effects from the bottom up. The International Food Policy Research Institute's (IFPRI) International Model for Policy Analysis of Agricultural Commodities and Trade (IMPACT) model is an example of a top-down approach. It connects climate change scenarios with food supply effects and market and price outcomes, and traces the economic consequences of food availability drivers to access and utilization of food, including food energy consumption and children's nutrition (Brian et al., 2009; Nelson et al., 2010).

Studies at the micro level of communities and households that are exposed to climate shocks capture more adaptation capabilities than macro models such as IMPACT - for example, asset drawdown, job-switching migration, social policy responses and collective action for assistance (Kato et al., 2011; Silvestri et al., 2012; Trærup, 2012). Although these approaches provide finescale detail, they omit the associated risks of climate change that cut across broad regions. Given the expected changes in the geography of agricultural production under climate change, the comparative advantage to producing certain products at regional and international levels is also likely to alter. This will have production implications for all agricultural output - food, feed, fuels and fibres - and that will affect food trade flows, with implications for farm incomes and access to food (Hertel, et al., 2010).

The utilization of food is closely linked with the general health environment and with water and sanitation. Any impact of climate change on the health environment also has an impact on food utilization. The clearest link found in the literature on climate change is the research on freshwater resources. There is widespread agreement that climate variability and change will have an impact on water resources and the availability of clean drinking water (Kundzewicz et al., 2007; Delpa et al., 2009). Hygiene is also likely to be affected by extreme weather events, such as flooding in environments where sound sanitation is absent
(Griffith et al., 2006; Hashizume et al., 2008; Shimi et al., 2010). Additionally, uptake of micronutrients is affected negatively by diarrheal diseases, which are strongly correlated to temperature (Schmidhuber and Tubiello, 2007).

Other indirect impacts of climate change on nutrition may be seen through risks to the safety and quality of food. Contamination of food by mycotoxins is a major health and nutrition issue in areas where changes in climate could increase human exposure to toxins in the food chain. For example, the soil-borne fungus Aspergillus flavus can infect the pods of groundnut or developing grains of maize, where under certain conditions it produces the mycotoxin, aflatoxin. The chain of influence on the processes that lead to contaminated produce are complex, but they are partly dependent on weather conditions close to the time of harvest and during crop storage. Increased storage costs and storage pest attacks may result from ecological shifts in a warmer world (Paterson and Lima, 2010; Tefera, 2012). Science and innovation have a role to play here, such as the progress in recent years on improving food utilization through fortification and biofortification ${ }^{3}$, which connects food availability with the utilization dimension of food security, such as through the development of vitamin A-enhanced sweet potato varieties (Bouis, 2003; Nestel et al., 2006).

While problems of insufficient and poor-quality food persist, changes in the global environment are creating new nutritional issues, such as the "nutrition transition" - a process by which globalization, urbanization and changes in lifestyle are linked to changes in diet towards excess caloric intake, poor-quality diets, and low physical activity. Together, such changes can lead to rapid rises in obesity and chronic diseases, even among the poor in developing countries (Popkin et al., 2012). The nutrition transition will unfold in parallel with the climate change process in coming decades.

3 Biofortificationapplies plant breeding techniques to enhance desirable nutrient elements. Fortification is adding desirable nutrients to food intake in whatever form. 


\section{figure 7}

Projected yield changes for maize in East Africa for the year 2050 (from Thornton et al., 2009)
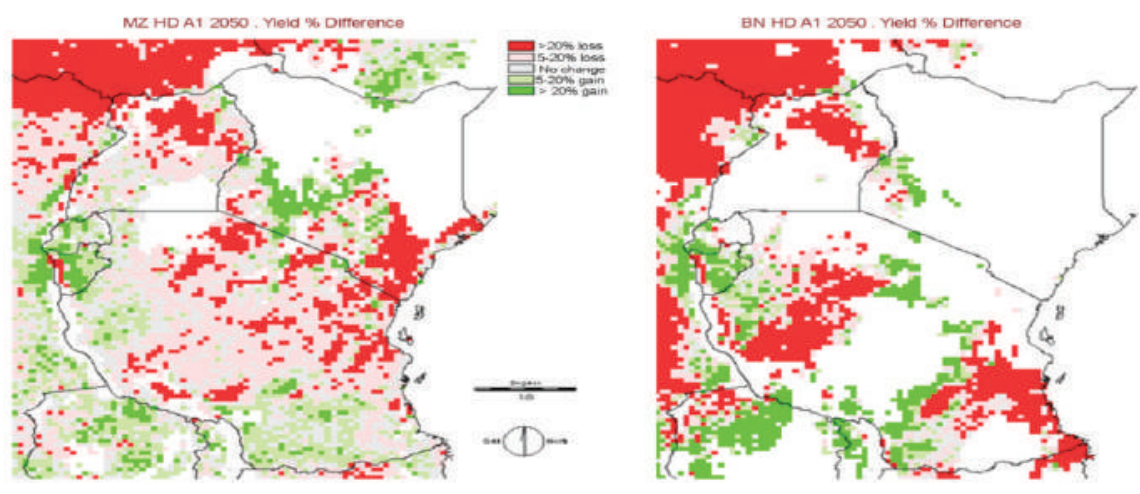

Wheeler and von Braun (2013) concluded that the stability of entire food systems may be at risk under climate change, largely because of shortterm variability and extreme events in agricultural markets. Climate change is likely to increase food market volatility from the production and supply side (see, for example, Mearns et al., 1996). Stability can also be endangered from demandside shocks, such as bioenergy subsidy and quota policies (Beckman et al., 2012), and a broader set of risks that can trigger ripple effects for broader destabilization of food security. These include: the risk of high and volatile food prices, which temporarily limit poor people's food consumption (Arndt et al., 2012; Campbell et al., 2010; de Brauw, 2011; Torlesse et al., 2003); financial and economic shocks, which lead to job loss and credit constraints (Smith et al., 2002); and risks posed by political disruptions and failed political systems (Berazneva and Lee, 2013). These complex system risks can assume a variety of patterns, and can become catastrophic in combination.

\section{Mitigation and adaptation in the agricultural sector}

A key incentive for adaptation in the agricultural sector is that the world is already committed to some degree of climate change resulting from past emission of greenhouse gases (IPCC, 2007b) and can expect a further degree of climate change from future greenhouse gas emissions. A need already exists for adaptation to the impacts on global food security that will be experienced because of emission of greenhouse gases in the past. Adaptation can address potential negative impacts or it may exploit any opportunities that may arise from climate change (for example, Figure 6). It is important to recognize possible opportunities even though negative impacts, quite rightly, get the bulk of attention, particularly in developing countries.

Local context and detail are vital to adaptation in practice. Autonomous adaptation is likely to take place spontaneously. In the farming sector, for example, a sorghum farmer - without any new technology or climate-smart policy incentives can make decisions about the timing of sowing and harvesting, the choice of crop types from those available, and the management of labour, providing that he or she has access to a range of technologies and the knowledge to use them effectively. However, this does not rule out features of adaptation that operate at much larger scales, such as the development of agrotechnologies and the importance of national and international policies. Clearly, there are both large-scale and small-scale aspects to adaptation to climate change impacts. 
Planned adaptation requires investment and significant lead times, to cover capital costs and/ or for development of technology. For example, the development of heat-tolerant crop varieties, or the installation of post-harvest storage facilities for a warmer climate, require considerable expertise, capital investment and long lead times. However, many production-related adaptation actions will remain local by nature. More broadscale adaptations are often trade-related and/or public policy-related, such as social protection for nutrition.

There will never be "perfect" adaptation of agriculture to climate change. Some negative impacts are likely to remain even after adaptation actions and investment. This "residual damage" may result in increased food insecurity and dealing with it requires a degree of resilience to climate change (Pingali et al., 2005). The concept of "resilience" came from the field of ecology and describes the ability of an ecological system to recover from a shock, climatic or otherwise. In recent years, those working on adaptation to climate change have applied these concepts to other natural and social systems. The thinking is that better resilience to climate variability and change can be increased by building institutional capacity to respond to shocks, investing in infrastructure, establishing social protection measures and the like. An appealing aspect of this approach is that it does not matter what the precise degree of projected climate change is for a particular location or time frame - a more resilient agricultural system, better able to cope with the impacts of variability in the current climate, should be better prepared for climate change.

Crop technologies that provide better protection against extreme weather events can be a useful contribution to more resilient food production systems and, in many cases, can be the only effective approach. For the example of heat stress effects on flowering, described in Section 4, the impact of extreme heat depends on the timing of the sensitive crop phase (flowering), the degree of heat at that time and the genetic tolerance of that crop variety to heat during this sensitive phase (Wheeler et al., 2000). The duration of the heat-sensitive phase is often short - a matter of a few days, or even just the morning hours within the day (Prasad et al., 1999). Agricultural management options to mitigate these impacts are therefore limited. In theory a more heat-tolerant crop variety could be sown at the start of a season when hotter than average weather conditions are forecast by seasonal climate models, but this strategy contains two serious drawbacks. First, no climate model can forecast, three to six months ahead of time, the air temperature in a particular location at the fine time scale required to anticipate heat stress at flowering. Second, even if a robust forecast of heat wave conditions were available at the time of sowing, it is unlikely that there would be a supply of seed of alternative varieties available in sufficient quantities to allow large numbers of farmers to change their sowing plans at the last moment. The seed system itself would need to be responsive to changes in agricultural decisions about sowing, and that requires large-scale, concerted, sector-wide management long before the time of sowing.

Crop improvement programmes that provide planting material with increased tolerance for extreme weather in current varieties - or varieties that are at least as acceptable as current ones - are a valuable part of an adaptation and resilience strategy. For the crop heat stress example, Jagadish et al. (2008) have identified more heat-tolerant genotypes of rice based on the N22 variety. Considerable progress has also been made throughout Asia in breeding rice with tolerance to flooding. Flash floods and typhoons often result in heavy production losses for paddy rice. In Bangladesh and India alone, such losses amount to an estimated 4 million tonnes of rice per year - enough to feed 30 million people. Five days of complete submergence will destroy most rice crops. However, identification of submergence tolerance displayed by an Indian variety, called FR13A, has led to successful breeding of submergence-tolerant varieties known as "scuba" rice that can withstand up to 17 days of complete submergence. Marker-assisted backcrossing 
was used to transfer flood-tolerant traits, such as the gene sub1A, into commercially valuable rice varieties without losing useful characteristics such as high yield, good grain quality or pest and disease resistance.

Typically, during a flood, rice plants will extend the length of their leaves and stems in an attempt to escape submergence. The sub1A gene is activated when the scuba rice plant is submerged, effectively making the plant dormant and allowing it to conserve energy until the floodwater recedes. This gene also induces tillering (production of lateral branches), once water has receded. Six rice "mega varieties" - flood-tolerant versions of high-yielding local rice varieties, popular with farmers and consumers - were tried and tested on farmers' fields across Asia. The first variety developed, Swarna-Sub1, showed high survival under submerged conditions compared to the original variety Swarna, and gave yield advantages of 1 to 3 tonnes per hectare over Swarna when submerged. The improved Swarna-Sub1 variety is now targeted to replace Swarna on some 5 to 6 million hectares of rice in eastern India and Bangladesh. The development of new Sub1 varieties is now underway in Cambodia, Indonesia, Lao PDR, Myanmar, the Philippines, Thailand and Viet Nam. Salt tolerance has already been introduced into Sub1 varieties and the introduction of drought tolerance and tolerance to stagnant flooding is currently being examined.

A recent programme developed by the International Livestock Research Institute seeks to increase the stability of the livelihoods of smallscale herdsman in northern Kenya, who are vulnerable to drought. An innovative insurance product has been developed that uses satellites to detect the "greenness" of the natural pasturelands as an indicator of potential mortality of livestock. Herdsman pay about one-third of the cost of one animal as the premium to insure 10 animals. When a shortage of pasture is detected, the insurance pays out. The Government of Kenya intends to roll out the livestock insurance product further in 2014, providing herdsmen with improved financial resilience to climate variability.
The agriculture sector is a major contributor to human-induced climate change, through emissions of greenhouse gases and changes in land use. Estimates vary regarding the contribution of the agriculture sector to climate forcing, but are usually in the range of 20 to 25 percent of the global total (IPCC, 2007b). The latest IPCC report estimates that the net temperature change attributable to the agriculture sector will be about $1^{\circ} \mathrm{C}$ over a $100-$ year time horizon (IPCC, 2013b). Processes such as methane generation from paddy rice cultivation and from ruminant livestock, nitrous oxide release from fertilizers applied to soils and agricultural energy use are the dominant contributors. Smith et al. (2013) termed these factors supply-side options. They can be targeted to reduce climate forcing from agriculture, depending on the balance of costs. In contrast, demand-side options address both climate mitigation and food security targets; examples include reduction of waste throughout the food chain and large-scale changes in diet towards more efficient and lower-emission options. Smith et al. (2013) identify these demand-side mitigation options as potentially the most effective interventions for achieving multiple gains from the agricultural sector.

\section{Understanding and working with uncertainty about climate change impacts on food security}

Many aspects of climate change are subject to uncertainties, although those who study climate change impacts are better equipped than those in other disciplines for trying to quantify these. It is important to acknowledge a fair degree of uncertainty in the evidence of climate change impacts on food security that arise from projections of climate change, sources of natural variability in climate and future emissions of greenhouse gases, as well as uncertainties in our understanding of the underlying science, both of climate and impacts. Hawkins and Sutton 
(2009) showed how the uncertainties from intrinsic variability, climate models and emission scenarios on global temperature can change over time. Such trends in sources of uncertainty over time will also be apparent with respect to impacts on food systems. Food systems, however, are ultimately driven by people and their behaviour, responding to real and perceived changes in their local climate. Additional uncertainties regarding the impacts of climate change on people arise because there are many influences on people's lives other than climate, making it difficult to second-guess how individuals, communities and countries will respond to climate change and its impacts on food systems.

Most evaluations of possible climate change impacts use the output from a climate model, usually a GCM. Models of climate change impact on agriculture vary in scale from global to local. Whichever scale is chosen, there is a reliance on GCMs to accurately simulate changes in climate variables, which are then averaged for a likely regional value or downscaled to give an indication of local change. Climate models are not always able to accurately simulate current climates (Semenov and Barrow, 1997) and the uncertainty inherent in any modelling process should be taken into consideration in any assessment of climate change impacts. Climate models are particularly prone to errors in rainfall, which is sometimes excluded (Mall et al., 2004) or modified (Žalud and Dubrovsky, 2002) in agricultural impact assessments. Most studies use present-day climate maps to train the models, and adjust these using modelled differences ("anomalies") between current and future results from the GCM in order to project future impacts.

GCM models typically operate on spatial scales of about $200 \mathrm{~km}$, which is much larger than the spatial scale of most crop models (Hansen and Jones, 2000; Challinor et al., 2003). To overcome differences in spatial scale, climate data can be downscaled to the scale of a crop model (e.g., Wilby et al., 1998), or a crop model can be matched to the scale of climate model output (e.g., Challinor et al., 2004).
Simulation modelling of crop growth, development and yield has traditionally focused on field-scale simulations, using detailed information on soils, climate, crops and management as inputs to the modelling. Therefore, for climate change impact studies, there is a spatial disparity between the scale of projections of climate derived from GCMs at grid sizes of $200 \mathrm{~km}$ or more and field-based crop simulations. One method that addresses this difference in spatial scale and the heterogeneity of small-scale crop management is to upscale crop parameter values. A Bayesian approach ${ }^{4}$ has been developed to upscale crop parameter values for paddy rice in Japan using a crop parameter ensemble to represent small-scale heterogeneity in crop characteristics (lizumi et al., 2009).

Climate input for crop simulation models can also be downscaled to field scale. For example, the computing power of the Earth Simulator supercomputer at the Japan Agency for Marine-Earth Science and Technology in Yokohama, Japan, is being used to run higher resolution global climate models at grid sizes of $25 \mathrm{~km}$. Crucially, higher resolution produces weather-resolving climate models with improved descriptions of water and other fluxes between the land surface vegetation and the atmosphere. Statistical downscaling using weather generators can also provide weather data directly at a point scale, for input to crop simulation models based on the features of observed weather at that point. For example, the Long Ashton Research Station (LARS) weather generator has been used to study the impacts of extremes of weather on wheat; for simulations in the United Kingdom, this approach has revealed the importance of extremes of high temperature for the yield of wheat under climate change (Semenov, 2009).

Another approach to bridging the scales of climate and crop models is to use an intermediate complexity crop model that is run at the same spatial scale as a climate model. The General

\footnotetext{
$4 \quad$ A statistical approach based on probabilistic inferences.
} 
Large Area Model (GLAM) for crops takes this approach and, because it is process-based, it is able to reproduce the effects of variability in climate on crop yields (Challinor et al., 2004). In addition to climate, crop management and agricultural technology have strong influences on yields attained in farmers' fields.

Projections of impacts on food systems to date have used the output of climate models to drive crop simulations for future conditions. However, climate and land surface processes are intrinsically linked by feedbacks - for example, in the exchange of energy, carbon and water. The dynamic nature of natural vegetation change has often been included in the land surface schemes of climate models or integrated Earth system models; these have been used to explore the role of land surface processes in global environmental change but croplands have only recently been included (for example, Osborne et al., 2008). Cultivating crops that require management such as irrigation, fertilizer application and harvesting, will also affect the interaction between the land surface and atmosphere.

The research science community routinely explores the uncertainty in climate change impacts and understanding of the contributions of different sources of uncertainty to climate change projections of some aspects of food security continues to increase. However, real issues may arise regarding how this uncertainty is communicated to those who want to use research evidence. Despite the very real uncertainties in the underlying science, decisions still need to be made by a whole range of decision-makers, from policymakers to practitioners in the agricultural sector. Moreover, decisions can only be made using the best evidence that is available at the time and they cannot wait until "perfect" knowledge is achieved.

\section{Towards climate- compatible food policies}

A reasonable aspiration for many of those working in national and international policy bodies is to use evidence from the research community to develop new policies and to inform policy-relevant decisions. Although original research outputs can be important sources of evidence for policy, synthesis reports are particularly vital. Clearly, there is an important role for regular synthesis reports, such as those of the IPCC and relevant reports of series such as the World Development Reports, whose 2010 edition concerned development and climate change. However, such extensive reports require considerable commitment from thousands of experts over long periods of time. Although these reports have good coverage of emerging consensus findings from the evidence on climate change impact, they inevitably lack a lot of country- or location-specific detail. In addition, the period between major synthesis reports can be quite long - such as the seven years that elapsed between the IPCC $4^{\text {th }}$ and $5^{\text {th }}$ assessment reports. So there is also an important role for national and international organizations, such as think tanks and consultancy organizations, to provide finerlevel and more rapid analyses tailored to specific policy requirements for information and knowledge. Web-based global knowledge networks have also been created to disseminate climate change knowledge - for example, the Climate and Development Knowledge Network (www.colkn. org) - and these can be portals for sharing more experiences and lessons of policy initiatives. For all these sources of information for policy-makers, the way in which knowledge is communicated is paramount.

\section{Conclusions}

Much attention has been focused recently on how the global food system can cope over the coming decades with increases in the human population, changes in diet, and greater demands on energy and water resources. Climate variability and change will add further stresses to food production in the future. Understanding these complex impacts on food crops is a grand global challenge for research. The impacts of climate 
change on food security will vary from one part of the world to another and they will change over time. Local context within large-scale global trends is important for providing information to farmers and their advisers seeking to adapt to these new challenges. Adaptation strategies and investment will be needed in response to climate change, from developing new technologies - such as improved crop and livestock varieties - to building resilience to climate within agricultural communities.

In addition to these challenges from climate change, there is clearly a need for a more productive agricultural sector, in order to meet the increasing demand for food products expected over the coming decades and hence to contribute to global food security. On balance, we should anticipate substantial risks to the volume, volatility and quality of food crop and animal feed supply chains as the result of climate change. Adaptation strategies and investment informed by high-quality research evidence will be needed, both to respond to climate change and to meet the anticipated higher demand for food products in the years to come. Those making policy decisions will need robust, evidence-based advice on which to base their actions.

Based on the current evidence regarding climate change impacts on food security, one clear message for decision-makers, whether as policymakers, retailers or practitioners, is that there is no single trajectory of climate change impacts for the future. Instead, there will be a range of possible outcomes - some more likely than others - and all of them will depend on the part of the world being considered. Nevertheless, we can be confident about one thing: the climate change risks to agricultural output, to food systems and to food security will increase over time and therefore must not be ignored by those making medium- and long-term planning decisions about food security.

\section{References}

Arndt, C., M. Hussain, \& L. Osterdal, 2012. Effects of food price shocks on child malnutrition: the Mozambican experience 2008/09. UNU-WIDER Working Paper 2012/89, United Nations University. ISBN 978-92-9230-553-6

Beckman, J., T. Hertel, F. Taheripour, \& W. Tyner, 2012. Structural change in the biofuels era. Euro Rev Agr Econ 39: 137. doi: 10.1093/erae/jbr041

Berazneva, J. \& D. Lee, 2013. Explaining the African food riots of 2007-2008: an empirical analysis. Food Policy 39: 28. doi: 10.1016/j. foodpol.2012.12.007

Bouis, H., 2003. Micronutrient fortification of plants through plant breeding: can it improve nutrition in man at low cost? P Nutr Soc 62: 403.

Bryan, E., T. Deressa, G. Gbetibouo \& C. Ringler. 2009. Adaptation to climate change in Ethiopia and South Africa: options and constraints.

Environmental Science \& Policy, Volume 12, Issue 4, June 2009, Pages 413-426.

Campbell, A., S. de Pee, K. Sun, K. Kraemer, A. Thorne-Lyman, R. Moench-Pfanner, M. Sari, N. Akhter, M. Bloem \& R. Semba. 2010. Household rice expenditure and maternal and child nutritional status in Bangladesh. J Nutr 140: 189S-194S. doi: 10.3945/jn.109.110718

Challinor, A., J. Slingo, T. Wheeler, P. Craufurd \& D. Grimes, 2003. Towards a combined seasonal weather and crop productivity forecasting system: determination of the spatial correlation scale. Journal of Applied Meteorology, 42: 175-192.

Challinor, A., T. Wheeler, P. Craufurd, J. Slingo \& D. Grimes, 2004. Design and optimisation of a large-area process-based model for annual crops. Agricultural and Forest Meteorology, 124: 99-120. 
Cline, W., 2007. Global warming and agriculture: impact estimates by country. Center for Global Development, Peterson Institute for International Economics, Washington, DC. ISBN 978-0-88132403-7

Craufurd, P. \& T. Wheeler, 2009. Climate change and the flowering time of annual crops. Journal of Experimental Botany 60 (9): 2529-2539

de Brauw, A., 2011. Migration and child development during the food price crisis in El Salvador. Food Policy 36: 28. doi: 10.1016/j. foodpol.2010.11.002

Delpla, I., A. Jung, E. Baures, M. Clement, \& O. Thomas, 2009. Impacts of climate change on surface water quality in relation to drinking water production. Environment International 35: 1225. doi: 10.1016/j.envint.2009.07.001

Dong, J., J. Liu, F.L. Tao, X. Xu, \& J. Wang, 2009 Spatio-temporal changes in annual accumulated temperature in China and the effects on cropping systems, 1980s to 2000. Clim Res, 40(1): 37-48.

Drake, B., M. Gonzàlez-Meler, \& S. Long, 1997. More efficient plants: a consequence of rising atmospheric $\mathrm{CO}_{2}$ ? Annual Review of Plant Biology 1997.

Easterling, W., P. Aggarwal, P. Batima, K. Brander, L. Erda, S. Howden, A. Kirilenko, J. Morton, J. Soussana, J. Schmidhuber \& and F. Tubiello, 2007. Food, fibre and forest products. In M. Parry, O. Canziani, J. Palutikof, P. van der Linden and C. Hanson, eds., Climate Change 2007: Impacts, Adaptation and Vulnerability. Contribution of Working Group II to the Fourth Assessment Report of the Intergovernmental Panel on Climate Change, Cambridge University Press, Cambridge, UK, 273-313.
FAO, 1996. Rome declaration on world food security and World Food Summit plan of action. World Food Summit, Rome, 13-17 November 1996.

FAO, WFO, IFAD, 2012. The state of food insecurity in the World 2012. Economic growth is necessary but not sufficient to accelerate reduction of hunger and malnutrition. Food and Agriculture Organization, Rome, 2012.

Godfray, H., J. Beddington, I. Crute, L. Haddad, D. Lawrence, J. Muir, J. Pretty, S. Robinson, S. Thomas \& C. Toulmin. 2010. Food security: the challenge of feeding 9 billion people. Science 327 (5967): 812.

Griffith, D., L. Kelly-Hope, \& M. Miller, 2006. Review of reported cholera outbreaks worldwide, 1995-2005. Am J Trop Med Hyg 75: 973.

Hansen, J. \& J. Jones, 2000. Scalingup crop models for climate variability applications. Agricultural Systems, 65(1): 43-72.

Hashizume, M., et al., 2008. Factors determining vulnerability to diarrhea during and after severe floods in Bangladesh. J Water Health 6: 323. doi: 10.2166/wh.2008.062

Hawkins, E. \& R. Sutton, 2009. The potential to narrow uncertainty in regional climate predictions. Bulletin of the American Meteorological Society, 90(8): 1095-1107.

Hertel, T., M. Burke, \& D. Lobell, 2010. The poverty implications of climate-induced crop yield changes by 2030. Global Environ Chang 20: 577.

Huber, M. \& R. Knutti. 2012. Anthropogenic and natural warming inferred from changes in Earth's energy balance. Nature Geoscience 5: 31-36. 
lizumi, T., M. Yokozawa, \& M. Nishimori, 2009. Parameter estimation and uncertainty analysis of a large-scale crop model for paddy rice: application of a Bayesian approach. Agricultural and Forest Meteorology, 149(2): 333-348.

IPCC, 2007a: Summary for Policymakers. In M. Parry, O. Canziani, J. Palutikof, P. van der Linden and C. Hanson, eds., Climate Change 2007: Impacts, Adaptation and Vulnerability. Contribution of Working Group II to the Fourth Assessment Report of the Intergovernmental Panel on Climate Change, Cambridge University Press, Cambridge, UK, 7-22.

IPCC, 2007b: Summary for Policymakers. In S. Solomon, D. Qin, M. Manning, Z. Chen, M. Marquis, K. Averyt, M. Tignor and H. Miller, eds., Climate Change 2007: The Physical Science Basis. Contribution of Working Group I to the Fourth Assessment Report of the Intergovernmental Panel on Climate Change. Cambridge University Press, Cambridge, UK and New York, NY, USA.

IPCC, 2013a: Summary for Policymakers. In T. Stocker, D. Qin, G. Plattner, M. Tignor, S. Allen, J. Boschung, A. Nauels, Y. Xia, V. Bex \& P. Midgley, eds., Climate Change 2013: The Physical Science Basis. Contribution of Working Group I to the Fifth Assessment Report of the Intergovernmental Panel on Climate Change. Cambridge University Press, Cambridge, UK and New York, NY, USA.

IPCC, (2013b). IPCC AR5 2013, draft Chapter 8: Anthropogenic and Natural Radiative Forcing Fig 8.34,http://www.climatechange2013.org/images/ uploads/WGIAR5 WGI-12Doc2b FinalDraft Chapter08.pdf

Jagadish, K., P. Craufurd \& T. Wheeler, 2007. High temperature stress and spikelet fertility in rice (Oryza sativa L.). Journal of Experimental Botany, 58: 1627-1635.

Jagadish, S., P. Craufurd \& T. Wheeler, 2008. Phenotyping parents of mapping populations of rice for heat tolerance during anthesis. Crop Science 48: 1140-1146.

Kato, K., C. Ringler, M. Yesuf, \& E. Bryan, 2011. Soil and water conservation technologies: a buffer against production risk in the face of climate change? Insights from the Nile basin in Ethiopia. Agr Econ, 42: 593. doi: 10.1111/j.15740862.2011.00539.x

Kimball, B., 1983. Carbon dioxide and agricultural yield: An assemblage and analysis of 430 prior observations. Agron. J. 75:779-788.

Knox, J., T. Hess, A. Daccache \& T. Wheeler, 2012. Climate change impacts on crop productivity in Africa and South Asia. Environ Res Lett 7: 034032.

Kundzewicz, Z., L. Mata, N. Arnell, P. Döll, P. Kabat, B. Jiménez, K. Miller, T. Oki, Z. Sen, \&I. Shiklomanov, 2007. Freshwater resources and their management. In M. Parry, O. Canziani, J. Palutikof, P. van der Linden \& C. Hanson, eds., Climate Change 2007: Impacts, Adaptation and Vulnerability. Contribution of Working Group II to the Fourth Assessment Report of the Intergovernmental Panel on Climate Change, Cambridge University Press, Cambridge, UK, 173-210.

Lobell, D.B., Bänziger, M., Magorokosho, C. \& Vivek, B., 2011. Nonlinear heat effects on African maize as evidenced by historical yield trials. Nature Climate Change 1: 42-45.

Long, S., E. Ainsworth, A. Leakey, J. Nösberger, \& D. Ort, 2006. Food for thought: lower-than-expected crop yield stimulation with rising $\mathrm{CO}_{2}$ concentrations. Science 319 (5863): 607-610.

Madan, P., S. Jagadish, P. Craufurd, M. Fitzgerald, T. Lafarge \& T. Wheeler, 2012. Effect of elevated $\mathrm{CO}_{2}$ and high temperature on seed-set and grain quality of rice. Journal of Experimental Botany 63 (10): 3843-3852. 
Mall, R., M. Lal, V. Bhatia, L. Rathore \& R. Singh, 2004. Mitigating climate change impact on soybean productivity in India: a simulation study. Agricultural and Forest Meteorology, 121(1): 113 125.

Mearns, L., C. Rosenzweig \& R. Goldberg, 1996. The effect of changes in daily and interannual climatic variability on CERES-Wheat: a sensitivity study. Climatic Change 32: 257. doi:_10.1007/ BF00142465

National Academy of Sciences, 2010. America's Climate Choices, Panel on advancing the science of climate change, National Research Council.

Nelson, G., M. Rosegrant, A. Palazzo, I. Gray, C. Ingersoll, R. Robertson, S. Tokgoz, T. Zhu, T. Sulser, C. Ringler, S. Msangi \& L. You. 2010. Food security, farming, and climate change to 2050: scenarios, results, policy options. International Food Policy Research Institute, Washington DC. ISBN 978-0-89629-186-7

Nestel, P., H. Bouis, J. Meenakshi, \& W. Pfeiffer, 2006. Biofortification of staple food crops. J Nutr, 136: 1064.

Osborne, T., D. Lawrence, A. Challinor, J. Slingo \& T. Wheeler, 2007. Development and assessment of a coupled crop-climate model. Global Change Biology, 13: 169-183.

Osborne, T., G. Rose \& T. Wheeler, 2012. Variation in the global-scale impacts of climate change on crop productivity due to climate model uncertainty and adaptation. Agricultural and Forest Meteorology.

Parry, M., C. Rosenzweig, A. Iglesia, M. Livermore, \& G. Fischer, 2004. Effects of climate change on global food production under SRES emissions and socio-economic scenarios. Global Env Change 14: 53. doi: 10.1016/j.gloenvcha.2003.10.008
Paterson, R. \& N. Lima, 2010. How will climate change affect mycotoxins in food? Food Res Int 43: 1902. doi: 10.1016/i.foodres.2009.07.010

Pingali, P., L. Alinovi, \& J. Sutton, (2005). Food security in complex emergencies: enhancing food system resilience. Disasters, 29(s1), S5-S24.

Pope, P., L. Kendon, J. Lowe, F. Carroll \& S. Tempest, (eds). 2010. Evidence: The state of the climate. Exeter: Met Office Hadley Centre.

Popkin, B., L. Adair \& S. Ng, 2012. Global nutrition transition and the pandemic of obesity in developing countries. Nutr Rev 70: 3.

Prasad, P., P. Craufurd \& R. Summerfield, 1999. Fruit number in relation to pollen production and viability in groundnut exposed to short episodes of heat stress. Annals of Botany, 84(3): 381-386.

Richard, A., 2012. A new estimate of the average earth surface land temperature spanning 1753 to 2011. Geoinformatics \& Geostatistics: An Overview. Berkeley Earth Surface temperature project, http://berkeleyearth.org/. Figure at http://www.bbc.co.uk/news/scienceenvironment-15373071

Rosenzweig, C. \& M. Parry, 1994. Potential impact of climate change on world food supply. Nature 367 (6459): 133.

Royal Society, 2010. Climate change: a summary of the science. September 2010

Schmidhuber, J. \& F. Tubiello, 2007. Global food security under climate change. Proc. Natl Acad. Sci. 104: 19703. doi: 10.1073/pnas.0701976104.

Semenov, M., 2009. Impacts of climate change on wheat in England and Wales. Journal of the Royal Society Interface, 6(33): 343-350. 
Semenov, M. \& E. Barrow, 1997. Use of a stochastic weather generator in the development of climate change scenarios. Climatic change, 35(4): 397-414.

Shimi, A., G.A. Parvin, C. Biswas, \& R. Shaw, 2010. Impact and adaptation to flood: A focus on water supply, sanitation and health problems of rural community in Bangladesh. Disaster Prevention and Management 19: 298. doi: 10.1108/09653561011052484

Silvestri, S., E. Bryan, C. Ringler, M. Herrero, \& B. Okoba, 2012. Climate change perception and adaptation of agro-pastoral communities in Kenya. Reg Environ Change 12: 791. doi: 10.1007/ s10113-012-0293-6

Smith, J., D. Thomas, E. Frankenberg, K. Beegle, \& G. Teruel, 2002. Wages, employment and economic shocks: Evidence from Indonesia. J Popul Econ 15: 161. doi: 10.1007/pl00003837

Smith, P., H. Haberl, A. Popp, K. Erb, C. Lauk, R. Harper, F. Tubiello, A. Pinto, M. Jafari, S. Sohi, O. Masera, H. Böttcher, G. Berndes, M. Bustamante, H. Ahammad, H. Clark, H. Dong, E. Elsiddig, C. Mbow, N. Ravindranath, C. Rice, C. Abad, A. Romanovskaya, F. Sperling, M. Herrero, J. House \& S. Rose. 2013. How much land-based greenhouse gas mitigation can be achieved without compromising food security and environmental goals? Global Change Biology 19 2285-2302, doi: 10.1111/gcb.12160

Tao, F., M. Yokozawa, Z. Zhang, Y. Hayashi, H. Grassl \& C. Fu, 2004. Variability in climatology and agricultural production in China in association with the East Asian summer monsoon and El Niño Southern Oscillation. Climate Research, 28(1): 2330.

Tans, P. \& R. Keeling, 2013. $\mathrm{CO}_{2}$ Measurements at Mauna Loa, Hawaii by the NOAA. NOAA/ESRL (www.esrl.noaa.gov/gmd/ccgg/trends/), Scripps Institution of Oceanography (scrippsco2.ucsd.edu/)
Thornton, P., P. Jones, G. Alagarswamy \& J. Andresen, 2009. Spatial variation of crop yield response to climate change in East Africa. Global Environmental Change, 19(1), 54-65.

Torlesse, H., L. Kiess \& M. Bloem, 2003. Association of household rice expenditure with child nutritional status indicates a role for macroeconomic food policy in combating malnutrition. J Nutr 133: 1320.

Trærup, S. 2012. Informal networks and resilience to climate change impacts: a collective approach to index insurance. Global Environ Chang 22: 255 (2012). doi: 10.1016/j.gloenvcha.2011.09.017

Von Grebmer, K., C. Ringler, M. Rosegrant, T. Olofinbiyi, D. Wiesmann, H. Fritschel, O. Badiane, M. Torero, Y. Yohannes. 2012. Global hunger index: The challenge of hunger: ensuring sustainable food security under land, water, and energy stresses. Welthungerhilfe/International Food Policy Research Institute (IFPRI)/Concern Worldwide. ISBN 978-0-89629-942-9 .

Wheeler, T. \& J. von Braun, 2013. Climate change impacts on global food security. Science 341 , (6145): 508-513.

Wheeler, T., P. Craufurd, R. Ellis, J. Porter, P. Vara Prasad, 2000. Temperature variability and the yield of annual crops. Agriculture, Ecosystems and Environment, 82: 159-167.

Wilby, R., T. Wigley, D. Conway, P. Jones, B. Hewitson, J. Main \& D. Wilks, 1998. Statistical downscaling of general circulation model output: A comparison of methods. Water Resources Research, 34(11): 2995-3008.

World Bank, 2010. World Bank development report 2010: Development and Climate Change. World Bank, Washington DC.

Žalud, Z., \& M. Dubrovský, 2002. Modelling climate change impacts on maize growth and 
development in the Czech Republic. Theoretical and Applied Climatology, 72(1-2): 85-102.

Zhai, P., A. Sun, F. Ren, X. Liu, B. Gao, \&

Q. Zhang, 1999. Changes of climate extremes in China. In Weather and Climate Extremes (pp. 203218), Springer Netherlands.

Zunya, W., D. Yihui, H. Jinhai, \& Y. Jun, 2004. An updating analysis of the climate change in China in recent 50 years. Acta Meteorologica Sinica, 62(2): 228-236. 
$T$ he threat of climate change on the global food supply is growing. Increasing vulnerabilities pose serious challenges for food security and nutrition and require concerted responses based on robust scientific evidence. While significant uncertainties remain about the future of climate and food, a scientific consensus is emerging on certain key results. Climate impacts to caloric production are likely to be strongly negative across the vast majority of low latitude and tropical regions, mostly mixed in the mid-latitudes, and somewhat positive in high latitude regions. Climate change is also expected to adversely affect the nutrition content of most crops, exacerbate water scarcity in many arid regions, and damage coastal cropland due to rising seas and salt water inundation.

Tackling the climate challenge to food security requires a multi-front strategy that deploys resilience-enhancing adaptation and mitigation measures with food security co-benefits. Trade can also play an important role by helping to stabilize prices and supplies, provided trade policies are well-aligned with global climate mitigation objectives.

This book presents wide-ranging assessments of climate change and the global food system. Acknowledged experts in their fields present the latest available scientific evidence on the expected impacts of climate on regional and global food systems (crops and livestock). The evidence is presented in a way that is widely accessible to policy decision makers and practitioners and makes a distinct contribution towards a greater science-policy interchange. Put together, the different analyses in the book paint a comprehensive perspective linking climate change to food, nutrition, water, and trade along with suggested policy responses.

\section{ISBN 978-92-5-108699-5}

